\title{
El Ferrocarril de Caldas: una obra de titanes
}

\author{
Armando Ramírez Villegas
}
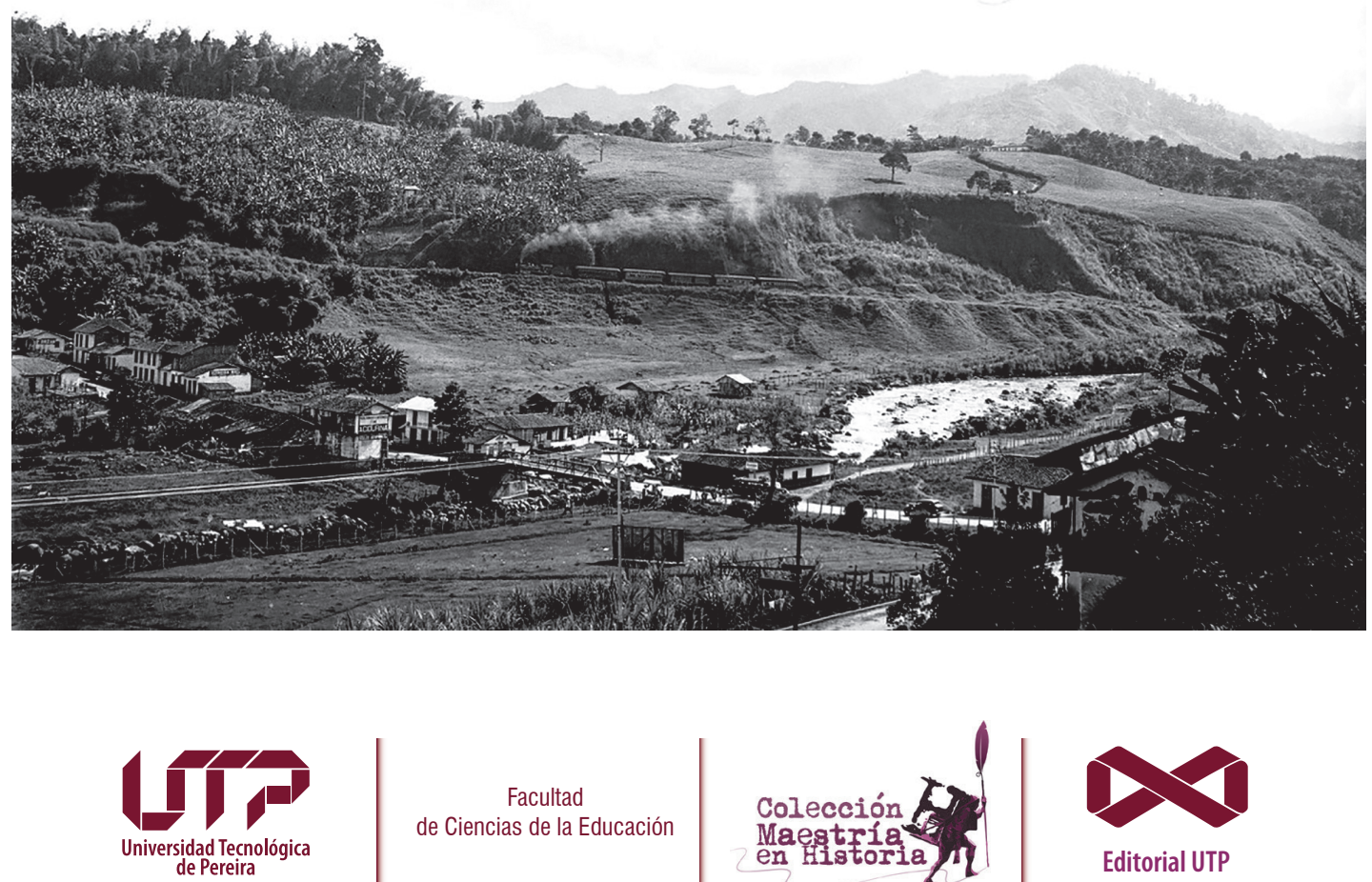

Facultad

de Ciencias de la Educación
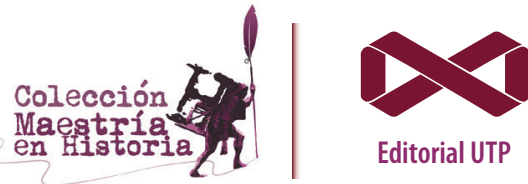

Editorial UTP 


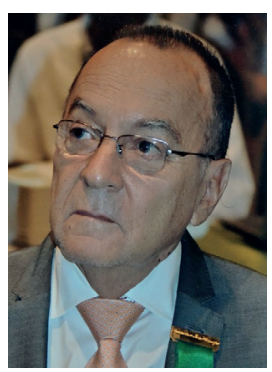

Armando Ramírez Villegas,

(Pereira, Risaralda, Colombia, 1938).

Ingeniero Civil de la Universidad Nacional de Colombia, Especializado en Diseño de Estructuras de Concreto.

Ha trabajado para distintas entidades públicas y privadas, como el Municipio de Pereira, en el cual estuvo vinculado como ingeniero director de las obras de ampliación, pavimentación e iluminación del aeropuerto Matecaña y ha ejercido en forma independiente la profesión de ingeniero calculista.

Coautor del libro Historia de un barrio: La Circunvalar de Pereira.

Ha publicado artículos relacionados con la historia de Pereira.

armando.is.ramirez@gmail.com 


\section{EL FERROCARRIL DE CALDAS:}

\section{Una obra de titanes}

Armando Ramírez Villegas

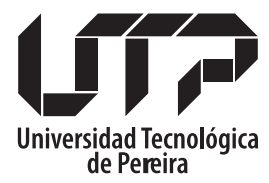

Colección Ensayos

Facultad de Ciencias de la Educación

Colección Maestría en Historia

2020 


\section{Ramírez Villegas, Armando \\ El ferrocarril de Caldas : una obra de titanes / Armando}

Ramírez Villegas. - Pereira : Editorial Universidad Tecnológica de Pereira, 2019.

264 páginas : ilustraciones. - (Colección Ensayo).

ISBN: 978-958-722-372-9 elSBN: 978-958-722-528-0

1. Transporte ferroviario - Historia - Caldas (Colombia) 2. Transporte ferroviario - Ingeniería de transporte 3. Construcción de túneles - Historia - Caldas (Colombia) 4. Industria minera Historia - Caldas (Colombia)

CDD. 385.986135

El Ferrocarril de Caldas: una obra de titanes

(C) Armando Ramírez Villegas

(C) Universidad Tecnológica de Pereira

1a Edición, 2019

ISBN: 978-958-722-372-9

eISBN: 978-958-722-528-0

Colección Ensayos

Foto portada: Donato García Ramírez

\section{Universidad Tecnológica de Pereira}

Vicerrectoría de Investigaciones, Innovación y Extensión

Editorial Universidad Tecnológica de Pereira

\section{Coordinador editorial UTP}

Luis Miguel Vargas Valencia

luismvargas@utp.edu.co

Tel:3137381

Edificio 9, Biblioteca Central "Jorge Roa Martínez"

Cra. 27 No. 10-02 - Los Álamos

Pereira, Colombia

www.utp.edu.co

\section{Montaje y producción:}

Universidad Tecnológica de Pereira

Centro Recursos Informáticos y Educativos, CRIE

diseno@utp.edu.co

El material académico e investigativo de esta publicación puede ser reproducido sin autorización, siempre que se mencione su procedencia en el marco del respeto a los derechos de autor consagrados en la legislación nacional e internacional al respecto.

Impresión y acabados:

Gráficas Olimpica

\section{Reservados todos los derechos}




\section{Tabla de contenido}

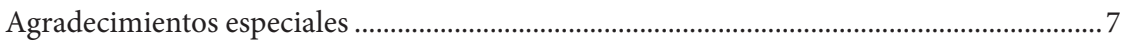

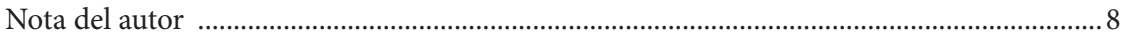

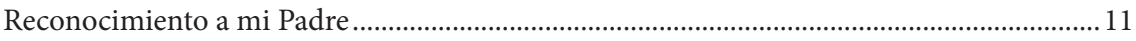

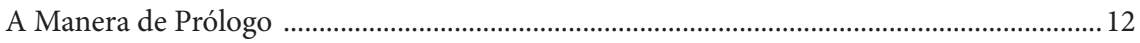

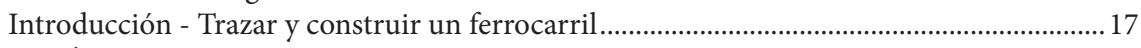

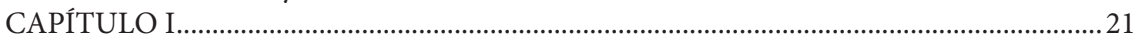

Trazado del ferrocarril Puerto Caldas - Pereira .....................................................................2 21

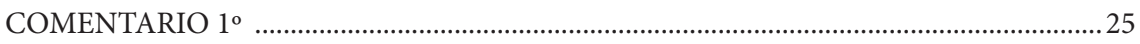

El centenario de Puerto Caldas ................................................................................................2 25

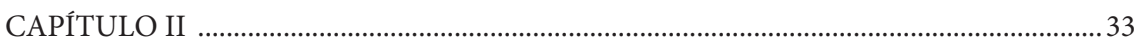

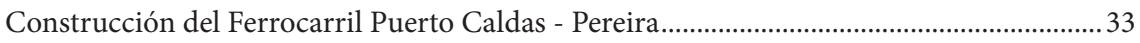

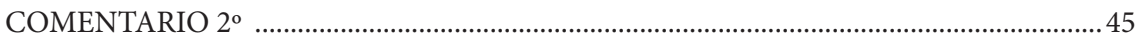

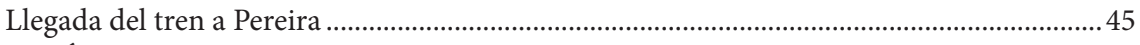

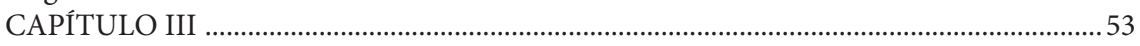

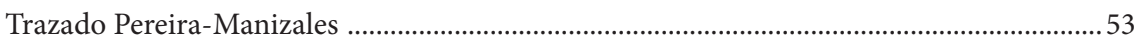

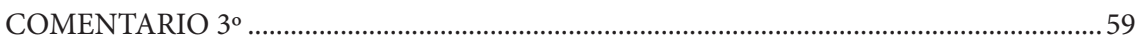

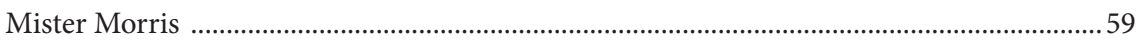

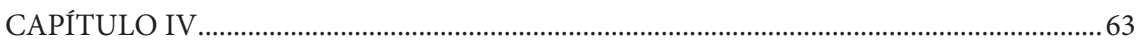

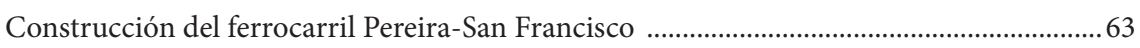

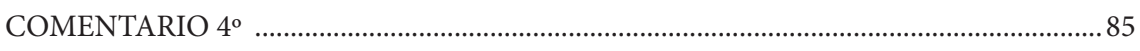

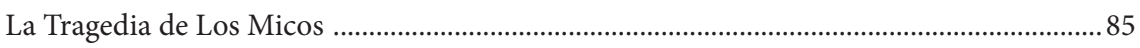

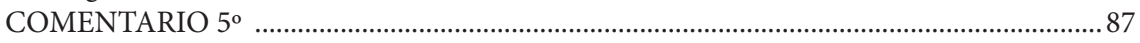

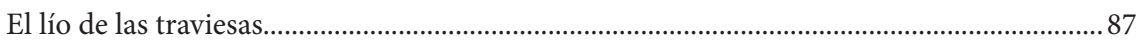

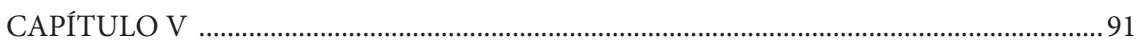

Construcción de San Francisco a Manizales......................................................................... 91

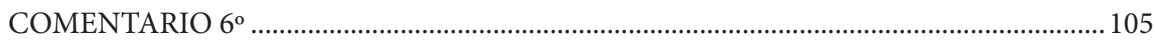

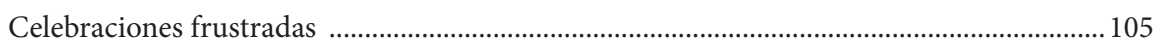

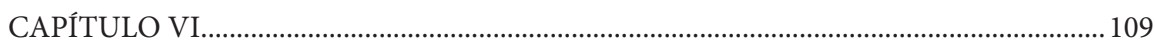

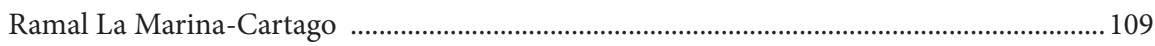

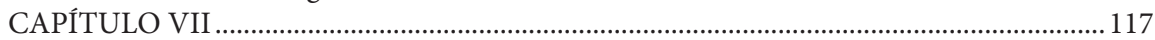

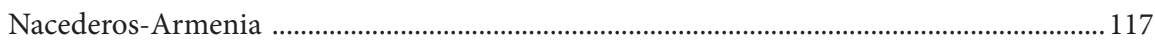

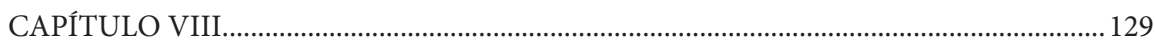

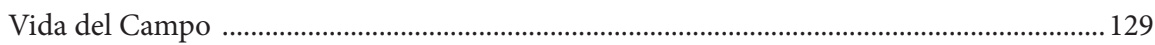

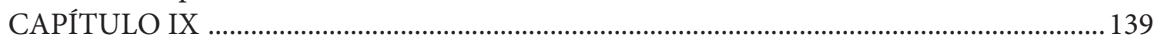

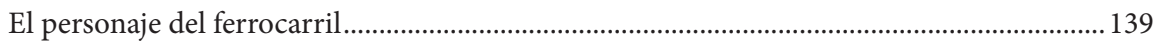

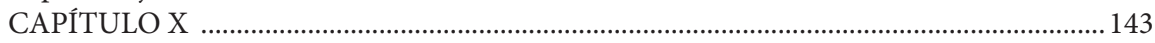

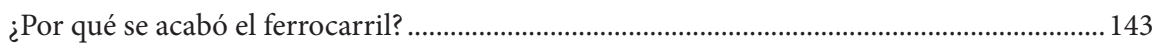

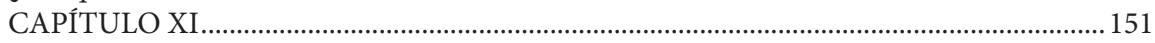

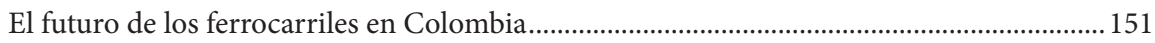

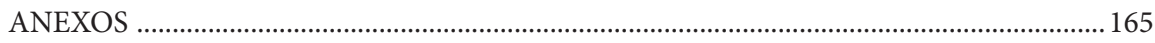

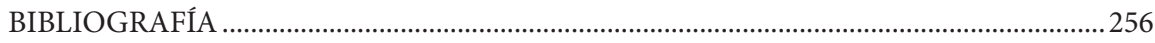

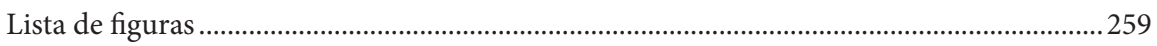





\section{Agradecimientos especiales}

Al historiador y prologuista, Álvaro Zuluaga Ramírez, compañero de luchas, con sus riesgos, sinsabores y alegrías que acarreara esta investigación, y quien, además, me introdujera amablemente en su círculo de amistades y colegas versados en el tema. Con él esculcamos cuanto archivo histórico se nos atravesara en la búsqueda de información relacionada con los ferrocarriles.

A los profesores: Albeiro Valencia Llano, Vicente Fernán Arango Estrada y Pedro Felipe Hoyos Körbel, por su atención, por compartir sus conocimientos, por sus consejos y por el ánimo que me infundieran para la continuación de esta investigación.

A la arquitecta María Eugenia Beltrán y al economista Gonzalo Alberto Valencia, coautores del libro Armenia enclave exportador de café 1927-1958, por su generosidad al compartir su interesante y bonito texto.

Al artista y emprendedor, Felipe Chiquito y al señor Jhon James, funcionarios del Municipio de Villamaría, por su amable atención, por el suministro de importante información y por su acompañamiento por los antiguos senderos del ferrocarril.

Al profesor Jaime Ochoa por su valiosa colaboración como revisor de textos.

A Víctor y Manolo conductores de transporte veredal por su hábil e intrépido manejo por entre trochas y barrancos, vestigios de la antigua banca del ferrocarril.

Y a todos aquellos, que, en una u otra forma, ayudaron a que esta investigación saliera a luz pública, muchas gracias. 


\section{NOTA DEL AUTOR}

La narración que presento a ustedes tiene como "columna vertebral", o fuente primaria, el libro El Ferrocarril de Caldas (1927) de Néstor Echeverri, texto sin el cual la historia del Ferrocarril de Caldas, como historia detallada y global, no existiría ni habría posibilidad de reconstruirla por la infortunada desaparición de su documentación en los incendios de la ciudad de Manizales en el siglo pasado.

La autoridad del doctor Echeverri para narrar los hechos está respaldada por su participación en la administración del ferrocarril en varias oportunidades y por su vinculación como Secretario de Hacienda del Departamento de Caldas en los años 1922 y 1925.

La edición consultada pertenece a mi biblioteca personal y llegó a mis manos por la afectuosa donación de la señora Ligia Serna de Isaza, hija del ingeniero Eleuterio, protagonista destacado en la construcción del Ferrocarril.

El relato del libro obedece a una estructura cronológica que transcurre entre el año de 1911, cuando se produce la Ordenanza No24 de la Asamblea del Departamento de Caldas, por medio de la cual se declara de utilidad pública una vía férrea que comunique a la capital de Caldas con un puerto fluvial en el río Cauca, hasta 1929 con la terminación del ferrocarril Nacederos-Armenia.

Concordante con este orden, su localización se desplaza entre Puerto Caldas, situado en la desembocadura del río La Vieja al río Cauca, que corresponde al sitio de la primera estación del Ferrocarril de Caldas, pasando por la estación La Marina, frente a Cartago y continuando hacia Pereira, San Francisco y Villamaría, hasta llegar a Manizales.

En el capítulo VI se relata el trazado y construcción del ferrocarril NacederosArmenia y en el capítulo VII la conexión de la estación La Marina con el ferrocarril del Pacífico en Cartago. 
La narración está dividida en capítulos, correspondientes al trazado y la construcción del ferrocarril, en los cuales el texto pretende ajustarse a la verdad histórica, y en "comentarios", donde me refiero a acontecimientos, eventos o circunstancias relacionados con el tema del Ferrocarril de Caldas; en ellos me tomo la libertad de utilizar un estilo menos rígido, más no menos cierto, cargado de adjetivos y calificaciones personales ${ }^{1}$.

En esta segunda edición se incluyen dos nuevos capítulos que obedecen a las inquietudes manifestadas durante la presentación de la primera edición. El primero se refiere a la logística para organizar la vida de 1.000 o más trabajadores en el campo y, el segundo, al futuro de los ferrocarriles en Colombia.

Esta nota pretende aclarar, orientar y facilitar la lectura del libro, el cual, en su primera edición fue reconocido por la Sociedad Colombiana de Ingenieros con el premio Rafael Álvarez Salas. Este reconocimiento se le otorga al mejor trabajo presentado en los últimos dos años en torno al tema de ferrocarriles.

1. El trabajo en torno a la consulta de textos sobre la historia del Ferrocarril de Caldas se hizo de forma exhaustiva en varios archivos del país. Debido a la naturaleza de las fuentes, en ocasiones, no fue posible indicar la referencia completa, pero se dejan a disposición de los lectores la mayor cantidad de datos posibles para orientar posteriores indagaciones sobre las temáticas aquí tratadas. 


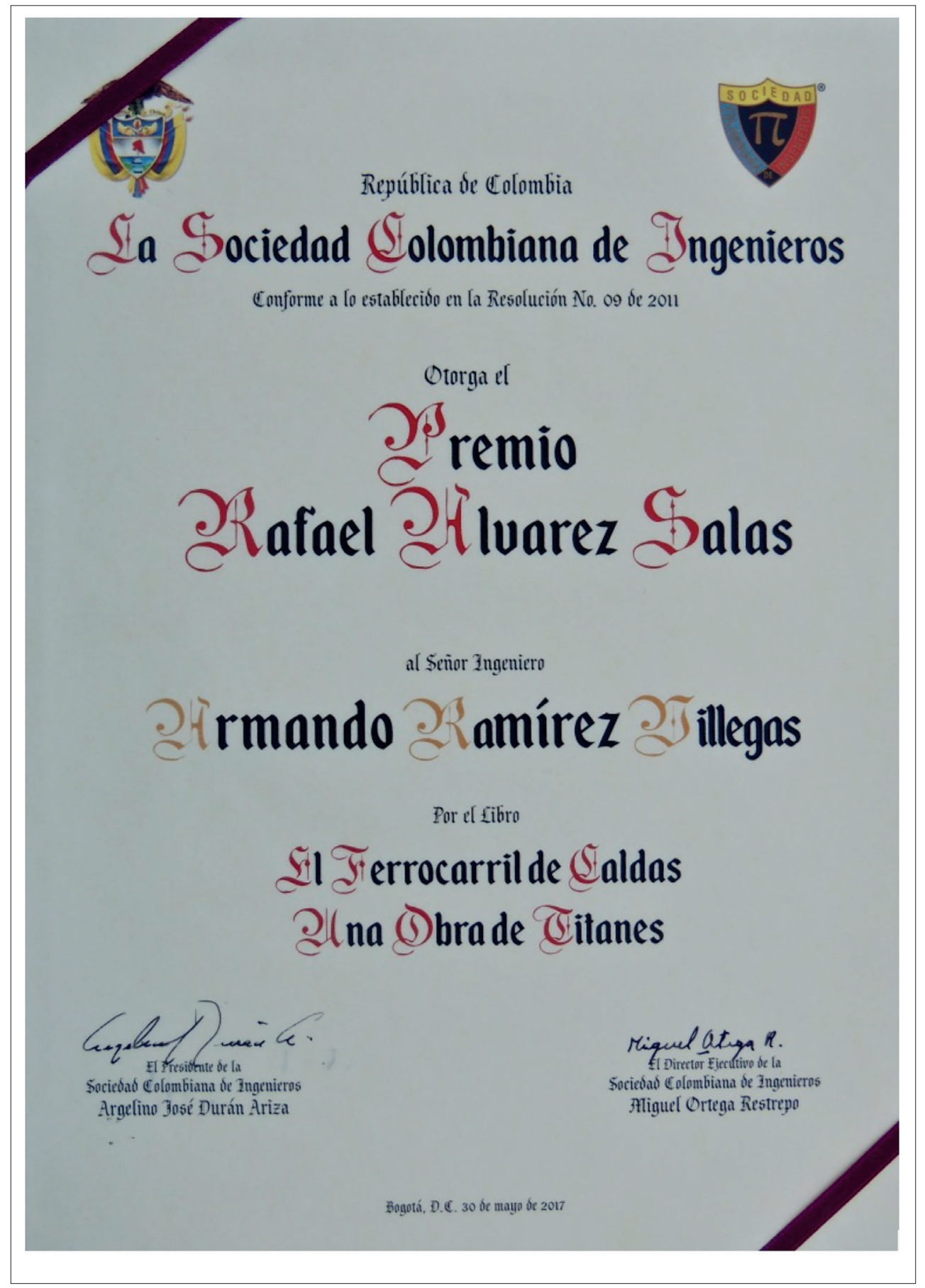

Figura 1. Premio Rafael Álvarez Salas 
RECONOCIMIENTO A MI PADRE

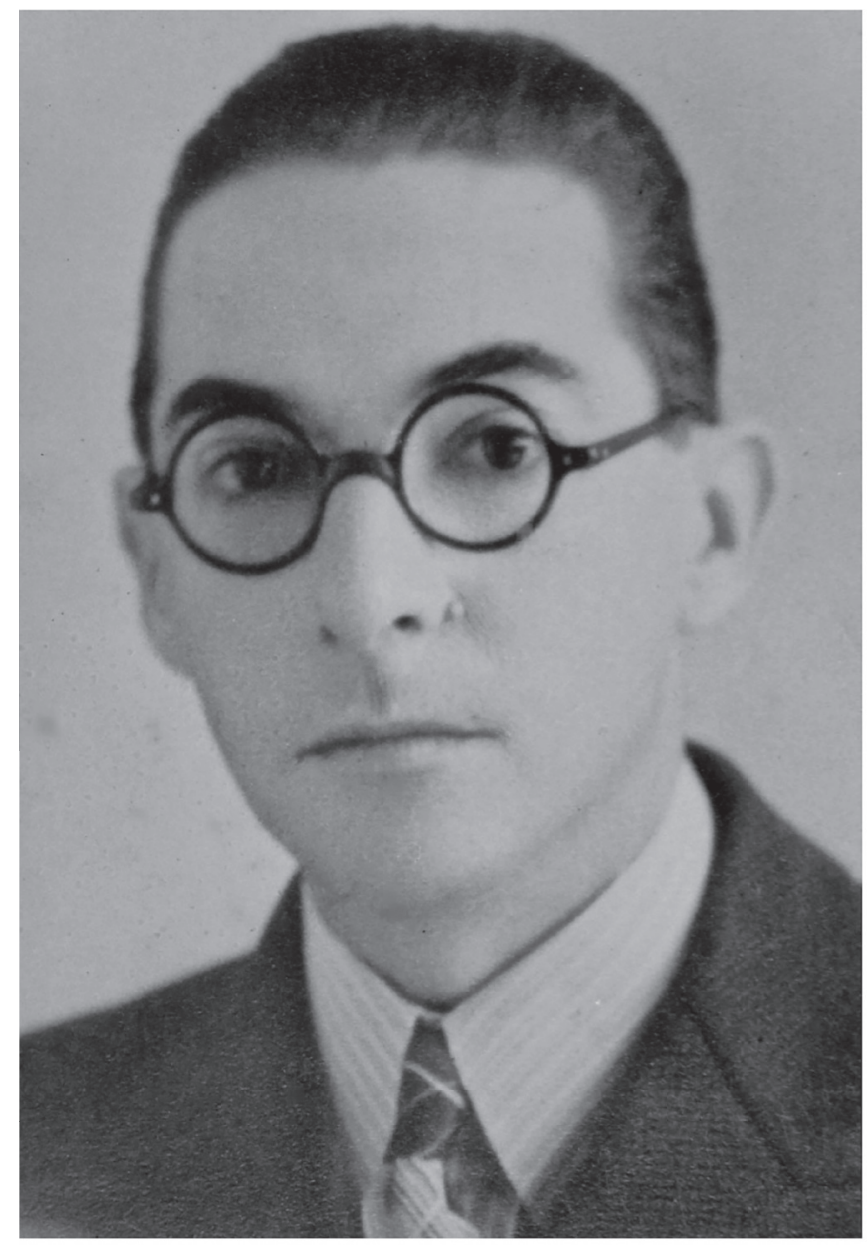

Figura 2. Ingeniero Ernesto Ramírez Jaramillo

Fuente: fotografía archivo personal. 


\section{A manera de prólogo}

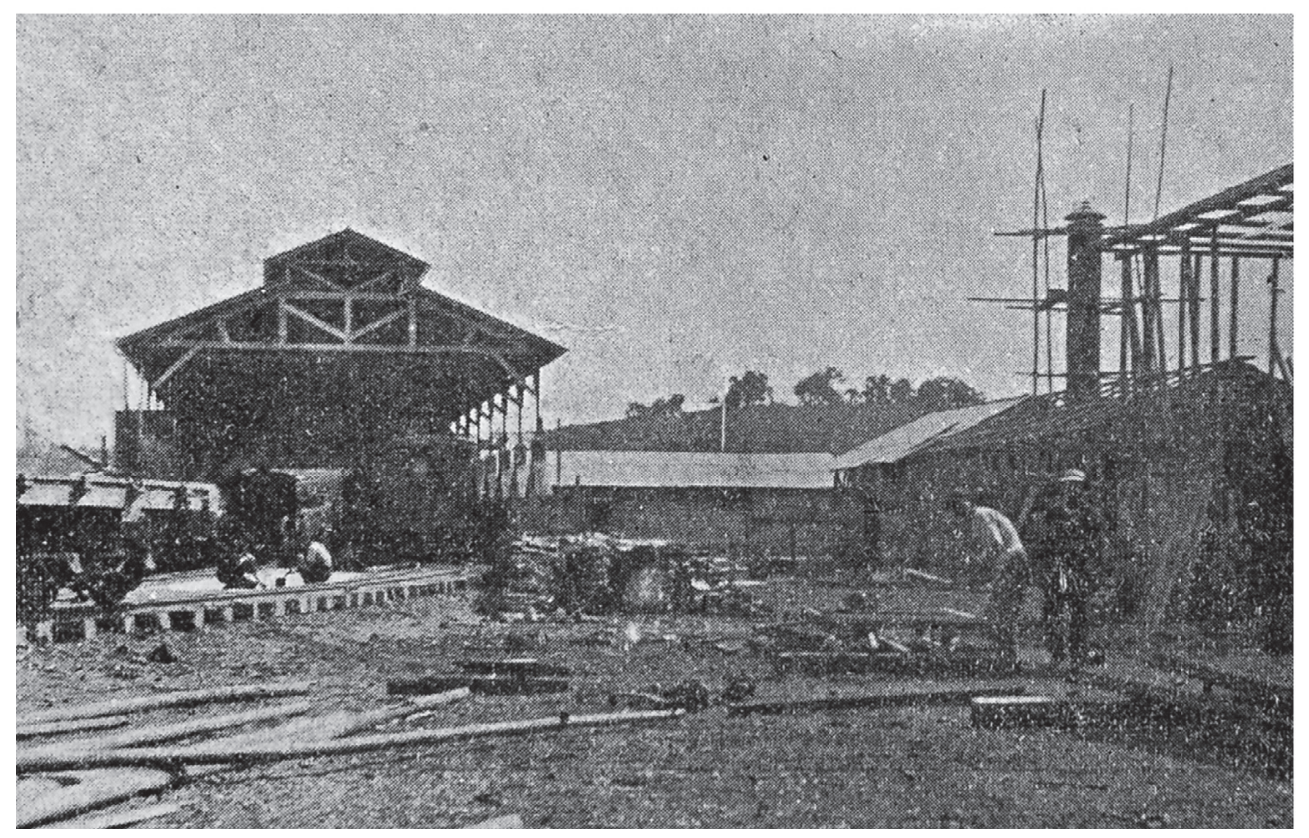

Figura 3. Talleres del Ferrocarril en Pereira

Fuente: Revista Cromos N²70. Agosto 13 de 1921.

$\mathrm{E}$ 1904, asumió la Presidencia de la República el progresista general Rafael Reyes Prieto, uno de los mandatarios más capaces y visionarios de toda la historia colombiana, destacado con numerosas y novedosas iniciativas durante la Asamblea Nacional Constituyente de 1905; por ejemplo, la reforma de la división político administrativa del país. Entre las argumentaciones para esta reforma estaba la resolución de conflictos seculares entre los diferentes estados soberanos de finales del Siglo XIX. En desarrollo de esta idea se creó el Departamento de Caldas, como una cuña insertada entre el liberal Estado Soberano del Cauca y el conservador Estado Soberano de Antioquia, tomando para ello una buena porción del último y otra parte considerable del nordeste del primero, las provincias de Córdoba y del Quindío darían lugar a la efímera "mariposa verde". Las tres ciudades más representativas del nuevo departamento, Manizales, Pereira y Armenia, con menos 
de medio siglo de fundadas, habían nacido del vigoroso proceso migratorio iniciado en Antioquia a principios del siglo anterior, el cual había encontrado en el cultivo del café una gran fuente de riqueza, la misma que llevó al nuevo territorio a convertirse en uno de los más prósperos de la nación.

Pero, en ese momento, el nuevo departamento solamente tenía como vía de exportación para el grano pésimos caminos como el que iba de Manizales a Honda, donde el café se embarcaba en los vapores que lo llevarían a la Costa Atlántica; y los de herradura que iban de Pereira y de Armenia a Cartago, donde el grano se cargaba en vapores que navegaban por el río Cauca, lo llevaban a Cali y, finalmente, a Buenaventura. Por esos caminos, se transportaba el café en mulas y bueyes hacia el departamento del Cauca y, por ellos mismos, se traían el cacao y otras mercancías que requería la población que ya vivía en esta nueva porción de Colombia. Lo anterior llevó a la dirigencia caldense -apoyada por el nuevo impulso que le venía proporcionando el gobierno nacional a la construcción de obras públicas y, particularmente, a los ferrocarriles- a solicitar, en 1911, a la administración de Carlos E. Restrepo -abogado antioqueño, conservador moderado y opositor de Rafael Reyes- la inclusión, dentro de la subvención oficial, de una ferrovía que conectara la capital de Caldas con los vapores del río Cauca. De esa manera, en diciembre de 1911, los gobiernos nacional y departamental firmaron un contrato en el que la Nación autorizaba al gobierno de Caldas a construir un ferrocarril desde el río Cauca hasta Manizales, de propiedad del departamento y, además, le otorgaba una subvención para la construcción de la obra, tal como lo había dispuesto la ley en los gobiernos de la Regeneración, en 1888.

La Gran Guerra, conocida como Primera Guerra Mundial, y la consecuente disminución en las exportaciones de café a los países contendientes, hizo que se aplazara la obra hasta 1915 ya bajo la autoridad del ingeniero antioqueño Luis A. Isaza. El puerto sobre el río Cauca, Puerto Caldas, origen del trazado, tendría una efímera pero fastuosa existencia. El inicio de la construcción, el 16 de julio de 1915, en el sitio mencionado, se llevó a cabo con una ceremonia a la cual llegaron personalidades importantes de la región; el tramo comprendido entre sus primeros 10 kilómetros, estuvo a cargo de los ingenieros Jorge Escobar y Alfonso Bernal, quienes, pese a numerosos inconvenientes asociados con factores climáticos que produjeron grandes desbordamientos e inundaciones de los ríos Cauca y La Vieja sobre el corredor previsto, y los cuales a su vez obligaron a implementar obras no previstas como alcantarillas y puentes, lograron llegar a la estación de La Marina, cercana a Cartago, el 20 de julio de 1917, y hacer entrega al gobierno nacional de 
dicho tramo de diez kilómetros, punto de partida de un ascenso que culminaría solo diez años después en la Avenida Cervantes de la ciudad de Manizales.

El 8 de julio de 1921 arribó a Pereira la primera locomotora en medio del orgullo y las celebraciones carnavalescas de nuestros coterráneos, pero, por diversas razones, el alcalde, Valerio Salazar, decidió que la ceremonia oficial de inauguración se llevaría a cabo el 7 de agosto con la presencia de autoridades de carácter nacional, departamental y municipal. Recordemos que en los siguientes diez años -conocidos como la "década de Oro"- nuestra ciudad pasaría de ser una aldea con techos de paja y pisos en tierra a ser la primera ciudad de Latinoamérica con planta automática de teléfonos, empresa exportadora de energía, sede de múltiples entidades bancarias, clubes sociales, y demás características que destacan la pujanza y la visión de sus dirigentes, quienes apoyados en el avance tecnológico del ferrocarril impulsaron empresas y entidades que aún nos caracterizan ante el concierto nacional como la Sociedad de Mejoras Públicas, la Cámara de Comercio y el Hogar del Anciano para poner solo unos ejemplos.

En ese momento, se da partida a la quijotesca empresa de conectar la capital del departamento con la red ferroviaria nacional, empresa que no respondía a ningún estudio de factibilidad ni a ningún concepto técnico objetivo, siempre se adelantó en medio de las insalvables dificultades topográficas que hacían de dicha línea un absurdo tecnológico y comercial. Menos de treinta años después ya se había suspendido su funcionamiento en el último tramo y de manera inexplicable en los demás mencionados. Con minucioso detalle, a continuación, se presentan los pormenores de esta épica gesta que transformó definitivamente el carácter de todos los involucrados y le otorgó vocaciones a unas aldeas cuyo horizonte estaba condenado a repetir la historia de sus raíces perpetuando una economía feudal con algunos desvaríos pastoriles. Se logró convertir el fruto regional en el primer producto de exportación colombiano y soporte de su economía durante todo el siglo XX.
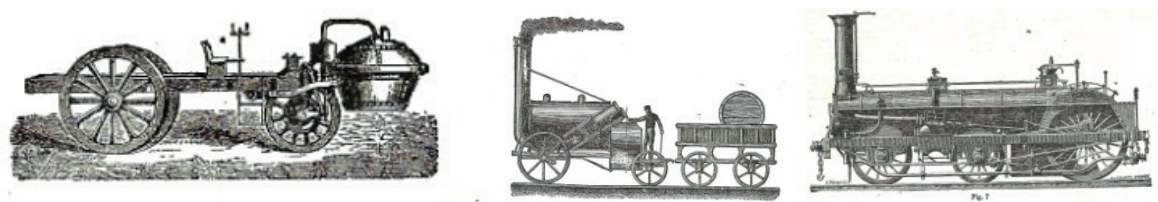

Figura 4. Locomotoras antiguas 


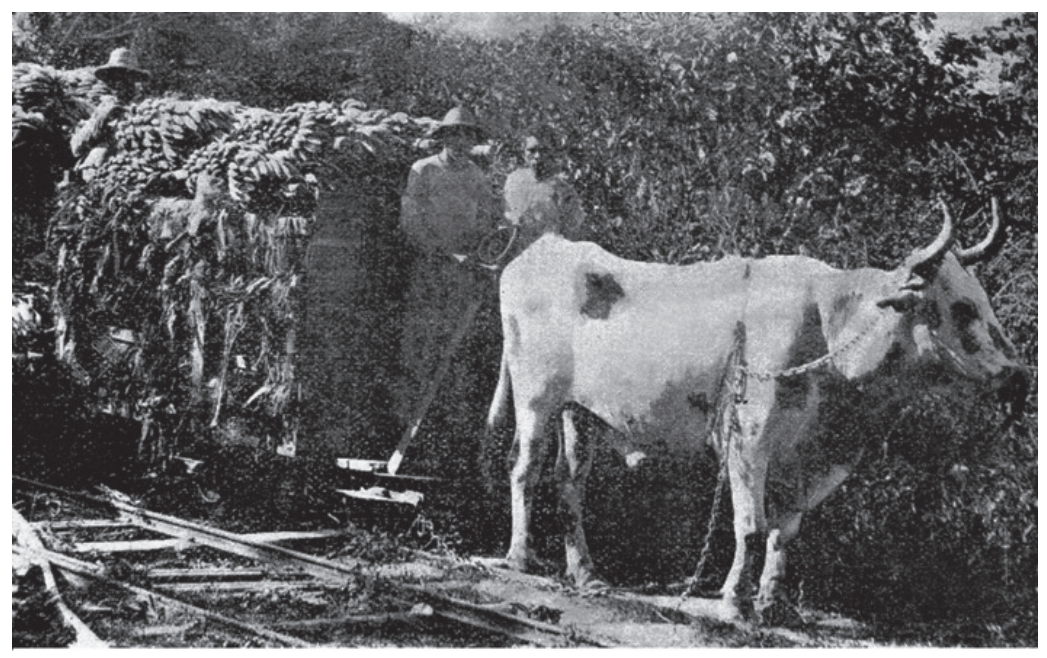

Figura 5. Transporte a las estaciones férreas

Fuente: Monsalve, Diego. (1927). Colombia Cafetera.

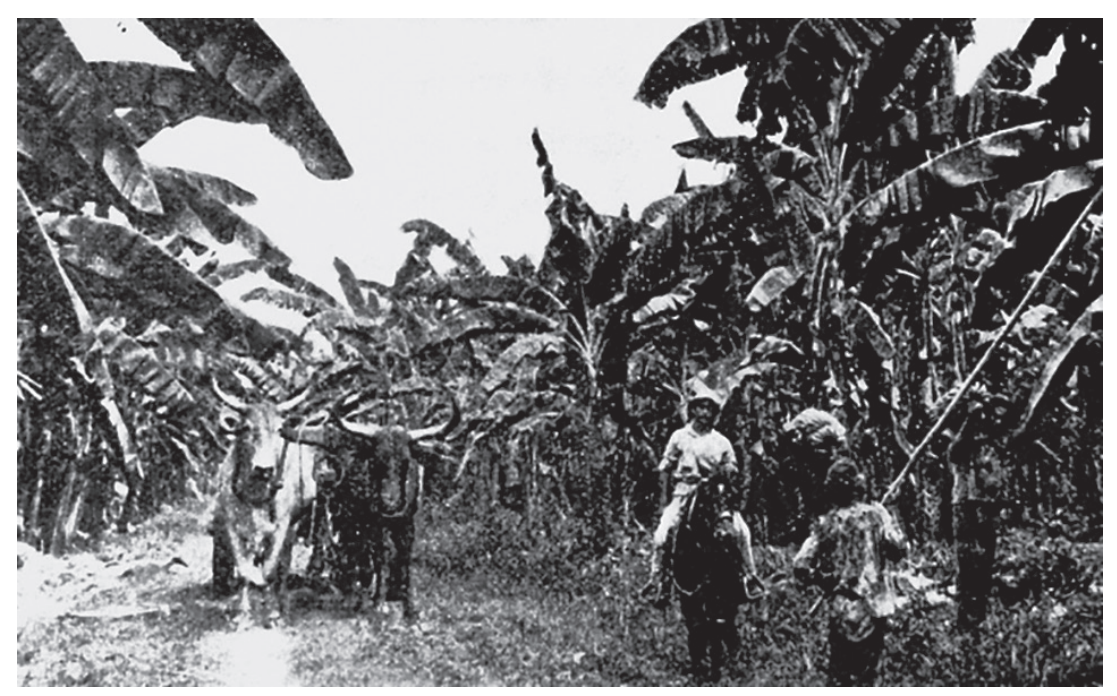

Figura 6. Bueyes arrastrando carga a las estaciones férreas Fuente: Monsalve, Diego. (1927). Colombia Cafetera. 


\begin{abstract}
Ahora
para hacer el camino a la locomotora las lomas y los riscos disciplinaron; las colinas, las abras, se tornaron sabios cortes e insignes terraplenes, simétricos taludes; y líticos ciclópeos pontones;

y rectas y tangentes y curvas y espirales -curvas voluptuosas,

amplias-, y desnivel dosificado -un dos por milpara la fácil marcha de los trenes futuros, futuros, y la difícil de los actuales peatones. Dañaron el paisaje -que a mí no asaz me petacomo un pintor y un lienzo y la paleta:

dañaron el paisaje con técnicas absurdas y fórmulas tediosas, los sabios (infatuados como cualquier poeta), los sabios infatuados de ciencia ingenieril.
\end{abstract}

León de Greiff (1975) 


\section{INTRODUCCIÓN}

\section{Trazar y construir un ferrocarril}

$\mathrm{T}$ razar y construir un ferrocarril es cosa fácil. Nos asignan dos puntos sobre el planeta para construir entre ellos una vía férrea. Acudimos de inmediato a cualquier aparato, computador, tableta o teléfono, que pueda conectarse a la red, y con solo mencionarlos nos aparecen en la pantalla, localizados en un mapa, los dos sitios buscados. Pero no solo eso. Nos suministran sus coordenadas geográficas, su altitud, la distancia entre ellos y en tres dimensiones la orografía y el detalle de los accidentes geográficos interpuestos entre los dos. Simplemente le pedimos a un programa de computador que nos trace entre estos en pantalla la opción que mejor se ajusta a nuestros requerimientos. Podremos entonces incluir una nueva variable: costos, para que el programa nos dé una serie de alternativas de trazado, dentro de las cuales podamos escoger la que nos parezca más apropiada, de acuerdo con nuestro saber y entender. Es así de fácil en el siglo veintiuno. Hace un siglo la cosa era a otro precio. Empezando porque no existían mapas detallados de las regiones de Colombia. Solo algunos levantados a ojo y sin mayores detalles. Para el ingeniero de trazado la primera incógnita era saber en dónde estaba parado. Con un poco de suerte, con la información de los escasos residentes, con la ayuda de los baquianos, con los relatos de los arrieros, con la observación de las estrellas, podría imaginarse una posición. ¿Pero cómo saber hacia dónde queda el sitio al cual debe dirigirse? Una espesa montaña se le atraviesa para donde dirija la vista. ¿Hacia dónde arrancar? Posiblemente lo mejor sea seguir el camino de herradura. Si es que existe uno.

He ahí el dicho de que el mejor ingeniero de trazado era la mula. Pues bien, arrancamos, pero pronto nos damos cuenta que las pendientes y las curvas de los caminos están lejos de nuestras especificaciones para un ferrocarril y que no tenemos más remedio que empezar a descuajar monte para poder visualizar una ruta más adecuada. Más adecuada no quiere decir más fácil. El cerro de roca dura y empinada o el zanjón profundo del río empiezan a dirigirnos hacia otros lados por donde podamos vadearlos con menor esfuerzo pero alargándonos el camino hacia un infinito. A riesgo de volvernos repetitivos, describamos, primero que todo, cómo era el proceso del trazado de una vía en esos tiempos, fuera carretera o férrea. Hay que recordar que la ingeniería no contaba con ninguna de las herramientas de 
que se dispone en la actualidad, ni con las ayudas tecnológicas que hoy facilitan enormemente el trabajo. Ni bulldozer, ni retroexcavadora, ni compactadora, ni nada parecido. Solo palas, palines, picas y carretas de mano. Ni aerofotografías, ni mapas del terreno y mucho menos un Google Earth que los orientara por dónde arrancar y seguir. Ni siquiera los tránsitos o teodolitos tenían la sofisticación de hoy en día. Solo existía un elemento valioso para su trabajo: la dinamita, sin ella hubiera sido imposible atravesar las montañas rocosas.

La primera labor era hacer un reconocimiento del terreno por donde se creía que debería pasar la vía. Lo hacía el ingeniero jefe o aquel ingeniero que tuviera más experiencia en trazado de vías. Aperado con un "locke", o nivel de mano, y acompañado por su equipo de cadeneros y trocheros, salían, a pie o en mula, por los caminos de herradura o por las trochas abiertas por los peones, siguiendo una línea que cumpliera con una pendiente aproximada, escogida por el ingeniero, sobre la cual se iban poniendo estacas a una distancia especificada para identificar la dirección de la línea. Posteriormente vendría el ingeniero encargado de trazar una preliminar, que consistía en trazar una línea, con la ayuda de un teodolito o tránsito, que seguiría el estacado puesto en la inspección inicial, sobre la cual se pondrían estacas cada 10 o 20 metros, dependiendo de la topografía del terreno, y desde estas, se trazarían perpendiculares, con longitudes de 10 o 20 metros a cada lado de la línea principal, para que sobre ellas, un tercer ingeniero, con la ayuda de un nivel de precisión, fuera tomando las alturas del terreno, a unas distancias que podrían variar dependiendo de la topografía de la sección transversal. Con los datos anotados en el campo, en las carteras de tránsito y de niveles, se procedía a dibujar en un plano, normalmente en el campamento, lo encontrado en el terreno. Vendría el ingeniero de trazado, y sobre el plano elaborado, dibujaría la planta de la que sería la línea definitiva, poniendo en la parte inferior del dibujo, el perfil correspondiente a la planta dibujada. Con este plano, ajustadas las pendientes requeridas y diseñadas las curvas horizontales, el ingeniero de trazado, volvería al terreno para hacer la localización definitiva de la línea. Detrás de este ingeniero vendría otro encargado de levantar la topografía definitiva, con los cortes y llenos correspondientes, para proceder a calcular los volúmenes del movimiento de tierras. Como puede verse era un verdadero y difícil trabajo de equipo. 


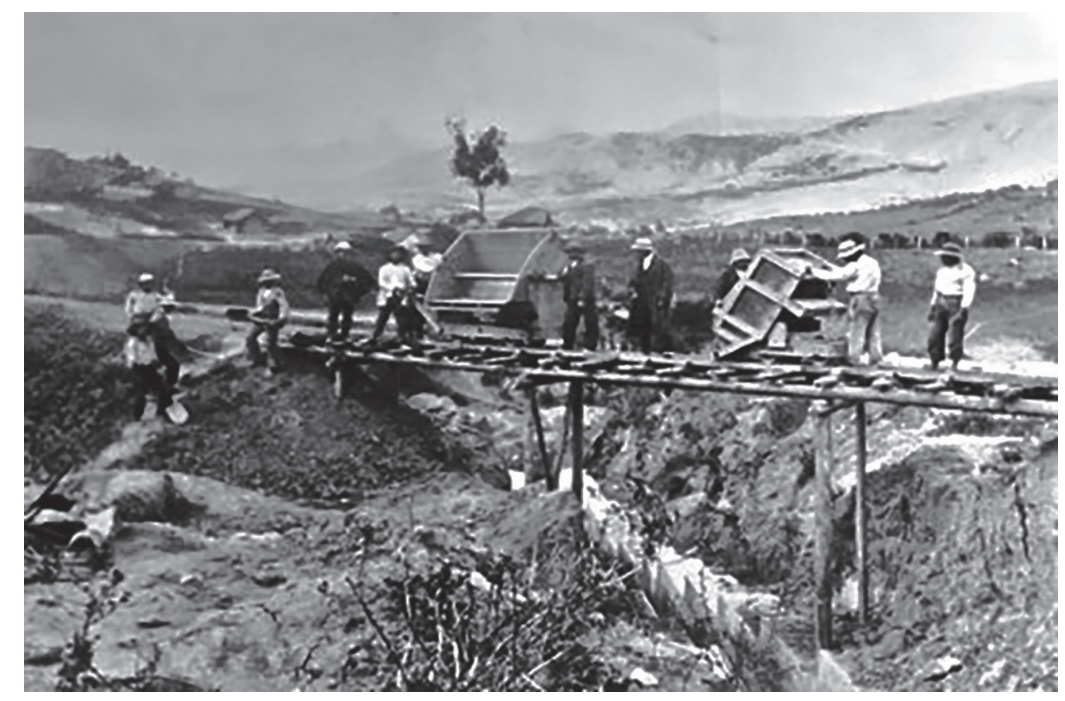

Figura 7. Construcción de un Ferrocarril

Fuente: Foto del Archivo de Pedro Felipe Hoyos K.

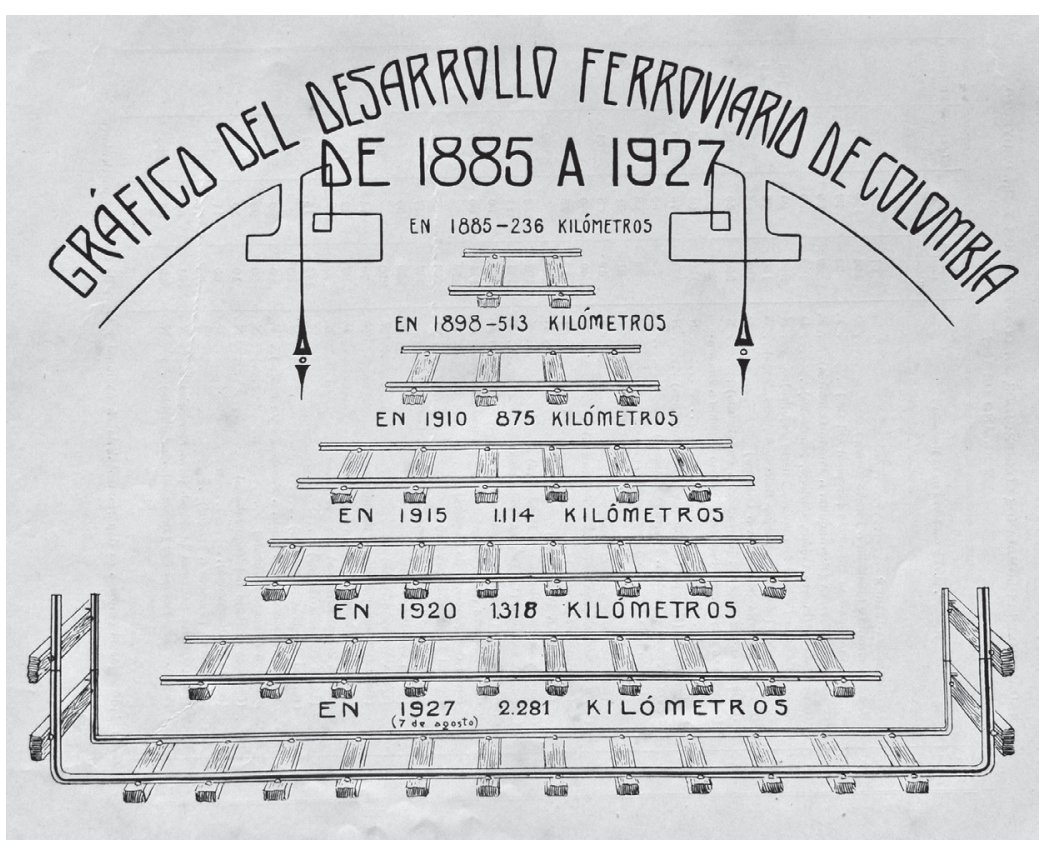

Figura 8. Desarrollo Ferroviario de Colombia Fuente: Monsalve, Diego. (1927). Colombia Cafetera. 


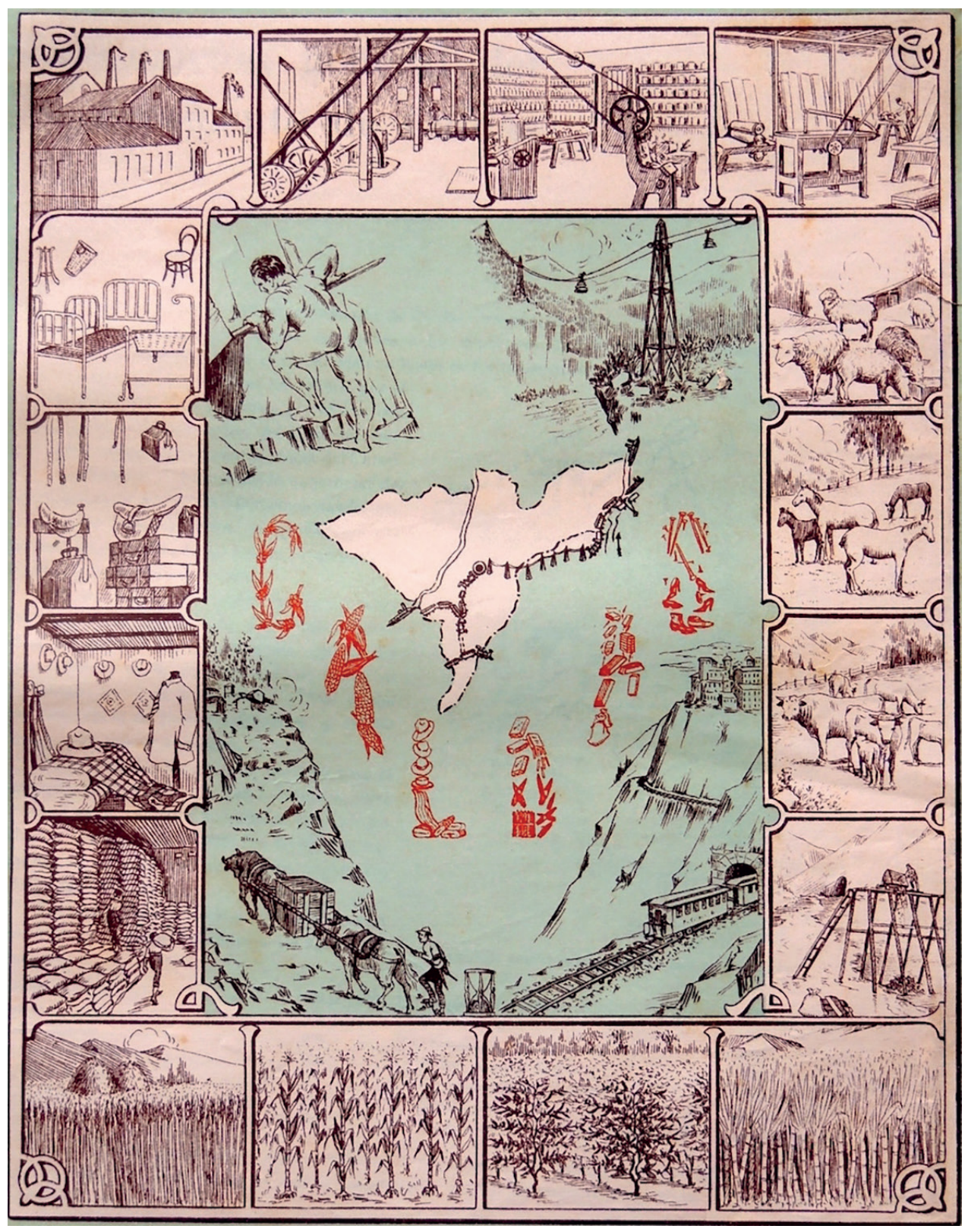

Figura 9. Alegoría al Departamento de Caldas.

Fuente: Monsalve, Diego. (1927). Colombia Cafetera. 


\title{
CAPÍTULO I
}

\section{Trazado del ferrocarril Puerto Caldas - Pereira}

\begin{abstract}
A 1 reunirse la primera Asamblea del Departamento de Caldas, en el año de 1911, Ala necesidad de una vía que diera salida rápida y barata a nuestras fértiles comarcas se había apoderado ya de la conciencia pública. El gobierno Nacional estaba presidido por Carlos E. Restrepo, y el Departamental por el general Ramón Jaramillo (Echeverri, 1927).
\end{abstract}

La Ordenanza 24 de 1911 declara de utilidad pública una vía férrea que comunique la capital de Caldas con un puerto fluvial en el Cauca, en busca de la vía al Pacífico, o uno en el Magdalena para encontrar los puertos del Atlántico. Se crea una Junta Autónoma compuesta por el señor Gobernador, tres miembros elegidos por la Asamblea, y el Secretario general de la Gobernación, la misma que unos meses después fue modificada para aumentarla a cuatro miembros, además del señor Gobernador y su Secretario general, y fijándole un periodo de dos años. La Junta designó como ingeniero jefe de las obras a Julián Arango quien debía organizar los estudios y trabajos preliminares. Se logró la venida del ingeniero Felipe Zapata, gerente del Ferrocarril de la Sabana, para que emitiera su concepto sobre la viabilidad de la empresa y demás inquietudes técnicas.

El ingeniero Zapata hizo un reconocimiento del terreno entre Manizales, Cartago y el río Cauca, y en su informe a la Junta, el $1^{\circ}$ de enero de 1912 (Anexo $\mathrm{N}^{\circ} 1$ ), divide el proyecto en tres secciones: la primera entre el río Cauca y Pereira, la segunda, entre Pereira y San Francisco (hoy Chinchiná) y la tercera, entre San Francisco y Manizales. Sugiere, además, que se inicie en un punto del río Cauca cerca de la ciudad de Cartago y que se tenga en cuenta un posible ramal hacia la ciudad de Armenia para dar salida a los grandes centros productores del Quindío. La Junta contrata, con el ingeniero Jorge Páez, un estudio más detallado, atendiendo las sugerencias del ingeniero Zapata. En su informe de mayo de 1912 (Anexo No2), planteaba dos posibilidades: la primera iniciar el trazado en Puerto Dagua, situado sobre el río Cauca, cercano a La Virginia, y la segunda, iniciarlo en el Puente Bolívar, a la salida de Cartago. 
En marzo de 1912, el ingeniero Páez, acompañado por los ingenieros Julián Arango, Héctor Acevedo y Alonso Restrepo, inicia el trazado definitivo que arrancaba del río Cauca, ascendía por la hacienda Alsacia (entre La Virginia y Cerritos), y continuaba hasta la Quiebra de Vásquez (hoy Boquerón) (Echeverri, 1927).

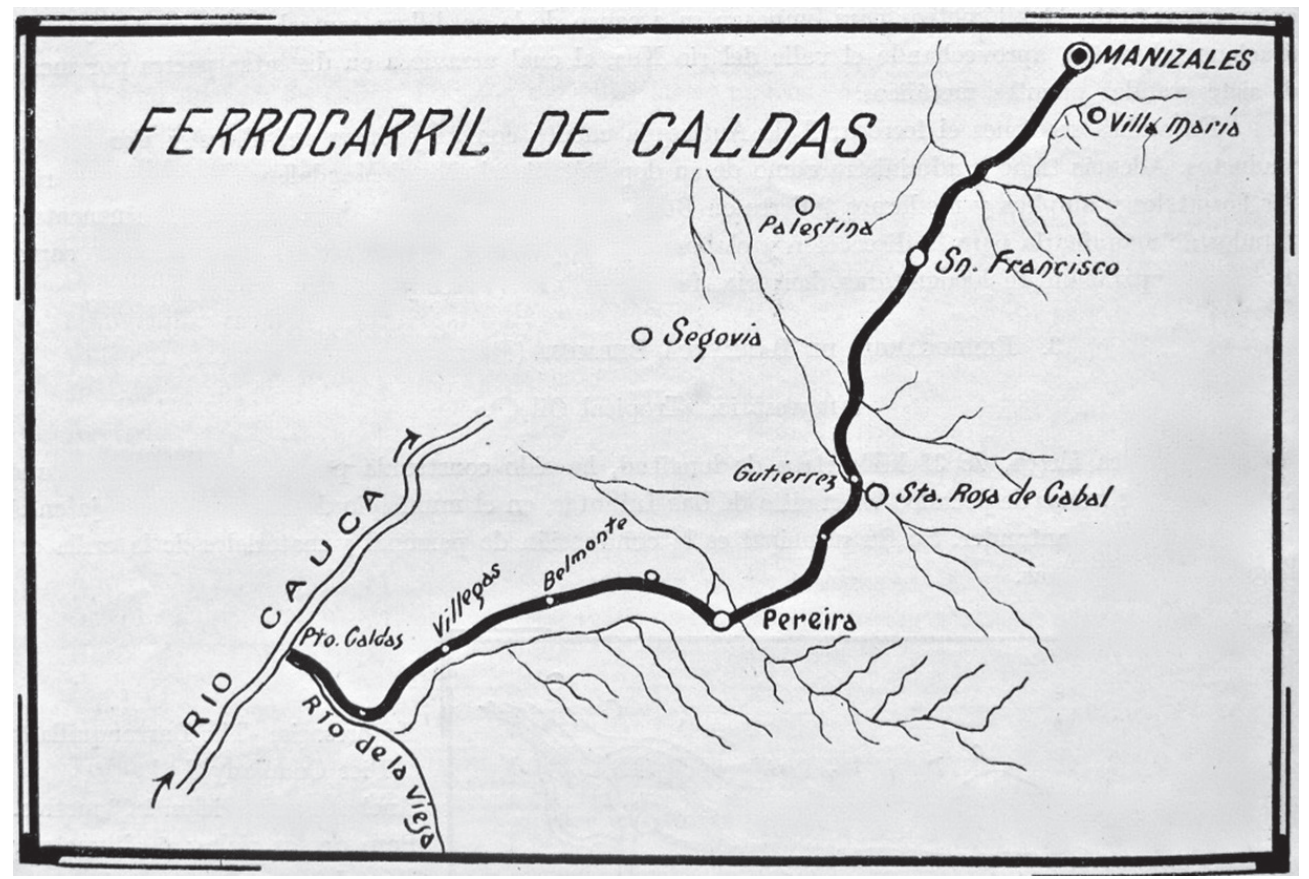

Figura 10. El recorrido del Ferrocarril de Caldas

Fuente: Monsalve, Diego. (1927). Colombia Cafetera.

El año de 1913 fue funesto para la obra. Se propagó un sentimiento de incertidumbre sobre la bondad y facilidad de la obra, hasta el punto de contagiar a la Asamblea Departamental, la cual produce la Ordenanza 26, que exigía la suspensión indefinida de la obra. En 1914, bajo la Gobernación de don José Ignacio Villegas Jaramillo, vuelve a revivirse la idea logrando la aprobación de la Ordenanza 27, que establece la reanudación de los estudios y trazados de la vía. El ingeniero Luis A. Isaza, en su calidad de Ingeniero Jefe, propuso el estudio de una variante del trazado inicial de tal forma que en lugar de tomar la dirección hacia la Hacienda Alsacia, arrancara del sitio denominado Puerto Caldas, ubicado en la desembocadura del río La Vieja al río Cauca, y se dirigiera, siguiendo la margen derecha de dicho río, 
hacia las cercanías de Cartago, a la que sería la Estación La Marina, para continuar después su ascenso a la ciudad de Pereira, por la margen derecha del río Consota, hasta el sitio denominado Zanjón Hondo (K29 o Belmonte), en donde encontraría el antiguo trazado que ascendía por la Hacienda Alsacia. La Junta sometió la propuesta al estudio de la Sociedad Colombiana de Ingenieros, en cabeza del ingeniero Álvarez Salas, y del ingeniero Carlos de la Cuesta, miembro de la Junta. Obtenida la aprobación de los consultores se procedió al trazado de la "Variante Consota", en el cual intervinieron los ingenieros Luis A. Isaza, Florencio Mejía, Eleuterio Serna, Francisco Luis Arango, Carlos Vicente de la Cuesta y Benjamín Suárez. El trazado desde Belmonte hasta Pereira se hizo siguiendo la ladera por la margen izquierda del Río Otún, hasta encontrar la Quebrada Egoyá y siguiendo esta, aguas arriba, hasta llegar al sitio llamado Plaza de Ferias (hoy Parque Olaya Herrera), en el sur de la ciudad y fue terminado a finales de 1919, durante la administración del gobernador Pompilio Gutiérrez.
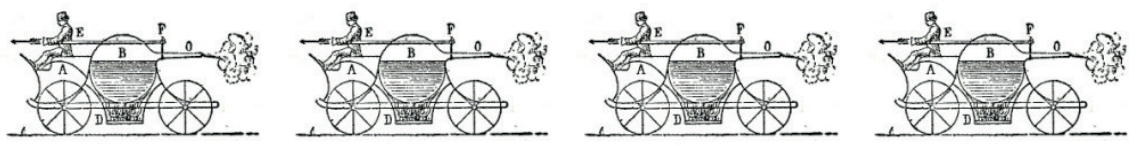

Figura 11. Vagones impulsados por vapor

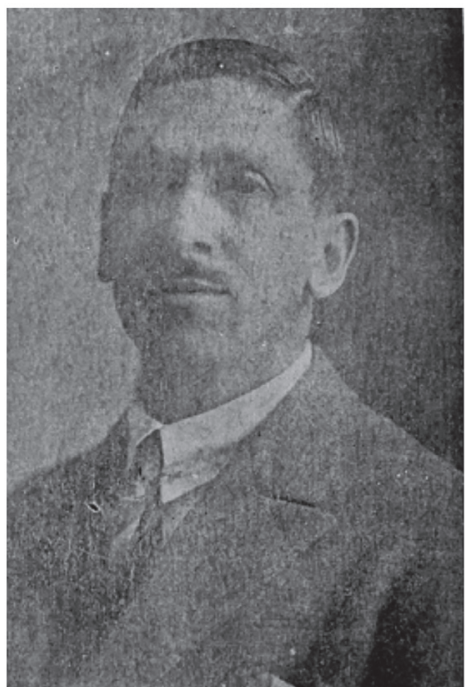

Figura 12. Ingeniero Jorge Páez González 


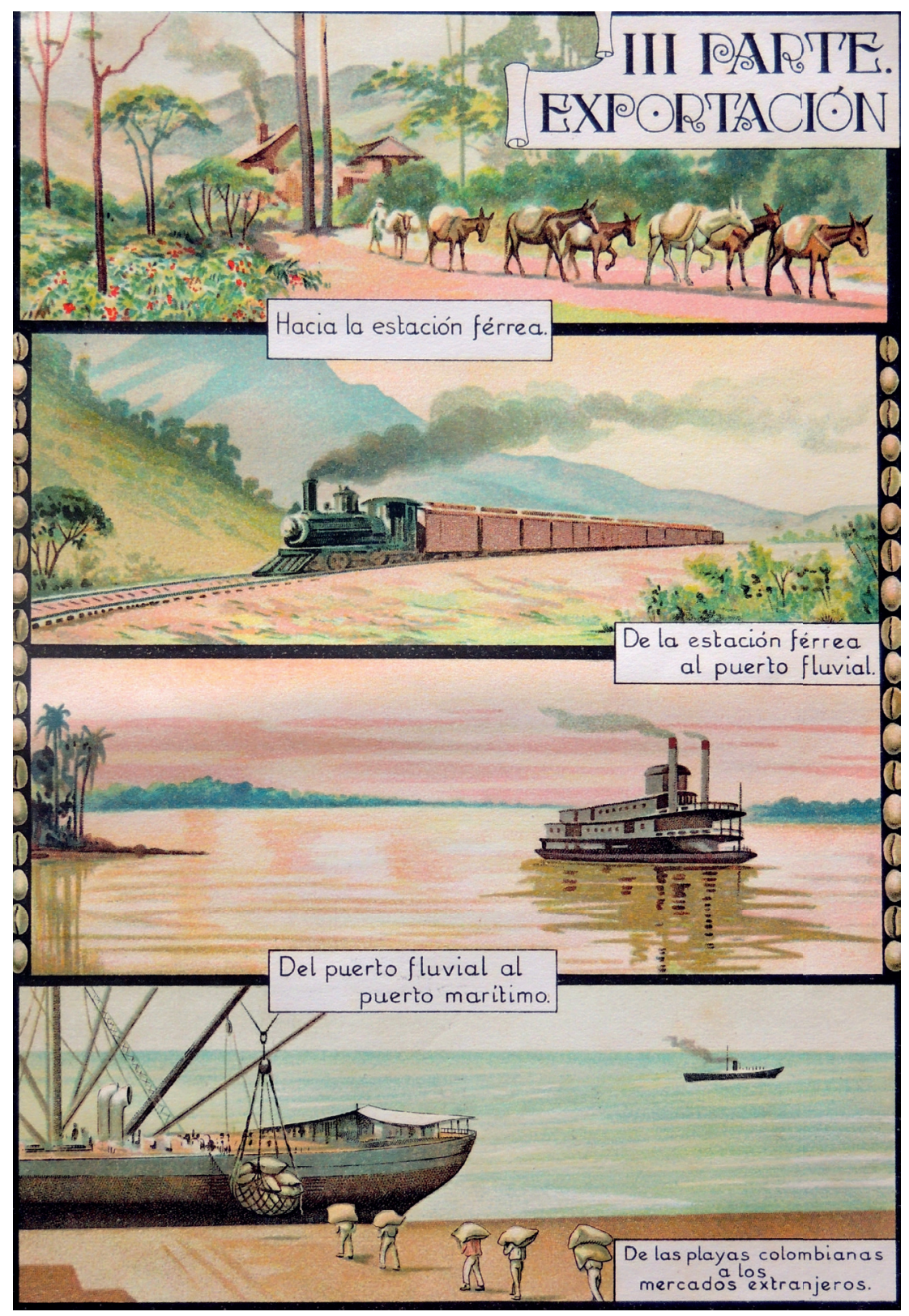

Figura 13. Alegoría a los tipos de transporte hacia las estaciones férreas Fuente: Monsalve, Diego. (1927). Colombia Cafetera. 


\section{COMENTARIO $1^{\circ}$}

\section{El Centenario de Puerto Caldas}

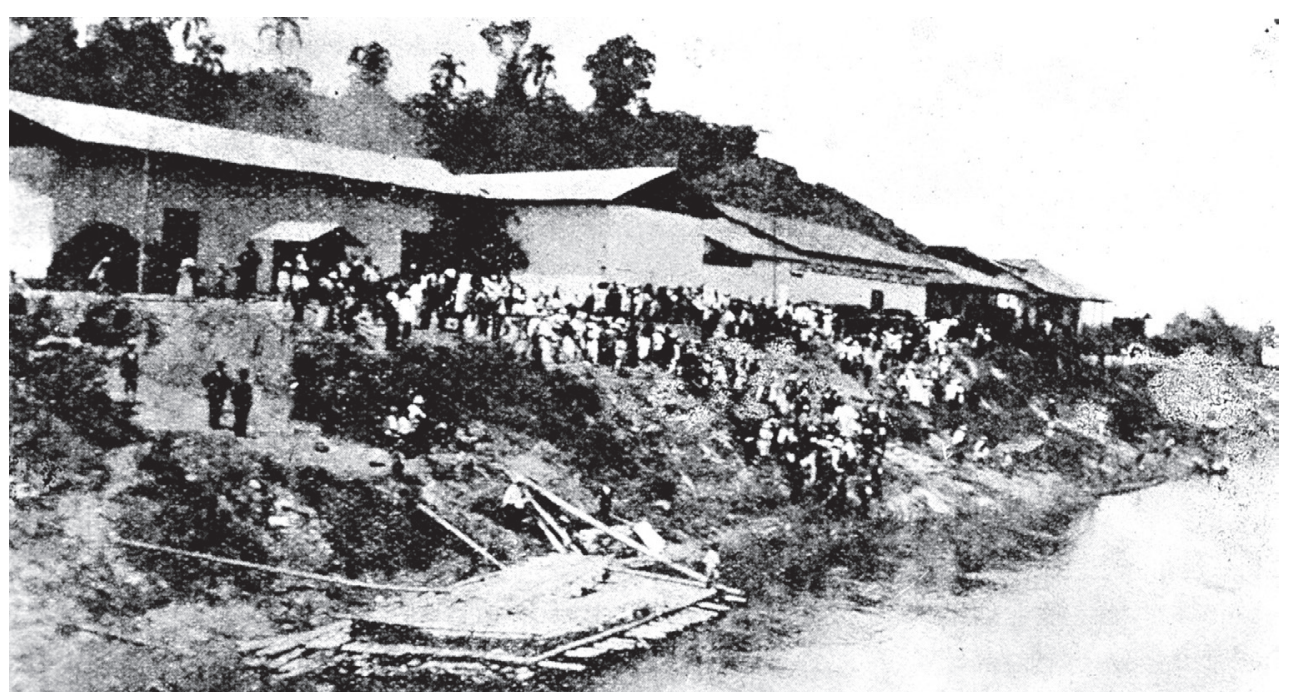

Figura 14. Puerto Caldas en el Río Cauca

Fuente: Fabo, Pedro (1926, p. 276). Historia de la ciudad de Manizales.

Manizales: Tipografía Blanco y Negro

U n simple cruce de ríos se convirtió, de repente, en un flamante puerto fluvial intermodal. A mitad de la segunda década del siglo veinte, surgió, como por arte de magia, un caserío en la confluencia del río Cauca con el río La Vieja, cuyo destino era convertirse en la posesión de una estación de ferrocarril, pero no cualquier estación: la estación inicial del Ferrocarril de Caldas. El sitio, conocido como La Isla o Calabazas, cayó bajo el ojo avizor de un ingeniero bogotano, de apellido Zapata, que buscaba con ansias cómo conectar con un ferrocarril, el río Cauca, en ese entonces, importante vía fluvial llena de vapores, con Manizales, importante ciudad aislada por su agreste topografía del resto del mundo, en aras de mejorar su conectividad. Era el año de 1915, más exactamente el 16 de julio de 1915, cuando un grupo de señores, entre políticos y personajes cívicos, se dieron cita en el lugar, para fundar un pueblo e iniciar la construcción de un ferrocarril, soñado por un ingeniero y necesitado por toda una región, de cuya reunión dejaron escrita constancia para el conocimiento del resto del país y como testimonio de un reto, que ellos mismos querían asumir pero que no estaban seguros de poder cumplir. 
Antes de que cantara un gallo, aquel valle boscoso y pleno de guaduales, se vio invadido por trabajadores que con hachas y machetes en mano, asolaban y abrían el campo, dando espacio para iniciar construcciones que conformarían lo que pronto sería la estación de Puerto Caldas. Pero no fue fácil su evolución. La naturaleza, dándose cuenta de su atropello, decidió entrar en franca lucha, desatándose un tremendo invierno, como no se veía en muchos años, provocando grandes avenidas de los dos ríos que cubrieron sus vegas llevándose sin piedad cuanto caía a su alcance. Y, como si esto fuera poco, la insalubridad de la zona se acentuó, dejando centenas de enfermos de disentería y fiebre amarilla. La terquedad y el anhelo del hombre, al fin se impusieron y el 21 de octubre de 1916, se inició la puesta de los primeros rieles del Ferrocarril de Caldas. Ya contaba el incipiente caserío con un edificio para atender la llegada y salida de los trenes y unas bodegas para el almacenamiento de las mercancías que llegaran, en los trenes, o en los vapores del Cauca, para su intercambio correspondiente, dado su condición de intermodalidad. Primero, era necesario que llegaran, en el sentido estricto de la palabra, los trenes compuestos de locomotoras, vagones de pasajeros, vagones de carga, jaulas para ganados, plataformas para materiales de construcción y los otros elementos y herramientas necesarios para su correcto funcionamiento. Como todos estos equipos eran producidos en el exterior, deberían llegar por vía marítima a Buenaventura y de allí por vía férrea a Yumbo, para ser embarcados, nuevamente por vía fluvial, hasta alcanzar nuestro Puerto Caldas. Los invito a imaginarnos, por un momento, cómo se sucederían los acontecimientos en aquel entonces. Superadas, en alguna forma, las dificultades para movilizar y transbordar las piezas en que deberían venir desbaratadas las locomotoras para ser embarcadas en el río Cauca, y luego, llegar en los planchones a la orilla del río, al frente de Puerto Caldas, nos aparece el problema de trasladar esas enormes y pesadas piezas desde los planchones hasta la ribera del río, que se encuentra unos tres o cuatro metros más alta que su nivel, para luego desplazarlos hasta los talleres.

¿Cómo hacerlo sin disponer de grúas, remolques o equipos de fuerza que faciliten la operación? No lo sabemos a ciencia cierta. Solo sabemos que contaban con la fuerza bruta de mulas y bueyes, la de algunos obreros forzudos y la inagotable imaginación y creatividad de los ingenieros y maestros de obra.

¡Es que todo fue así en el Ferrocarril de Caldas! Desde la superación de las afugias económicas, hasta la construcción a través de lomas y montañas escarpadas que ponían en jaque los conocimientos y experiencias de los ingenieros. Todo, todo fue una obra de titanes. 


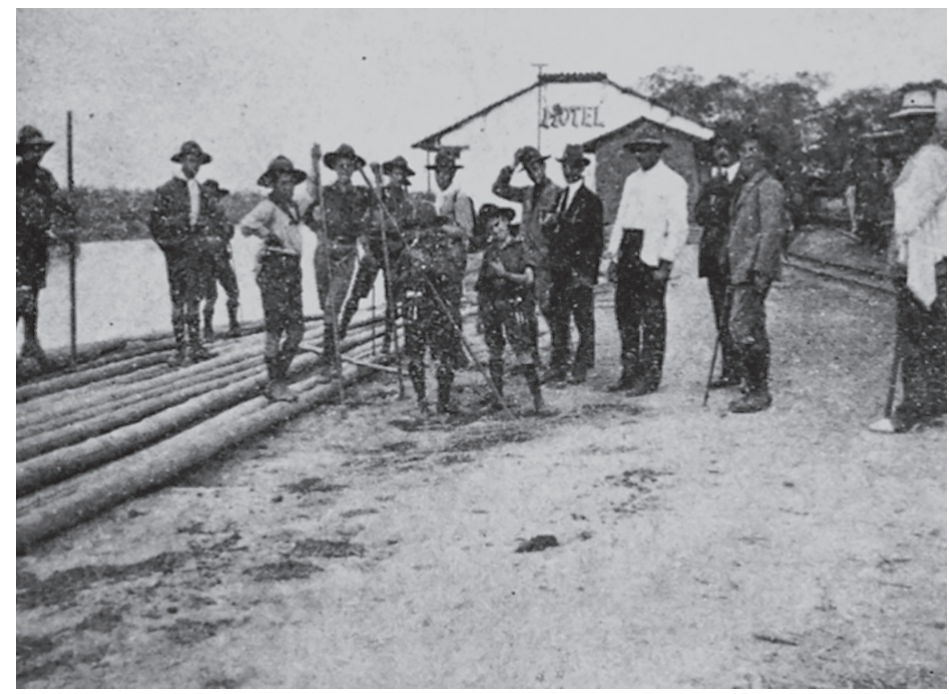

Figura 15. Excursionistas en Puerto Caldas

Fuente: Revista Cromos N²70. Agosto 13 de 1921

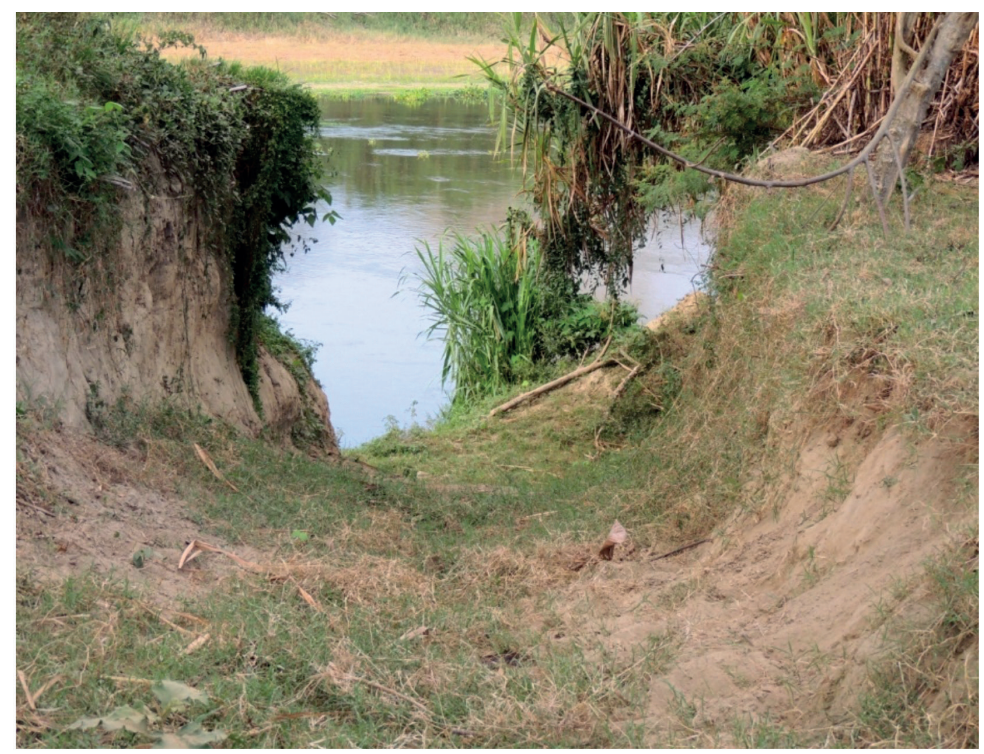

Figura 16. Rampa hacia el río Cauca.

Fuente: fotografía Armando Ramírez Villegas (2016) 


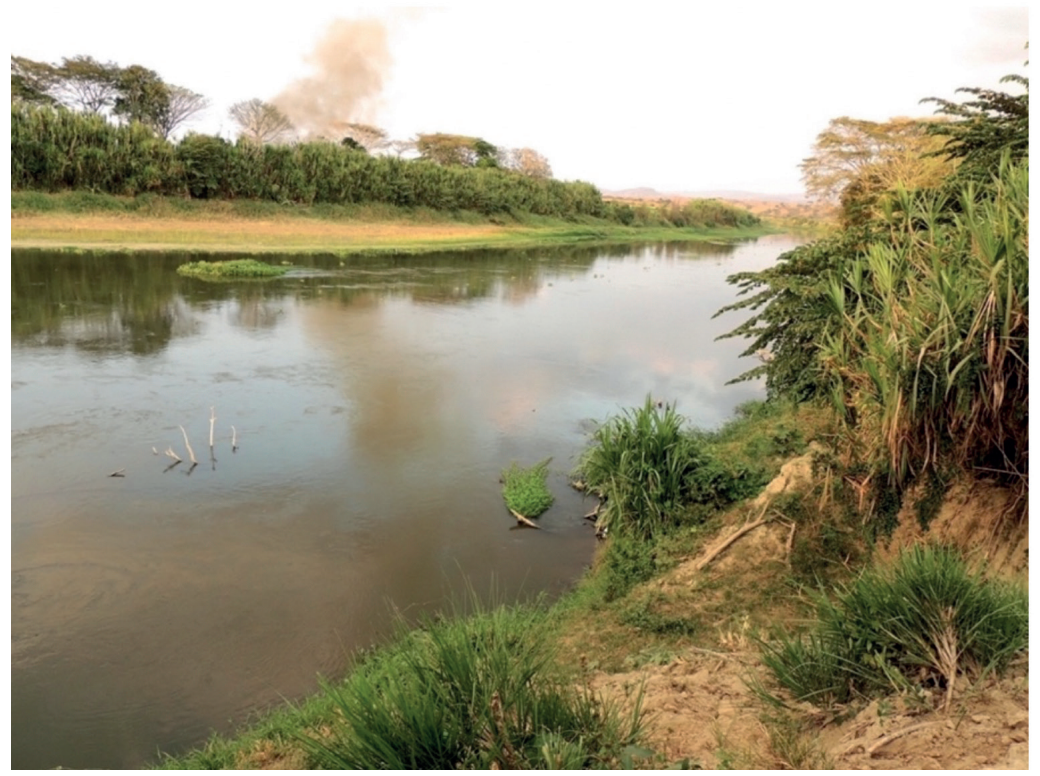

Figura 17. Río Cauca

Fuente: fotografía Armando Ramírez Villegas (2016)

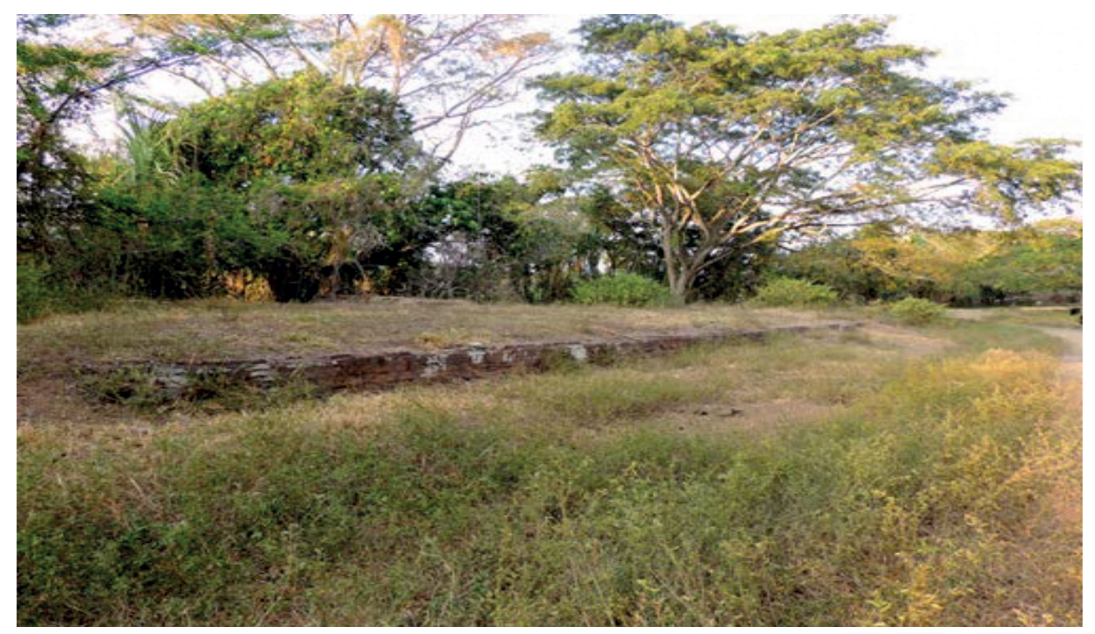

Figura 18. Vestigios de la Estación del Ferrocarril en Puerto Caldas Fuente: fotografía Armando Ramírez Villegas (2016) 


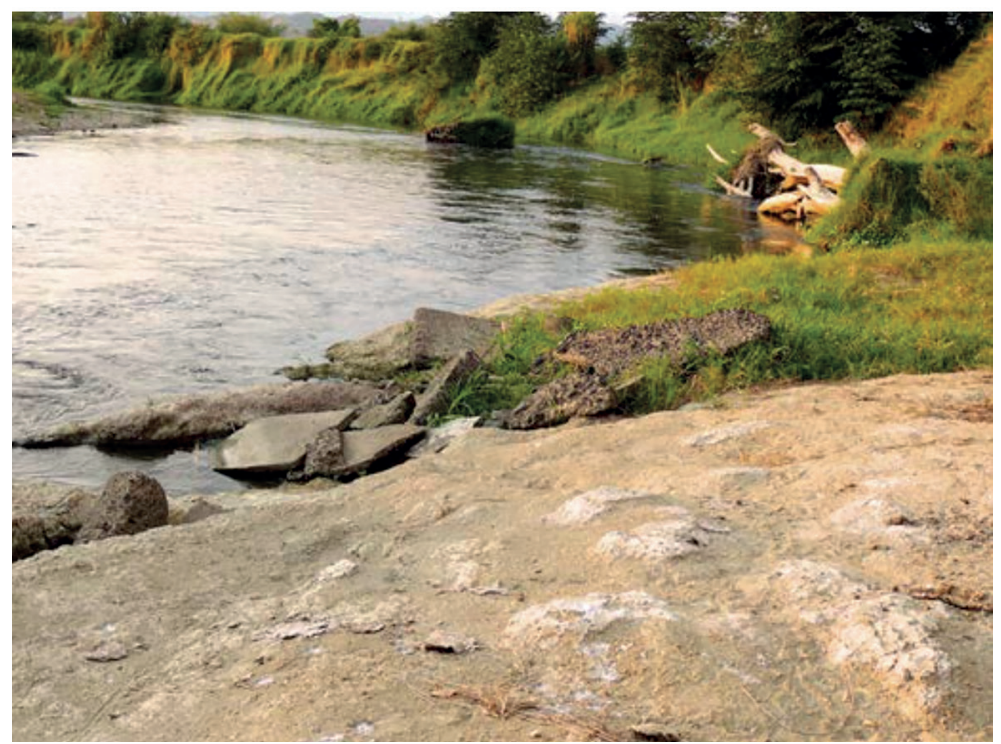

Figura 19. La Vieja en su desembocadura al río Cauca en Puerto Caldas Fuente: fotografía Armando Ramírez Villegas (2016)

Volvamos a Puerto Caldas. No solamente se construyeron los edificios de la estación y las bodegas para la carga, allí también se encontraban los grandes corrales para recibir las reses de toda la región, las cuales se despacharían en ferrocarril hacia los centros de consumo, principalmente a Pereira, en donde se realizaban las grandes ferias de la región. Estaban los talleres en donde se ensamblaban las locomotoras y los distintos vagones que llegaban en las barcazas, y en donde se ejercían todos los trabajos de mantenimiento del material rodante. Este taller estuvo localizado en Puerto Caldas siete años, hasta el año 1922 cuando se construyó uno nuevo en la ciudad de Pereira, con equipos modernos y con personal más especializado.

Otra construcción muy particular fue un depósito bajo tierra para almacenar la dinamita, la misma que se importaba para ser utilizada en la construcción de la vía férrea y que por motivos de seguridad convenía tenerla muy bien protegida.

Por supuesto, estaban los campamentos y viviendas para alojar a todos los trabajadores y empleados del ferrocarril, que tenían sus frentes de trabajo alrededor de la estación, y que podían ascender a varios cientos de personas. Una vez terminada 
la línea férrea hasta Pereira, el tren se volvió, no solamente un medio de transporte de carga y pasajeros en función de su trabajo, sino un atractivo turístico que movía pasajeros hacia lugares que ofrecieran alguna diversión, paisaje o recreación especial. Por esa época se puso de moda utilizar los barcos que navegaban el río Cauca, algunos de ellos dotados de las máximas comodidades para pasar la luna de miel en un crucero, que se podía extender hasta la ciudad de Cali. Fueron muchos los parientes y conocidos que tuvieron esa oportunidad y que la supieron aprovechar.

Todo este movimiento de pasajeros requería un sitio apropiado para descansar y pernoctar lo cual se suplió con la construcción de un hotel. La sola cifra de 800.000 sacos de café de exportación que se movilizaron por sus bodegas, entre los años 1917 y 1923, es suficiente testimonio de la importancia que tuvo Puerto Caldas, no solamente con su función dentro del Ferrocarril de Caldas, sino en el desarrollo económico de la región y del país.

Como se puede ver, Puerto Caldas, no fue un simple muelle para recibir algunos barcos que surcaran el río Cauca, sino un poblado con mucha actividad cuya pujanza duró diez años, hasta el año 1924, cuando llegó la primera locomotora del Ferrocarril del Pacífico a la ciudad de Cartago, estableciéndose la comunicación directa por vía férrea hasta Buenaventura, lo cual simplificó el transporte de pasajeros y mercancías desde y hacia el puerto marítimo, dando al traste no solamente con Puerto Caldas sino con la navegación del río Cauca.

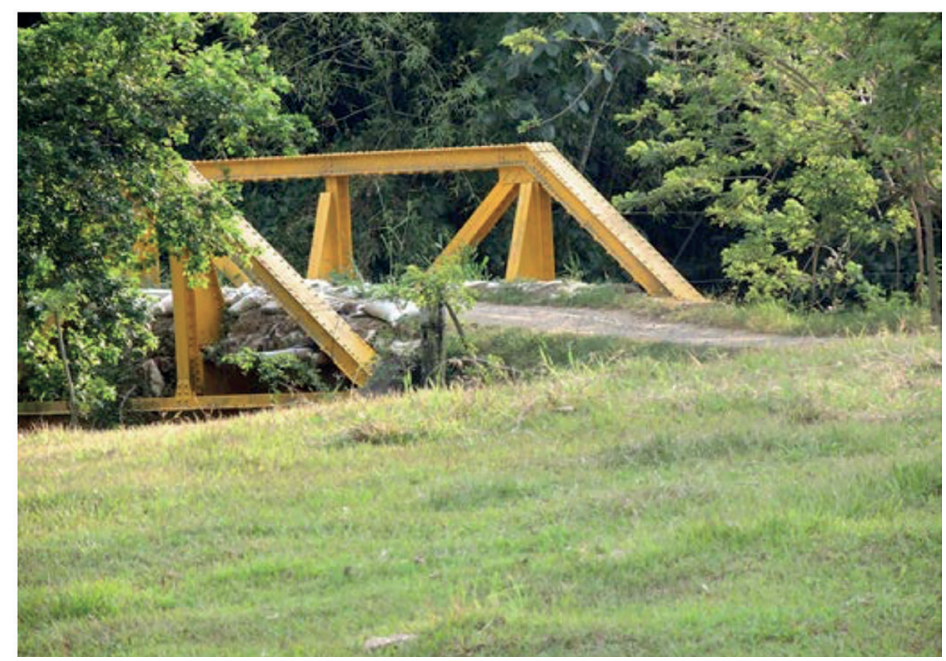

Figura 20. Puente sobre la quebrada Chapas

Fuente: fotografía Armando Ramírez Villegas (2016) 


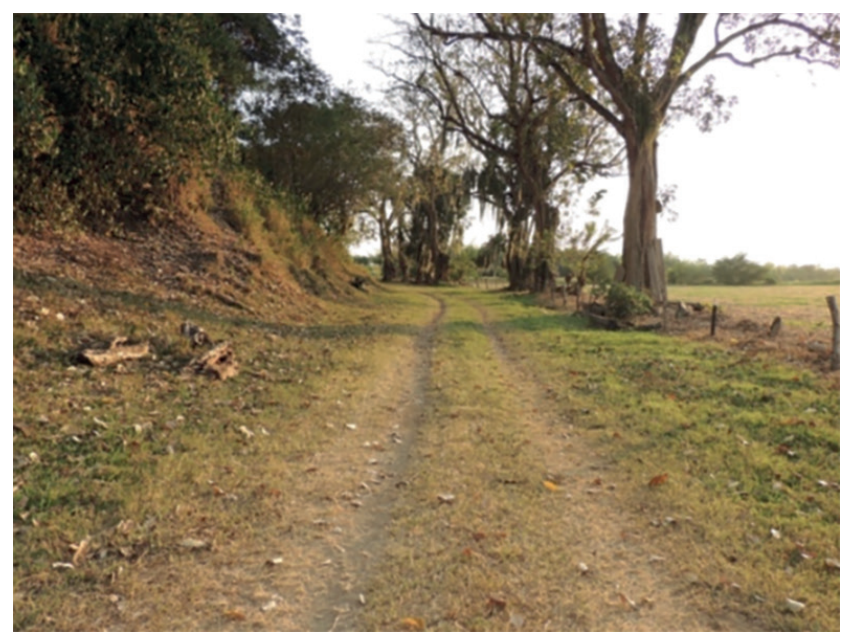

Figura 21. Antigua banca del Ferrocarril en la entrada a la estación Fuente: fotografía Armando Ramírez Villegas (2016)

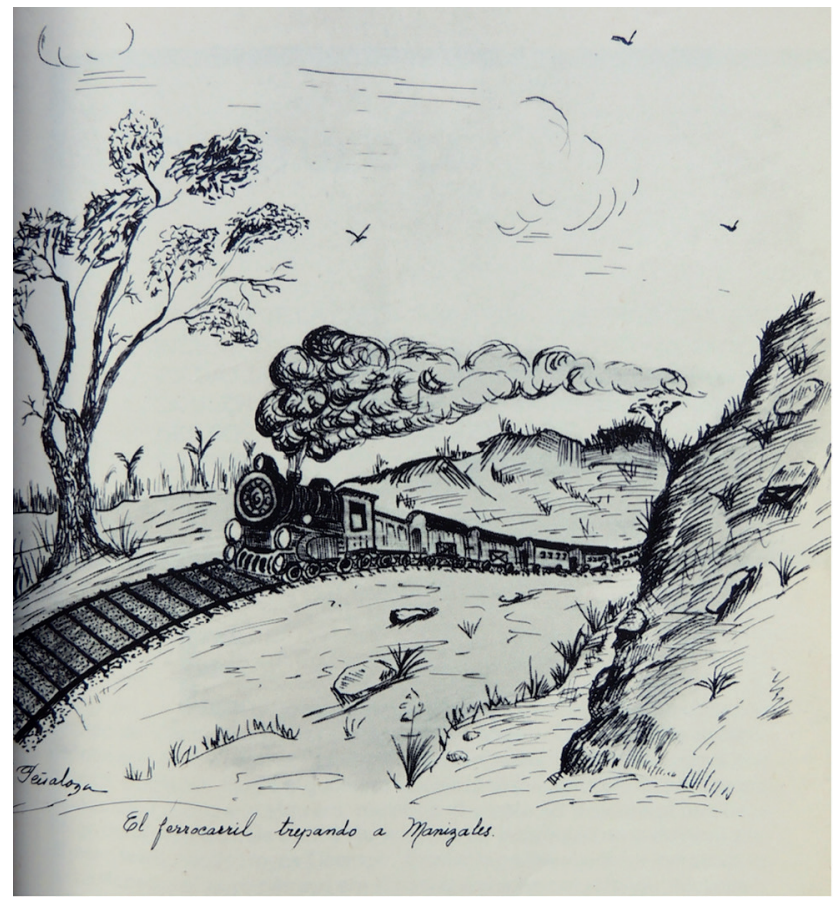

Figura 22. Plumilla de Peñaloza 


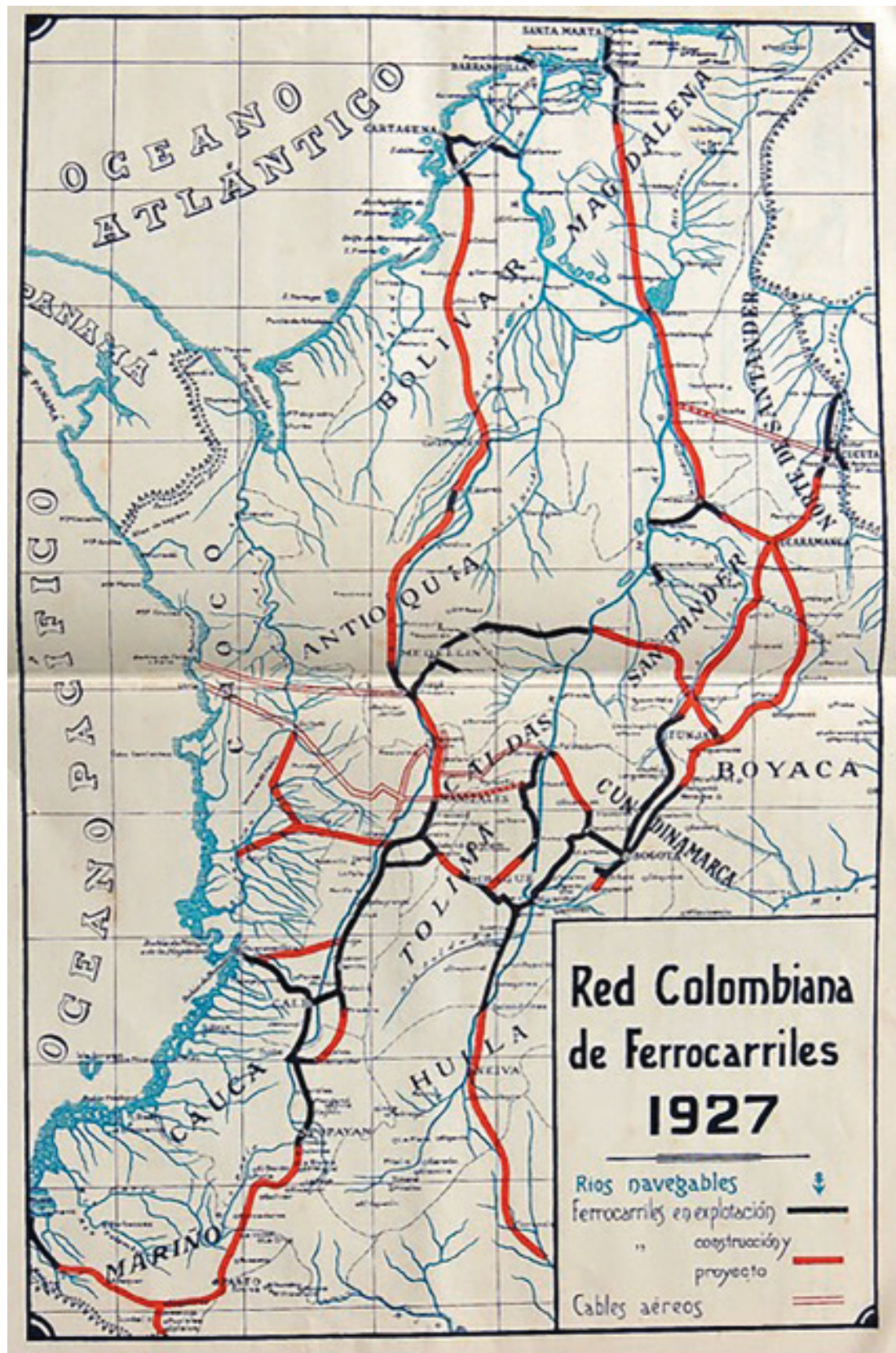

Figura 23. Red colombiana Ferrrocarriles 1927. Fuente: Planoteca Biblioteca Nacional Bogotá. 


\section{CAPÍTULO II}

\section{Construcción del ferrocarril Puerto Caldas - Pereira}

$\mathrm{E}$ 1 día 16 de julio de 1915 se iniciaron, solemnemente, los trabajos de construcción, a partir de la desembocadura del río La Vieja al Cauca, sitio conocido como La Isla y en el cual, en el mismo acto, fue fundada la población de Puerto Caldas (Acuerdo Municipal Número 17, 1921, julio 17). Asistieron a la ceremonia el señor Gobernador de Caldas doctor José Ignacio Villegas Jaramillo, el doctor Daniel Gutiérrez Arango como Presidente de la Junta del Ferrocarril de Caldas, el ingeniero Luis A. Isaza en su calidad de Ingeniero Jefe, el General Pompilio Gutiérrez y los señores Valeriano Marulanda Arango, Alfonso Jaramillo Gutiérrez, Roberto Marulanda Botero, Elías Arango, Jesús Cano Montoya, Guillermo Velásquez Urdinola, Alonso Restrepo, Bernardo Arango, Bernardo Gutiérrez, José J. Salazar, ingeniero Julián Arango, Jaime Castro Castro y Rodulfo Valencia (Echeverri, 1927). El 21 de octubre del mismo año, es decir, tres meses después, se procedió a la puesta de los rieles en la dirección hacia Cartago para seguir posteriormente, por la variante Consota, hacia Pereira. En forma similar a lo acontecido en la inauguración de la obra del ferrocarril, la puesta del primer riel constituyó motivo suficiente para una gran celebración. Asistieron a ella los siguientes personajes: El doctor José Ignacio Villegas Jaramillo, gobernador del Departamento, el ingeniero jefe, Luis A. Isaza, el Pbro. Julio C. Chaves, doctor Juan Pinzón, doctor Alfonso Villegas Arango, ingeniero Jorge Escobar, Sr. Alejandro Concha, señora María Ignacia Romero de Concha, señorita Margarita Concha Romero, Braulio Romero, ingeniero Alfonso Bernal, Lázaro Mejía, José María González, Manuel Vásquez, Tulio Arango, Aristídes Sánchez, Juan de J. Álvarez, Melitón Echeverri, Emilio Botero G., Ramón Guzmán, Camel Ilián, Nacile Chujfi, Pedro J. Mejía, Marco Tulio Sánchez y Guillermo Vélez (Echeverri, 1927). El 20 de julio de 1917 se entregaron los diez primeros kilómetros, hasta la Estación La Marina, frente a Cartago, obra realizada por los ingenieros Jorge Escobar y Alfonso Bernal. Es de anotar que un fuerte invierno, causante de grandes inundaciones de los ríos Cauca y La Vieja, entorpecieron el avance normal de la obra, tomándose casi dos años la construcción de diez kilómetros.

Don Carlos Echeverri Uribe, expresaba así sus impresiones personales, en el Semanario Bien Social, de julio 28 de 1917: 
"Vivamenteinteresados en laempresa de mayorsignificaciónque, enlomaterial, adelanta hoy el departamento de Caldas, concurrimos el 20 del presente, a la inauguración del primer trayecto de $10 \mathrm{~km}$ construido y dado al servicio público.

La hermosísima región que atraviesan las paralelas de hierro, fue, hasta hace poco tiempo, un inmenso valle solitario donde, en conventual silencio, rodaban hasta confundirse las aguas del Cauca y la Vieja. Hoy, ese silencio somnoliento, esa quietud inalterable, han sido sustituidos por los estridentes silbidos del vapor, el constante traqueteo del hierro que choca y el vertiginoso movimiento de las locomotoras empenachadas que vuelan atravesando selvas y llanuras.

Al llegar al punto terminal del trayecto que iba a ser entregado, con agradable sorpresa vimos un gentío inmenso que, con vivo interés observaba y examinaba las construcciones, aguardando ansioso la llegada del tren.

De pronto se hizo silencio y la multitud dirigió sus miradas en dirección de la vía férrea: había sonado el pito de la máquina salvadora. El silencio seguía. A cada nuevo silbido la multitud se conmovía, como si a todos tocara una corriente eléctrica.

Majestuosa e imponente apareció al fin la locomotora Zapata con su séquito de carros. Los acordes sonidos de la banda municipal, unidos al grito prolongado que lanzaba la multitud delirante de alegría, fueron repetidos por las selvas que por vez primera sintieron conmoverse el aire con tan extrañas vibraciones.

Botando chorros de vapor a diestra y siniestra, suspendió su marcha la hermosa maquinaria, como un monstruo fatigado que descansa, $y$, sin dilaciones ni venías, el pueblo trepó sobre su lomo.

Poco después, atronando las selvas con su estrepitosa marcha regresó el tren al puerto, llevando un lleno completo de entusiastas espectadores. Cuando había recorrido dos tercios de la vía, se oyeron los silbidos de los vapores que venían a saludar a su valiente colaborador y al enfrentarse este con aquellos, pudimos observarelmás hermoso espectáculoquealahumanidadpresentala civilización.

Los vapores Santander y Risaralda, apareados en la mitad del río, avanzaban lentamente, dando a cortos intervalos y a dúo sus ruidosas salutaciones, lujosamente adornados, llevando en la popa, el hermoso pabellón de Colombia, en tanto que la locomotora bajaba paralela a la rivera, contestando con atronadores silbidos los saludos que le 
enviaban, y dejando oír los armoniosos acordes del Himno Nacional ejecutados por la Banda Municipal que ocupaba uno de sus carros.

Al llegar a ponerse en frente, los tres vehículos hicieron alto y sus tripulantes salieron: los del ferrocarril a conocer los vapores y los de estos a conocer aquél. Los trenes siguieron hasta la tarde, bajando y subiendo cargados de individuos de todas clases, sexos, edades y condiciones, en revuelta confusión y con mayores o menores incomodidades.

El acta de la entrega y recibo de la obra fue leída, en acto solemne por uno de los empleados de la empresa, estando presentes el señor Gobernador del Departamento doctor José Ignacio Villegas, el representante del gobierno nacional señor Alfredo Ortega, el ingeniero en jefe Doctor Jorge Escobar, el Superintendente interino señor don Alfonso Bernal, y el representante de la Junta del Ferrocarril señor Carlos Vicente de la Cuesta, quienes la firmaron, y un concurso numeroso de espectadores.

Enseguida el señor Gobernador pronunció un hermoso discurso en el cual nos hizo conocer, desde su principio hasta el presente, la historia de Ferrocarril de Caldas, haciendo una mención honrosa de sus predecesores en el gobierno y del hábil y activo ingeniero don Luis Isaza.

Habló enseguida el señor don Manuel Vázquez Hoyos, excitando de manera noble y generosa a los habitantes de Pereira y Cartago, como eslabones inmediatos de Caldas y el Valle, a darse el estrecho abrazo de hermanos en tan propicia ocasión, excitación que fue muy de nuestro agrado, pues siempre hemos

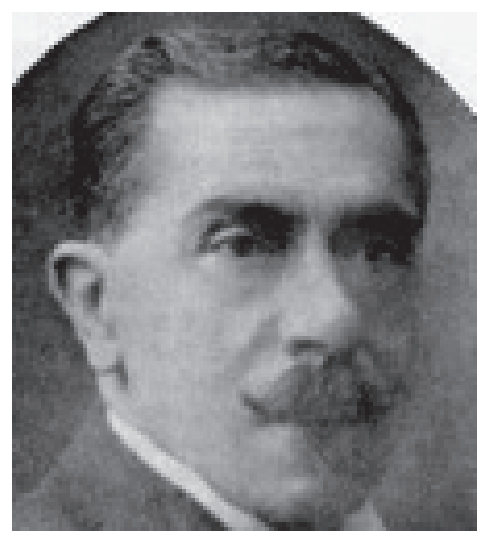

Figura 24. Daniel Gutiérrez A. Fuente: Echeverri, N. (1927). El Ferrocarril de Caldas. Bogotá: Imprenta Nacional abogado porque se esfumen viejas rencillas $\mathrm{y}$ entremos resueltamente a trabajar por el engrandecimiento de nuestro suelo, de brazo con nuestros amables vecinos.

Para tan solemne festividad creemos, por lo que vimos, que no se elaboró programa ninguno y que los dirigentes obligados de ello, fueron imprevisivos, pues sabiendo que crecido número de personas honorables, a quienes por telégrafo invitaron, concurrirían al acto, no hubo en el paraje adonde fueron citados ninguno de ellos, ni siquiera un representante que hiciera los honores a sus huéspedes y que organizara la festividad de una manera correcta. 
Muy sinceramente deploramos este incidente.

Carlos Echeverri Uribe"

El ingeniero Alfredo Ortega, autor del libro Ferrocarriles Nacionales (1922), fue el encargado por el Gobierno Nacional para recibir la obra.

\section{Ortega (1923, pp. 337-339), en su informe, manifiesta:}

“Señor Ministro de Obras Públicas - En su Despacho.

En cumplimiento de la Resolución de Su Señoría, de fecha 10 de los corrientes, por medio de la cual se me comisiona para recibir en nombre del Gobierno Nacional el primer trayecto de 10 kilómetros de ferrocarril que el Departamento de Caldas ha construido por administración, entre el rio Cauca y el camino de Cartago a Manizales, tengo el honor de rendir el siguiente informe:

Asociado a los señores ingenieros Alfonso Bernal, Superintendente de la Empresa, y Jorge Escobar, Ingeniero Director del Ferrocarril, se procedió a examinar detenidamente y a medir la línea construida, desde el origen, en Puerto Caldas, hasta el poste kilométrico número 10, situado dentro de una curva de once grados y diez y ocho centésimos de grado, y a una distancia de 129,92m, del Puerto Caldas. Se tomó la nota detenida de las obras de arte, edificios, material rodante y demás anexidades de la empresa, y se recorrió además la carrilera en un tren compuesto de la locomotora Zapata, de 17,5 toneladas, un carro de pasajeros de segunda clase y tres plataformas, a una velocidad que llegó en algunos trayectos hasta 30 kilómetros por hora.

Por haber encontrado la obra construida en condiciones satisfactorias la di por recibida en nombre del Gobierno Nacional, según consta en el acta correspondientenúmero 1", que remito a Su Señoría adjunta al presente informe, y en tal virtud el señor Gobernador de Caldas la declaró oficialmente inaugurada al servicio público. El estado en que se encuentra el ferrocarril es el siguiente:

Línea. El punto de arranque de la carrilera está situado en la extremidad del cobertizo para vagones de la estación de Puerto Caldas, y tiene de cota 
903,95m sobre el nivel del mar. La carrilera toma la hoya del río de La Vieja en ascenso continuo hasta llegar a la cota $956 \mathrm{~m}$. en el kilómetro 10. Sube $5,55 \mathrm{~m}$ en trayectos de pendiente del 2 por 100 como máximo, que alterna con gradientes menores y secciones a nivel. La longitud total de estas es de $4.693 \mathrm{~m}$. y de los trayectos en pendiente de $5.307 \mathrm{~m}$. El alineamiento mide $6.784,80 \mathrm{~m}$ en tangentes, y en curvas $3.215,20 \mathrm{~m}$. El radio mínimo no llega a $80 \mathrm{~m}$, que es el límite fijado por la Ley 105 de 1.914. Los rieles pesan 27 kilos por metro lineal. Miden de longitud 9,14 m, y están soportados por catorce traviesas, lo cual da un total de 1.526 por kilómetro. Tiene las junturas alternadas en todo el trayecto, y están unidos por eclisas angulares. El ancho de la plataforma en corte es de 4,50 m, y en corona de $5 \mathrm{~m}$. Las traviesas son de diferentes maderas, entre las cuales prevalecen el dinde, el comino, el olor, etc. La carrilera está toda balastada con cascajo.

Obras de arte. Las obras de arte tienen carácter definitivo, como lo exige la Ley. En la abscisa 3.340 hay un puente metálico de $12 \mathrm{~m}$ de luz, y 5,50 m de altura, con estribos de hormigón sobre la quebrada Chapas. En la de San Pablo hay un pontón de madera, que se sustituirá próximamente por otro metálico, que mide 2,20 m de luz. Hay tres alcantarillas de 0,60 m de luz, y una de $1,50 \mathrm{~m}$, todas de arco de medio punto. Los desagües laterales están establecidos por cunetas, y los transversales por tubos metálicos de hierro galvanizado, corrugado, de 0,0015 $\mathrm{m}$ de espesor, protegidos por una capa de cemento. Hay once tubos de $0,44 \mathrm{~m}$ de diámetro y una longitud de $126,50 \mathrm{~m}$, y nueve tubos de $0,61 \mathrm{~m}$ de diámetro y $150,10 \mathrm{~m}$ de longitud.

Edificios. En Puerto Caldas existen los siguientes edificios para la empresa: un cobertizo en construcción y uno terminado; dos bodegas para carga; una fragua, un hotel y un tejar. En la abscisa 7.720 existe la estación denominada Villegas, y una casa para el personal de ingenieros. En la extremidad del trayecto recibido y sobre el camino de Cartago hay una bodega de carga. Tienen todos ellos cubierta de teja metálica y muros de adobe.

Cambios y apartaderos. Hay un cambio en cada una de las estaciones de Puerto Caldas y La Marina, y un apartadero en la primera de estas. Falta construir la Y simétrica de cambio para las máquinas.

Material Rodante. Hoy tiene en servicio la Empresa una locomotora de 17,5 toneladas en orden de marcha; un carro de pasajeros de segunda clase, de buena apariencia; ocho carros de carga; dos más para ganado mayor; seis plataformas y dos carros de empuje. Ha pedido una segunda locomotora de 35 toneladas. En memoria del ingeniero señor Felipe Zapata bautizó su 
primera máquina, e intenta seguir denominándolas con los apellidos de los demás ingenieros a su servicio.

Anexidades. La carrilera está dentro de una zona de 30 metros de anchura, cercada con alambre de púas, que la independiza de los predios vecinos. Esta anchura impedirá los incendios que ocasionen las locomotoras, siempre que se la mantenga completamente limpia. La demarcación kilométrica está hecha de postes de madera barnizados. Hay un estanque elevado en Puerto Caldas, que se alimenta con una bomba de mano, y tiene $12 \mathrm{~m} 3$ de capacidad.

La Empresa instaló una línea telefónica para el servicio de las estaciones de la línea férrea. Actualmente no existe el taller de maquinaria, y las reparaciones se hacen en una fragua establecida en Puerto Caldas.

Observaciones. El aspecto general de la línea es satisfactorio; los cortes tienen su talud pulido y con la inclinación que corresponde a tierras y cascajo conglomerado; por consiguiente no hay riesgo de que se presenten deslizamientos sobre la zona.

Como se trata de una línea recientemente construida, que es necesario atender continuamente, principalmente en los terraplenes, no se han establecido aun las curvas de transición entre las tangentes y las curvas de empalme. Con todo, la línea es suave y da la sensación de solidez al paso de los trenes. El peralte en las curvas se ha hecho en la proporción de 0,046 por grado de curva".

Continuó la construcción hacia el sitio conocido como La Hoya, en el río La Vieja, para entrar luego, en el trayecto entre las abscisas Km 15 a $\mathrm{Km} 21$, el de mayor dificultad de la ruta debido al trabajo en roca sobre el acantilado del río Consota, con cortes de hasta 50 metros de altura y en donde fue necesario construir un túnel de 35 metros de longitud, en la ladera sur del montículo de Cerritos. 


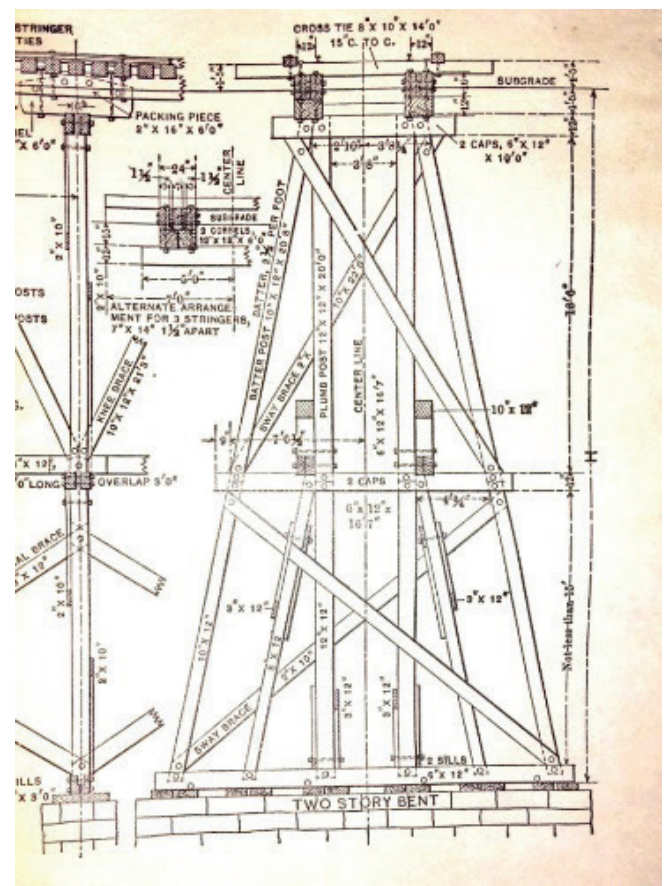

Figura 25. Cimbra para puente

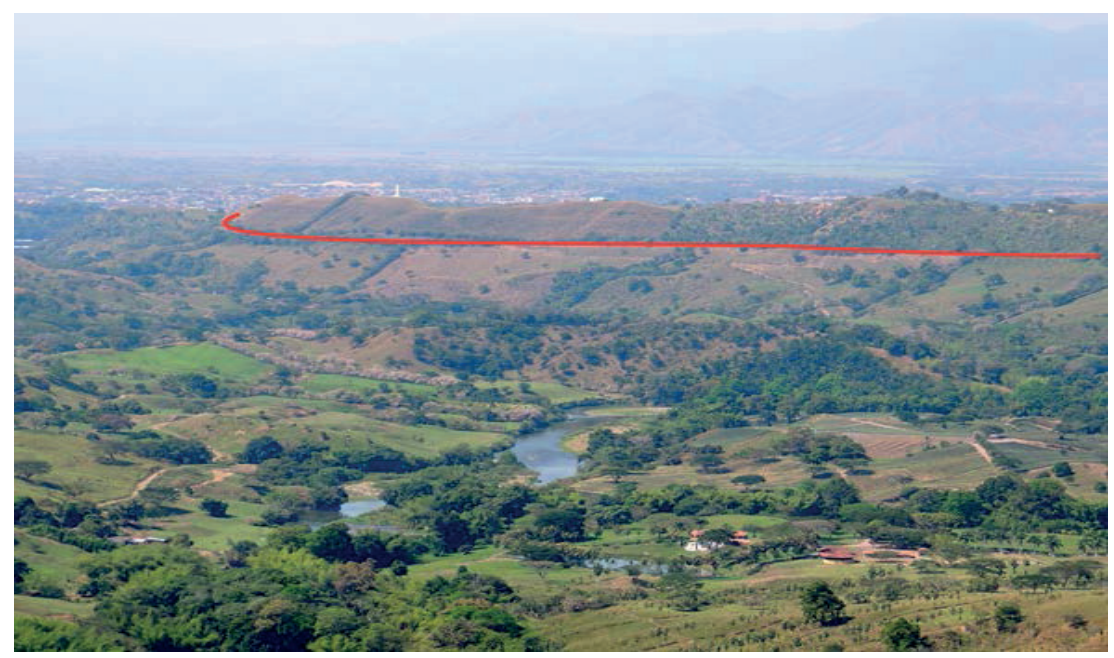

Figura 26. Banca del Ferrocarril entre Estación La Marina y La Hoya Fuente: fotografía Armando Ramírez Villegas 


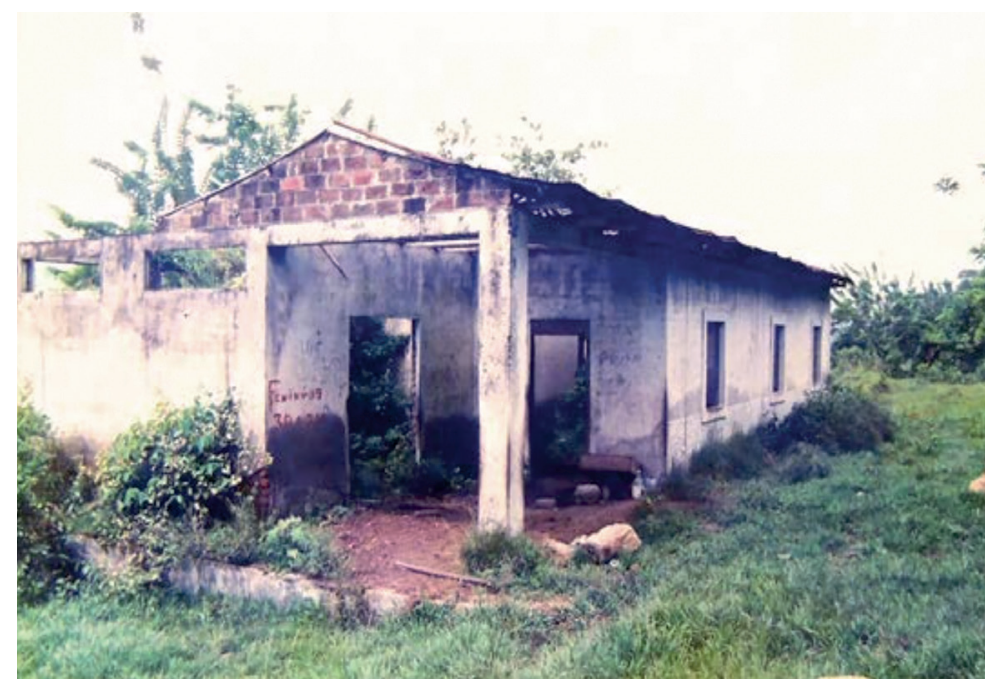

Figura 27. Paradero La Hoya

Fuente: fotografía Álvaro Camacho (1995)

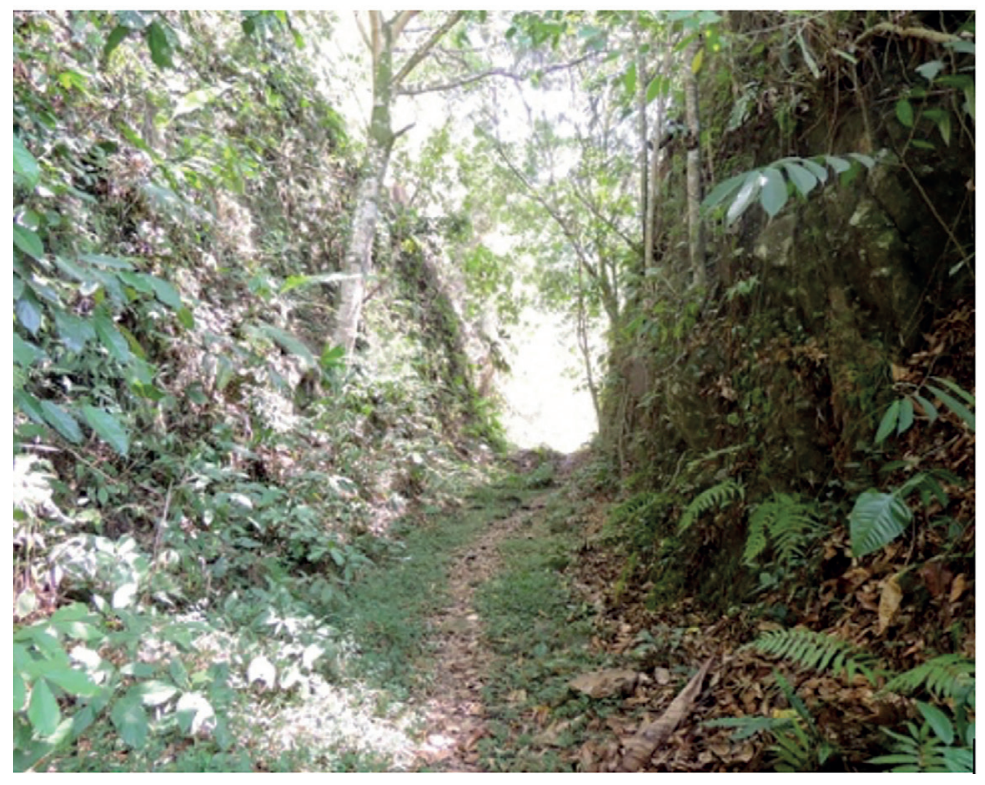

Figura 28. Aspecto de la Banca en Cercanías del Túnel de Consota. $\mathrm{N}^{\circ} 1$ 


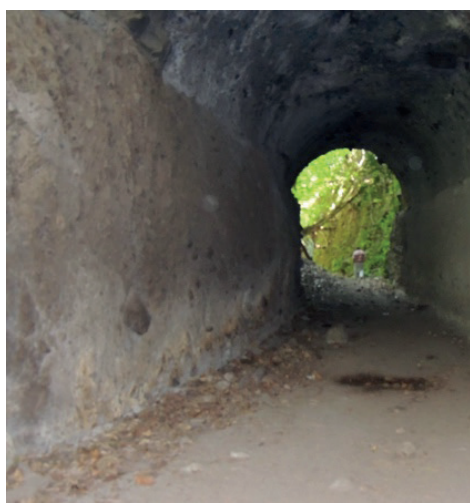

Figura 29. Túnel de Consota $\mathrm{N}^{\circ} 1$. Km 12. Fuente: fotografía Armando Ramírez Villegas (2016)

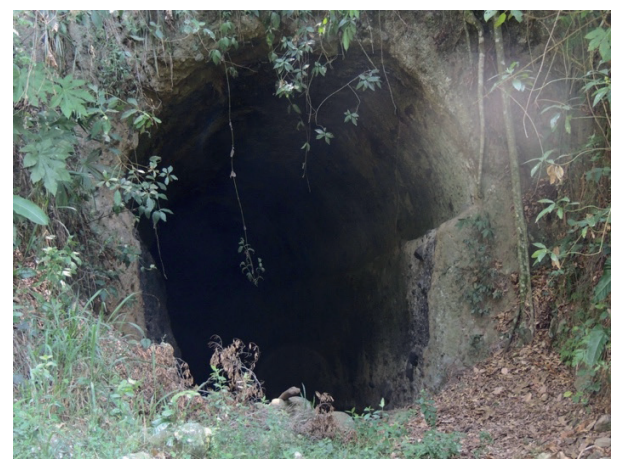

Figura 30. Túnel del Consota. Portal Oriental. Fuente: fotografía Armando Ramírez Villegas (2016)

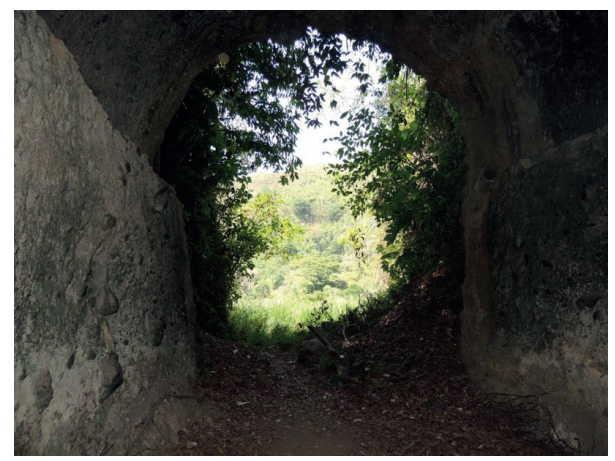

Figura 31. Túnel de Consota. Portal Occidental. Fuente: fotografía Armando Ramírez Villegas (2016) 


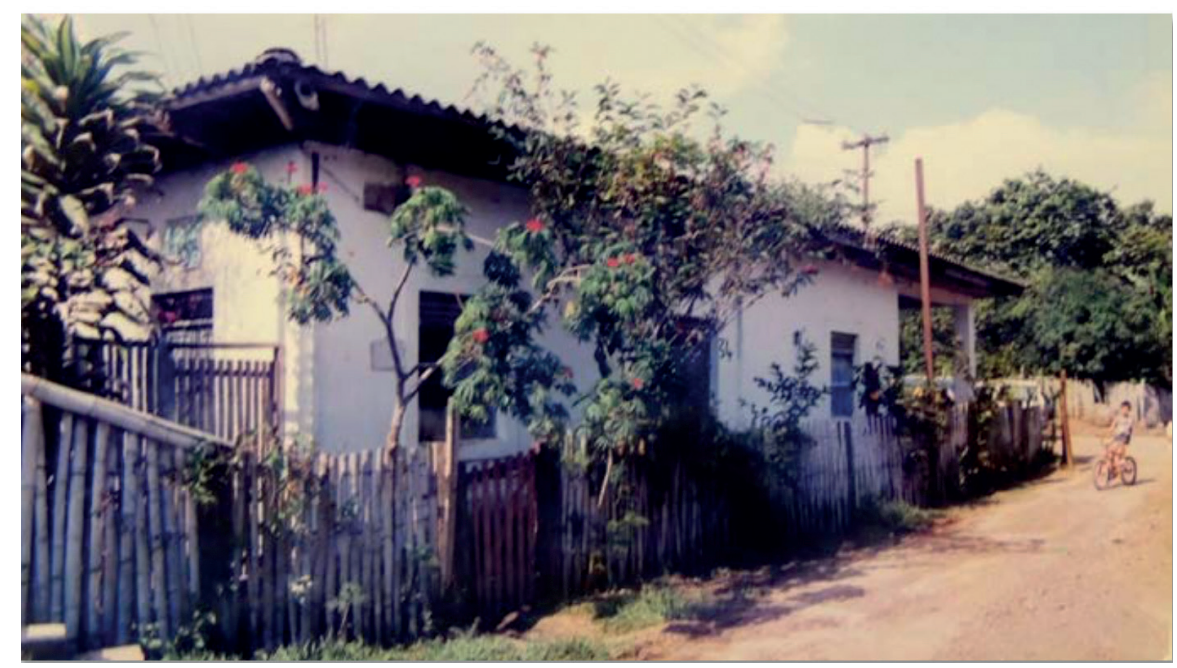

Figura 32. Estación Villegas

Fuente: fotografía Álvaro Camacho (1995)

El 17 de enero de 1919, se llegó al punto en donde se localizaría la Estación Villegas, correspondiente a la abscisa Km 22, y bautizada así en reconocimiento al ex Gobernador José Ignacio Villegas J. por sus innumerables servicios a la causa del ferrocarril.

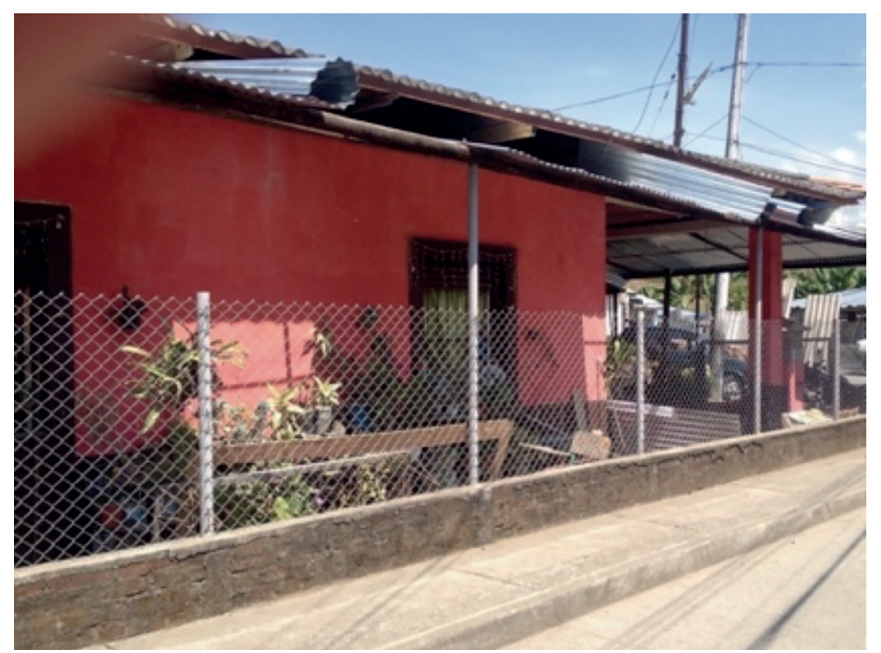

Figura 33. Estación Villegas 2016

Fuente: fotografía Armando Ramírez Villegas (2016) 


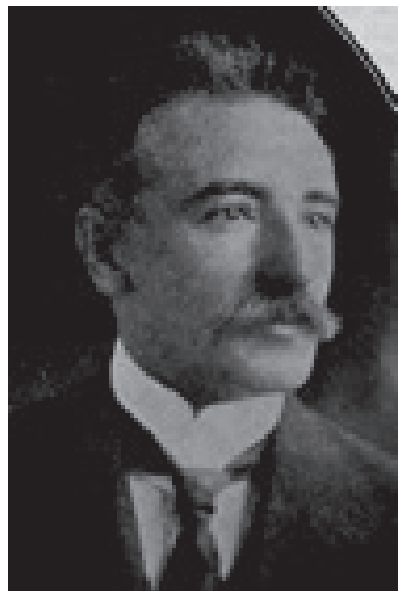

Figura 34. Dr. José Ignacio Villegas J.

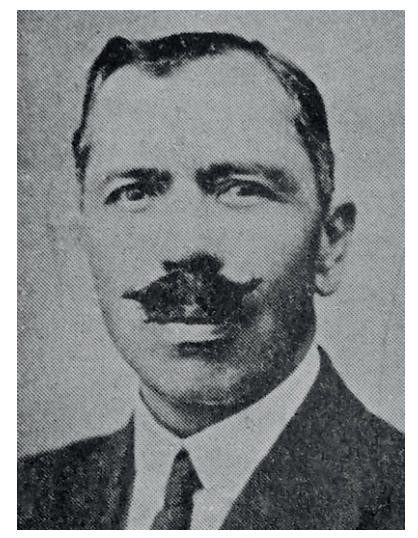

Figura 35. General Pompilio Gutiérrez

Fuente: Echeverri, N. (1927). El

Ferrocarril de Caldas. Bogotá:

Imprenta Nacional
En noviembre de 1919, llegó la tendida de los rieles hasta la Estación Belmonte (Km 29), continuó hacia la Estación de Nacederos (Km 35), y a Pereira llegó la locomotora No. 2 (La Páez), el día 8 de julio de 1921 (Echeverri, 1927). Vale la pena resaltar que el gobernador general Pompilio Gutiérrez, se trasladó a la zona desde mediados de junio, para avivar e impulsar los trabajos con el objeto de llegar en el menor tiempo posible a la ciudad de Pereira.

El 7 de agosto fue la inauguración oficial. Se le hizo entrega del trayecto al ingeniero Alfonso Bernal, representante del Gobierno Nacional. El doctor Néstor Echeverri, ex secretario de Hacienda Departamental en diversos periodos y ex gerente del Ferrocarril de Caldas en 1926, se expresaba así en1927:

La ciudad de Pereira, con aquella gentileza y gallardía que la hace famosa, celebró festividades muy suntuosas para solemnizar aquel fausto suceso. Fueron invitados a aquellas festividades los poderes nacionales, los municipios del departamento y la ciudad de Cartago. De manera fastuosa y elegante supo lucir aquella riente ciudad sus atavíos y sus galas y poner de relieve las grandes virtudes de su raza conquistadora y potente, en el momento en que llegaba a sus puertas el mago que operaría, en pocos años, de modo profundo, su transformación hasta convertirla en una ciudad que hoy es orgullo de este país y admiración de propios y extranjeros. (Echeverri, 1927) 


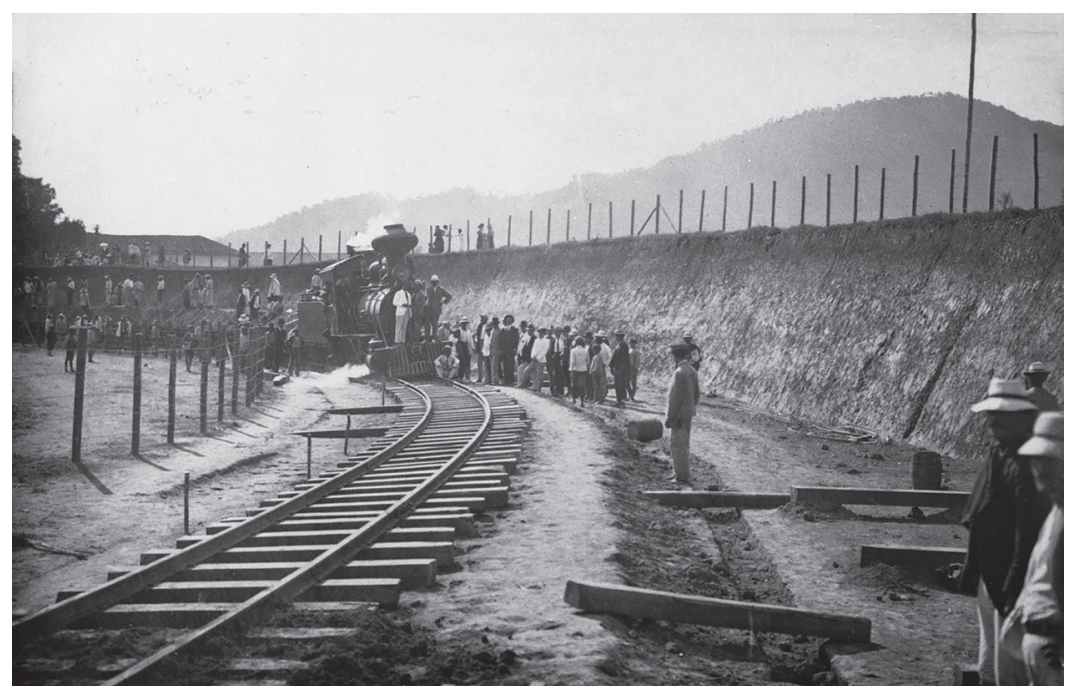

Figura 36. Primera locomotora en Pereira

Fuente: foto Sánchez

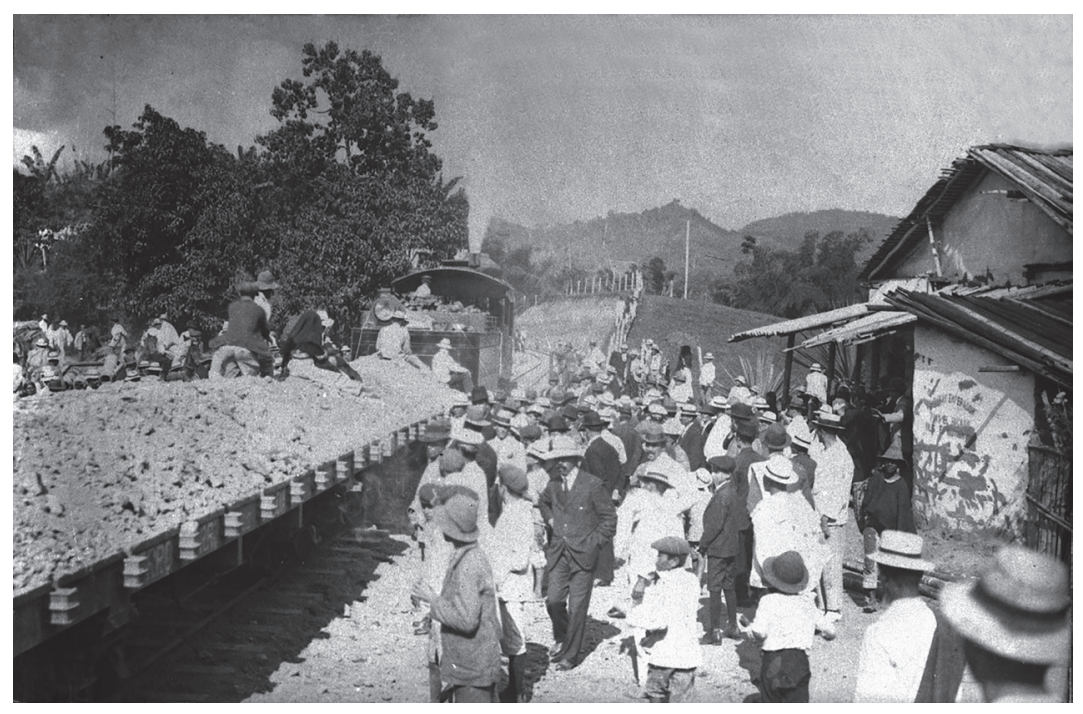

Figura 37. Primer tren en Pereira, 8 de julio de 1921

Fuente: foto Sánchez 


\section{COMENTARIO $2^{\circ}$}

\section{Llegada del tren a Pereira}

\section{Ultima hora.}

Pereira, 8 de julio de 1921. Junta Ferrocarril.-Manizales.

Acaba de pitar la primera máquina del Ferrocaril de Caldas en la Plaza de Ferias. Seguiré hoy esa.

Pompilio Gutiérrez.

Figura 38. Telegrama Pompilio Gutiérrez
Zn el año 1919 habían llegado los Crieles hasta la Estación Belmonte, completando así 29 kilómetros de recorrido desde la Estación Puerto Caldas, punto de origen del Ferrocarril de Caldas. La situación económica del país pasaba por una época difícil y la financiera del ferrocarril estaba peor. Las consecuencias de la gran guerra se sentían con especial dureza; Europa estaba devastada, más de 12 millones de muertes y la desaparición de sus potencias, causaron una crisis económica sin precedentes, de la cual no escapó Colombia. Las arcas del Departamento estaban vacías y la importación de rieles y material rodante era cada vez más difícil. Sin embargo, la apertura y afirmado de la banca seguían su marcha, acogidos al trazado que elaborara el ingeniero Morris, y estaban a punto de llegar a la plaza de ferias de Pereira, que en ese entonces, quedaba en lo que hoy es el Parque Olaya Herrera. La Dirección del ferrocarril estaba cada vez más ansiosa por terminar el trayecto hasta la ciudad de Pereira, hecho que causaría, no solo la culminación de la tercera parte de la distancia programada, sino, la oportunidad de multiplicar sus ingresos al tener una estación en una ciudad importante, con reconocimiento nacional y polo indiscutible de acopio de la producción cafetera. Era tanto su afán que el propio gobernador, el general Pompilio Gutiérrez, decidió trasladar su despacho a la ciudad de Pereira, con el objeto de estar directamente encargado de todo lo relacionado con el avance de la obra.

A finales del mes de mayo de 1921 llegó el General a Pereira, con su séquito más cercano, e inmediatamente empezó a tratar de resolver cuanto problema resultase para el acelerado progreso de los trabajos. Sus esfuerzos se vieron recompensados y el propio General lanzó el grito de triunfo, en el siguiente mensaje: una nutrida multitud lo esperaba en la improvisada estación de la ciudad. Con gritos y aplausos 
acompañados con bandas musicales, en medio del estridente pero eufórico pitido de la locomotora, la ciudad entera se enloquecía de alegría. No podían creer lo que tenían frente a sus ojos. Ese negro mastodonte que los redimiría de la mula y del cargue al hombro, estaba entre nosotros. Seguramente no alcanzaban a imaginar lo que representaría en un futuro cercano: la comunicación con el mundo, la llegada del conocimiento, el desarrollo económico, la apertura de mercados para sus productos, la multiplicación de sus ingresos, la diversión y el conocimiento de la geografía, en fin, una verdadera revolución en sus vidas. Varios días les tomó acostumbrarse a la presencia y al ruido de sus turbinas. Un mes para terminar los detalles de construcción de apartaderos y la "Y" para el cambio de sentido de movimiento de las locomotoras.

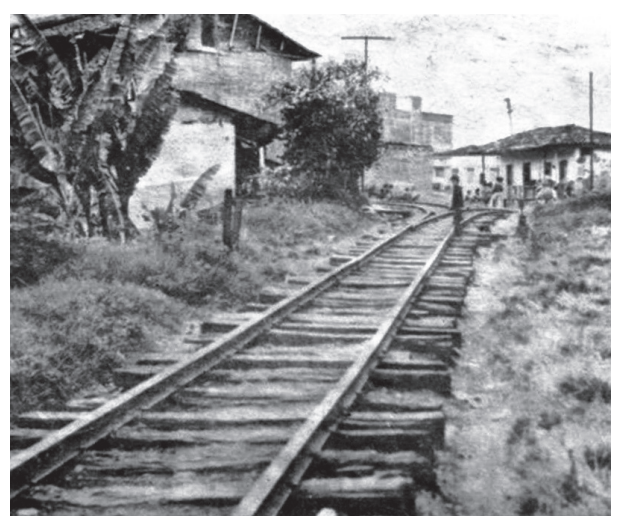

Figura 39. La Y.

Fuente: Grupo Fotografías Antiguas de Pereira (2015).

Mientras tanto, la ciudad entera se preparaba para celebrar como se debía ese hecho tan trascendental. La fecha escogida era el 7 de agosto, día de fiesta patria, día de la batalla libertadora, consonante con el sentido de libertad que aportaba la nueva línea de comunicación. Además, caía domingo, día libre para celebrar como Dios manda, sin preocupaciones laborales que atender. La Gobernación del Departamento, la Junta del Ferrocarril, la Alcaldía Municipal, las juntas cívicas de la ciudad y cuanta entidad o grupo representativo existiera, elaboraban sus propios programas para la celebración.

Así se refería el editorialista de La Patria a la ocasión:

"Mañana se inaugurará oficialmente el servicio ferroviario en la próspera ciudad dePereira,yseráesteelmomento oportunopara consagrarunhomenajede admiración y simpatía para quienes han puesto su esfuerzo en esaobragigantesca, verdadero monumento de gloria para el Departamento de Caldas, que puede ofrecerse como tributo en el día de aniversario de nuestra libertad en Boyacá.

En esas paralelas de acero que besan ya el suelo de la primera ciudad caldense tienen fincado su orgullo los hijos de este noble Departamento; a sus luchas, a los avances, a sus caídas, a todas sus vicisitudes va unido el nombre de Caldas y es natural también que en esta primera grande etapa de adelanto nos sintamos 
orgullosos de los resultados y esperemos nuevos progresos merced a la actividad gubernativa y al patriotismo de todos cuantos habitan esta región del País.

Desde el rudo trabajador que echa sobre la banca o sobre la carrilera el sudor de su esfuerzo, desde el inteligente ingeniero que calcula y acierta y dirige, hasta la honorable Junta que manda y aconseja en la capital, todos ellos en haz fraternal, tienen derecho al reconocimiento de los buenos hijos de Caldas. A la obra han consagrado sus energías y sus luces, a su entusiasmo se debe en mucho el progreso de la ferrovía, a sus esfuerzos corresponde la obra con una realidad palpable, vista ya en las ciudades, con beneficio inmediato y fecundo para regiones inmensas y ricas. Pero queremos señalar un nombre a quien el Departamento de Caldas y la obra del ferrocarril deben mucha parte de su empuje formidable: nos referimos al General Pompilio Gutiérrez, Gobernador, que luchando contra dificultades y contra intereses, contra adversidades y ambiciones, contra pequeños y grandes enemigos, ha logrado infundir aliento vivificador de su indomable energía a esa obra nuestra, de todos los hijos de Caldas, obra de eficiencia, de progreso, de riqueza.

El General Gutiérrez no solo ha podido llevar fe a los espíritus abatidos, sino que con su conducta de verdadero gobernante ecuánime y emprendedor ha vencido las mayores resistencias que se oponían al paso de las locomotoras; ha hecho volver humo todas las leyendas acumuladas alrededor de la obra del ferrocarril, muchas de ellas fruto de la incomprensión o de la mala fe".

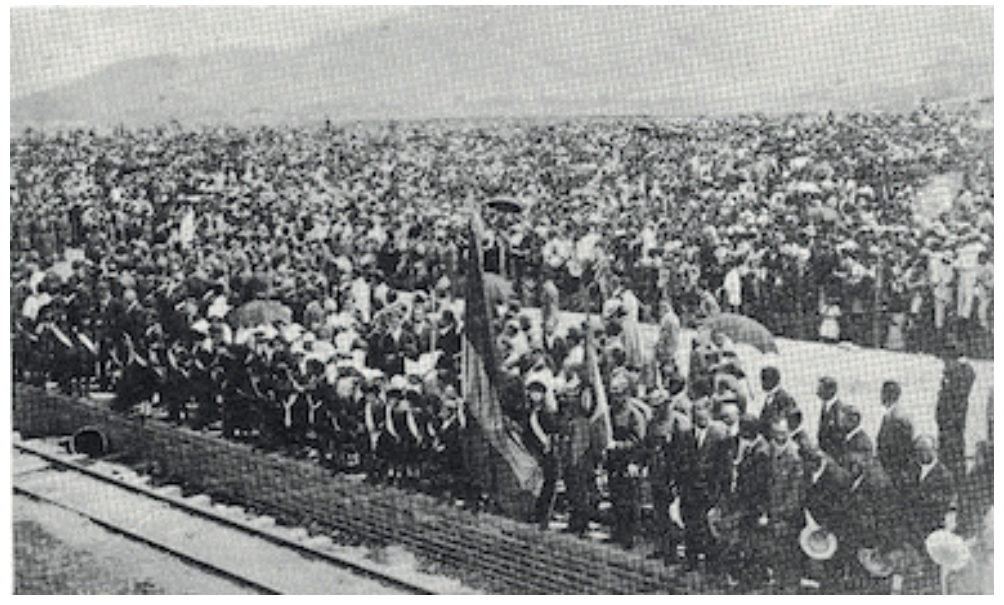

Figura 40. Llegada del tren 1

Fuente: Revista Cromos º270. Agosto 13 de 1921. 


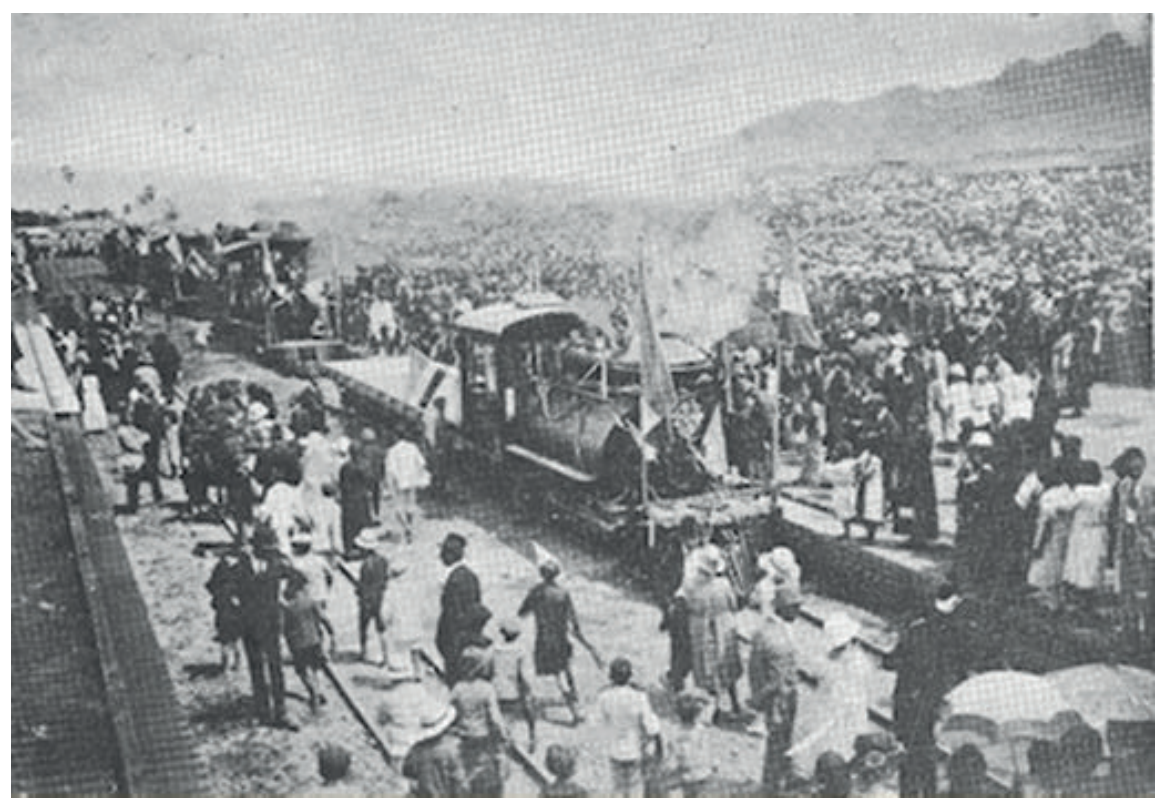

Figura 41. Llegada del tren 2

Fuente: Revista Cromos ํo270. Agosto 13 de 1921.

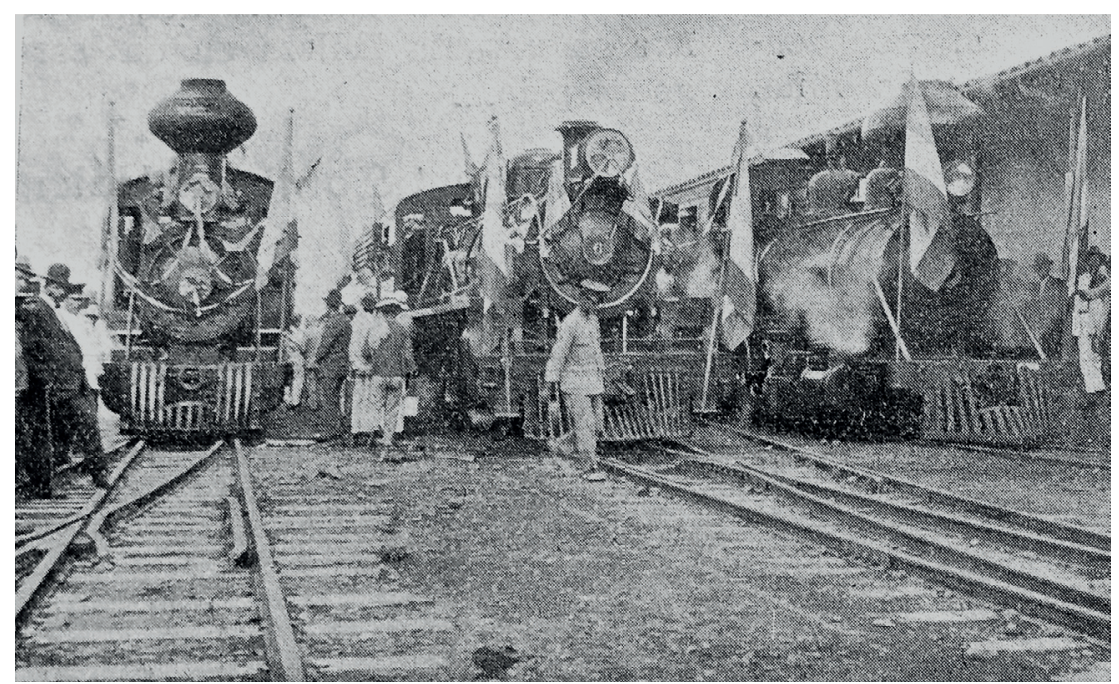

Figura 42. Locomotoras en Pereira

Fuente: Revista Cromos N²70. Agosto 13 de 1921. 
Llegado el día se dio rienda suelta a la celebración. Pero dejemos que sea el corresponsal del mismo diario La Patria, quien nos cuente, en forma "telegrafiada", como se acostumbraba en esa época enviar las corresponsalías por falta de otro medio, y cuyo estilo quedamos pocos que lo recordamos con simpatía, y que, algunas veces, tuvimos oportunidad de utilizarlo:

Continúan festejos, inauguración ferrocarril, espléndidos. Anoche gran retreta gala honor señor Gobernador, quien declinóla honorable Concejo. Gran velada lírico cinematográfica beneficio del templo. Bellísimo baile Club Colombia, derroche, elegancia, cultura; concurrieron más de doscientas personas. Esta mañana veintiún cañonazos, salvas fusilerías, bandas musicales recorrieron calles población, entonando himnos patrióticos. Celebróse solemnísima misa campal y tedeum, acto seguido efectuóse bendición locomotoras entrando estas lujosamente adornadas pabellón nacional, dando cada una veintiún pitazos como saludo a la ciudad y al progreso. Pronunciaron magníficos discursos que fueron muy aplaudidos, el presbítero doctor Darío Márquez, señor Gobernador, y los señores, Juan de Dios Gutiérrez, Eduardo Correa Uribe, Eleuterio Serna. Más de quince mil espectadores presenciaron acto con delirante entusiasmo, guardando admirable compostura, dando con esto ejemplo de civismo. Medio día gremios obreros, recorrieron ciudad portando Bandera Nacional, bellísimo carro alegórico, y corona adorna locomotoras. Acto seguido salió tren especial de estación Pereira a Belmonte, con Gobernador, representantes oficiales. Concejo, autoridades, jefe Regimiento; gran número distinguidas damas y caballeros, bandas de música; llevaba carro descubierto lujosamente decorado con arcos, festones, gallardetes, bandera nacional, ocupado por bellísimas, elegantes señoritas y jóvenes. Hízose entrega oficial línea a doctor Alfonso Bernal, representante Gobierno Nacional. Señor Gobernador ofreció copa champaña. Tren regresó Pereira a las cuatro. En seguida trenes libres entre Pereira Belmonte. Toros plaza Colón para el pueblo. Carreras caballos avenida República. Actualmente desfile antorchas batallón infantil y juegos artificiales Plaza Bolívar; maravillosas combinaciones luz exhibición un ferrocarril artísticamente representado. Recorren ciudad numerosas cabalgatas, danzas de disfraces magníficos. Ciudad profusamente adornada pabellón tricolor, entusiasmo desbordante. Señor Gobernador muy cumplimentado y felicitado todas partes República.

Las celebraciones se prolongaron por varios días; veamos lo que dice el corresponsal el día 10 de agosto: 
"Continúan los festejos: El banquete ofrecido por la culta sociedad pereirana, en honor del Gobernador, sus secretarios, miembros de la Empresa del Ferrocarril y representantes de los pueblos, fue algo espléndido y suntuoso. Hubo derroche de todo; en él llevó la palabra, por medio de un magistral discurso, el señor Manuel F. Calle. En el día de ayer se efectuó el gran paseo a La Virginia, con el fin de inaugurar el puente Mocatán sobre el río Risaralda. Trescientas veintidós personas, en su mayor parte señoras y señoritas, ocuparon los carros de un tren expreso, y estas mismas personas fueron acomodadas en Puerto Caldas, en el magnífico y cómodo Vapor Cali, de la Compañía Antioqueña. Un poco incómodos pero risueños y contentos, se efectuó uno de los números más salientes de las fiestas.

En la inauguración habló el señor Gobernador, el señor Secretario de Hacienda, el Presbítero Restrepo y don Bernardo Ríos. Todos muy aplaudidos. A las ocho de la noche se regresó a la ciudad donde se efectuaban maravillosos juegos de pólvora. Hoy gran recepción en la casa que ocupa la Gobernación; en ella ofreció el señor Gobernador una copa de champaña a un grupo de caballeros y señoritas que han tomado participación en los festejos. Esta noche gran baile de fantasía como despedida a los Representantes del Ejecutivo. Hoy siguieron para Cali, don Juan de Dios Gutiérrez, don Bernardo Ángel y don José Manuel Gutiérrez, los cuales van en viaje de paseo. Acaba de partir un tren expreso para Puerto Caldas, con la Policía Departamental y con el Regimiento que vinieron de allá; esta atención es merecida por el buen servicio prestado por estos servidores, en los festejos".

Todo nos indica que fue una celebración apoteósica por un acontecimiento trascendental para el pueblo. El sistema de transporte empezó a funcionar y sus efectos favorables, pronto empezaron a aparecer. Lo primero que vieron transformar fue la ramada improvisada, que fungiera de estación para recibir a "La Zapata", como se bautizó a la primera locomotora, y dar paso a una construcción "en material" y con las comodidades y facilidades para cumplir honrosamente sus funciones. Seguidamente, y casi en forma simultánea, aparecieron las bodegas para recibir y almacenar la carga, los embarcaderos para el ganado, las trilladoras de café, el edificio de la Federación de Cafeteros, el edificio en donde operarían los talleres del ferrocarril, que entre otras cosas, venían funcionando en Puerto Caldas desde el año 1916, y que ahora, con una mejor posición geográfica con respecto a toda la línea, y la posibilidad de modernizarlos, se establecieron en Pereira, en donde funcionaron hasta el año 1928 cuando fueron trasladados a Villamaría, bajo el pretexto de que la prestación de los servicios públicos era muy deficiente, demasiado costosos y sin ninguna consideración tarifaria con el Ferrocarril. 


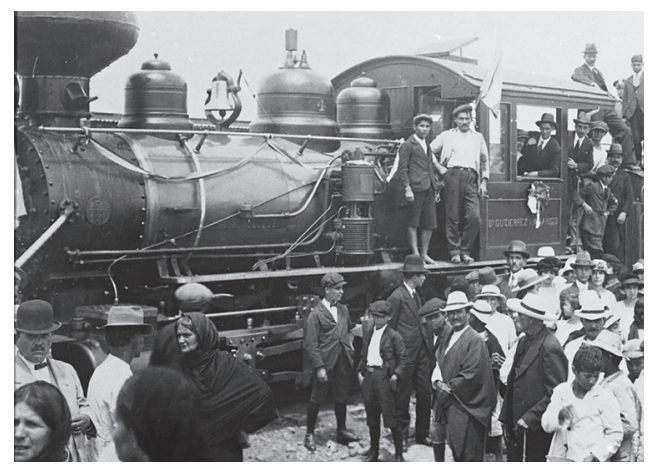

Figura 43. Primera locomotora en Pereira.

Fuente: Archivo de Donato García.

Acompañó a todo este desarrollo, la construcción del Parque Olaya Herrera y la prolongación de las calles 17 y 19, con la construcción de sendos terraplenes sobre la quebrada Egoyá, por parte del Ferrocarril, para proporcionar fácil acceso a la estación. Sin embargo, a pesar del mejoramiento urbano de la ciudad que todo esto representaba, el efecto más importante estuvo, sin duda alguna, en el despegue económico de la población, que como por arte de magia, pasó de una simple aldea a una ciudad pujante. El hecho de constituirse en el centro de acopio, tanto de pasajeros como de carga, para el Ferrocarril de Caldas, disparó la economía local a tal punto que constituyó la época de oro de nuestra ciudad. La telefonía automática, el tranvía, la pavimentación de las calles, la construcción de carreteras hacia las poblaciones vecinas y el mejoramiento de los servicios públicos fueron algunos de los hechos concomitantes con la llegada del tren.

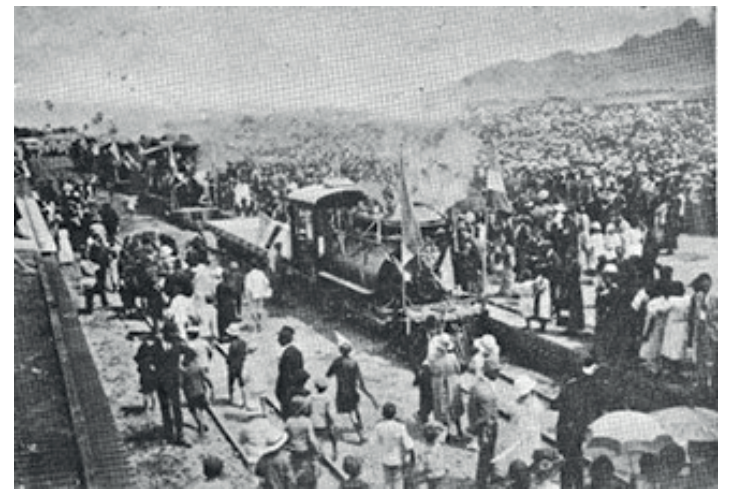

Figura 44. Inauguración del Ferrocarril en Pereira

Fuente: Revista Cromos º270. Agosto 13 de 1921. 

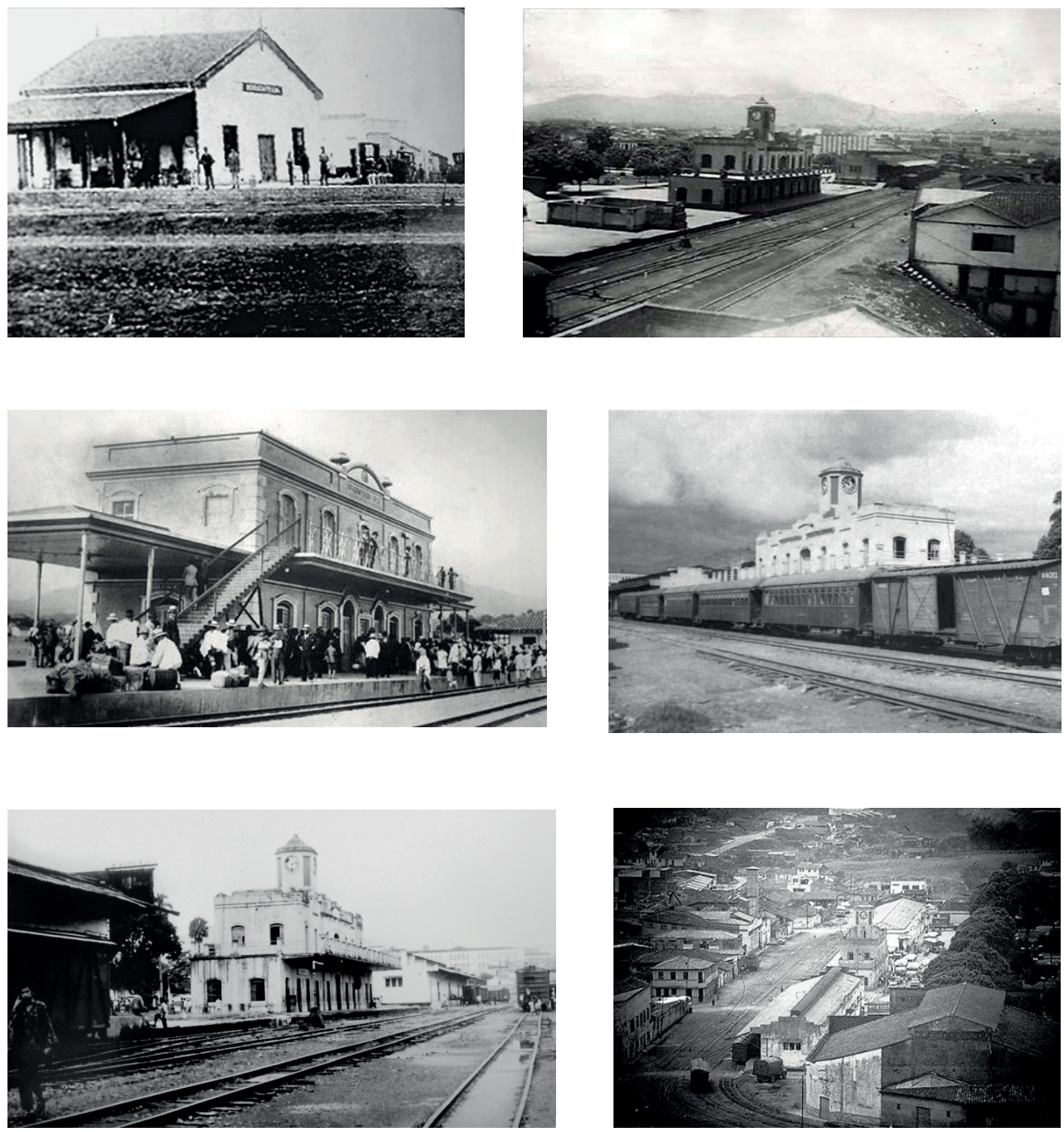

Figura 45. La estación de Pereira a través de los años 1922-1960 Fuente: Grupo Fotografías Antiguas de Pereira (2015). 


\section{CAPÍTULO III}

\section{Trazado Pereira-Manizales}

U na vez llegados los estudios y trazados a la ciudad de Pereira en 1919, la Junta debió sortear una serie de inquietudes técnicas relacionadas con la escogencia de la mejor ruta, con la pendiente máxima que se debía adoptar y con el tipo de tracción que debería utilizarse para el trayecto Pereira-Manizales (Echeverri, 1927).

Importantes asuntos que generaron interesantes discusiones en el equipo de ingenieros. La Junta, tratando de coger el toro por los cuernos, resolvió contratar con el ingeniero americano de amplia experiencia, A. F. Morris, sus servicios por el término de un año. Encontró, el ingeniero Morris, un estudio elaborado por los ingenieros Enrique Uribe, Julián Arango y Florencio Mejía, para la ruta PereiraManizales, con una pendiente máxima del 3\% y otro de los ingenieros Eleuterio Serna y Julián Arango, para el tramo Pereira-Santa Rosa, con una pendiente máxima del 2\%. El ingeniero Morris propone una línea con una pendiente del 3\% máximo hasta Chinchiná, y de allí a Manizales con el 5\%, propuesta que pronto fue desechada por la sencilla razón de que existía una regulación de carácter nacional que obligaba a tener una pendiente máxima del 3\% para poder obtener ayudas del Tesoro Nacional para su ejecución. La línea entre Puerto Caldas y Pereira tenía una pendiente máxima del $2 \%$ compensada que encajaba perfectamente dentro de las pendientes que se utilizaban en las grandes troncales que se estaban construyendo en el país.

Repitió el ingeniero Morris su trazado de Pereira a Manizales, con una pendiente máxima del 3\% compensado. Surgió, entonces, la polémica sobre la incidencia, desde el punto de vista económico, que tendría apartarse de las pendientes máximas con las cuales se estaba trabajando en el resto del país, que estaban entre el 2 y el 2.5\% compensado, lo cual podría negar al Ferrocarril de Caldas la posibilidad de unirse a las redes nacionales, generando un efecto negativo en la operación y sus rendimientos económicos. 


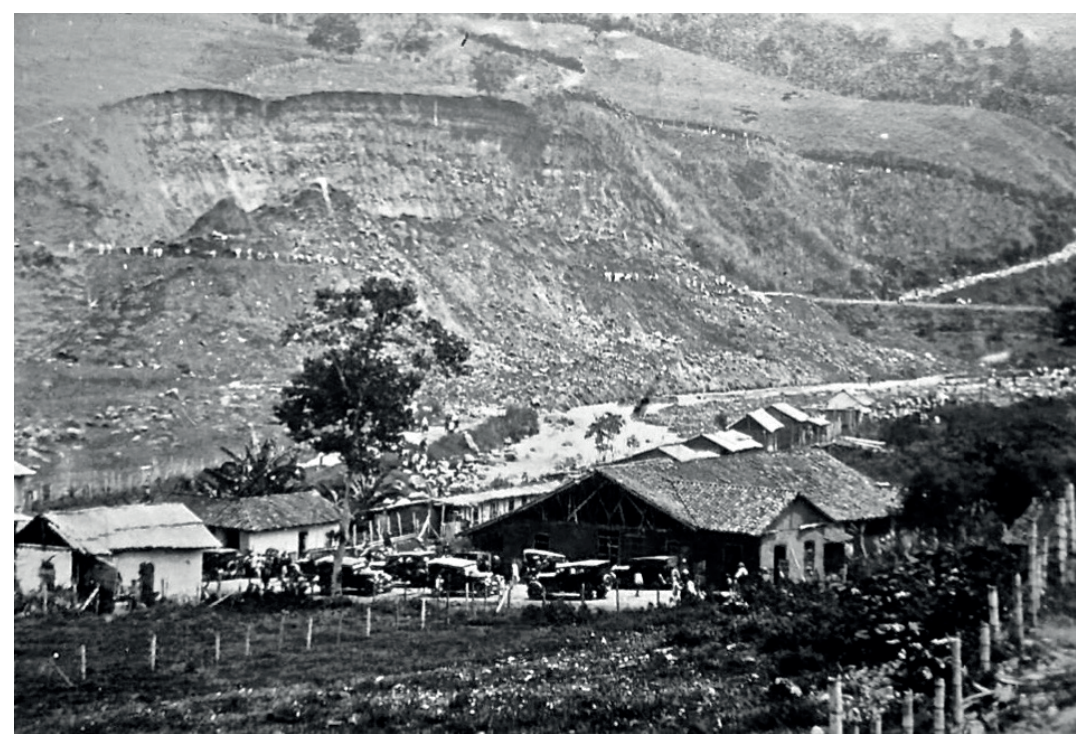

Figura 46. Derrumbe de la banca del ferrocarril en la subida a La Popa, 1926 Fuente: Grupo Fotografías Antiguas de Pereira (2015).

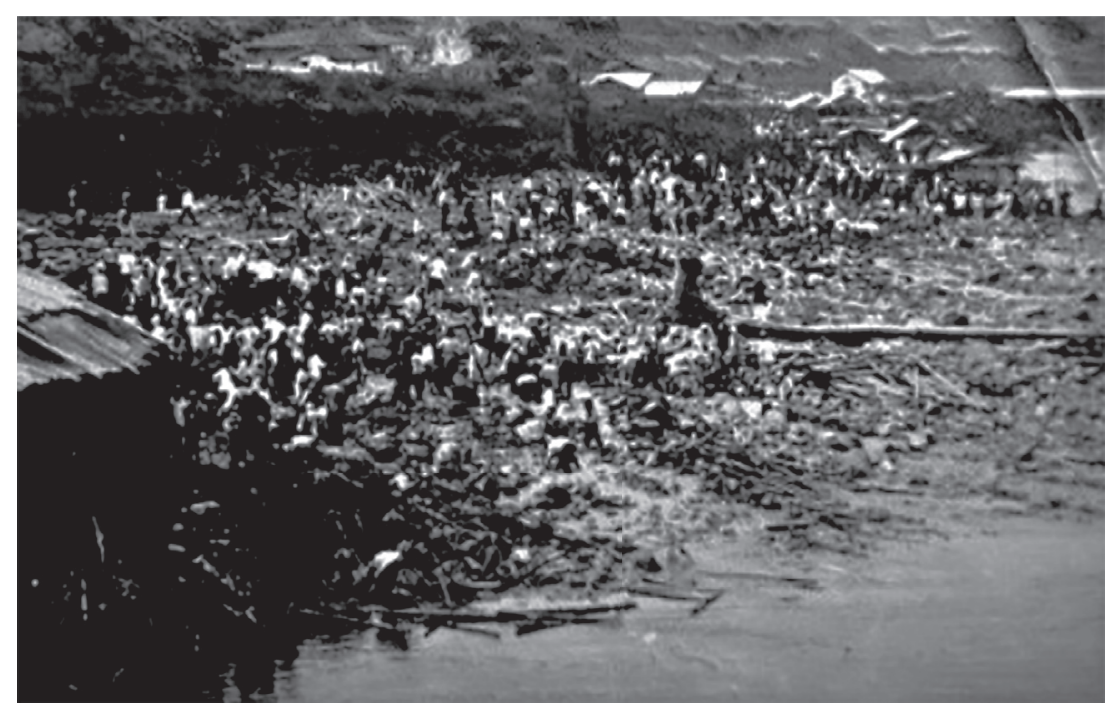

Figura 47. Tragedia en Pereira como consecuencia de un derrumbe en la banca del ferrocarril, 2 de noviembre de 1926

Fuente: Grupo Fotografías Antiguas de Pereira (2015). 
Al consultar sobre el mismo tema a los ingenieros Eleuterio Serna, Carlos Vicente de la Cuesta y Rafael Botero S. opinaron, en su informe del 10 de diciembre de 1920 (Echeverri, 1927), que la línea debería trazarse con una pendiente máxima del 2\%, entre Pereira y Chinchiná, y del 4\%, entre Chinchiná y Manizales, basados en que el tramo entre Pereira y Chinchiná debería considerarse como parte de la troncal nacional de Occidente, y el trayecto entre Chinchiná y Manizales como un ramal de la troncal, que podría tener un movimiento menor y que podría servirse con equipos distintos a los de las líneas nacionales.

Ante esta disparidad de opiniones, la Junta del Ferrocarril decide adoptar la propuesta del ingeniero Morris, de tener una pendiente máxima del 3\% compensada entre Pereira y Manizales. Para aclarar un poco la idea, podemos decir, que con una pendiente del $3 \%$, necesitamos una longitud de $3333 \mathrm{~m}$ para alcanzar $100 \mathrm{~m}$ de altura, mientras que con el $2 \%$ la longitud, para llegar a la misma altura, sería de $5000 \mathrm{~m}$.

Si generalizamos un poco este concepto y lo trasladamos al terreno que nos ocupa, tendríamos que la diferencia de alturas sobre el nivel del mar, entre Manizales y Pereira, es aproximadamente de $700 \mathrm{~m}$, lo cual representaría una diferencia de $12 \mathrm{Km}$ más en la longitud del trazado con una pendiente del $2 \%$ compensada que con una del $3 \%$, lo que, a la vez, se vería reflejado en un mayor costo de construcción para la línea del 2\%. Así las cosas, se tendría que definir cuanto costaba el Km de vía férrea construida para poder estimar la diferencia en costos entre una y otra propuesta.

El otro concepto que es bueno aclarar tiene que ver con la palabra compensado, cuando se habla de una pendiente compensada del 3\%. Resulta que en las curvas de la carrilera se presenta una fuerza centrífuga, que trata de sacar a la locomotora hacia afuera de sus rieles. Esta fuerza que es proporcional al peso, a la velocidad de la locomotora y al radio de la curva, produce una fricción adicional en los rieles, que debe ser considerada como un aumento de pendiente. Esto quiere decir, que la pendiente, en sentido estricto de la palabra, debe disminuirse en las curvas, lo cual debe tenerse en cuenta en el cálculo de la pendiente total de la vía. 


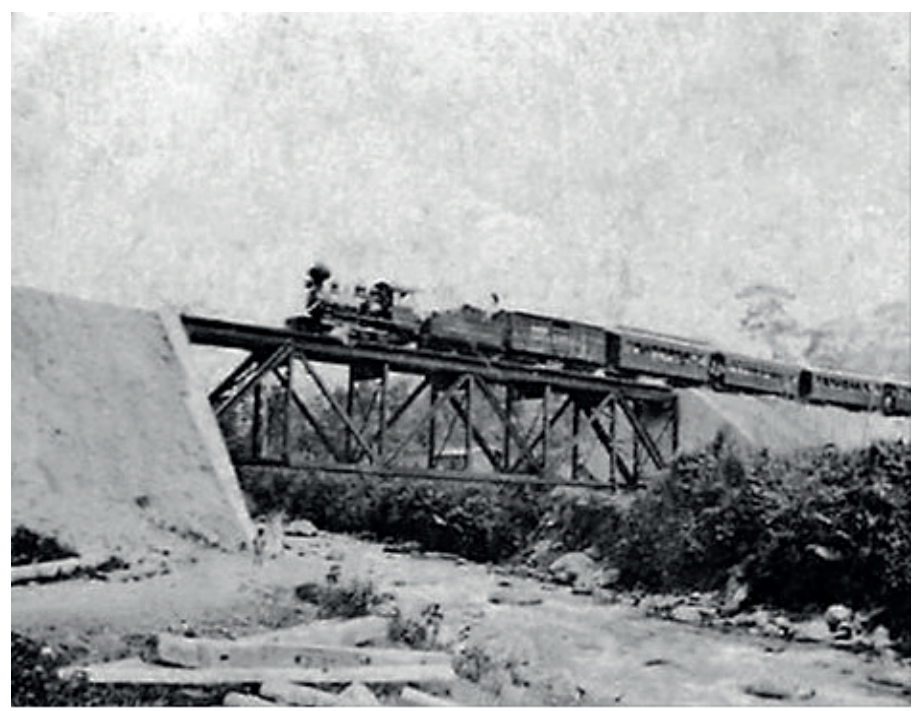

Figura 48. Puente de la máquina sobre el río Otún

Fuente: Grupo Fotografías Antiguas de Pereira (2015).

No obstante, la decisión de la Junta de adoptar una pendiente del 3\%, el ingeniero Serna, en su calidad de ingeniero jefe en 1921, insiste en estudiar una variante entre Pereira y Boquerón que representaba una mejora sustancial y una mayor economía en su construcción, variante que fue aprobada por el Ministerio de Obras Públicas y por la Junta del Ferrocarril (Echeverri, 1927).

Así mismo, presenta una alternativa al trazado del ingeniero Morris, entre el sector de Boquerón y Los Cuervos, adelante de Chinchiná, con una pendiente máxima del $2 \%$. Habiendo sucedido al ingeniero Serna en la jefatura de los ingenieros, a finales del año 1922, el ingeniero Gabriel Mejía Villa, autoriza su trazado preliminar que fuera ejecutado por el ingeniero Ernesto Ramírez Jaramillo. Esta línea que sigue la vertiente del río San Eugenio, pasando por el sitio La Capilla, cruza el río Campoalegre por el puente del camino antiguo, atraviesa la quiebra El Lembo, para llegar a la población de San Francisco, hoy Chinchiná. La localización del trazado fue ejecutada por los ingenieros Elías Calvo y Rafael Botero S., entre los años 1923 y 1924. En el año de 1922, después de cuatro años de servicios deja la Gobernación del Departamento, el general Pompilio Gutiérrez y es reemplazado por el doctor Gerardo Arias Mejía, quien desde un principio se propuso dar a la empresa del ferrocarril la organización y el impulso necesario, para culminar la obra que se venía adelantando con tanto ahínco. Fue así como llamó al ingeniero Luis A. Isaza, ya conocido en la empresa como excelente funcionario, para que asumiera el puesto de ingeniero jefe. Fue determinación del ingeniero Isaza, culminar los estudios y 
trazados hasta la ciudad de Manizales. Para ese efecto decidió trasladar al ingeniero Eleuterio Serna, quien se encontraba trabajando en los diseños del ferrocarril Nacederos-Armenia, para que se pusiera al frente del trazado entre Chinchiná y Manizales. El ingeniero Serna, con la ayuda de los ingenieros Ernesto Ramírez J., Alberto Arango Tavera, Manuel Escobar, Carlos Pardo, Benjamín Suárez, Juan de Dios Villegas, Alfredo Castillo y Emilio Domínguez, se dio a la tarea de estudiar varias rutas para tratar de resolver el complejo problema de ascender con un ferrocarril a las alturas de la ciudad de Manizales partiendo de la población de Villa María; para salvar una diferencia de alturas de $300 \mathrm{~m}$. con una pendiente del 4\%, en un espacio horizontal de $1800 \mathrm{~m}$., sería necesario un recorrido de $7500 \mathrm{~m}$. Un desafío nada fácil. El trazado hasta la ciudad de Manizales fue concluido a finales de 1924.

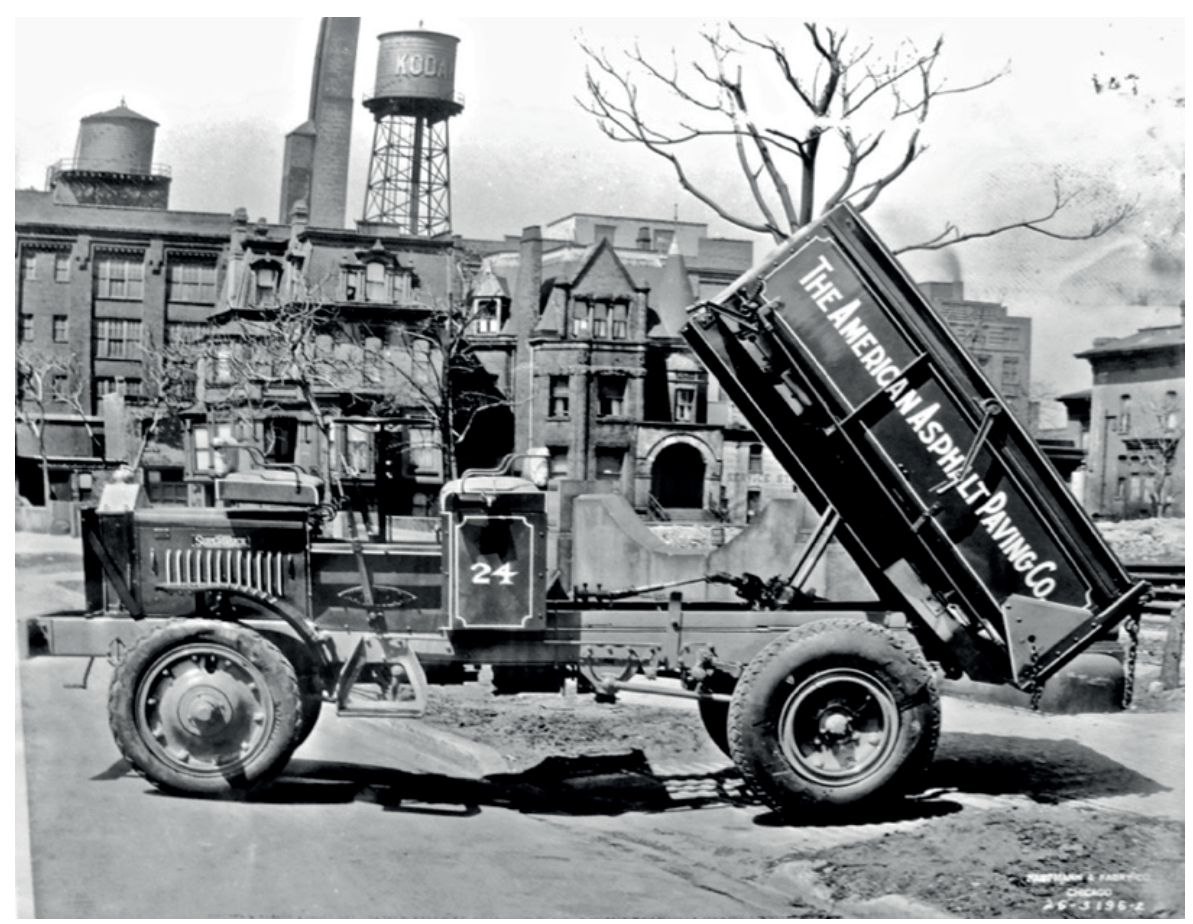

Figura 49. Volqueta

Fuente: Archivo General. Fondo Ministerio de Obras Públicas. SR: 65. 


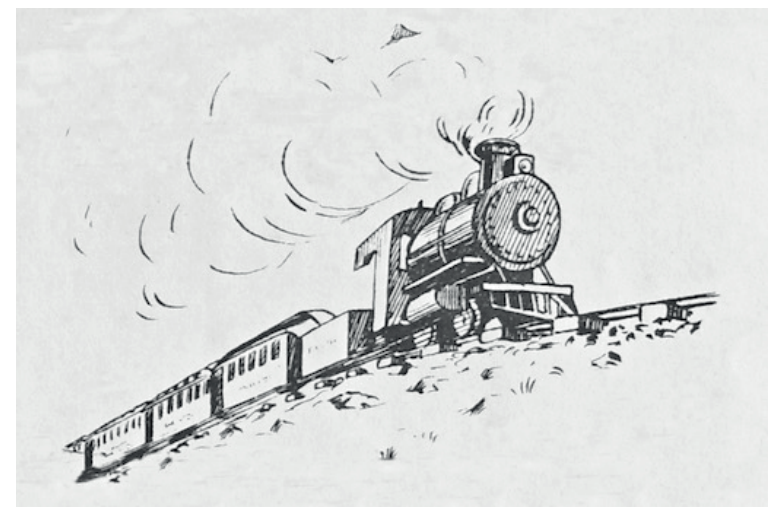

Figura 50. Locomotora

Fuente: Monsalve, Diego. (1927). Colombia Cafetera.
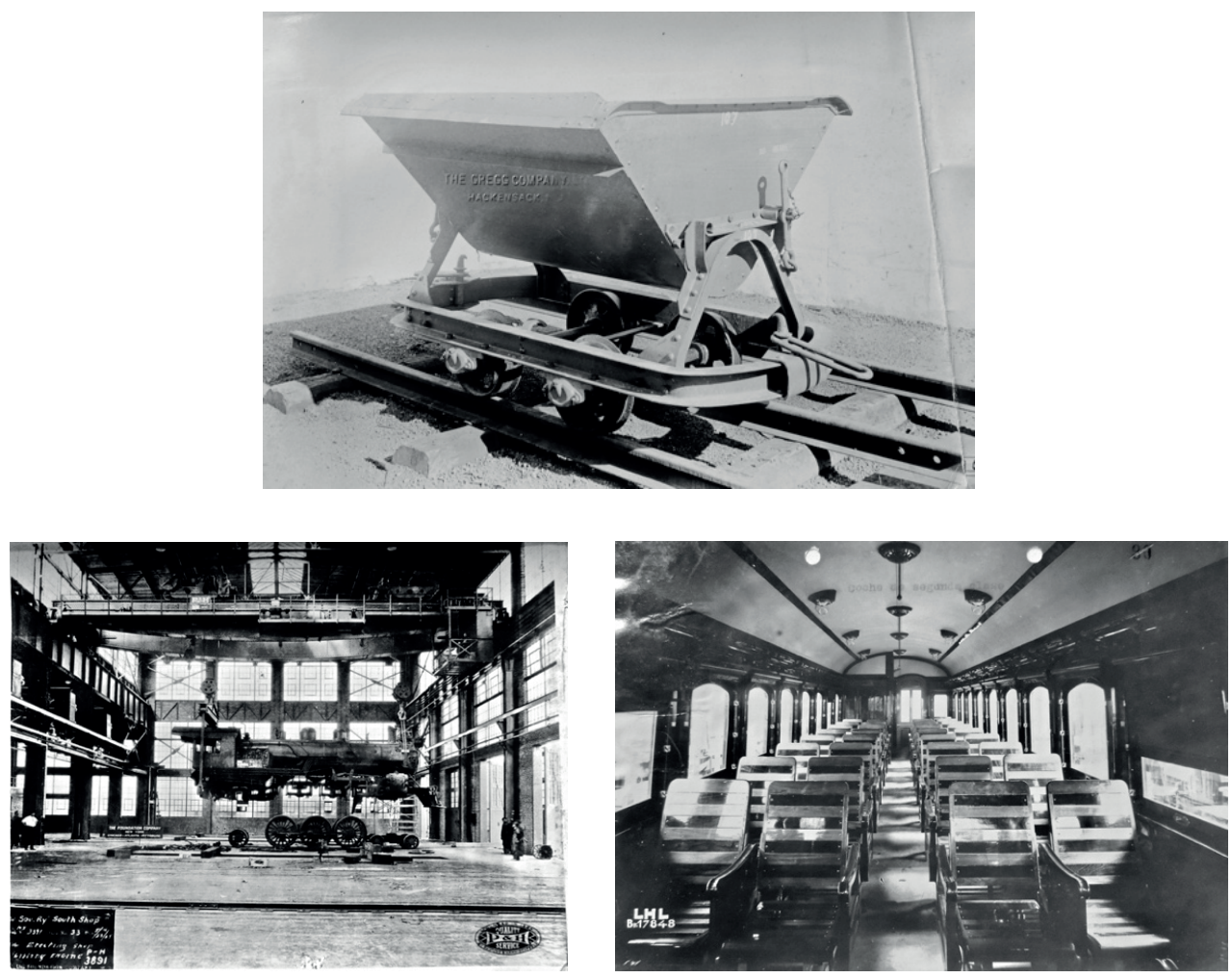

Figura 51. Catálogo de venta

Fuente: Archivo General de la Nación. Fondo Histórico F.N.C. 


\section{COMENTARIO $3^{\circ}$}

\section{Míster Morris}

U na vez llegada la primera locomotora a la ciudad de Pereira, en junio de 1921, empezó el verdadero viacrucis del Ferrocarril de Caldas. Las vegas del río La Vieja y las empinadas laderas del Consota, con túnel incluido, que les habían ocasionado algunas dificultades, se tornaban en un simple bizcochuelo. Ahora tenían al frente una verdadera pared. El alto de Boquerón, la Serranía del Lembo, las montañas rocosas de Río Claro y, al final, la empinada cuesta para llegar a Manizales, parecían inabordables.

Nuestros ingenieros se habían devanado los sesos tratando de encontrar la mejor forma de afrontar los desafíos que representaba esa temible orografía. El ingeniero Jorge Páez, en 1912, había trazado una línea preliminar entre el río Cauca y la Quiebra de Vásquez, hoy Boquerón, con una pendiente máxima del 2\%, y los ingenieros Julián Arango, primer ingeniero jefe del Ferrocarril de Caldas, Enrique Uribe y Florencio Mejía, habían trazado una preliminar entre Pereira y Manizales, con una pendiente máxima del 3\%. Un poco después, el ingeniero Arango, en unión del ingeniero Eleuterio Serna, había presentado un trazado de Pereira a Santa Rosa, con una pendiente máxima del $2 \%$. Pero, como nadie es profeta en su tierra, la Junta Administradora, poseedora de la última palabra, resolvió que era mejor traer a alguien del exterior para que resolviera los problemas del interior.

Comunicada su decisión a sus representantes en Nueva York, encontraron al mayor A. F. Morris, militar con experiencia en ferrocarriles, con quien firmaron un contrato por el término de un año, y una remuneración de $\$ 700$ mensuales más gastos de viaje. Es bueno comentar que el sueldo de nuestro nativo ingeniero jefe, era de \$330 mensuales. No sabemos a ciencia cierta qué tanta y tan calificada era la experiencia de este ingeniero en ferrocarriles pero, lo que sí podemos concluir, con los resultados de sus propuestas, es que el conocimiento de nuestra topografía, de nuestros suelos y de nuestra idiosincrasia, era ínfimo por no decir nulo. Su primera propuesta de trazado entre Pereira y Manizales, contenía tramos con pendientes del $5 \%$ cuando la máxima permitida en el país era del 3\%, no solamente para estar acorde con las especificaciones de las troncales del país, sino, para Caldas poder recibir la subvención que ofrecía el estado colombiano, por cada kilómetro construido. Obviamente, para no perder el auxilio nacional, la propuesta fue rechazada por la Junta. El ingeniero Morris modificó su trazado para ajustarlo todo a una pendiente máxima del 3\% y la Junta, en el afán de continuar la construcción desde Pereira hacia Manizales, aprobó la propuesta, en el mes de febrero de 1920. 
Más pronto de lo imaginado empezaron a aparecer las variantes para tratar de componer lo que se había planeado. En la salida de Pereira, bajando hacia el río Otún, estaba planteado un descenso de aproximadamente un kilómetro de longitud con pendiente continua de 3\%, y cruzando el río, un ascenso igual para llegar a La Popa.

Este problema, de tramos tan largos con pendientes máximas, que causaba limitaciones muy graves en la capacidad de las locomotoras para ascender con su carga, tuvo que ser solucionado por medio de una variante trazada por el ingeniero Eleuterio Serna. Un poco más adelante, al tratar de afrontar el ascenso a Boquerón, aparecieron nuevas discrepancias entre los criterios del ingeniero Morris y los ingenieros del ferrocarril. En pocas palabras, el trazado del ingeniero Páez, del año 1915 , contemplaba una línea con una pendiente máxima de $2.5 \%$, desplazada hacia el lado derecho de Boquerón que ascendía, aproximadamente, por el camino antiguo de "La Marcada", enfrentando la pendiente a media ladera, cerca a la zona por donde hoy en día se presenta airoso el serpentín de la Autopista del Café.

En cambio, el trazado Morris, atacaba de frente la montaña, obligándolo a realizar un sinnúmero de eses para un ascenso largo y sinuoso. Ni siquiera la observación de don Valeriano Marulanda, viejo zorro con la experiencia del abridor de caminos: "no se meta por ahí, mijo, que donde crecen los ochuvos morados la tierra es floja y deleznable", fue atendida. Dolores de cabeza produjo su construcción. Derrumbes a diestra y siniestra interrumpían constantemente la marcha de los trabajos. La Viuda, El Palo, El Infierno, El Olvido, fueron los nombres adjudicados a algunos de los muchos derrumbes que se presentaron. La época de invierno, cuando todavía estaba bien definida, en los meses de septiembre, octubre y noviembre, agredió despiadadamente a cuanto corte y terraplén se ejecutara. El ingeniero Luis C. Isaza, experimentado y práctico, quien fuera llamado de urgencia para tratar de sacar la obra del atolladero en que se encontraba, el mismo que propusiera la variante Consota en los comienzos del Ferrocarril de Caldas, expresó: "si no fuera por estar ya invertida una gran cantidad de dinero en la pendiente de Boquerón, hubiera solicitado autorización para volver con la línea a Pereira y emprender desde allí el avance por una nueva ruta, tal vez, la de Páez”.

Tal fue el desespero de los dirigentes, contagiados de las opiniones ligeras de los ciudadanos que achacaban a la impericia o a la ambición desmedida de lucro de los ingenieros, que unas decisiones y comentarios desafortunados de la Junta, provocaron la renuncia inmediata e irrevocable del señor superintendente don Manuel Felipe Calle y de los ingenieros Gabriel Mejía Villa, Rafael Betancourt, Francisco Londoño y Elías Calvo, que estaban al frente de la obra, y de los ingenieros Tiberio Ochoa Uribe y Roberto Cardona, encargados de la construcción del túnel de 130 metros de longitud que se venía abriendo cerca de la cresta de la montaña, 
lo que constituyó, en diciembre de 1924, la mayor crisis administrativa de toda la construcción.

Aplacados un poco los ánimos y reconsiderados los términos que ocasionaron la crisis, los ingenieros Ochoa y Cardona, retornaron a sus labores en el túnel y el ingeniero jefe, Isaza, acompañado por el ingeniero Hernando Piedrahita, continuaron con la construcción de la obra, ahora acompañados de un verano salvador que les permitió arribar airosos a Santa Rosa de Cabal, en el mes de julio de 1925. Pero no fueron estos los únicos trastornos que causara la traída de Mr. Morris. El problema del ascenso hacia Manizales contenía otra variable que el ingeniero Morris no podía solucionar, simplemente porque no sabía de ese tema. Se trataba de escoger el tipo de tracción apropiado para las locomotoras.

Decidió, entonces, la Junta, traer otro gringo que supiera del tema, porque, realmente, por estos lares, y contrario a lo que sucedía con los ingenieros de trazado, no había personal capacitado para resolver el problema de la tracción. Llegó el capitán Wilson, y después de un análisis detenido de la situación, propuso una matriz de alternativas que contemplaba distintos tipos de locomotora, distintos recorridos y la combinación de los mismos, tratando de ajustar la capacidad de tracción de cada tipo de locomotora a la pendiente necesaria en cada tramo.

La primera alternativa: para el recorrido total Pereira-Manizales, tres opciones: $1^{\mathrm{a}}$. tracción por vapor, $2^{\mathrm{a}}$, , vagones eléctricos de corriente alterna monofásica y $3^{\mathrm{a}}$. locomotoras eléctricas de corriente directa a 1200 voltios. Segunda alternativa: para el tramo entre Pereira y San Francisco (hoy Chinchiná), locomotoras a vapor y el tramo entre San Francisco y Manizales, vagones eléctricos de corriente alterna monofásica, y tercera alternativa: Las mismas locomotoras a vapor entre Pereira y San Francisco y locomotoras eléctricas de corriente alterna monofásica entre San Francisco y Manizales. Interesante ejercicio pero difícil de digerir.

La Junta que esperaba una propuesta concreta quedó viendo un chispero. Para escoger cuál alternativa era la mejor volvieron a consultar a Mr. Morris quien responde que, en su concepto, la mejor es la propuesta de locomotoras eléctricas en el tramo total de Pereira a Manizales.

La Junta la consideró inaplicable y resolvió, en su sabiduría, adoptar la propuesta número 1: de vapor en toda la línea. Lo cual quiere decir que la pendiente de la línea no podría exceder del 3\%, obligándola a tener una mayor longitud para lograr ascender a la cima de cualquier montículo que se atraviese, pero exagerada para la carga que debería arrastrar una locomotora de vapor. 
Esta determinación fue fatal para los rendimientos económicos del ferrocarril $\mathrm{y}$, sin duda, definitiva para la terminación de su operación. Con decir que, una locomotora especifica podía arrastrar diez vagones cargados, por poner una cifra, entre Cartago y Pereira, pero, tenía que desenganchar cinco en Pereira para poder ascender hacia Manizales. Esta situación implicaba que era necesaria otra locomotora, establecida en Pereira, para terminar de llevar la carga hasta Manizales. Todo esto representaba, obviamente, un sobrecosto inmenso para la operación en ese tramo. La dirigencia caldense, en su afán de subir el tren a Manizales, hizo uso de su inagotable imaginación y descubrieron dos tipos nuevos de pendientes: la de exportación, es decir, la correspondiente a la vía que conducía hacia el puerto la carga, que consideraban más importante que era el café, y la de importación, para el sentido de llegada de los distintos bienes de importación, que podían ser manejados con menos apremio. Pero de poco les valió su invento porque la agreste topografía los obligaba a ascender cuestas en ambos sentidos.

Si fue justificada o no, la traída de los dos norteamericanos, no podemos afirmarlo. Pero lo que sí pone en evidencia es la indecisión de la Junta frente a determinaciones que, por su magnitud o su desconocimiento, los ponían a dudar y trataban, con la mejor buena fe, encontrar el camino apropiado a través del consejo extranjero, no siempre con el resultado esperado.

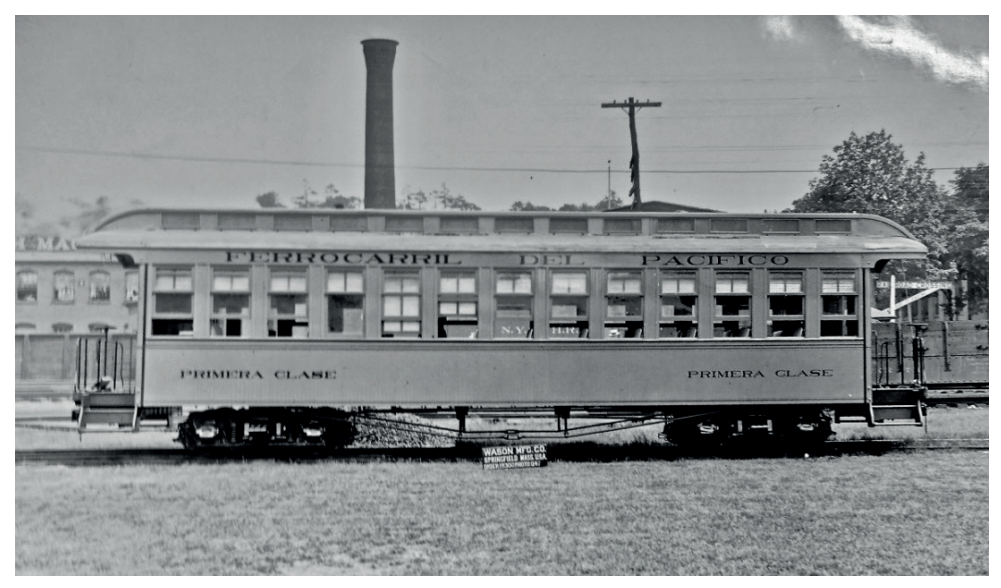

Figura 52. Vagón de pasajeros

Fuente: Archivo General de la Nación 


\section{CAPÍTULO IV}

\section{Construcción del ferrocarril Pereira-San Francisco}

$C^{n}$ el año de 1920, es decir, un año antes de llegar el enrielado a la ciudad de EPereira, ya se habían iniciado los trabajos de explanación para la vía férrea hacia Santa Rosa de Cabal. Bajo la dirección del ingeniero Eleuterio Serna la obra se extendió hasta el sitio en donde quedaría la Estación Gutiérrez (Km 48), llamada así en honor al general Pompilio Gutiérrez, gobernador e insigne defensor e impulsor del Ferrocarril de Caldas. El tramo fue inaugurado el 12 de octubre de 1922 y al acto asistieron las autoridades y personajes del Departamento y de las ciudades de Santa Rosa de Cabal y Pereira. El mismo día de la inauguración de la estación Gutiérrez se celebró la llegada de tres locomotoras nuevas, para completar cinco, al servicio del Ferrocarril de Caldas y los nuevos talleres en la ciudad de Pereira. Continuaría la construcción hacia el sitio de Boquerón bajo la dirección del ingeniero Luis A. Isaza, en reemplazo del ingeniero Serna, quien había presentado renuncia del cargo. Fue este tramo uno de los más difíciles para su construcción, sino el más, de toda la línea del Ferrocarril de Caldas.

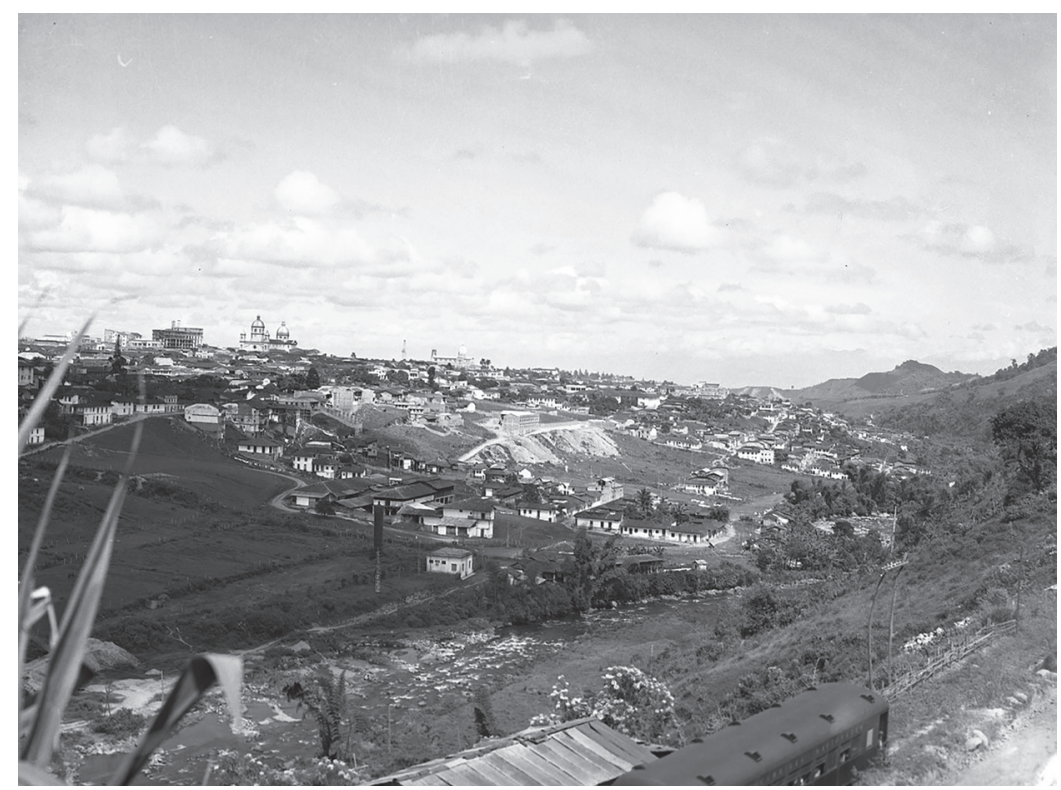

Figura 53. Tren en La Popa

Fuente: Donato García R. 


\section{El Guardagujas}

Juan José Arreola

Recientemente, doscientos pasajeros anónimos escribieron una de las páginas más gloriosas en nuestros anales ferroviarios. Sucede que en un viaje de prueba, el maquinista advirtió a tiempo una grave omisión de los constructores de la línea. En la ruta faltaba el puente que debía salvar un abismo. Pues bien, el maquinista, en vez de poner marcha hacia atrás, arengó a los pasajeros y obtuvo de ellos el esfuerzo necesario para seguir adelante. Bajo su enérgica dirección, el tren fue desarmado pieza por pieza y conducido en hombros al otro lado del abismo, que todavía reservaba la sorpresa de contener en su fondo un río caudaloso. El resultado de la hazaña fue tan satisfactorio que la empresa renunció definitivamente a la construcción del puente, conformándose con hacer un atractivo descuento en las tarifas de los pasajeros que se atreven a afrontar esa molestia suplementaria. (Betancur y Zuluaga, 1995)

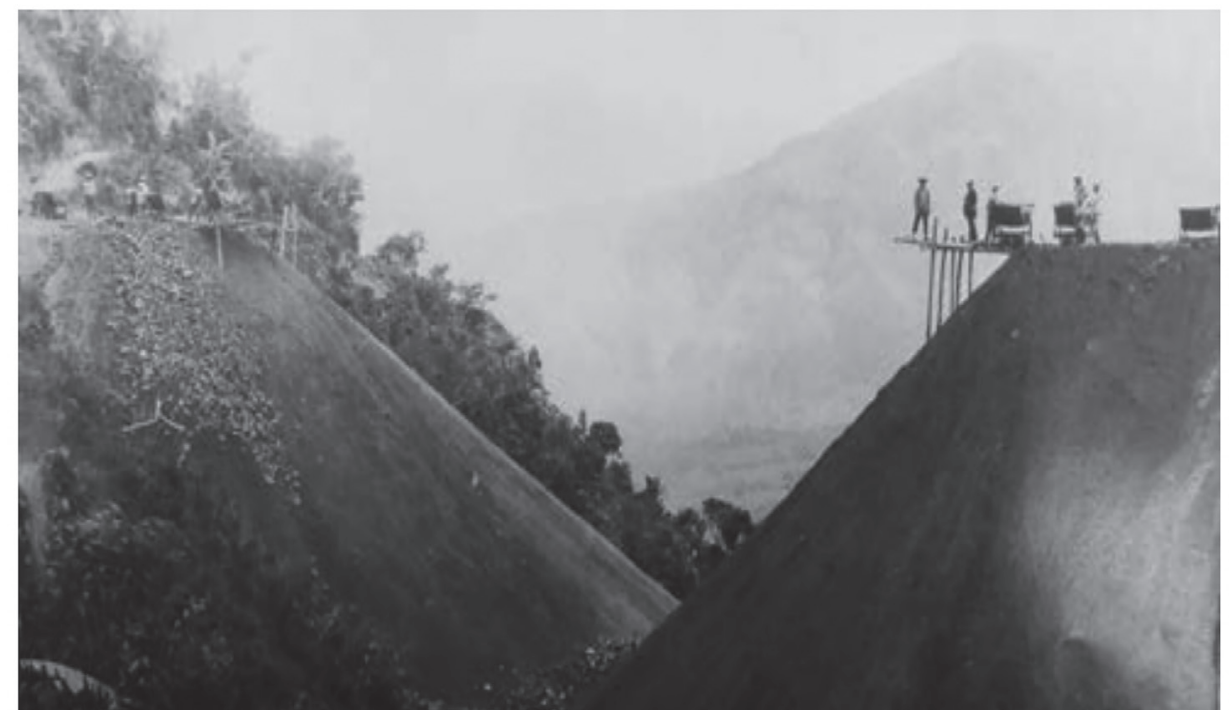

Figura 54. Construcción de un ferrocarril 


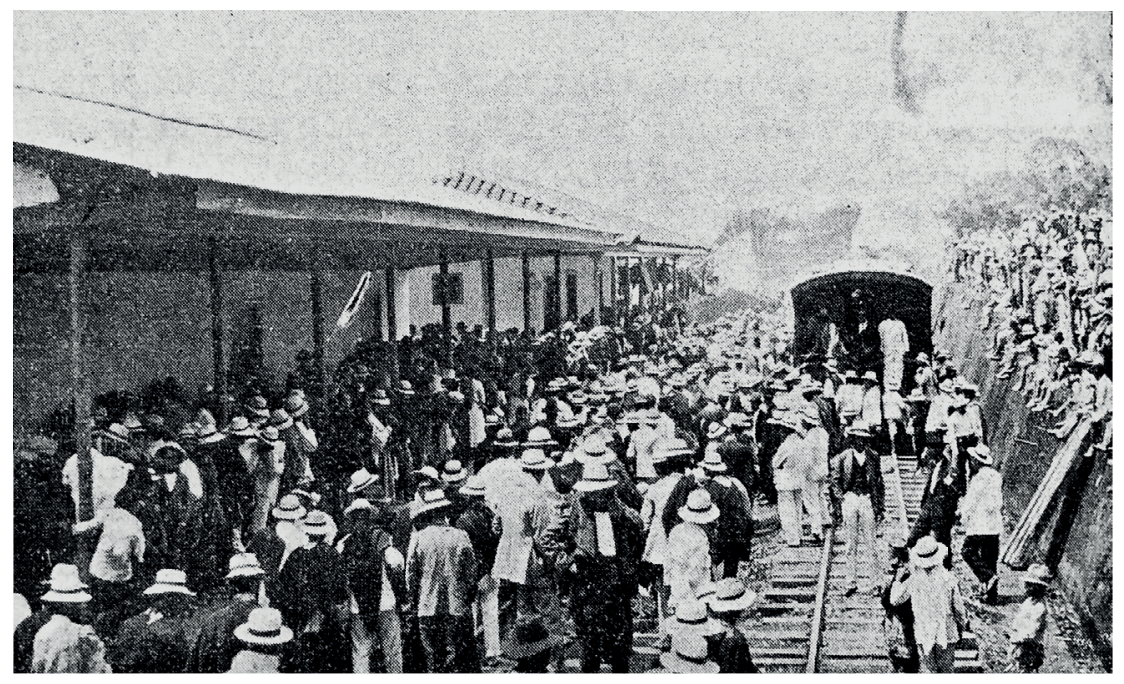

Figura 55. Inauguración de Estación Gutiérrez Fuente: Revista Cromos N³31. Noviembre de 1922.

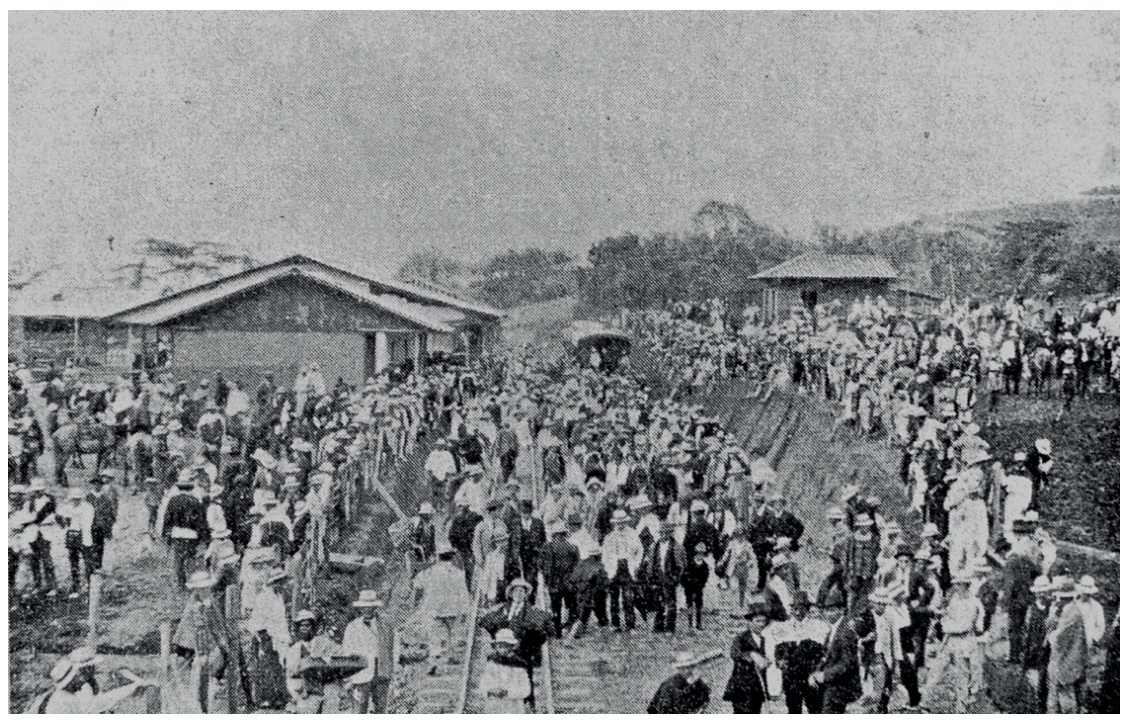

Figura 56. Inauguración de Estación Gutiérrez Fuente: Revista Cromos N³31. Noviembre de 1922. 

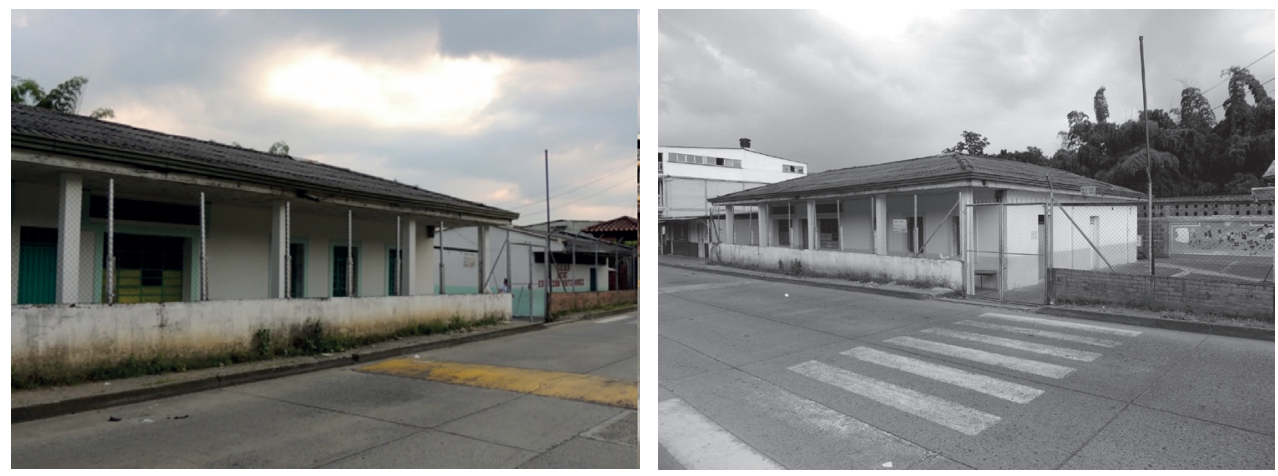

Figura 57. Estación Gutiérrez (2016)

Fuente: fotografía Armando Ramírez Villegas (2016)

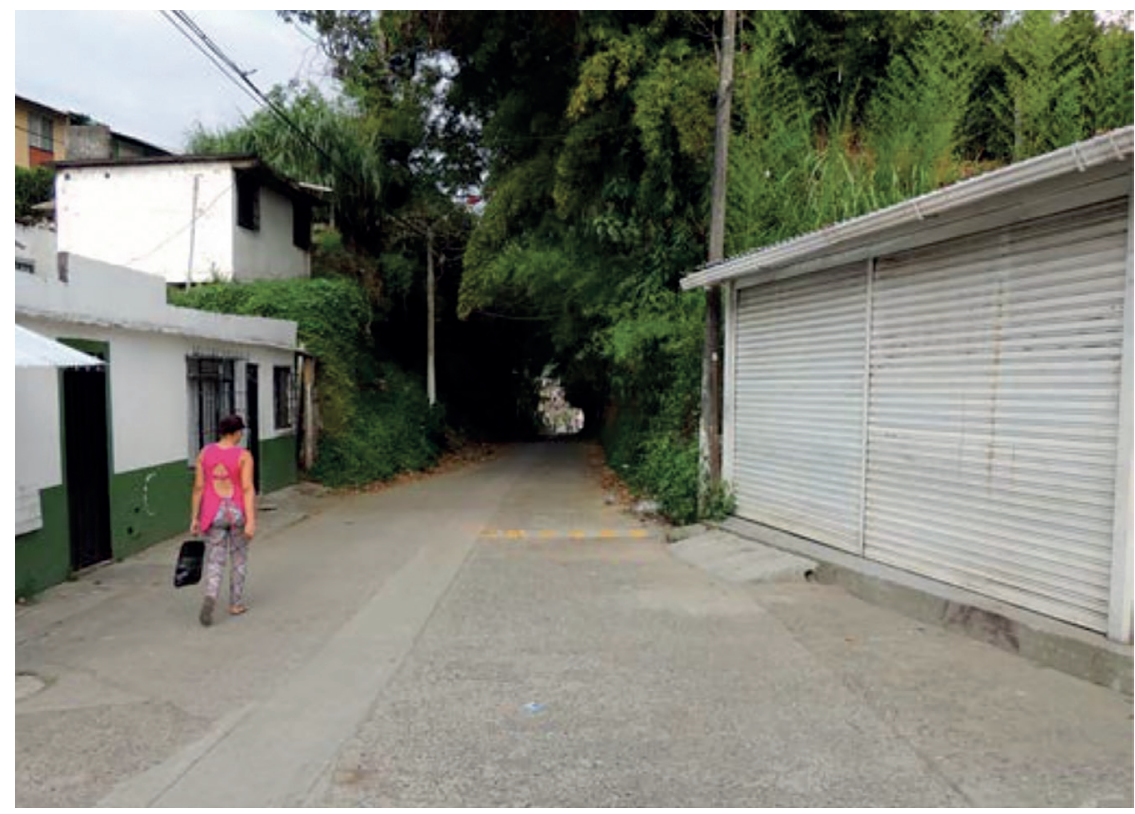

Figura 58. Antigua banca del ferrocarril

Fuente: fotografía Armando Ramírez Villegas (2016) 


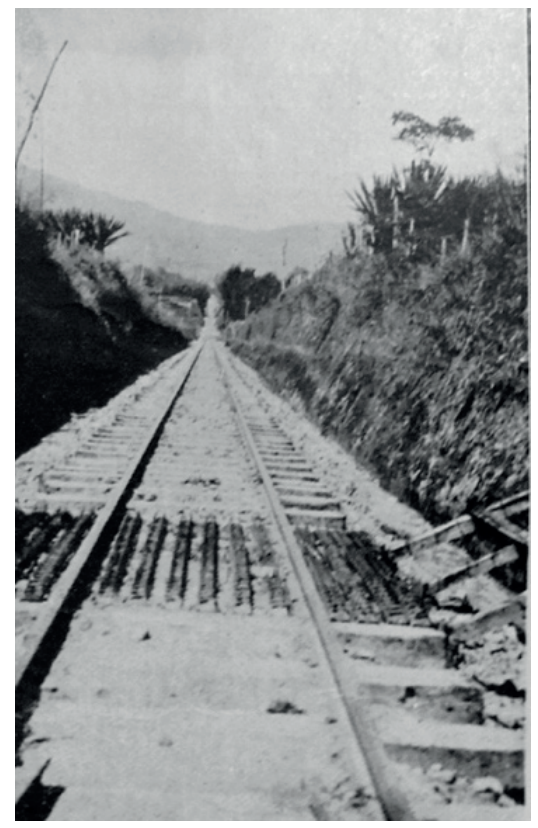

Figura 59. Carrilera en Dosquebradas Fuente: Revista Cromos, 1924.

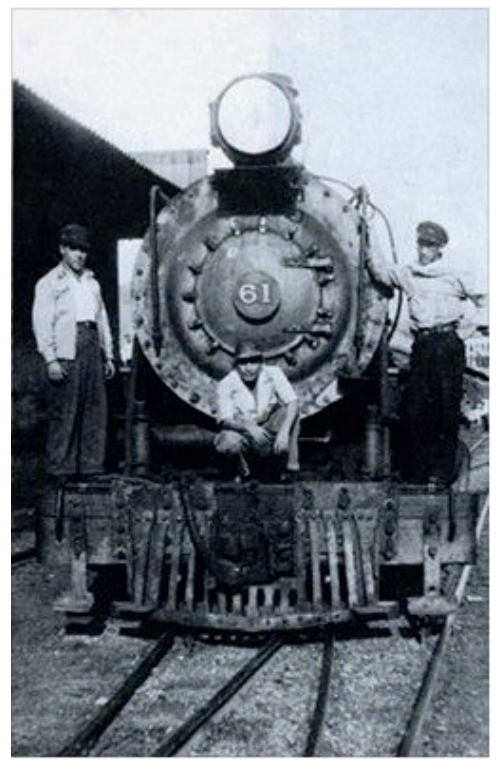

Figura 60. Maquinistas

Fuente: Grupo Fotografías Antiguas de Pereira (2015). 
Numerosas "obras de arte", muros de contención y un túnel en curva de 130 metros de longitud, que acarreó serias dificultades técnicas, fueron necesarios para salvar la montaña. La topografía escarpada, los suelos inestables y un invierno como no se tenía hacía mucho tiempo, hicieron de la construcción de este tramo un verdadero infierno.

Los numerosos derrumbes, que cubrían de nuevo, lo que se había explanado, y tapado el enrielado que se había colocado, sembraron la desolación y el pesimismo sobre el éxito de la obra, a tal punto de que en diciembre de 1924, dos años después de iniciada la obra y haber avanzado solo 4 kilómetros, se produjo la renuncia masiva del superintendente Manuel Felipe Calle y de los ingenieros Gabriel Mejía Villa, Tiberio Ochoa, Rafael Betancourt, Roberto Cardona, Francisco Londoño y Elías Calvo a quienes, algunos, sin dar crédito a las adversidades naturales, creían responsables de la demora de la obra. Pronto cambió el clima, los derrumbes desaparecieron y los ingenieros Ochoa y Cardona, acompañados por el ingeniero Hernando Piedrahita, decidieron continuarcon los trabajos parallevar los rieleshasta la ciudad de Santa Rosa.

En el término de dos meses, en febrero de 1925, la locomotora atravesó el túnel y cuatro meses después, en julio, una vez terminado el puente metálico sobre el río San Eugenio, llegaría triunfante a Santa Rosa, lo que demuestra que la causa de las demoras había que buscarla en los fenómenos naturales y no en las debilidades humanas.

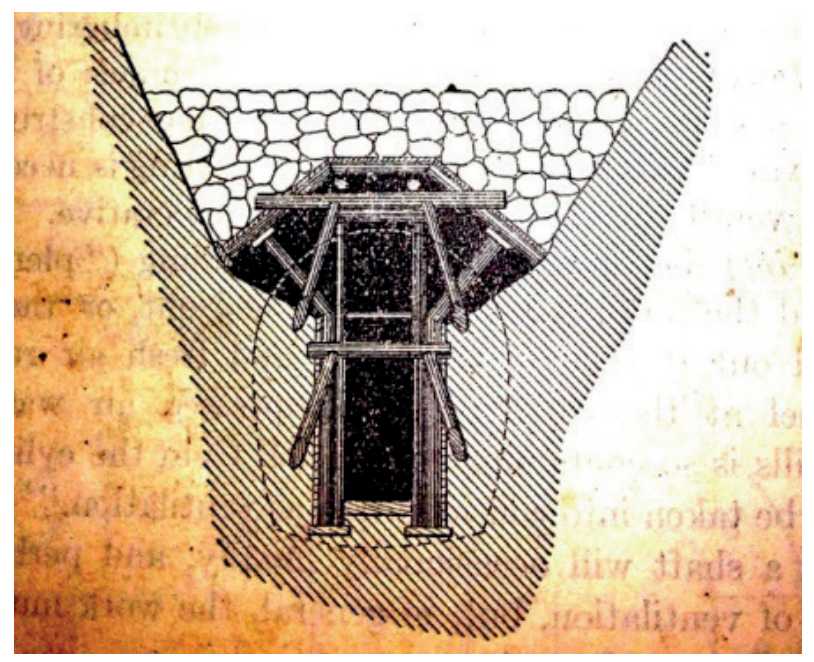

Figura 61. Cimbra para alcantarilla 


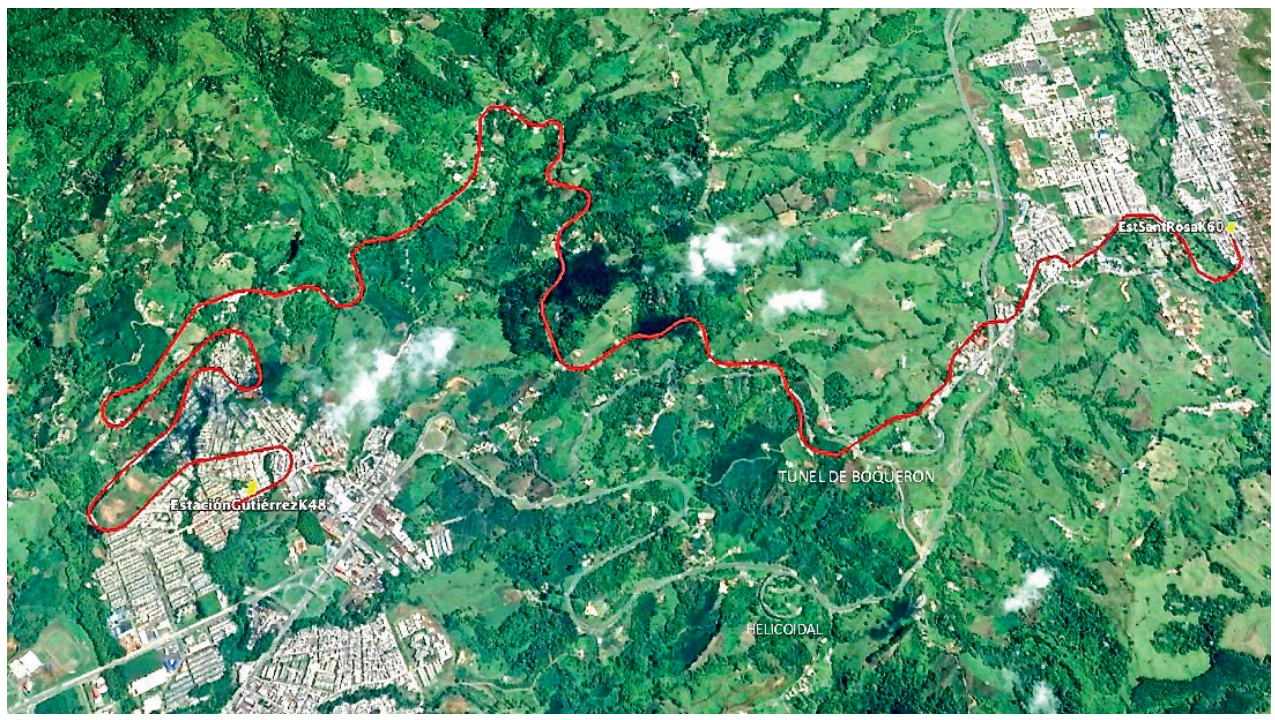

Figura 62. Trazado del ferrocarril. De la estación Gutiérrez a Santa Rosa de Cabal Fuente: Montaje sobre imagen de Google Earth. Armando Ramírez Villegas, 2016.

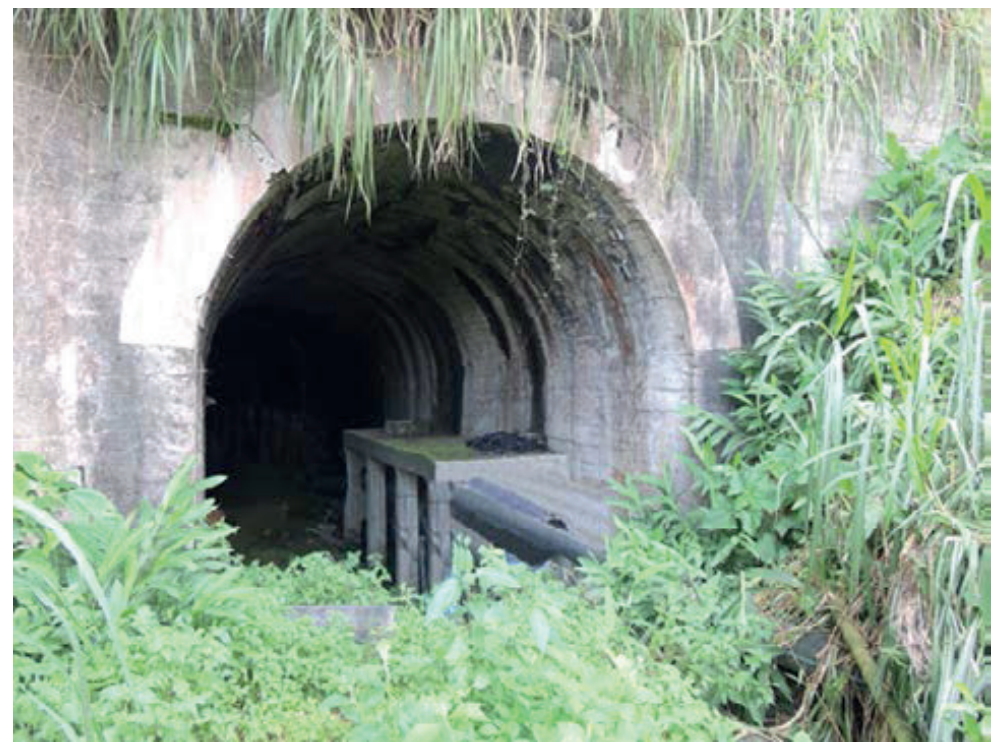

Figura 63. Túnel $N^{\circ} 2$. Boquerón.

Fuente: fotografía Armando Ramírez Villegas (2016) 


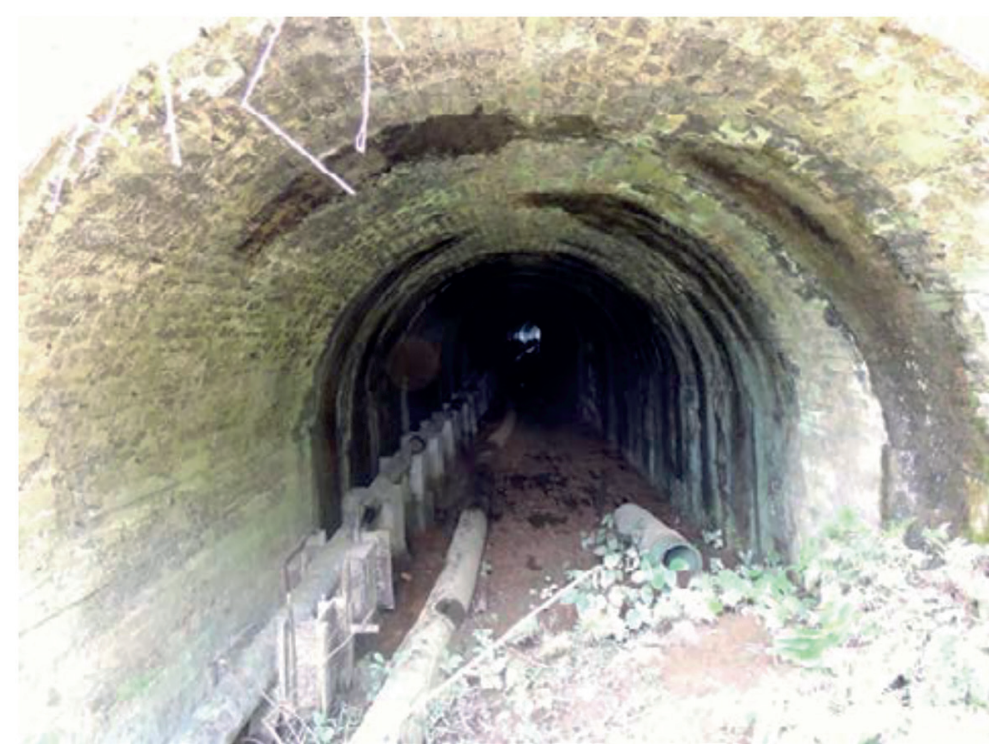

Figura 64. Túnel N². Boquerón.

Fuente: fotografía Armando Ramírez Villegas (2016)

\section{PUENTE SOBRE EL RÍO SAN EUGENIO}

1923

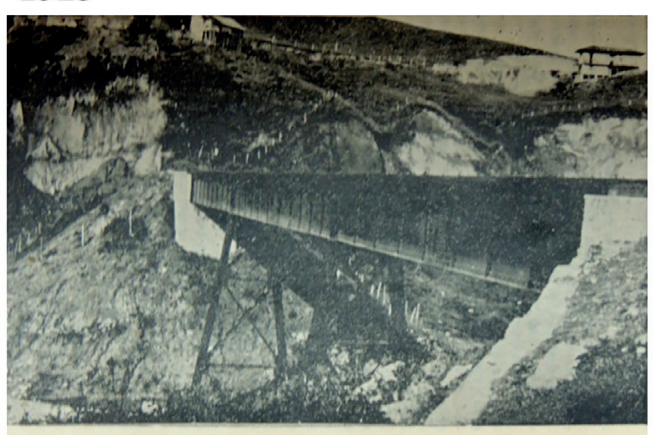

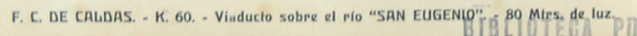

2016

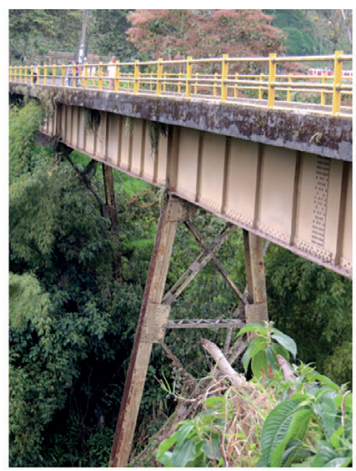

Figura 65. Puente sobre el río San Eugenio. 1923-2016 


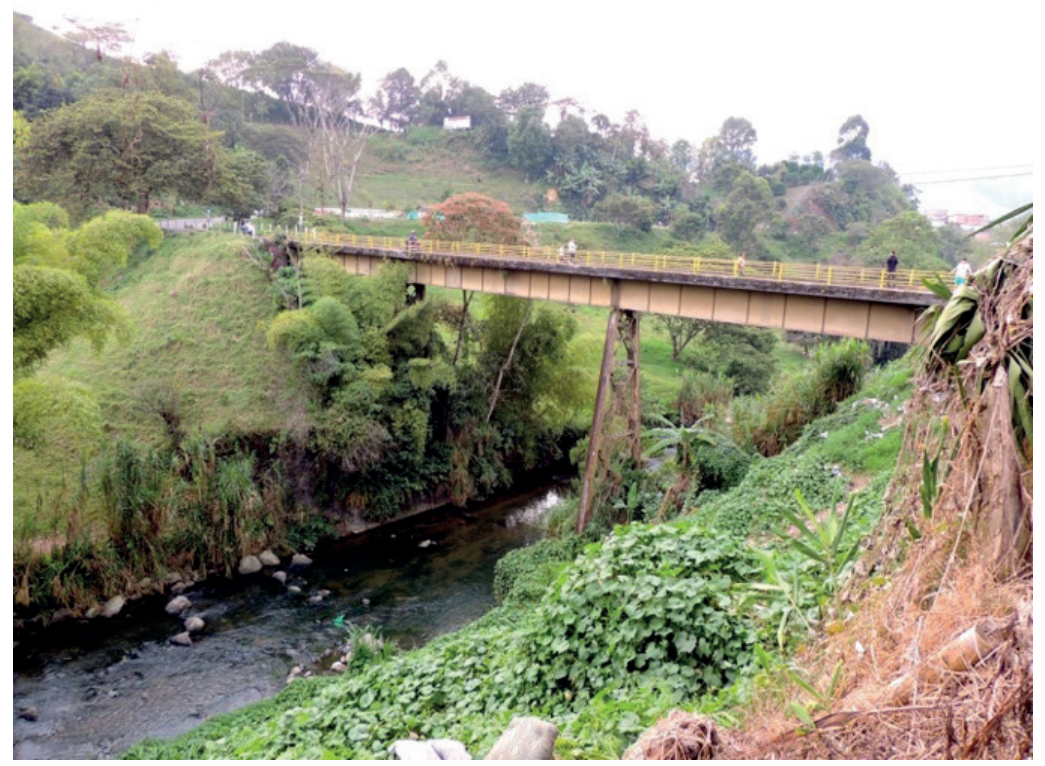

Figura 66. Puente sobre el río San Eugenio

Fuente: fotografía Armando Ramírez Villegas (2016)
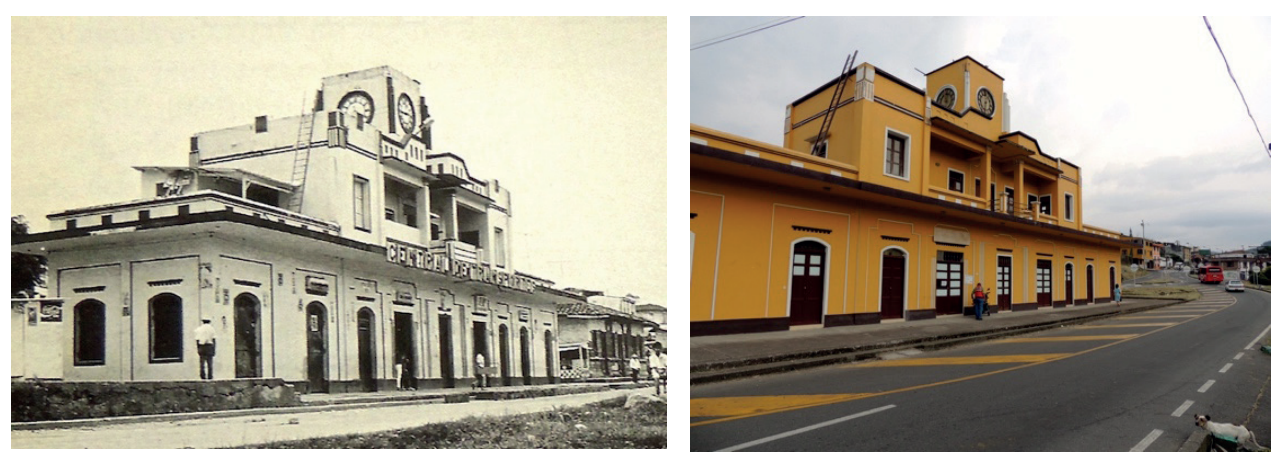

Figura 67. Comparación estación Santa Rosa de Cabal. 1906-2016

Fuente: imagen de la izquierda Grupo de Fotos Antiguas de Pereira (2015) e imagen de la derecha fotografía Armando Ramírez Villegas (2016) 


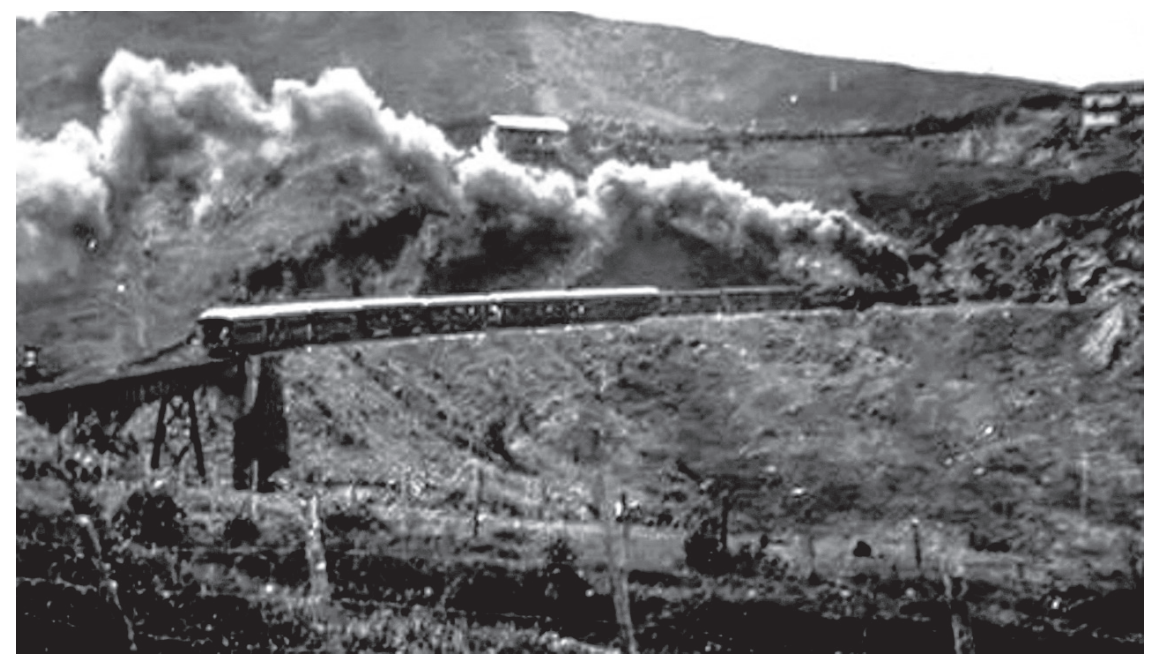

Figura 68. Tren saliendo del puente sobre el río San Eugenio hacia Pereira Fuente: Grupo Fotografías Antiguas de Pereira (2015).

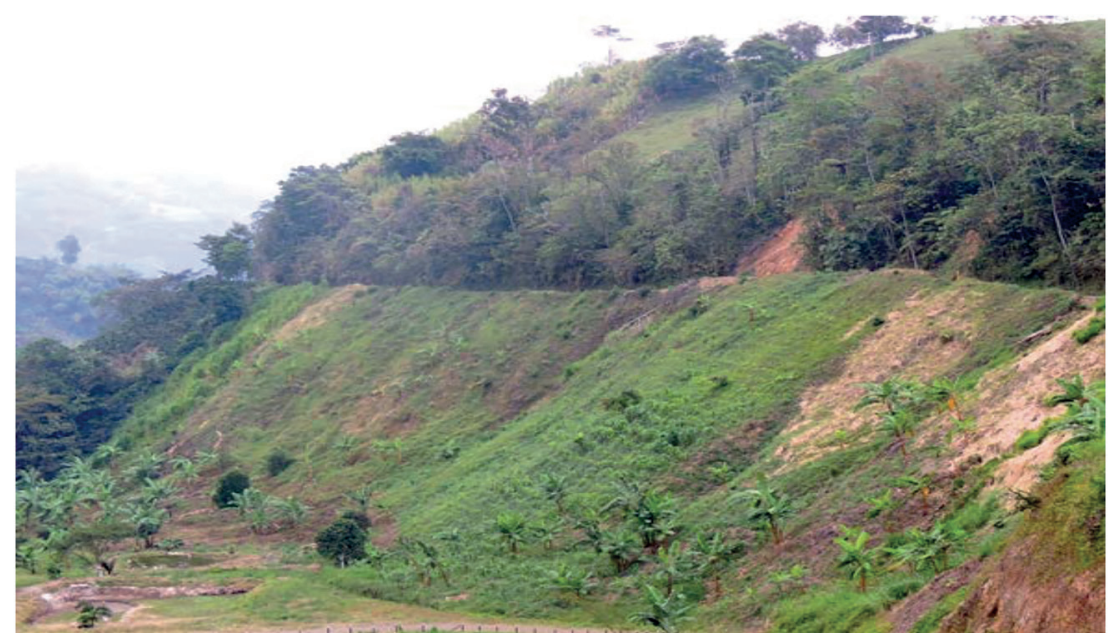

Figura 69. Ascenso hacia la estación La Capilla

Fuente: fotografía Armando Ramírez Villegas (2016) 
Justo es reconocer la decisión del nuevo superintendente el ingeniero civil don Francisco Jaramillo O., de terminar en el menor tiempo posible el tramo faltante y la ayuda sin tregua ofrecida por el ingeniero Isaza para tal logro. Cuando se aprestaba la ciudad de Santa Rosa de Cabal a celebrar la llegada del ferrocarril a sus puertas, se recibió la infausta noticia del incendio en la capital del departamento, lo que produjo la cancelación de toda festividad en solidaridad con la ciudadanía de Manizales.

En sesión de la Junta del Ferrocarril, del día 9 de noviembre de 1924 (Echeverri, 1927), se decidió cambiar el sistema de contratación con los ingenieros, que venían trabajando por el sistema de administración delegada, por la de contratos de obra, basados en precios unitarios de los distintos ítems, y celebrados con ingenieros que tuvieran la capacidad económica, los conocimientos y la experiencia apropiada para ese tipo de obras, para lo cual se hizo la convocatoria a nivel nacional.

Así las cosas, se celebró un contrato con los ingenieros Tiberio Ochoa U. y Roberto Cardona, para construir el tramo comprendido entre los kilómetros 68 (adelante de Guayabito) y 76 (río Campoalegre). Se inició la construcción, siguiendo la margen derecha del río San Eugenio, y superando algunas dificultades en el cruce de Las Peñas, nombre proveniente de una gran montaña de roca, en donde hubo necesidad de utilizar explosivos bajo la dirección de personal norteamericano, que fuera traído expresamente para dar la instrucción sobre el manejo, más eficiente y seguro, de la dinamita.

Se encontraron, un poco más adelante, un gran corte de tierra en el sitio denominado San Juan, que en varias oportunidades originó derrumbes que tapaban completamente la banca, para lograr llegar al kilómetro 71, en donde se inauguró la estación de La Capilla, en febrero 17 de 1926. La Capilla es un caserío muy bien conformado, con una calle amplia, perpendicular a la carrilera, que desemboca en un parque en donde está una capilla, que le da el nombre al caserío. Siguió la construcción hacia la estación de Campoalegre, cruzando el paso denominado Los Micos, en donde fue necesario construir un box culvert, o caja de concreto con una sección de 1.60 por 1.70 metros y una longitud de 80 metros, y a continuación, hacer un gran corte en la montaña de roca, utilizando dinamita y aprovechando la experiencia y las instrucciones recibidas de los americanos en el corte de Las Peñas, como se relató anteriormente. 
El Ferrocarril de Caldas: una obra de titanes

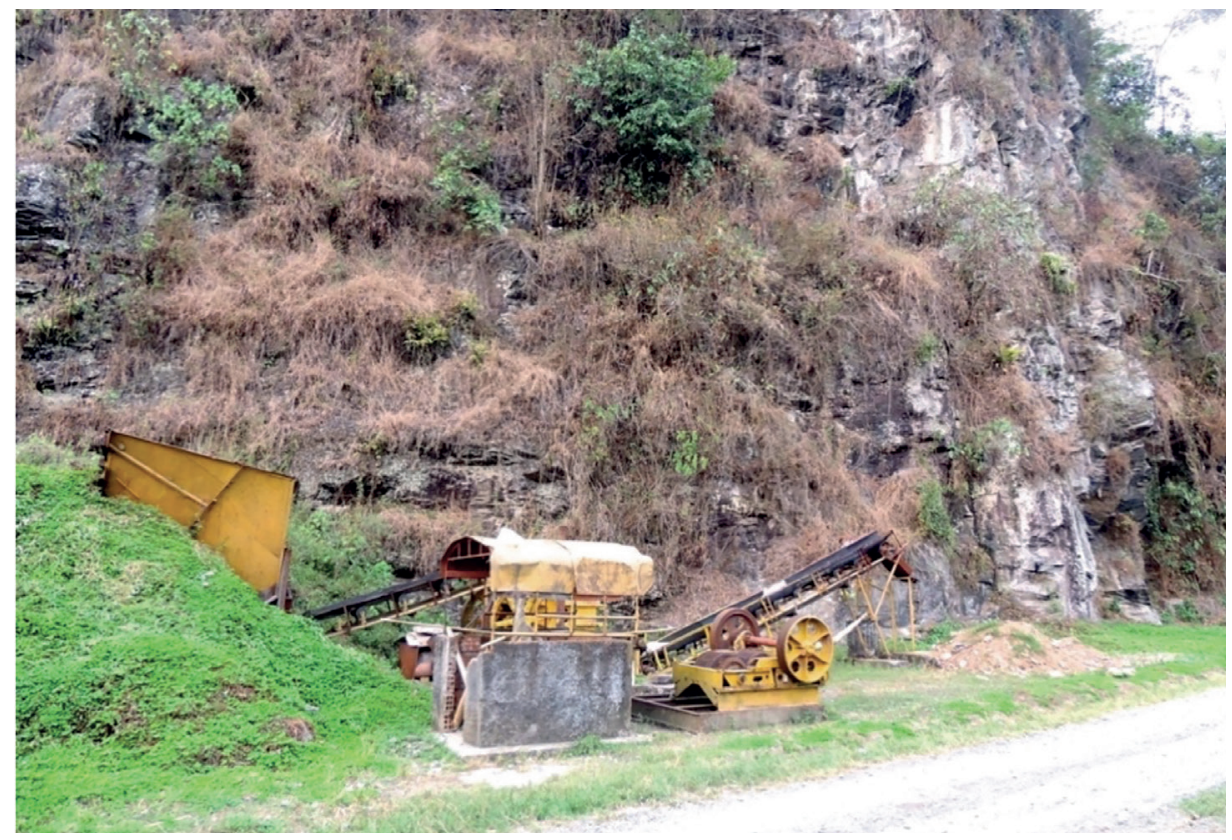

Figura 70. Las Peñas

Fuente: fotografía Armando Ramírez Villegas (2016)

Desafortunadamente, en la manipulación de la dinamita, se presentó un terrible accidente al producirse la explosión sorpresiva de unos tacos que ocasionaron la muerte instantánea de tres de los trabajadores del ferrocarril. Profunda consternación y dolor produjo esta tragedia en todo el personal de la obra, que conmovidos, no tuvieron más remedio que continuar en la lucha diaria, para tratar de llegar lo antes posible con el ferrocarril a la población de San Francisco, que era la meta inmediata, que se proponía toda la dirigencia, en su afán de permitir la llegada de los materiales y elementos necesarios para la reconstrucción de la ciudad de Manizales. Los ingenieros contratistas, Ochoa y Cardona, concluyeron la obra contratada, entre el kilómetro 68, adelante de Guayabito, al 76, en el cruce con el río Campoalegre, en el mes de abril de 1926. 


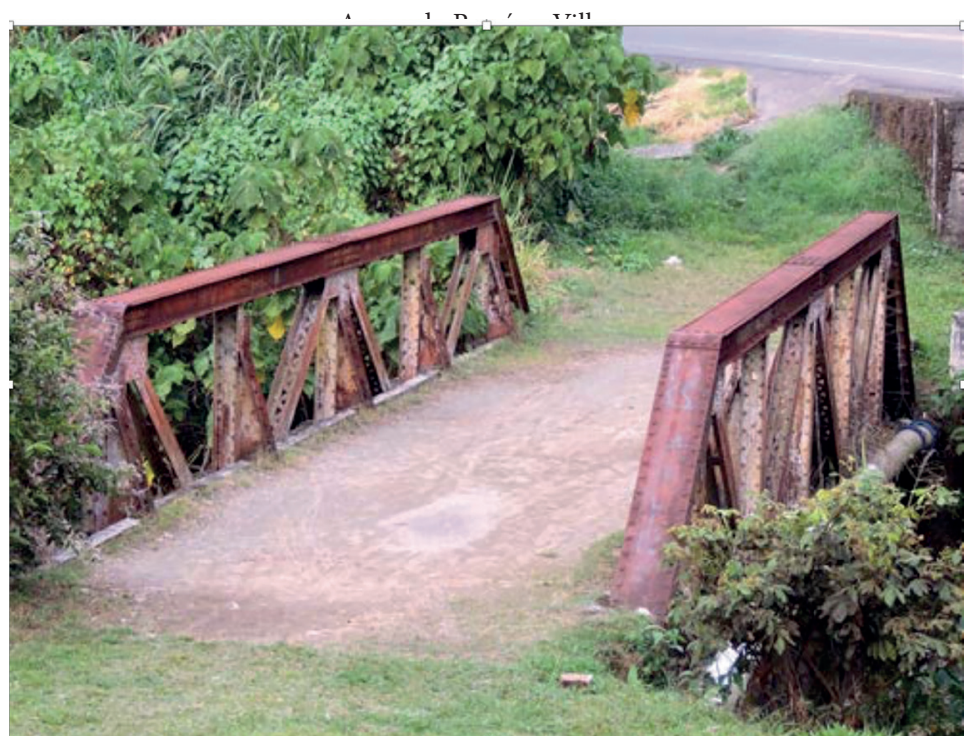

Figura 71. Puente sobre el río Campoalegre

Fuente: fotografía Armando Ramírez Villegas (2016)

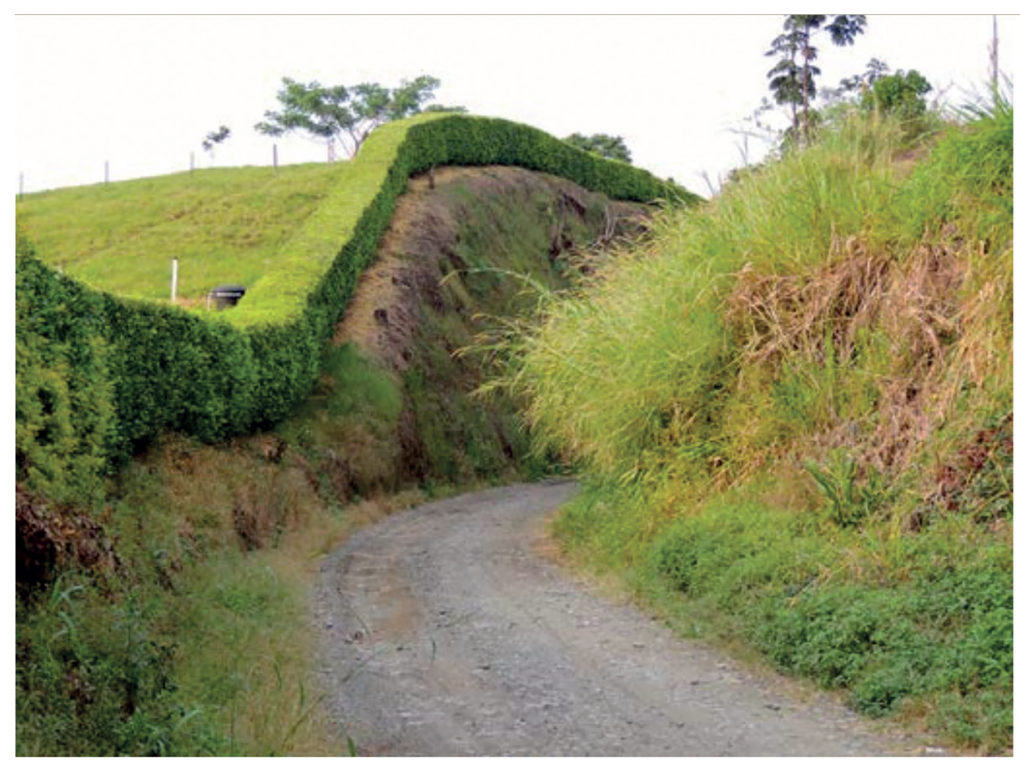

Figura 72. Banca hacia La Capilla. Kilómetro 61

Fuente: fotografía Armando Ramírez Villegas (2016) 


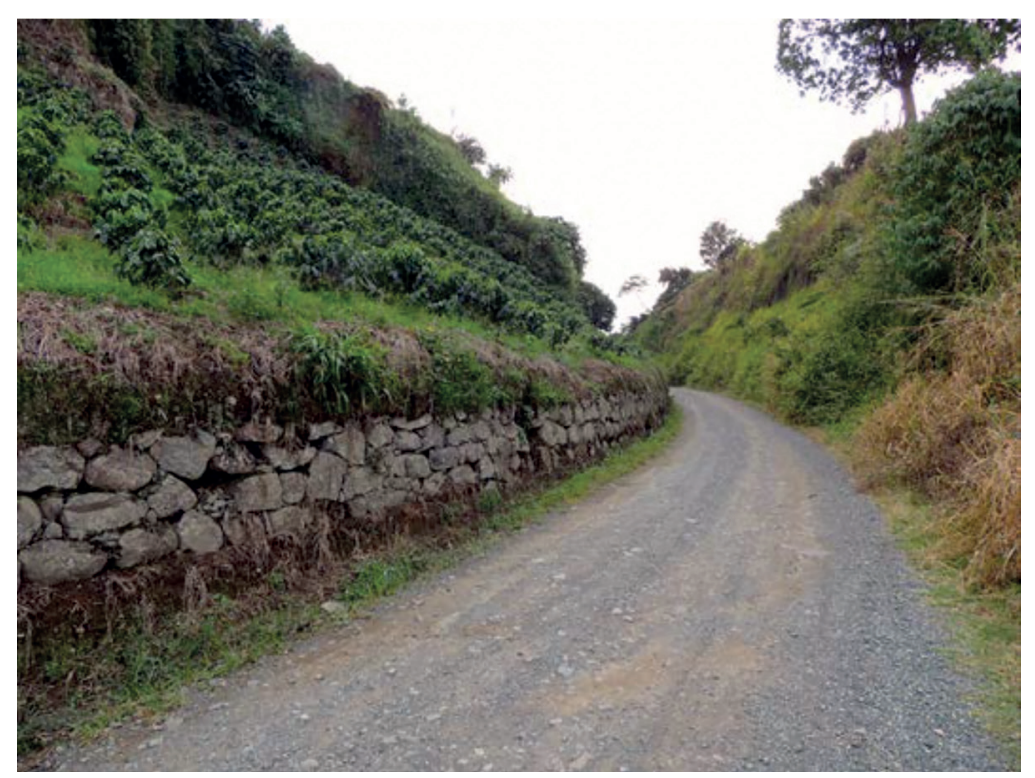

Figura 73. Muro "De Pata" en el paso San Juan

Fuente: fotografía Armando Ramírez Villegas (2016)

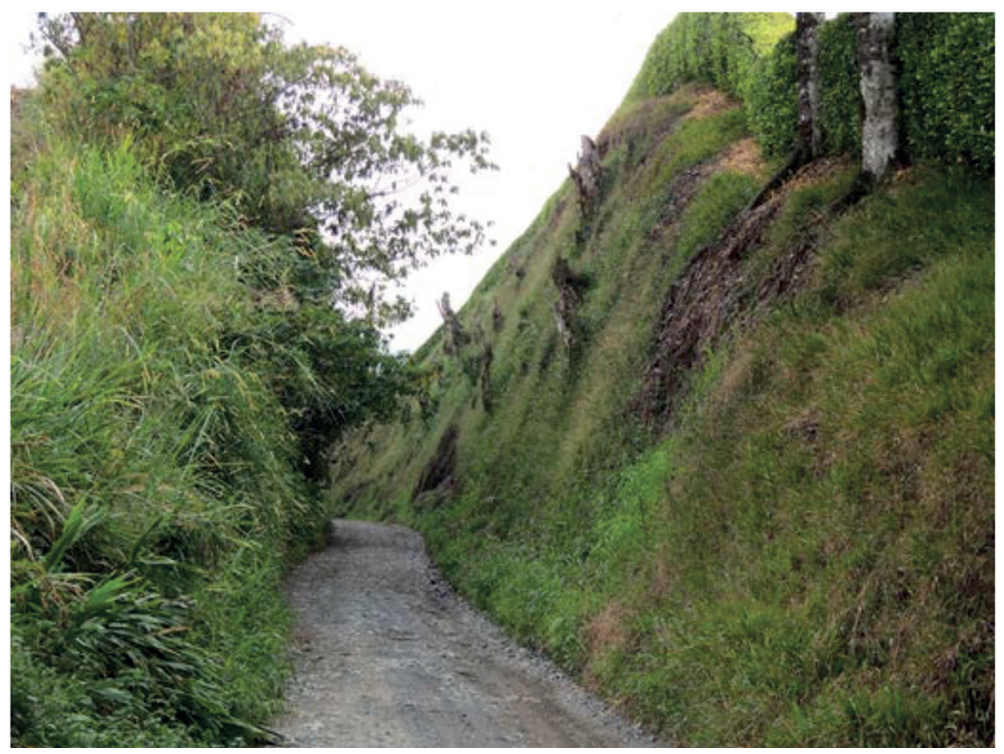

Figura 74. Antigua banca. Kilómetro 65

Fuente: fotografía Armando Ramírez Villegas (2016) 
Armando Ramírez Villegas

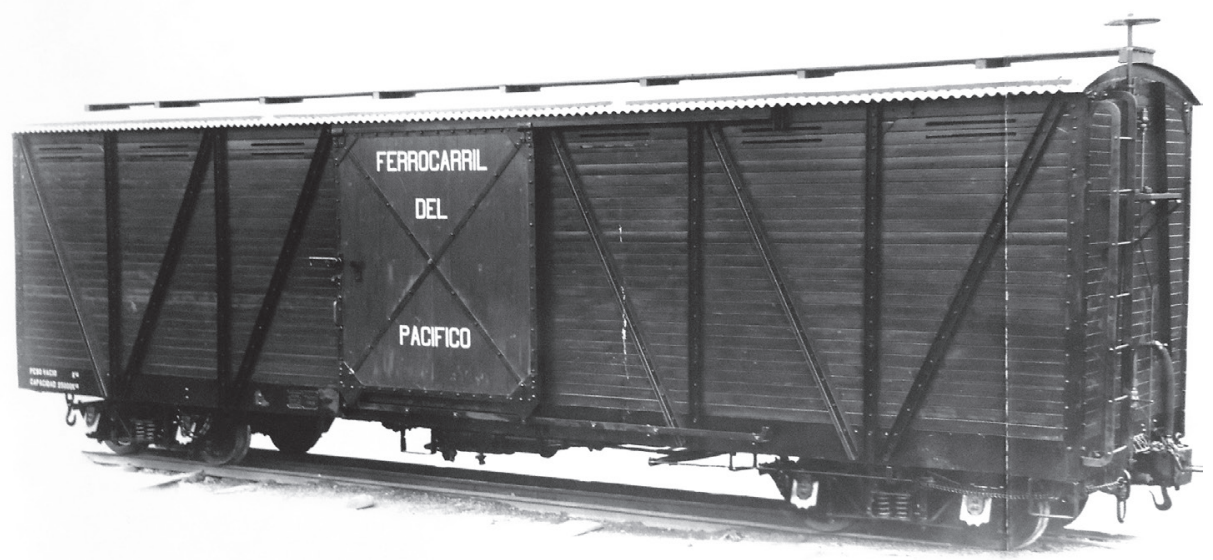

Figura 75. Vagón de carga

Fuente: Archivo General de la Nación. Fondo Ministerio de Obras Públicas

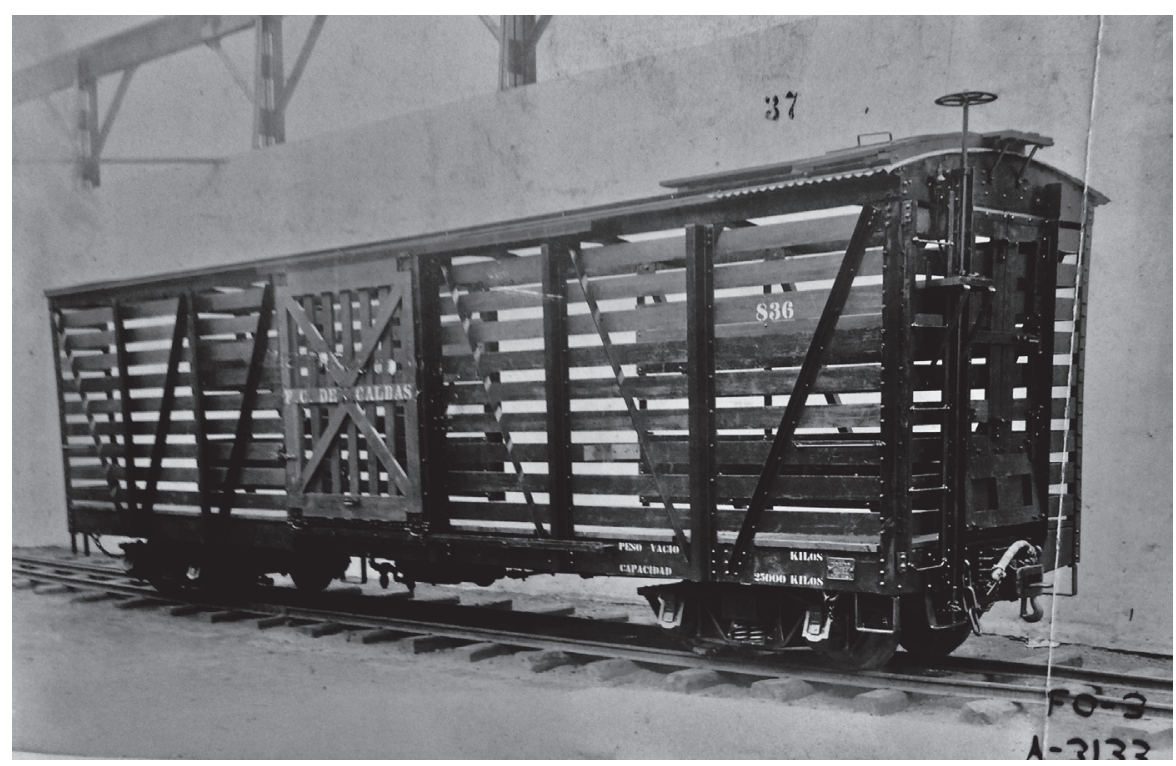

Figura 76. Jaula para ganado

Fuente: Archivo General de la Nación. Fondo Ministerio de Obras Públicas 

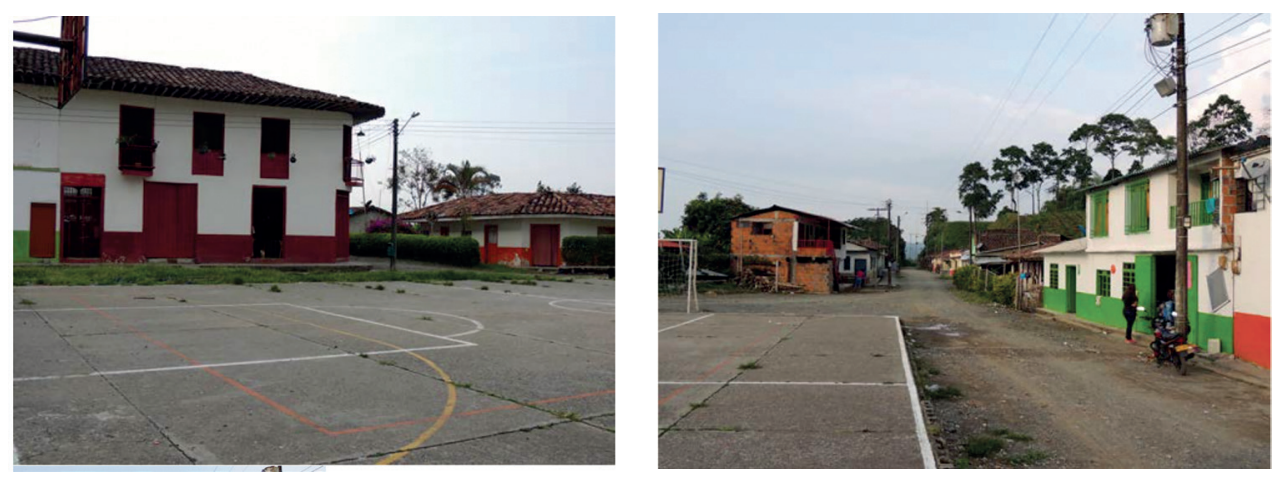

Figura 77. Parque y antigua banca del ferrocarril en La Capilla. Kilómetro 71 Fuente: fotografía Armando Ramírez Villegas (2016)

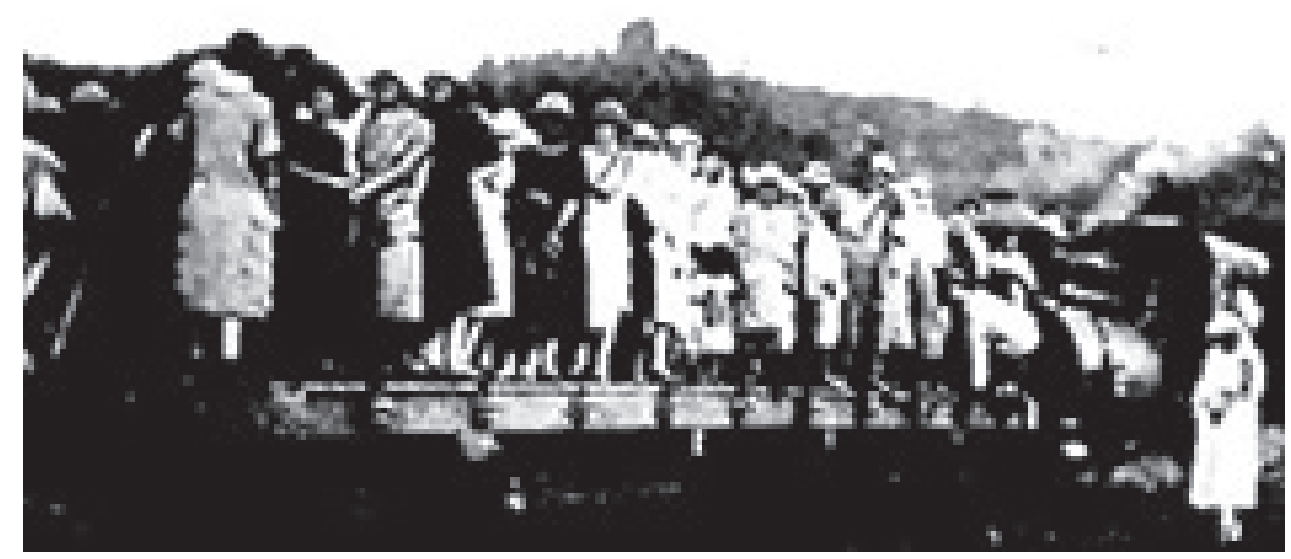

Figura 78. Inauguración de la estación La Capilla. Febrero 17 de 1926

Fuente: Grupo Fotografías Antiguas de Pereira (2015).ç 


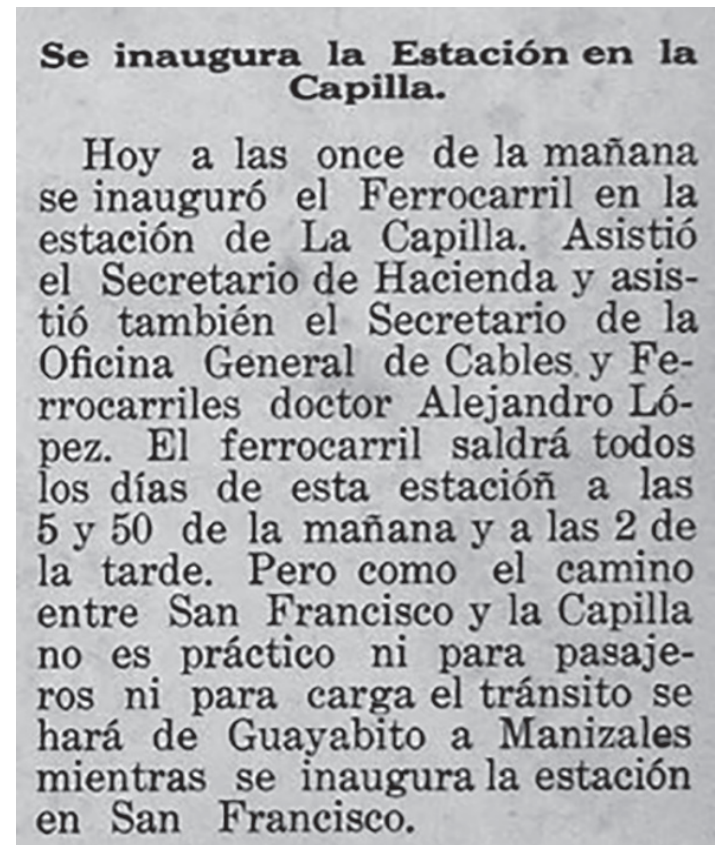

Figura 79. Nota de prensa sobre la inauguración de La Capilla

Fuente: Periódico La Voz de Caldas (1926, febrero 17). Inauguración de la estación La Capilla

El 14 de febrero del mismo año 25, se había firmado el contrato con los ingenieros Eleuterio Serna y Alfredo Castillo, para la construcción entre los kilómetros 76, (Río Campoalegre) y el 93 (Río Claro). El contrato se superponía en los tiempos, con el firmado por los ingenieros Ochoa y Cardona, de tal forma que cuando los primeros estaban terminando su obra en el puente sobre el Campoalegre, los ingenieros Serna y Castillo ya habían avanzado en forma apreciable en la explanación de la banca hasta el sitio conocido como Los Mangos, un poco antes de la población de San Francisco, lo cual representaba una ganancia importante en el tiempo para alcanzar la tan necesaria meta de San Francisco. Rápidamente, se podía proceder al tendido de los rieles acercando el tren a esa población.

Desafortunadamente, todavía tenían por delante dos grandes obstáculos para llegar al sitio de la estación: el cruce de la cuchilla de Los Mangos, para lo cual era necesario la construcción de un túnel, y un gran movimiento de tierra para atravesar el cerro de El Lembo. El túnel, llamado de La Doctora, de unos 40 metros de longitud, fue construido en corto tiempo, para enfrentar, luego, el voluminoso movimiento de 
tierra de El Lembo. Los largos acarreos y la escasez de sitios apropiados para el depósito de la tierra, dificultaron el paso y el tiempo corría inmisericorde, provocando angustias a todos los dirigentes. En el entretiempo, se improvisó un paradero del tren en el sitio Los Mangos, hasta donde los curiosos, afanados por conocer ese extraño aparato, subían en romería, uno tras otro, y muchos de ellos aprovechaban para dar su paseo en tren hasta Santa Rosa o Pereira. Pero no solo sirvió a los curiosos. Ese paradero se convirtió en una estación provisional hasta donde llegaban los materiales, tan necesarios para la reconstrucción de Manizales, los cuales eran luego transportados en mulas hasta su destino final. Ya en el mes de junio se logró llegar con la locomotora hasta el sitio de la estación de San Francisco. Como era lógico, lo tan ansiado y luchado por tanto tiempo veía su final y los dirigentes y la población en general, airosos, se dieron a celebrar este triunfo. Las autoridades, departamentales y municipales, organizaron los programas para los festejos y las invitaciones se repartieron por todo el país. Una gran comitiva se transportó en el tren engalanado, desde la población de Santa Rosa, para hacer su entrada triunfal en San Francisco.

No faltaron los fuegos artificiales, la banda de música y los correspondientes discursos. Fue un día esplendoroso; un día de verano, como se habían sucedido tantos en los días anteriores.Pero,derepente, todocambió;ungranaguaceroseprecipitó,lascelebraciones se vieron interrumpidas y los asistentes buscaban afanosamente en donde guarecerse.

¡Todo se vino a pique! Las aguas lluvias empaparon los terrenos recién movidos provocando deslizamientos a diestra y siniestra, tapando la banca del ferrocarril en numerosos puntos e impidiendo el movimiento de los trenes. Fácil es imaginar la angustia de los organizadores, con los ingenieros a la cabeza. ¿Cómo devolver a esa cantidad de invitados a sus lugares de origen? ¿Dónde darles alojamiento decente mientras se encuentra la forma apropiada para movilizarlos? Todo un caos. No hubo más remedio que acudir al transporte caballar para movilizar a las damas y caballeros, que con sus trajes poco apropiados para estos menesteres, se vieron obligados a aceptarlo para lograr llegar siquiera a Santa Rosa, en donde podrían abordar algún tren que los llevara a sus lugares de origen o al menos a algún lugar apropiado para sus conexiones. Una verdadera lástima. ¡Aquí sí podría decirse que se quedaron con los crespos hechos!

Pero no fue solamente el hecho frustrante de la celebración interrumpida. Para apreciar la magnitud de lo sucedido basta decir que se tomó seis meses la remoción de los derrumbes, la limpieza de la banca y el alineamiento de los rieles, en medio de un invierno como no se tenía hacía muchos años, en el tramo comprendido entre La Capilla y la estación de San Francisco. La sola enumeración de los derrumbes es aterradora: San Juan, La Calera, Los Micos, Jorgito, El Papayo, El Caimán, Campo 
Alegre, Guayabal, El Lembo y La Nubia, en un tramo de 12 kilómetros; es casi uno cada kilómetro, lo que muestra lo difícil e inestable que eran los terrenos que atravesaba la línea del ferrocarril. Solo en el mes diciembre se pudo dar al servicio la línea, con la continuidad y seguridad requeridas. ¡Seis meses más, alargando las dificultades, para atender en forma debida la reconstrucción de la Capital!

\section{TUNEL № 3 LA DOCTORA}

\section{5}

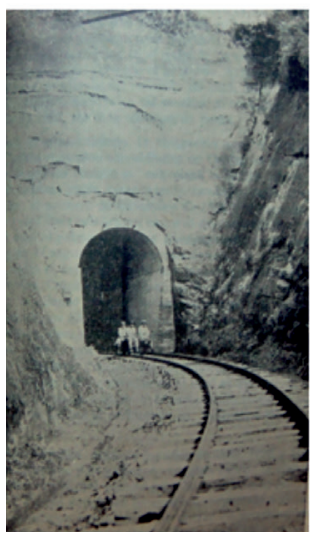

2016

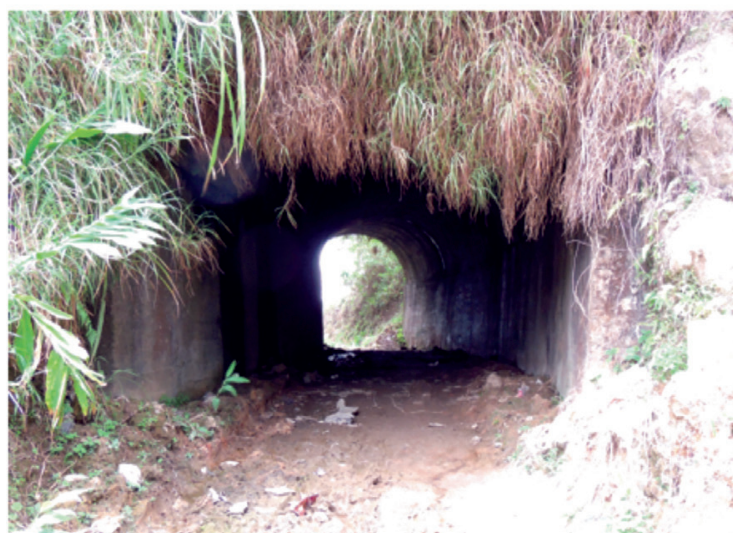

Figura 80. Comparación túnel de La Doctora

Fuente: fotografía Armando Ramírez Villegas (2016)

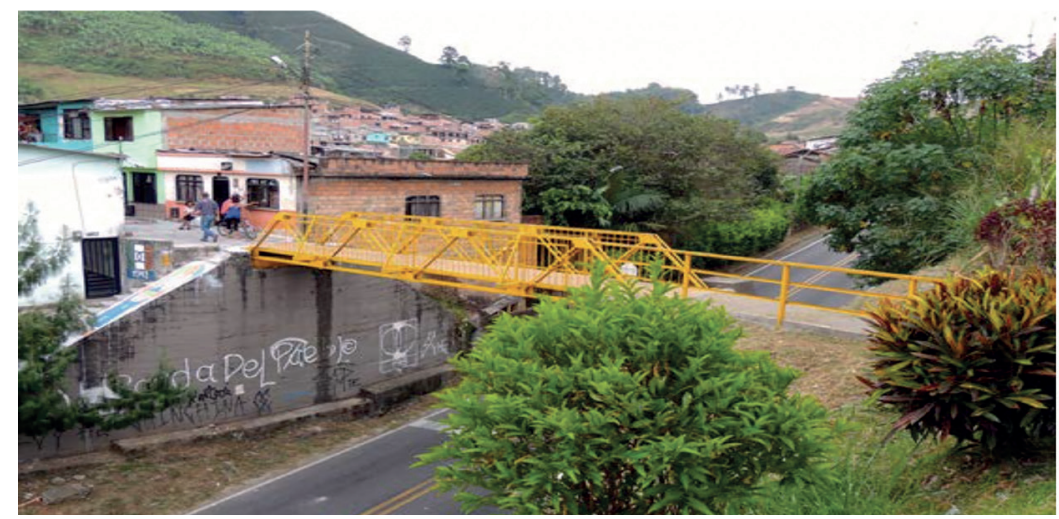

Figura 81. Antiguo puente sobre la vía a San Francisco

Fuente: fotografía Armando Ramírez Villegas (2016) 


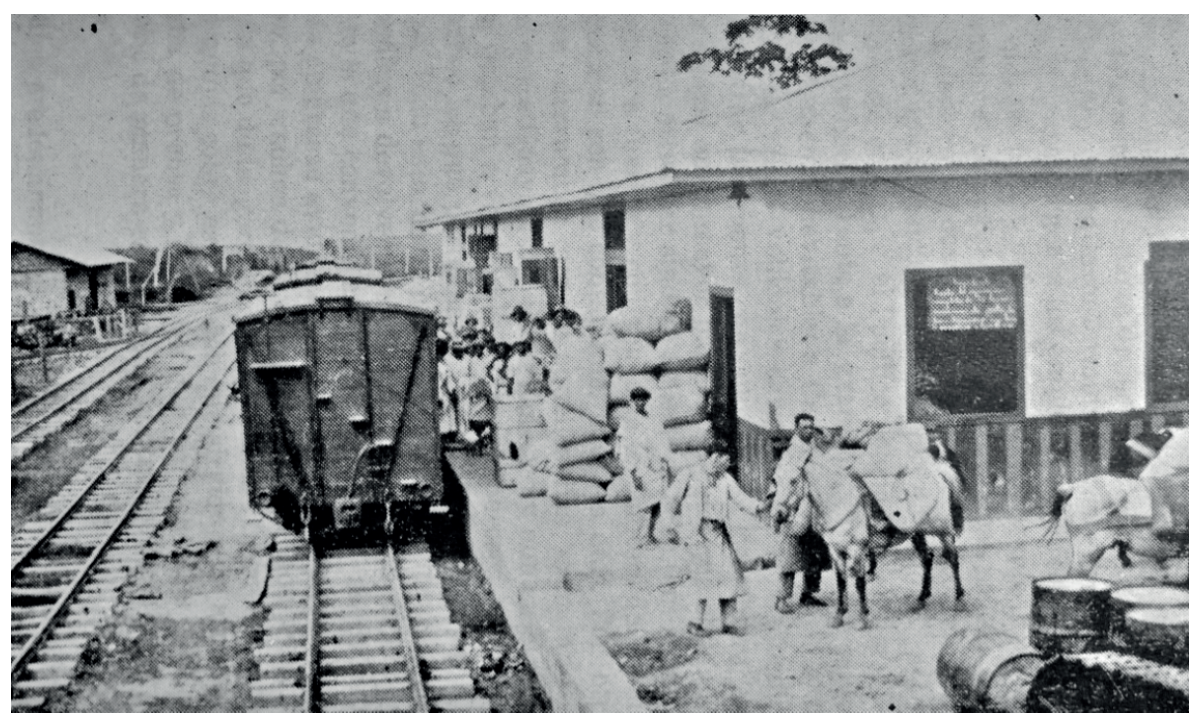

Figura 82. Banca del ferrocarril cerca a San Francisco

Fuente: fotografía Armando Ramírez Villegas (2016)

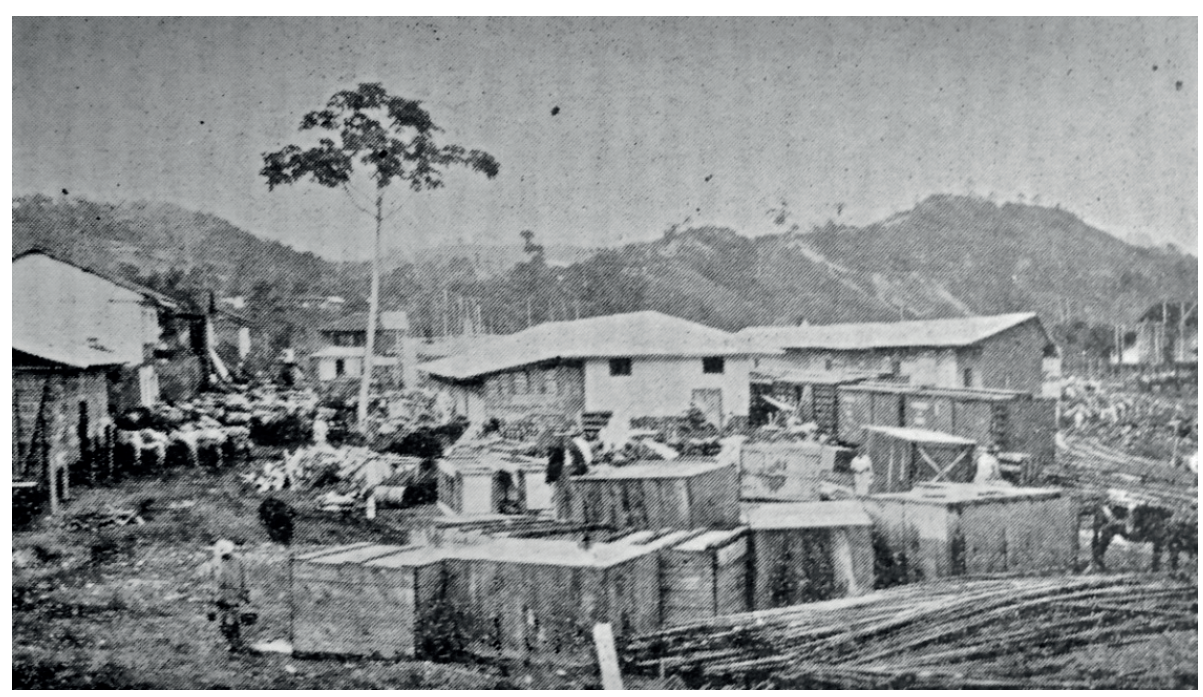

Figura 83. Estación de San Francisco

Fuente: Echeverri, N. (1927). Ferrocarril de Caldas. Bogotá: Imprenta 


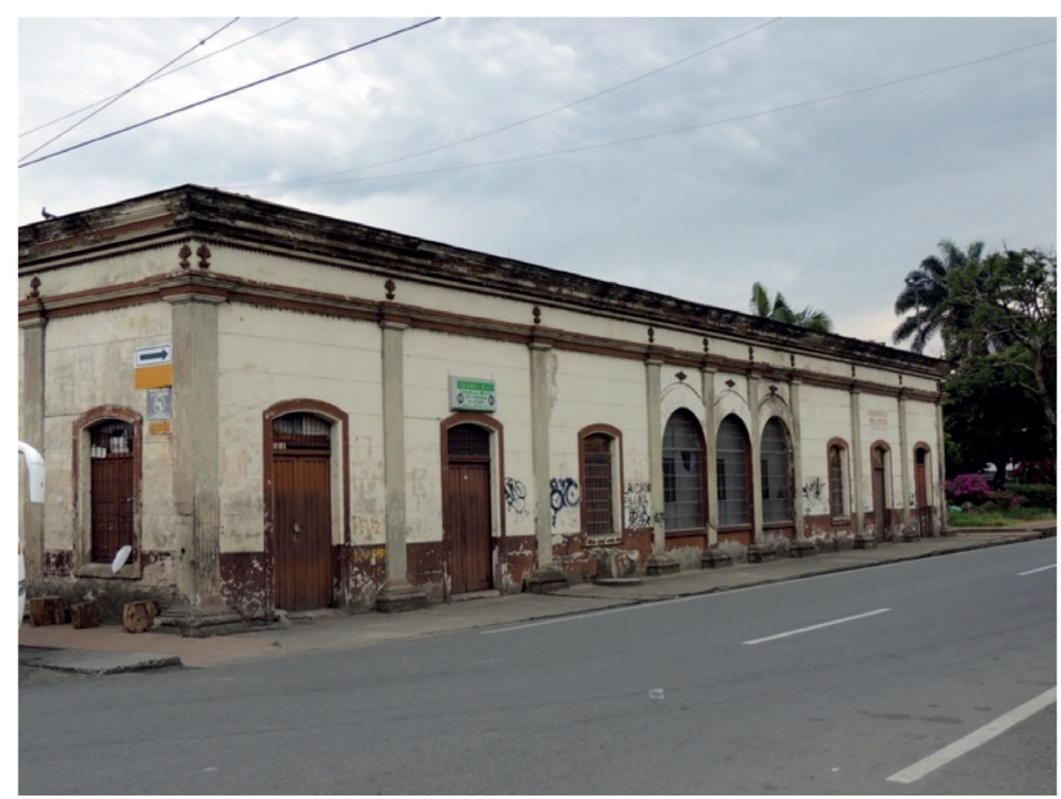

Figura 84. Estación San Francisco

Fuente: fotografía Armando Ramírez Villegas (2016)

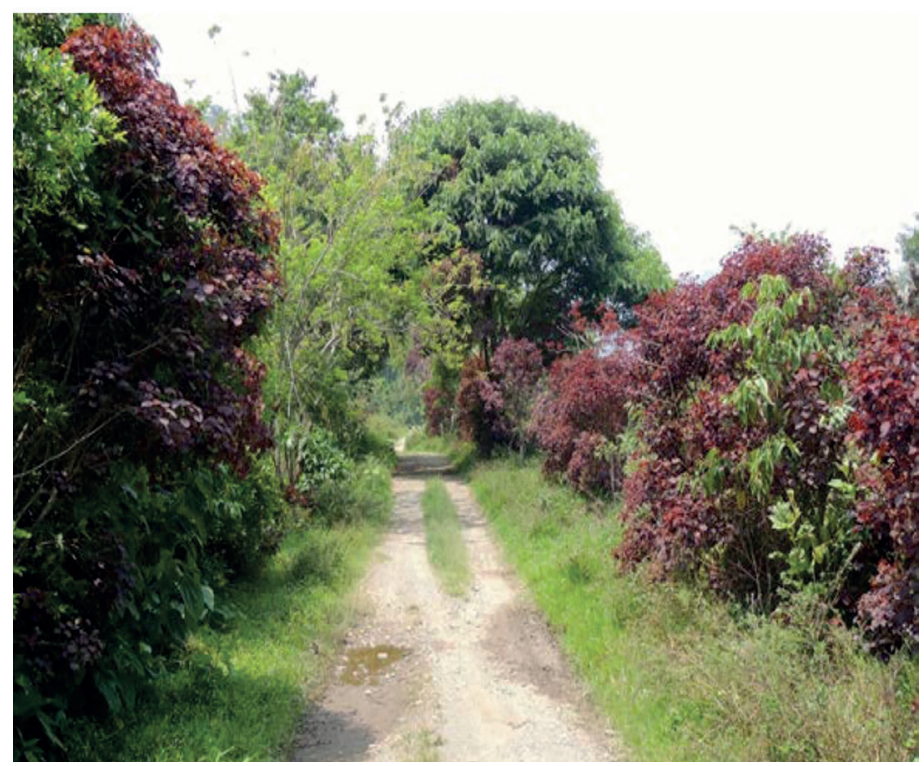

Figura 81. Banca del ferrocarril cerca a San Francisco

Fuente: fotografía Armando Ramírez Villegas (2016) 


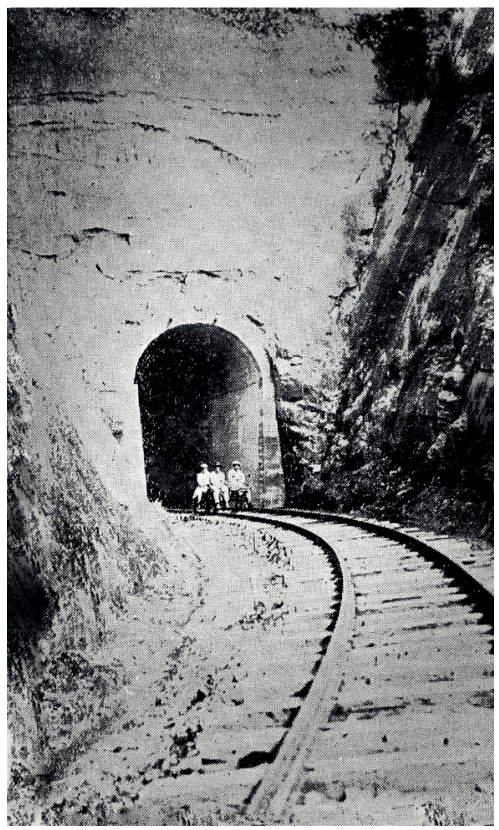

Figura 86. Túnel La Doctora. Kilómetro 81. Longitud 40 metros. Fuente: Echeverri, N. (1927). Ferrocarril de Caldas. Bogotá: Imprenta Nacional

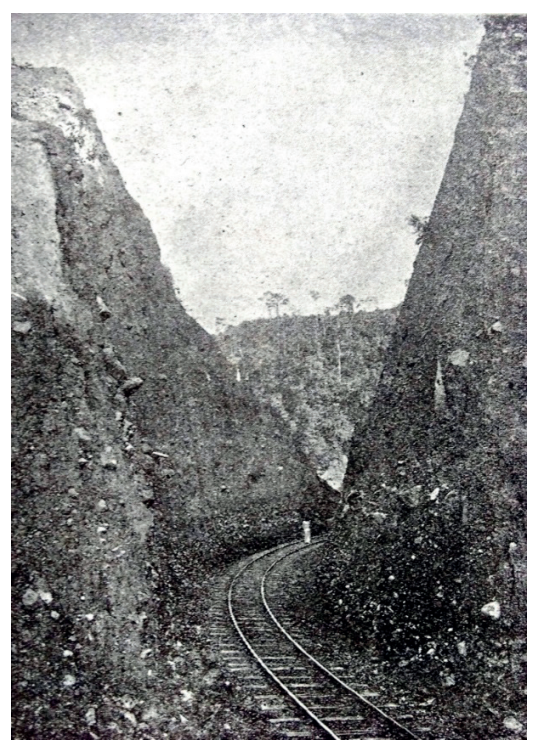

Figura 87. Corte de El Lembo

Fuente: Echeverri, N. (1927). Ferrocarril de Caldas. Bogotá: Imprenta Nacional 


\section{COMENTARIO $4^{\circ}$}

\section{La tragedia de Los Micos}

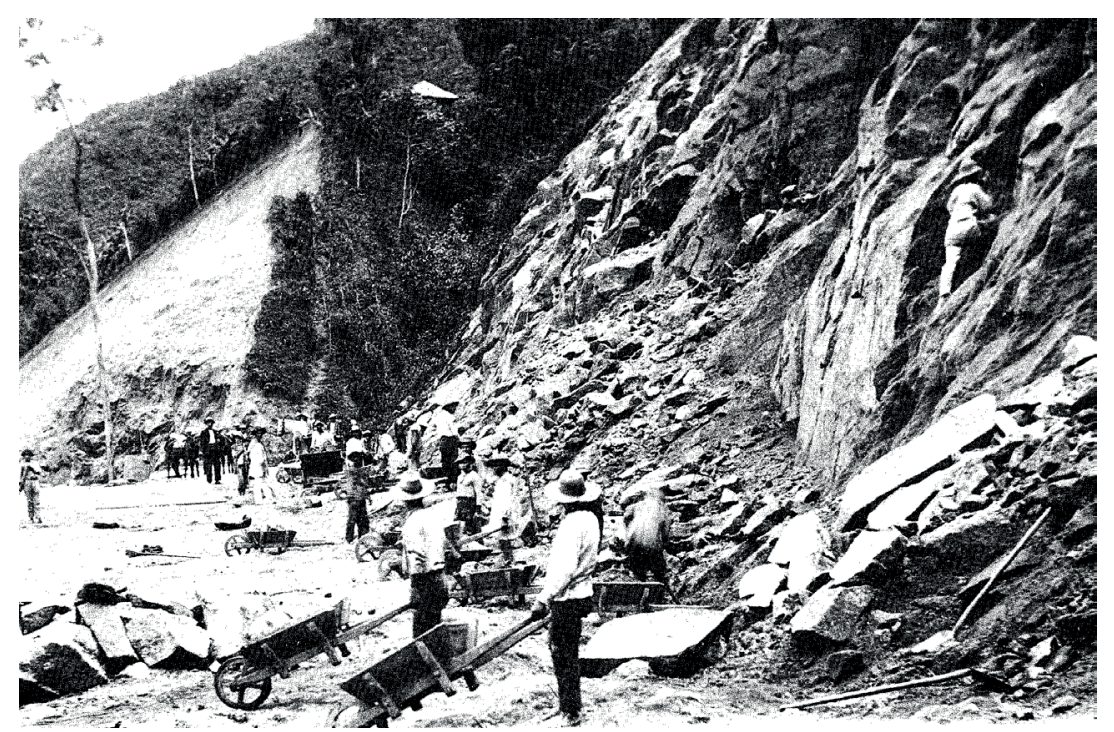

Figura 88. Paso de Los Micos

Fuente: Archivo de Pedro F. Hoyos K.

$\mathrm{H}$ abía pasado el tren por Santa Rosa y la construcción de su banca avanzaba rauda, como sobre rieles, para utilizar un dicho que se ajusta a nuestro relato, hasta llegar a la estación de Guayabito. La topografía suave y el tiempo bueno proporcionaban las condiciones adecuadas para su acelere. Pero la dicha duró poco. Una alta montaña de roca dura apareció de repente. Y ni forma de pasar por entre la montaña y el río San Eugenio que torrentoso bordeaba la peña. Una cuadrilla de trabajadores trataba de perforar con cinceles de mano la dura roca para la colocación de la dinamita, un elemento poco conocido entre nosotros. Pero, ni los trabajadores ni los ingenieros tenían la experiencia necesaria para afrontar ese tipo de roca y solo lograban aruñar la mole sin ningún avance significativo. ¿Qué hacer? Pues, como siempre, acudir a los gringos para que nos dijeran cómo se debía actuar. Se hicieron los contactos respectivos y en el término de algunos días estuvieron entre nosotros los expertos que con poco español pero mucho ejemplo lograron la transmisión del conocimiento. Cómo se agrupaban las perforaciones, a qué profundidad y en qué dirección se hacían, cómo se manipulaba la dinamita y cómo se debía colocar 
la mecha, fueron las instrucciones elementales que nuestros obreros e ingenieros asimilaron rápidamente. Lentamente y en varios frentes la roca fue cediendo el paso y el ferrocarril logró salir a un terreno más suave, para dirigirse hacia La Capilla. El paso de Las Peñas, como se bautizó ese cruce, marcó un hito en la construcción del Ferrocarril de Caldas. Pero, como todo no puede ser negativo, encontraron allí la forma de explotar una balastera que les suministró abundante y buen material para el afirmado de la carrilera. Un poco más adelante se encontraron otra loma, no tan alta ni tan dura como la anterior, pero digna de ser intervenida con la dinamita. No se sabe, a ciencia cierta, si por una falla en la instrucción que ofrecieron los gringos, por un mal entendimiento, por problemas de traducción o simplemente por descuido, un oficial y dos ayudantes, trataban de manipular unos tacos de dinamita, con tan mala fortuna que esta hizo explosión y los tres trabajadores, lamentablemente, perecieron inmediatamente. La loma se llamaba Los Micos y de allí «la tragedia de Los Micos». Algo terrorífica y descarnada la corresponsalía de don Emilio Correa A. para el diario La Voz de Caldas, describe el suceso con detalle:

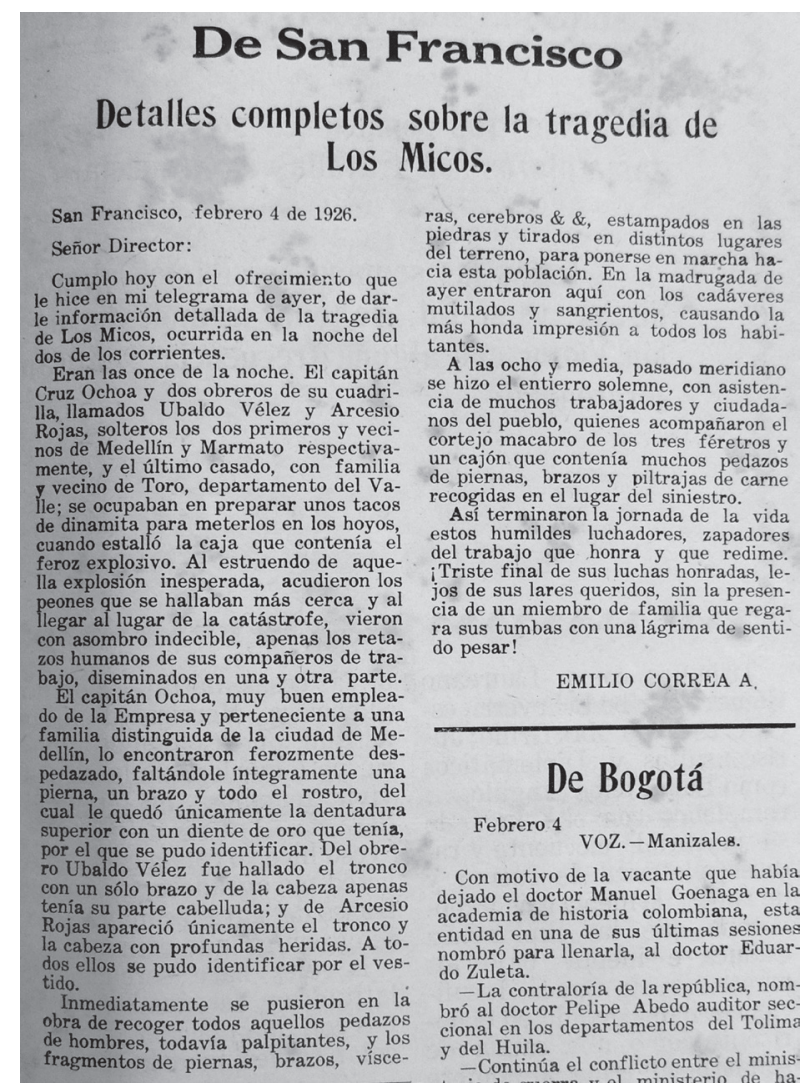

Figura 89. Descripción de la tragedia 


\section{COMENTARIO $5^{\circ}$}

\section{El lío de las traviesas}

$\mathrm{L}$ as traviesas no son ningunas niñas alegres y dañinas; no, en el lenguaje ferrocarrilero las traviesas, o polines, o durmientes, son los elementos que soportan los rieles del ferrocarril, los mantienen alineados y distribuyen las cargas del tren sobre el terreno. Antiguamente solían ser de madera, hoy en día son de concreto reforzado o metálicas. En el Ferrocarril de Caldas, a principio del siglo veinte, todas eran de madera, de madera fina: comino, roble, guayacán, quebracho, nato rojo o de pinotea. En realidad, son unos troncos o vigas de 2 metros de longitud y una sección rectangular de 20 centímetros de ancho por 15 de alto y son puestas transversalmente a los rieles a una distancia de 60 centímetros. Es decir, que en cada kilómetro de carrilera hay 1.700 traviesas lo cual representa más de doscientas mil para el Ferrocarril de Caldas, sin contar las necesarias para los cambios y apartaderos. Es una cifra gigantesca por sí misma; pero más aún, si pensamos en el daño ecológico que produciría su obtención con la tala de árboles de secciones y alturas suficientes para lograr tal cantidad de troncos. Si a esto le añadimos que el combustible para las primeras locomotoras del ferrocarril era la leña, que se obtenía de los bosques cercanos a la vía o de las zonas selváticas como los alrededores de La Virginia, hacia donde se construyó la primera carretera de la región, en el año de 1926, entre Estación Villegas y La Virginia, cuyo objetivo principal era poder transportar la leña para abastecer las locomotoras, diríamos que fue una verdadera masacre ecológica. Pero todo tiene su precio. Si miramos las bondades que trajo el ferrocarril para la zona y para el país, podríamos perdonarnos los daños que produjo a la naturaleza y al medio ambiente. Al fin y al cabo, en esos tiempos todo era exageradamente abundante, valga la redundancia, y no existía conciencia ecológica. ¡Todo sobraba y se pensaba que nunca se acabaría!

Bueno, pero no nos descarrilemos y volvamos al cuento de las traviesas. Resulta que, en los años 1925 a 1927, se produjo un inusitado afán por terminar la construcción del Ferrocarril de Caldas o, por lo menos, alcanzar la estación de San Francisco, originado por la necesidad de transportar y recibir los materiales y demás elementos necesarios para la reconstrucción de la ciudad de Manizales, que había sido devorada por las llamas en el pavoroso incendio de 1925. Era tanta la velocidad con que se adelantaba la obra que no daba abasto la producción de las traviesas nacionales y fue necesario acudir a una importación de los Estados Unidos. Se hizo un pedido de 10.000 traviesas de pinotea, madera liviana y duradera, en condiciones económicas favorables, que llegaron al puerto de 
Buenaventura en el mes de abril de 1926. Simultáneamente, arribaron, al mismo puerto, 35.000 adicionales procedentes de las selvas del Pacífico, que habían sido compradas a comerciantes nacionales. Es decir, que en el puerto de Buenaventura había almacenadas 45.000 traviesas y que era urgente enviarlas al frente de construcción que se hallaba entre las poblaciones de Santa Rosa y San Francisco.

La forma obvia de hacerlo era transportarlas en el Ferrocarril del Pacífico, que conectado, como ya estaba, con el Ferrocarril de Caldas en Cartago, podría llevarlas hasta el frente de trabajo sin ninguna dificultad, o en el peor de los casos, acercarlas hasta la estación de Cartago. Pero las cosas no funcionaban como la lógica lo indicaba. Las relaciones entre las dos empresas ferroviarias no eran las mejores. La competencia, a veces desleal, el hecho de que el avance de una perjudicaba a la otra, la escasez de material rodante en la empresa del Pacífico unida a su desorganización administrativa, constituía un coctel peligroso de inflamarse en cualquier momento. A las reiteradas solicitudes de la dirigencia caldense a la del Pacífico, se respondía con evasivas que permitían dilatar en el tiempo la toma de una decisión definitiva. El gerente del Ferrocarril del Pacífico era el general Alfredo Vásquez Cobo, personaje conocido por sus malas pulgas, mandón y altanero, que no hacía fácil la interlocución de los bandos. El general se encontraba en Bogotá y estaba encargado de la gerencia el ingeniero Arturo Arcila. Ante la demora en atender la solicitud de transporte, por parte del Ferrocarril del Pacífico, el Ferrocarril de Caldas, previas autorizaciones, resolvió enviar uno de sus trenes con el objeto de recoger las traviesas de su propiedad para conducirlas al sitio en donde se necesitaran. Pero, oh sorpresa, el gerente Arcila, no permitió que se entregaran las traviesas hasta tanto el Ferrocarril del Pacífico no tuviera satisfecha su necesidad de traviesas. ¡Quién dijo miedo!

Los manizaleños, con razón, entraron en estado de

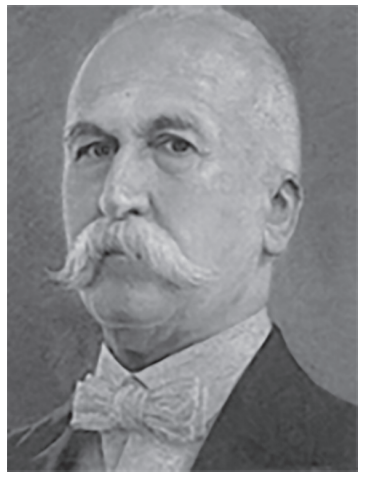

Figura 90. Presidente Pedro Nel Ospina profunda indignación, y con su señor gobernador doctor Gerardo Arias Mejía a la cabeza, empezaron a enviar mensajes a todo el mundo, inicialmente en forma cordial y respetuosa, pero a medida que las respuestas eran más absurdas y evasivas, más subía el tonito de sus reclamos, hasta el punto de tildarlos de secuestradores de un bien privado o de opositores al desarrollo de Caldas, sin descartar las amenazas de paros cívicos o hechos de mayor violencia. Era Presidente de la República el general Pedro Nel Ospina y su ministro de Obras Públicas el ingeniero Laureano Gómez C., y entre ellos se tiraban la pelota de las traviesas, sin definir nada al respecto. Hay que recordar que durante el mandato del presidente Ospina, ingresaron al país los 25 millones de dólares 
correspondientes a la indemnización por la pérdida de Panamá, los cuales fueron destinados, fundamentalmente, al desarrollo vial del país y muy especialmente al desarrollo de los ferrocarriles. En la mente del Presidente había un proyecto estratégico, preferido por su importancia para el país, como era la troncal férrea que comunicaría Bogotá con el puerto de Buenaventura. Dentro de este proyecto estaban la variante Zarzal-Armenia, propuesta dentro de los alcances del Ferrocarril del Pacífico, y el cruce de la cordillera Central con el túnel de La Línea, que haría parte del Ferrocarril del, Tolima, entre Ibagué y Calarcá. ¿Cómo, entonces, pretender que el Presidente y su Ministro de Obras, no cayeran en la tentación de preferir sus propios intereses a los intereses de un departamento, que por muy encerrado que estuviera, podría dar espera a sus propósitos inmediatos? Es cierto que el Ferrocarril de Caldas necesitaba con urgencia esas traviesas, que eran suyas, y que solo faltaba transportarlas al lugar apropiado, pero el problema de fondo era otro: la lucha de intereses comerciales entre las dos compañías. La lucha por ser la primera, no solo en poner en funcionamiento un tren que acaparara el mayor número de pasajeros y carga, sino, satisfacer el orgullo de los dirigentes empeñados en tan fantásticas empresas. Los acontecimientos se sucedieron atropelladamente. Primero trataron de arreglar las cosas directamente con el gerente del Ferrocarril del Pacífico, pero en vista de su ausencia, cayeron en manos del gerente encargado señor Arturo Arcila, quien no tuvo reato alguno al manifestar que no dejaría transportar las traviesas ni en el tren del Ferrocarril de Caldas, que había sido enviado para traerlas, ni en ningún otro, pasando por encima de la propiedad privada, y todo con la aprobación previa del gerente Vásquez Cobo. Y como si esto fuera poco atrevimiento, el Ferrocarril de Caldas debería cancelar al del Pacífico, una tarifa de almacenamiento de las traviesas. En vista de este ultimátum, el señor gobernador Arias Mejía, decidió acudir a su jefe inmediato, el señor presidente de la República, general Ospina, con el objeto de que interviniera a su favor.

Desafortunadamente, por las razones comentadas anteriormente, el Presidente contestó con evasivas, lo cual obligó al gobernador a presentar renuncia irrevocable de su cargo, convirtiendo el lío en un problema de Estado. A todas estas, la Asamblea de Caldas y el Concejo de Manizales, emitían sendas resoluciones brindando el total respaldo a la determinación del señor gobernador, mientras los medios convocaban a la realización de un paro cívico. La situación se puso tan álgida que el señor Presidente no tuvo más remedio que intervenir para que las traviesas fueran entregadas, sin dilación alguna, al Ferrocarril de Caldas. Las traviesas llegaron y el Departamento perdió un Gobernador excelente. 


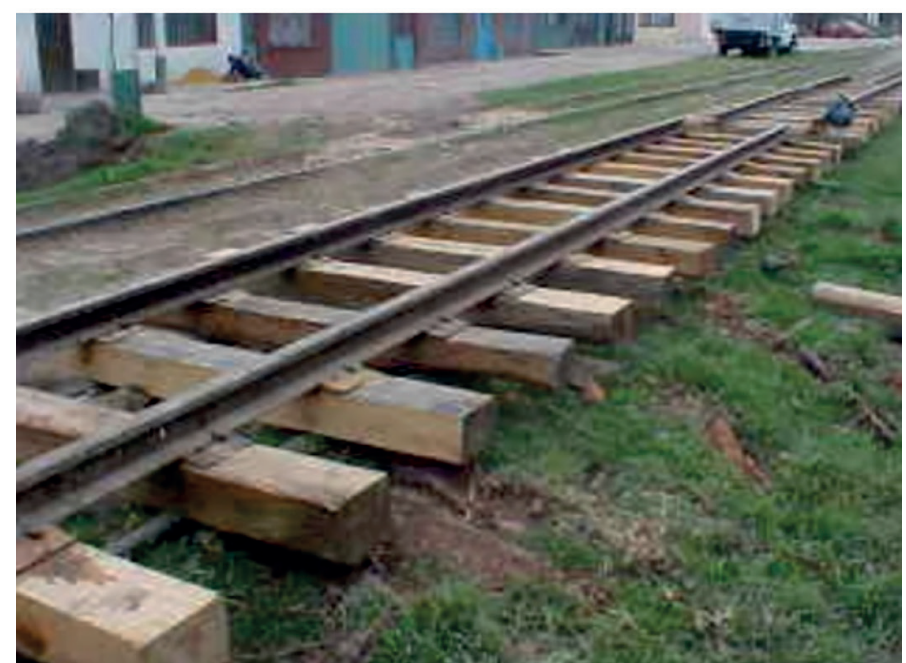

Figura 91. Traviesas

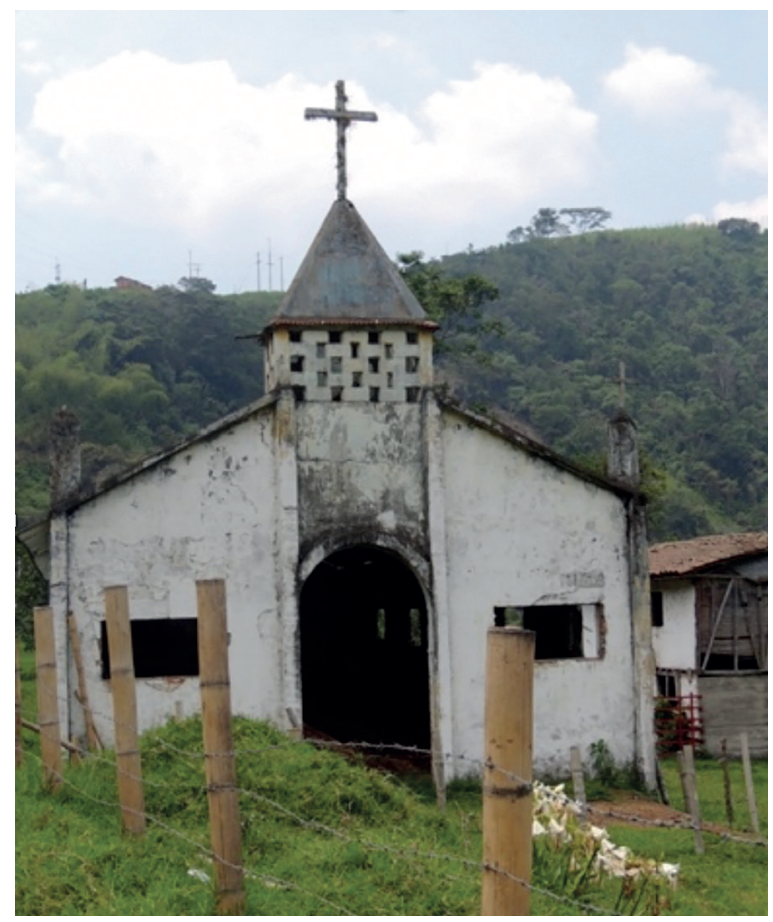

Figura 92. Antigua capilla de Rio Claro

Fuente: fotografía Armando Ramírez Villegas (2016) CAPÍTULO V 


\section{Construcción de San Francisco a Manizales}

$\mathrm{M}$ ientras esto sucedía, por el otro lado, los trabajos de explanación de la banca continuaban rápidamente hacia Río Claro. Tomando a media ladera el risco que da hacia el río Chinchiná, para descender a la margen izquierda del mismo, avanzaron por los planes que se presentan en su orilla derecha, aguas arriba, hasta llegar a la estación de Río Claro, en el kilómetro 93 de la línea. En el mes de diciembre los rieles estaban colocados hasta dicha estación, lo que quiere decir, que estando ya estabilizada la banca en el tramo La Capilla-San Francisco, el ferrocarril quedaba con una longitud en servicio de 93 kilómetros hasta la estación de Puerto Caldas, punto inicial de la vía. A propósito de la estación Río Claro, es oportuno recordar que lo que era un caserío próspero e importante, fue arrasado repentinamente, por la avalancha, producida a raíz de la erupción del volcán Nevado de El Ruiz en diciembre de 1985, al taponar el cauce en la parte superior del Río Claro, y producirse su posterior ruptura.

En pocos minutos el río arrastró cuanto encontró a su paso, dejando un manto de lodo sobre lo que era el poblado. El puente del ferrocarril sobre el Río Claro fue arrancado, con estribos incluidos, sin dejar huella de su posición. Fue la misma avalancha que al desembocar en el río Chinchiná, dejó a su paso, solo tristeza y desolación, sin escaparse el puente de la carretera a Manizales, al frente de las instalaciones de Cenicafé, puente que fuera arrastrado por la vertiginosa corriente. Las pérdidas de vidas y los daños materiales fueron incontables. Después de la ciudad de Armero, desaparecida en la misma ocasión, lo de Río Claro fue el suceso más lamentable de esa noche trágica. Los sobrevivientes fueron reubicados en un sitio más alto, protegido de posibles inundaciones, al cual se le dio el nombre de Nuevo Río Claro.

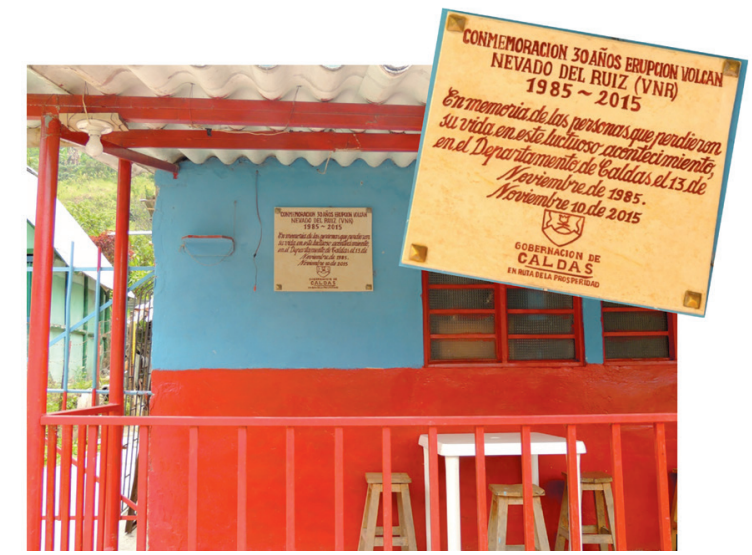

Figura 93. Tienda con placa conmemorativa

Fuente: fotografía Armando Ramírez Villegas (2016) 
Como desde el 12 de agosto de 1925, se había firmado el contrato con los ingenieros Ernesto Ramírez J., Humberto Bruno y Rafael Botero S. para la construcción del trayecto entre Río Claro y Villa María, para esta época, diciembre de 1926, los trabajos estaban bastante adelantados. La línea arrancaba de la estación de Río Claro, en el cañón de dicho río y seguía, aguas arriba, hasta llegar al sitio apropiado para la construcción del puente que cruzaría el río, el mismo que fuera destruido por la avalancha. El trazado se dirigía en busca de cañón del río Chinchiná, un cañón aún más profundo que el de Río Claro. Serpenteando la montaña, se avanza hasta alcanzar su margen izquierda, la que bordearían tratando de llegar a la población de Villa María. En este trayecto hubo necesidad de construir cinco túneles denominados el Río Claro 1, Río Claro 2, El Arango, El Arroyo y El Chupadero. Todos con su revestimiento en concreto y con sus portales hermosamente adornados con una cenefa en la parte superior y un recuadro en el cual aparece vaciado, en alto relieve, el número del puente, correspondiente a su orden a partir del inicio de la carrilera en la estación de Puerto Caldas. Unas verdaderas obras de arte, para utilizar el léxico de los ingenieros, tantas veces malentendido por los legos en la materia. A ellos se refiere el ingeniero Jorge E. Ardila Rueda, en su trabajo de grado para alcanzar la Maestría en Historia, en la Universidad Javeriana de Bogotá, así: los túneles del Arango, Chupadero y el Arroyo, construidos bajo contrato celebrado con los ingenieros Humberto Bruno, Rafael Botero S. y Ernesto Ramírez, túneles estos construidos con tal habilidad que le permitirían a los rieles de la línea avanzar sin ningún contratiempo a su paso y llegar finalmente en mayo de 1927, a la estación de Villamaría, la cual sería inaugurada por el doctor Sebastián Ospina, quien para la fecha desempeñaba el cargo de jefe de la oficina de ferrocarriles y cables. (Rueda, 2012). ${ }^{2}$

\begin{tabular}{|l|c|c|c|c|l|}
\hline \multicolumn{1}{|c|}{ Túnel } & Tramo & Abscisa & Longitud (m) & Año & \multicolumn{1}{c|}{ Contratista } \\
\hline Consota & 1 & K 19.6 & 35 & 1919 & Jorge Escobar \& Alfonso Bernal \\
\hline El Boquerón & 2 & K 56 & 130 & 1924 & T. Ochoa, R. Cardona \& H. Piedrahita \\
\hline La Doctora & 2 & K 81 & 40 & 1925 & E. Serna \& A. Castillo \\
\hline Los Cuervos & 3 & K 87 & 60 & 1925 & E. Serna \& A. Castillo \\
\hline La Cascada* & 3 & K 91 & 53 & 1925 & E. Serna \& A. Castillo \\
\hline Rio Claro (1) & 3 & K 97.2 & 90 & 1926 & H. Bruno, R. Botero \& E. Ramírez \\
\hline Rio Claro (2) & 3 & K 97.7 & 91 & 1926 & H. Bruno, R. Botero \& E. Ramírez \\
\hline El Arango & 3 & K 98.2 & 82 & 1926 & H. Bruno, R. Botero \& E. Ramírez \\
\hline El Arroyo & 3 & K 100.9 & 58 & 1926 & H. Bruno, R. Botero \& E. Ramírez \\
\hline Chupadero & 3 & K 101.2 & 64 & 1926 & H. Bruno, R. Botero \& E. Ramírez \\
\hline Avenida Cervantes & 3 & K 117 & 72 & 1926 & E. Serna \& A. Arango \\
\hline
\end{tabular}

Figura 94. Tabla del ingeniero Jorge E. Ardila Rueda 


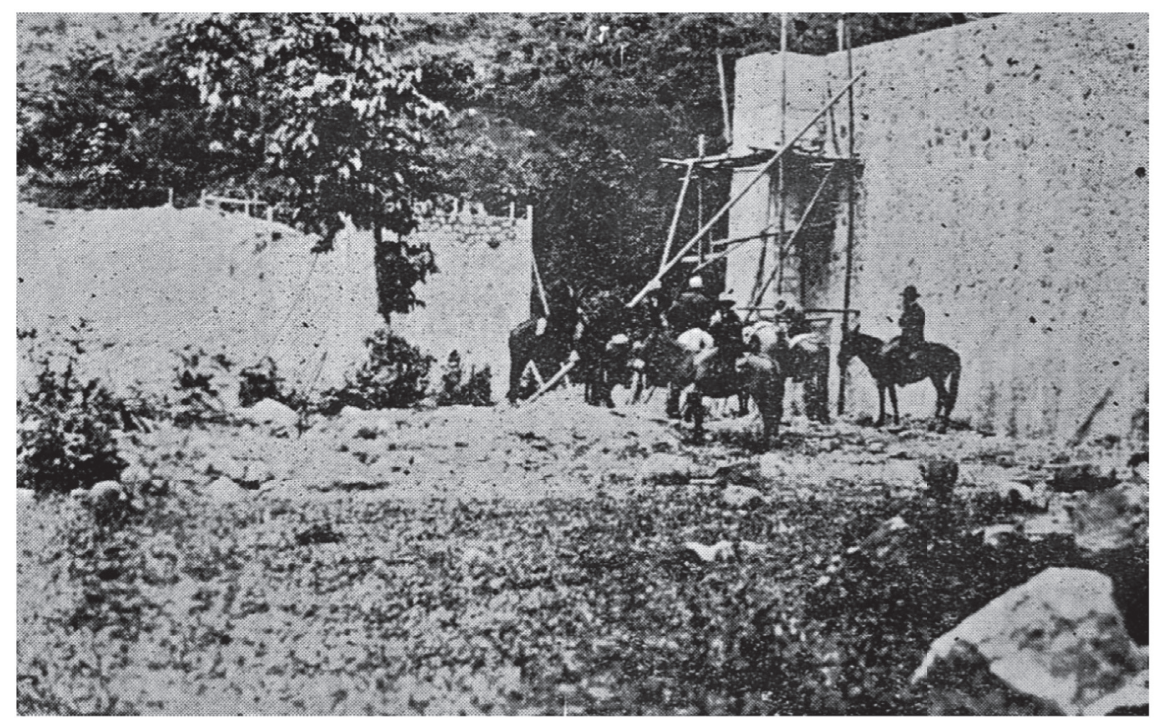

Figura 95.Construcción sobre el puente de Río Claro 1

Fuente: Echeverri, N. (1927). Ferrocarril de Caldas. Bogotá: Imprenta

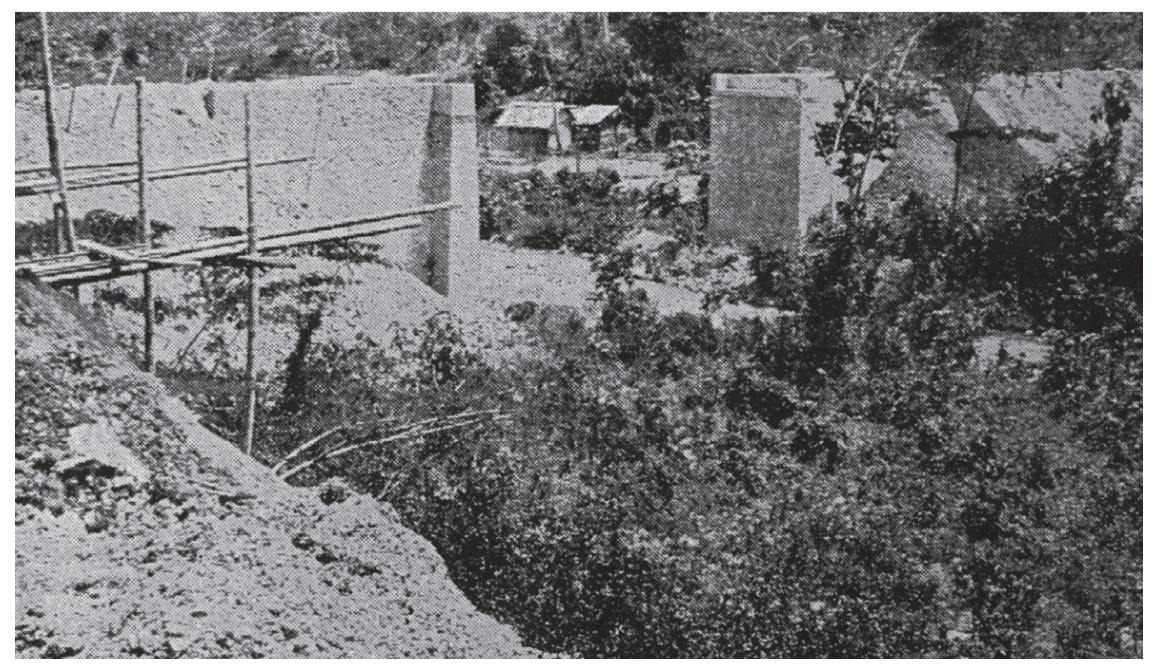

Figura 96. Construcción del puente sobre el Río Claro

Fuente: Echeverri, N. (1927). Ferrocarril de Caldas. Bogotá: Imprenta Nacional 


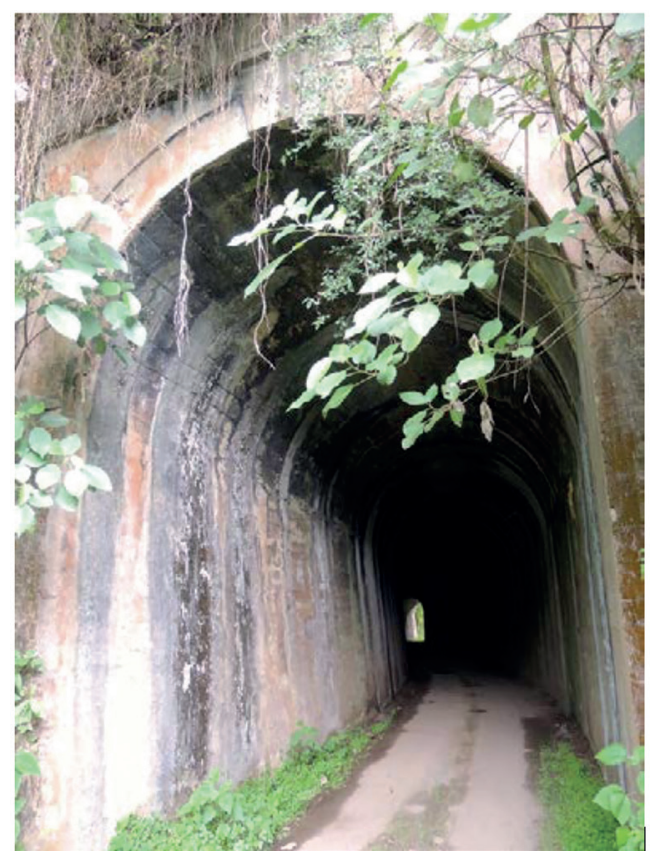

Figura 97. Túnel N6 Río Claro 1

Fuente: fotografía Armando Ramírez Villegas (2016)

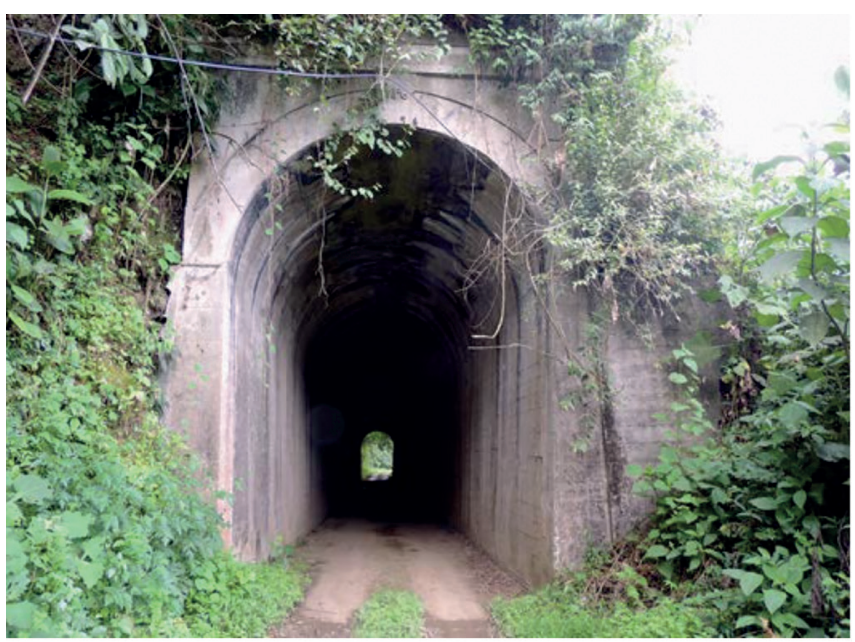

Figura 98. Túnel $N^{\circ} 7$ Río Claro 2

Fuente: fotografía Armando Ramírez Villegas (2016) 

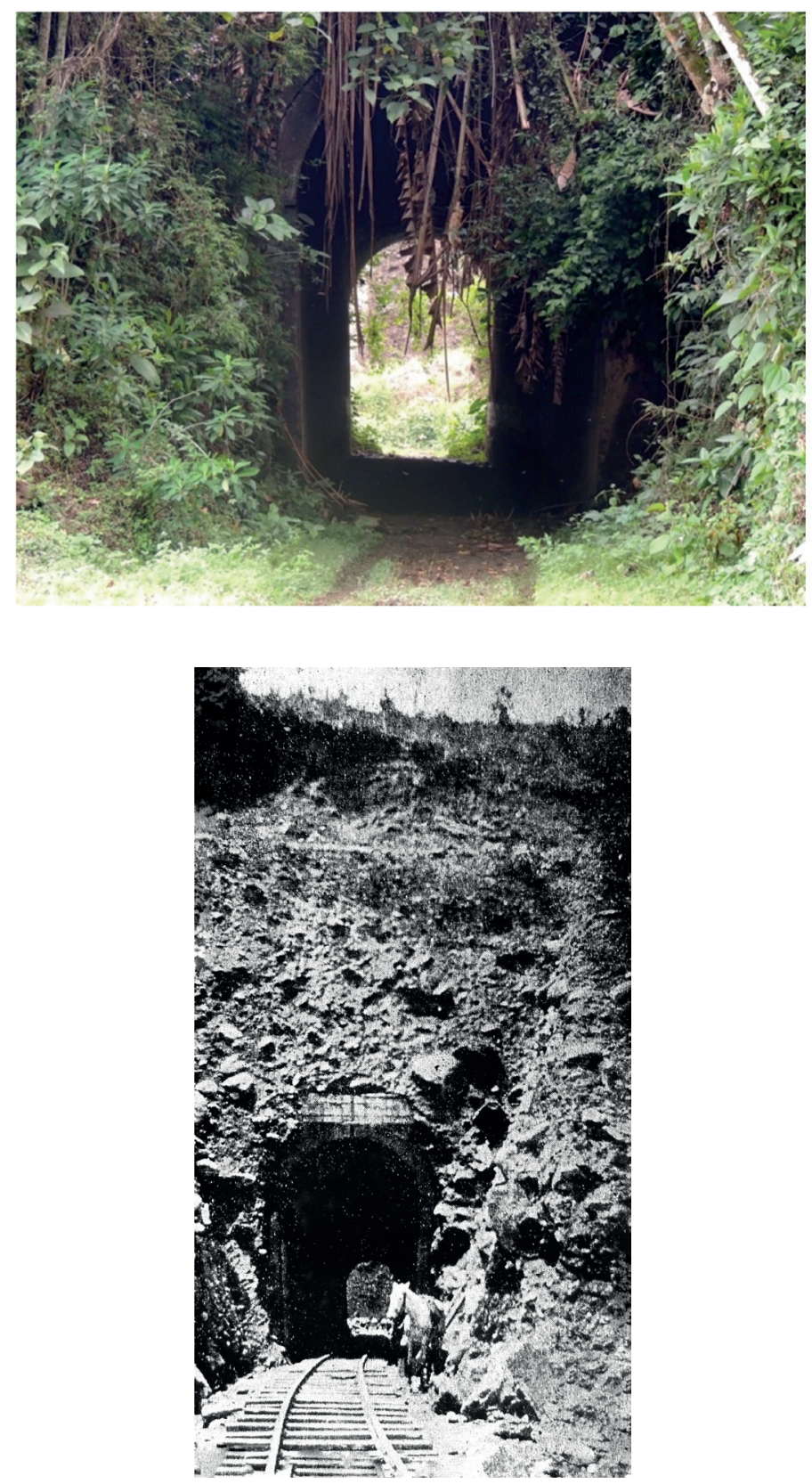

Figura 99. Túnel El Arroyo

Fuente: imagen superior fotografía Armando Ramírez Villegas (2016) e imagen inferior Echeverri, N. (1927). Ferrocarril de Caldas. Bogotá: Imprenta Nacional. 

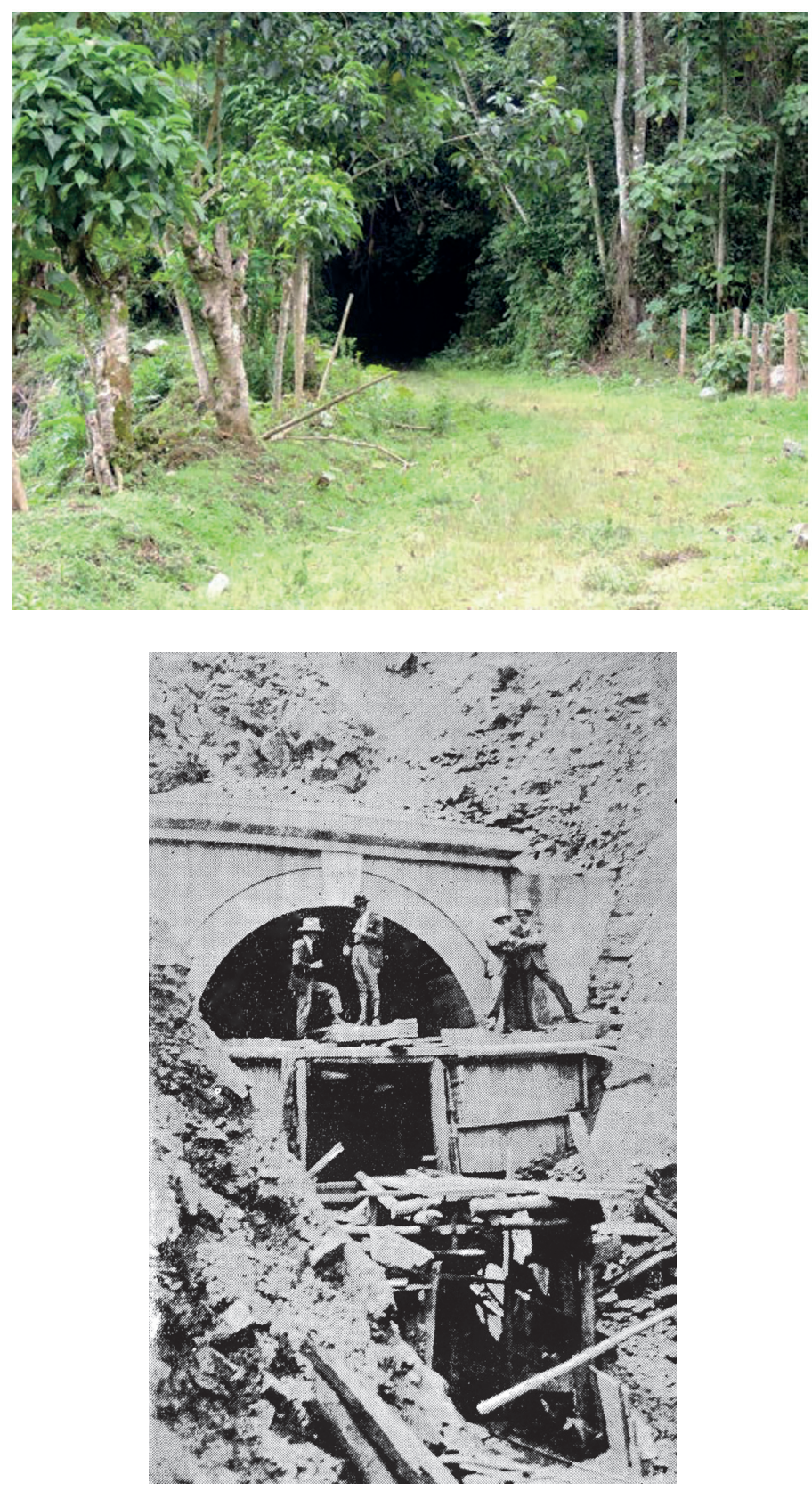

Figura 100. El Arroyo. Kilómetro 101. Longitud 58 metros

Fuente: imagen superior fotografía Armando Ramírez Villegas (2016) e imagen inferior Echeverri, N. (1927). Ferrocarril de Caldas. Bogotá: Imprenta Nacional. 


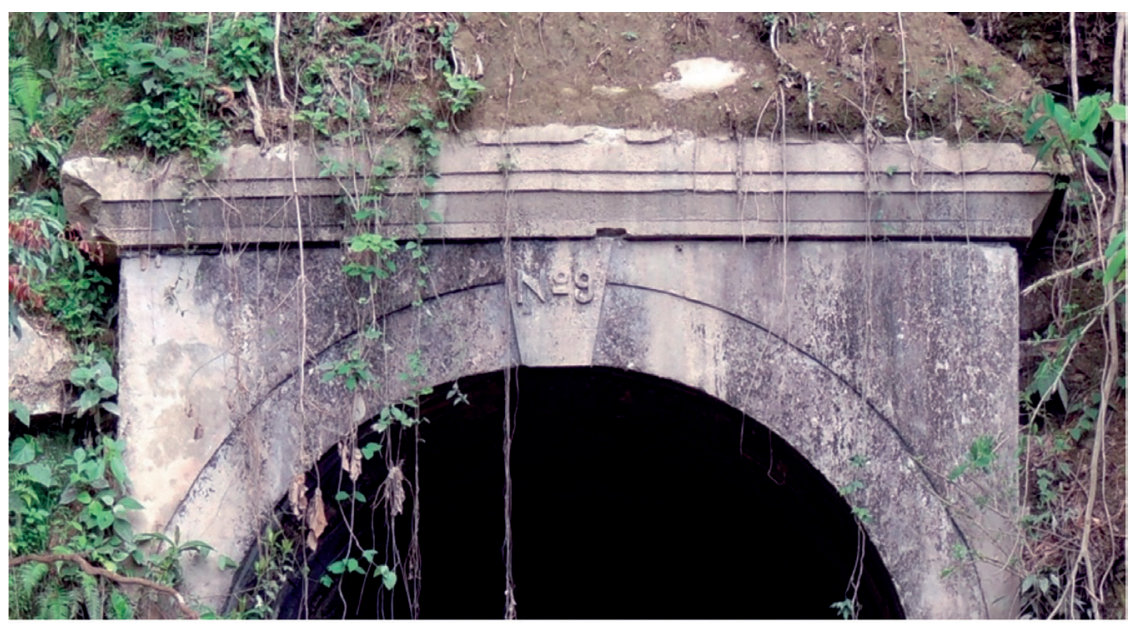

Figura 101. El Chupadero

Fuente: fotografía Armando Ramírez Villegas (2016)
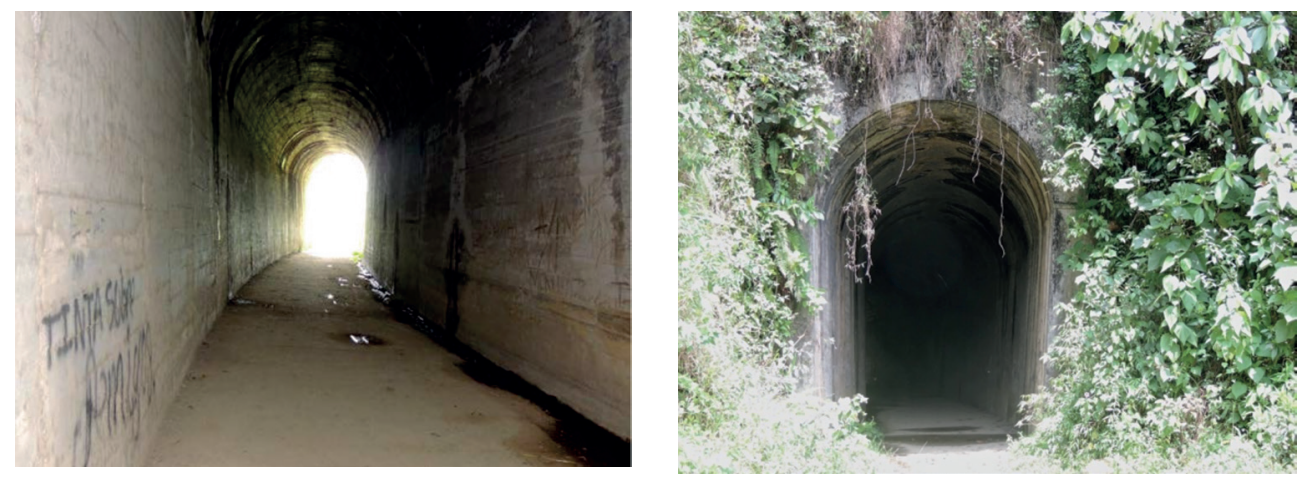

Figura 102. Interior de El Chupadero

Fuente: fotografía Armando Ramírez Villegas (2016) 


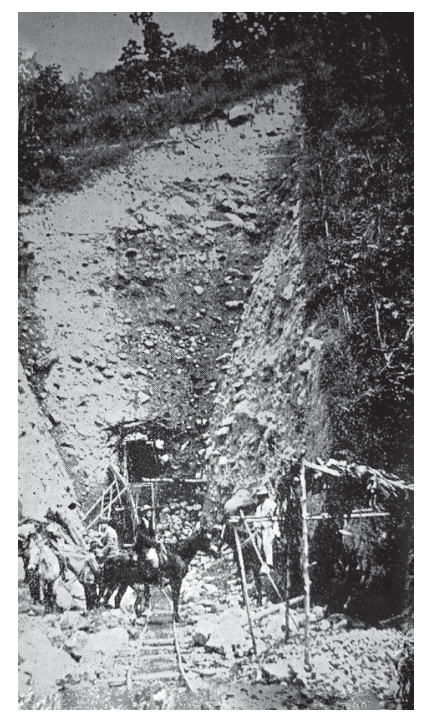

Figura 103. Caballo en El Chupadero

Fuente: Echeverri, N. (1927). Ferrocarril de Caldas. Bogotá: Imprenta Nacional

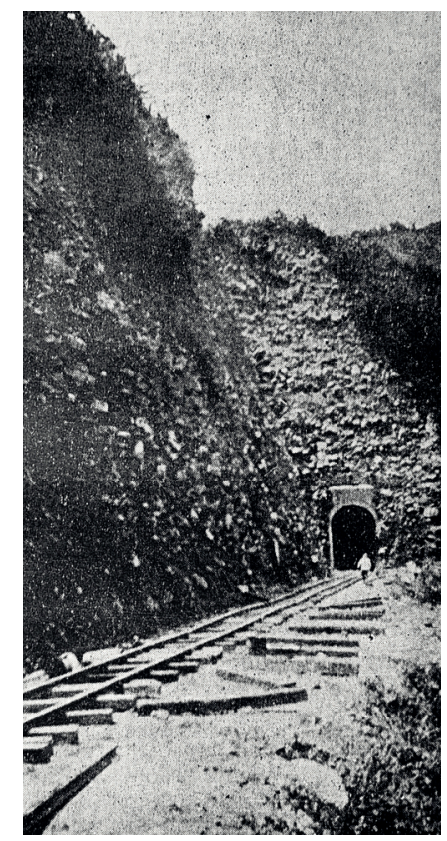

Figura 104. Túnel El Chupadero. Kilómetro 101. Longitud 64 metros Fuente: Echeverri, N. (1927). Ferrocarril de Caldas. Bogotá: Imprenta Nacional 


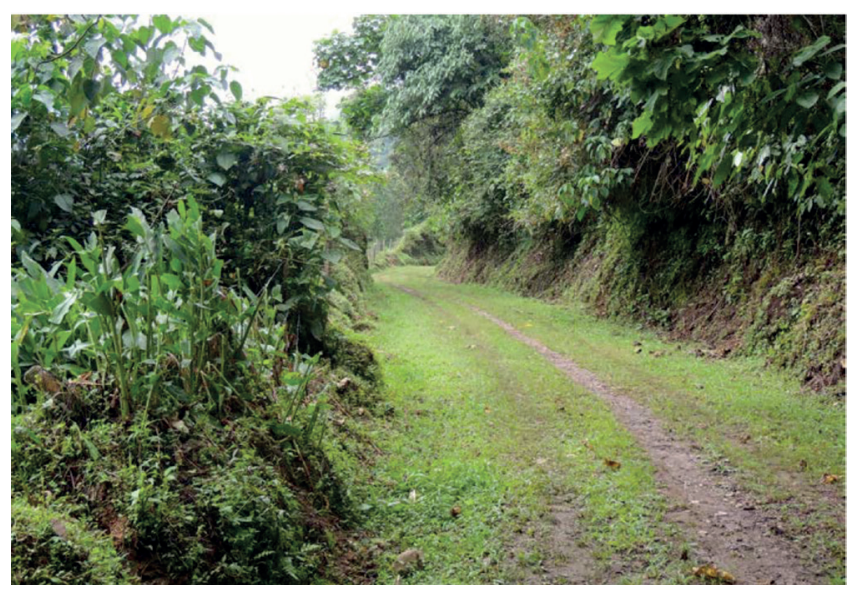

Figura 105. Antigua banca del ferrocarril próxima a Villamaría

Fuente: fotografía Armando Ramírez Villegas (2016)

Con el perdón de mis amables y pacientes lectores, no puedo dejar de hacer alusión a una experiencia personal. Un choque de sentimientos estremecieron mi humanidad al recorrer y admirar los caminos y obras, que hace casi un siglo, caminara y construyera mi padre. Alegría, tristeza, admiración, pesar, agradecimiento, acompañados de un sinnúmero de interrogantes, hoy sin respuesta alguna, me acompañaron a lo largo de mi excursión, y en verdad, no ha sido fácil dominarlos y superarlos. El solo hecho de recordar que fue en ese tiempo y en ese espacio, cuando y en donde, mi padre conociera a mi madre, es suficiente motivo para explotar mi curiosidad y hacerme las preguntas, que en vida de mis padres, hubiera podido obtener respuestas adecuadas, pero, esa ley de la vida que nos hace indiferentes al pasado cuando estamos jóvenes, impidió que se produjera esa intercomunicación. Pero, ahora, pensándolo bien, en lo recóndito de mi alma, todo eso fue la razón fundamental de esta investigación. Retornando a la realidad, la continuidad de nuestro recorrido se dificultó un poco por la ausencia de un puente que nos permitiera cruzar el río Claro. Hubo necesidad de buscar la antigua línea férrea en sentido contrario. Es decir, trasladarnos a la población de Villa María y empezar a indagar por donde pasaba la antigua banca del ferrocarril.

Afortunadamente, encontramos en esa ciudad la colaboración y el entusiasmo que no habíamos encontrado antes en nuestro recorrido. Las autoridades municipales y en especial el joven Felipe Chiquito, pintor muralista, y el señor Jhon James, Director de la Oficina de Turismo, nos brindaron, con una amabilidad sorprendente, toda la información y el acompañamiento requeridos. Pudimos así "descubrir" la banca del 
ferrocarril que por lo escarpado de la zona, se encuentra prácticamente perdida en la manigua, y reconstruir, casi exactamente, por donde subía el ferrocarril a Manizales, ruta totalmente afectada por los desarrollos urbanísticos de la ciudad. El encuentro, inesperado pero afortunado, con el señor Duberty Correa, residente desde hace muchos años en el Barrio Aranjuez quien nos condujo por todos los sitios, a través de los distintos barrios por donde pasó en alguna época remota, el ferrocarril, nos permitió establecer claramente la penosa ruta para ascender a la ciudad de Manizales.

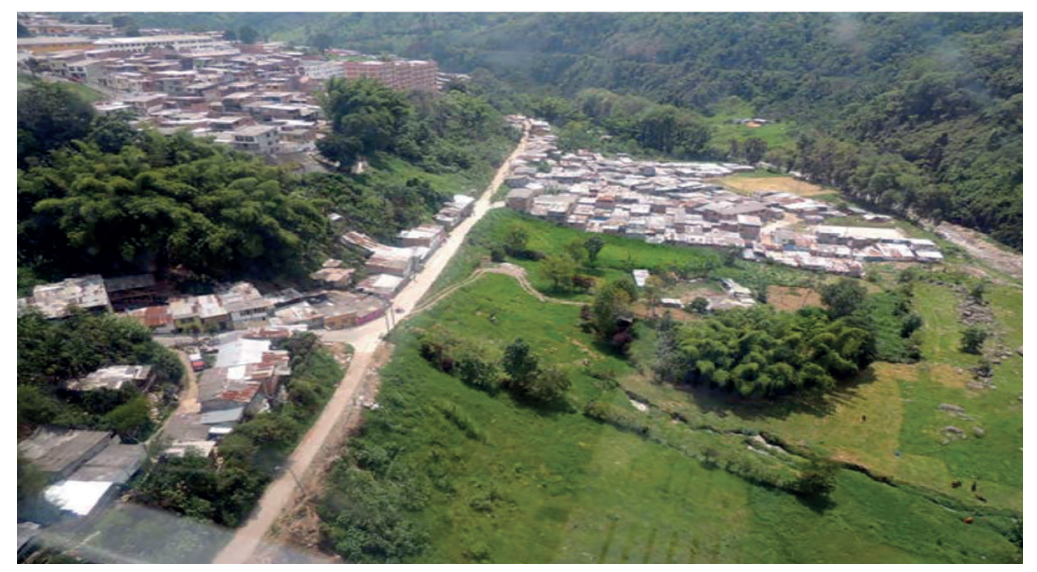

Figura 106. Antigua banca en Villamaría

Fuente: fotografía Armando Ramírez Villegas (2016)

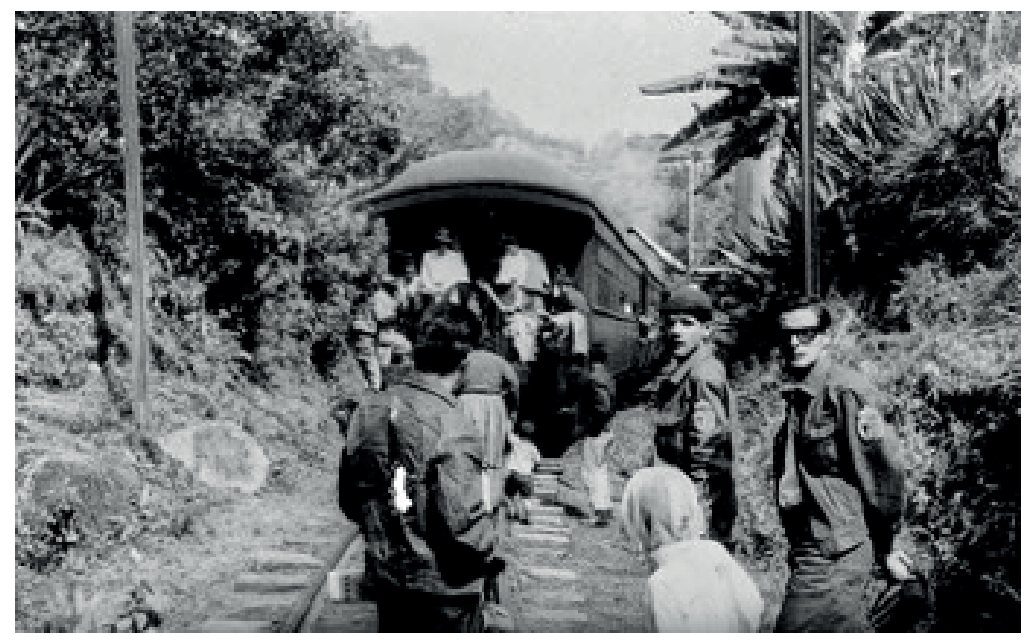

Figura 107. Tren en Villamaría

Fuente: foto del Archivo de la Oficina de Turismo 


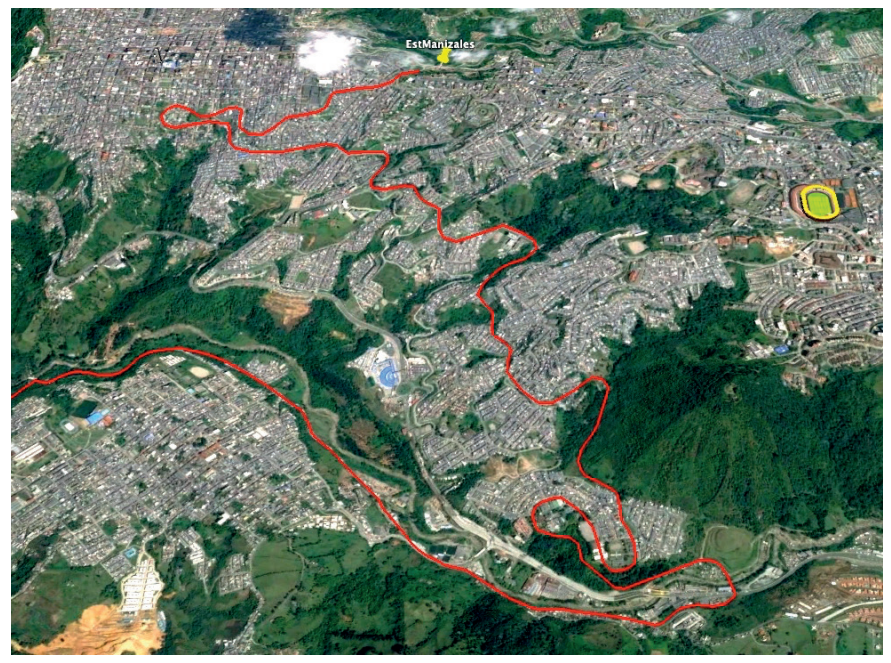

Figura 108. Línea del ferrocarril de Villamaría a Manizales sobre foto de Google Earth Fuente: foto de Armando Ramírez Villegas (2016)

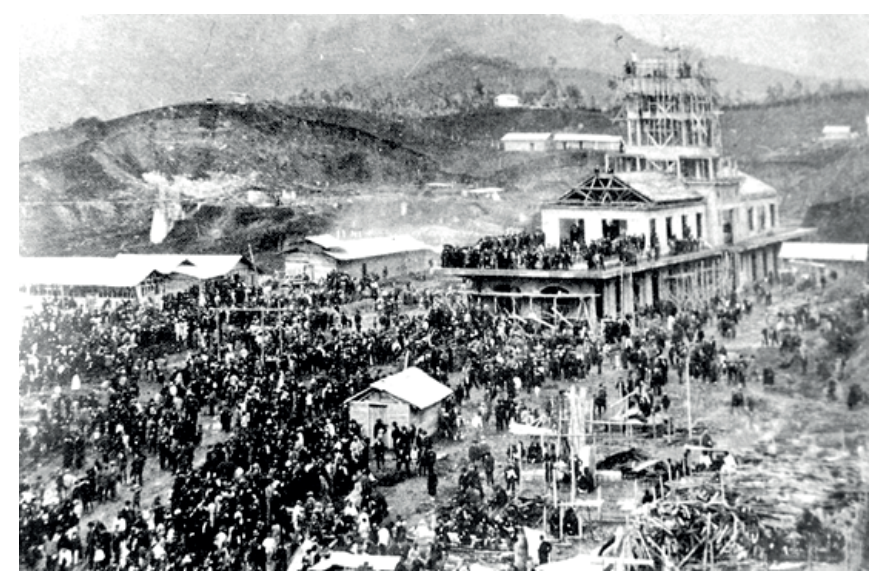

Figura 109. Estación de Manizales

Fuente: Archivo de la Oficina de Turismo de Villamaría

Experiencia sin igual para apreciar el desafío que representó para la ingeniería tal ascenso y la forma ingeniosa en que lo afrontaron. Una serie continúa de serpentines, que en algunas partes parecían más bien corbatines, les permitió ascender poco a poco, con pendientes variables entre el 4 y el 5\%, hasta el lomo de la cuchilla, 
en donde se encuentra explayada la ciudad de Manizales. Una vez en la cima, encontramos el punto en donde en el pasado estuvo localizado el último túnel de la línea férrea, el túnel llamado "Cervantes", por cruzar por debajo de la que se llamara avenida Cervantes, hoy Avenida Santander. Y me refiero al sitio, porque el túnel desapareció para dar paso a una nueva avenida que constituye el acceso a la antigua estación del ferrocarril, hoy en día restaurada y ocupada por la Universidad Autónoma de Manizales. Es un edificio imponente, diseñado y construido por la firma Ullen, la misma encargada de la reconstrucción de la ciudad de Manizales, después del incendio de 1925. Es este el fin del fin. Aquí culmina, después de 10 años de luchas, triunfos, descalabros, alegrías y tristezas, el sueño de una raza decidida a no dejarse aislar por la naturaleza, poniendo a prueba toda su capacidad de trabajo, físico e intelectual, y retando la lógica y la razón para demostrarle al mundo que todo lo que en principio parece absurdo, no lo es. ¡La obsesión y la dedicación, mezcladas con inteligencia, logran lo que parece un imposible!

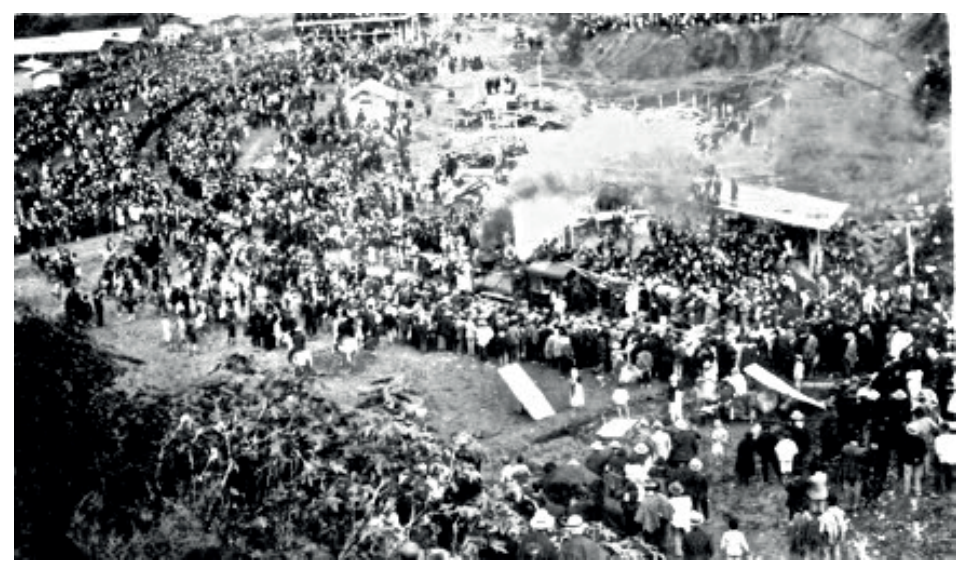

Figura 110. Llegada del primer tren a Manizales

Fuente: Archivo de la Oficina de Turismo de Villamaría

El 15 de septiembre de 1927 entra triunfante la primera locomotora a la ciudad de Manizales en medio de vítores y aplausos de una comunidad, que, en medio de la alegría, miraba asombrada cómo un monstruo negro con estrepitosos aullidos se desplazaba por sus angostas y empinadas calles. La mayoría, sin entender claramente su significado y sin apreciar lo que este acto significaría para la vida de todos ellos. No comprendían que se estaba abriendo una comunicación con un mundo externo, lo que permitiría un intercambio de conocimientos y riquezas, que cambiaría costumbres y modos de vida para el bien de todos los habitantes. Toda la dirigencia 
caldense y numerosos e ilustres invitados se hicieron presentes para manifestar su satisfacción por la culminación de la obra soñada. (Fabo, 1926)

El corresponsal de La Patria Gonzalo Sánchez Zuleta, recuerda así la inauguración, en una crónica del 13 de noviembre de 1979: "Para la inauguración oficial del Ferrocarril de Caldas se preparó una Feria Exposición Nacional, que tuvo su sede en el edificio del Instituto Universitario y que se prolongó del 20 de diciembre de 1927 hasta el 6 de enero de 1928. Se tuvieron carnavales animadísimos los dias 28, 29 y 30 de diciembre de 1927. La inauguración solemne y oficial del Ferrocarril se hizo en la Estación de Manizales el 27 de diciembre de 1927. Se contó para ella con la presencia del señor Presidente de la República, doctor Miguel Abadía Méndez, del señor Nuncio del Papa en Colombia, Monseñor Paulo Giobbe (de sus labios recibimos en Roma en 1970 el testimonio de aquella jornada memorable para Manizales y para Caldas); del señor Obispo de la Diócesis Monseñor Tiberio de J, Salazar y Herrera, que celebró Misa Campal en la Estación; del Gobernador del Departamento, doctor Daniel Gómez y Arango; del Gerente del Ferrocarril don Eleuterio Serna, de muchas otras personalidades entre las que se contaban varios Ministros de Estado, varios Gobernadores de Departamentos vecinos e innumerable público de Manizales y de todo Caldas".

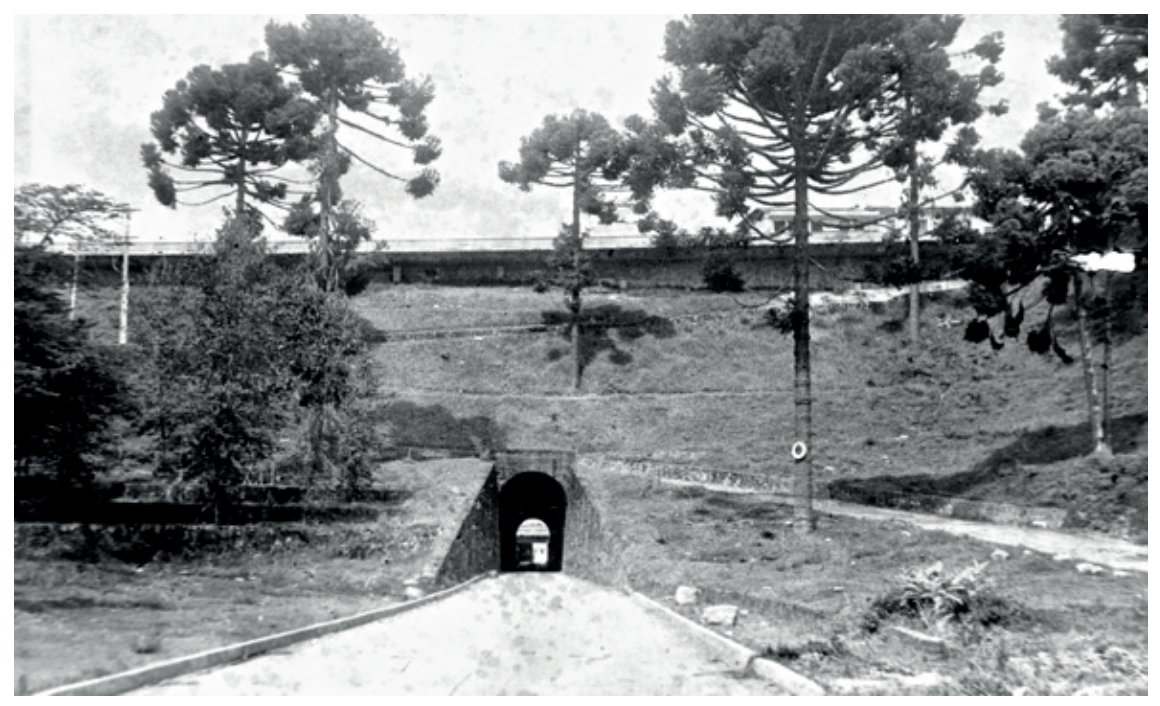

Figura 111. Túnel $\mathrm{N}^{\circ} 10$ Avenida Cervantes

Fuente: Archivo de la Oficina de Turismo de Villamaría 


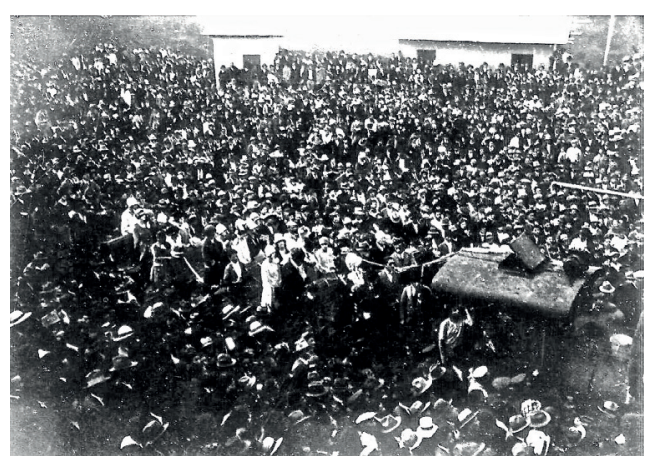

Figura 112. Inauguración Manizales

Fuente: Archivo de la Oficina de Turismo de Villamaría

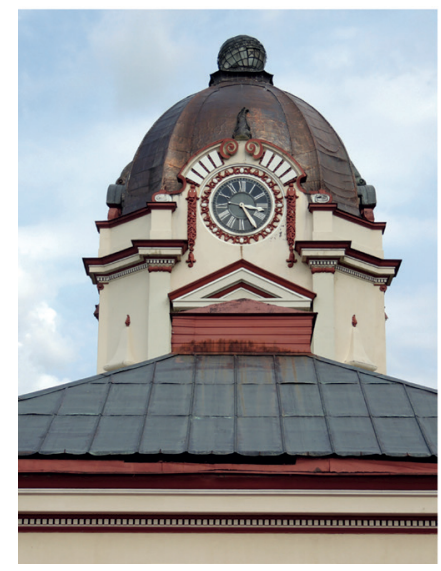

Figura 113. Torre del reloj. Estación Manizales

Fuente: foto de Armando Ramírez Villegas (2016)

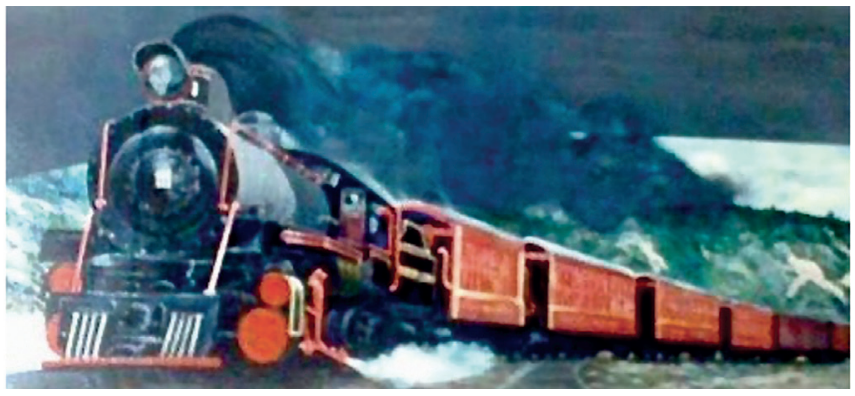

Figura 114. Mural

Fuente: foto de Luis Carlos Ramírez J. 


\section{COMENTARIO $6^{\circ}$}

\section{Celebraciones frustradas}

Corría el año 1925, los cielos estaban despejados y del intenso invierno de finales del 24 ya no quedaba sino el recuerdo de las grandes tormentas que provocaran los sucesivos derrumbes y el taponamiento total de la banca del ferrocarril. El ascenso a Boquerón, que constituyó un hueso duro de roer, ya se había culminado y la pala de vapor que había sido traída para despejar el derrumbe de La Viuda, ya la habían retirado. El túnel ya había abierto sus puertas y los ingenieros Ochoa, Cardona y Piedrahita, avanzaban alegres con su locomotora por los lados de La Hermosa mientras el ingeniero Isaza, a todo vapor, izaba las últimas vigas metálicas del puente, de 50 metros de luz, sobre el San Eugenio, todo, bajo la mirada inquisitiva del nuevo superintendente: Francisco Jaramillo Ochoa, quien apuraba las obras para recuperar el tiempo perdido en «las serpentinas de Boquerón», como las denominara el ingeniero alemán Petri.

A finales del mes de junio de 1925 entró, triunfante, con el séquito de ingenieros y dirigentes a bordo, la primera locomotora a la población de Santa Rosa. No faltaron aplausos y vivas de la ciudadaníaquealborozada veía, alfin, el logrode su comunicación con el mundo exterior. Se aprestaban, entonces, a hacer, a ese acontecimiento, la celebración debida con todas las pompas y fiestas que se merecía. Las autoridades se convocaban, las bandas preparaban sus marchas, los juegos artificiales estaban contratados, las señoras de la sociedad alistaban sus mejores galas, los señores preparaban sus más elegantes atuendos, y el pueblo, esperaba feliz el acontecimiento. Pero, de repente, llegó, como un baldado de agua fría, la infausta noticia de que Manizales, su ciudad capital, había sido devorada por las llamas, y todo se derrumbó.

El día 3 de julio de 1925 se produjo el primero y más voraz, de los tres incendios que se ensañaron sobre la ciudad, dejando convertido en cenizas la mayor parte de su centro histórico. La alegría se tornó en tristeza y desesperación. Toda la impactada población, decidió contener su alegría para convertirla en solidaridad y ayuda por su devastada capital. Las celebraciones fueron suspendidas inmediatamente y todos se quedaron con los crespos hechos. Fue esta la primera inauguración frustrada del Ferrocarril de Caldas. Como el tiempo apremiaba, y ahora con más veras, lo más importante era tratar de llegar con el ferrocarril lo antes posible, a la población de San Francisco, desde donde se podría trasladar a la ciudad de 
Manizales, a lomo de mula, en un principio y en rudimentarios coches, después, todos los materiales y elementos necesarios para su reconstrucción. Raudo arrancó el tren de Santa Rosa hacia Guayabito y con algunas dificultades en el cruce de Las Peñas por sus empinados taludes rocosos, en donde tuvieron que ayudar, a nuestros empíricos técnicos, dinamiteros americanos que proporcionaron una importante transferencia de tecnología, llegó a la estación La Capilla que tuvo una sencilla pero elegante inauguración. La premura de llegar a Chinchiná no daba tregua para hacer muchas fiestas. El tiempo estaba radiante y había que aprovecharlo. Se cruzó el alto de Los Micos, en el cual, desgraciadamente, murieron tres obreros en desafortunado accidente con la manipulación de una dinamita. Probablemente no habían asimilado correctamente las recomendaciones de los gringos, que habían venido a dar instrucciones de cómo se debería colocar y manejar la dinamita. Superada la tragedia, alegres cruzaron Campoalegre para enfrentarse a un temible corte en el sitio conocido como El Lembo, en las puertas de San Francisco.

Afortunadamente la situación económica del ferrocarril se veía ahora favorecida con la aprobación de un empréstito por valor de $\$ 10.000 .000$, y se contaba con recursos suficientes para enfrentar cuanta dificultad topográfica se pusiera por delante. Un corte de 35.000 metros cúbicos fue removido rápidamente y gloriosos lograron llegar con los rieles en el mes de junio de 1926, a la población de San Francisco, etapa definitiva para la reconstrucción de la capital.

Felices los manizaleños por la oportunidad que se les abría al poder, no sólo de sacar su café para la exportación sino, ingresar cuanto material se requiriese para rehacer su ciudad, prácticamente desaparecida por el fuego, decidieron acompañar a los Franciscanos para celebrar, como se debía, ese hecho maravilloso de tener su comunicación férrea disponible. Los preparativos para la gran fiesta no se hicieron esperar; telegrama va, telegrama viene, invitaciones al por mayor se reparten, las programaciones se estudian al dedillo, las damas preparan sus mejores galas, los caballeros sus mejores trajes sin olvidar cuanta condecoración tengan para exhibir, los funcionarios preparan sus discursos y, en fin, todo está listo para el día de la gran inauguración. El tren inaugural, engalanado con flores de todos los colores, inicia su recorrido en Santa Rosa, transportando a los funcionarios e invitados especiales con sus esposas y familiares, y logra su entrada triunfal en medio del jolgorio colectivo, trepidando su sirena encendida, a las once de la mañana de un día de junio de 1926.

No hacía mucho había terminado el rosario de discursos, de cuanto funcionario o delegado tuviera en su bolsillo, cuando al hermoso verano de que se había disfrutado en los últimos meses, le dio por terminarse súbitamente. Un tremendo aguacero se descuajó sobre la población y sus alrededores, dando al traste con cuanta festividad 
se había programado. ¡Una verdadera lástima! Lo peor no había comenzado. Las intensas lluvias desprendieron de sus taludes, en forma inmisericorde, grandes cantidades de tierra que cubrieron los rieles por donde debería regresar la locomotora con su carga de invitados. La celebración se tornó en una desgracia. La lluvia no amainaba y cada vez era peor la situación. Derrumbe que, como locos, trataban de despejar los ingenieros, era reemplazado por otro peor. En la población no había camas pa tanta gente. En medio del caos, no hubo más remedio que alistar las mulas y caballos como medio de transporte para tan elegantes invitados y llevarlos de regreso a San Rosa. Las satinadas y planchadas faldas de las damas eran ahora un revoltijo húmedo y arrugado, y los almidonados cuellos de los señores se veían desgarrados y sucios. Quizás algunos de los invitados hayan tomado la situación como una ocasión adicional para mejorar la festividad, diciendo que todo está dentro del paseo, pero creo, que para la gran mayoría fue un fiasco duro de afrontar. Fue esta la segunda inauguración frustrada.

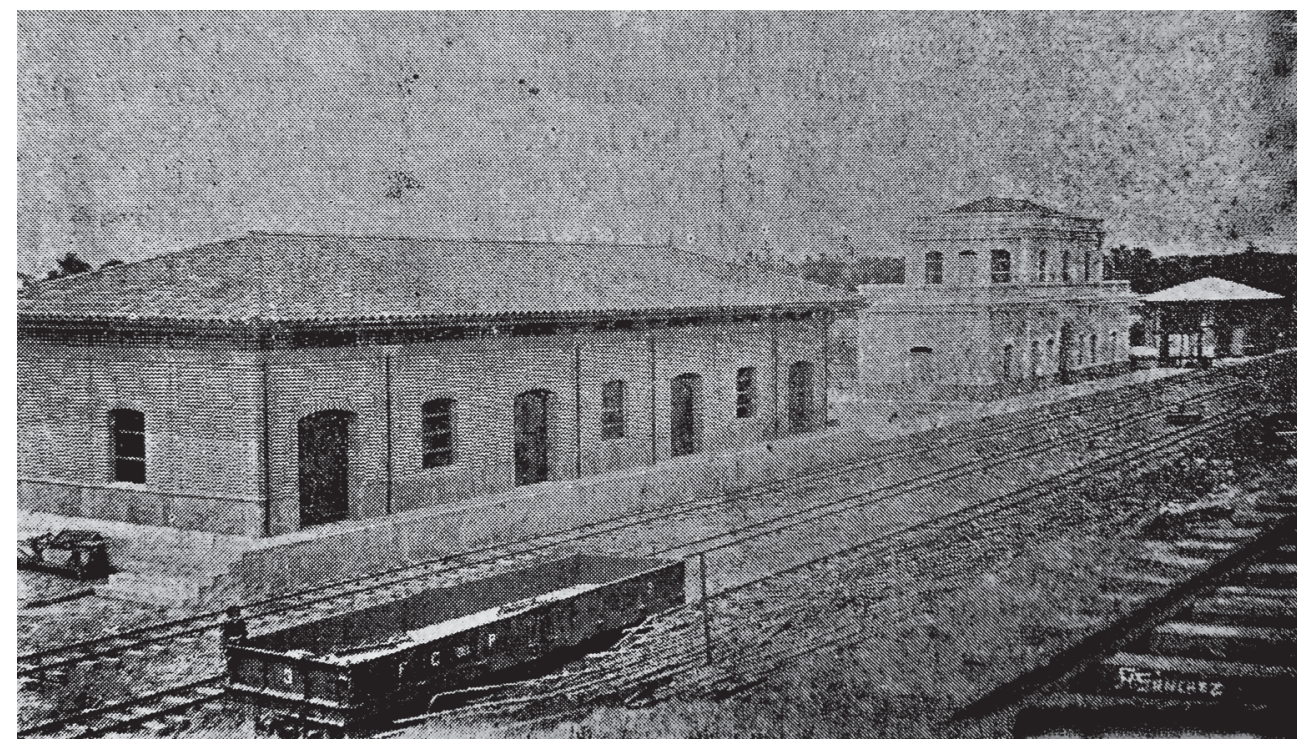

Figura 115. Estación de Cartago

Fuente: Revista Cromos N²413. Julio de 1924. 


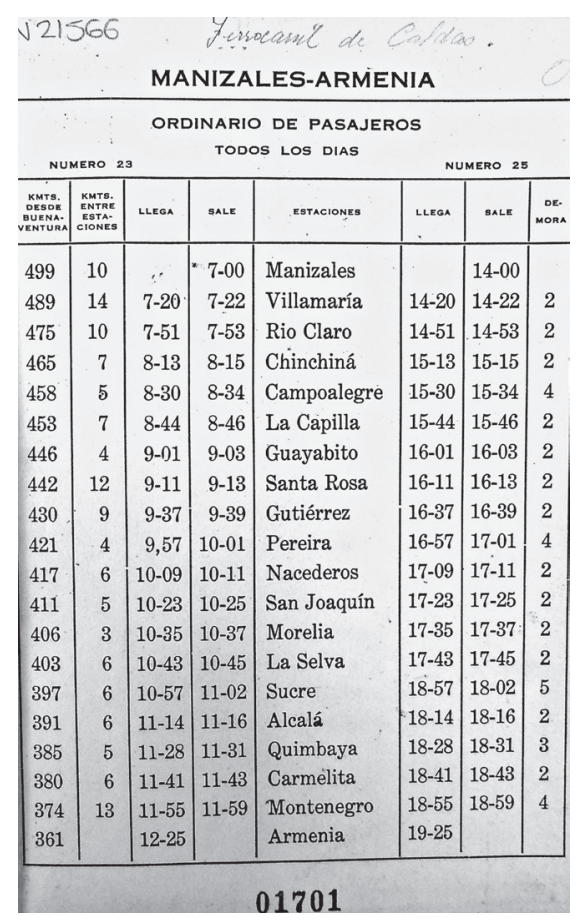

\begin{tabular}{|c|c|c|c|c|c|c|c|}
\hline \multicolumn{8}{|c|}{ PEREIRA-CARTAGO } \\
\hline \multicolumn{8}{|c|}{$\begin{array}{l}\text { M I X TOS } \\
\text { TODOS LOS DIAS }\end{array}$} \\
\hline 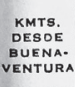 & 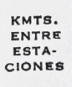 & LLEGA & SALE & ESTACIONES & LLEGA & SALE & $\begin{array}{l}\text { DE- } \\
\text { MORA }\end{array}$ \\
\hline 380 & 5 & & $10-10$ & Pereira & & $17-10$ & \\
\hline 375 & 6 & $10-20$ & $10-22$ & Nacederos & $17-20$ & $17-22$ & 2 \\
\hline 369 & 8 & $10-34$ & $10-36$ & Belmonte & $17-34$ & $17-36$ & 2 \\
\hline 361 & 14 & $10-51$ & $10-53$ & Villegas & $17-51$ & $17-53$ & 2 \\
\hline 347 & & $11-24$ & & Cartago & $18-20$ & & \\
\hline
\end{tabular}

Figura 116. Itinerario de los trenes de pasajeros

Fuente: Imprenta departamental de Manizales, 1935. 


\section{CAPÍTULO VI}

\section{Ramal La Marina-Cartago}

I a dirigencia de Caldas, aprovechando la visita del presidente Marco

Lidel Suárez, en su periplo hacia la ciudad de Popayán, logró obtener su compromiso para que el Gobierno Nacional se hiciera cargo de la construcción de este ramal, incluido el puente de 70 metros de luz, que era necesario para cruzar el río La Vieja, reflejado en el decreto 421 del 21 de febrero de 1920. El 25 de enero de 1921 se adquieren los terrenos de la finca La Marina, necesarios para el paso de la línea férrea, al señor Alejandro Concha. Este señor Concha es el mismo distinguido señor cartagueño que estuviese presente en la colocación del primer riel en el sitio de Puerto Caldas, en compañía de su señora esposa y de una hija, y que ofreciera a nombre de la población de Cartago, un clavo de plata, como reconocimiento de la importancia que esta construcción significaba para toda su región (Fabo, 1926). A mediados del año, el ingeniero Eleuterio Serna dio comienzo a la construcción del ramal, que tiene una longitud de 1700 metros, y fue terminado el día 17 de abril de 1922. Hay que tener en cuenta que la primera locomotora del Ferrocarril del Pacífico llegó a Cartago el día 21 de junio de 1924, es decir dos años después de haber terminado el ramal de La Marina a la estación de Cartago.

El Ferrocarril del Pacífico le permitió al de Caldas construir, en terrenos de la futura estación, una bodega para el almacenaje de la carga, tanto llegada como para despachar, y al mismo tiempo, para el despacho y arribo de pasajeros, que hicieran uso de sus equipos. En ese momento aún no estaban construidas las edificaciones de la estación del Tren del Pacífico en la ciudad de Cartago. La terminación de este ramal, y su empalme con el ferrocarril del Pacífico, permitiría el transporte del café sin transbordos, desde Pereira, en un principio, y más tarde desde Manizales, hasta Buenaventura, lo que evitaba la tortuosa ruta de Puerto Caldas, río Cauca, Yumbo, Buenaventura, con todos sus cargues y descargues, y los acarreos en mulas. Pronto se hizo evidente la importancia, que tanto para el ferrocarril de Caldas como para el del Pacífico, tenía esta conexión y por qué razón se modificó el trazado inicial para adoptar la variante Consota, como se denominó en ese entonces, que acercaba la ruta a la ciudad de Cartago, tal como lo vislumbrara el ingeniero Isaza. Podría decirse que esta conexión de los dos ferrocarriles representó una ampliación de la longitud total del de Caldas, de unos 400 kilómetros.

Telegrama del corresponsal del diario La Patria en el cual relata la llegada del primer tren a la ciudad de Cartago: 
“Cartago,18 de abril 1922

PATRIA-Manizales

Tuvo lugar ayer el paso de la primera locomotora del Ferrocarril de Caldas por el hermoso puente sobre el río La Vieja. Llegó en ella el Gobernador General Gutiérrez, Asamblea de Caldas, numerosas personalidades del comercio de Manizales y Pereira. De Cali vinieron a solemnizar el acto, el Ilustrísimo Señor Obispo, una comisión de la Asamblea, el doctor José Ignacio Vernaza, el Ingeniero Jefe del Ferrocarril, el Secretario de Hacienda del Valle en representación del Gobernador y muchas personas más. A las diez de la mañana llegó la locomotora adornada con la bandera Nacional, se detuvo en medio del puente, donde la bendijo el señor Obispo quien acaba de celebrar la Misa Campal en la orilla del río. El Padre Montoya, jesuita, pronunció un discurso alusivo al acto y luego la locomotora siguió a la estación, donde el Concejo de la ciudad esperaba el arribo del tren. En su nombre habló el doctor José Ignacio Durán. Hizose luego un desfile hasta la Plaza principal, en donde el General Pompilio Gutiérrez pronunció un elocuente discurso e hizo entrega del puente al ingeniero doctor Ortega, nombrado por el Gobierno Nacional. En nombre de la Cámara habló el doctor Gerardo Arias Mejía y del Senado don Jaime Gutiérrez y de la Asamblea del Valle el General Enrique Palacios. A las tres de la tarde efectuóse un desfile de todos los Colegios y Escuelas de la ciudad, realzado por la presencia de señoritas de los más distinguido, señoras, el Gobernador de Caldas, los ingenieros del Ferrocarril y carros alegóricos entre los cuales llamó la atención el alusivo a la primera locomotora. En el Teatro Rivera ofreció a nombre de Cartago una hermosa medalla de oro con el escudo de la ciudad al Gobernador Gutiérrez, el doctor José Ignacio Vernaza. El General Gutiérrez hondamente conmovido dio las gracias y manifestó que conservaría ese trofeo para la gloria de sus hijos. También habló el doctor Manuel G. Lucio y el Secretario de Hacienda de Caldas. La Junta de los festejos ofreció tres tarjetas de oro a los ingenieros del Ferrocarril, doctores Eleuterio Serna, Carlos de la Cuesta y Sebastián Ospina. Por la noche dióse una Retreta de Gala en la plaza principal y en casa de don Camilo A. Gómez, Prefecto, le fue ofrecida una soirée al señor Gobernador y comitiva a la cual concurrió parte de lo más selecto de la Sociedad. Hoy el Concejo ofrecerá una copa de champaña a los huéspedes de honor y se dará una tarjeta de oro al Capitán Miguel Baraona, quien arribó por primera vez en el Vapor "Ricaurte", frente a la ciudad, 
remontando el río La Vieja. Leyéronse en el acto de entrega de la medalla los telegramas de los hijos de Cartago ausentes, fechados en esa ciudad, Cali, Palmira, etc.

\section{CORRESPONSAL"}

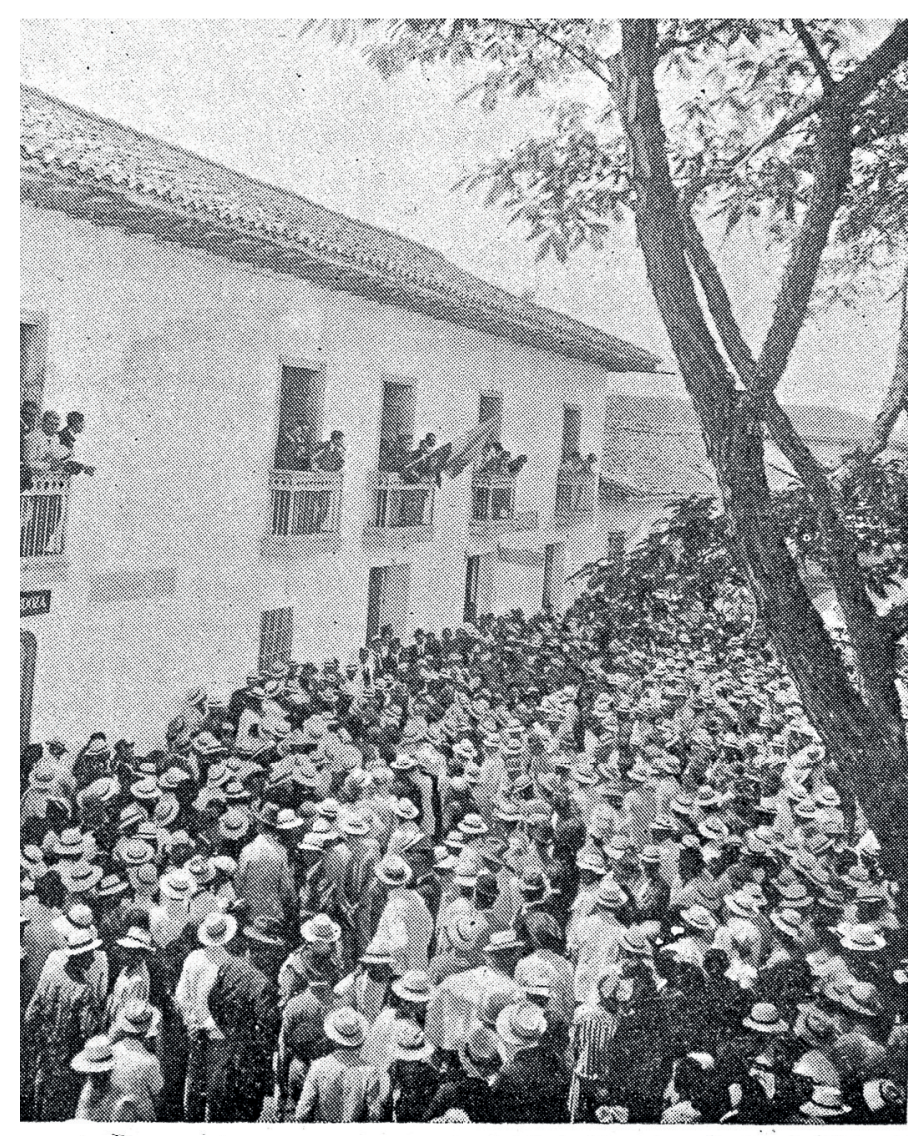

Gobernador de Caldas, General Pompilio Gutiérrez, hace entrege del Ramal a Cartago al comisionado del Gobierno Nacional.

Figura 117. Llegada del primer tren de Caldas a Cartago 


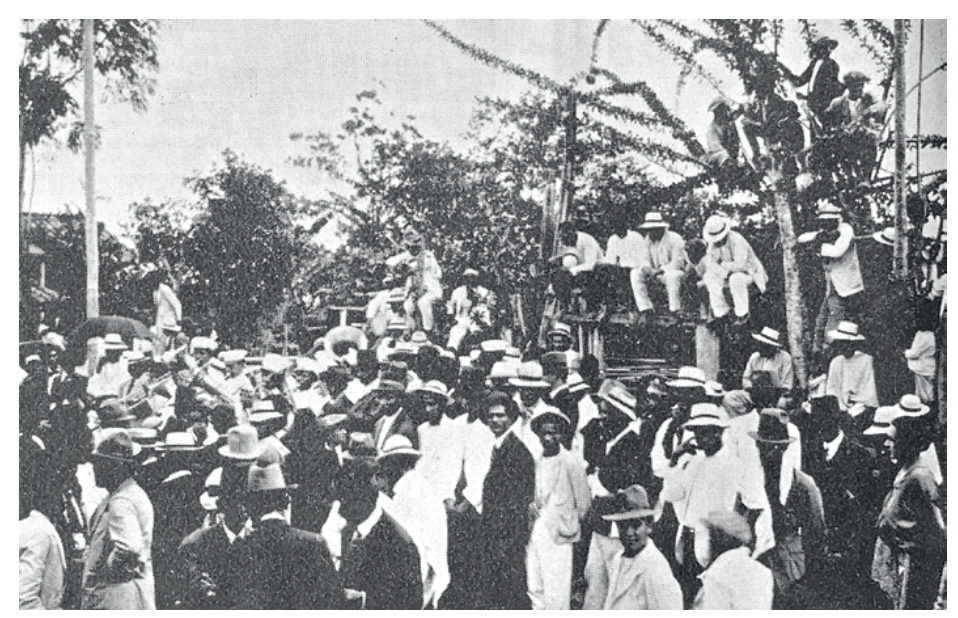

Figura 118. Primer tren en Cartago

Fuente: Revista Cromos N³05. Mayo de 1922

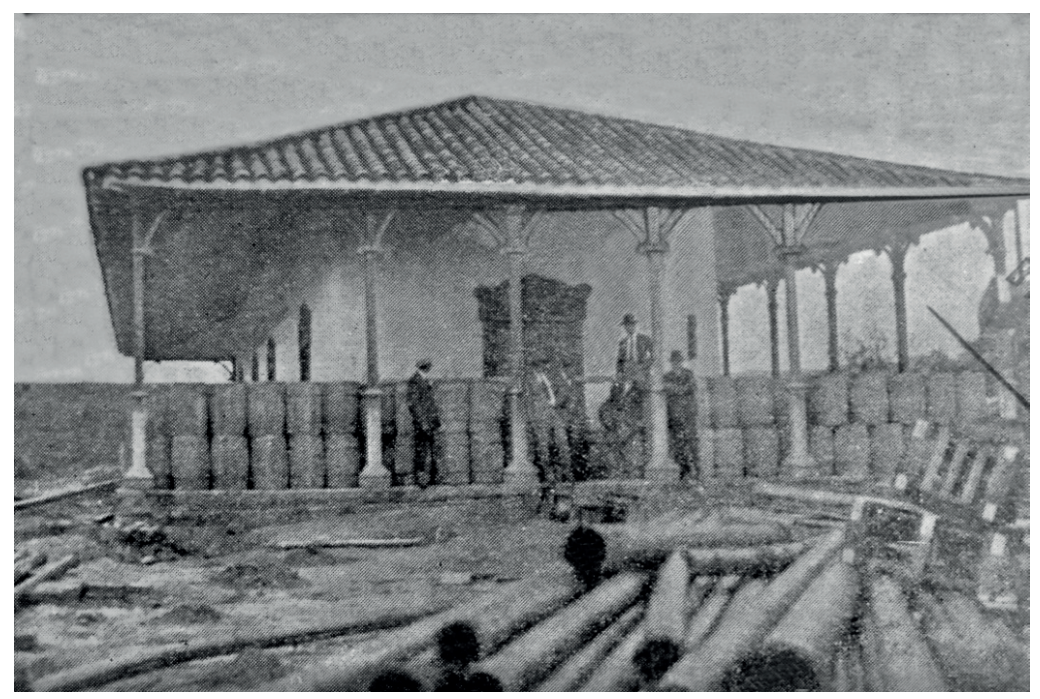

Figura 119. Estación La Marina

Fuente: Echeverri, N. (1927). Ferrocarril de Caldas. Bogotá: Imprenta Nacional 


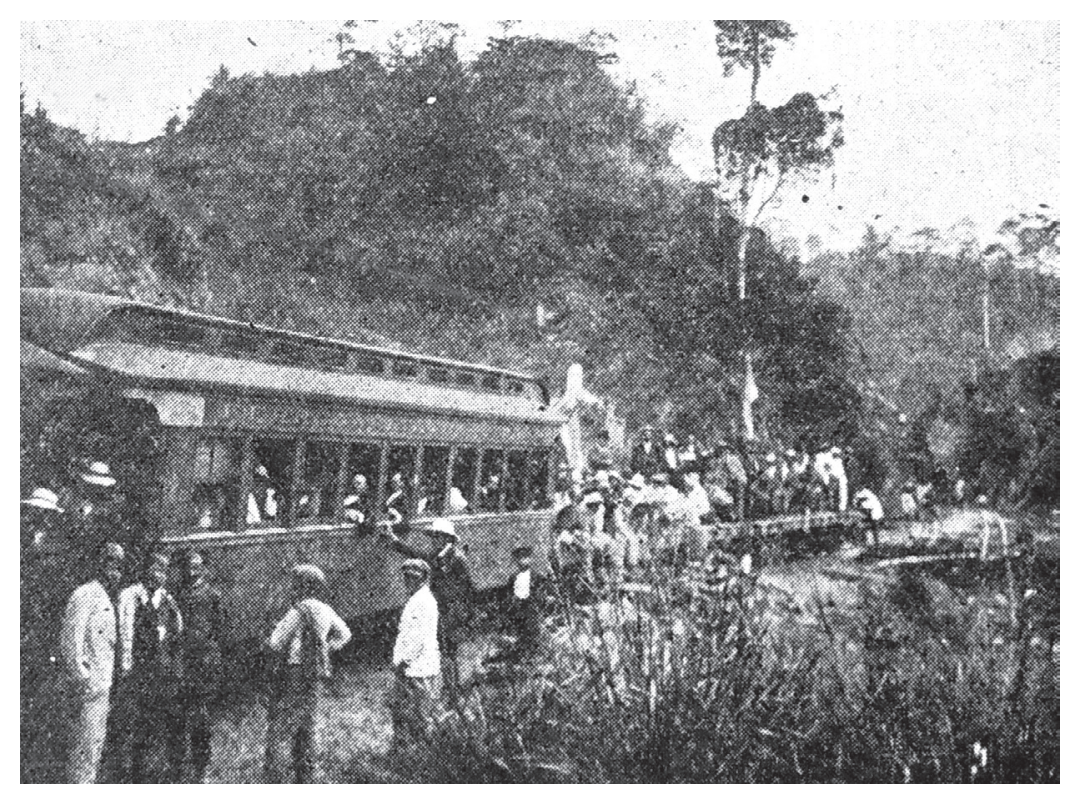

Figura 120. Primer vagón de pasajeros a Cartago

Fuente: Revista Cromos N³05. Mayo de 1922
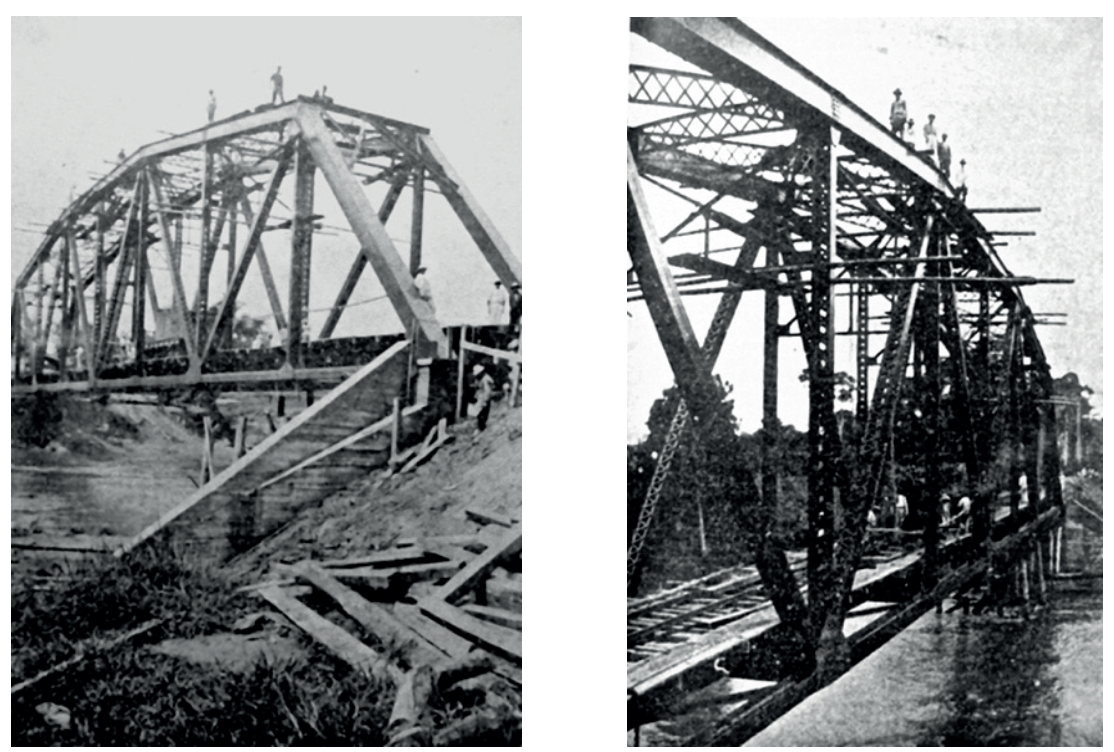

Figura 121. Construcción del puente sobre el río La Vieja Fuente: Revista Cromos N³05. Mayo de 1922 


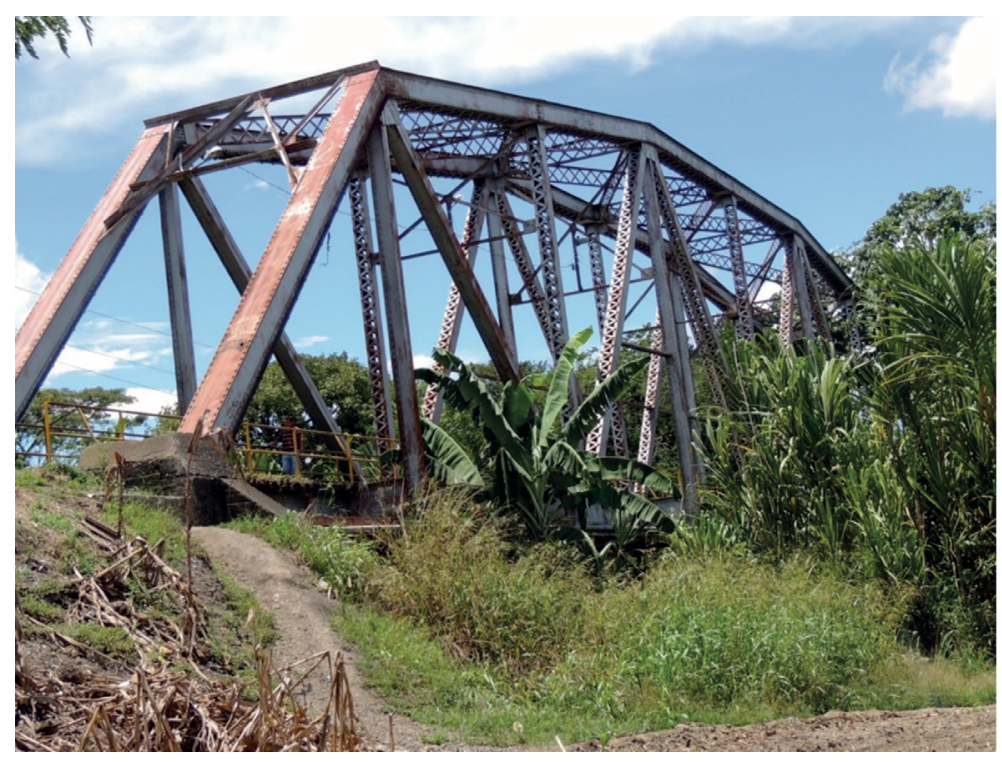

Figura 122. Puente actual sobre el río La Vieja

Fuente: fotografía Armando Ramírez Villegas (2016)

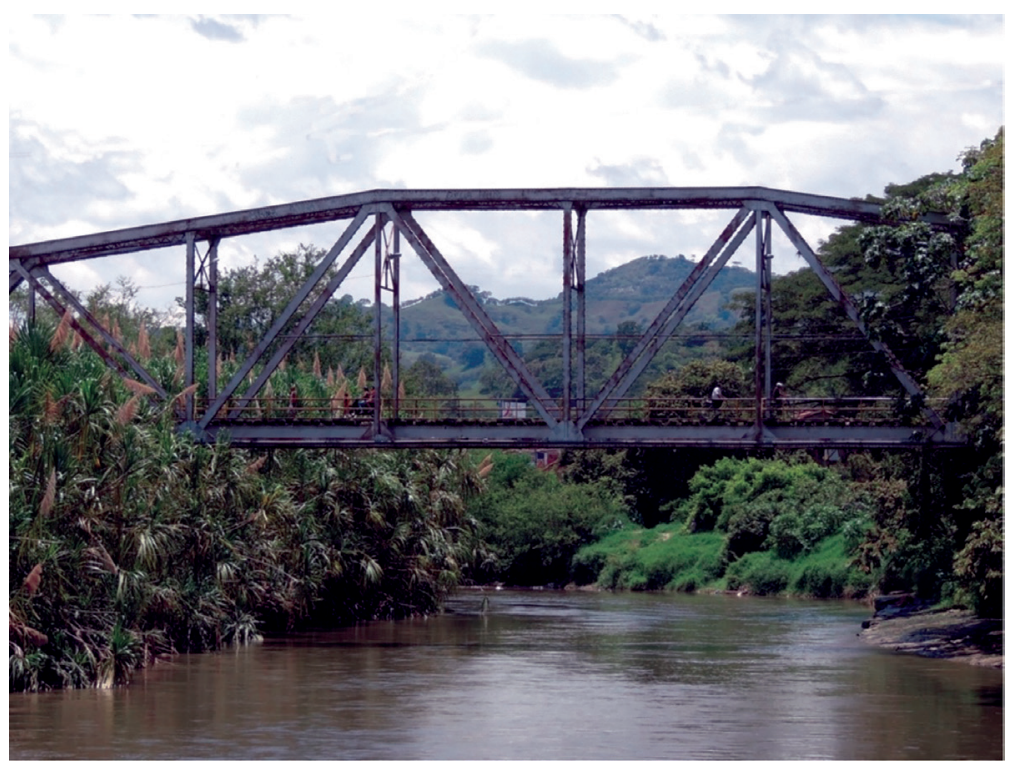

Figura 123. Puente actual sobre el río La Vieja

Fuente: fotografía Armando Ramírez Villegas (2016) 

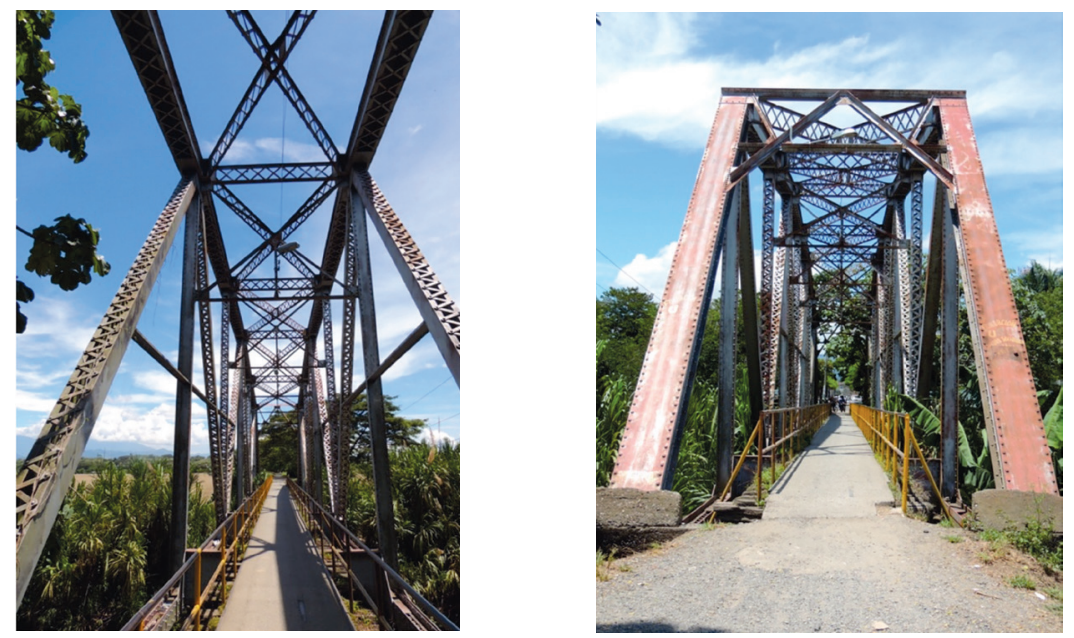

Figura 124. Puente actual sobre el río La Vieja

Fuente: fotografía Armando Ramírez Villegas (2016)

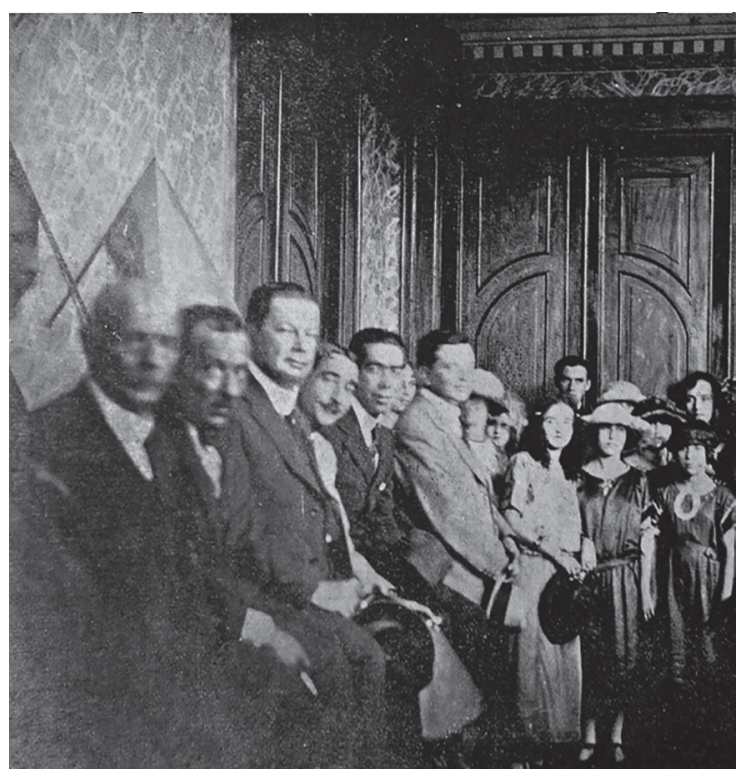

Figura 125. Inauguración del ferrocarril del Pacífico en Cartago. Funcionarios e ingenieros de orden nacional, departamental y municipal.

Fuente: Revista Cromos N²413. Julio 12 de 1924 


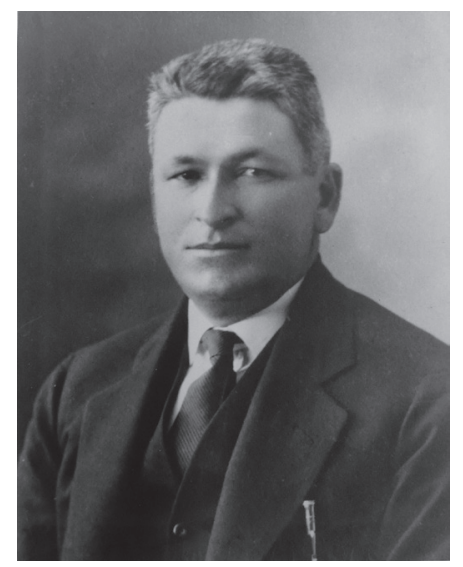

Figura 126. Ingeniero Eleuterio Serna G.

Fuente: Archivo de Jaime Serna G.

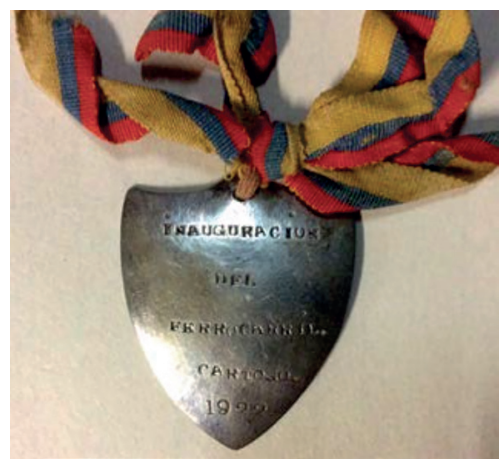

Figura 127. Medalla del municipio de Cartago por la llegada del tren, 1922 Fuente: Archivo de Jaime Serna G.
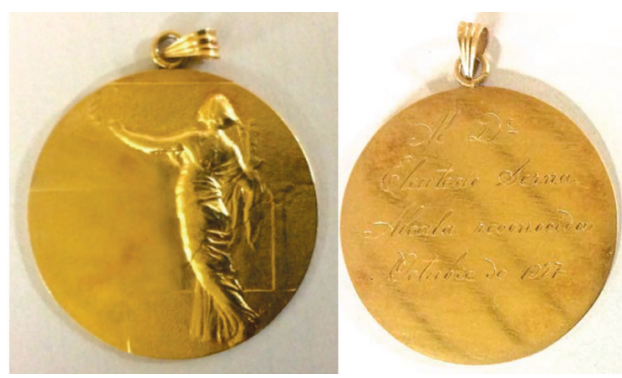

Figura 128. Medalla del municipio de Alcalá por la llegada del tren, 1927

Fuente: archivo de Jaime Serna G. 


\section{CAPÍTULO VII}

\section{Nacederos-Armenia}

$\mathrm{D}^{\mathrm{c}}$ esde los primeros trazados del Ingeniero Zapata se consideró como altamente conveniente para el ferrocarril y para toda la región, la extensión de la línea férrea hasta la ciudad de Armenia. En 1919, el Departamento contrató con el ingeniero Julián Arango un estudio taquimétrico de la línea (Echeverri, 1927), que inició en el sitio denominado Galicia, sobre el Ferrocarril de Caldas, y pasaba por las poblaciones de Alcalá y Montenegro hasta llegar a Armenia. Poco después de entregar el estudio, en el año 1920, con solo 30 años de edad, fallece el ingeniero Arango, lo que representó una gran pérdida, no sólo para el Ferrocarril, sino para toda la comunidad, que siente profundo dolor por el fallecimiento de una persona tan apreciada y valiosa para toda la sociedad. En 1923 se encomienda al ingeniero Eleuterio Serna, el trazado de la vía, quien tuvo como colaboradores a los ingenieros Ernesto Ramírez J., Juan de Dios Villegas, Alfonso Ramírez y Carlos Pardo. El trazado de la vía, de 52 kilómetros, se inicia en la ciudad de Armenia, pasa por las poblaciones de Montenegro y Quimbaya, sigue hacia Alcalá para dirigirse al sitio conocido como Zanjón Hondo, sobre el ferrocarril de Caldas, un poco más adelante de la estación Belmonte. A finales de 1924, se inicia el trazado definitivo con la variación al trazado del ingeniero Serna, desde el cruce del Río Barbas, con el objeto de cambiar el punto de llegada que pasó de ser en Zanjón Hondo, a la Estación de Nacederos. En este trazado, de 56 kilómetros, intervinieron los siguientes ingenieros: Benjamín Suárez, Elías Calvo, Alfonso Ramírez, Juan de Dios Villegas y Eduardo Cardona, Capitolino Sánchez, Hernando Payán y Rafael Betancourt. La localización de la línea entre el cruce del Río Barbas y Armenia, fue contratada con el ingeniero Tiberio Ochoa U.

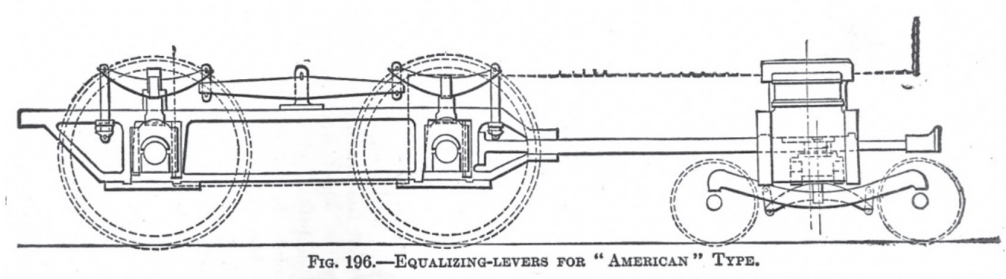

Figura 129. Niveles ecualizadores 


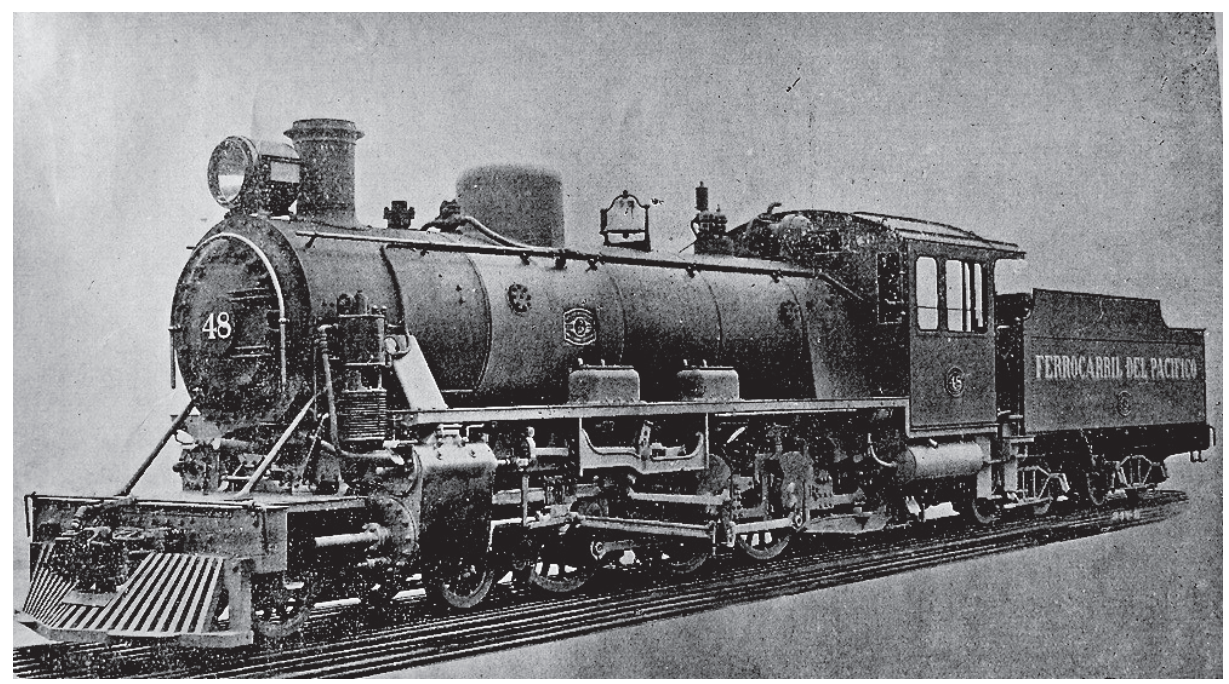

Figura 130. Locomotora doce ruedas. Según Luis de Greiff, esta locomotora fue diseñada para Colombia por Paul Dewhurst

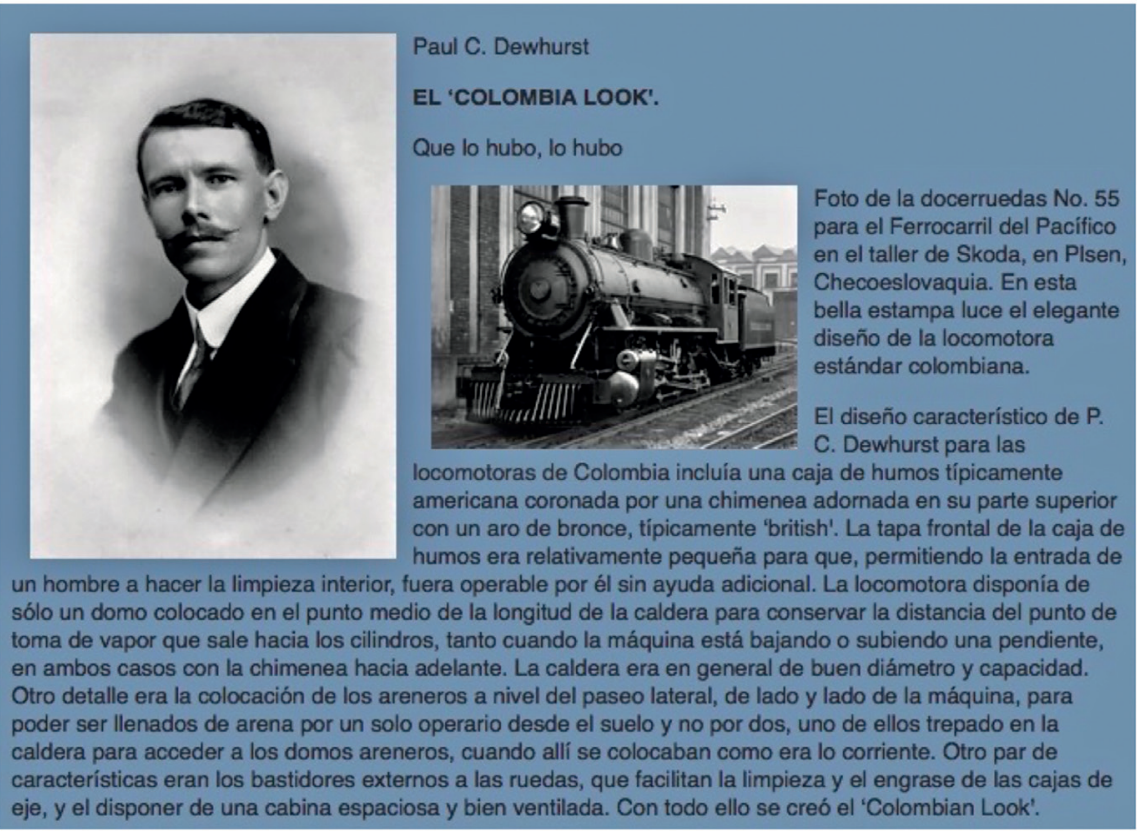

Figura 131. Ingeniero Paul C. Dewhurst 


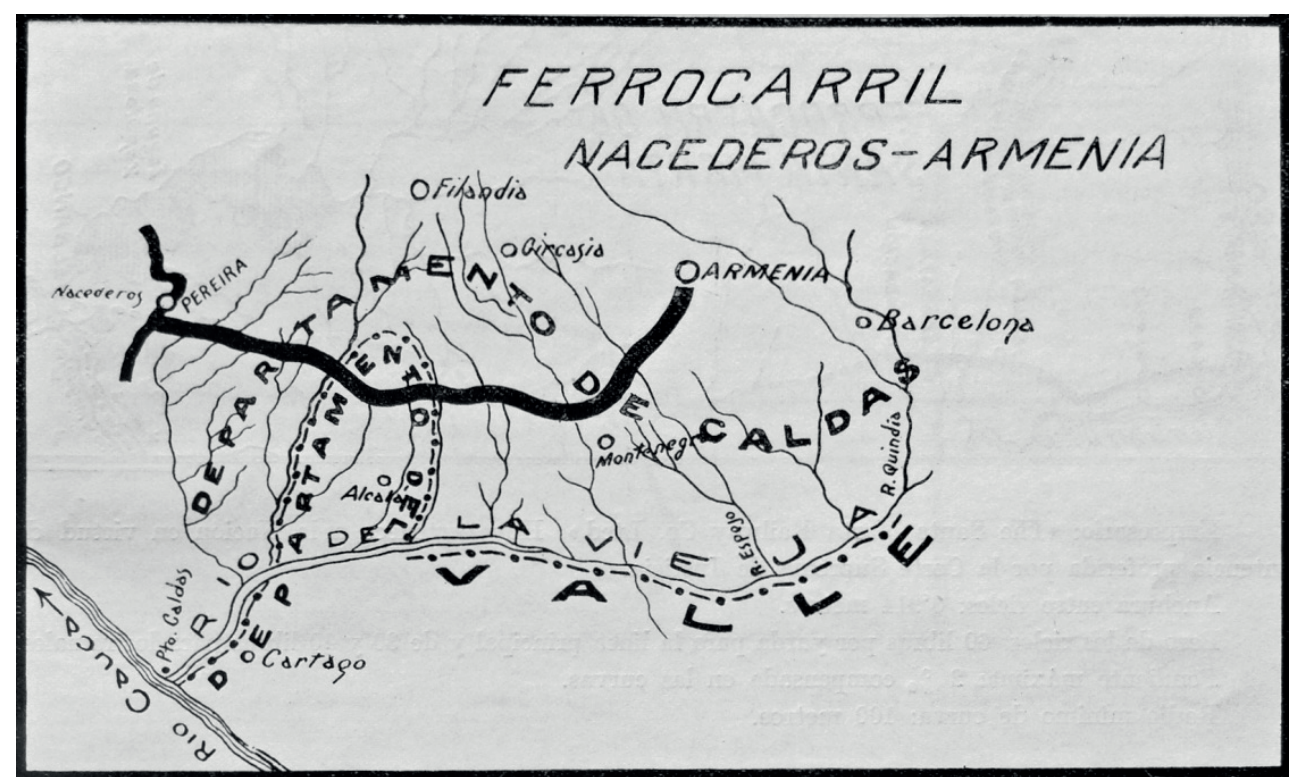

Figura 132. Trazado del ferrocarril Nacederos-Armenia Fuente: Monsalve, Diego. (1927). Colombia Cafetera.

En 1925, el Departamento de Caldas logra que el Gobierno Nacional se haga cargo del costo de la obra, y el 4 de julio se firma el contrato entre el ministro de obras públicas doctor Laureano Gómez y el señor Roberto Marulanda en representación del departamento de Caldas. En esa forma el ferrocarril de Nacederos-Armenia quedaba de propiedad nacional pero era administrado por el Ferrocarril de Caldas. Aprobados los planos por el Ministerio se inicia la obra, en agosto, dirigida por el ingeniero Manuel M. Mosquera, como Ingeniero Jefe del Ferrocarril de Caldas, y el ingeniero Hernando Piedrahita como su ayudante.

Los terrenos que enfrentaban eran los conocidos como "el abanico del Quindío", suaves y fértiles montículos, que hoy conforman el hermoso paisaje cafetero. Nada que ver con la agresividad de los profundos cañones o las grandes montañas, cuando no rocosas, deleznables y húmedas, del trayecto de Pereira a Manizales. Pero, detrás de tanta belleza se hallaba escondido un monstruo que causó más daño y dolor que las luchas con la topografía en los tramos anteriores. Los terrenos se encontraban cubiertos por espesos guaduales, que, en la riqueza de los suelos, se desarrollaban frondosos y gigantes. Hábitat perfecto para la multiplicación sin límite del zancudo 
anofeles, los mismos que encontraron su alimento preferido en cuanto humano trataba de atravesar su territorio. El paludismo apareció por doquier, llevando a la cama a una gran mayoría de los trabajadores del ferrocarril y muchos de ellos hasta su lamentable fallecimiento. Una situación grave e imprevista, difícil de afrontarla por la limitación de los medicamentos apropiados y los medios para atenderlos y movilizarlos. La obra se vio afectada en su rendimiento y por supuesto en sus costos de construcción. Poco a poco y con grandes cruzadas sanitarias se logró avanzar con los trabajos. En septiembre 26 de 1926 se inaugura la colocación del primer riel en la estación de Nacederos. ${ }^{3}$ En octubre de 1927 arriban a la población de Alcalá, en donde, los ciudadanos agradecidos, hacen entrega de una medalla al ingeniero Eleuterio Serna G., como reconocimiento a su trabajo denodado como director de las obras del ferrocarril.

En septiembre de 1928 llegan los rieles a la población de Quimbaya y el 14 de marzo de 1929 llegan a la estación de Montenegro. El editorial del diario La Patria se refiere así, al acontecimiento:

Ferrocarril en Montenegro. Hoy llegan a la población de Montenegro los rieles del ferrocarril Nacederos- Armenia. Esta importante ferrovía es de gran significación para la vida económica y administrativa del Quindío, la Arcadia colombiana, para recordar la frase consagratoria del ilustre "Luciano Pulgar”. El ferrocarril Nacederos-Armenia fue iniciado en los últimos meses del año 1925, siendo gobernador de Caldas el doctor Gerardo Arias Mejía. El gobernante caldense encomendó la obra a las manos expertas de Eduardo Serna, uno de los valores sustantivos de Caldas y de las inteligencias que aprestigian este departamento. Desde un principio el doctor Serna se rodeó de un personal competente y honorable, velando con los cien ojos de Argos para que los dineros del tesoro nacional no fueran dilapidados. En las postrimerías de la administración Serna tócale al doctor Francisco José Ocampo en su carácter de gobernador inaugurar los primeros diez kilómetros y clavar el riel que conecta esa vía a nuestro ferrocarril. El doctor Ocampo en página memorable hizo el elogio merecido de la obra, destacando la labor realizada por el doctor Serna. El segundo gerente de esta empresa fue don Justiniano Londoño, patriota de recia contextura y hombre de iniciativas claras y precisas. Don Justiniano Londoño siguió la trayectoria marcada por Eduardo Serna e introdujo mejoras de innegable importancia, alcanzando el título de Modelo su obra entre todas las realizadas en el país. La labor de Justiniano Londoño queda consignada en los kilómetros que se hicieron hasta la estación de Sucre

3. Comunicación del Ferrocarril de Caldas al Concejo Municipal de Pereira (Anexo No7) 
y ha sido revaluada por el veredicto de la opinión consiente de Caldas. Y, por último, don Emilio Latorre, gerente de los ferrocarriles de Caldas y de Nacederos-Armenia, continuó la labor fecunda realizada por los gerentes anteriores. Porque en ninguna obra nacional, departamental o municipal, se ha llevado a cabo una acción de economía y pulcritud como en la del ferrocarril del Quindío.

Pero sería un olvido imperdonable si no consignáramos aquí los nombres de los ingenieros Manuel María Mosquera, Eleuterio Serna y Ernesto Ramírez, colaboradores eficaces y conscientes en la construcción de esta importante ferrovía. También queremos dejar constancia escrita de los inteligentes servicios prestados a la obra por Germán Congote, Leocadio Gáomez, Juan Mejía Duque, J. Enrique Duque, Luis Londoño Vélez y Jaime Londoño Villegas, empleados de las oficinas de la empresa, ya que todos ellos, cuál más cuál menos, en el rol de sus funciones han trabajado ahincada tesoneramente en la organización maravillosa de esa empresa. Una voz de aplauso sincero enviamos a todos los caballeros atrás citados y a los trabajadores de la obra, labradores silenciosos, los cuales han dejado a través de ella pedazos de vida, sin que su labor sea retribuida por la justicia de los hombres.

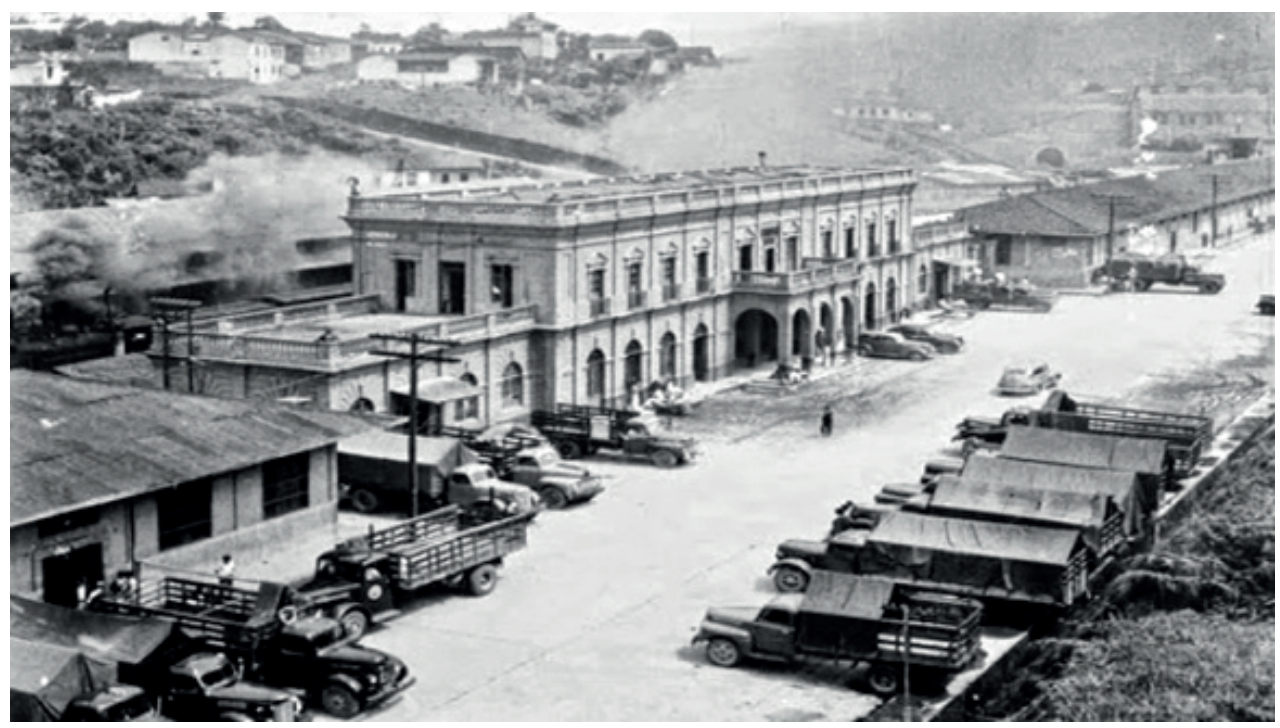

Figura 133. Estación de Armenia

Fuente: Grupo de Fotografías Antiguas de Armenia 
El 14 de octubre, es decir, 7 meses más tarde, se inaugura la llegada del ferrocarril a la ciudad de Armenia.

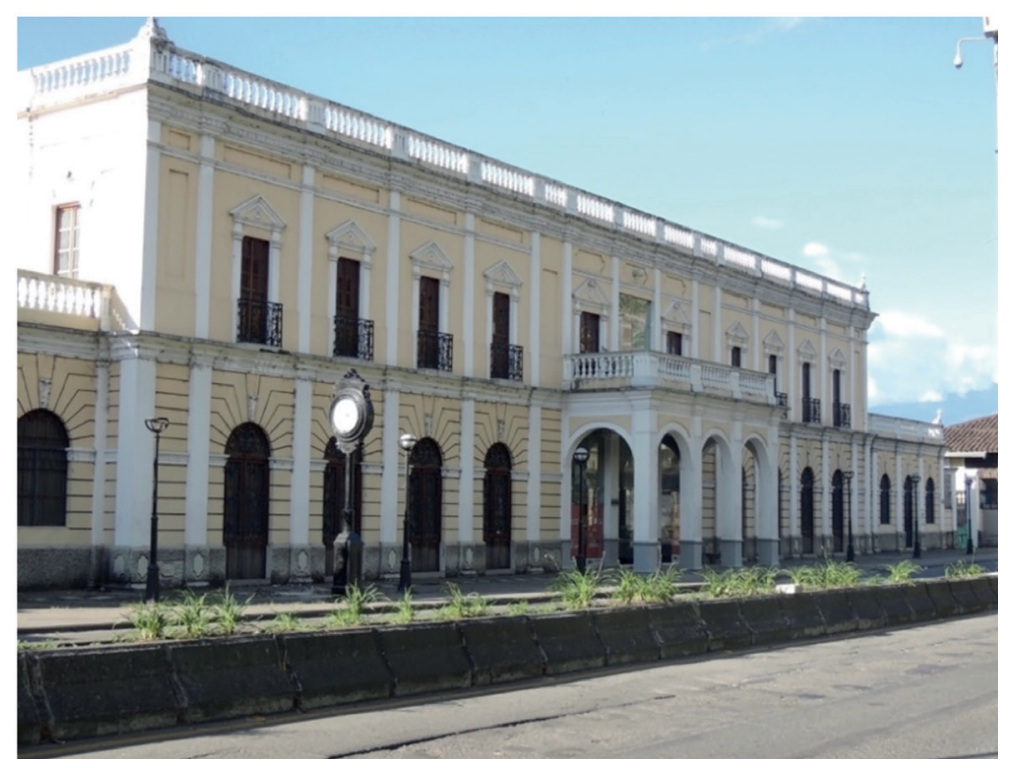

Figura 134. Estación en la ciudad de Armenia

Fuente: fotografía Armando Ramírez Villegas (2017)

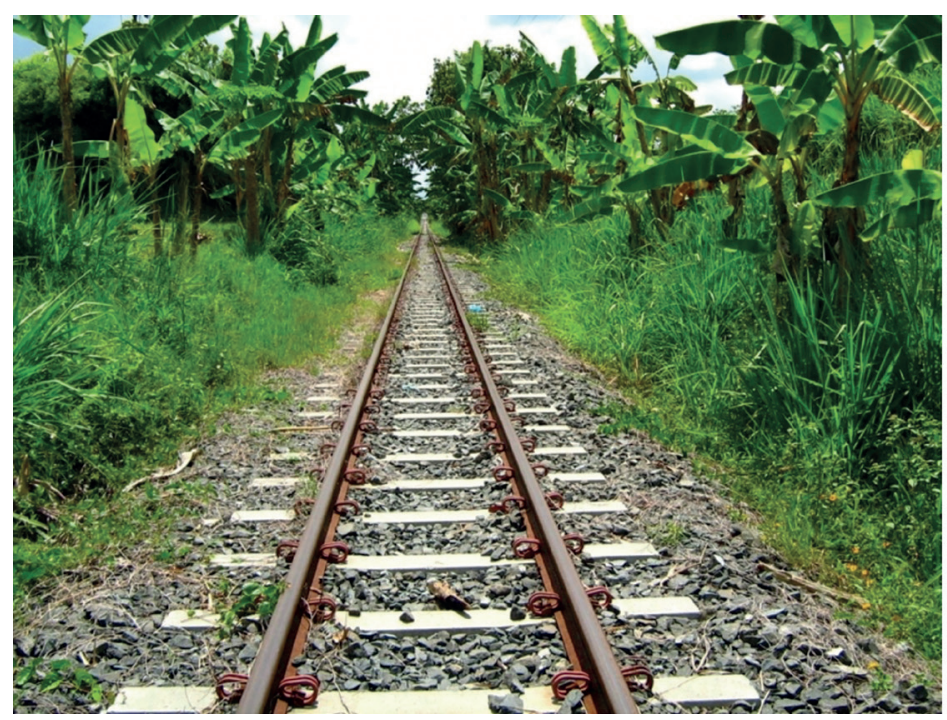

Figura 135. Trayecto Montenegro-Armenia

Fuente: fotografía Esteban Romero (2015) 


\section{Informe del Señor Emilio Latorre, Administrador del Ferrocarril Nacederos-Armenia}

Pereira, mayo 24 de 1928

Señor

Director General de los Ferrocarriles

Bogotá

Correspondiendo a los deseos manifestados por usted en su atento oficio número 415 de fecha 9 de abril último tengo el gusto de dar a ese despacho el informe relativo al ferrocarril Nacederos-Armenia en la forma siguiente:

"De acuerdo con lo dispuesto en el artículo primero de la ley 67 de 1923 octubre 23 y después de haber verificado el estudio de una vía férrea entre el municipio de Armenia y un punto del ferrocarril de caldas entre Cartago y Pereira cuyos planos fueron aprobados por el Ministerio de Obras Públicas el gobierno nacional procedió a celebrar con el departamento de caldas El respectivo contrato de construcción con fecha 4 de julio de 1925 el cual suscribieron los señores doctor Laureano Gómez en su calidad de ministro de obras públicas y el señor Roberto Marulanda como representante del departamento y cuyo texto corre publicado en el diario oficial número19956 de 24 del citado mes de julio los trabajos de construcción se iniciaron en los primeros días del mes de agosto del año 25 partiendo del punto denominado nacederos corregimiento de Pereira distante 4 kilómetros de esta ciudad y situado en la línea del ferrocarril de caldas entre la mencionada población y la de Cartago para poblado de dirección técnica del doctor Manuel M Mosquera ingeniero jefe del ferrocarril de caldas, tuvo como ingeniero ayudante al doctor Hernando Piedrahita hasta el 19 de enero de 1926 en cuyo periodo herencia la empresa el Señor Francisco Jaramillo Ochoa como gerente de Ferrocarril de caldas después y en virtud de nombramiento de hecho por el gobernador del departamento de caldas doctor Gerardo Arias Mejía se hizo cargo de la Administración Federal de esta ferrovía el doctor Eduardo Serna R. continuando la dirección técnica de la obra el mismo doctor Mosquera ayudado en sus labores por el doctor Francisco Londoño ingeniero de construcción y mediante contrato celebrado entre aquel Mosqueda y el doctor Sebastián Ospina y el desempeño por algún tiempo las funciones de director general de ferrocarriles y cables en el departamento de caldas durante el tiempo del contrato de construcción hecho con el citado otro Mosquera estuvo súper vigilada la obra por el doctor Eleuterio Serna G. ingeniero jefe del Ferrocarril de Caldas, y administrada por el señor Justiniano Londoño, quien reemplazó al doctor Eduardo Serna en los primeros días de octubre de 1926". 
Terminado el contrato con el doctor Mosquera, a mediados del mes de diciembre de 1927, los trabajos de construcción han seguido adelantándose en forma de administración, hasta el momento actual, bajo la dirección inmediata del mismo doctor Eleuterio Serna G., como ingeniero jefe, acompañado de los doctores Ernesto Ramírez y Rafael Botero, estos últimos como ingeniero de construcción el primero y de sostenimiento el segundo, de la parte construida y en explotación la cual se está haciendo informalmente de acuerdo con disposiciones del Ministerio de obras públicas y a exigencias de los habitantes de la región que atraviesa la línea ya que esta no ha sido entregada definitivamente al gobierno nacional, pues no ha sido posible balastarla convenientemente por escasez de tal material en el trayecto construido y además por carecer de los recursos pecuniarios indispensables para atender el gasto, no está por demás hacer constar aquí la conveniencia que resultaría para la estabilidad de seguridad de los 32 kilómetros construidos el gobierno nacional procediera a la mayor brevedad posible a contratar su balastada con el Ferrocarril de Caldas empresa está que posee actualmente, en los puntos denominados Las Peñas y Miralindo, situados aquel entre las estaciones de la capilla de Guayabito, y este, entre las estaciones de Villegas y la Marina, apreciables balasteras de las cuales podría tomarse la cantidad que se requiere para el efecto indicado. (Ver la continuación del informe en el Anexo $\mathrm{N}^{\circ} 8$ )

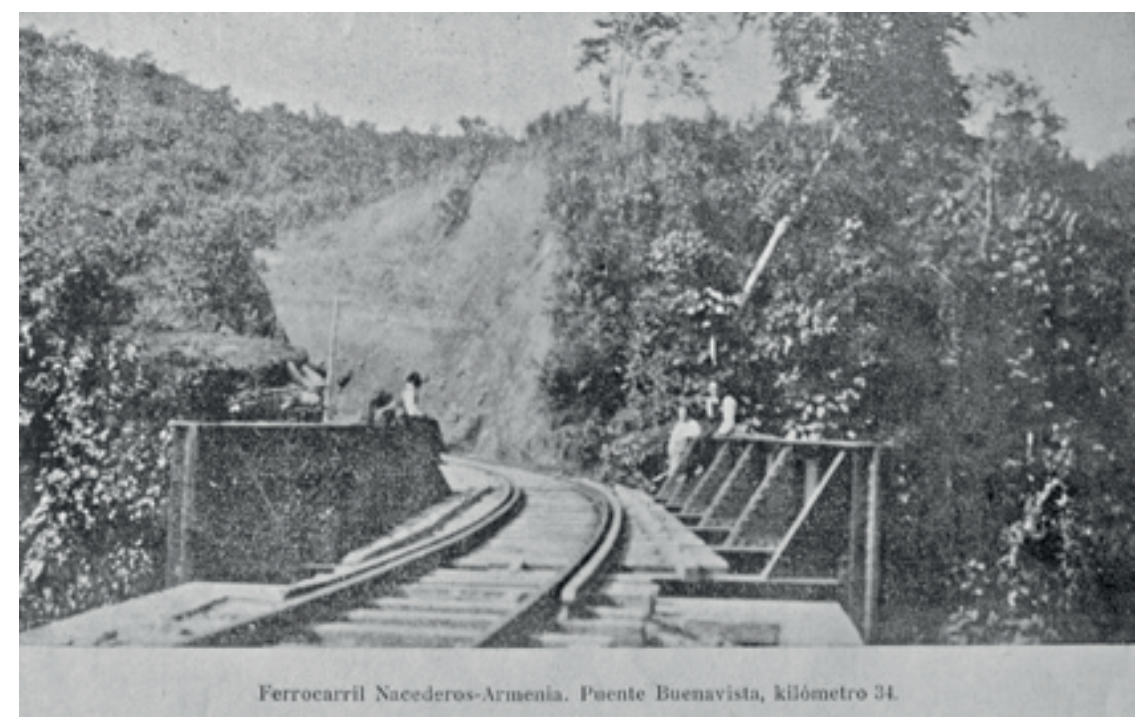

Figura 136. Puente sobre el río Buena Vista. Kilómetro 34

Fuente: Revista Cromos, 1929. 


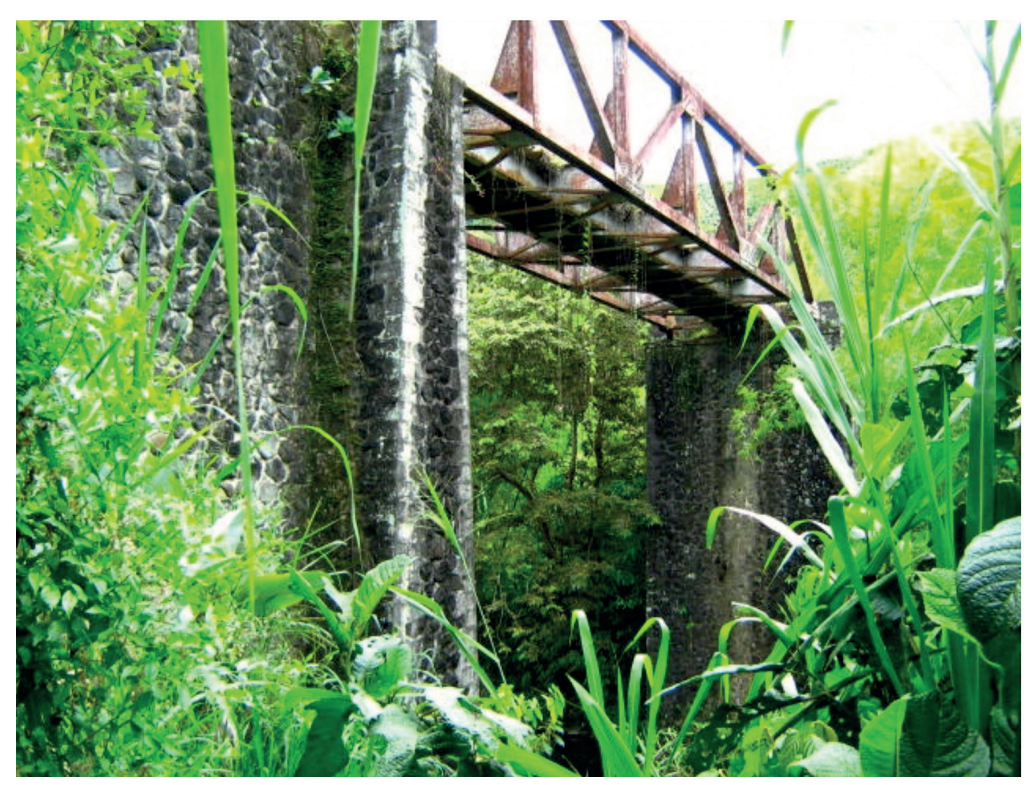

Figura 137. Puente sobre el río Espejo

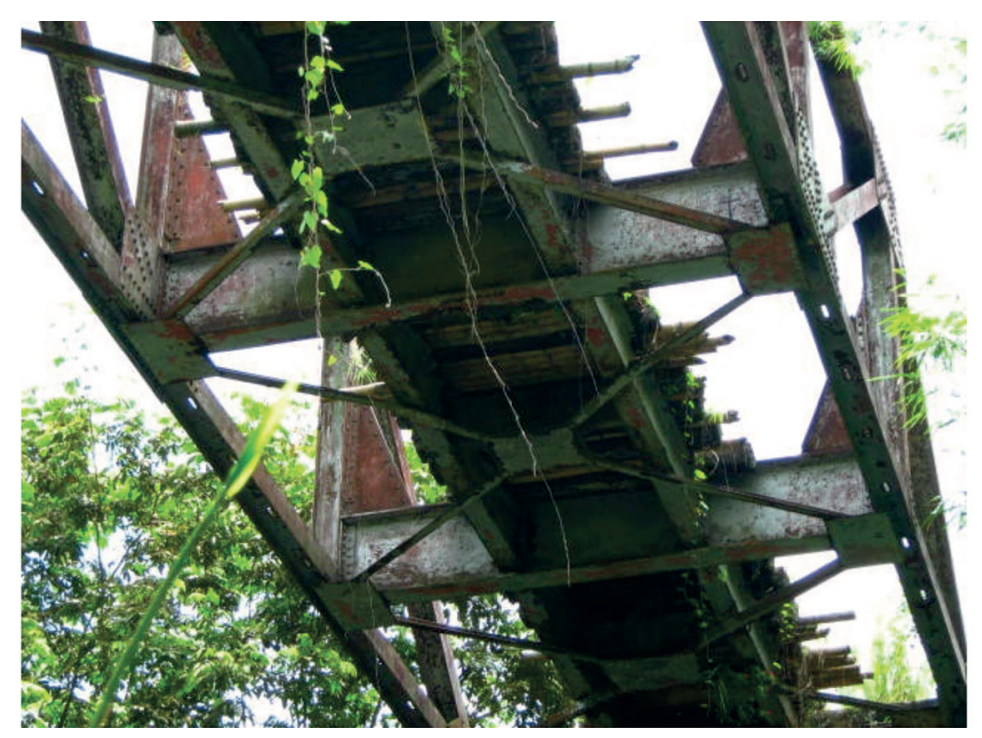

Figura 138. Puente sobre el río Espejo

Fuente: fotografía Esteban Romero (2015) 


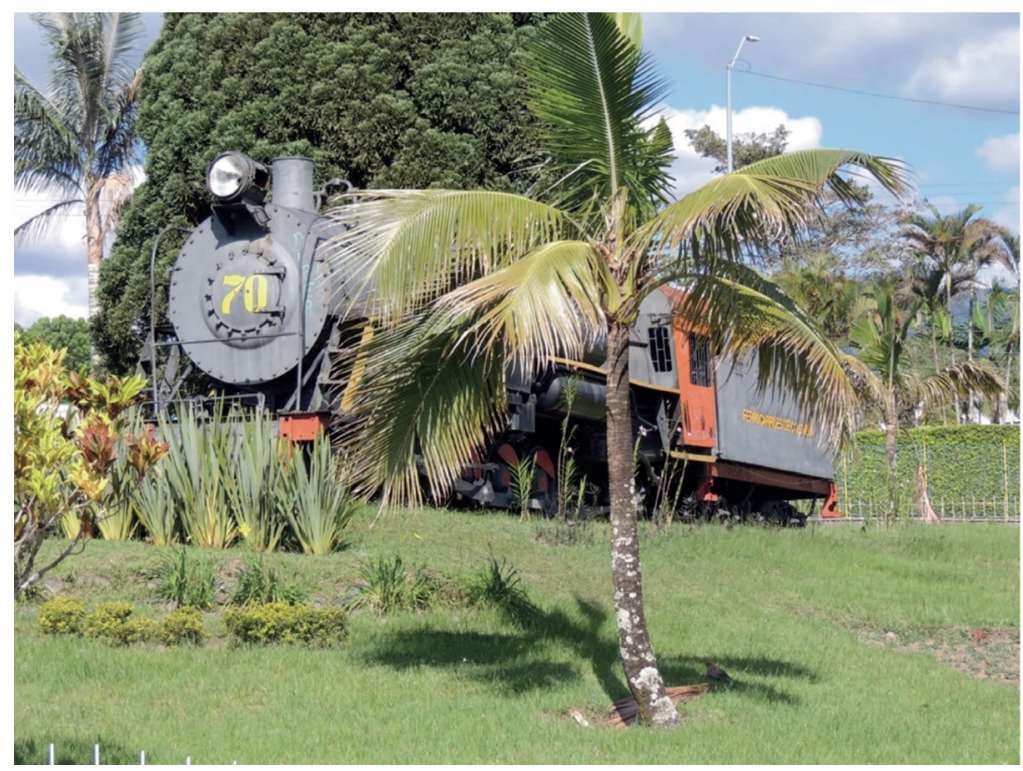

Figura 139. Locomotora en parque de Armenia

Fuente: fotografía Armando Ramírez Villegas (2018)

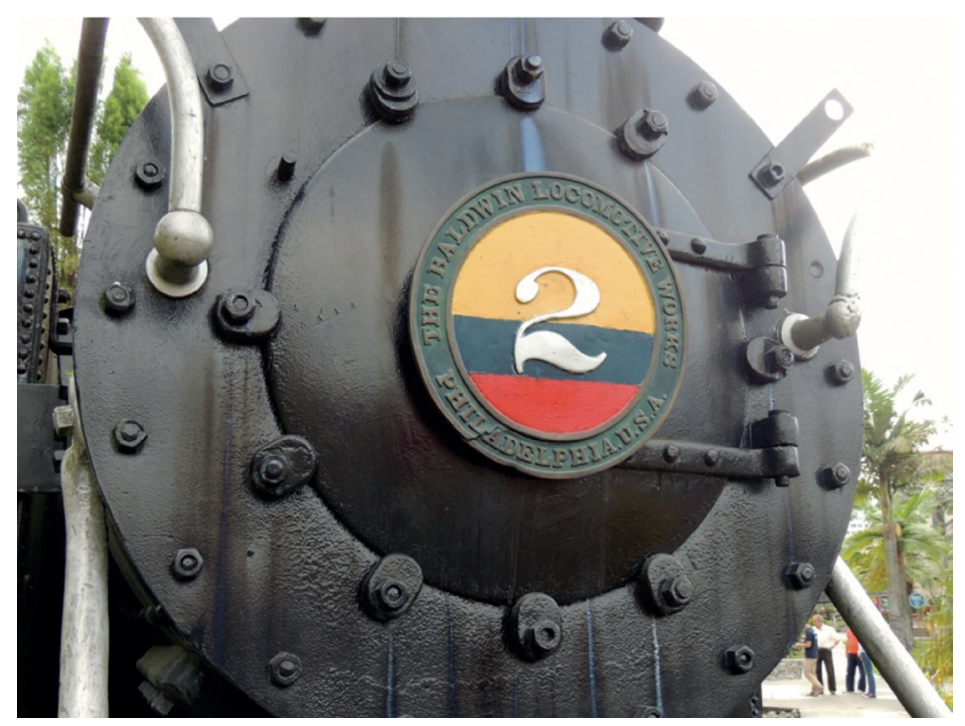

Figura 140. Locomotora Baldwuin $\mathrm{N}^{\circ} 2$ en Universidad Autónoma de Manizales Fuente: fotografía Armando Ramírez Villegas (2018) 

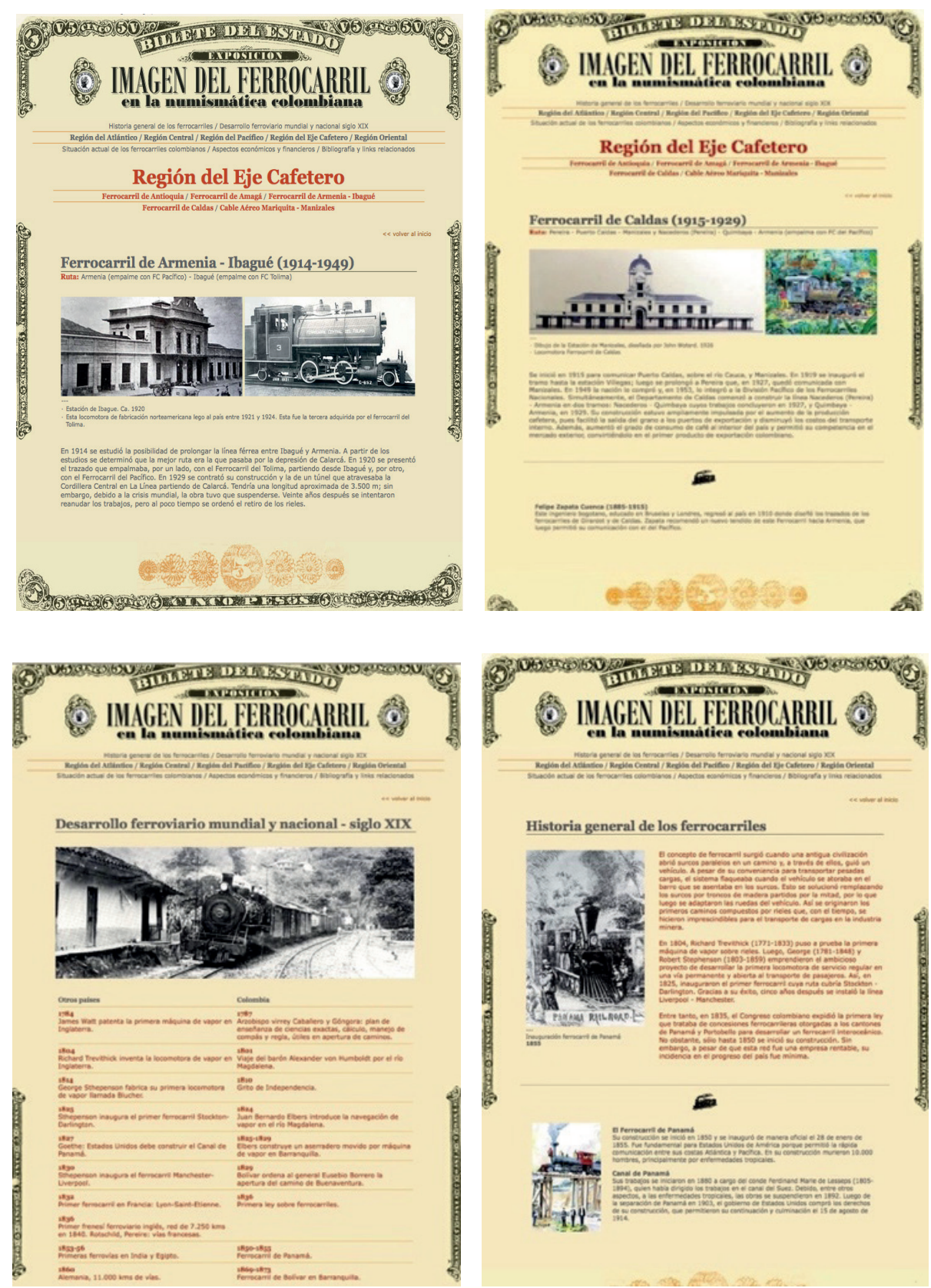

Figura 141. Billetes de Estado "Imagen del Ferrocarril" en la numismática colombiana

Fuente: fotografía Armando Ramírez Villegas (2018 


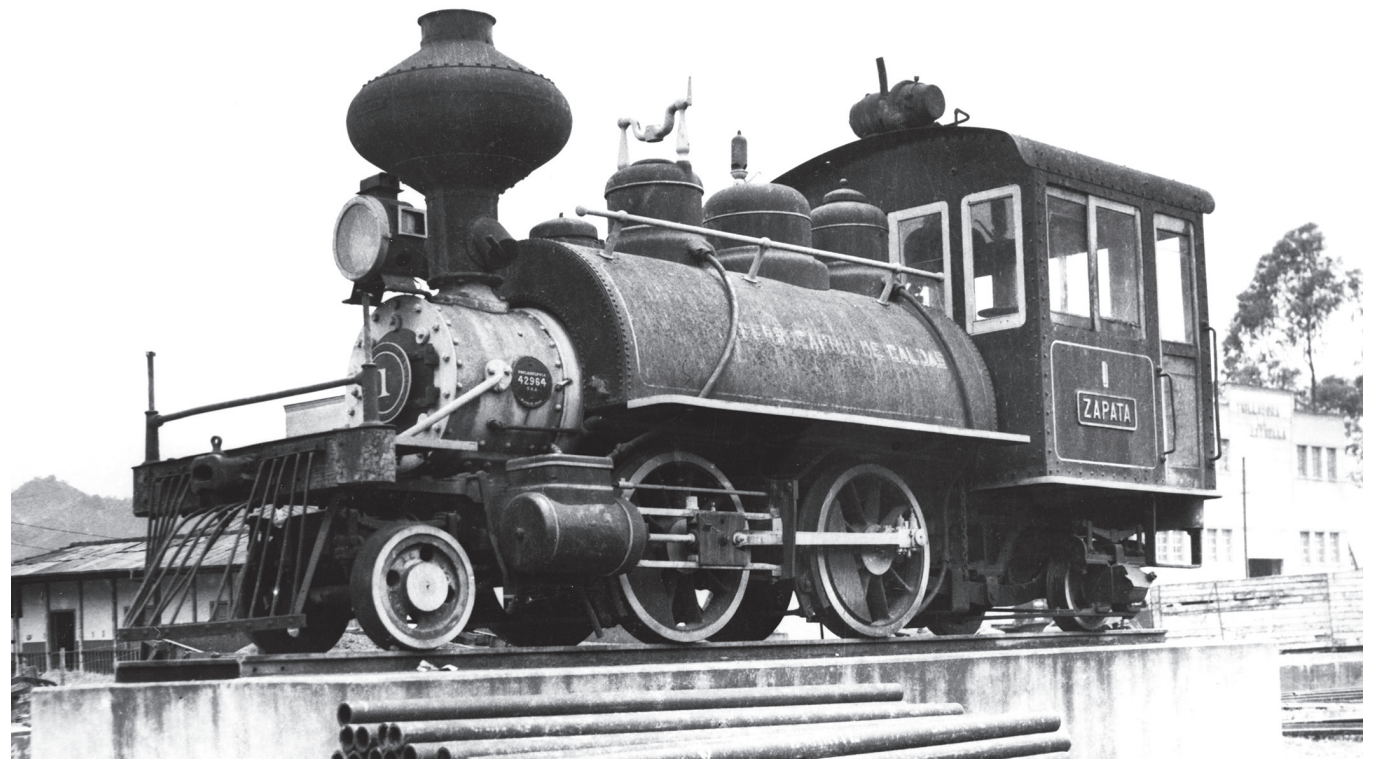

Figura 142. Locomotora La Zapata

Fuente: Fotografías antiguas de Manizales 


\section{CAPÍTULO VIII}

\section{Vida en el campo}

través de todo el recorrido de la investigación siempre apareció la inquietud
personal de cómo harían los ingenieros de esa época para establecer una
logística en los temas de la movilización, el abastecimiento, la alimentación, los
servicios médicos y sanitarios, para una población itinerante de mil o más personas.

Esta pregunta se quedó sin respuesta para el tiempo de la primera edición del informe, pero, como siguiera en forma permanente en el subconciente, de repente, y como suele suceder en los trabajos de investigación, cuando uno está buscando algo, aparece por sorpresa lo que uno no estaba buscando en ese momento pero lo estuvo buscando en forma insistente en otras oportunidades, es decir, una serendipia.

Así fue como, al solicitar un libro relacionado con el trazado de ferrocarriles en una de las bibliotecas consultadas, me encontré con un texto magnífico, que además de ser didáctico a la perfección, era práctico, realista y bien escrito. Se trataba del libro "Trazado de ferrocarriles y carreteras -1939" del ingeniero Florencio Mejía V., quién había trabajado en el Ferrocarril de Caldas, en los años 20, en el trazado de la línea férrea de Pereira hacia Manizales. De ese tratado he extractado el siguiente capítulo (Mejía, 1939, capítulo XII) que nos aclara cómo debía planearse la Vida en el campo.

\section{Transportes.}

"En nuestro incipiente país, despoblado y falto de vías, apenas por excepción puede contarse con un río navegable o con un a carretera paralela a los estudios que se intentan y que sirva como medio de transporte para hombres y equipo. Por regla general solo se encuentran, cuando más, algunos caminos de herradura más o menos alejados del trazado, y se está por lo tanto obligado a hacer grandes distancias a pie, lo que fatiga excesivamente el personal y disminuye mucho su rendimiento. Es de la mayor importancia, desde el reconocimiento, estudiar todos los caminos y sendas existentes en los alrededores del trazado, así como las casas y sitios para campamentos, con el fin de formarse el 
plan de movilización y vivienda en las mejores condiciones que sea posible.

En general los transportes se harán a lomo de mula, y posiblemente, en algunas regiones muy salvajes se harán a la espalda de cargueros o portadores. En este caso hay que aumentar el personal corriente con algunos hombres que abran poco a poco una senda practicable para el personal del trazado, y para hacer los trasteos periódicos hacia adelante.

Para el personal superior. ingenieros y aún cadeneros, deben conseguirse mulas fuertes, jóvenes y mansas. Recuérdese que los ingenieros no son amansadores y que una caida, una patada. o un accidente semejante, reviste en la montaña caracteres particularmente graves.

El cuidado de las mulas, tanto las de silla como las de carga, debe confiarse a un arriero diligente y experimentado que les dé de comer $y$ de beber oportunamente; que pueda herrarlas, que sea capaz de componer sus aparejos y de curar sus heridas; que sepa cargar $y$ descargar sin daño para ellas ni para la carga y que sepa conducirlas prudentemente sin golpes ni maltrato; que las bañe con frecuencia, etc., etc. Las mulas son auxiliares poderosos que trabajan como esclavos $y$ merecen por lo menos buen trato, descanso y alimentos, si se quiere que den buen rendimiento. Una pequeña ración de maíz y de panela que se les dé todas las tardes, complementa muy bien su alimentación, especialmente donde los potreros estén en malas condiciones. Es indispensable que tengan agua abundante para beber en todo tiempo.

En caminos buenos de piso firme y pendientes poco pronunciadas pueden admitir cargas de 100 a 140 kilos; en caminos malos carga proporcionalmente menor.

Cuando no es posible utilizar mulas para el transporte, no queda otro camino que transportar a la espalda, operación extraordinariamente lenta y penosa exige el concurso de todo el personal que hace perder uno o dos dias de trazado. Cuando haya de ocurrir esta condición conviene estudiar muy atentamente el equipo a fin de reducir los términos de lo estrictamente indispensable en cuanto a peso y dimensiones. Existe la tendencia a dejar los instrumentos en el campo, lo que debe evitarse en absoluto en cuanto a los instrumentos de precisión. Podrían dejarse trípodes, jalones y miras, recostados a un árbol grande, pero en general es preferible llevarlos a la casa todas las tardes. 


\section{Alojamiento}

Se procurará conseguir el mejor alojamiento posible para la cuadrilla, en lugares altos y ventilados provistos de agua potable. Siempre que sea posible conseguir una casa, es preferible hacerlo, porque asi se encuentran comodidades que no se encuentran en las tiendas de campaña o toldas. Pero en lugares despoblados no hay más remedio que apelar a ellas. Los lugares de emplazamiento de los campamentos deben estar situados a $6 \mathrm{u} 8 \mathrm{~km}$ de distancia entre sí para no hacer necesarios viajes extremadamente largos al lugar del trabajo. Una vez que este avance 3 o $4 \mathrm{~km}$ de un campamento hacia delante, se pasará este al nuevo emplazamiento. Las toldas serán erigidas correctamente en lugares secos, y se hará por el contorno de sus paredes una zanja para recoger las aguas y mantener seco el recinto. Es conveniente poder disponer de tablas o de un pedazo de lona fuerte para el piso.

Los muebles deben ser pocos, livianos y portátiles. Catres, mesas, sillas etc. etc. deben ser plegadizas para facilitar el transporte. Es conveniente darle cama a todo el personal para que su cuerpo fatigado pueda reposar convenientemente y encontrarse fresco a la mañana siguiente. Por lo demás, peones que después de un día completo de trabajo, llegan extenuados al campamento, a dormir sobre el suelo, no sólo no reciben el descanso conveniente, sino que están expuestos a contraer enfermedades que pueden ser evitadas a un costo insignificante. El ingeniero debe preocuparse no sólo por obtener el mayor rendimiento de su gente, sino también por tratarla con las consideraciones que debe a sus semejantes y colaboradores, sin cuyo concurso nada le sería posible hacer.

\section{Alimentación}

Debe procurarse una ración abundante y bien preparada para todo el personal. La ración para un peón antioqueño se compone de:

250 gramos de carne

400 gramos de maíz trillado

125 gramos de frisoles

62 y medio gramos de arroz

375 gramos de panela 
30 gramos de manteca

30 gramos de sal

1 pastilla de chocolate

Yucas, plátanos y papas de vez en cuando. Para los ingenieros puede ser usada esta misma ración, disminuida algún tanto, y agregar huevos, leche mantequilla, pan y frutas.

Con los elementos descritos anteriormente, un cocinero inteligente puede hacer comida muy agradable y nutritiva. La ración para peón, es la que se usa en Antioquia desde hace muchos años, y la experiencia ha probado que es ampliamente suficiente.

Además del cocinero, habrá un sirviente o sirvienta extra para aseo del campamento, para servir los alimentos, lavar y aplanchar las ropas y ayudar al cocinero. Los alimentos en crudo se confían al cuidado del garitero quien despachará o entregará diariamente lo que corresponde al consumo. Este trabajador estará además encargado de proveer de combustible y de llevar los alimentos preparados al campo.

\section{Higiene}

La observación de ciertas reglas higiénicas, trae como consecuencia la mayor parte de las veces, que sea posible evitar enfermedades y molestias más o menos graves y salir indemne de una larga correría por climas malos.

Debe usarse ropa holgada y de buena calidad y cantidad suficiente para poder cambiarla con frecuencia, especialmente cuando se humedece mucho. En clima cálido, al llegar del trabajo por la tarde, es conveniente tomar un baño corto y ponerse vestidos secos. Las botas deben ser de cuero fuerte, de la mejor calidad, y herradas con clavos de cabeza gruesa. Se deben usar polainas hasta las corvas para evitar golpes y heridas y aún las mordeduras de las culebras. Los pantalones son del modelo llamado breeches y se complementará el vestido con un saco de tela ligera o simplemente con una camisa fuerte, abierta y con bolsillos. En clima frío no es conveniente el baño por la tarde y la ropa, como es natural, será más abrigada. Donde 
haya mosquitos es indispensable el toldillo. En regiones palúdicas se tomarán todos los dias $30 \mathrm{cg}$ de sulfato de quinina y se procurará mantener el estómago corriente con el uso de laxantes o aun tomando un purgante de vez en cuando. Debe tenerse mucho cuidado con las aguas, especialmente en regiones pobladas en donde se sospeche que puedan estar contaminadas. El cocinero mantendrá una buena provisión de agua hervida y fría para el uso del campamento, de la cual se llevará además al campo en vasijas apropiadas. La fiebre tifoidea, la disentería y algunas otras enfermedades del aparato digestivo se contraen casi siempre por el uso de aguas contaminadas.

En nuestras tierras medias son abundantes las chinches, que producen la fiebre recurrente. Deben evitarse aunque para ello se haga necesario el cambio de alojamiento. Es bueno además, atomizar en las camas y en las habitaciones frecuentemente algún insecticida como Flit u otro semejante.

La comida debe ser moderada y a horas uniformes y se reposará algún tiempo después de cada una de ellas, antes de emprender alguna tarea. Debe evitarse el abuso de los licores, pero una pequeña cantidad de alcohol, en ciertas ocasiones quizás es más benéfica que nociva.

Al producirse una herida, deben tocarse los bordes con una muñeca de algodón mojada en tintura de yodo y taparse con un poco de gasa estéril y un pedazo de esparadrapo. Si la herida es de alguna importancia y ha interesado alguno o algunos vasos, deben buscarse los extremos y retorcerlos con unas pinzas mientras se forma el coagulo, o amarrarlos con cat-gut, habiendo hecho la desinfección previa con tintura de yodo. Puede ponerse uno o más puntos de sutura, poniendo en seguida gasa y un vendaje.

No es raro el caso en que se producen luxaciones ofracturas, y esto necesita personas esencialmente capacitada para reducirlas y vendarlas. Cuando la fractura es abierta es el caso más peligroso. Se esterilizará la herida y se cubrirá con gasa y un vendaje y se mandará el herido a la población más vecina o se hará venir rápidamente un médico si es posible. Una luxación no necesita por lo general otra cosa que poner los huesos en su lugar, estirando el miembro lastimado, colocar un vendaje e inmovilizar al paciente unos dias.

El accidente más grave que puede ocurrir en el campo es la mordedura de una culebra venenosa, accidente que exige una intervención pronta. A causa de que la difusión del veneno es bastante rápida, no sólo es inútil sino nocivo para el paciente la cauterización con hierro candente o con 
pólvora, la abertura amplia de las heridas o cualesquiera otra de estas barbaridades. A lo más, puede abrirse la herida un poco con un cuchillo, lavarla abundantemente y depositar en el fondo unos pocos cristales de permanganato de potasa. Pero el único tratamiento racional es inyectar cuanto antes alguna cantidad de suero anti venoso preparado con veneno de las mismas culebras de la región. El suero polivalente preparado con veneno de varias especies está particularmente indicado. El suelo debe ser fresco y su provisión debe renovarse de vez en cuando, a fin de asegurar su actividad.

Sería muy conveniente que todo ingeniero que esté a punto de emprender una correría de esta índole, se gaste algunos días con un médico amigo en conversaciones sobre estos puntos, para que se los enseñe con una mayor extensión, e inclusive que asista a una clínica quirúrgica para que aprenda por lo menos a curar una herida. La vida de uno cualquiera de sus hombres $y$ aún de si mismo puede depender de un detalle insignificante ejecutado a tiempo.

En el campo debe mantenerse permanentemente una cajita con lo siguiente:

1 jeringa hipodérmica de $5 \mathrm{~cm}^{3}$ con agujas de platino.

4 onzas de alcohol

1 onza de tintura de yodo

1 paquete de algodón

1 paquete de gasa.

2 vendajes

1 carrete de esparadrap

$1 / 2$ docena de imperdibles.

2 ampollas de morfina.

2 ampollas de suero antivenenoso

1 cuchillo

1 tijeras

2 pinzas hemostáticas.

2 pinzas diente de ratón.

1 aguja de Reverdin.

2 agujas curvas .

2 tubos cat.gut.

Además, en la casa de completarse el botiquín con lo siguiente:

6 frascos sal de frutas.

2 libras sulfato de soda.

2 onzas de permanganato de potasio.

8 onzas de tintura de yodo.

6 tubos cafiaspirina. 
6 tubos de plasmoquina.

2 tubos de eldoformo.

6 tubos de atebrina.

2 potes de mentolatum.

1 libra de aceite de ricino aromatizado.

1 irrigador de un litro con sus accesorios.

$1 / 4$ de mostaza pulverizada.

6 ampollas de morfina.

6 ampollas de aceite alcanforado.

24 ampollas de emetina.

12 ampollas de estricnina.

6 ampollas de quinoformo.

2 carretes de esparadrapo.

6 vendajes.

2 potes de antiflogistina.

6 paquetes de algodón.

6 paquetes de gasa.

2000 pildoras de quinina de 10 centigramos.

1 juego de pinzas dentales.

\section{Equipo}

El equipo que se describe enseguida es el equipo mínimo normal para una comisión de trazado que ha de operar en una región desierta en donde no puede contarse con habitaciones ya construidas para los campamentos.

En donde se pueda contar con ellas, puede suprimirse toldas y mobiliario.

Instrumentos y enseres de trazado

2 tránsitos con estadia.

2 niveles de horquillas.

2 cintas metálicas de veinte metros.

10 cintas de lienzo de veinte metros.

6 jalones.

4 miras telescópicas de cinco metros.

4 niveles Locke.

1 nivel Abney.

1 barómetro Aneroide.

1 brújula prismática.

6 piquetes.

3 plomadas.

2 escuadras para normales.

2 hachas de cuatro libras.

12 machetes de 22 pulgadas con sus cubiertas.

6 machetes de 14 pulgadas con sus cubiertas.

2 libras de puntillas para centro.

6 docenas de tiza de marcar.

2 docenas de carteras de tránsito.

2 docenas de carteras de nivel.

2 docenas de carteras de topografia. 


\section{Útiles de dibujo}

1 caja de compases

3 escalas.

1 regla metálica de un metro.

6 escuadras de xilonita surtidas.

1 transprtador.

6 frascos de tinta china negra, siena, roja, azul y verde.

2 frascos de tinta ordinaria.

3 docenas de lápices $2 \mathrm{H}$

2 docenas de lápices $3 H$

$1 / 2$ docena de lápices $4 H$.

1 tajalápices.

2 aguzaminas de papel de lija.

2 docenas de borradores blandos.

$1 / 2$ docena de borradores medios.

$1 / 2$ docena de borradores duros.

25 metros de papel cuadriculado.

25 metros de papel blanco para dibujo.

1 juego de curvas transparentes.

$1 / 4$ de metro cuadrado de película para curvas.

Papel y sobres.

Papel ordinario para cuentas.

Plumas para dibujo y plumas corrientes.

2 libretas para cuentas.

1 libro de caja.

1 libro mayor.

1 ejemplar de tablas de logaritmos.

1 ejemplar de tablas taquimétricas.

1 ejemplar de tablas trasversas.

1 máquina calculadora.

1 máquina de escribir portátil.

1 calculador Cox para stadia.

2 ovillos de cáñamo.

1 caja de chinches.

4 tubos de hojalata para planos.

\section{Menaje}

4 toldas de 4.20 por 5.20. metros con sobretolda.

2 toldas de 4.0 por 5.20 metros simple para cocina y salón de dibujo.

6 asientos plegadizos.

24 catres plegadizos.

1 mesa de dibujo.

3 mesas corrientes.

3 lámparas de gasolina Coleman.

4 lámparas de petróleo Dietz Víctor.

1 docena de camisetas,

1 docena de quemadores.

1 docena de mechas para lámparas de petróleo.

6 candeleros.

6 docenas de bujías esteáricas (no de parafina). 
2 docenas de cucharas.

1 docena de cuchillos.

1 docena de tenedores.

1 docena de cucharitas.

1 romana.

1 reloj despertador.

1 cucharon.

1 espumadora.

2 docenas de platos hondos esmaltados.

2 docenas de platos pandos esmaltados.

$1 / 2$ docena de platos chicos esmaltados.

2 docenas de tazas grandes esmaltadas.

1 docena de pocillos para café.

$1 / 2$ docena de vasos de vidrio grueso.

1 filtro Delfin de bugía.

1 juego de 6 ollas.

1 juego de cuarto bandejas.

1 sopera.

2 sartenes.

1 callana.

6 totumas.

2 bateas.

2 cuchillos de cocina.

2 chocolateras.

1 cafetera.

1 azucarera.

1 lechera.

1 salero.

1 plancha para ropa.

3 manteles.

12 servilletas.

6 trapos para cocina.

1 martillo de carpintero.

2 regatones.

2 palas.

1 barra.

1 piedras de afilar.

3 libras de clavos de 2".

3 libras de clavos de 3".

1 serrucho.

3 barrenos surtidos.

\section{Elementos de transporte}

6 mulas de silla.

6 avios completos.

4 mulas de carga.

10 enjalmas con sus aparejos.

12 sacos de empaque.

1 avio de herrar

2 libras de cabuya en rama". 


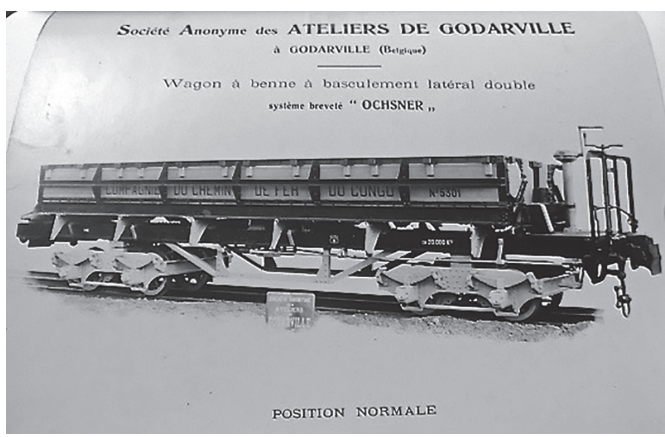

Figura 143. Vagones basculantes "Oshner”, de Godarville, Bélgica. Posición normal

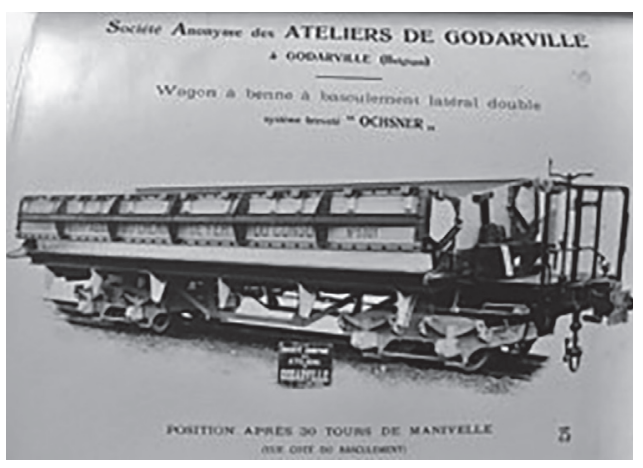

Figura 144. Vagones basculantes “Oshner”, de Godarville, Bélgica. Posición después de 30 vueltas de manivela

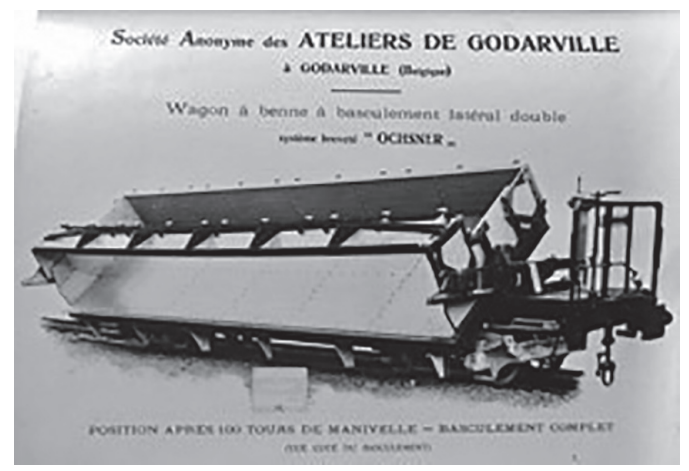

Figura 145. Vagones basculantes "Oshner", de Godarville, Bélgica. Posición después de 100 vueltas de manivela.

Fuente: Archivo General de la Nación, Ferrocarril de Caldas, 1919. 


\section{Capítulo IX}

\section{El Personaje del Ferrocarril}

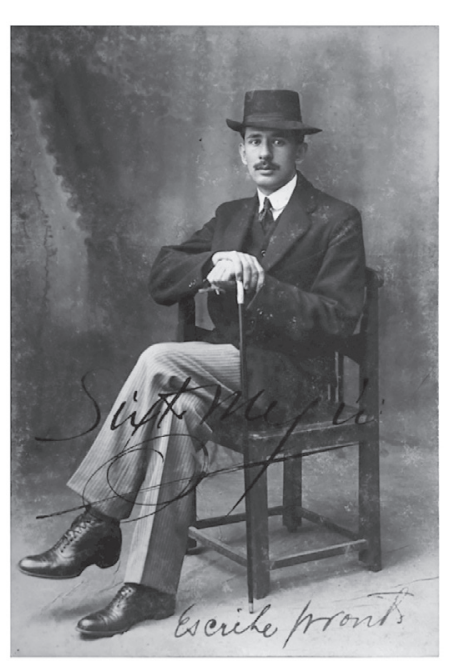

Figura 146. Retrato Manuel Felipe Calle con dedicatoria a su amigo el Dr. Sixto Mejía

Fuente: Archivo familiar de Armando Ramírez Villegas.

Fotografía tomada por Manuel $\mathrm{H}$. Rodríguez
Onsciente de la dificultad que representa tratar de valorar las actuaciones de las personas y el peligro inmenso de sobre apreciar un comportamiento o desconocer la gracia y el esfuerzo que representa otro, me atrevo a lanzar mi opinión sobre quién fuera la persona más importante dentro de la construcción del Ferrocarril de Caldas. Muchos fueron los personajes que actuaron dentro de la ardua y titánica labor que representó llevar un ferrocarril hasta las alturas de Manizales. Algunos desde sus posiciones dentro de los fueros de gobernantes, otros con la destreza y el conocimiento de sus profesiones: ingenieros, contadores, abogados o dirigentes. Gobernadores, como don Ramón Jaramillo R., inculcador de la idea, o el médico y político Emilio Robledo defensor de la misma ante la Asamblea, o el doctor José Ignacio Villegas, iniciador e impulsor de los trabajos, o el general Pompilio Gutiérrez, quien trasladara su despacho a Pereira para dirigir e impulsar personalmente los trabajos, o el doctor Gerardo Arias Mejía protagonista en la guerra de las traviesas como defensor del Ferrocarril de

Caldas, o el doctor Daniel Gutiérrez y Arango, que tuvo la oportunidad de aparecer en la iniciación de los trabajos como simple testigo y en su alegre culminación como Gobernador de Caldas, cualquiera de ellos, podría considerarse como el personaje más importante.

Pero el hecho de que sus actuaciones estén ligadas al desempeño de una Gobernación y limitadas en el tiempo a los periodos de gobierno, podría poner en entredicho los méritos personales y considerarlos como actuaciones propias de su cargo. Lo mismo podría decirse de los secretarios de hacienda o los superintendentes. Los economistas, en ese tiempo, hábiles comerciantes que sabían dónde ponen las garzas, y que con esa habilidad innata, propia de la raza, no se amilanaban frente 
a las grandes crisis económicas provocadas por la falta de recursos en las fuentes del Estado, como consecuencia de las grandes conflagraciones mundiales o por los frecuentes y repetidos enfrentamientos políticos de nuestra nación o por nuestro propio desorden. Siempre encontraban la forma de pagar la planilla semanal de 500 o 600 trabajadores y los sueldos de ingenieros y empleados sin incumplir sus compromisos con las empresas proveedoras del material rodante y de todas las arandelas que los acompañan. También podrían estar en la baraja, los ingenieros, verdaderos héroes de la jornada. Los que, literalmente, estaban metidos en el barro; los que tenían que afrontar las inclemencias del clima, en sus cuerpos o en sus obras; los que soportaban estoicamente las incomodidades de su diario vivir durmiendo en improvisados campamentos y aceptando su alimentación transportada por gariteros, en fríos portacomidas, hasta el frente de trabajo; los que tenían la responsabilidad de adelantar las obras, fuera como fuera, hasta su destino final. Fácilmente podríamos encontrar por allí a nuestro héroe. O los trabajadores rasos, que con su fuerza bruta, y al sol y al agua, constituían las máquinas de la obra, empujando las pesadas carretas con material, o rompiendo con la pica la dura roca, o moviendo con sus palas la tierra atravesada. Cualquiera de ellos tendría méritos suficientes para constituirse en el personaje del ferrocarril de Caldas.

Sin embargo, hubo un señor, qué sin muchos títulos académicos, aparece por doquier, desde los primeros años de la obra hasta su culminación feliz en Manizales; en puestos de alta responsabilidad y mando, dirigiendo, ordenando, opinando, dando luces sobre todo lo humano y lo divino, siempre con profundo amor a la obra, inteligencia y sabiduría. Se trata de don Manuel Felipe Calle, oriundo de Abejorral, ese extraño pueblo antioqueño, en donde el conocimiento y la cultura, parece que llegasen envasados en teteros y en donde tuvo oportunidad de ser concejal y alcalde de su pueblo, para pasar luego a la carrera militar hasta llegar a ser comandante de la policía de Antioquia. La corriente de la colonización paisa lo arrastró hasta Manizales, en donde tuvo oportunidad de mostrar todas sus destrezas y habilidades ocupando diferentes cargos. Casi desde el inicio del Ferrocarril de Caldas, en 1918, aparece como miembro de su Junta Directiva; pero no como cualquier miembro; su asistencia permanente a las reuniones, que se sucedían hasta tres veces por semana, y su oportuna y productiva participación, por espacio de seis años, lo clasifican como el campeón de los aportes y del entusiasmo para la soñada obra. Así lo atestiguan las actas de las juntas que lograron sobrevivir a incendios, trasteos y desorden de los archivos oficiales. En 1922 asume la superintendencia de la obra, que representa una gerencia general con mando en lo administrativo y en lo técnico, hasta diciembre de 1924, cuando, en solidaridad con los ingenieros a su cargo, que se retiraban por una desafortunada e injusta intervención de la Junta en contra de ellos, en momentos difíciles vividos durante la construcción del ascenso a Boquerón, presenta su renuncia irrevocable. Gran dolor y frustración debió haberle causado el desacierto de esa Junta en que tantas veces tuvo la oportunidad de dirimir conflictos con la altura y decencia de un verdadero caballero. En el libro El Ferrocarril de Caldas, 
Néstor Echeverri (1927) relata:

"venía sirviendo a la empresa con la mayor honorabilidad y con la mayor eficacia desde el año 1918. Dejó el señor Calle en esa empresa obras perdurables que proclaman su esfuerzo y que recomiendan su nombre a la gratitud de los caldenses. A pesar de vicisitudes que ha sufrido la empresa y a pesar de trastornos que han sobrevenido en posteriores épocas, no han desaparecido normas de organización implantadas por la inteligencia del señor Calle, espíritu ordenado como pocos y habilidad que no es posible discutir". (Echeverri, 1927)

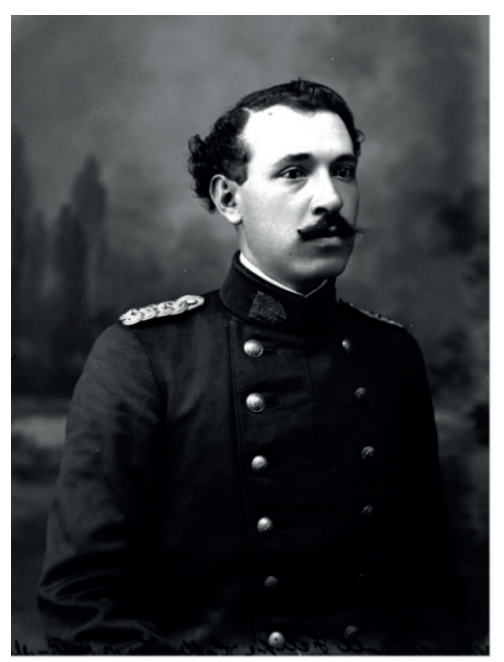

Figura 147. Manuel Felipe Calle G. Comandante de la Policía de Antioquia

Fuente: Archivo familiar de Armando Ramírez Villegas.

Fotografía tomada por Manuel H. Rodríguez (1915). 
Armando Ramírez Villegas

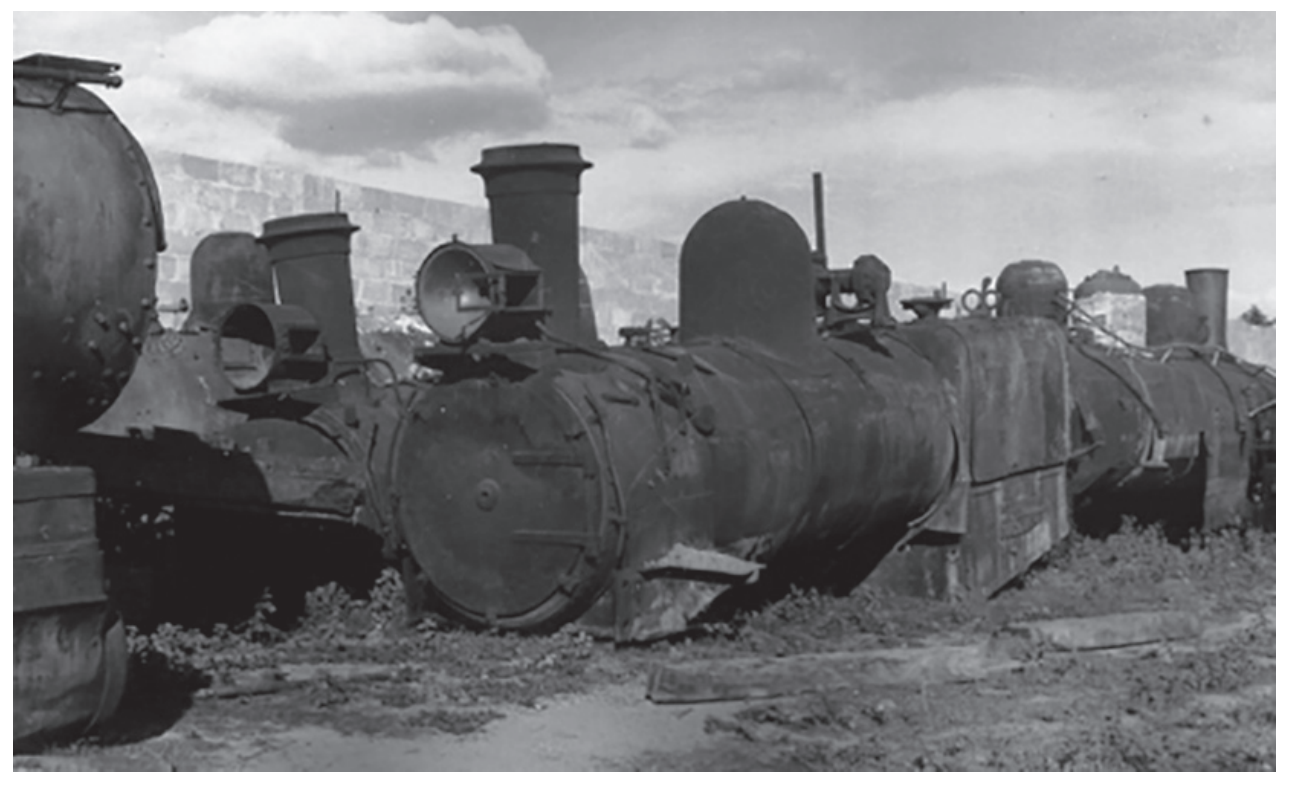

Figura 148. Locomotora chatarra

Fuente: foto del archivo personal de Pedro Felipe Hoyos K. 


\section{CAPÍTULO X}

\section{¿Por qué se acabó el ferrocarril?}

- sta pregunta es omnipresente en todas las conversaciones sobre el tema, que

Cinunda las redes sociales, y para la cual no hay una respuesta única y simple. Como en todos los desastres, la causa es una conjunción de motivos cuya sumatoria conduce, irremediablemente, a su ocurrencia. Así como en un accidente aéreo, en una bancarrota o en una ruptura de sociedades, para citar algunos ejemplos, no actúa una única razón sino una suma de sucesos que superan lo esperado, lo razonable o lo deseado, así sucedió en el Ferrocarril de Caldas.

Tendríamos que empezar por las razones puramente técnicas. Un ferrocarril a vapor, con pendientes superiores a un dos por ciento, con radios de curvaturas menores de 90 metros, con un ancho de trocha (la separación entre los rieles) de menos de un metro, no ofrece las cualidades para un transporte rápido y eficiente de grandes mercancías a grandes distancias, que es el secreto del éxito de los ferrocarriles, en su lucha tenaz con los otros medios de transporte. El Ferrocarril de Caldas era un ferrocarril de montaña con todas las limitaciones que eso implica. Su trazado y su construcción fueron forzados a ajustarse a una topografía agreste y despiadada, a la cual solo podían vulnerar con pequeños pellizcos, logrados con los rudimentarios medios con que se contaba en esos tiempos.

Unos pocos túneles que nos asombran hoy en día, más por haber sido construidos con las uñas que por su longitud, no representan mayor mejora en las características de toda la vía. A los que nos tocó disfrutar de su funcionamiento, aún recordamos la angustia que nos causaba escuchar el sonido de las ruedas de la pobre locomotora, tratando de ascender lentamente la falda de La Popa, patinando sobre los rieles que parecían aceitados, con su chirrido estridente y con las bocanadas de humo negro que afloraba por su chimenea. Una muestra clara de la dificultad con que el ferrocarril trataba de satisfacer el oficio que se le había asignado. No se le podía exigir más. El tren que llegaba de Cartago a Pereira, estaba compuesto, casi siempre, de su locomotora y diez a doce vagones, repartidos entre seis de carga y seis de pasajeros, dependiendo de la demanda de unos u otros. Pero para iniciar el recorrido hacia Manizales era preciso dejar en esta ciudad por lo menos la mitad de los de carga, lo cual implicaba duplicar el número de viajes, es decir disponer de una locomotora adicional para terminar de subir la carga, circunstancia esta totalmente 
antieconómica. Todo lo anterior es consecuencia de las especificaciones del trazado referentes a las pendientes máximas y a los radios de las curvas. ¡Nada qué hacer; así se hizo y cambiarlo implicaba empezar de nuevo! Por otra parte, estaban los problemas administrativos. El Ferrocarril de Caldas era una entidad oficial de orden departamental, con todas las limitaciones y dificultades que esta condición representa para la operación eficiente, en términos económicos, de una empresa de transporte; pero, además, su desgreño administrativo en el manejo de las diferentes actividades, por su desconocimiento y falta de experiencia, la llevó al límite de la ineficiencia. Los distintos informes revelan las deficiencias en su contabilidad, con vacíos graves en el control de inventarios y en la valoración de los mismos; en el manejo de los talleres y la consecución de repuestos; en las importaciones de nuevo material rodante que no daban abasto para la suplencia del ya obsoleto; en fin, por donde se mirase, la empresa estaba en grandes dificultades.

La dirigencia caldense, que había logrado su propósito fundamental de dotar a Manizales con un medio de transporte que la sacara de su cautiverio, era consciente del problema que tenía entre manos, y a solo cuatro meses de haber celebrado con bombos y platillos la llegada del primer tren, no encontró otra medida más apropiada que ofrecer el Ferrocarril de Caldas al Gobierno Nacional.

Así se revela en la Ordenanza 22 del 14 de abril de 1928 que a la letra dice: "La Asamblea de Caldas, ordena: "Artículo 1. Autorizase al gobernador para que venda a la Nación la empresa del Ferrocarril de Caldas. Artículo 2. El gobernador hará las gestiones necesarias para que el Congreso nacional expida la ley que autoriza esta negociación y una vez expedida pondrá todo su empeño en llevar a cabo la venta. Artículo 3. El contrato que celebre el gobernador, necesita para su validez, la aprobación de la Asamblea Departamental.

Dada en Manizales, a 13 de abril de 1928.

El Presidente, Bernardo A. Ramírez

El Secretario, Enrique Cordobés”.

El gobernador era Daniel Gutiérrez Arango, el mismo que había estado presente, en su calidad de Presidente de la Junta del Ferrocarril de Caldas, en la inauguración de los trabajos en Puerto Caldas un 15 de julio de 1915, y el mismo al que le había 
tocado la inauguración de la llegada del Ferrocarril a Manizales. Ahora tenía la orden perentoria de poner todo su empeño en llevar a cabo su venta. ¡Vueltas que da la vida! Pero las cosas no marcharon tan apresuradamente como la Asamblea lo proponía. No era de esperar que una persona completamente comprometida con la construcción del ferrocarril como lo era Daniel Gutiérrez Arango, compañero de luchas y sinsabores, viniese ahora, a entregar el sueño de su vida, que tanto le había costado, cuando era la oportunidad de recuperar tanta inversión y gozar las mieles del triunfo. Valía la pena esperar un poco, tratar de encarrilar el funcionamiento de la empresa y sacarla del atolladero, como tantas veces le había tocado en el transcurso de obra.

Así fue; la Empresa, liberada de la carga económica que representaban los trabajos de construcción y dedicada únicamente al mantenimiento de su vía y a organizar el funcionamiento y mejoramiento del servicio, logró aliviar su situación económica y dar cumplimiento a las obligaciones financieras adquiridas para la culminación de los trabajos de construcción. Le acompañó en esta labor, el crecimiento de la producción cafetera y su transporte al puerto de exportación que le representó ingresos suficientes como para disfrutar de cierta holgura financiera. Hay que recordar que en ese tiempo las exportaciones de café representaban el 75 por ciento de los ingresos del país. Pero, pronto aparecieron los negros nubarrones de la gran depresión económica de los años 29 y 30, que azotara al mundo entero y a los cuales no pudo escapar la Empresa del Ferrocarril de Caldas. Fueron años difíciles; sin embargo, una vez más, logró sobrevivir para entrar luego en su periodo de mayor bonanza económica durante los años 43 a 45. Desafortunadamente, de nuevo, los desaciertos administrativos y la complejidad del manejo de una empresa de transporte que había crecido en una forma acelerada y desorganizada, dieron al traste con los éxitos alcanzados y la empresa se vio envuelta en un torbellino sin salida que obligó a la dirigencia caldense a buscar definitivamente, y a toda costa, la entrega de la joya de la corona, al gobierno nacional.

En 1948, la Ley 110 autorizó a la Nación para comprar al Departamento de Caldas su ferrocarril, que ya le generaba pérdidas al Departamento por la competencia de las carreteras. La ferrovía fue entregada para su operación, primero, al Ferrocarril del Pacífico y después, en 1951, fue asumida, como todos los ferrocarriles de la Nación, por el Consejo Nacional de Ferrocarriles. (Poveda, 2003)

Menciona el profesor Poveda, de soslayo, una sola causa: la competencia de las carreteras. Y fue ésta, en verdad, la principal causa. La construcción de las carreteras que unieron a las tres ciudades principales del antiguo Caldas, y a su vez, a estas con 
el resto del país y con el puerto de Buenaventura, abrieron la puerta para la entrada de la tractomula, transporte más versátil, más rápido y más cómodo, por el hecho de ser puerta a puerta, que atrajo la preferencia de los industriales y exportadores.

Se aduce con insistencia que el ferrocarril es un medio de transporte mejor y más económico que el transporte por carretera, lo cual es cierto, pero para grandes distancias y grandes volúmenes de carga. Se nos olvida que el Ferrocarril de Caldas era un ferrocarril de montaña, con ciertos pecados en sus especificaciones, como se mencionó antes, lo cual lo limitaba para alcanzar siquiera uno de los dos requerimientos. ¡Y qué decir de la llegada de los contenedores, y del transporte de pasajeros en lujosos buses que compiten en comodidad y precio aún con el transporte aéreo? Todo se confabuló para acabar con la viabilidad del tren de Caldas. Pero es oportuno mencionar, además, el efecto que produjo su entrega al Ferrocarril del Pacífico. Diría que fue salir de Guatemala para caer en Guatepeor. La ferrovía del Pacífico se convirtió en la red de mayor extensión en el país al incluir el ferrocarril del Cauca y ahora el de Caldas. Pero si nos atenemos a los informes sobre la carencia de material rodante para atender su propia red, y a la desorganización manifestada por usuarios y transportadores, la situación era bastante complicada.

El movimiento de trenes en la zona del antiguo Caldas fue menguando en la medida que pasaban los años hasta tal punto que en los años cincuenta el movimiento de pasajeros y carga estaba reducida a su mínima expresión, con el agravante de su incumplimiento permanente en la atención de los horarios programados. El Ferrocarril de Caldas, ahora del Pacífico y pronto de los Ferrocarriles Nacionales, cayó en ese remolino tenebroso que llevó, prácticamente, a la desaparición de todos los ferrocarriles en Colombia. Los repetidos intentos para recuperarlos con cambios de nombres y organización, han fracasado, y hoy en día son contados en los dedos de las manos los que subsisten. El cuento de que el final del Ferrocarril de Caldas se debió a que una turba enardecida en la ciudad de Pereira, el día 4 de mayo de 1959, con el beneplácito del ministro de Obras Públicas Virgilio Barco, había arrancado los rieles en la ciudad porque estos entorpecían el desarrollo de la ciudad, no es más que eso: un cuento, simplista y mal contado. Ese episodio sucedió; pero, no fue ninguna turba enardecida que arrancara todos los rieles en la ciudad, sino una iniciativa, más como un acto simbólico de protesta que una interrupción definitiva (fue un solo riel), de un grupo de dirigentes de la ciudad que hacía varios años venía solicitando al gobierno, ahora nacional, que se construyera una variante para la red férrea que en ese entonces atravesaba la ciudad, con más de 50 cruces de calles a nivel, sin medidas de precaución ni avisos de atención, en los cuales se sucedían frecuentemente choques del ferrocarril con automóviles y 
buses, muchos de ellos con víctimas humanas o pérdidas materiales cuantiosas. La variante propuesta por el Municipio de Pereira y diseñada por el ingeniero Alfonso Hurtado Sarria, se iniciaba en el Puente de la Máquina, en la carrera 1a. con calle 3, avanzaba por donde hoy en día está la Avenida del Río hasta llegar a la zona de Turín, en donde empalmaba nuevamente con la ferrovía hacia Cartago. A pesar de las numerosas solicitudes presentadas al gobierno y de varios viajes a Bogotá, la variante solicitada no se ejecutaba. Un grupo de personas conformado, no solo por políticos sino por industriales, profesionales y gente del común, identificados todos por su civismo y amor a la ciudad, a raíz de un nuevo accidente presentado en sus calles, decidieron, hacer una manifestación pacífica de protesta al gobierno nacional. En ningún momento la acción estuvo dirigida contra los manizaleños o contra el gobierno caldense y mucho menos contra el ferrocarril, que siempre fue considerado como un medio de transporte importante para el desarrollo de la ciudad.

Desafortunadamente, en ese momento histórico, el palo no estaba para cucharas y algunos dirigentes caldenses la tomaron como si fuera contra ellos, apostándole a la mala idea de convocar al pueblo a un paro general, que no hizo otra cosa que exacerbar los ánimos y causar daños materiales innecesarios. Es de anotar que la línea férrea interrumpida fue la de Pereira a Manizales; la vía a Cartago, y la conexión Nacederos a Armenia, siguió funcionando varios años más. Sin embargo, como se mencionó antes, la disminución de la demanda y la desorganización administrativa dieron al traste con su operación. Como anécdota, debo recordar dos hechos, que dan testimonio de las últimas operaciones del Ferrocarril del Pacífico: el Bolívar de Arenas Betancourt, que adorna la plaza principal de la ciudad de Pereira, fue transportado en 1963, desde el puerto de Buenaventura hasta esta ciudad, en el ferrocarril; y en el año de 1968, se celebró en la ciudad el Congreso Nacional de Ingeniería y una de sus actividades principales consistió en una visita, organizada por los Ferrocarriles Nacionales, transportando los ingenieros en el tren, a la hidroeléctrica de la Esmeralda, siguiendo la vía a Cartago, La Virginia, Arauca. Fue este, quizás, el último tren que circuló por esa ruta. 


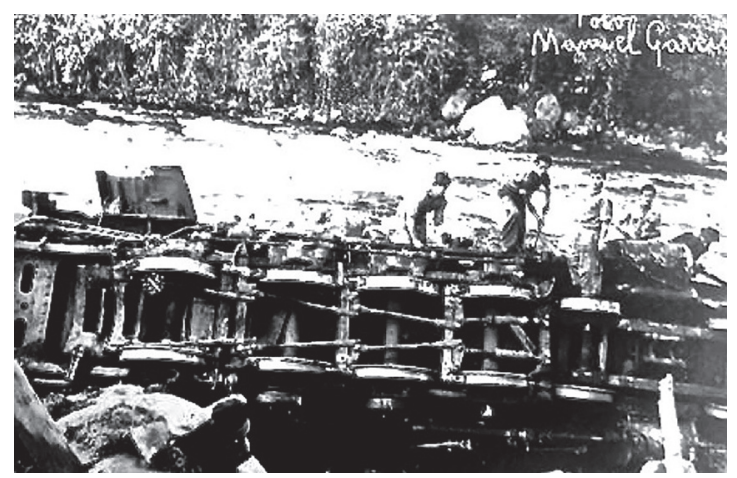

Figura 149. Descarrilamiento del tren en el puente sobre el río Otún Fuente: foto Manuel García

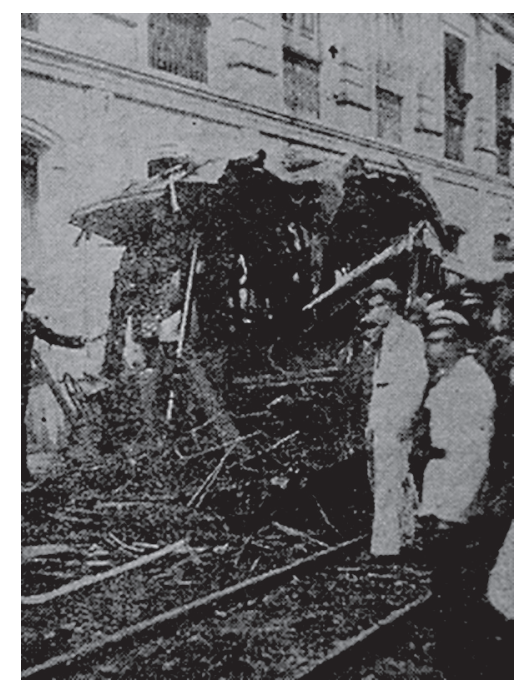

Figura 150. Choque del tranvía con el tren en las calles de Pereira Fuente: Grupo Fotografías Antiguas de Pereira (2015).

Para concluir la argumentación sobre el fin del Ferrocarril de Caldas, nada mejor que acudir al doctor Ernesto Gutiérrez Arango, manizaleño de pura cepa, quien dice en su artículo, escrito en 1994:

"Se conoce, al ver tan variados y múltiples métodos de financiación de una obra pública, que hemos avanzado en nuestros métodos administrativos, 
pues generalmente, en el día de hoy no se emprende una obra de envergadura sin tener un plan de financiación seguro que evite todos estos tropiezos y vicisitudes que ocurrieron durante la construcción del Ferrocarril de Caldas. Así tuvo nuestro departamento cumplido uno de sus grandes anhelos. Las circunstancias económicas del país hicieron, qué, gracias a una negociación especial, el Ferrocarril de Caldas pasara a manos de la nación y por efectos de un trato más que cerró así la historia financiera del Ferrocarril de Caldas. El último empréstito extranjero que permitió una emisión de bonos, muy desvalorizados durante la crisis financiera del año 30, incidía en las finanzas departamentales y era necesario hacer algo para mejorar la situación. Se logró en el año de 1955 que la Nación se hiciera cargo de amortizar aquellos bonos, que se cotizaban apenas al $30 \%$ en la Bolsa de Nueva York, a cambio de recibir el Ferrocarril de Caldas que pasó a ser bien nacional y fue incorporado al Ferrocarril del Pacífico, para su administración y explotación.

En el año de 1959 el Gobierno Nacional resolvió por intermedio del ministro de Obras Públicas de ese entonces Dr. Virgilio Barco Vargas, levantar los rieles que continuaban desde Pereira a Manizales, desgraciadamente con mucha complacencia de algunas personas y personalidades de la que entonces era la segunda ciudad del departamento de Caldas. Así terminó el Ferrocarril de Caldas, por una acción que en aquellos momentos nos obligó a hacer un paro cívico, pero que hoy, revisando la historia del Ferrocarril de Caldas, de los ferrocarriles nacionales y las circunstancias de aquellos días, con el desplazamiento del tráfico de carga hacia el transporte por carreteras, más barato y más rápido, tenemos que confesar que aquel famoso paro no pasó de ser una manifestación de nuestro temperamento, a veces, o mejor muchas veces, irreflexivo, violento y desproporcionado.

Además del progreso y expansión del transporte por carretera que lo hacen más económico, se agregaban otras circunstancias desfavorables a nuestro ferrocarril: eran la estrechez de la línea que no permitía la utilización de las locomotoras diesel más modernas; algunos trayectos como el de Boquerón y como el de Villamaría-Manizales con especificaciones limitadas en cuanto a su pendiente y a una situación de orden social muy semejante al que viven hoy los ferrocarriles nacionales y a las de los Puertos de Colombia y tantas otras empresas arruinadas por los compromisos adquiridos con los jubilados con bajas edades. Una empresa arruinada sin posibilidades de mejorar sus condiciones estaba condenada a desaparecer irremediablemente". (Gutiérrez, 1994) 


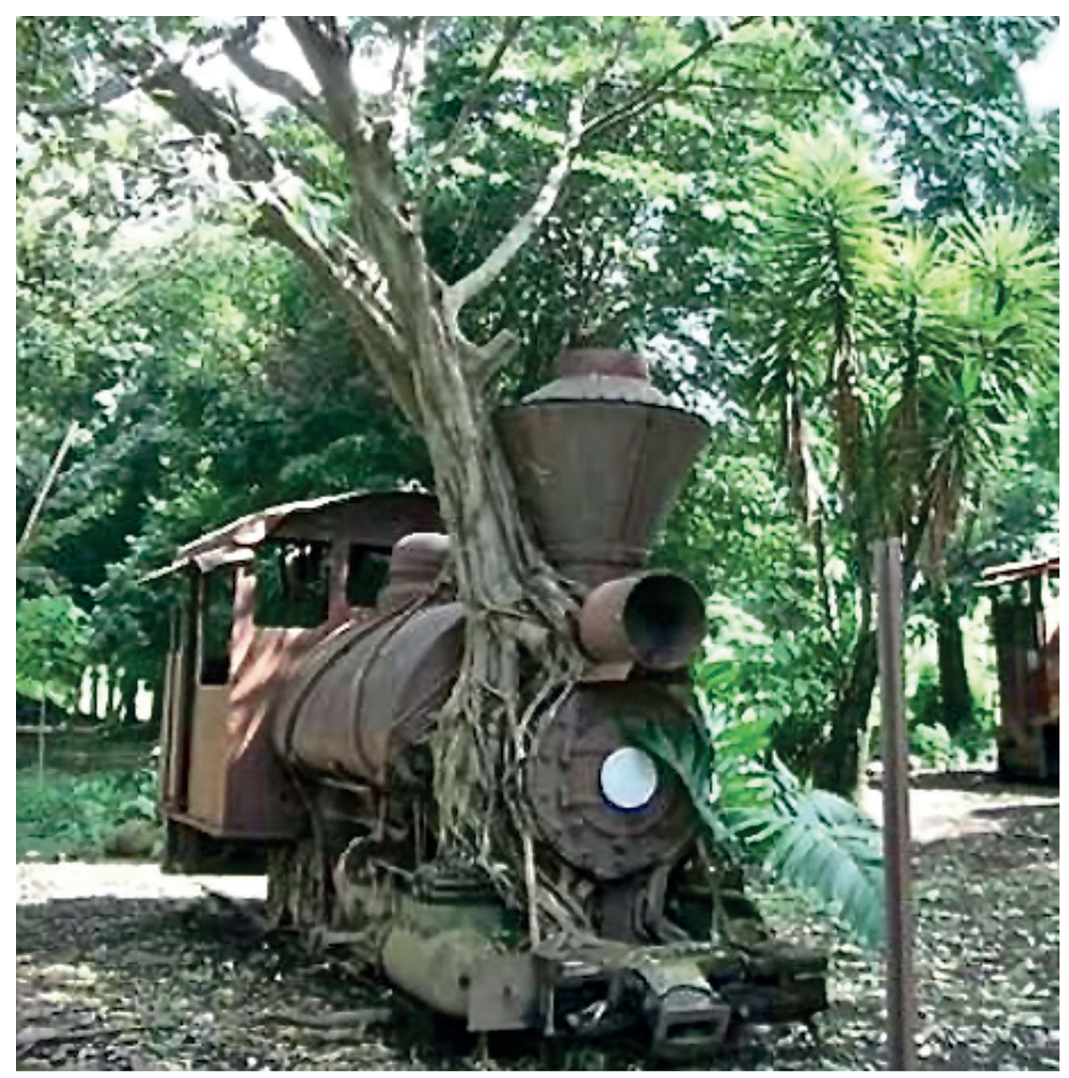

Figura 151. Locomotora con tronco

Fuente: Grupo Fotografías Antiguas de Pereira (2018). 


\section{CAPITULO XI}

\section{El futuro de los ferrocarriles en Colombia}

$\mathrm{Z}^{\mathrm{n}}$ el desarrollo de las presentaciones de la primera edición de este libro, Esurgió una pregunta que se repitió en casi todas las oportunidades: ¿qué opina usted sobre el futuro de los ferrocarriles en Colombia?

Ahora, ad portas de una nueva edición, sería una omisión imperdonable no referirme, así sea de la manera más simplificada, al tema en cuestión.

A falta de unos estudios más profundos y detallados, como sería, no solo lo más conveniente sino, lo indispensable, me voy a permitir presentarles mis propias reflexiones, que no son más que un mapa mental de ideas sobre lo que podría ser el desarrollo de los ferrocarriles en Colombia.

El título define claramente los tres aspectos del tema que queremos abordar. Futuro: nos indica que estaremos refiriéndonos a lo que debería suceder en los años venideros. Ferrocarriles: nos encauza en un medio de transporte específico y Colombia: nos limita a una parte del mundo en la cual se debe desarrollar la propuesta.

Empezaremos por el primer aspecto. Está implícito que nos debemos olvidar de lo que sucedió en el pasado con el diseño y la construcción de los ferrocarriles; específicamente sobre aspectos como trocha angosta, radios de curvatura pequeños, altas pendientes, motores a vapor, sumados a los medios rudimentarios para su construcción. Debemos, además, considerar las motivaciones económicas actuales, con la valoración adecuada de los tiempos de movilidad, en un mundo moderno, cuyo uno de sus referentes es "el tiempo es oro", y el enfrentamiento a otros medios de transporte como el avión, las "tractomulas" y los buses "pullman", con una cercana posibilidad de ser autoconducidos. Es decir, debemos ubicarnos en la modernidad con todo lo que ella significa en términos de tecnología, seguridad, comodidad y rendimientos económicos.

En segundo término, debemos mirar el desarrollo actual de los ferrocarriles en los países más adelantados, para alcanzar siquiera un nivel adecuado para un país tercermundista. Lo que esperamos tener aquí en un futuro es lo que tiene, por ejemplo, España desde hace veinte años. Esta comparación nos sirve para aterrizar un poco nuestra propuesta, mostrar que es apenas adecuado nuestro propósito y que estamos en mora de lograrlo. 
¿Y qué es lo que tiene España? Trenes eléctricos de alta velocidad. Hacia estos es a los que debemos apuntar.

Pero, ¿en dónde los vamos a proponer? En Colombia. ¿Y eso que implica? Muchas cosas completamente diferentes. Para iniciar, nuestra topografía: un país atravesado de sur a norte por la cadena montañosa de los Andes. Pero no en forma similar a lo que sucede en los demás países suramericanos por los cuales cruza, sino, para complicar la plana, subdividida en tres cordilleras. Es decir, tres grandes obstáculos para pretender comunicar el país en el sentido transversal.

En segundo lugar, los costos: ¿está el país en condiciones de afrontar los exorbitantes costos de construcción que implican los ferrocarriles de alta velocidad? Probablemente nuestro erario no alcance para solventar costos de 20 millones de dólares por kilómetro o algo así. Pero en tiempos de concesiones de cuarta generación podría auscultarse el interés de las compañías extranjeras. Un campo abierto para nuestros avezados economistas.

En tercer lugar, nuestra idiosincrasia. ¿Tendremos la cultura ciudadana, la educación, el respeto, la disciplina y el orden para atender, proteger y aprovechar tal servicio? Diremos que por algo hay que empezar y que tenemos en "los paisas" el ejemplo que podemos capitalizar.

Concretando un poco más la propuesta, tendríamos que nuestras limitaciones topográficas sólo nos dejan libres dos corredores en sentido norte sur, los que corresponden a los valles de los ríos Magdalena y Cauca. Afortunados en tenerlos y es por allí por donde se puede pensar en tender las dos troncales de alta velocidad que facilitarían la movilidad de carga y pasajeros en ambos sentidos, sur norte, de nuestro país. Serían dos líneas sin intersecciones a nivel y protegidas a ambos lados del corredor para evitar accidentes con vehículos, personas o animales que traten de cruzar la vía. Otra característica de las nuevas vías férreas sería que el trazado de las mismas no debe pensarse en llegar a las ciudades como solía plantearse antiguamente sino, obedecer a las facilidades que nos brinde la topografía para lograr radios mínimos de curvatura de 1500 metros en adelante y pendientes no mayores al dos por ciento. La línea férrea uniría algunas plataformas logísticas situadas estratégicamente y a donde deben confluir no solamente las mercancías y productos de exportación e importación, sino los pasajeros que necesiten movilizarse a través de la red.

Podría pensarse, en principio y a manera de prototipo, en comunicar Girardot con Santa Marta o Barranquilla, aprovechando las riveras del Río Magdalena, y Cali con Cartagena, siguiendo la cuenca del río Cauca. Las estaciones o centros de embarque 
podrían estar localizados en las cercanías de Girardot, La Dorada, Puerto Berrio, Puerto Wilches, Santa Marta o Barranquilla, para la primera línea, y Cali, La Virginia, La Pintada, Santa Fe de Antioquia, Caucasia, Cartagena, para la segunda línea.

Con referencia a los tipos de trenes a utilizar, diríamos que deben ser trenes eléctricos de velocidad media, es decir, con posibilidades de desarrollar velocidades promedio de 250 kilómetros por hora. Para lograr estas velocidades necesitamos, como lo dijimos inicialmente, radios mínimos de curvaturas de 1500 metros y pendientes máximas del 1.5\% compensada. Estas condiciones podrían cumplirse relativamente fácil a lo largo del corredor del Magdalena y un poco más difícil en el del Cauca, especialmente en los trayectos La Virginia a la Pintada y Santa Fe de Antioquia a Puerto Valdivia, sin convertirse en un problema insoluble.

En esas condiciones estaríamos logrando tiempos de viaje entre Girardot y Santa Marta o Cali a Cartagena, de tres horas de viaje, lo cual significa unos tiempos de movilización competitivos, tanto para carga como para pasajeros, al enfrentarlos con las tracto-mulas o los buses y carros particulares, y aún, con el aéreo, cuyas demoras por razones ajenas a la voluntad humana, como es el incontrolable fenómeno climatológico, sumado a la localización lejana de los aeropuertos en relación con los sitios de destino, dan al traste con nuestra programación de viaje, con todas las implicaciones negativas a que ello conduce.

Siguiendo el ejemplo español, diríamos que la longitud de los trenes sería de diez vagones halados por dos locomotoras, cada uno, lo cual representa andenes o plataformas para embarque de por lo menos doscientos metros de longitud. Inicialmente podría pensarse en dos trenes para cada ruta, uno de pasajeros y uno de carga, cuyos itinerarios podrían programarse de tal forma que los de pasajeros se realizaran en las horas de la mañana y los de carga en las horas de la tarde, dejando el tiempo restante para revisión y mantenimiento. Por supuesto que es la demanda la que dirá la última palabra en el número de trenes y las frecuencias de cada uno, pero este podría ser un primer esquema para la evaluación de su pre-factibilidad económica. 
El Ferrocarril de Caldas: una obra de titanes

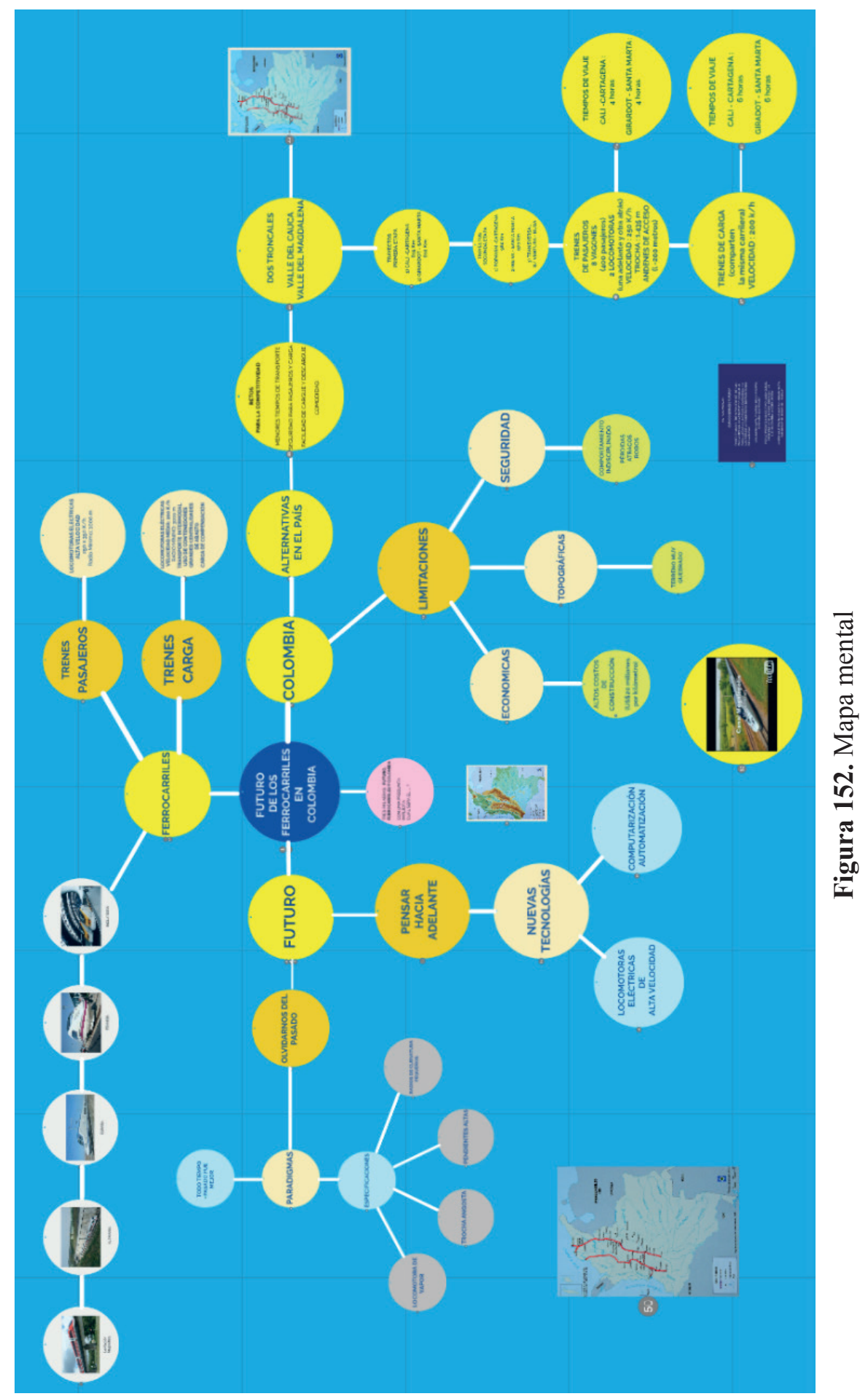




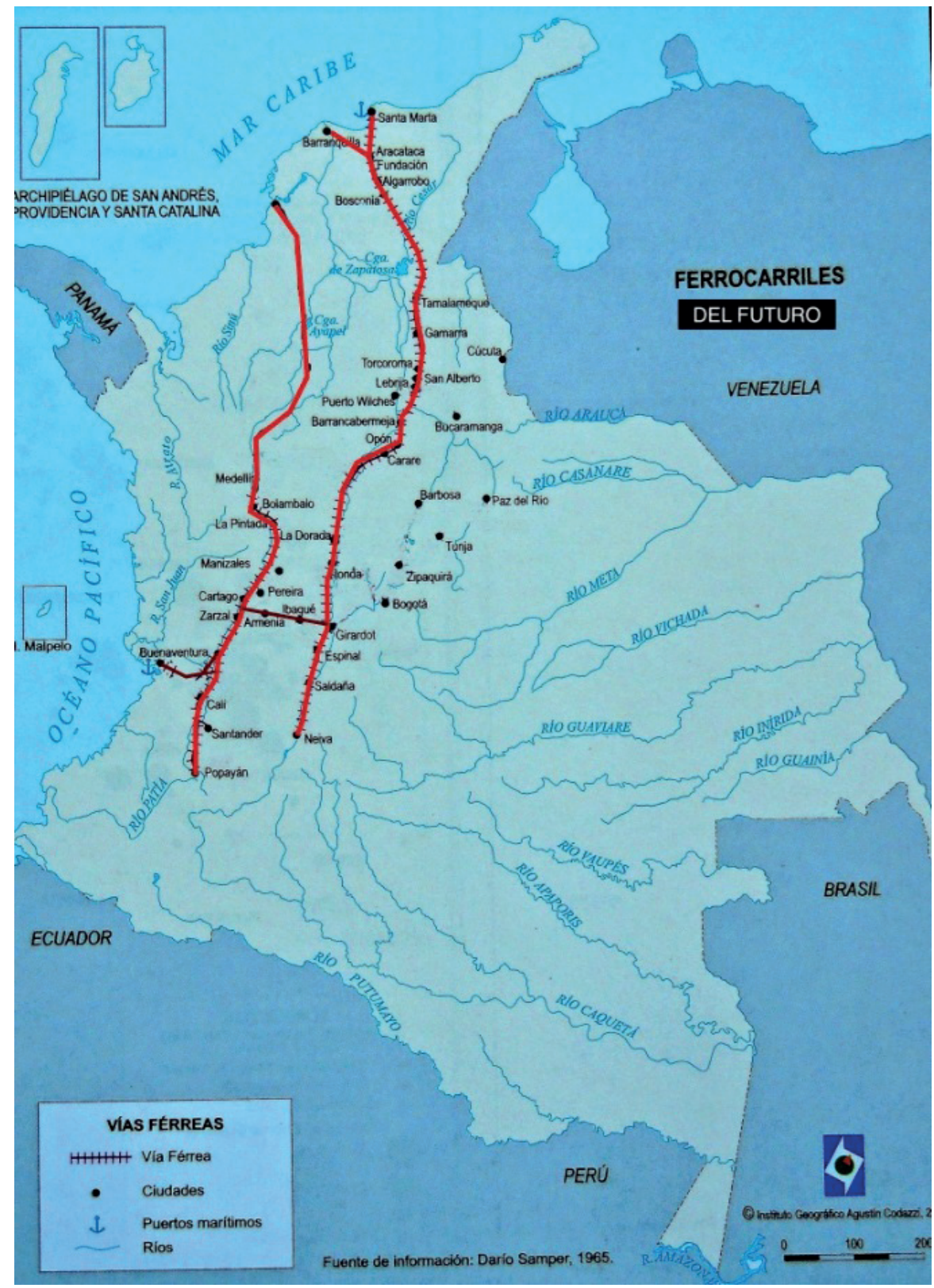

Figura 153. Posibles rutas del tren rápido trazadas sobre mapa del IGAC 


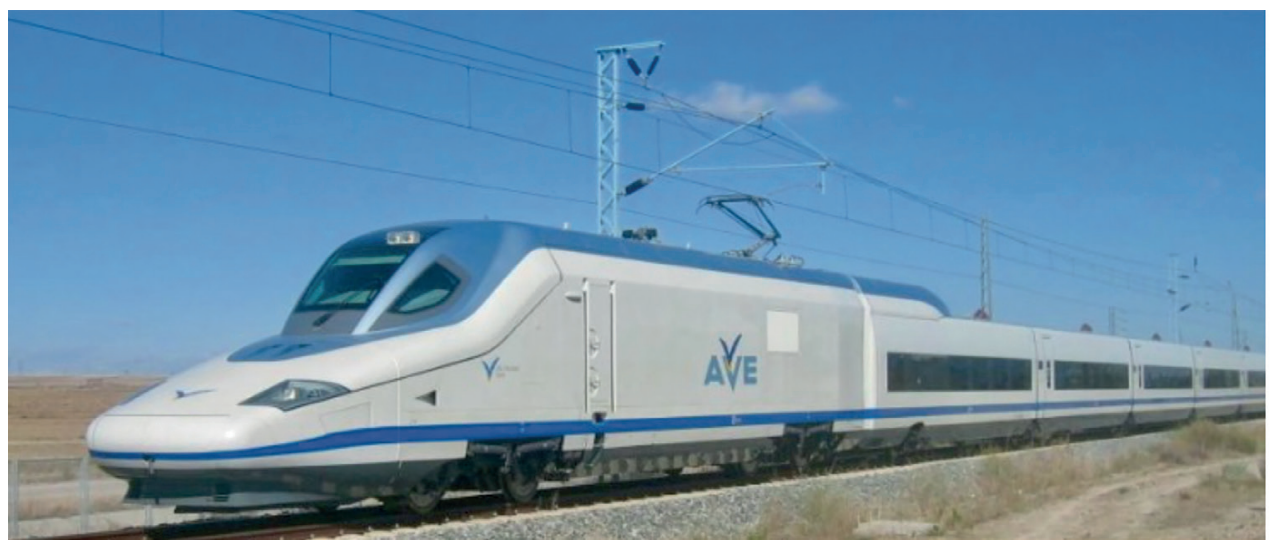

Figura 154. Tren rápido de Líneas Españolas, AVE. 


\section{BIOGRAFÍA}

\section{Ernesto Ramirez Jaramillo}

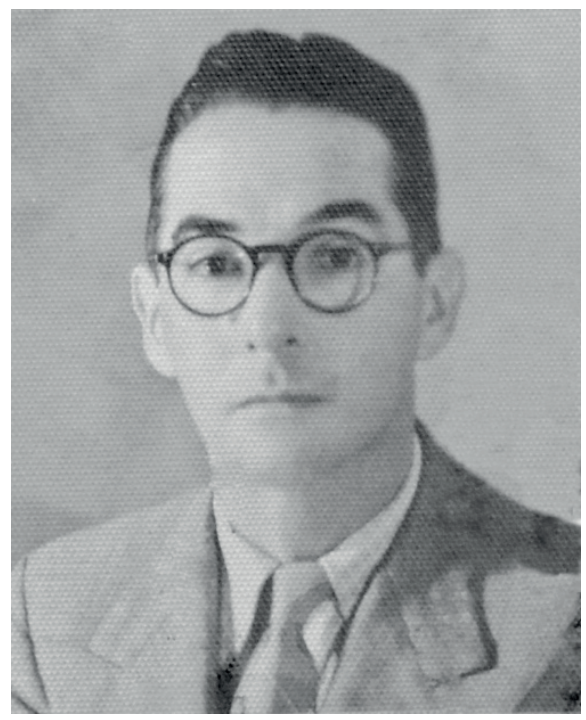

Wació en Abejorral en 1897, en el hogar conformado por Isaac Ramírez Martínez 1 y Débora Jaramillo Gutiérrez; su formación escolar la obtuvo en el colegio de su pueblo natal y la secundaria y profesional en el Instituto Técnico Central de Bogotá, en donde obtuvo el título de Ingeniero de Caminos y Ferrocarriles en 1922, título validado posteriormente como Ingeniero Civil de la Universidad Nacional de Colombia.

En septiembre de 1927 contrajo matrimonio en la ciudad de Manizales, con Lucrecia Villegas Villegas de cuya unión hubo seis hijos: María Teresa, Hernán, Leonor, Javier, Armando y Diego.

En1929fijósuresidencia en Pereiray en 1972 fallecióen la ciudaddeMedellín.

Trabajó, inicialmente, en el ferrocarril de la Sabana para pasar, luego, al Ferrocarril de Caldas en donde trabajó durante 8 años en sus trazados y en su construcción, incluyendo el tramo Nacederos-Armenia y la construcción de los cinco túneles situados entre Río Claro y Villamaría. Después del ingeniero Eleuterio Serna G. fue el ingeniero que más tiempo trabajó para el Ferrocarril de Caldas. 
Posteriormente, trabajó como contratista, en el trazado y construcción de varias carreteras entre las cuales se encuentran:

Febrero de 1933: Carretera La Virginia-Pueblo Rico

Diciembre de 1933: Ingeniero Jefe de construcción carretera Manizales-Río Magdalena (renuncia en julio 5 de 1935)

Agosto a noviembre 22 de 1935: Director General de Caminos y Carreteras del departamento de Caldas.

Octubre de 1938: Carretera Río Verde-Pijao

En septiembre de 1942: Termina Carretera Dorada-Manzanares

En septiembre de 1943: Contrato del trazado y localización carretera Barragán-Génova

(Secretario de Obras Públicas Ing. Roberto Franco Arango) 


\section{FTHRTROCATRIL DF CALDAS}

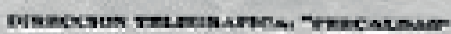

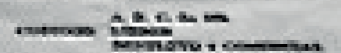

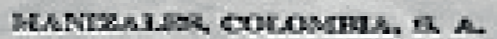

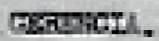

tordi 22 te 1927

Setior De Da

Inseato Pardrez.

Ia rigrests.

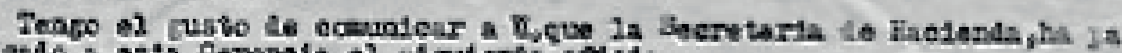

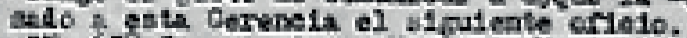

"Ho.650-3ecretaria de Haolenda-jentavies, ardi 22 ce 1927 -Beilor Gerento

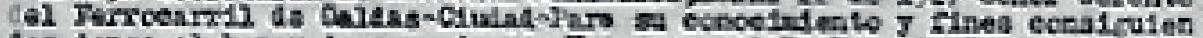

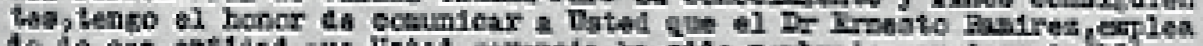

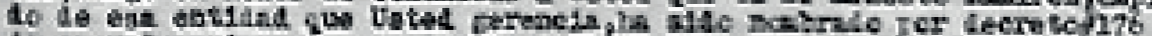

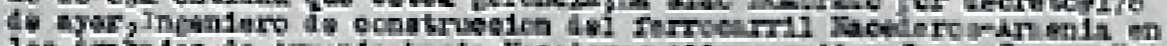

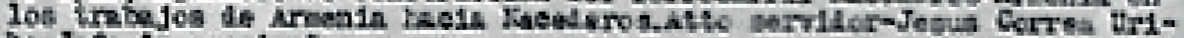
De-jesa do sacelca".

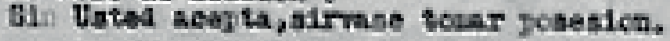

Atto 3.3.

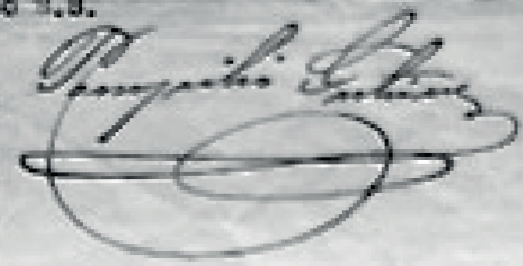

Figura 155. Archivo personal de Ernesto Ramírez Jaramillo 


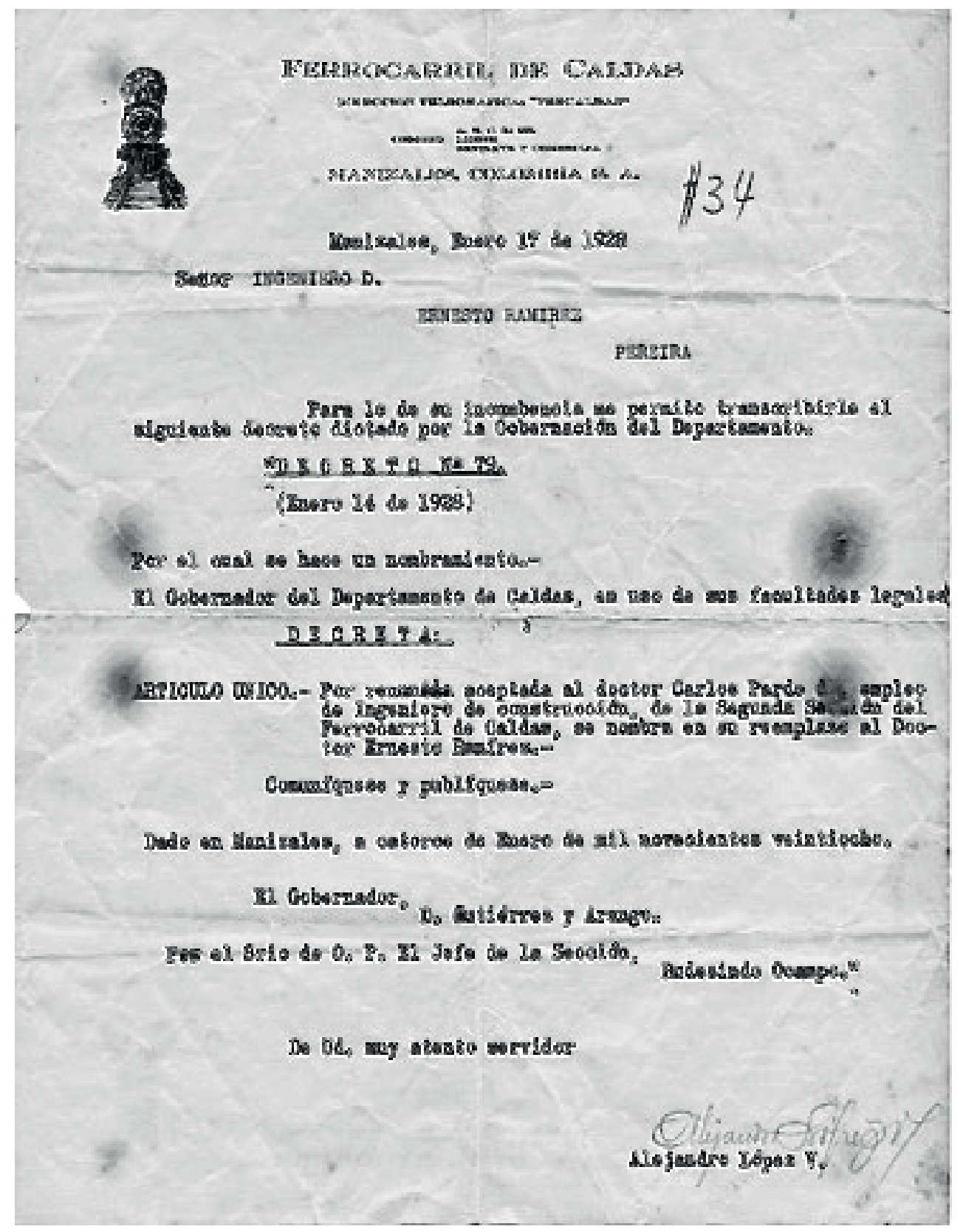

Figura 156. Archivo personal de Ernesto Ramírez Jaramillo 


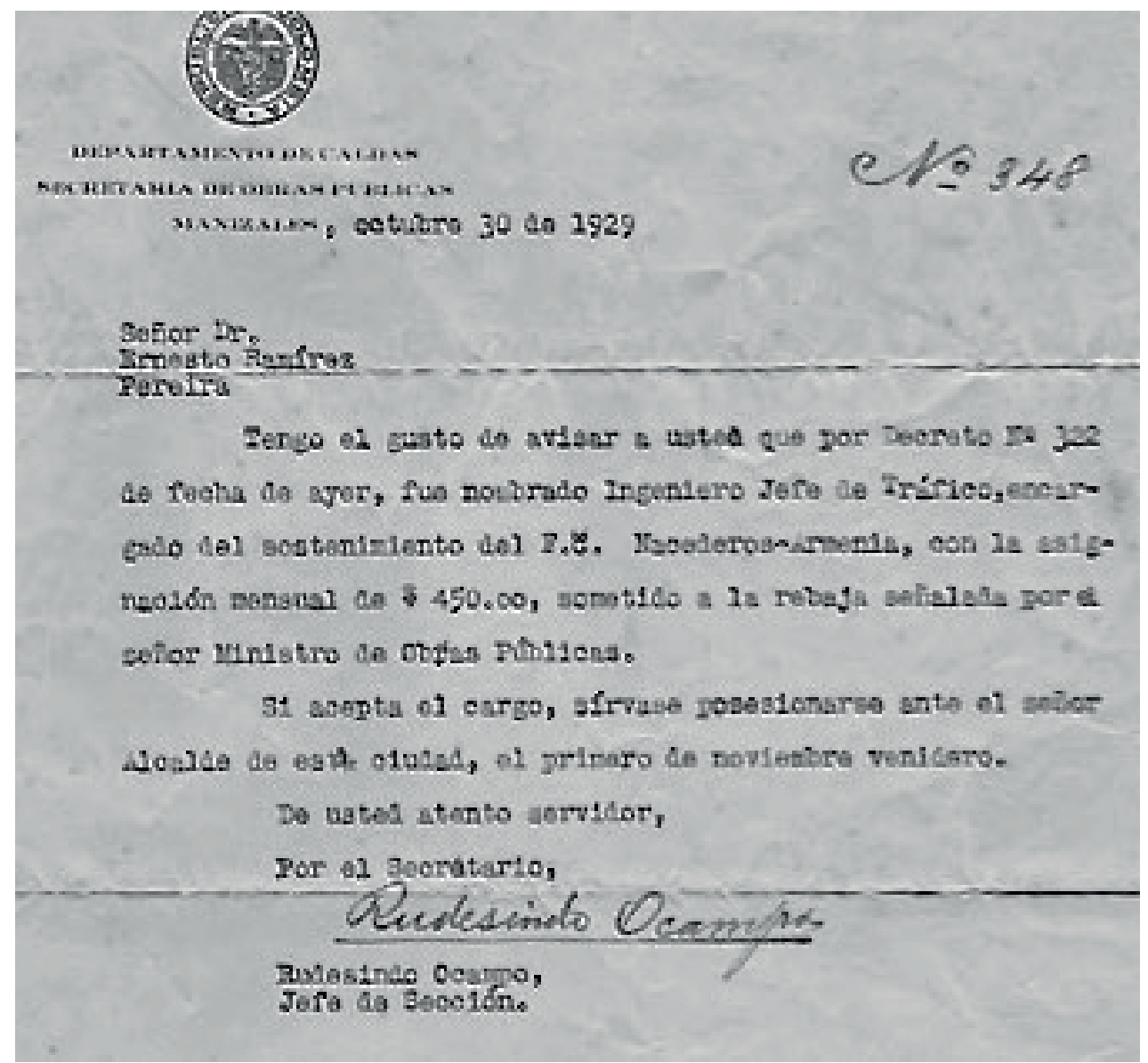

Figura 157. Archivo personal de Ernesto Ramírez Jaramillo 


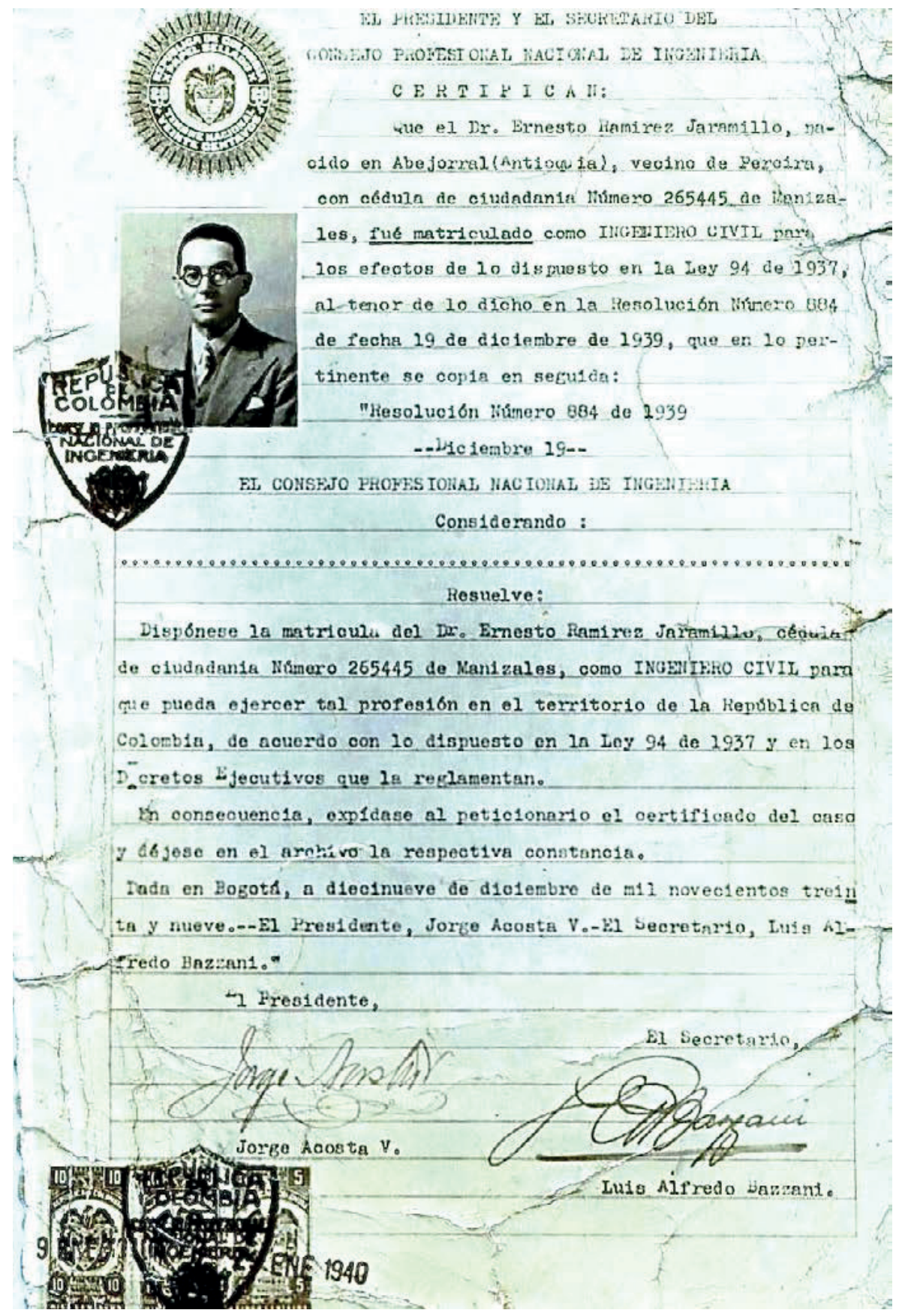

Figura 158. Archivo personal de Ernesto Ramírez Jaramillo 


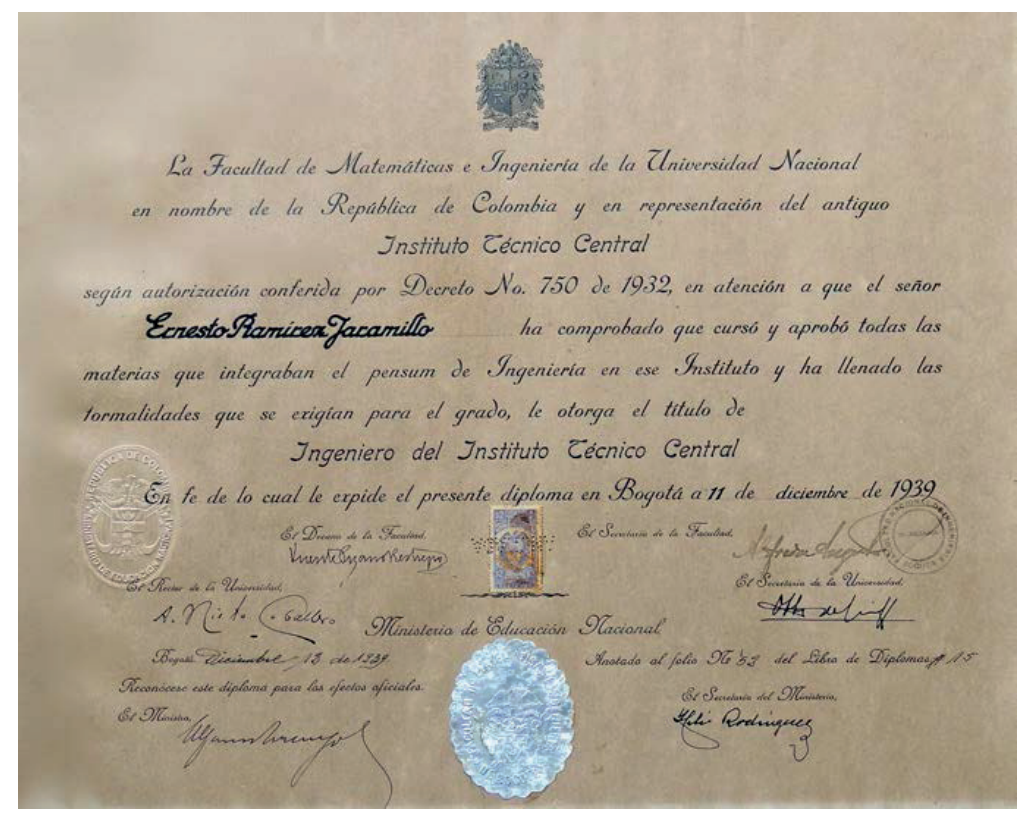

Figura 159. Archivo personal de Ernesto Ramírez Jaramillo

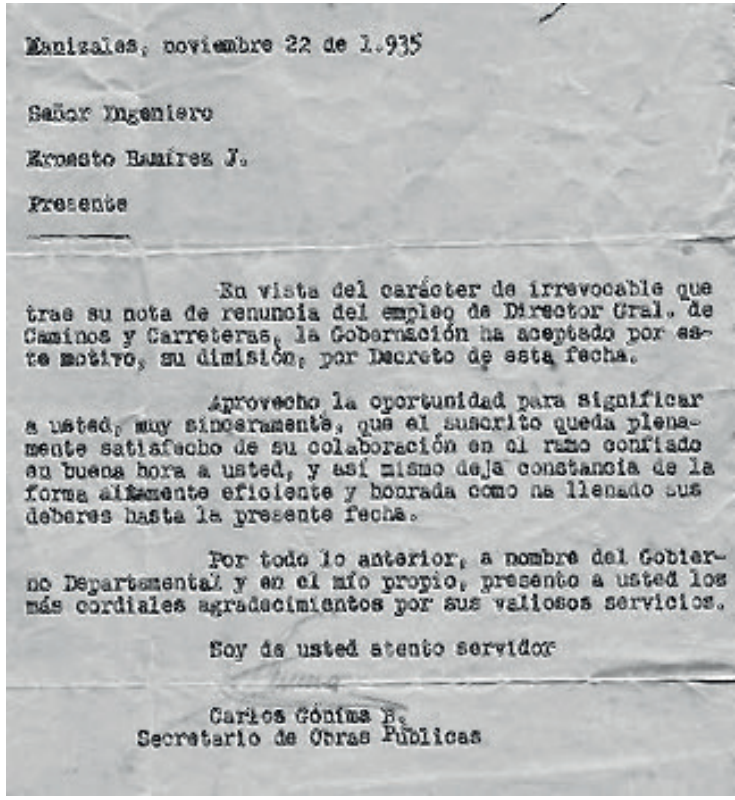

Figura 160. Archivo personal de Ernesto Ramírez Jaramillo 


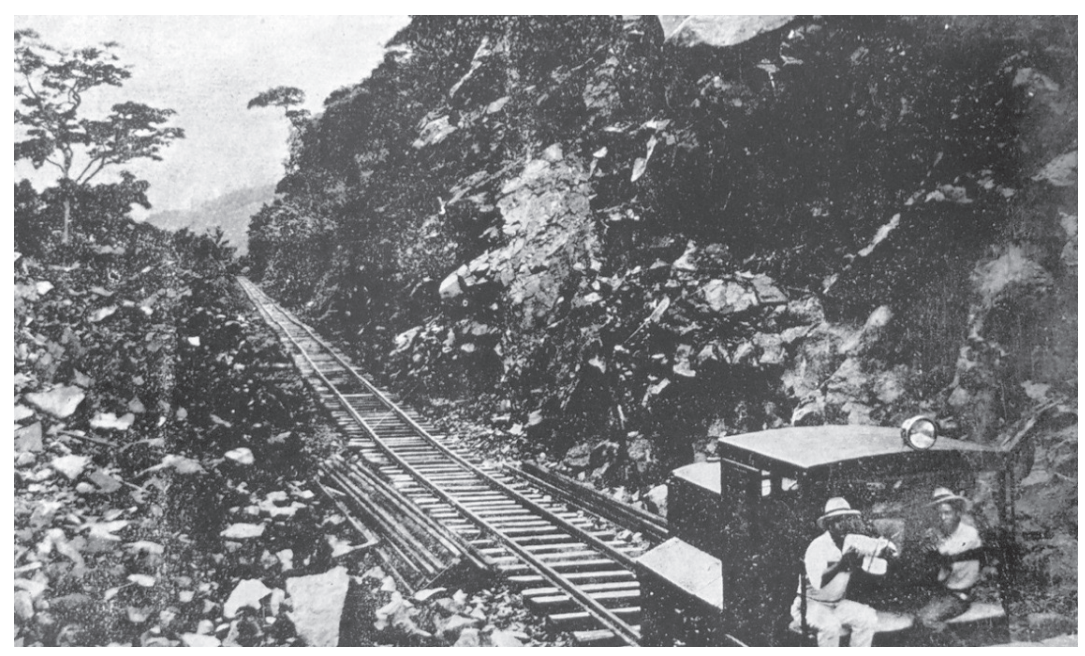

Figura 161. Cruce Los Micos. Kilómetro 63

Fuente: revista Manizales ayer y hoy

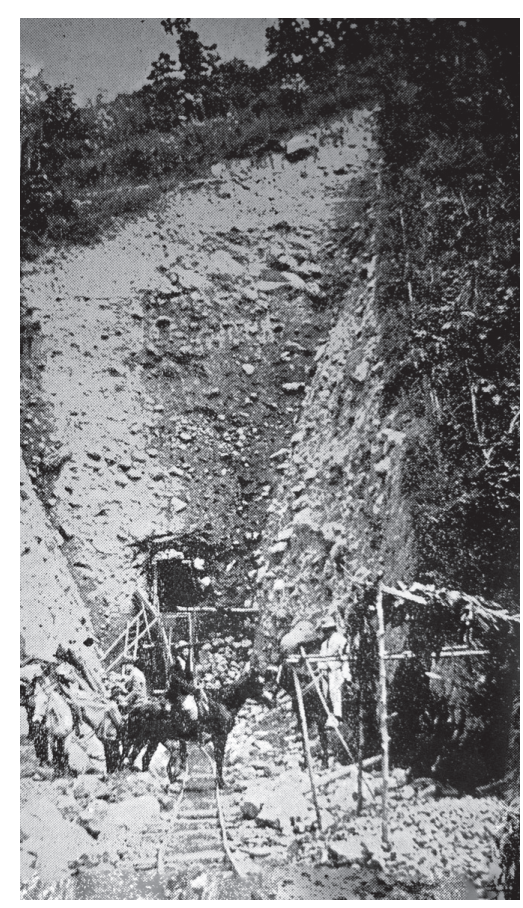

Figura 162. Caballo en el túnel de Los Micos 


\section{ANEXOS \\ DOCUMENTOS HISTÓRICOS DE SOPORTE}

\section{ANEXO No 1}

\section{Informe Presentado por el Dr. Felipe Zapata Cuenca}

Bogotá 1. ${ }^{\circ}$ de enero de 1912

Señor Presidente de la Junta del ferrocarril de Caldas- Manizales

Tengo el honor de presentaros el informe, resultado de la excursión hecha entre Manizales, Cartago y las márgenes del río Cauca en el mes de noviembre próximo pasado.

Para mayor claridad he dividido este trabajo en las siguientes partes:

I - Descripción del trayecto entre Manizales y Cartago y el río Cauca.

II -Cuadro de las principales alturas tomadas con el aneroide.

III -Observaciones.

DESCRIPCIÓN GENERAL DEL TRAYECTO ENTRE MANIZALES Y CARTAGO Y EL RÍO CAUCA

Las poblaciones de Pereira, Santa Rosa y San Francisco se hallan todas situadas en la proximidad de una línea imaginaria trazada de Cartago hacia Manizales, en la dirección noreste, y dividen este trayecto en tres secciones de casi igual longitud. La distancia total es aproximadamente de quince leguas.

Entre la desembocadura del río de la Vieja y el puerto de La Virginia, el 
descenso del río Cauca es insignificante y el valle tiene una altura media de 980 metros sobre el nivel del mar.

Desde Pereira hasta Cartago se extiende un plano inclinado que llega casi hasta la orilla del río Cauca, y está limitado al norte por el río Otún y al sur por la quebrada llamada Consota.

La parte del plano más inmediata al río Cauca tiene una altura de 1200 metros. El descenso al río es rápido. Entre esta extremidad del plano y Pereira hay casi 20 kilómetros, y la diferencia de nivel es solamente 250 metros.

El camino de Pereira a Cartago sigue por la parte más alta del plano, el cual tiene marcadas ondulaciones causadas por las aguas.

En este camino y a 16 kilómetros de Pereira, cerca del punto donde se desprende la trocha que conduce a La Virginia, hay una colina llamada el Cerrito, que tiene 1330 metros y de la cual se obtiene magnífica vista de toda la región. El terreno es firme, y hay grandes bosques de maderas admirables para construcciones y traviesas, en la vecindad de la de Virginia. De Pereira a San Francisco el terreno es mucho más quebrado y el camino cruza los ríos Otún, San Eugenio, Campoalegre y las cuchillas que los separan.

Estos ríos se dirigen todos del este al oeste, bajando de la Cordillera Central al río Cauca, y presentan numerosas cascadas, qué en un porvenir no lejano, podrán ser fuentes inagotables de riqueza bajo las formas de energía hidráulica y eléctrica.

Entre Pereira $(1450 \mathrm{~m})$ y San Francisco $(1490 \mathrm{~m})$ hay relativamente poca diferencia de altura, pero existen puntos intermedios mucho más elevados, como la depresión llamada Quiebra de Agua Azul (1860 m), el paso sobre el río Campoalegre (1530 m), el Alto de las Guacas (1710 m) y Santa Rosa (1770m).

Los terrenos por lo general parecen sólidos y la tierra estaba en gran parte cultivada.

La tercera sección, o sea la que está comprendida entre San Francisco (1490) y Manizales (2240) está limitada por el río Chinchiná y es sumamente montañosa. El ascenso a Manizales por el camino es fuerte. Subiendo por el valle del río Chinchiná es más suave hasta llegar a La Aldea.

En resumen, vemos que las tres sesiones que la futura vía férrea cruzará son enteramente distintas. 


\section{Cuadro de las principales alturas tomadas con el aneroide}

\begin{tabular}{|l|}
\hline Plaza de Cartago 1000 metros \\
\hline Puerto de La Virginia 980 metros \\
\hline Partida de La Virginia a Cartago 1250 metros \\
\hline El Cerrito 1330 metros \\
\hline San Isidro, casa de 1250 metros \\
\hline Alsacia, casa de 1260 metros \\
\hline Alto de El Tambo 1405 metros \\
\hline Pereira. Tenería 1455 metros \\
\hline Pereira. El Polo 1450 metros \\
\hline Pereira. Plaza de Bolívar 1500 metros \\
\hline Puente Mosquera sobre el río Otún 1451 metros \\
\hline La Popa 1550 metros \\
\hline La María, casa de 1550 metros \\
\hline Puente de Frailes 1530 metros \\
\hline Dos Quebradas 1575 metros \\
\hline Alto de Vásquez 1920 metros \\
\hline Quiebra de Agua Azul 1860 metros \\
\hline Santa Rosa, plaza de 1770 metros \\
\hline Puente sobre el río Campoalegre 1530 metros \\
\hline Plaza de San Francisco 1490 metros \\
\hline La Frontera 1370 metros \\
\hline Puente sobre el Chinchiná 1470 metros \\
\hline Alto de San Antonio 2150 metros \\
\hline Puente sobre el Chinchiná, frente a la Aldea 1810 metros \\
\hline Plaza de la Aldea 1890 metros \\
\hline Alto del perro 2250 metros \\
\hline Plaza de Manizales 2160 metros \\
\hline
\end{tabular}




\section{OBSERVACIONES}

Estudio de las tres sesiones de la línea proyectada- Puesto que uno de los principales objetos de los ferrocarriles es el de enlazar los centros poblados, parece lo más justo que el punto inicial del ferrocarril sea Cartago, o un punto sobre el río Cauca inmediato a Cartago, pero si es que se piensa llevar el ferrocarril de Caldas hasta la Bahía de Utría, u otro puerto sobre el Pacífico, entonces debe iniciarse la línea en el puerto de la Virginia, subiendo fácilmente el plano inclinado por la cuchilla de Salazar. Al no hacer esto, y suponiendo que Cartago será punto obligado de prolongación del ferrocarril del Cauca, opino que la línea debe principiarse en Cartago o un punto inmediato a Cartago sobre el río Cauca, aprovechándose del tráfico importante entre Pereira y Cartago (el derecho del peaje en el puente Bolívar sobre el río la Víeja, se remató por la suma de 27700 pesos papel moneda mensuales últimamente, por lo cual se puede guzgar de la importancia de dicho tráfico) y evitando un penoso trayecto de navegación hasta la Virginia por el río Cauca, navegación que, debido a la poca profundidad del río en épocas de verano prolongado, impide el establecer itinerario figo y causa demoras grandes en la movilización de la carga. A la salida de Cartago se necesita construir un puente 70 metros de luz sobre el río a la Vieja, el cual se puede hacer en dos tramos de 35 metros. No habrá otra obra de arte importante de Cartago a Pereira y la vía seguirá casi paralelamente al cambio actual. Como la diferencia de nivel entre Cartago y Pereira es más o menos de 470 metros, la pendiente media de 1.88 por 100 y está concentrada casi toda en la subida al plano. Al ojo de buen cubero y el término medio del movimiento de tierras para líneas de 60 centímetros de ancho, no pasará en ningún caso de 6000 metros cúbicos kilómetro en terrenos fáciles de excavar. La estación de Pereira con sus anexidades debe construirse en el terreno llamado el Polo.

La segunda sección es de construcción más difícil y más costosa. Cruzando el río Otún, pocos metros arriba del punto actual, seguiremos por la falda opuesta hasta llegar a la altura llamada La Popa(1550), cruzando la cuchilla de Agua Azul por túnel que no tendrá menos de 150 metros de largo, salimos arriba del río San Eugenio, al pie de Santa Rosa (1770). El río San Eugenio se cruza por un puente de 20 metros de luz. Del río San Eugenio al río Campoalegre hay que trasmontar la cuchilla sobre la cual está situado el alto de Las Guacas, en el camino de Santa Rosa a San Francisco. El movimiento de tierras entre Pereira y San Francisco es 
considerable y no puede ser menor de 15.000 metros cúbicos en varios kilómetros. Fuera del túnel en Agua Azul la explanación considerable para pasar del valle del río San Eugenio al valle del río Campoalegre, y varias otras obras de arte, tenemos los siguientes puentes:

Uno sobre el río Otún, de 30 metros de luz.

Uno sobre el río San Eugenio, de 20 metros de luz.

Uno sobre el río Campoalegre de 25 metros de luz.

Uno sobre el río San Francisco, de 20 metros de luz.

La línea de Pereira a San Francisco, viene a ser lo que los ingenieros americanos llaman cross country road, en la cual los puntos extremos de Pereira (1450) y San Francisco (1460) están casi a la misma altura, pero separados por cuchillas más elevadas y obligándonos a buscar las depresiones más bajas de las cuchillas y los pasos más altos sobre los ríos.

De San Francisco a Manizales creo que no se deben considerar sido dos vías entre las varias que se presentan.

La primera llevaría la vía por La Frontera (1370) hasta el Rosario, punto que podría ponerseencomunicaciónconManizales, seaporunfunicular, ounaseriedeswitchbacks.

Por la segunda vía se tomaría el valle del río Chinchiná, pasando arriba de laAldea y regresando por el pie del alto del Perro, a salir cerca del cementerio de Manizales. Esta vía sería la más costosa por las numerosas obras de arte que habría que construir.

Trazado - Del estudio concienzudo del trazado depende en gran parte la construcción y explotación económica del ferrocarril. El estudio debe principiarse por una exploración que se hará rápidamente con el compás (brújula) y el nivel (nivel inclinómetro) en toda la extensión de la línea proyectada, para obtener una idea general de la topografía del terreno y de las pendientes. De este modo se determina la dirección general del trazado. La exploración es un estudio de zonas más bien que de líneas.

Como son varias las zonas que se presentan, hay riesgo de equivocarse al hacer la selección entre ellas; los peores defectos y errores en la localización definitiva provienen siempre de una exploración defectuosa. Concluida la exploración, debe procederse al estudio de la línea del trazado preliminar, tomándose la topografía del distrito dentro del cual se estima que se hallara la línea definitiva. El anchor de esta zona depende de la naturaleza del terreno. Hecho el estudio preliminar, se puede empezar a localizar la línea sobre el plano topográfico, y estudiada la línea en la oficina, pasarla el terreno y hacerle las modificaciones necesarias para establecer la 
localización definitiva del trazado.

En resumen, para el estudio completo se necesita:

$1^{\circ}$ Una exploración por la cual se determinan con precisión los límites de la zona por la cual pasará la vía férrea.

$2^{\circ}$ Un trazado preliminar para determinar la dirección general del eje, y la topografía del terreno de lado y lado de la vía en una anchura de 1000 metros (500 metros de cada lado).

$3^{\circ}$ Una línea de primera localización, que se obtiene transportando sobre el terreno la línea obtenida sobre el plano por medio del trazado preliminar.

$4^{\circ}$ Una línea de localización definitiva, que es el perfeccionamiento sobre el terreno de la línea de primera localización.

Juzgo que para hacer debidamente el estudio entre Manizales y Cartago se gasten unos doce meses, contando con el siguiente personal:

$1^{\circ}$ Un ingeniero jefe, encargado de la dirección del trazado, con un sueldo de 350 pesos

$2^{\circ}$ Un grupo con el teodolito:

Un ingeniero ................................. \$250

Un peón ayudante............................... \$ 30

Dos cadeneros a 30 pesos mensuales............... \$ 60

Dos peones a 20 pesos mensuales...................\$40

$3^{\circ}$ Un grupo para la nivelación

Un ingeniero con el nivel..........................\$ 200

Dos peones ayudantes con la mira, a $\$ 30 \ldots \ldots \ldots \ldots \ldots . . \ldots 60$

Dos peones para cortar y clavar estacas, a $\$ 20 \ldots \ldots \ldots . \$ 40$

$4^{\circ}$ Un grupo para la topografía y el dibujo:

Dos dibujantes a $\$ 80 \ldots \ldots \ldots \ldots \ldots \ldots \ldots \ldots \ldots \ldots . \ldots 160$

Un escribiente. ................................ \$ 80 
$5^{\circ}$ Un grupo encargado del campamento y el transporte:

Un cocinero, a ...........................................................\$ 20

Un muchacho, a ....................................................\$ 10

Total..............................................\$ 1.300 oro

$\$ 1.300$ por mes, o sea en un año $\$ 15.600$ en oro.

Agregando a esta suma \$ 4.400 en oro, por valor de instrumentos, accesorios, tendremos \$ 20.000 como valor total del trazado.

Estimo también que el trazado debe hacerse en su totalidad de una vez y no por partes, a medida que se vaya construyendo la línea.

El trabajo de construcción en cada sección puede iniciarse a medida que se aprueben los planos correspondientes.

En una línea de trazo tan delicado como es la de Manizales a Cartago sería un grave error creer hacer un estudio completo y por consiguiente llevar la obra a cabo con éxito, dedicándole menos trabajo que el enumerado arriba.

Toda economía que se trate de realizar en este sentido, resulta en una verdadera pérdida de tiempo y dinero. Una de las principales causas del mal resultado de muchos ferrocarriles, ha sido la falta de un estudio cuidadoso del trazado. La suma de \$20.000 pesos en oro es de importancia por sí sola, pero es insignificante comparada con el valor total de la obra.

TRÁFICO PROBABLE. El ferrocarril de Caldas está llamado a sostener un tráfico importante, tanto de pasajeros como de carga, sin causar perjuicio al cable aéreo que proyectaban de Mariquita y Manizales, puesto que las dos vías se alimentarán mutuamente. El municipio de Manizales tiene 30.000 habitantes, el de San Francisco 7.000, el de Pereira 20.000, el de Santa Rosa 14.000 y el de Cartago 8.000. Total: 79.000 habitantes. No nos equivocamos al suponer un promedio diario de 200 pasajeros de todas las clases en los 80 kilómetros de largo que tendrá la línea, lo cual nos da en un año 72.000 pasajeros; admitiendo que cada pasajero no recorra sino la mitad del trayecto, y que la tarifa media sea uno y medio centavos oro por kilómetro, obtenemos un producto total de 40 por 72.000 por 0,015 igual a $\$ 43.200$ en oro. 
En el año pasado entiendo que el movimiento de carga en esta región fue el siguiente: 109.000 sacos de café, 5.780 bultos de pieles, 30.642 bultos de carga de importación y exportación, o un total de 10.486 toneladas más o menos anualmente. Agregando a esta cantidad la carga local, que es de mucha importancia, y el aumento de tráfico debido al desarrollo que traerá el ferrocarril a estas regiones y a la movilización en gran escala de los concentrados de minas, etcétera, no nos equivocaremos al suponer un tráfico de 18.000 toneladas por año (el ferrocarril de la Sabana moviliza 72.000 toneladas anuales). Suponiendo también que estas 18.000 toneladas no recorran sino la mitad del trayecto, y que el flete medio sea a razón de $\$ 0,08$ oro por tonelada por kilómetro, tendremos un producto total de 18.000 por $\$ 0,08$ por 40 ó un total de $\$ 57.600$ en oro.

$$
\begin{aligned}
& \text { Total: Producto de tráfico de pasajeros por año.....\$ } 43.200 \text { oro } \\
& \text { Producto del tráfico de carga por año } \ldots \ldots \ldots \ldots \ldots . \$ 57.600 \text { oro } \\
& \text { Total ............................................\$ } 100.800 \text { oro }
\end{aligned}
$$

Abierta la línea al tráfico, los gastos de explotación no deben pasar del 50 por 100 , teniendo en cuenta la solidez de los terrenos y las buenas condiciones de la línea por lo general. La utilidad líquida sería de \$ 50.400 anuales. Estoy seguro de que esta utilidad aumentaría y se duplicaría en pocos años.

\section{Anchura entre rieles de la vía}

Tuve ocasión de manifestar a esa honorable Junta que la vía podría tener un ancho mínimo entre rieles, de 60 centímetros. Mis razones al hacer esta indicación eran de orden económico, porque con este tipo de paralela el volumen de metros cúbicos del movimiento de tierras es un 20 ó $25 \%$ más reducido que para vía ancha de un metro o una yarda. Ahora bien, si al hacer el trazado se da la posibilidad de construir la línea económicamente a la paralela de una yarda, que es la del ferrocarril del Cauca, de Antioquia y de Amagá, es claro que de preferencia se debe emplear esta última paralela, teniendo en cuenta el posible enlace de las tres vías en un porvenir no lejano. Fuera de esta razón no hay porqué el militar por la yarda de preferencia a la vía de sesenta centímetros, para la cual se construyen hoy día máquinas y vehículos que reúnen todas las condiciones necesarias de capacidad, resistencia y eficacia para un tráfico veinte veces mayor que el que pueda haber en el ferrocarril de Caldas. 


\section{Costo aproximado de la obra.}

Es casi imposible hacer un cómputo de lo que pueda costar la línea, sin hacer el estudio completo, y el presupuesto que doy en seguida no es más que una simple aproximación. Se deben emplear rieles de 50 libras por yardas, con eclisas angulares de 24 pulgadas de largo y traviesas de guayacán, dinde, diomate, etcétera.

La carrilera se debe balastar con piedra triturada. Con estos elementos el gasto el conservación se reduce notablemente, y como de la bondad de la cabellera depende directamente la duración del material rodante, el deterioro de este último será muy reducido.

El costo de un kilómetro de carrilera sería de 50 toneladas de rieles de 50 libras, a

$\$ 70$ tonelada, puestos en Cartago

4 y media toneladas de accesorios, a $\$ 100$ tonelada............................\$ 450

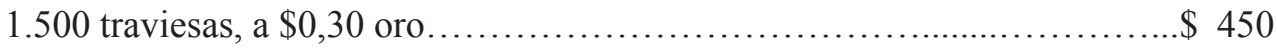

1.000 metros cúbicos de balasto, a $\$ 0,60$ el metro cúbico.......................\$ 600

Dirección, colocación vía, etc..................................................\$ 1.000

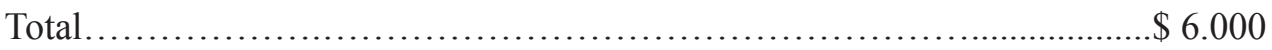

Este presupuesto se refiere a la línea de sesenta centímetros de ancho. En la primera sección podemos tener un promedio de movimiento de tierras de 6.000 metros cúbicos.

En la segunda sección, de 15.000 metros cúbicos.

En la tercera sección, de 25.000 metros cúbicos.

Como los terrenos son de consistencia variable, podemos calcular un costo de $\$ 0,50$ oro el metro cúbico.

\section{En este caso la primera sección costaría:}

$1^{\circ}$-Carrilera ......................................................... $\$ 6.000$

$2^{\circ}-6.000$ metros cúbicos de movimiento de tierra a $\$ 0,50$ el metro cúbico.. $\$ 3.000$

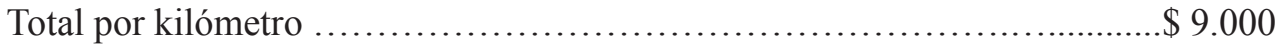

Y en 25 kilómetros................................................... $\$ 225.000$

\section{La segunda sección:}

$1^{0}$-Carrilera.......................................................... $\$ 6.000$

$2^{\circ}-15.000$ metros cúbicos de movimiento de tierra a $\$ 0,50$ el metro 
cúbico

Total por kilómetro

$\$ 13.500$

Y en 25 kilómetros

$\$ 337.500$

La tercera sección (vía al valle de Chinchiná):

$1^{\circ}$-Carrilera $\$ 6.000$

$2^{\circ}$-25.000 metros cúbicos a $\$ 0,50$ el metro cúbico. $\$ 12.500$

Total por kilómetro $\$ 18.500$

Y en 30 kilómetros $\$ 555.000$

\section{RESUMEN}

Primera sección $\$ 225.000$

Segunda sección $\$ 337.000$

Tercera sección $\$ 555.000$

Total $\$ 111.750$

1-Para los puentes, alcantarillas, etc., no podemos computar menos de. $\$ 500.000$

2- Costo de los edificios varios (estaciones, bodegas, etc. $\$ 100.000$

3- Valor de un taller con sus máquinas y herramientas $\$ 75.000$

4- Valor del material rodante necesario:(material rodante para vía de $60 \mathrm{cms}$ ):

4 carros de primera clase, a $\$ 3.000$ $\$ 12.000$

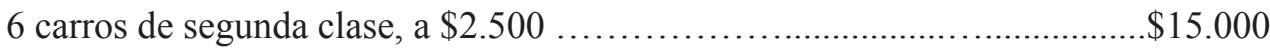

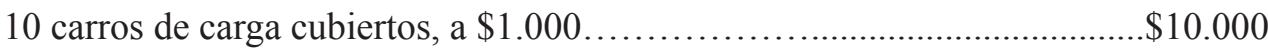

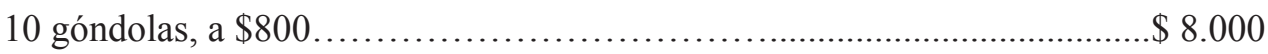

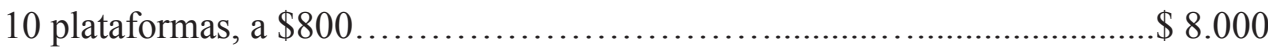

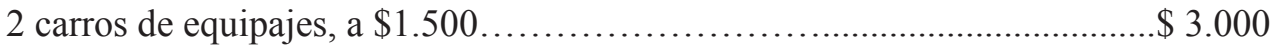

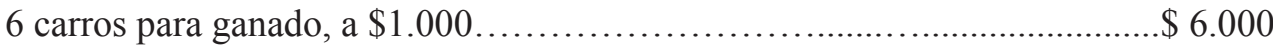

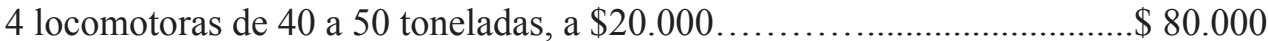

Valor de fletes, etc $\$ 8.000$ $\$ 150.000$

5- Valor del telégrafo y del teléfono, a \$200 el kilómetro, en 80 kms..........\$ 16.000 6-Valor de las cercas en 80 kilómetros, a \$300 el kilómetro $\$ 24.000$ 
Total $\$ 865.000$

No computando el valor de las zonas, el cual se puede cubrir posteriormente, tenemos:

Valor de la línea. $\$ 1.117 .500$

Valor del material para equipo, etc. \$ 865.000

Valor del trazado 20.000

Total $\$ 2.002 .500$

Agregando 20 por ciento para gastos de administración e imprevistos, obtenemos $\$ 2.403 .000$, es decir, en números redondos $\$ 2.400 .000$ en oro, como costo de la línea equipada, o a razón de de $\$ 30.000$ por kilómetro. Esta cifra parece elevada a primera vista, pero si se tienen en cuenta las grandes dificultades que hay que vencer en la segunda y tercera secciones, resulta en realidad muy moderada.

Si el ferrocarril duplica su tráfico en poco tiempo, y así lo creo, producirá una utilidad líquida de \$100.000, es decir, 4,12 por 100 anual sobre $\$ 2.403 .000$.

Hemos visto que en la primera sección, del río Cauca a Pereira el costo kilométrico de la carrilera y de la explanación asciende a \$9.000. Juzgo que los 25 kilómetros equipados del Cauca a Pereira se pueden realizar con $\$ 500.000$ oro.

Me permito también indicar que en ningún caso la pendiente máxima debe pasar del 2 y medio compensada, y que el radio mínimo de las curvas no debe ser menor de 60 metros, salvo casos excepcionales, si la línea se hace a paralela de sesenta centímetros.

\section{CONCLUSIÓN}

Por la exposición que precede, llegamos a las siguientes conclusiones:

$1^{\text {a }}$ El ferrocarril del río Cauca a Manizales es una obra importante para el comercio del Departamento de Caldas. Su realización completa podría hacerse en un lapso no mayor de cuatro años.

La primera sección del río Cauca a Pereira se haría en un año.

La segunda en uno y medio años, y la tercera en dos años.

$2^{\mathrm{a}}$ La obra entera podrá costar aproximadamente.

repartidos de la manera siguiente:

Estudio del trazado...

$\$ 20.000$ 
Primera sección, sin obras de arte $\$ 225.000$

Segunda sección, sin obras de arte...... $\$ 337.500$

Tercera sección, sin obras de arte ... $\$ 555.000$

Obras de arte en toda la línea. $\$ 500.000$

Edificios varios (estaciones, bodegas, etc.) $\$ 100.000$

Taller y herramientas. $\$ 75.000$

Material rodante $\$ 150.000$

Telégrafos, teléfonos y cercas $\$ 40.000$

Total $\$ 2.002 .500$

Más 20\% para la administración e imprevistos $\$ 403.000$

Suma total $\$ 2.405 .500$

$3^{\text {a }}$ La Estación inicial debe ser Cartago o un punto inmediato sobre el río Cauca, si se desea conectarlo con el ferrocarril del Pacífico, o La Virginia, si se hace la vía a Utría.

$4^{\mathrm{a}}$ Convendría hacer un estudio cuidadoso para la construcción de un ramal a Armenia, por ser esta región muy rica y de un gran porvenir comercial.

Soy del señor Presidente, atento seguro servidor,

Ingeniero FELIPE ZAPATA C. ${ }^{4}$

4. Anales de Ingeniería, Sociedad de Ingenieros de Colombia, pag. 254 


\section{ANEXO No 2}

\section{Informe del Ingeniero Jorge Páez González}

Nota del Autor: "Se presenta a continuación, la primera parte del Informe del Ingeniero Páez González, por considerarlo de valor histórico en el recuento de la construcción del Ferrocarril de Caldas. En la segunda parte, el ingeniero hace un pormenorizado estudio de las alternativas del trazado y construcción de la línea férrea entre la zona de Malabar y los distintos puntos de posible llegada al río Cauca, a saber: la Fresneda (hoy Anacaro) pasando por Cartago, el de la desembocadura del río La Vieja al río Cauca (Calabazas) y el de Puerto Dagua, un poco más abajo de la Virginia, con las valoraciones de sus beneficios y cargas, sus dificultades constructivas y los costos respectivos. Después del exhaustivo estudio, concluye que la mejor opción es iniciar la carrilera en el sitio de Calabazas, en la desembocadura del río La Vieja al Cauca, o sea, en el mismo sitio en donde se localizó la estación de Puerto Caldas, primera estación del Ferrocarril de Caldas.

Es bueno recordar, que de acuerdo con esta conclusión, se inició la construcción del ferrocarril en Puerto Caldas, con dirección hacia Malabar, y después de llevar algunos kilómetros explanados, se planteó una variante que pasaría frente a la ciudad de Cartago y ascendería hacia Pereira por la margen derecha del río Consota, hasta encontrar la línea original cerca al sitio conocido como Zanjón Hondo, hoy estación Belmonte. Habiendo sido aprobada esta variante por el Ministerio de Obras Públicas, se reinició la construcción en ese sentido.

Una de las consideraciones de mayor peso para el cambio de dirección, fue sin duda, la perspectiva de que el Ferrocarril del Pacífico llegara a Cartago en corto tiempo, lo cual significaría que el Ferrocarril de Caldas podría conectarse con él, y así, dicho ferrocarril se "alargaría" automáticamente hasta el Puerto de Buenaventura, como en efecto sucedió.

Por estas razones, decidí, omitir la narrativa de todas esas consideraciones que hoy no tienen ningún significado". 
Pereira, enero 30 de 1913

Señor Presidente, señores miembros de la Junta Directiva del Ferrocarril de Caldas. - Manizales.

Tengo el honor de rendiros informe general acerca de los trabajos trazados para este ferrocarril, hasta hoy ejecutados. En Marzo del año pasado bajamos por primera vez de aquí para el rio Cauca a iniciar la labor. Encontramos entonces que se presentaban o proponían dos opciones para la decisión del delicadísimo problema de la fijación del punto inicial del Ferrocarril sobre el rio Cauca, estando en consecuencia, dividida la opinión a ese respecto, aduciendo cada cual las razones más o menos justas o exageradas en pro o en contra de cada proyecto.

Estas dos soluciones eran la dela Fresneda pasando por Cartago y la de puerto Dagua, distantes uno de otro, estos dos puertos, 25 kilómetros por rio. A causa de esta indeterminación no fue, pues, posible principiar inmediatamente en firme el trazado. Por eso después de recorrer todo el terreno entre esos dos puertos y no encontrando nosotros tampoco a primera vista y como según parece no las ha habido, razones de orden superior o general suficientemente claras o terminantes que obligaran a fijar a priori el puerto, se hizo necesario el recurrir a los estudios técnicos sobre el terreno, y el acopio del mayor número de datos posibles con el fin de hacer luz e ilustrar lo más pronto el punto, para tratar de poner en su justo valor, a lo menos algunas de las apreciaciones de las diferentes opiniones, por lo cual determinamos el hacer ante todo dos trazados meramente provisionales o de reconocimiento en pendiente próximamente del dos por ciento ( $2 \%$ ); uno a Cartago (pues ahí se desprendían dos soluciones análogas; una a la Fresneda y otra a bocas del rio de La Vieja); y otro a puerto Dagua. En el informe que sobre este y otros temas rendí con fecha primero de mayo del año pasado, manifesté como resultado de estos dos estudios, que la línea a la Fresneda, lo mismo que a bocas del rio La Vieja, pasando por Cartago, saldría unos ocho (8) kilómetros más larga que la de Puerto Dagua; y que pasaría en algún trayecto por un terreno más abrupto y rocoso. Este es el de la región llamada de las Chapas que está caracterizada por una inclinación media trasversal de $45^{\circ}$, al paso que el terreno de la vía de Puerto Dagua tiene generalmente una inclinación media de $30^{\circ}$. Estos dos hechos hacían, naturalmente, más costosa la línea por Cartago. En cambio, por puerto Dagua se necesitaban unos veinte kilómetros más de navegación, por la distancia entre Fresneda y aquel puerto. Entonces este dato lo di apreciado a ojo y por referencias. Hoy, después de levantar el plano entre puerto Dagua y bocas de la Vieja que mide diez y ocho (18) kilómetros, y habiendo navegado entre Fresneda y bocas de La Vieja, puedo aseverar que aquella distancia no es menor de veinticinco kilómetros (25). Después de ejecutar este trabajo y mientras se decidía el punto de la elección del puerto, nos trasladamos a Pereira a hacer el trazado, de 
allí para abajo, teniendo necesidad naturalmente de levantar previamente planos y perfiles en la zona elegida para obtener datos precisos respecto a las pendientes que se podrían adoptar. Se estudió también entonces, la salida de Pereira para Manizales y se trazaron algunos kilómetros.

\section{Descripción de la línea}

La línea parte como se ve en el plano, del lado de abajo del puente de Mosquera sobre el rio Otún, muy cerca de dicho puente para cruzar el rio en ese lugar con la línea hacia Manizales, sin tocar con el camino de herradura. A los cuatrocientos metros debajo de este punto de origen, estudiamos detenidamente la localidad y levantando un plano acotado se proyectó allí la estación para Pereira en el sitio llamado El Polo, como se verá en el plano especial correspondiente. La línea sigue después rio Otún abajo con pendiente compensada de uno con cuatro por ciento (1.4\%). La compensación se ha hecho en toda la línea a razón de $0.04 \%$ por cada grado de ángulo al centro en cuerda de veinte metros (20). En las curvas que quedan inmediatamente arriba de las estaciones o paraderos la compensación se ha elevado a 0.1 por ciento. Como el rio lleva en esta parte una pendiente de más o menos dos por ciento, la línea aunque continúa por las vertientes o faldas entre la cuchilla del camino a Cartago y el rio, se va separando poco a poco de este hasta que en el kilómetro diez (10), en el sitio llamado zanjón-hondo, la línea al alcanzar la cuchilla toca en el camino pero sin atravesarlo. De ahí para abajo como la cuchilla tiene bruscos descensos y depresiones relativamente profundas fue necesario aumentar la pendiente al uno y medio por ciento $(11 / 2 \%)$ compensando. Sigue la línea separándose definitivamente del rio hasta pasar en el sitio llamado Malabar, kilómetro 16, a las vertientes de la quebrada llamada "Quebrada Grande", que desemboca directamente en el rio Cauca. Continúa bajando hasta caer a la quebrada en el kilómetro veinte [20] a la cual sigue con pendientes muy moderadas, hasta el kilómetro 22 más 500 metros. En este punto la quebrada se hace corrientosa y principia a tener fuertes saltos y caídas sin que sea posible seguirla con un trazado, y la línea, que vuelve otra vez al $11 / 2 \%$, se le separa hacia la izquierda llegando a la cuchilla que divide las aguas de esta quebrada de las de la quebrada de Hato Viejo, que es la cuchilla por dónde va el camino a puerto Dagua. Atraviesa esta cuchilla, y continua al dos por ciento $(2 \%)$ compensando cortando las vertientes que bajan de la meseta de la hacienda de Alsacia en una serie de cuchillas y profundas cañadas entre las cuales hay algunas corrientes de agua poco considerables y que todas al rio Cauca, hasta llegar a dicho rio en el sitio llamado Calabazas kilómetro 36 más 400 metros, donde se proyecta la estación, un kilómetro debajo de la desembocadura del río de La Vieja. 
En este trazado se han dejado pequeños trayectos a nivel en previsión de que convenga establecer paraderos, en los siguientes sitios: en donde corta el camino de Segovia, kilómetro 4; en el caserío de Nacederos, kilómetro 5 más 700 metros; en Malabar, kilómetro 16; camino de puerto Dagua, kilómetro 23 más 800 metros, y loma de El Billar, kilometro 20 más 700 metros. El terreno que se recorre, así como en general el de toda esta región es muy engañoso, pues, aunque aparentemente se ve como muy ameno y fácil, al ir a la práctica se encuentra que está cortado con frecuencia por profundas cañadas, y que donde no son mesetas cruzadas por tales cañadas, se atraviesa terreno de falda de inclinación trasversal considerable, donde las rugosidades, cuchillas y cañadas se hacen más frecuentes y sensibles. En la parte que no se ve por estar cubierta de bosque es aún más quebrada. En general no se encuentra roca dura o de costosa excavación en ninguna parte de la línea, de tal manera que se puede deducir por la muy poca que se ve, que a lo sumo ascenderá a un cinco por ciento $(5 \%)$ del volumen total por remover. $\mathrm{Y}$ sin embargo no se ven tampoco derrumbes y la consistencia del terreno es al propio tiempo tal, que se puede contar por lo que se ve en obras ya hechas, con que resistirá muy bien un talud de medio horizontal por uno vertical [1/2 x 1] y aún más próximo a la vertical sin derrumbarse. No obstante, este gran número de cuencas y cañadas, por lo que pudiera creerse que saldría muy costoso el capítulo de obras de arte, no sucede así porque generalmente no corre agua permanente por tales cuencas y la que se recoja en las lluvias no podrá ser de mucha consideración debido a que como generalmente va la línea a poca distancia de las cuchillas donde tales cañadas tienen su origen, la longitud de ellas raras veces asciende a dos o tres kilómetros de la línea para arriba. Por eso he considerado que generalmente con colocar tubos de treinta 30 a sesenta centímetros de diámetro bajo de los terraplenes es suficiente. Estos tubos pudieran ser de arcilla vitrificada, de acero, fundición o cemento. Los primeros son baratos pero más fáciles de romperse, los metálicos son más durables pero más costosos. Para los de cemento no tengo a la vista datos seguros sobre precios pero una vez que se sepa a como cuesta el cemento que en todo caso habrá que importar, y como tal vez se puedan construir los tubos en el mismo sitio de su colocación se puede entonces juzgar y resolver con más precisión. Otro motivo que induce a dar la preferencia a los tubos, es que en más de la mitad de la línea, desde poco debajo de Pereira hasta Quebrada Grande y en varios otros trayectos se carece, casi en absoluto, de piedra de construcción. Será preciso, y lo mejor, usar hormigón, pues el cascajo y piedra pequeña son menos escasos. Por lo ex-puesto se comprende que no hayan resultado, como se ven en el perfil, fuera de los tubos, generalmente sino pequeñas alcantarillas de sesenta centímetros de luz, cuatro alcantarillas de uno a dos metros de luz, sobre las quebradas de Egoyá, Hato-Viejo y Alsacia, y otra pequeña corriente, y dos pontones de tres a cuatro metros de altura; uno sobre quebrada Grande, y otro para un paso superior sobre el camino del matadero público 
en Pereira. Como se ve todas estas son obras insignificantes. La única digna de mencionarse como especial es un viaducto de más de cien metros de largo [100] y treinta metros de pila de mayor altura. Las fundaciones para estas pocas obras serán también muy poco costosas pues el terreno se presenta sólido y resistente desde casi superficialmente.

El material propio para balasto no se encuentra en cantidad abundante o suficiente sino en la parte baja de la línea, en las cercanías del rio Cauca, de manera que habrá que transportarlo hacia arriba. Las características del trazado, como se ve en los planos, son los siguientes: pendiente máxima el dos por ciento $(2 \%)$ compensando; radio mínimo de curvas de setenta y un metro con ochenta y cinco $\mathrm{cm}$. $[71,85]$ ( $16^{\circ}$ grados métricos), alineamientos recto mínimo treinta y cinco metros [35]; longitud total de los alineamientos rectos 25.259 metros, longitud de las curvas 11.141 metros; número de grados 6.204 $14^{\prime}$. Habrá que construir un edificio para estación en Pereira y otro en Calabazas. Además, algunos pequeños para simples paraderos. Mientras llega el momento oportuno para la construcción de un taller definitivo para el servicio de toda la línea hasta Manizales, en clima benigno y con energía hidráulica, será preciso establecer uno pequeño y provisional en Calabazas. Considero que será suficiente un torno, una taladora, una cepilladora, un pequeño cubilote de fundición y dos fraguas bien surtidas. Todo movido con un motor de explosión que es más económico que el de vapor. Queda así descrita en su aspecto y caracteres generales la línea adoptada. Al ejecutarse la localización final, después de despejado el terreno del bosque y del rastrojo, se harán todavía modificaciones que mejoren la línea, y se pondrán las curvas de transición o empalme entre alineamientos rectos y curvos. Al ir bajando con este trazado, de paso estudiamos el valle del rio Consota que ofrecía mejorar la pendiente y aparentaba facilidad y economía para la construcción, pero no resultó ser así. Trazamos seis (6) kilómetros pasando de un valle a otro por la depresión de Nacederos, donde se desprendía esta línea y fuimos hasta Zanjón-hondo. La línea por allí se alargó un kilómetro; el perfil quedó, sino peor, igual al de la línea de 0tún, fuera de que se necesitaba un pequeño túnel para atravesar la cuchilla en Nacederos. Este exceso de costo no quedaba compensando, como se puede demostrar, con la disminución de solo unos $0.2 \%$ por ciento en la pendiente, y teniendo en cuenta que muy cerca habría que volver a usar mayor pendiente y cruzar nuevamente el camino.

\section{Elección del puerto y de la vía}

Antes de terminar el trazado y al llegar con él al sitio de Malabar preguntamos a la Honorable Junta Directiva sobre la decisión que se hubiera tomado respecto a la elección de puerto para saber la dirección que debíamos seguir con la línea. La Junta entonces dispuso en su sesión de 2 de Agosto en esta ciudad: 'Ejecútese a la mayor 
brevedad posible un trazado definitivo que partiendo de un punto comprendido entre puerto Chávez y la desembocadura de La Vieja vaya a Manizales sin mirar en la elección de este otra cosa que las conveniencias técnicas y económicas de la línea propiamente tal, trazado que es indispensable para basar futuras resoluciones toda vez que el señor Ingeniero Jefe Io asegurara como que reúne las condiciones que debe satisfacer".

Puerto Chávez es un punto situado a pocas cuadras abajo de Puerto Dagua y dista en consecuencia más de diez y ocho [18] kilometres, por el rio, de la desembocadura del rio de la Vieja.

Se hizo preciso, pues, buscar la línea que mejor se ajustara o consultara las conveniencias técnicas y económicas, entre todas las soluciones que entre aquellos dos límites: Puerto Chávez y rio la Vieja, se pudieran presentar. En consecuencia, para poder resolver debidamente el problema había necesidad de conocer lo más detalladamente posible toda la extensión de terreno dentro de la cual debería encontrarse la solución. Por eso procedimos inmediatamente a levantar taquimétricamente un plano general principiando en el sitio de Malabar, donde las distintas soluciones podrían comenzar a presentarse, por el camino a la Fonda de Chiqueros y a Cerritos, y del área comprendida entre los dos caminos a Cartago y a Puerto Dagua, el rio de la Vieja y el rio Cauca. Sobre este plano anotamos además las direcciones de algunas cuchillas y corrientes de agua que se consideraron como más necesarias, así como las alturas de gran número de puntos, que eran indispensables. En mi primer informe manifesté la opinión de que la pendiente en este trayecto del rio Cauca hasta Pereira no debería ser superior al dos por ciento [2\%]. La topografía general del terreno a la cual está pendiente parecía acomodarse sin artificios y las ventajas económicas de la línea para la explotación, así lo indicaban. Elegida, pues, esta pendiente, era claro que la mejor solución técnica y muy probablemente, puede decirse seguramente, la más barata era aquella que de un extremo a otro llevara la línea de manera directa y natural sin rodeos, retrocesos, ni ninguna clase de trazos forzados. El estudio del plano levantado y el conocimiento que habíamos adquirido del terreno con las líneas que se habían recorrido, nos indujeron a pensar que, no obstante aparecer las distancias directas bastantes más cortas de lo necesario para una pendiente dada, por lo engañoso y arrugado del terreno, sería posible llegar al rio Cauca a las cercanías de las bocas de la Vieja con la línea directa de pendiente del dos por ciento (2\%) además allá existía un buen punto muy apropiado para puerto el cual habíamos visitado anteriormente en ocasión en que habíamos tenido el honor de hacer compañía al señor Gobernador y a otras personas importantes en una excursión en la cual subimos en buque de vapor desde Puerto Dagua hasta aquel puerto, en donde sin inconveniente ninguno arrimó el buque y comodamente desembarcamos. Dadas estas ventajas técnicas y económicas estaba claramente indicada aquella 
como la solución buscada. Por esto hacia allá emprendimos el trazado cuyos planos y perfiles os presento, habiendo efectivamente llegado al puerto deseado, sin que nos hubiera resultado, ni un hectómetro de mas ni de menos de la distancia necesaria y sin tener que hacer desarrollos especiales. A ese puerto llegamos en plena época de lluvias, estando el rio Cauca en altas aguas, y sin embargo la cota roja en terreno firme, para la estación tiene cinco (5) metros sobre las aguas, y el punto más bajo del terreno, antes de llegar a la estación, todavía dos (2) metros sobre aquellas mismas aguas. Resuelta de esa manera la dificultad conviene, o mejor dicho, se debe estudiar el asunto desde otros puntos de vista más trascendentales para el Departamento y para el éxito de la Empresa misma y que, seguramente, han de imponer la solución. A este respecto ofrece también la línea trazada importantes ventajas a mi modo de ver.

Primera. -A igualdad de pendiente, es evidente que cualquier otro puerto que quede abajo del adoptado gravará los cargamentos que viajen por el río con el flete correspondiente a la distancia a que se encuentren los dos puertos, ya que Ia vía férrea tiene que resultar por lo menos de igual longitud. En puerto Dagua, por, ejemplo, pagarían diez y ocho [18] kilómetros del rio fuera del flete férreo que sería lo mismo.

Segunda- EI puerto adoptado elimina o por lo menos reduce a su menos valor el peligro que ofrecen los otros puntos de ahí para abajo, de que en las épocas de verano, cuando la navegación del rio queda suspendida, el Ferrocarril quede también en seco, es decir, sin carga, por lo menos hasta Malabar u otro lugar cercano al camino de herradura. Este peligro crece naturalmente con la distancia a que se baje el puerto. En efecto: es evidente, que si, por ejemplo, se adopta Puerto Dagua para inicial del Ferrocarril, y ocurre una suspensión de la navegación (lo que sucedió en el año pasado durante cuatro meses), es evidente, digo, que una recua que al venir de Cali, por ejemplo, se encuentre en Cartago seguirá más bien por el camino actual hacia Pereira, o por lo menos hasta la primera estación que encuentre, Malabar, por ejemplo, que está a trece $\{13\}$ kilómetros de Cartago, que bajar a Puerto Dagua, a una distancia de Cartago de, por lo menos, cuatro leguas, por clima más fuerte y para llegar a recargarse con unos kilómetros de Ferrocarril que habría podido evitarse con menos jornada por camino de herradura. Análoga cosa sucederá con los cargamentos que bajen de Pereira, los cuales abandonarían el Ferrocarril en Malabar para seguir de allí a Cartago por tierra, más bien que recargarse con el flete de kilómetros hasta Puerto Dagua para después subir de allí para llegar a Cartago. Todas estas consideraciones y distancias se aprecian claramente en el plano general de esa región, que adjunto.

Tercera-Como uno de los principales argumentos en favor de la vía de El Dagua 
ha sido el del tráfico y desarrollo de las regiones hacia el rio Risaralda y sus vecinos, y para los partidarios de Cartago el del tráfico de esa población y sus alrededores, con la línea adoptada pasando o cruzando el camino que se dirige a Puerto Dagua a una distancia insignificante de cinco[5] kilómetros de dicho puerto queda así de hecho servida la región del Risaralda, para continuar después acercándose a Cartago a procurar servir y beneficiar esa región también. No sucedería lo mismo si la línea fuera a Puerto Dagua, pues esta, en absoluto, no servirá a la región de Cartago. Surge ahora de esta consideración, y teniendo en cuenta que evidentemente al ferrocarril le conviene moral y pecuniariamente el aprovechar el tráfico que le pueda producir Cartago, otra duda, a saber: Será mejor pasar con el Ferrocarril por el puerto elegido para llevarlo a terminar en Cartago, o viceversa, pasarlo primero por frente a Cartago para venir a terminar en el río?. En ambos casos se alargará la línea por lo menos de siete a ocho kilómetros. Para aclarar esta duda estudiemos, en primer lugar las soluciones para llegar primero a Cartago. La más directa y que solo exigiría el dos por ciento ( $2 \%$ ) de pendiente seguiría, más o menos, nuestra primera línea de reconocimiento que figura en el plano entre Malabar y Puente Bolívar. Pero esta solución ofrece dos desventajas: primera, la de que recorre toda la región de las Chapas formada en terreno abrupto por frecuentes y profundas cañadas separadas por cuchillas angostas y prolongadas, motivo por el cual es esta la línea de mayor costo kilométrico; y segunda, la de que es la que más se retira de Puerto Dagua y por consiguiente ofrece el menor servicio para esa región. Por eso, en mi concepto, la mejor solución para llegar frente a Cartago, sería la que desprendiéndose de la línea que hemos trazado, en el punto en que esta corta el camino para ir a puerto Dagua, marcado "Pedro Rojas" en el plano general, fuera a buscar algún sitio algo más abajo del puente de Bolívar. Como la distancia entre estos dos puntos es mayor que la que hay por la línea adoptada, a Calabazas, ofrecería la ventaja de que la pendiente podría ser del uno y medio por ciento (1.5\%) compensando, es decir, la misma que, como máxima, lleva la línea desde Pereira, hasta el camino de puerto Dagua. El exceso de longitud hasta Cartago, de esta línea, seria de poco más de tres kilómetros. Sentado esto: veamos cuál de las dos soluciones ofrece mayores ventajas para el público por menor costo de los transportes y para la Empresa por asegurarle más fácilmente el tráfico. Con este fin anotemos en primer lugar ciertas distancias que los datos del plano general nos suministran, y admitamos los siguientes precios aproximados para los transportes:

\section{Distancias por vía férrea}

De Pedro Rojas a Calabazas:

Por la vía adoptada o directa 13 kilómetros.

Por Cartago 14 "

De Malabar a Cartago: 
Por la vía adoptada o sea por Calabazas 29 "

Directamente 24 "

\section{Distancias por camino de herradura}

De Pedro Rojas a puerto Dagua 5 "

De Malabar a Cartago 13 "

\section{Tarifas}

Para el ferrocarril por toneladas y por kilómetro \$10 papel

Precio más bien alto.

Para caminos de herradura por tonelada y por kilómetro $\$ 10$ "

Precio más bien bajo.

Para la navegación por buque $\$ 5.92$

Precio actual vigente deducido del exceso que cobran los buques para la carga de puerto Dagua sobre el de la Fresneda que viaje de, o para otro puerto arriba de éste, que lo que es el precio para la que viaje propiamente entre estos dos puertos es cinco y media veces más alto.

Con estos datos analicemos ahora los casos que se pueden presentar:

\section{Primero - Línea a Calabazas terminando en Cartago.}

La carga que vaya o venga por el rio queda expuesta a la competencia hasta Pedro Rojas así:

Por buques hasta puerto Dagua y de ahí por recuas hasta Pedro Rojas. Veamos que fletes pagaría:

Por Ferrocarril a \$ 10 tonelada

En 13 kilómetros $\$ 130$

Por buque 18 kilómetros a $\$ 5.92 \$ 106.56$

Por camino de herradura 5 kilómetro a $\$ 10 \$ 50$

Suma $\$ 156.56$

Diferencia a favor del ferrocarril $\$ 26.56$

La carga de Cartago queda expuesta a la competencia del camino de herradura así: Por ferrocarril en 29 kilómetros \$ 290 
Caminos de herradura en 13 kilómetros $\$ 130$

Diferencia en contra del ferrocarril \$ 160

Es decir que por esta vía la Empresa cuenta fácilmente desde el puerto con la carga del rio que, como veremos más adelante es la más, por poderle ofrecer el mínimo flete, y que tiene peligro de perder la carga de Cartago hasta Malabar o de tener que rebajar o poner $\$ 160$, por tonelada hasta ese punto.

\section{Segundo. - Línea a Cartago terminado en Calabazas.}

La carga del rio queda expuesta a la competencia hasta Pedro Rojas así:

Flete férreo en 24 kilómetros \$ 240

Flete buques y herradura $\$ 15.656$

Diferencia en contra del ferrocarril \$ 8.344

Es decir que el ferrocarril queda expuesto a perder la carga del rio que es más hasta Pedro Rojas, o a tener que rebajarle $\$ 8.344$ por tonelada.

La carga de Cartago queda expuesta a la competencia del camino de herradura hasta Malabar así:

Flete férreo en 24 kilómetros $\$ 240$

Flete de herradura en 13 kilómetros $\$ 130$

Diferencia en contra del ferrocarril \$110

Total en contra del ferrocarril en este segundo caso $\$ 193.44$

En resumen: Por la línea directa a Calabazas la Empresa tendrá segura toda la carga del rio pero quedara expuesta a perder la de Cartago hasta Malabar a menos de rebajarle \$160.000 en tonelada; al paso que con la línea por Cartago queda expuesta no solo a perder la carga del rio hasta Pedro Rojas, si no la de Cartago también hasta Malabar, o hacer una pérdida por ambas de \$193.44 por tonelada. Por supuesto que Ios anteriores resultados numéricos no son en valor absoluto exactos, pero si en valor relativo hacen ver claramente lo que sucederá.

Para no alargarme demasiado no hago otra comparación análoga para la vía directa del dos por ciento (2\%) entre Malabar y Cartago terminado en bocas de rio de la Vieja, por la cual se ve que esa línea queda también muy expuesta a sufrir la competencia hasta el Cerrito para toda la carga [tanto la del rio como la de Cartago] 
y aun hasta Malabar para la de Cartago. Dije arriba que la mayor cantidad de carga será la que viaje por rio.

Esto es obvio a primera vista, pero para mayor certeza en las previsiones conviene estudiar los pocos datos estadísticos de que se dispone. El doctor Zapata al calcular el tráfico probable estimó que podría aceptarse como base el de 18.000 toneladas anuales distribuidas así: 10.500 por café, pieles y carga de importación y exportación y el resto por crecimiento de este mismo tráfico a causa del ferrocarril y por el tráfico local hasta Manizales; luego es evidente que la mayor parte del tráfico según este cómputo será de importación y exportación y por consiguiente muchísimo mayor que el local que pueda suministrar a Cartago y sus alrededores. En un documento que tengo a la vista en que se me suministró de Cartago de forma oficial aunque de manera tan solo aproximada, es verdad, el tráfico que pasa por el puente de Bolívar, encuentro que por cacao, café, mercancías etc. corresponden 7.350 toneladas anuales, y por pasajeros y ganados mayor y menor, suponiendo a siete por tonelada por razón de fletes $[\$ 10.0$ ton.km. para la carga y $\$ 1.50$ por $\mathrm{km}$. para pasajeros y ganados], 4.800 toneladas anuales. Es, pues, según este dato también mayor la cantidad de carga que viaja por el rio que la de Cartago. Luego es evidente que la línea que mejor protege y se asegura el mayor tráfico es la que va directamente a Calabazas. Esta solución ofrece todavía otra ventaja: la de que la construcción de los siete u ocho kilómetros entre Cartago y Calabazas se puede posponer para cuando los recursos de la Empresa lo permitan y las necesidades del tráfico lo exijan o lo justifiquen, en tanto que si la línea pasa primero por Cartago, la Empresa se vería obligada a hacer mayor gasto inicial para la construcción de once (11) kilometres más para llegar al rio, ya que ese es el objetivo del ferrocarril, el cual trata de aprovechar las ventajas de la navegación, estimulando la competencia del rio Cauca con el ferrocarril del Pacifico el día que este venga a Cartago. Existe todavía otra solución de construcción menos costosa y que es preciso, por eso, conocer en sus diferentes fases para poder apreciarla debidamente. Es la que con pendiente todavía mayor del dos por ciento $(2 \%)$ vaya directamente a puerto Dagua. El estudio del plano general del área, y del perfil de la línea trazada hace ver qué si se parte más o menos de la estación 22 kilómetros más 500 metros, en Quebrada Grande, donde esta principia a hacerse correntosa, se podría llegar casi directamente a aquel puerto con una línea del tres por ciento (3\%) compensado, de ocho [8] kilómetros. Esto es, con un acortamiento de seis kilometres (6) respecto a la línea del dos por ciento $(2 \%)$ y por lo tanto con un ahorro de unos ciento ochenta mil pesos oro (180.000) en gastos del primer establecimiento. Si fuera esto lo único que se tuviera en cuenta seria indudablemente la línea del tres por ciento la solución indicada. Pero sucede que si, en caso del $2 \%$ y el $1.5 \%$, a esta economía de primer establecimiento en favor de la primera se agregan otras ventajas, como, principalmente, la de que por la línea del $2 \%$ se asegura en mejores condiciones para la Empresa y para el público la parte más considerable del tráfico, en caso del $3 \%$ al 2\%, es al contrario: a la economía 
de establecimiento en el 3\%, además de la consideración de la pendiente, se oponen otras circunstancias que hay que tener en cuenta, a saber:

Primera. La del peligro de que el ferrocarril se quede sin carga en las épocas de verano, de que ya hablamos.

Segunda. La de que por esta vía se prescinde en absoluto de| tráfico de Cartago; y Tercera. La de que para el público no ofrece ventaja sobre la que se trazó; en efecto: por el acortamiento de seis kilómetros de vía férrea se ahorrarían a razón de $\$ 10$ tonelada-kilómetro, \$60 por tonelada, pero. en cambio se alargaría la navegación en diez y ocho (18) kilómetros, lo que costaría como vimos anteriormente \$106.56. Se podría demostrar con datos deducidos de los publicados por el F.C. de Antioquia, por ejemplo, para no hacer uso de coeficientes extranjeros quizás menos adecuados a las circunstancias, que un exceso de costo para mejorar Ia pendiente en el trayecto que se estudia solo quedaría justificado, por disminución de gastos en la exploración, para un tráfico varias veces más alto que el que con amplitud, se ha presupuesto para esta Empresa. Pero para no alargarme demasiado, me limito a consignar que el número de toneladas anuales no debería ser menor de cien mil (100.000). Además, consideraciones de ese orden poco valor tiene en este caso, ante las ya tenidas en cuenta respecto a las probabilidades de aprovechar o de perder en ese trayecto, la porción más considerable del tráfico y que más interesa al Departamento, a un precio kilométrico muy aceptable por el ferrocarril. En resumen: he trazado en firme la línea a las bocas del río de la Vieja en el sitio Calabazas porque ofrece las siguientes ventajas:

Primera. - Dada la pendiente del 2\%, muy adecuada al terreno y técnicamente muy aceptable, es seguramente la línea de construcción menos costosa.

Segunda - Ofrece las mayores ventajas asegurando el menor flete para la mayor y principal parte de la carga del Departamento.

Tercera - Porque sin prescindir de la región servida por Puerto Dagua, puesto que pasa a cinco kilómetros de muy buen camino de dicho puerto se acerca también y va a buscar el tráfico de Cartago. Por todo lo cual tiene todas las probabilidades de ser la que sirve mejor número de intereses y produce por tanto el mayor rendimiento. Todo esto, por supuesto en la hipótesis de que, como parece lo más probable, por mucho tiempo el tráfico del Departamento vaya a buscar la vía de Buenaventura, que si va a buscar la vía Utría lo que tal vez esta remoto, entonces, como con razón Io dijo el Doctor Zapata, el puerto indicado es el de Dagua.

\section{Personal}


El trabajo ha sido ejecutado en asocio de los señores Héctor 0. Acevedo y Julián Arango quienes han colaborado inteligentemente dedicando con consagración sus conocimientos y pericia a la Empresa, el primero corno encargado del tránsito y el segundo del nivel. Desde septiembre nos acompaña también el señor Alonso Restrepo García Herreros como dibujante y topógrafo quien ha desempeñado igualmente a satisfacción, con habilidad y con constancia. Desgraciadamente el señor Acevedo no nos ha podido ayudar desde diciembre por motivos de salud, pero esperamos que pronto esté restablecido para contar nuevamente con sus servicios. Como lo he manifestado a la Honorable Junta Directiva, si se quiere, como me lo ha significado, que los trabajos avancen más rápidamente se hace preciso aumentar el personal de ingenieros. Esta necesidad es más imperiosa si, como parece lo más natural, se dispone la ejecución de la obra en la sección que se ha terminado.

Últimamente me ha comunicado el señor Gobernador que vendrán dos ayudantes más quienes se dedicarán por ahora a la terminación de los dibujos, atrasados por motivo de la enfermedad del señor Acevedo. El personal de trabajadores ha sido constantemente de diez a veinte.

\section{Generalidades}

Como se habrá observado en el curso de este informe, para todos los estudios me he colocado siempre, como era natural, en el punto de vista de los intereses del Departamento, y como he considerado, además que la Empresa después de tener el informe general del doctor Zapata que de manera preliminar dada idea clara respecto al estilo, costo y magnitud generales de la obra, lo que se propuso al ordenar la ejecución del trazado, fue el verificarlo como para realizar efectivamente la obra, y para obtener en consecuencia, datos ya más precisos, y sobre todo, acertar o procurar a lo menos en todo caso acertar con la mejor solución, por eso hemos hecho los estudios con el detenimiento y cuidado indispensables, pero esforzándonos al propio tiempo por no hacer en ningún caso ni menos de lo necesario ni más de lo suficiente. El primero y más delicado y trascendental problema que se ha presentado ha sido el de la elección del puerto sobre el rio Cauca, y la decisión de la vía entre las diferentes soluciones que se presentaban. La gravedad de este punto se comprende a primera vista como que de la acertada o desacertada solución puede quizás depender más tarde el éxito o fracaso motivo de severas críticas, tal vez justas, o con fundamento. La misma indecisión que ha habido a esos respectos patentiza que no ha habido razones suficientemente claras o que a primera vista resalten, para uniformar la opinión y que hubieran impuesto la elección a priori del puerto y de la vía. Por eso en este caso, mejor que en ningún otro ha tenido aplicación y justificación el reconocido aforismo de que en asuntos de Ingeniería, todo lo que se invierte en estudios previos y concienzudos es dinero que se gana con creces, y el 
acertado proceder de la Honorable Junta Directiva al ordenar y autorizar, como lo ha hecho, la ejecución de todos los trabajos conducentes a esclarecer el punto. Con este fin hemos llevado a cabo largos trabajos sobre el terreno, así: El estudio de tres líneas de Malabar para abajo [a Cartago, a bocas de la Vieja y a puerto Dagua], en terreno montañoso y cubierto de bosque, en vez del de una sola que hubiera bastado al haber estado de ante mano elegido el puerto. Todas estas líneas agregadas a la del trazado de Malabar para acá, a la de Pereira hacia Manizales, y a la del estudio por el rio Consota, de todas las cuales se ha hablado ya, ascienden a una longitud total de ochenta y seis [86] kilómetros, algo más larga que la presupuesta por el Dr. Zapata para distancia entre Manizales y el rio Cauca. Con el mismo objeto se levantó además, el plano general de varias leguas cuadradas que, como se habrá observado, de tanta utilidad ha sido para el estudio comparativo de las distintas soluciones. Teniendo en cuenta lo anteriormente expuesto, por una parte, y por otra que, siendo Pereira, como lo es, por sus condiciones comerciales y demás, un punto puede decirse obligado de la línea, que delimita o marca una de las secciones de ella, me propuse desde el principio hacer el estudio detenido de esta sección a fin de presentar, [como tengo esperanzas de haberlo conseguido] tan pronto como sea posible y dadas $\mid$ a5 condiciones y circunstancias de la Empresa, la mejor línea ya lista y definida, en donde sobre seguro se pudiera emprender activamente trabajos, si se quiere simultáneamente en toda ella. Cualquiera, que sea la vía que tenga a bien adoptar la Honorable Junta Directiva se podrían abrir los trabajos puesto que, aun no siendo adoptada la propuesta, aquello implicaría únicamente la ejecución de un corto trazado a lo más del kilómetro 22 para abajo, ya que de ahí para arriba no parece que haya motivo justo de variación. La pronta iniciación de los trabajos es indudablemente, cuestión de vital importancia para la Empresa. Tiene en efecto, Ia construcción de esta sección, entre otras las siguientes ventajas: una vez puesta en servicio estaría por ese solo hecho asegurada la terminación hasta Manizales pues sería la mejor base para poder levantar el capital necesario para el resto de la obra. Como por ahora es la parte que relativamente, mas rendimiento promete dejar, puesto que a la vez que es menos costosa que el resto de la línea, reúne o abarca, [aparte del tráfico local de aquí para arriba], la casi totalidad del tráfico que por aquí haya de transitar. Es esta una gran ventaja con que la mayor parte de nuestras empresas ferrocarrileras no han podido contar. Ta vez el presupuesto representa una suma considerable de dinero, pero ese no parece ser motivo para entorpecer o vacilar en una obra de carácter oficial que tiene en mira, más que el beneficio directo en dinero, el progreso y desarrollo del Departamento. Antes bien esto pone de manifiesto la necesidad de darle principio cuanto antes a fin de asegurar así la obra y poder tener esperanzas de contar con ella no tan demasiado tarde. Si Empresas que, justamente hoy, están siendo ya tan útiles y productoras, o en camino de serlo, como las del Cauca, Antioquia y Girardot no se hubieran principiado desde hace 40 años, por estar esperando a tener el dinero suficiente, y a que fueran comercialmente 
productivas, desde sus comienzos, no habría habido riesgo de acometerlas ni, por lo tanto, de llegar a obtener como Io estamos principiando a palpar hoy, sus redentores y benéficos resultados. Una vez terminado o siquiera adelantado este ferrocarril y terminado el cable a Manizales queda este Departamento en condiciones tales, como ninguno otro de los del interior del país lo está, con dos vías que a la vez que se complementan se ejercen mutuamente una saludable acción competidora controlada por el Gobierno, para completar así la que existirá entre el Magdalena y el Pacífico, y poder adoptar entonces la salida que mejor convenga, lo que producirá los resultados más favorables para su progreso y desarrollo. Estas dos vías prepararan debidamente a Manizales para la lucha de competencia que indudablemente tendrá que resistir por los ferrocarriles de Amagá y del Pacifico a medida que estas dos líneas avancen a Cartago. La Empresa, es verdad, exige dinero y no es obra fácil y común. Pero eso no importa: bueno es saberlo, y esto es lo que se necesita para no proceder impulsivamente ni por sorpresas o engaños, más o menos aparentemente justificables, pero siempre engaños con sus consiguientes desalientos, sino con pleno conocimiento de causa, de tal manera que podamos hacerlo como Io deseaba para los franceses algún hombre célebre: como pueblo consiente que sabe y quiere. Por eso sería de desearse que la próxima Asamblea terminara la patriótica obra de la del año pasado votando alguna partida del presupuesto para dar principio a los trabajos mientras fuera posible alguna de las operaciones de préstamo o de contrato que aquella autorizó. La simple iniciación de los trabajos, mejoraría enormemente el prospecto para una operación de préstamo.

\section{Línea de aquí para Manizales}

Respecto a esta línea informo que se ha dado principio en este mes a los estudios preliminares de zona y a tomar los datos topográficos necesarios, de manera de poder, tan pronto como los ayudantes disponibles dedicados por ahora a los dibujos, se desocupen, proceder de manera continua a los estudios y trazos definitivos. Están trazados dos kilómetros y medio de esta ciudad hasta la meseta de la Badea. Por los datos adquiridos y el conocimiento del terreno me inclino a creer que haya necesidad de emplear pendientes hasta del tres por ciento para obtener mayores ventajas. Como lo he manifestado ya a la Honorable Junta Directiva se debe aumentar el personal de Ingenieros si se quiere que el trabajo avance más rápidamente.

Nota: Para el caso de que no se abran pronto los trabajos, y por si fuere de utilidad más tarde, se han puesto catorce (14) mojones de piedra (puntos de tránsito y de nivel), en puntos de tangencia en varios lugares de la línea, como ha quedado anotado en las carteras y en los planos.

Ingeniero Jorge Páez González ${ }^{4}$

4. Informe del ingeniero Jefe, Ferrocarril de Caldas, Imprenta El Renacimiento, Manizales, 1913 


\section{ANEXO No 3 \\ Acta de instalación de los trabajos del Ferrocarril de Caldas y de fundación del puerto y población de Puerto Caldas. ${ }^{5}$}

A las 12 del día 16 de Julio de 1915, se reunieron en el paraje que se ha llamado La Isla, en la confluencia del rio La Vieja en el Cauca, paraje que en lo sucesivo se denominará "Puerto Caldas", perteneciente al Municipio de Pereira, los señores que en seguida se expresan: José Ignacio Villegas, Gobernador del Departamento de Caldas, Daniel Gutiérrez y Arango, miembro de la Junta del Ferrocarril, Pompilio Gutiérrez, Valeriano Marulanda, Luis A. Isaza, José Jesús Salazar, Alfonso Jaramillo, Elías Arango, Guillermo Velásquez, Julián Arango, Alonso Restrepo, Roberto Marulanda, Jaime Castro, Bernardo Gutiérrez, Jesús Cano, Antonio José Botero, Francisco Luis Arango, Bernardo Arango y Rodulfo Valencia.

El Gobernador manifestó que, habiendo llegado el momento de instalar los trabajos de construcción de la vía férrea que ha de unir la Capital del Departamento con un Puerto navegable sobre el río Cauca, y hallándose presente el Ingeniero que ha venido a encargarse de la dirección general de la obra, los declaraba formalmente instalados en el punto expresado que es el arranque del Ferrocarril; este punto fue elegido de conformidad con la Ley 105 de 1914 que facultó para ello al Departamento y consultando las conveniencias, tanto de la vía férrea como del comercio de aquella, porque según los estudios de los ingenieros es más fácil y económico su construcción adoptando este punto de partida y la dirección consiguiente del trazado, fuera de que los materiales pueden llegar directamente por el río Cauca al punto preciso en donde empieza el ferrocarril y es asimismo más ventajoso para el comercio, porque este tendrá con el tiempo dos vías a su elección: la fluvial del Cauca, actualmente en servicio, y, más tarde la del Ferrocarril del Pacífico cuando este llegue a la ciudad de Cartago, pues no hay duda de que la Nación construirá más adelante el corto trayecto de vía férrea entre aquella población y Puerto Caldas. Declara asimismo que los trabajos quedaban bajo la dirección suprema del Ingeniero Jefe, Sr. D. Luis C. Isaza, en quien se tiene plena confianza por su probada experiencia y versación en esta clase de empresas, y que esperaba que los (trabajadores) ingenieros subalternos, que son jóvenes inteligentes y pundonorosos, le prestarán obediencia, lo mismo que los demás trabajadores, y que, en cuanto a los habitantes de esta región, creía superfluo decir nada, pues le constaba la simpatía que todos tienen por esta magna obra, por lo cual confiaba en que darían apoyo a quien iba a encargarse de su dirección, contribuyendo todos de esta suerte, al éxito de la empresa.

5. Tomada del libro El Ferrocarril de Caldas, de Néstor Echeverri 
Acto continuo el Gobernador procedió a clavar una piedra en el punto de partida de la ferrovía.

Terminada esta operación declaró el mismo funcionario que habiéndose dispuesto el establecimiento y fundación de un puerto y una población, para lo cual se ha levantado ya el respectivo plano por los Drs. Julián Arango y Alonso Restrepo, designados al efecto por la Junta del Ferrocarril, la que les había impartido ya su aprobación, procedía a inaugurar ambas fundaciones. Se acordaron los nombres de las plazas, avenidas y calles principales así: Plaza de Bolívar (la principal), Plaza de Quimbaya, Plaza de Miranda y Plaza de Córdoba. Avenida Manizales, Avenida Pereira, Avenida Concha, en honor del actual Presidente de la República. Avenida Marulanda, en honor de los señores Juan María, Valeriano y Francisco Marulanda, por su labor meritoria en pro del progreso del Quindío en donde han descuajado selvas en una extensión de 32.000 hectáreas de tierra, convertidas luego en dehesas de pastos artificiales.

Las carreras $1^{\circ}, 2^{\circ}$ y $3^{\circ}$ llevan los nombres de Zea, Camilo Torres y Sucre. Se determinó en el terreno y se señaló sobre el plano lotes reservados para los siguientes edificios: Casa Municipal y Oficinas Nacionales, Casa Cural y Templo, bajo la advocación de la Virgen del Carmen por corresponder este día al de su fiesta, Escuela Pública de niños, Hospital, Cárcel y Coso, Matadero público, Mayoría, Casa del Departamento, Plaza de Mercado y Cementerio. Se procedió en seguida a clavar estacas para localizar los edificios y lugares mencionados. También se sembró en la mitad de la plaza principal una ceiba.

El Gobernador dispuso que, en primer término, se procediera a trazar y abrir el camino que debe unir la futura población con la vía pública que gira hacia Cartago, a fin de que el comercio de importación y exportación adopte esta vía que es la más corta y está libre de toda clase de gravamen, con lo que ahorrará mensualmente una suma de consideración, ya que podrá aprovechar los vapores del río que, en lo sucesivo cargarán y descargarán en este Puerto, en el que se va a construir en breve amplias y seguras bodegas. Con esto se dio por terminado el acto, del que se extiende por triplicado esta Acta que firman todos los que concurrieron a la diligencia. Un ejemplar de ella corresponde a la Junta del Ferrocarril que la guardará en sus archivos; otro a la Población de Puerto Caldas, que se enviará a la Municipalidad de Pereira para que lo conserve hasta que le sea reclamado por autoridad competente. El tercer ejemplar pasará a la Oficina de la Gobernación. Se advierte que en esta diligencia actuó como secretario ad-hoc el Dr. Daniel Gutiérrez y Arango, quien, como tal, autoriza la presente, que firmamos en Puerto Caldas, a la una de la tarde del día diez y seis de Julio de mil novecientos quince. 
Firman:

José Ignacio Villegas, Daniel Gutiérrez y Arango, Luis A. Isaza, Francisco Luis Arango, Alonso Restrepo, Valeriano Marulanda, Pompilio Gutiérrez, José Jesús Salazar, Bernardo Gutiérrez, Elías Arango, Roberto Marulanda, Jesús Cano M., Alfonso Jaramillo, Julián Arango, Jaime Castro, Guillermo Velásquez, Ronulfo Valencia.

\section{ANEXO N4}

\section{Acuerdo municipal n¹7 - fundación de Puerto Caldas}

Fuente:Archivo Municipal de Pereira

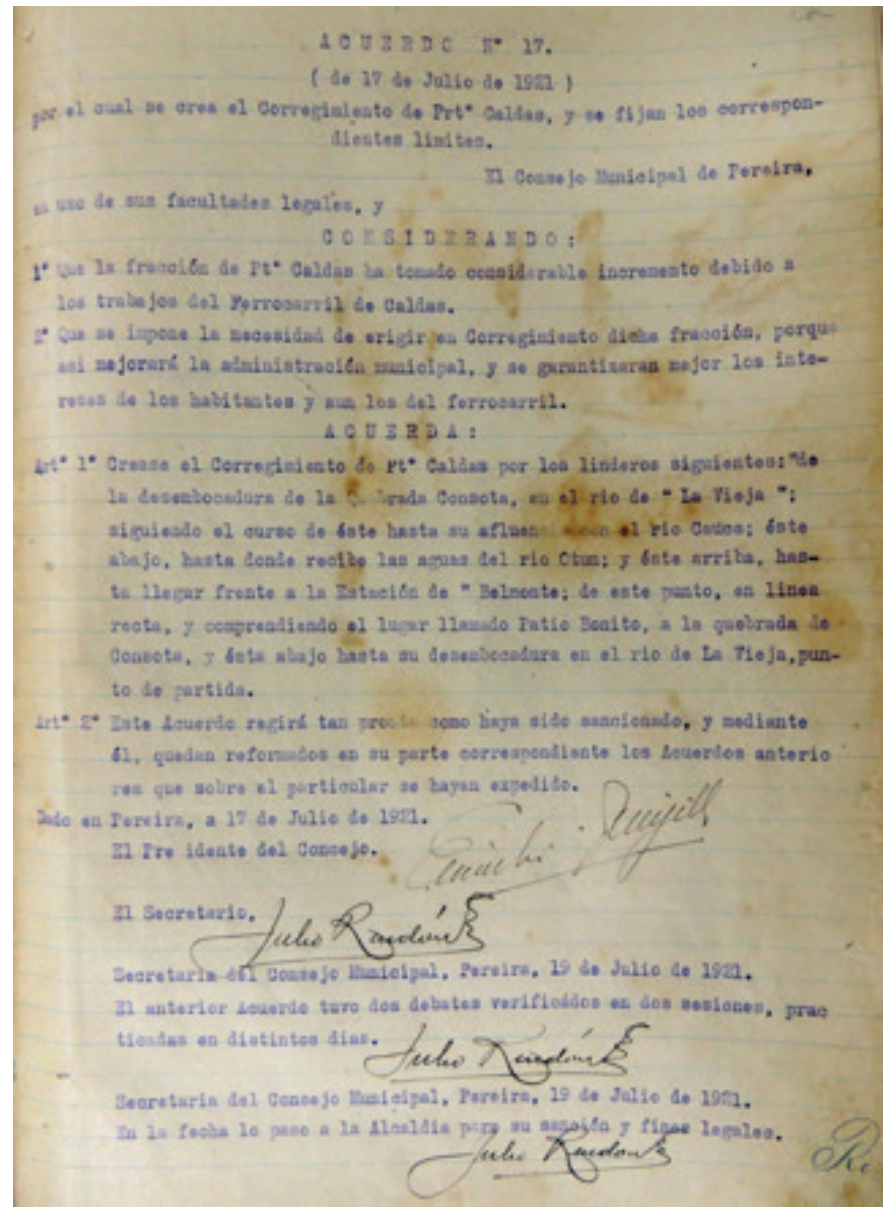




\section{ANEXO N ${ }^{\circ} 5$}

Nota del Autor: Ejemplares Números 24 a 29, impresos en Manizales, entre octubre 30 de 1919, y enero 15 de 1921, contienen las actas de 21 reuniones de la Junta Directiva del Ferrocarril de Caldas, informes del Superintendente y del Ingeniero Jefe, balances e informes sobre importaciones y mercancías movilizadas en el tren, entre otros temas de importancia para el ferrocarril.

Estos facsímiles fueron encontrados en la Biblioteca Nacional, en Bogotá.

Es de anotar que fue imposible encontrar información sobre los primeros 23 ediciones y las siguientes al mes de enero de 1921, hasta su culminación en el año 1927. Una verdadera lástima porque constituyen una fuente de información básica sobre la construcción del ferrocarril. Los 3 sucesivos incendios de la ciudad de Manizales, entre los años 22 y 26, dieron al traste con la mayoría de estos archivos, y los pocos que se lograron salvar fueron, posteriormente, destruidos por la orden incomprensible, por decir lo menos, de un mandatario departamental, en razón de que constituían un estorbo en las oficinas y no servían para nada.

En la ciudad de Pereira, se editó otro semanario con el mismo nombre, El Ferrocarril de Caldas, entre los meses de enero 16 a junio 01 de 1912 (16 ejemplares), dirigido a informar sobre los avances de la obra, para mantener a la población enterada de la forma en que se desarrollaban las obras y se trataba de crear y estimular el ánimo de la gente a favor de la obra. El periódico estaba financiado por la publicidad que se presentaba en cada ejemplar, sin faltar el editor o el dueño de la propaganda que regalaban sus expensas para sacar el tren adelante. 


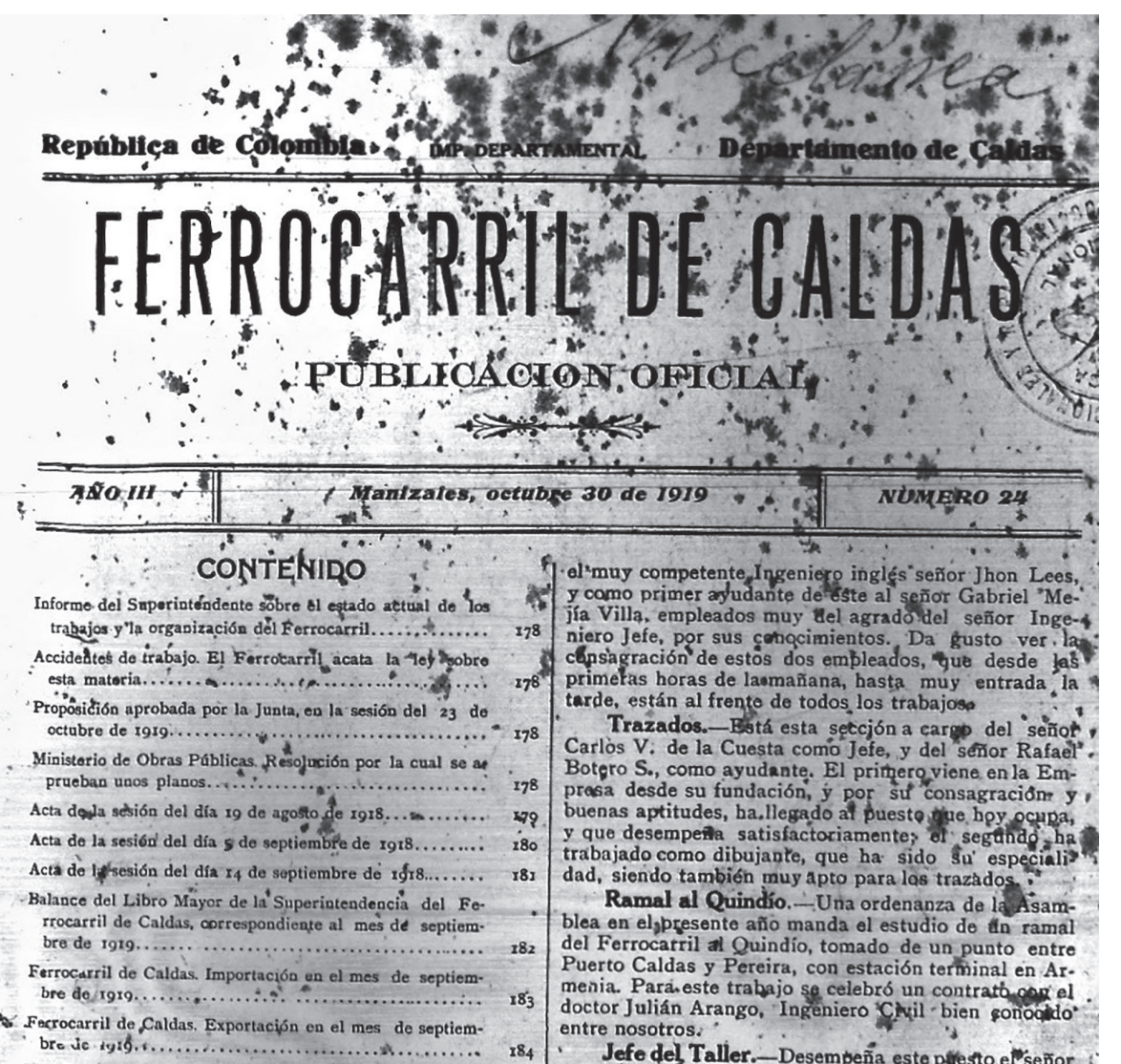

(de..............................

\section{FERROCARRIL DE CALDAS}

Informe del Superintendepte sobre el estado ac tual de los trabajos y su organización. Señores Miembrots de la Junta Directivà del Ferracarril de Cal.
das.-Ptes.

Aprovectho nh venida a esta ciudad, por noyeda des de familia, para rendir a la $\mathrm{H}$. Iunta un, intorine del' estado actual de los trabajos, y nás "que todo de su organización, estimada por muchos que ni siquiera conocen los trázados, scomo un desastre para los inte. reses del Departamento.

Ingeniero Jefe. 1 Estŕ doctor Eleuterio Serna doctor Eleuterio Serna, Ingeniero muy formpetente, que hizo'sus estudios completes en Fa Escuelar de Mpas de Medellín; posłe además jina práctica 'de algơ más de tres años en los' trabajos de. nuesto

- primero como Ingenierö Jefe de Sección, ty mís tarde como Divisionario. Cyando el doktor Jorge Escobar se retiraba de la Empresa, és que conocía amuy affondo al doctôr Serna, manife $\$$ a al suscritol que en ningu. na otra persolos podia faedar pejor la directión, $y_{1}$ a fe que estaba en lo vie $\sigma_{s}$ A su competencia se agreged una cọnsagràción excép pát lo que de seguro no hay pero menos modesto que el actual

Construcciont mo el actyal Rafael Atrucciónt-Por, regorlendación del doctar Carlos Jefe del Taller.-Desempeña este p*testo el"señor Carlos Martín Restrepo, considerado como uno dejos mejores mecánicos de Antioquia, y tal ve no hay nin $\rightarrow$. gtino mejor que él en el país. Sin elementos, pues to. davia no hay maquinarias de ninguna clase, ha pues a funcionar dos locomotoras, que por haber lleg do en tiempos anormales, por cequsa do la guerra eţiobe vinieron muy deficjentes, Debido a sus muchos cpnov. cimientos ha logrado"sostener el servicio de ja mactuino número 3 , de la casta Glover, de mala calidad, tque se recibio incompleta Actualiftente se gcupa, en $l$ armàdura de una'byena máquina, bastente poten te, y de huena clase, qua eștarA para darke ál servicio dent-

tro de unos quidte dias. Gobierno Nacional del trayecto coitsmndido Estaciót. Villegas y lua Hoya(hoy Eştâtión, Villegas) por $\$$ ks. que agregados a lo inaugutado anteriormen. te, da uf total de $15 \mathrm{ks}$; erfiftenos de dos sermanas

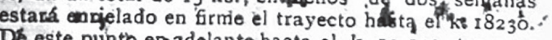
D6 este punto enadelante hasta el k. I, I I go tenemps

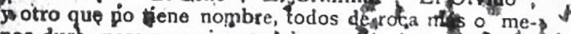
nos dura, pero que ninguno demorấ dos mesès ên estar terminado; sigue el corte compreńfido entre el "* k. 10.19I y el k. 19.38ुo, de therla blanda, "pero tao "suelta, que hay puntos' digude hace cosa de un thes no se da un baretonazo, fo sediça la cuaddrilla de ese punto al acarresp de la tierră que răeda.Se calcula que* esto $0^{*}$ córł

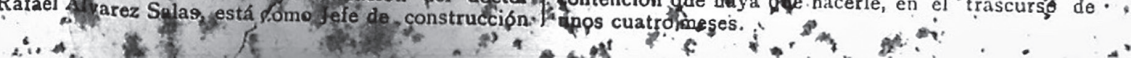




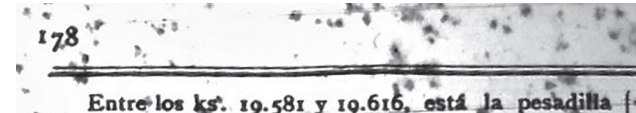

Entre los ks. 19.581 y 10.616 , esta la peshadilla qué es? "Ell Thúnel". Resulta que, la pasada de este obstáculo es soblo de tres meses. Actualntente se cohs.

- traye una galería de I, 50 por 2 metros, para fijar bien. los centros de la fínea, $y$ de ella se está hacierido a ra. zón de algo más'derun metro por día; hasta la fecha

is tenemos unps 18 metos, ẹn cuatro sęmanas de trabajo, sólo una de ellas con sus nochøs; terminar la mepcio. nada galería es cuestión de trés sémanas, con solo 4 peones, y por una sola boca; terninado ésto se pueden colocar de 7 a 8 trabajalóres en cáda lado, $y$ segúh cálculos de los Ingenieros, serán śuficientes poco más de dos meses para terminar ló que fuuchos han consi. derado un imposible, llegando algunos a propalar la especie de que êl mencionado túnel; según opinión de técnicos, hay que bajarlo a las corrientes de Consota, cincuenta o sesenta metros más bajo de doride hoy es. tá dispuesto, de conformidad con,los trazados.

El número de trabajadores fluctua entre 6 y 700 ; Eon este número bien organizado, y manejado como esth, teniendo en cuenta que del tünel para arriba no baý corte ninguno que demande más de cuatro meses de trabajo, no es aventurado calcular que antes de seis meses sê tiene enrielado hasta Galicia, $\mathrm{y}$ una con. - đerable cantidad de banca de Galicia hacia Pereira. Es bueno advertir que en aquel trayecto hay trabajadores suficientes,

Los almacenes de la Empresa están perfectamente bien surtidos de herramientas, por lo menos para I 500 peones; y para que los trabajos avancen con bastante rapidez, sóló hacen falta unos rieles Decauville, con sus respectivas vagonetas, pedidos al exterior des. de el męs de abril últimp; según aviso, de los Comi sionistas; esos elementos han debido salir de New York, desde fines del pasado septiembre, y si esto fue re así, estarán en Puerto Caldas en el trascurso de unas dos semánas.

- Para el mayor rendimiento en los trabajos se ha adoptado últimamente el sistema de contratos o tareas; los señores Ingenieros, que calculan el movimiento de tierra, y el costo aproximado según la calidad de los terrenós, procuran siempre que los contratistas bbtengan una ganancia moderada, trabajando normalponte, y may buena si le agregan unas horas más de lás que ordena el reglamento. A pesar de que los jor-' trales ya son búenos, êntre $\$ 0,75$ y 0,85 , según la calidad de los peones, y costando la alimentación $\$ 0,30$ y a lo sumo $\$ 0,35$, no es difícil qué con el sistema de contratos, pueda gahar el peón,un peso diario, libre de alimentación.: Es pues perfectamente falso que los peones de la Empresa estén muy' mal remunetados, siendo este el motivo para la deserción, como lo hacen saber algunos que necesitan de ellos para sus trabajoś particulares. $r$ para sus trat

La àlimentación es bastante buena, y como exis-

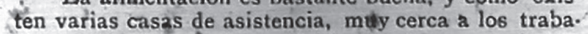
jos, cada pé́n, o' cada cuadrilla, puede escoger la que le guste; los que comen thal, to hacen por su voluntad, y'tal vez por obtener alguna economía. No es tan fácil, ni es legal, obligar a los trabajadores, como algunos lo acpnsejan, a comer de determinada casa, cuant. do son ellos los que deben pagar sus plimentos. Tal

*vez ésto se puede hacer en una finca, donde no hay

más que una cocina, y donde el peón trabaja por cierto precio libre, siendo unos 40 a lo sumo; pero preten. der bakerio con 6000 más, es un absurdo. El asunto de alimentación está tan bieñ organizado, como es po. sible hacerlo.

* El Hospital nada deja qué desear; es muy insig: nificánte el número de muiertos, y no se registra una ?

\section{FERROCARRIL DE CALD A}

sola defunción por descuido. La disenteria ha hecho cuàtro yíptimas, y tras la fiebre perniciosa, según informa el médico. La semana antepasada, uno do los oficiales de carpinteria se sintió enfermo, y creyendo fuerz mejor afendide en Pereira que en la Empresa,se vino para aquella población, y en pocos días pereció, a causa de una disenteria;de esta cruel enfermedad se han curado áltimamente diez en el Hospital de Chiqueros! Nó es puies tan desastrosó el servicio de Hospital, como algunos lo aseguran.

* Campamentos hay, de sobra, y de muy buena construcción; tenemos desocupados por lo menos para 600 peones más, y elementos apropiados para construír los que se quieran, en unos pocos' días.

Todo lo que digo en este informe, es la verdad desnuda; los que digan otra cosa, es porque no tienen conciencia de lo que bablan, han sido mal informados por los que no conocen, o lo hacen por maledicencia.

Manizales, octubre 22 de 1919.
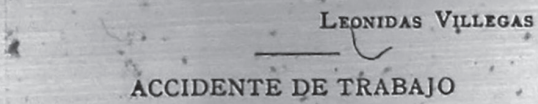

EL FIRROCARRIL ACATA LA LEY SOBRE ESTA MATERI Recibo

Declaro haber recibido del señor Superintendente del Ferrocarril de Caldas, en mi carácter de padre legítimo de Aureliano Granda, muerto en la obra del Ferrocarril en el kilometro 2I, la cantidad de doscien. tos setenta pesos moneda corriente, como valor de la indemnización por accidente de trabajo.

Certifico además que esta cantidad me fue reconocida tan pronto como presenté la documentación que exige la ley para casos semejantes, y que no se me puso obstáculo de ninguna clase.

Manizales, septiembre 26 de 1919. Fortunato Granda.

\section{PROPOSICION}

aprobada por la Junta, en la sesión del 23 de octubre de I919.

La Junta-Directita del Ferrocarril de Caldas teniendo en cuenta la generosa donación del señor don Aridrés Martínez, vecino de Pereita, de un lote de te. rreno para estación del Ferrocarril en la mencionada ciudad, le tributa los más sinceros agradecimientos en nombre de Ja'Empresa y del Depártamento; y como homenaje de reconocimiento ordena que por la Superintendencia se expida un tiquete de favor de primera clase; de fór vida, para el señor Martínez,a quien. so considerará como benefactor de la Empresa.

\section{MINISTERIO DE OBRAS' PUBLICAS}

\section{RESOLUCION}

por la cual se aprueban unos planos.

El Miniztro de Obras Públicas, en uso de sus atribuciones $7 e ̀ g a l e s, y$

$$
\text { - CONSIDERANDO: }
$$

- Que el señon Presidente de la Junta Directiva del Ferrocarril de Cáldas ha sometido a la aprobación de este Miništerio el phano y perfil de la línea de em- 


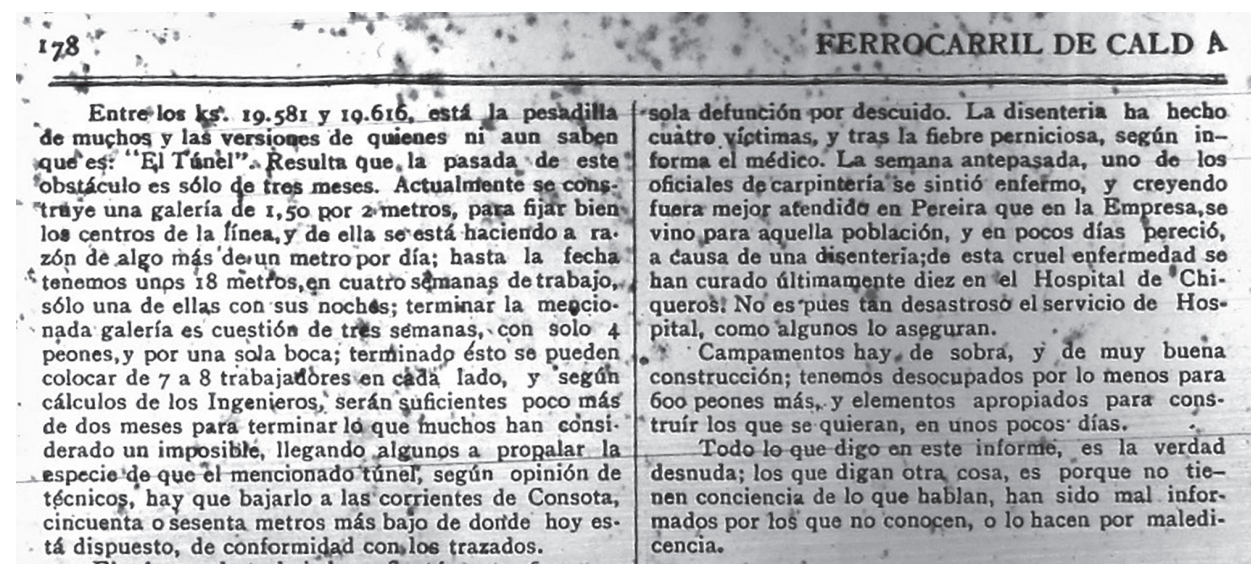

El número de trabajadores fluctúa ontre 6 y 700; Con este número bien organizado, y manejado como ests. teniendo en cuenta que del túnel para arriba np haý corte ninguno que demande más de cuatro meses de trabajo, no es aventurado calcular que antes de seis meses sè tiene enrielado hasta Galicia, y una con- đerable cantidad de banca de Galicia hacia Pereira. Es bueno advertir que en aquel trayecto hay trabajadores suficientes,

Los almacenes de la Empresa están perfectamente bien surtidos de herramientas, por lo menos para r 500 peones; y para que los trabajos avancen con bastante rapidez, sólo hacen falta unos rieles Decauville, con sus respectivas vagonetas, pedidos al exterior des: de el mẹs de abril últimp; según aviso, de los Comisionistas; esos elementos han debido salir de New York, desde fines del pasado septiembre, $y$ si esto fuere así, estarán en Puerto Caldas en el trascurso de unas dos semánas.

- Para el mayor rendimiento en los trabajos se ha adoptado últimamente el sistema de contratos o tareas; los señores Ingenieros, que calculan el movimien. to de tierra, y el costo aproximado según la calidad

de los terrenos, procuran siempre que los contratistas bbtengan una ganancia moderada, trabajando normalpente, y may buena si le agregan unas horas más de las que ordena el reglamento. A pesar de que los jor-

nales ya son búenos, êntre $\$ 0,75$ y 0,85 , según la calidad de los peones, y costando la alimentación \$0,30 y a lo sumo $\$ 0,35$, no es difícil que con el sistema de contratos, pueda gahar el peónıun peso diario, libre de alimentación. Es pues perfectamente falso que los peones de la Empresa estén muy mal remuyetados, siendo este el motivo para la deserción, como lo hacen saber algunos que necesitan de ellos para sus trabajoś particulares.

La alimentación es bastante buena, y como existen varias casas de asistencia, moy cerca a los traba. jos, cada peón, o cada cuadrilla, puede escoger la que le guste; los que comen tral, lo hacen por su voluntad.

$y^{\prime}$ tal vez por obtener alguna economía. No es, tan fácil, ni es legal, obligar a los trabajadores, como algunos lo aconsejan, a comér de determinada casa, cuan-

tr do son ellos los que deben pagar sus alimentos. Tal

"vez ésto se puede hacer en una finca, donde no hay

" más que una cocina, y donde el peón trabaja por cierto precio libre, siendo unos 40 a lo sumo; pero preten.

_er bacerio con 600 o más, es un absurdo. El asunto de alimentación está tan bieñ organizado, como es posible hacerlo.

* El Hospital nada deja qué desear; es muy insig: nificánte el número de mưertos, y no se registra uną'

Manizales, octubre 22 de igro.

\section{2.}

\section{LepNidas Villegas}

\section{ACCIDENTE DE TŔÁBAJO}

EL FERROCARRIL ACATA LA LEY SOBRE ESTA MATERIA Recibo

Declaro haber recibido del señor Superintendente del Ferrocarril de Caldas, en mi carácter de padre le. gítimo de Aureliano Granda, muerto en la obra del Ferrocarril en el kilometro 21, la cantidad de doscientos setenta pesos moneda corriente, como valor de la indemnización por accidente de trabajo.

Certifico además que esta cantidad me fue reconocida tan pronto como presenté la documentación que exige la ley para casos semejantes, y .que no se me puso obstáculo de ninguna clase.

Manizales, septiembre 26 de rgrg. Fortunato Granda.

\section{PROPOSICION}

aprobada porla Junta, en la sesión del 23 de octubre de 1919.

La Junta-Directiva del Ferrocarril de Caldas teniendo en cuenta la generosa donación del señor don Aridrés Martínez, vecino de Pereira, de un lote de terreno para estación del Ferrocarril en la mencionada ciúdad̂, le tributa los más sinceros agradecimientos en nombre de Ja'Empresa y del Depärtamento; y como homenaje de reconócimiento ordena que por la Superintendencia se expida un tiquete de favor de primera clase; de fór vida, para el señor Martínez, a quien. so considerará como benefactor de ta Empresa. ,

\section{MINISTERIO DE OBRAS' PUBLICAS}

\section{- RESOLUCION \\ por la cual se aprueban unos planos.}

El Ministro de Obras Públicas, en uso de sus atribuciones 1 egales, $y$

$$
\text { - CONSIDERANDO: }
$$

I Q Que el señon Presidente de la Junta Directiva del Ferrocarril de Cáldas ha sometido a la aprobación de este Miniśterió el plano y perfil de la línea de em- 
paime de esaria con el Ferrocarril del Pacífico en la cir:dad de Catago; $y$

${ }_{2}^{\circ}$ Que sgún el informe del Ingeniero Jefe de la Sección de ferocarriles de este Ministerio, el proyecto presentadc aunque tiene dos ligeras imperfecciones fácılment subsanables al ejecutar la obra,está en general bien laborado y puede aprobarse,

$$
\text { RESUELVE: }
$$

,

$I^{\circ}$ Apruéanse el plano y perfil presentados por el señor Presdente de la Junta Directiva del Ferrocariil de Caldaspara la línea de empalme de esa vía férrea con la dl Pacífico en la ciudad de Cartago; y

2. O Désecuenta al señor Presidente de dicha Junta de las obsrvaciones hechas al proyecto por el senor Ingenier Jefe de la Sección de Ferrocarriles de este Ministero, para que, al ejecutar la obra, se subsanen los defctos a que ellas se refieren.

Comunfruese y publiqueze.

Dada ơ Bogotá, a.... de octubre de rgrg.

El Midistro del Tesoro, encargado del Ministerio de Obras Públicas,

Esteban Jaramillo

\section{ACTA}

DE LA SESION DEL DIA I9 DE AGOSTO DE I 918.

En la ciudad de Manizalès, a las tres p. m. del día diez y nueve de agosto de mil novesientos diez y ocho, en la oficina de la Superintendencia y bajo la presidencia del señor Gobernador del Departamento, se reunió la Junta Directiva del Ferrocarril de Cal. das. Concurrieron: Et señor Secretario de Hacienda, el señor Superindente, don Leonidas Villegas, don Manuel F. Calle y el suscrito Secretario.

Se trató de lo siguiente:

I.-ACTa ANTERIOR.-Abierta la sesión se dio lec. tura al acta de fecha $x^{\circ}$ de julio del corriente año, la que fue aprobada $\sin$ modificación alguna.

II.-PETICION DEL SEÑOR CARLOS ECHEVERRI U.Fue puesta en consideración de la Junta una petición del sef̂tor Carlos Echeyerri U., en la que solicita, con fecha $I^{\circ}$ de los corrientes, que se cerque la faja que ha tomado el Ferrucarril para la construcción de la carrilera en los terrenos de "La Hoya". El señor Superindente presentó copia de varias cartas cruzadas por él mismo con Echeverri y con el Abogado de la Enpresa, y explicó verbalmente las pretensiones derechos del primero de estos dos en los mencionados terrenos; terminó presentando la siguiente proposición que fue aprobada:

'Pase al estudio del Abogado del Ferrocarril el asunto del señor Carlos Echeverri U., para que se sirva informar y presentar proyecto de resolución."

III. - REglamacion DEL seNor at.ejandRo CONCH A P. - Se-dfo lectura a una carta de fecha 22 de julio próximo pasado, en que el Sr. Alejandro Concha P.. solicita de la Junta se le reconozca la suma de $\$ 14.00$ oro como indemnización de un ternero que aporreó un tren el día 20 de julio en el kilómetro 9. liene esta carta acompañada de algunas otras cruzadas por el señor Conchn con el Superintendente $y$ el Administrador del Ferrocarril, $y$ de un informe del mayuinista que conducia el tren el día citado. Por disposición de la Presidencia pasó este asunto en co. nisión al señor Secretario de Hacienda y al Vocal Villegias para que presenten proyecto de resolución.

IV.-Solicitud DEL MEDICO DI LA EMPRESA. - Se dio lectura a una nota del Médico de la Empresa, doctor Joaquín E. Botero, fechada en Cartago el Io de los corrientes en la cual comunica al señor Presidente de la Junta que por motivos de salud ha tenido que separarse del oficio por dos meses y que en su reemplazo ha dejado al doctor José A. Gómez. Termina pidiendo se le acepte el reemplazo. Puesta en considepación, el señor Secretario de Hacienda propuso y fue aprobado:

"Concedase al doctor Joaquín E. Botero, Médico del Ferrocarril, el permiso que solicita y nómbrase en su reemplazo al doctor José A. Gómez., con retroactividad a la fecha en que entró a ejercer las funcio. nes."

En seguida se comisionó al vocal Calle para que estudiara todo lo concerniente a Médico y hospital y rindiera un informe relativo a esta cuestión.

V.-PETICION DEL DOCTOR ELEUTERIO SERNA G.Se dí́ lectura a una nota del 4 de los corrientes en que el doctor Serna pide se le conceda en dinero las vacaciones $a$ que se ha hecho acreedor por haber servido un año en los trabajos del Ferrocarril. Se leyó un certificado del Ingeniero-Jefe en que dice ser acreedor el peticionario a la gracia que solicita. A este respecto el vocal Villegas propuso la moción siguiente que fue aprobada:

"Reconócese al doctor Eleuterio Serna la suma de $\$ 150.00$, como equivalente a un mes de vacaciones remuneradas a que tiene derecho, de conformidad con las Reglas Generales del Reglamento."

Se comisionó al mismo sen̂or Villegas para que estudiara las Reglas Generales de los Reglamentos y presentara un proyecto de reforma.

VI.-RENUYCIA DEL SEÑOR BENJAMIN SUAREZ.Puesta en consideración la que presenta el señor Benjamín Suárez, con fecha 20 de de julio próximo pasado, el señor Superintendente manifestó que él le había concedido permiso para retirarse de la Empresa el I? de este mes, y propuso:

"Acéptase la renuncia que presenta el señor Ben. jamín Suárez del empleo de Ingeniero Ayudante y dénsele los agradecimientos por los servicios presta. dos a la obra del Ferrocarril."

Esta proposición fue aprobada.

VII.-SOLICITUD DIL PERSONERO MUNICIPAL DE PEREIRA. - Leída una nota de fecha cuatro de los corrientes, del señor Personero Municipal de Pereira, en la que solicita se le preste, se le arriende o se le venda un nivel inglés que posee el Ferrocarril, el vocal Villegas propuso y fue aprobado:

"Autorízase al señor Superintendente para vender el nivel que solicita el Personero Municipal de Pe. reira,"

VIII.-NOTA DEL SEÑoR MANUEL A. POSADA.Con fecha ${ }_{3} 3$ de los corrientes se ha dirigido el señor Manuel A. Posada., en nombre de la Sociedad deno minada Posada \& Co, a los miembros de la Junta solicitando permiso para colocar en la zona del Ferroca. rril y a inmediaciones de la Estación que debe inau. gurarse próximamente, una pieza portátil que preste el servicin de oficina. Puesta en consideración el vo cal Villegas propuso y se aprobó:

"Autorizase al señor Superintendente para 'que convenga con los señores Posada \& $\mathrm{C}^{\circ} \%$ demás comisioništas la manera como éstos deben situarse en la próxima Estación de La Hoya."

LX:-Peticios deri. MFuico Y DEI SINDico DEI HOSPITAL SAN JORGE.-Se dio lectura a una nota del 22 del mes próximo pasado en que solicitan el Médidico y el Síndico del Hospital "San Jorge" de Perei. ra un auxilio o subvención para atender a los rastos 
que demande este establecimiento. Pasó en comisión al señor Secretario de Hacienda.

X. - Consulta del contador-Cajero de ha SUPERINTENDENCIA. - En nota número $329 \mathrm{del} 27$ del mes pasado bace el Contador-Cajero de la Superintendencia la siguiente pregunta a los Miembros de la Junta:

"Habiendo dispuesto la H. Asamblea Departa. mental en sus últimas sesiones por medio de la Ordenanza sobre Presupuesto que el Tesoro del Departamento pagará al Banco Alemán Antioqueño el empréstito de $\$ 99.900$ oro que adeuda el Tesoro del Ferrocarril, el suscrito Contador-Cajero se permite preguntar a esa $\mathrm{H}$. Junta lo siguiente:

Debe eliminarse de los libros del Ferrocarril la cuenta aludida abonando al Tesoro del Departamento la cantidad mencionada y cargando esa misma cantidad al Banco acreedor?; o se continúa moviendo esa cuenta como hasta hoy, abonando al Departamento las cantidades que suministre para atender al pago de los expresados $\$ 99.900$ ?; o al contrario debe abrirse cuenta al Departamento y cargarle las cantidades que el Ferrocarril le dé para cancelar la cuenta del empréstito? En cualquiera de estos casos, quién debe pagar los intereses al Banco Alemán?" Esta nota pasó on comisión para su estudio e informe al señor Secretario de Hacienda y al vocal Villegas.

XI. - REMision de las cuentas de Junio y JUIo. - Leídas las notas números 3 ig y 337 , de fechas 9 y 27 del mes de julio próximo pasado respectivamente, con que el Contador-Cajero de la Superintendencia remite a la Junta las cuentas de la oficina a su cargo correspondientes a los meses de junio y julio del corriente año, éstas pasaron en comisión para su estudio a los señores Villegas y Calle.

XII.-Finanzas.-Por último, se trató de las finanzas de la Empresa y se convino en aplazar este punto para otra reunión.

A las cuatro y media p. m. se levantó la sésión.

El Presidente Josr Ignacio Villegas.

El Secretario, Alfonso Bernal.

$$
\text { ACTA }
$$

DE LA SESION DEL DIA 5 DE SEPTIEMBRE DE 1918 .

En la ciudad de Manizales, a las tres p. m. de día cinco de septiembre de mil novecientos diez y ocho, en el local de costumbre y bajo la Presidencia del señor Gobernador del Departamento, se reunió la Junta Directiva del Ferrocarril de Caldas. Concurrieron: E señor Secretario de Hacienda, don Miguel Salazar, don Leonidas Villegas, don Manuel F. Calle y el suscrito Secretario.

Se trató de lo siguiente:

I.-Acta anterior. - Abierta la sesión, se dio lectura al acta de fecha Ig del mes pasado, la que fue aprobada sin observación alguna.

II. - INFORME SOBRT FINANZAS DE LA EMPRESA, En seguida se informó a la Junta sobre la situación financiera de la Empresa, en lo que se refiere a las deudas del rerrocarril, y se comisionó a los vocales Salazar y Calle para que se entiendan con los Bancr de esta ciudad.en el sentido de conseguir nucvos cré ditos, para la Empresa.

III. - INFORMES DE COMISIONES, - $1^{\circ}$ - SOBRE LA OBRA DEL FERROCARRIL.- - Se dio lectura a un informe de fecha 4 de los corrientes que presenta el señor Manuel F. Calle después de visitar los trabajos del Fe rrocarril, y fue aprobada la parte resolutiva con que termina que dice:
"I. - Nbmbrase una comisión que estudie la posibilidad de obtener un empréstito por lo menos por la suma de cien mil pesos oro, ofreciendo como garantía los bonos que la Junta Directiva del Ferrocarril tiene en su poder."

"II.-Procédase a pedir al Exterior lo siguiente: 500 cajas de dinamita, 500 picos de doble punta y, 100 sacos de cemento."

Fue disposición de la Junta que se publicara es te informe en un perí́dico de la ciudad. Para pedir al Exterior los materiales de que trata la segunda proposición, se comisionó a los señores Villegas y Secretario de la Junta.

III.-SOBRE UNA RECLAMACION DEL SEÑOR ALEJANDRO CONCHA.- - Leido el informe que el señor Secretario de Hacienda presenta sobre una reclamación del sefior Atejandro Concha, la Junta aprobó la parte final resolutiva que dice:

"Autorízase ampliamente al señor Ingeniero-Jefe del Ferrocarril de Caldas para que se entienda directamente con el señor Alejandro Concha y vea la manera de llegar a un acuerdo satisfactorio en relación con la solicitud que ha hecho a la Junta para que se le reconozca la suma de catorce pesos oro como valor de los perjuicios que dice baberle causado una de las máquinas del Ferrocarril al aporrear un ternero de su propiedad."

IV.-SOBRE LAS PRETINSIONES DEL SEÑOR CARLOS ECHEV ERRI-U.-Con fecha 26 del mes pasado ha rendido el señor Abogado del Ferrocarril el informe relativo a las pretensiones del señor Carlos Echeverri U. en los terrenos de La Hoya, y de conformidad con lo dispuesto en la sesión pasada. dice:

Puesta en consideración la parte resolutiva que

< Oído el dictamen del señor Abogado del Ferro crrril en que expone los motivos equivocados en que se apoya el señor Carlos Echeverri para sus exigencias contra la Empresa, contestese a cicie sc:ar que la Junta se abstiene de considerar sus pretensiones》.

El señor Presidente la mpdificó en la forma siguiente y así fue aprobada:

Cído el dictamen del señor Abogado del Ferrocarril, la Junta estima que no está en el caso de acceder a lo solicitado por el señor Carlos Echeverri en su carta de fecha $10^{\circ}$ de agosto de este año».

En seguida se leyó una carta del mismo señor Abogado en la que consulta a la Junta algunos puntos relacionados con el terreno de ¿La Isla», en el cual es condueño el Ferrocarril. Pasó en comisión al seảor Secretario de Hacienda .

V.- SOBRE LA CONTABILIDAD DE LA EMPRESA.La comisión compuesta del señor Secretario de Ha cienda y del vocal Villegas, nombrada en la reunión pasada para estudiar la nota número 329 del Contador-cajero de la Superintendencia, informó por sepa. rado.

El señor Secretario da Hacienda propuso lo siguiente:

<Digase-al señor Contador-cajero de la Empresa; en resphesta a la consulta formulada en su oficio nú mero 329 de 27 de julio último, que la Junta Directiva coiceptúa que no đebe eliminạrse de los libros del Fe. rrocarril la cuenta con el Banco Alemán Antioqueño de Medellin y que ella se debe seguir moviendo en la forma en que se ha hecho hasta hoy.

El vocal Villegas propuso:

ca).-Elimínese de lôs libros, con abono a la cuenta del Tesoro del Departamento, la del Banco Ale. mán Antioqueño; 


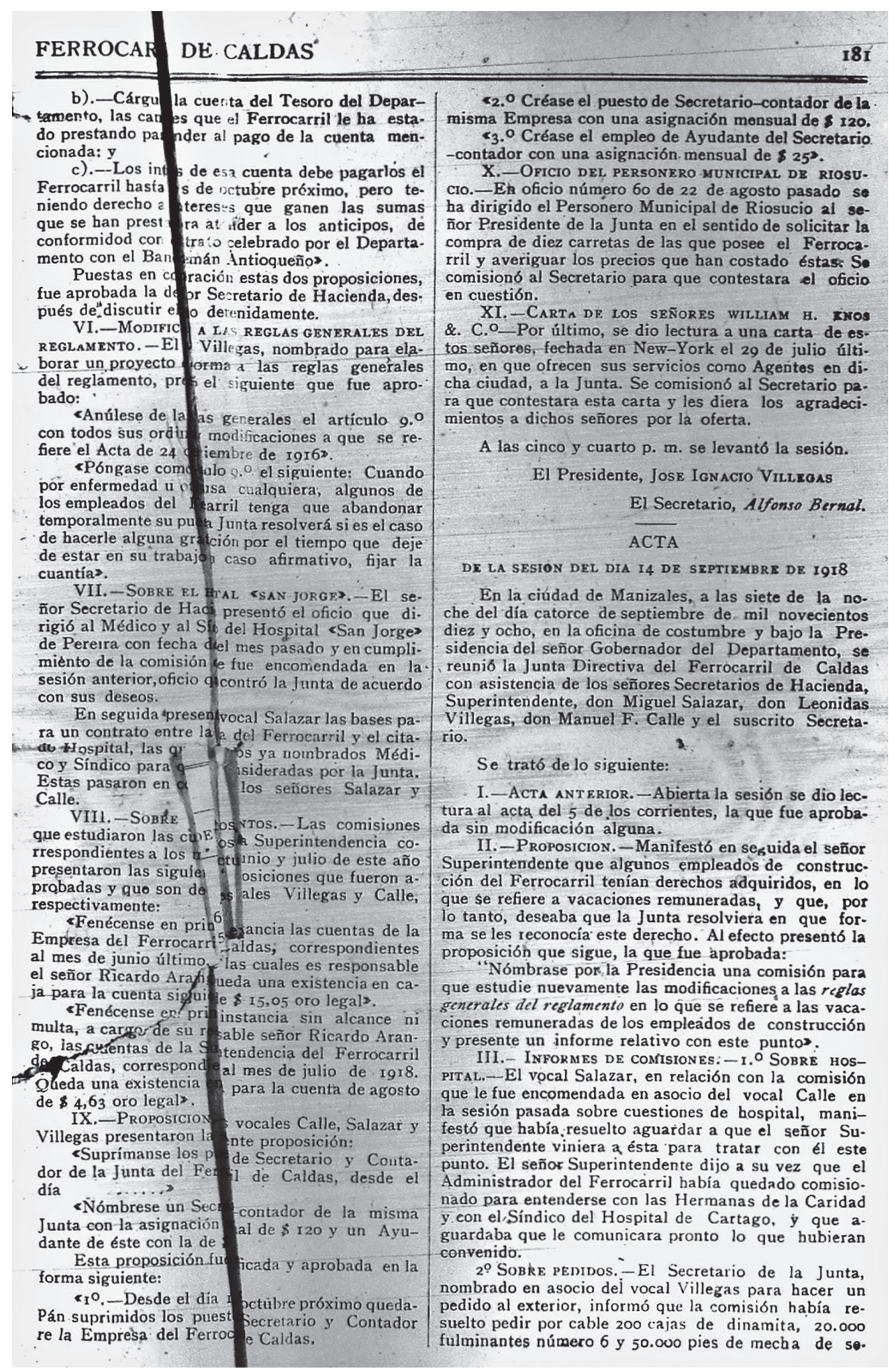


guridad; pero que después en atención a dos telegra: mas que se pusieron a Medellin, el uno at Ferrocarril de Antioguia y el otro al doctor Luis A. Isaza, solicitando estos elementos, habia resuelto esperar la contestacion.

IV.-PeDryo.-El señor Superintendente manifest 6 que se necesitaban algunos accesorios de plata. tormas en el Ferrocarril, y el sezior Presidente propu. so y fue aprobado:

- Autorizase al señor Superinténdente para hacer el sigraiente pedido a la casa de los señores Mecke \&. $\mathrm{C}^{\circ}{ }^{\circ}$ de New-York: 50 bronces para las primeras seis platafórmas; 6 resortes para las muñoneras de las mis. mas, y I2 resortes para los carretillos\$.

V. ERoposicion DEL voCAL CALLE. - Suscrita por el serior Calle fue presentada la proposicion que sigue, la que fue aprobada:

-Autorizase al sezor Superintendente para aumentar el personal de trabajadores basta el número que estime preciso para que, sin un gasto mayor de pesos

- 80.000 , se adelanten los trabajos hasta el kit6metro 25 inclusive $y$ pueda darseal servicio este trayecto el 7 de agosto de IgIg》.

VI.-AUTORTZACION.-El sex̃or Superintendente presento un telegrama que dice:

aCartago, 9 de septiembre de r918. - Fercaldas. Manizales - Luis Zarria de Roldanillo comprométese a sacar rieles ahogados a cinco pesos $(\$ 5)$ cada uno Hago contrato?-Polidoro\%.

Con relación a este asunto el señor Presidente propuso y se aprobó:

En atención al anterior telegrama del Administrador del Ferrocarril de fecha 9 de los corrilentes, se le autoriza para que contrate sacada de rieles ahogados en el río Cauca a un p cio no mayor de cinco pesos ( $\$ 5)$ cada uno?.

VII.-PROPOSICIONES DI vocal SALAzAR. - Las dos proposiciones que siguer ueron presentadas por el señor Salazar y aprobadasor la Junta:

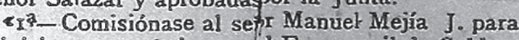
que inicie un empréstito parel Ferrocarril de Caldas, hasta por la suma de quiniéros mil pesos $(\$ .500,000)$ con el Banco Mercantil A r ricano de Colombia Inc. de Bogota, y llegado el cas suminístrensele los informes y datos que le sean icesarios, ?

2. Comisiónase al sior Manuel Mejía J. para que inicie un empréstito p a el Ferrocarril de Cal. das, hasta por la sumale quinientos mil pesos (\$ 500.000) can-el Equitale Trust Campany of Nero York $\mathrm{y}$, llegado el caso, su faístrensele los informes y datos que le sean necesarp?

VIII.-CREACION DEN EMglro. - Manifest6, por último, el señor Superint dente, que al aumentar el personal de trabajadores il Ferrocarril se necesitaba crear el empleo de Pagad-cajero, y que el individuo que lo desempeñara debíptorgar una fianza no menor de $\$ 2000$ y tener un signación mensual de $\$ 50$ \$ \$60. Se convino en qu cuando hubiera necesidad del empleo el Superintente daria cuenta a la Junta para proveer este puest

A las ocho $y$ veinteinutos de la noche se levant6 la sesión.

El Presidenf Josx IGNacio VimLrgas 1. Secretario, Alfonso Bernal.

BA LA NCF del Libro Mayor de la Superintendencia del Ferrocar de Caldas, correspondien-

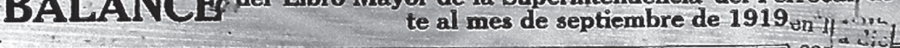

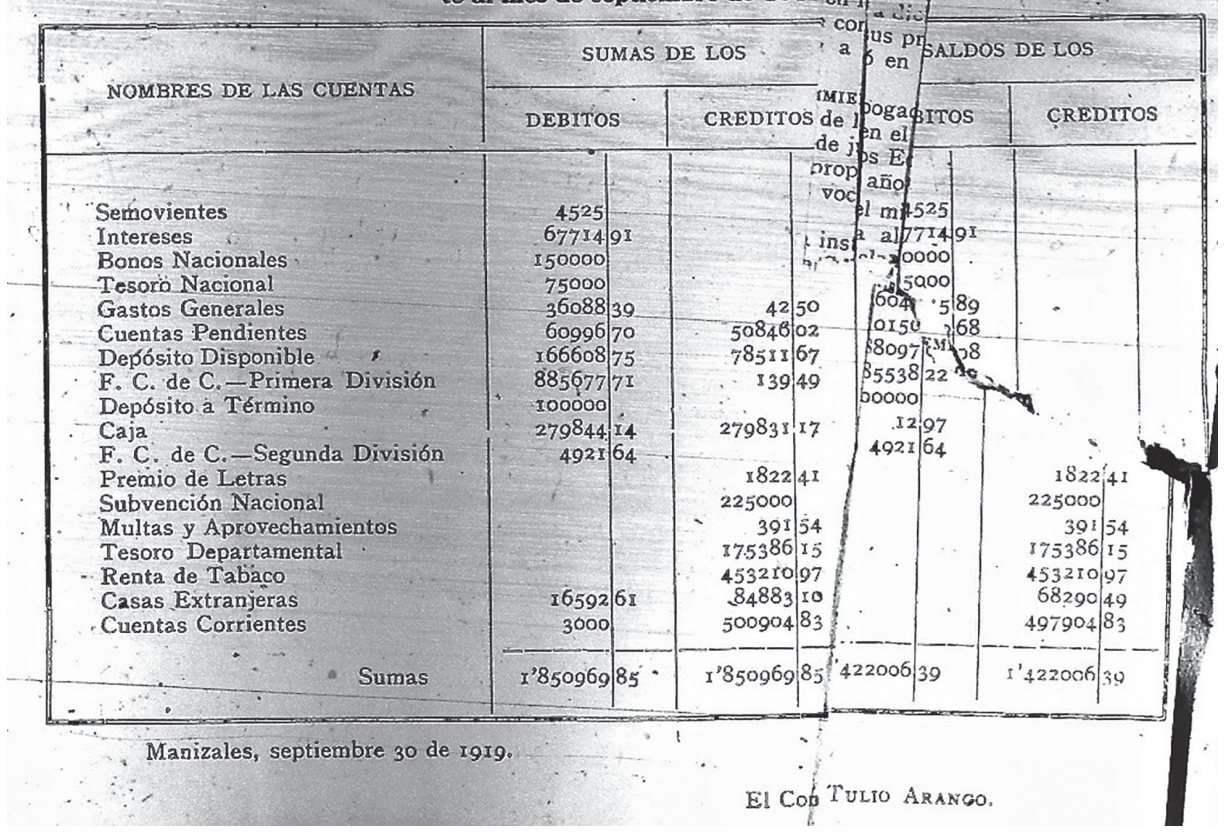




\section{FERROCARRIL DE CALDAS}

IMPORTACION EN EL MES DE SEPTIEMBRE DE 1919

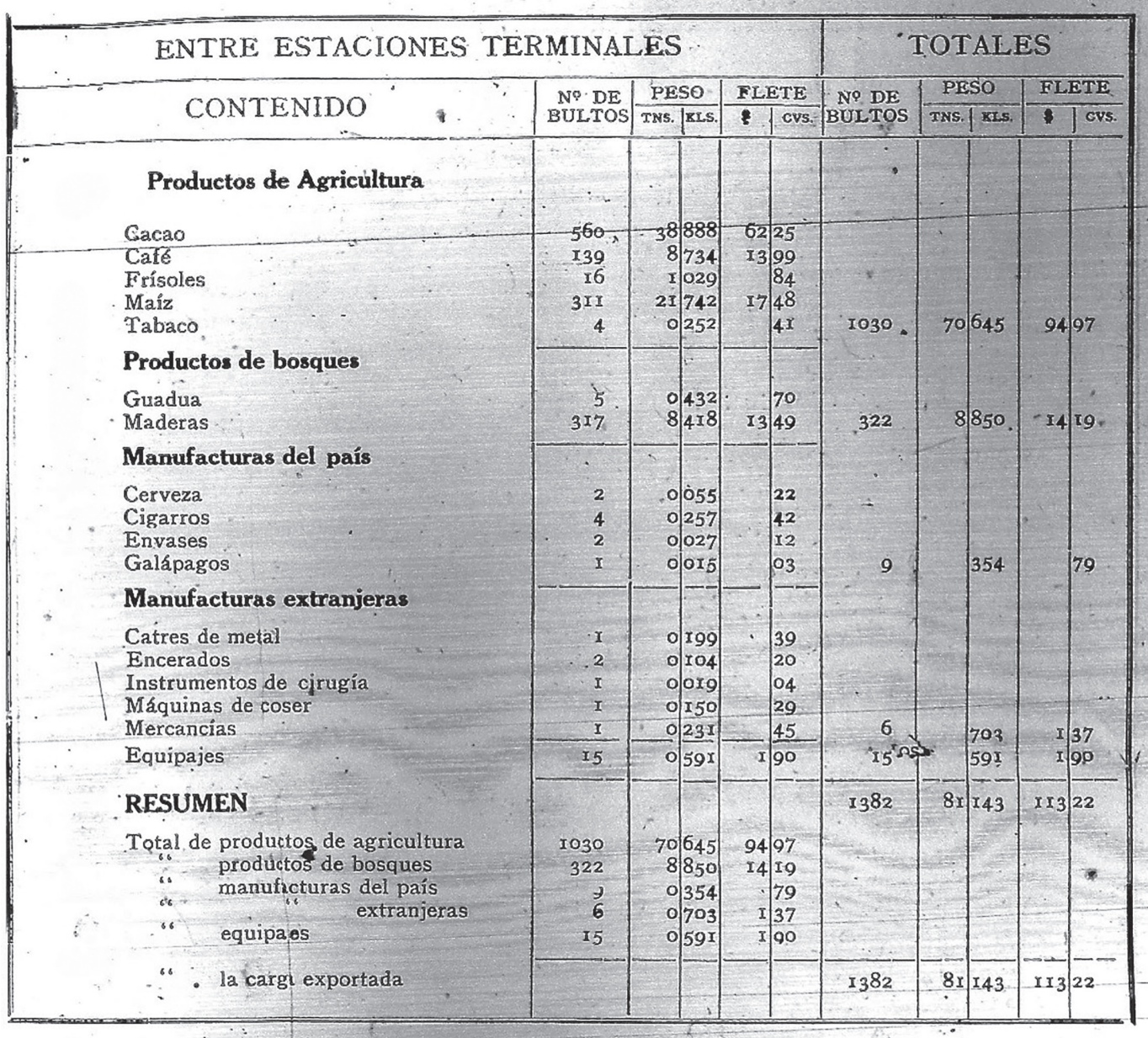

Producido por clases de la tarifa

\begin{tabular}{|c|c|c|c|}
\hline CLASES & ODMPUTADO & $\$$ & CVS. \\
\hline $\begin{array}{l}\text { Primera } \\
\text { Segunda } \\
\text { Tercera } \\
\text { Equipajes }\end{array}$ & $\left\{\begin{array}{r}800 \\
56.98 x \\
22.77 x \\
59 I\end{array}\right.$ & $\begin{array}{r}x \\
x \\
x \quad r \\
x\end{array}$ & $\begin{array}{l}74 \\
26 \\
32 \\
90\end{array}$ \\
\hline$\therefore$ Suma & $31 . x 43$ & $\mathrm{II}_{3}$ & 22 \\
\hline
\end{tabular}

Promedio que paga la tonelada-kilómetro

\begin{tabular}{|c|c|c|c|c|c|}
\hline $\begin{array}{l}N^{\circ} \mathrm{DE} \\
\text { BULTOS }\end{array}$ & PESO & FLETEE & $\begin{array}{l}\text { Tilómetros } \\
\text { recorrldos }\end{array}$ & $\begin{array}{l}\text { Tonoladas } \\
\text { kllomatros }\end{array}$ & $\begin{array}{l}\text { Promedio guto } \\
\text { paga ta tonula } \\
\text { da-kilónatro }\end{array}$ \\
\hline $1382^{\circ}$ & $8 x .143$ & × $13-22$ & 15 & $8 x^{\prime} 5.430$ & O-IIO \\
\hline & 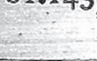 & $\begin{array}{c}-23.26 \\
-\end{array}$ & 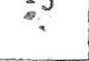 & & \\
\hline
\end{tabular}


184 FERROCARRIL DE CALDAS

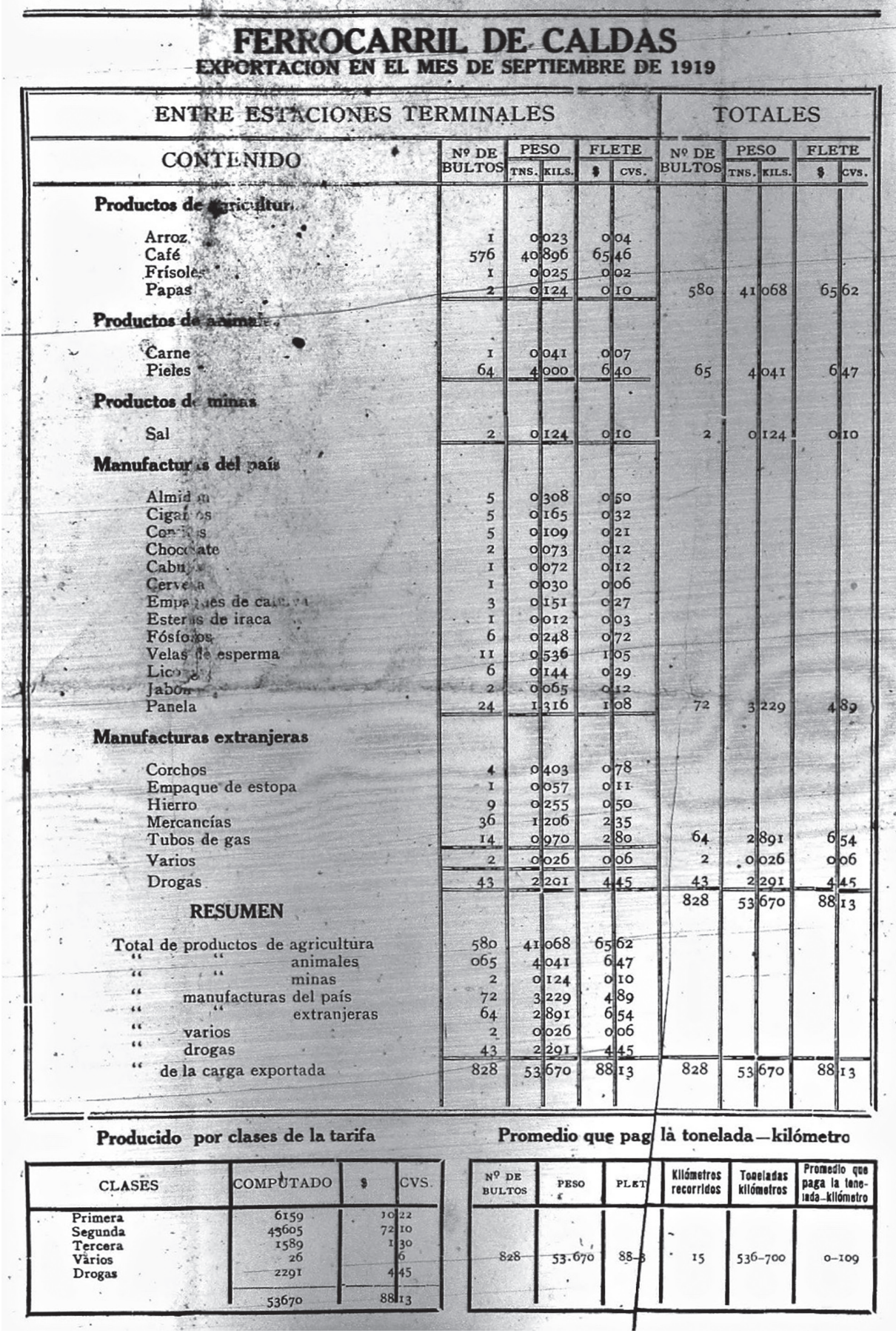




\section{Baght \\ República de Colombla \\ MMP. DÉPAGTAMENTAL \\ Departamento de Caldas \\ FERROCARRIL DE CALDAS}

\section{PUBLICACION ÓEICIAL}

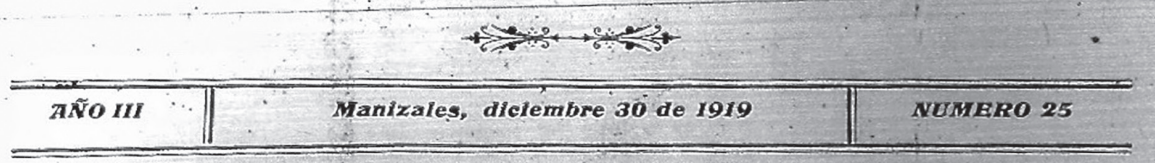

\section{CONTENIDO}

Actas de las sesiones de los días 14,24 y 30 de septiembre; 7,14 y 21 de octubre y $x_{5}$ de noxiembre de $x 918$.

Balance del Libro Mayor de la Superintendencia - del Ferrocarril de Caldas, correspondiente al mes de octubre de rgro..

Ferrocartil de Caldas. Importación del mes de octubre de $19 \mathrm{rg} . \ldots \ldots \ldots \ldots \ldots \ldots \ldots \ldots$ rgr

Ferrocarril de Caldas, Exportación, enjel,mes de octubre de $19 \times 9 \ldots \ldots \ldots \ldots \ldots \ldots \ldots \ldots$.. $x 9 z$ ACTA

DE LA SESTON DEL DIA IA DE SLTTIRMBRE DE IQI 8

- En la ciùdad de Manizales, a las diez y media a. m. del día catorce de septiembre de mil novecientos diez y-ocho, en el local de costumbre $y$ bajo la Presidencia del señor Gobernador del Departamento, se rẹunió la Junta Directiva del Ferrocarril de "Caldas con asistencia de los miembros ser̃or Secretario de Hacienda, dor Miguel Salazar, don Leonidas Ville. gas, don Manucl E. Calle y del suscrito Seoretarió.

Se trato de lo siguiente:

I-Acta anterior-Abierte la sesión, se dio léc tura al acta de fecba 5 de los corrientes, la que fue aprobada sin observación alguna.

I1. -INFORME. - En seguida informó el Secretario de la Junta que el día doce de este:mes] habia pedido

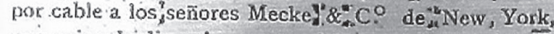
200 cajas de dinamita, 20.000 fulminantes número $6 \overline{\mathrm{J}}$ 50,000 pies de mecha de seguridad, y por correo los efectos a que se refiere el párrafo IV del acta anterior.

III.-RECLASIACION. - Se dio lectura a una nota que pasa el señor Superintendente al señor Manuel F. Calle G., Agente de la Antioguia Comercial Corporation de New Yor, en que le dice que de acuerdo con el Mecánico y ptro de los Ingenieros de la Empresa, estima el demérito'de la Locomotora número 3 , construída gor la casa Glover Mackine Works, en 8000 dollars. .
IV.--PROPOSTCION DEL VOCAL YILIEGAS, -Firmada por el señor Leonidas Villegas y con fecha de hoy, fue presentada la proposición quo sigue:

Procédase al nombramiento de. Secretario-Con. tador-Cäjero de la Junta del Ferrocarril".

"Como el doctor Allfonso Bernal ha venido des. empéñando el puesto de Secretario de la Junta, y el señor Ricardo Arango el de Contador Cajero, ambos a entera satisfacción, que se haga la elección por vctación secreta. Esta votación so contrae a los dos caBalleros mencionados".

Aprobada esta proposición se procedió a la votación en la forma indicada y resultó electo el señor don Ricardo Arango por tres votos contra dos a favor del Secretario que suscribe esta acta.

$\mathrm{Al}_{\text {zas }}$ los y cuarenta y cinco minutos $\mathrm{p}$. $\mathrm{m}$., se levantó la sesión.

EI Rresidente, Jose IgNacio VILLEGas

7. El Secretario, Alfonso Bernal.

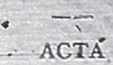

DE LA SESION DEL DIA 24 DE SEPTIEMBRE'DE 1958

En la ciudad de Manizales, a las tres y veinte minutos p. m. del día 24 de'septiembre de mil novecientos diez $\mathrm{y}^{\mathrm{o}}$ ocho, en el local de costumbre y bajo la Presidencia del señor Gobernador del Departamento, se reunió la Junta Directiva del Ferrocarril de Caldas, con asistencia de los-señores Secretario de Hácienda, don Miguel Salazar, don Leonidas Villegas, don Maruel $F$. Calle y del suscrito Secretario.

Se trató de lo siguiente:

I-ACTA ANTERIOR.-Abierta la sesión, se dio lectura al acta déla sesión anterior, la que fue aproba. da sin observación alguna.

II-CARTA DEL DR, DANIEL GUTIERREZ Y ARANGO. Se leyó una carta fechada en Nely York el 8 de agosto pasado, en la que el doctor Gutjérrez y Arango comu. nica a la Junta que se ha entendido con las casas de Antioquia Commercial" Corporation y de Aficke $\hat{\circ} \mathrm{C}$ ? que ba visto el interés que han tomado el el despactio de las locomotoras que la Junta les ha pedido. Dice además que ba obtenido cotizaciones de rieles nuevos y de segunda mano y el permiso del Gobierno de los Estados Unidos para embarcirios, Como alguno de los señorés de la Junia manifestara que tenía conocimiento de que el doctor Gutiérrez regresaba pronto a esta cjudad, se convino en que no se le contestara la carta por ser casi segruro que no alcanzaba a recibirla.

III-RENISTON DE T.AS CUENTASDE agosto. - Fue puesta en consideraciót la nota número $355 \mathrm{del} 16 \mathrm{de}$ los corrientes con que cl Contador-Cajero de la Super- 
intendencia remite a la Junta las cuentas de la ofici na a su cargo, correspondientes al pasado mes de agos. to. Dispuso la Presidencia que pasaran en comisión para su examen en primera instancia al vocal Villegas.

IV - Hospiral y medico.-Se deliberó en seguida sobre cuestiones de Hospital y Médico de la Em. presa sin que llegara a resolverse nada sobre este pernto.

V-Bunos Nacionales. - Manifestó el señor Vi. llegas que seria conveniente dirigir un telegrama al doctor José M. Arango G.. a Bogotá, diciéndole que haga incluír en el Presupuesto la suma de doscientos veinticinco mil pesos $(\$ 220.000)$ para atender a la subvención de los cinco kilómetros de ferrovia que se entregarán al Gobierno Nacional en este año y a los diez que se entregarán en el curso del entrante. Se comisionó al señor Presidente para que se dirija por te. légrafo al doctor Arango en el sentido indicado.

VI-PRoposicIoN DEL SEÑoR CALI.E. - La proposición que en seguida se copia fúe presentada por el señor Manuel F. Calle G.

"La Junta Directiva del Ferrocarril de Caldas deja constancia en el acta de este día de la meritoria labor del doctor José Ignacio Villegas, como Gobernador del Departamento y Presidente de esta Junta, en pro de los intereses del Ferrocarril y lamenta la separación de tan distinguido ciudadano al propio tiempo que confía en que el llamado a reemplazarlo sabrá inspirarse en el más alto espíritu que ha guiado siempre los actos del doctor Villegas en todo cuanto se ha relacionado con la obra del Ferrocarril de Cal. das. Copia auténtica de esta proposición le será pasa. da en nota de estilo al doutor Villegas.-Manizales, 2 I de septiembre de rgr 8 ".

Al ser leída esta proposición, el señor Presidente se retiró de la discusión, y, puesta en consideración por el señor Secretario de Hacienda, fue aprobada por unanimidad.

En seguida tomó la palabra el señor Presidente $y$ dio su agradecimiento a los Miembros de la Junta por el honor que se le hacía al ser votada esta proposición y por los valiosos servicios que habian prestado a la obra del Ferrocarril durante su administración. Terminó manifestando que esperaba de ellos seguirian trabajando en lo futuro con el mismo entusiasmo con que hasta hos lo han hecho, y que, mientras la obra estuviera bajo su dirección, marcharía en estado próspero.

No habiendo otro asunto de que tratar, a las cua. tro p. m. se levantó la sesión.

El Presidente, Juse Ignacio Vinilegas El Secretario, Alfonso Birnal.

\section{ACTA}

DE LA SESION DEL DIA 30 DE SEPTIEMBRE DE 1918

En la ciudad de Manizales, siendo las tres p. $m$. del día treinta dẻ septiembre de mil novecientos diez y ocho, en el local de costumbre y bajo la Presidetcia del señor Gobernador del Departamento, General Pom. pilio Gutiérrez, se reunió la Junta Directiva del Fe. rrocarril de Caldas; concurrieron: el señor Superinten. dente, don Miguel Salazar, don Leonidas Villegas, don Manuel F. Calle, y el suscrito Secretario.

Se trató de lo siguiente:

I-ACTA ANTERIOR-- Abierta la sesión se dio lec* tura al acta de fecha 24 de los corrientes, la que fue aprobada sin obsetvación alguna.

II - INFORMES DE COMISIONES- $1^{\circ}$-SOBRE EL TERRE. No DE" "LA ISLA".-Se leyó un informe del 24 de los co- rrientes del señor Secretario de Hacienda,sobre una con sulka que hace el Abogado del Ferrocarril en relación con los terrenos de "La Isla", consulta que le fue pa sada en comisión para su estudio e informe; en sesión đel día cinco de este mes, La Junta aprobó la parte resolutiva del informe que dice:

"Dígase al señor Abogado de la Empresa que la Junta Directiva del Ferrocarril conceptúa, en relación con la consulta formulada en su carta del 26 de agosto último, que la vía más expedita para solucionar la cuestión relativa a la comunidad de "La Isla", es la de iniciar el respectivo juicio divisorio, a menos que los comuneros se presten a someter sus pretensiones a un dictamen pericial, o que el señar Abogado logre llegar con ellos a un acuerdo amigable que sería sometido a la aprobación de la Junta".

20-SOBRE I.AS CuENTAS DE Agosto.-La comisión nombrada en la sesión anterior para estudiar las cuentas de la Superintendencia, relativas al mes de agosto próximo pasado, presentó el informe correspondiente, cuya parte resolutiva, que fue aprobada dice asi:

"Sólicítese del señor Contador-Cajero de la Einpresa, una aclaración de la forma en que le fue hecha la remesa de 2 de agosto, proveniente de pagos que le hicieron Posada \& Co y Eduardo Alvarez al Adminis. trador".

"Supliquese al señor Administrador de la Empre. sa, que antes de remitir las cuentas a esta ciudad, haga una confrontación minuciosa entre !ßs cuadros de trabajadores de los Capitanes y los certificados que él expide, para evitar tener que hacer enmendaturas aqui en los mencionados certificados".

III-SOBRE VACACIONES REMUNERADAS. - Con ESta misma fecha presentó el señor Miguel Salazar un informe sobre vacaciones remuneradas de los emplea. dos de construcción del Ferrocarril, cuya parte reso. lutiva dice:

"I Ferrocarril que tenian derecho a vacaciones remunerádas, la proporción a que tengan parte por el tiempo servido hasta la supresión de dichas vacaciones. Esta participación se les dará en vacaciones remuneradas o en dinero al terminar el año de servicio que les da. ba derecho a ello".

" 2 " A cada empleado de construcción que preste satisfactoriamente sus servicios a la Empresa durante un año, se le dará una gratificación igual a la mitad del sueldo que devengue".

Después de discutir un poco sobre estas proposiciones, el vocal Villegas propuso la mociẹn siguiente, que fue aprobada:

"Suspéndase la consideración de las proposicio. nes con que termina el informe que con esta fecha presenta el señor Salazar sobre vacaciones remuneradas, hasta hacer un estudio más detenido del asunto".

IV-Corzacionss. - Se leyó un cable de la $A n$ tioquia Comercial Corporation, en que cotizan con fecha 27 de los corrientes, rieles de segunda mano, de 56 libras por yarda con eclisas, tornillos y escarpias, sujetos a inspección, a 75 U. S. dollars la tonelada métrica. El señor Superintendente manifestó que sería conveniente pedir nuevas cotizaciones de rieles a varias casas comisionistas, y también de dinamita, por haber comunicado Veike $\cdots C$, con relación al pedidố cablegráfico del i 2 Je los corrientes, que la de mayor potencia que pueden despachar es de $50 \%$ de nitruglicerina. El señor Presidente propuso y se aprobó:

"Autorizase al señor Superintendente para que por cable pide otizaciones de rieles y de dinamita". 
V-Telegrama DEL SR. MANuEl MeJia.-Se puso en consideración un telegrama que dirige de Bogotá, con fecha 28 del presente mes, el señor Manuel Mejía a la Junta, en el que le comunica que ha tratado Colombia y que ha spnyenido en que su Jefe, señor Lawder, residente semana a visitar el Ferrocarril: Termina suplicando se le diga al señor Ingeniero-Jefe que lo atienda y le facilite los estudios que el visitante desee hacer. Dispuso la Presidencia que se trascriba este telegrama al señor Ingeniero-Jefe.

$\checkmark$ VI-CARTA DEL SINDICO DEL HOSPITAL DE, CARTAGo. - Se dio lectura a una carta que con fecha 22 del presente mes dirige el Síndico del Hospital de Cartago al Administrador del Ferrocarril, en que le comunica que la Junta de ese establecimiento ha fijado el valor de \$ $0-50$ como el mínimum a que puede atender a los enfermos del Ferrocarril. Después de discutir detenidamente sobre cuestiones de Médico y de Hospital de la Empresa, el señor Presidente propuso y fue aprobado:

Autorizase a los señores Superintendente y don Miguel Sälazar, para que arreglen los asuntos de Médico y Hospital de la Empresa".

VII-Nombramiento.-En nota de esta fecha, el Contador-Cajero de la Superintendencia propone que se nombre al señor. Jorge Arias C., Ayudante del Secretario-Contador de la Superintendencia. A este respecto se aprobó la moción que sigue del señor Presidente:

"Nómbrase al señor Jorge Arias C., Ayudante del Secretario. Contador de la Superintendencia del Ferrocarril de Caldas, con una asignación mensual de veinticinco pesos oro ( $\$ 25-00)$ ".

VIII-FAJAs.-El señor Superintendente manifestó que en la obra del Ferrocarril había actualmente 450 trabajadores, y que el 28 de este mes habían salido de esta ciudad 70 más; que el señor Emiliano González le había impedido continuar los trabajos de explanación por no haberse comprado la faja en su propiedad. Después de tratar sobre este punto, el señor Presidente propuso la moción siguiente que fue apro. bāda:

'Se faculta al señor Superintendente y al señor Miguel Salazar para hacer arreglos amigables sobre las fajas que ha de ocupar el Ferrocarril".

No habiendo otro asunto de que tratar, a las cuatro de la tarde se levantó la sesión.

El Presidente, Pompilio Gutierrez

El Secretario, Alfonso Bernal.

\section{ACTA}

DE LA SESION DEL DIA' 7 DE OCTUBRE DE 1918

En la ciudad de Manizales, a las tres y media p.in. del día siete de octubre de mil novecientos diez y ocho, en el lugar de costumbre y bajo la Presidencia del señor Gobernador del Departamento, se reunió la Junta del Ferocarril-de Caldas. Concurrieron los vocales señores Miguel Salazar, Manuel F. Calle, Leonidas Villegas y el suscrito Secretario.

Se trátó de lo siguiente:

I-ACTA ANTERIor. - Abierta la sesión, se dio lectura al acta de 30 de septiembre ante- rior, la que fue aprobada sin observación al. guna.

II-Cotrzaciones. - Se dio lectura a un cable de Antioquia Commercial Corporation en el que dice que puede despachar 500 cajas de dinamita a $\$ 0,29$ la libra, entregándola en San Francisco de California. El señor Presidente propuso lo siguiente que fue aprobado: "Trascríbase el cable anterior por medio de-oficio, al señor Superintendente para que éste resuelva lo que estime conveniente y lo comunique a la Junta por telégrafo".

El vocal Salazar sentó la siguiente proposición, que una vez discutida se aprobó:

" Camisiónase al vocal Villegas para que se informe can el señor Agente de Mecke \& $\mathrm{C}^{\circ}$, si éste ha recibido últimamente cotización sobre rieles y si el precio no satisface, procédase a pedir a la Antioquia Commercial 7 kilómetros de acuerdo con ell señor Superintendente:

III - INFORMES - Estando presente el señor Manuel Mejía J.informó verbalmente a la Junta sobre sus agencias con el Banco Mercantil de Bogotá, para ver de conseguir un empréstito para el Ferrocarril. Dijo que el señor Gerente'de dicho Banco le manifestó en un principio no poder atender la solicitud, pero que al día siguiente se comprometio a hacer una propuesta a la Junta una vez que conociera los trabajos del Ferrocarril, los que àl efecto conoció en visita reciente que hizo a la Empresa, después de la cual ha manifestado tener buenas intenciones, razón por la cual el señor Mejía no cree difícil la consecución del empréstito. Se dieron las gracias al expresado señor Mejía por sus desinteresados servicios.

El vocal Salazar informó sobre las gestiones hechas para arreglar amigablemente con el señor Emiliano González el valor de una faja de terreno de su propiedad que necesita el Ferrocarril. Que convino con el mentado señor González en hacer avaluar dicha faja, para lo cual cada una de las partes nombrará un perito.

El mismo vocal Salazar informó lo siguiente: Que de acuerdo con el Superintendente se suprimió el médico de la Empresa y se resolvió mandar en lo sucesivo los enfermos a Pereira, donde serán asistidos en el Hospital San Jorge, según contrato celebrado con el señor Síndico de dicho establecimiento.

Se comisionó al vocal Calle para mandar timbrar los esque letos para hospitalizaciones que necesitara la Enpresa.

IV-Proposiciones.-El señor Presidente y el vocal Salazar sentaron las siguientes, que fueron discutidas $y$ aprobadas:

\footnotetext{
" 1 a Comisiónase al señor Superintendente
} 
para que de acuerdo con el abogado de la Empresa celebre con el señor Emiliano González el contrato de avalúo de su faja, aceptando como perito por su parte al señor Jaime Castro y nombrando por parte del Ferrocarril al señon Valeriano Marulanda".

${ }^{12}{ }^{a}$ Comisionase al señor Superintendente $y$ al abogado del Ferrocarril para que hagan contratos con anticipación con los dueños de las fajas que ocupara la obra, por los cuales se obliguen a convenir los precios por arreglo amigable o por avaluo de peritos, dando cuenta oportunamente a la Junta".

El vocal Villegas sentó la siguiente, que también fue discutida y aptobada:

"No se haga modificación ninguna a la's Reglas Generales del Reglamento; y ellas queden tal como se aprobaron en el acta de 24 de septiembre de 1916 , sobre vacaciones remune. radas".

No habiendo otro asunto de que tratar, se levantó la sesión a las 5 de la tarde.

El Presidente, Pompruro Gumerrez El Secretario, Ricardo Arango.

\section{$=\frac{1}{2} \cdot \operatorname{ACTA}$}

DE LA SESION DEL DIA I4 DE OCTUBRE DE I9I 8

En la ciudad de Manizales, a las cuatro p.m. del dia catorce de octubre de mil novecientos diez y ocho, en el local de costumbre y ba- jolla Presidencia del señor Gobernador del Departamento, se reunio la Junta Directiva. del Ferrocarril de Caldas. Concurrieron: don Miguel Salazar, don Manuel F. Calle, don Leonidas Villegas y el suscrito Secretario.

Se trato de lo siguiente:

I-ACTa ANTERTor.-Abierta la sesión se dió-lectura-al acta de $\eta$ de los corrientes, -la que fue áprobada sin observación.

II-Cotizacrones, Se leyó un cable de Mecke \& $\mathrm{C}^{\circ}$, de II de los corrientes, sobre cotizacion de rieles y accésorios y el vocal Calle propuso lo siguiente que fue aprobado:

"Suspéndanse transitoriamente todas las gestiones sobre pedidos al exterior, mientras subsistan las noticias sobre terminacion de la guerra europea".

-III-INFORMES. - I' El vocal Calle informó sobre la oferta que hace el señor Bernardo Gutiérrez de 700 libras de dinamita y el señor Presidente propuso y la Junta aprobo:

"Comisiónase al vocal Calle para comprar 7ou libras de dinamita al señor Bernardo $G$ atiérrez".

$2^{\circ}$ : Se leyó el informe de la camisión que estudis las.cuentas de agosto de la Superinteñ- dencia y se aprobó la proposición con que termina, que dice:

"Fenécense en primerá instancia las cuentas del Ferrocarril de Caldas correspondientes al mes de agosto último, sin cargo de ninguna clase contra el responsable de ellas señor $R$ icardo Arango, quedando una existencia en caja para el mes siguiente de $\$ 47-\mathrm{II}^{\prime \prime}$.

$3^{\circ}$ Informo el Secretario que hoy se de:ben a Mecke \& Co de plazo vencido, unos 7000 dollars. Fueron comisionados los vocales Salazar y Calle para comprar en letras a la vis ta la expresada cantidad con el fin de atender a ese pagó.

$4^{\circ} \mathrm{El}$ mismo Secretario puso en conocimiento de la Junta que el Ferrocarril posee en esta ciudad, cerca al Instituto Universitario, un solar que se compró al Departamento. Se comisionó al rocal Villegas para que en vista de ese inmueble vea lo que deba hacerse en beneficio de la Empresa y lo proponga a la Junta.

$5^{\circ} \mathrm{El}$ mismo Secretario infurmó que las cuentas del mes de septiembre estaban listas para su examen en primera instancia y en esa virtud se comisionó al vocal Calle para su examen.

IV-NOTAS DEL SENTOR SUPERINTENDENTESe leyeron dos notas que este empleado dirige

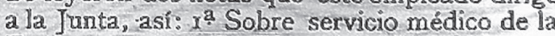
Empresa, que en lo futuro continuará prestándose en el Hospital de San Jorge, de Pereira. Adjunta a esta nota acompaña copia de la que dirigio al doctor Joaquín $\mathbf{E}$. Botero en que le avisa-que ha quedado suprimido su-puesto como médico de la Empresá; al mismo tiempo le da los agradecimientos por los servicios pres-

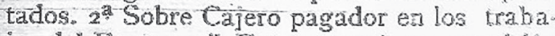
jos-del-Ferrocarril. Esta-se pasó en corrision al vocal Calle.

V-Terrero de la hoya - Fil wocal Calle sento la siguiente proposición que fie discutida y aprobada:

"Nómbrase una comisión para gue celebre contratos ad-reffrindum con los dueños de derechos en el terreno de La Hoya, especialmente con el Banco de Manzaies, Sara Jaramillo de Velísquez e Irés Viclásquez de Villegas".

Fueron comisionados para ésto los vocales, Salazar " Calle.

A las 4 y 45 minutos se levantó a sesion.

E1 Presidente, Pospil.ro Gurterrez

E.1 Secretario, Ricmrdo Arango. 


ACTA
DE LA SESION DEL DIA 2I DE OCTUBRE DE I9I8

En la ciudad de Manizales, a las tres $y$ media p. m. del día veintiuno de octubre de mil novecientos diez y ocho, en el local de costumbre y bajo la Presidencia del señor Gobernador del Departamento, se reunió la Junta Directiva del Ferrocarril de Caldas. Concurrieron: el señor Secretario de Hacienda, don Miguel Salazar, don Manuel Felipe Calle, don Leonidas Villegas y el suscrito Secretario.

Se trató de lo siguiente:

I-ACTA ANTERIOR.-Abierta la sesión se dio lectura al acta de $\mathrm{I}_{4}$ de los corrientes y fue aprobada sin observación.

II-INForme.-El vocal Calle informó sobre la comisión conferida en la sesión anterior relativa a la compra de 700 libras de dinamita al señor Bernardo Gutiérrez, que de acuerdo con éste había mandado una poca parte a los trabajos del Ferrocarril para que fuera ensayada y que si servía se compraban a razón de $\$ 0-35$ libra.

III-AYUDANTE DEL ADMINISTRADOR--INSPECTOR. - Se dio lectura al informe de la comisión que estudió la solicitud del señor Superintendente sobre nombre del empleo creado en la. sesión del I 4 de septiembre anterior $y$ se aprobó la proposición con que termina y que dice:

'El empleo creado según proposición aprobada el I 4 de septiembre pasado será el de Ayudante del Administrador Inspector. Se autoriza al señor Ingeniero Jefe para determinar las funciones que corresponden a dicho empleado. La asignación mensual del mismo será de cincuenta pesos oro y la fianza que debe otorgar será por valor de mil pesos de la mis ma moneda. Nómbrase para desempeñar el puesto de Ayudante del Administrador Inspector, al señor Arturo Arango Restrepo. Comuníquese al nombrado y al señor Ingeniero Jefe para lo de su cargo".

IV-SOLAR DEL FERROCARRIL.-Se leyó el informe de la comisión que estudió este asunto y fue aprobada la proposición con que termina $y$ que dice:

"Dígase al señor Administrador General del Tesoro que se sirva hacer otorgar la escritura de venta del solar que el señor Gobernador cedió a la Empresa del Ferrocarril de Caldas en è año de ı 9 เ6, y cuyo valor se pagó al señor Secretario de Hacienda en el mes de agosto de ese año. Digase al señor Rector del Instituto Universitario que puede hacer construír el campo para juegos que tiene principiado en solar del Ferrocarril, siempre que el menciohado Instituto se encargue de mantener cercado convenientemente ese local".
V-Correspondencia. - Se leyó una carta dirigida de Barranquilla por el señor Obdulio Betancur con fecha 7 del mes en curso al doctor José IgnacioVillegas como respuesta al telegrama que éste le dirigio el 25 de septiembre en su carácter de Gobernador del Departamento y en averiguación de si tenía para la venta dinamita; este telegrama fue contestado de la misma manera por el señor Betancur el 7 del presente mes, y el ir del mismo se le pidieron también por telégrafo ro cajas gelatina de $62 \%$ a $\$ 50$ cada una de acuerdo con lo ofrecido por el expresado señor Betancur. Como en la carta que acaba de leerse manifiesta éste que el servicio telegráfico es muy malo con Barranquilla, y como por otra parte no se ha recibido aviso del despacho de lo pedido, se comisionó al señor Secretario para contestar por carta al señor Betancur, trascribiéndole el telegrama en que se le hizo el pedido de la gelatina y dándole las gracias por los ofrecimientos que hace.

VI-PEdidos.-De nuevo se trató sobre pedido de rieles y tubos y el vocal Villegas sentó la siguiente proposición que fue aprobada:

"Pidanse por correo a Antioquia Com. mercial Corporation 400 pies de tubos de hierro galvanizado de 18 pulgadas y 400 de 24 pulgadas".

A las $4 \frac{1}{2}$ de la tarde se levantó la sesión.

El Presidente, Pompilio Gutierrez El Secretario, Ricardo Arango $D$.

\section{ACTA}

DE LA SESION DEL I5 DE NOTIEMBRE DE IgI 8

En la ciudad de Manizales, a las 8 y 40 minutos de la mañana del día quince de noviembre de mil novecientos diez y ocho, en el local de costumbre y bajo la Presidencia del señor Gobernador del Departamento, se rẻunió la Junta Directiva del Ferrocarril de Cal. das. Concurrieron: señor Secretario de Hacienda, señor Superintendente, don Miguel Salazar, don Manuel Felipe Calle, don Leonidas Villegas y el suscrito Secretario.

Se trató de lo siguiente:

I-ACTA ANTERIOR.--Abierta la sesión se dio"lectura al acta de 21 de octubre último y se aprobó sin observación alguna.

II-CARTA DEL SENor abogado DEL FERrocarril - Se dio lectura a la que con fecha I I de los corrientes dirige el señor Abogado a la Junta Directiva, en la'cual da cuenta de las dificultades que se han presentado a última hora para el avalús de la faja de terreno del señor Emiliano González, y el vocal Calle sentó la siguiente próposición que fue discutida y
aprobada: 
"Acéptase como perito avaluador de la faja del señor Emiliano González. por su parte, al señor don Julio Castro, en reemplazo del señor Jaime Castro. Comuníquese lo anterior al señor Abogado de la Empresa, por telégrafo".

III -CARTA DEL SENOR. ALEJANDRO CONCHA. - Se leyó la que con fecha 24 de octubre dirige al señor Presidente de la Junta en el sentido. de que no se cambie el nombre de "La

* Márina".Fue comisionado el señor Superintendente para contestar al señor Concha.

IV-CARTA DEL SETOOR CARLOS DE LA CUESTA. - Se dio lectura a la que con fecha 4 de los corrientes dirige a la Junta Directiva suplicando se aumente el sueldo que devenga su hijo Carlos Vicente de la Cuesta Restrepo co. - mo Ingeniero Ajudante del Ferrocarril. Pas6 en comisión al señor Superintendente y al vo* cal Calle.

V-CARTA DEL SINDICO DEL HOSPITAL DE SAN JORGE.-Se puso en conocimiento de la Junta la que dirige a. los HH. MM. Salazar y Calle con fecha $3 x$ de octubre, en la que solicita algunos fondos para ampliar el local del Hospital con el fin de separar convenientemen- te los enfermos del F.C. El vocal Calle sèt la siguiente proposicion que fue aprobada:

"Autorizase al señor Superintendente para anticipar al Síndico del mencionado Hospital hasta la suma de $\$ 250$ destinada a ampliar el edificio y para todo lo demás que sea necesario para la buena asistencia de los enfermos. Igualmente se autoriza al señor Superintendendente para nombrar, cuando lo estime conveniente, médico de la Émpresa y para fijarle sueldo".

VI-MrMoriay, de QUINTILIANO BUENo.Se leyó el que dirige al señor Gobernador del Departamento sobre indemnización de perjuicios por haber ocupado el Ferrocarril una faja de terreno de propiedad de la'señora Leticia Bueno, esposa del peticionario, en ta finca de "La Isla". En comisión al señor Secretario de Hacienda.

VII-EDMricios EN LA VIA. -El señor. Presidente sentó la siguiente proposición que dis:cutida fue aprobada:

"Autorízase al señor Superintendente para eliminar los edificios que tenga la Empresa en la via y que a su juicio no sean indispensa. bles para el servicio de la misma".

(Continuara)

BALANCE del Libro Mayor de la Superintendencia del Ferrocarril de Caldas, correse pondiente al mes de octubre de 1919.

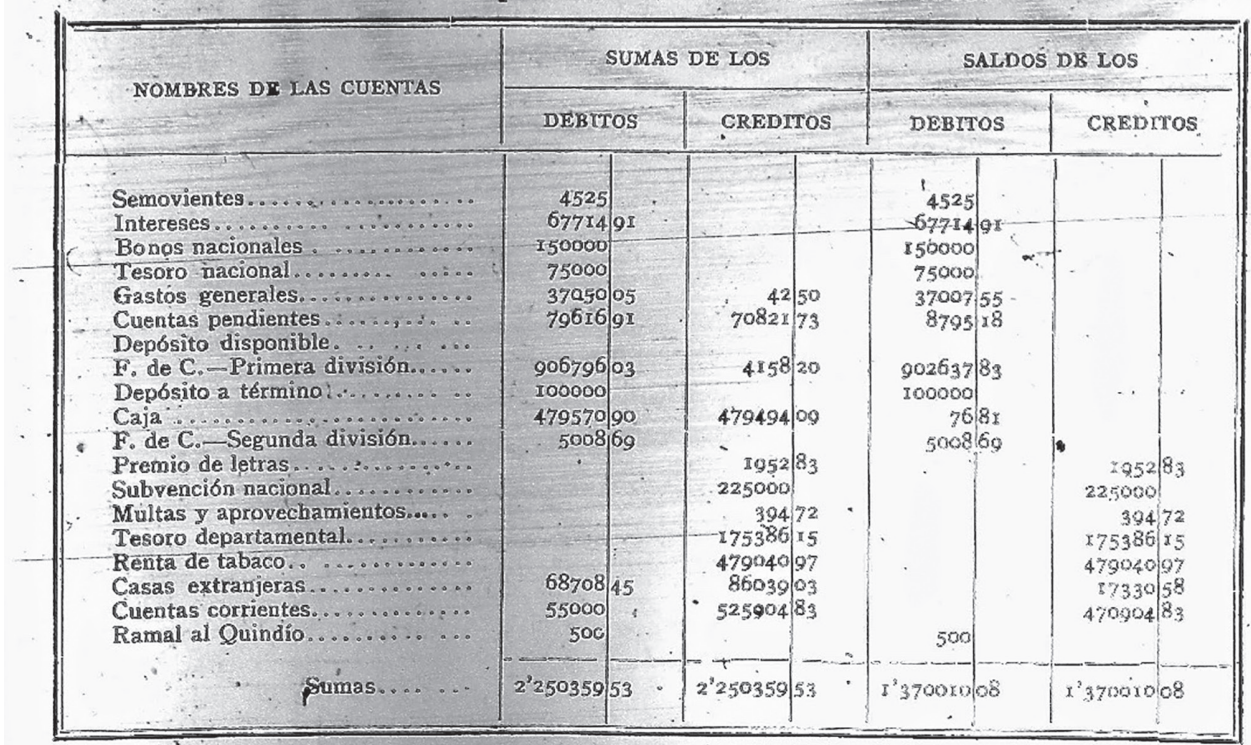

Maniżales, noviembre $x^{c}$ de 1910. 
FERROCARRIL: DE CALDAS

IMPORTACION EN EL MES DE OCTUBRE DE 1919

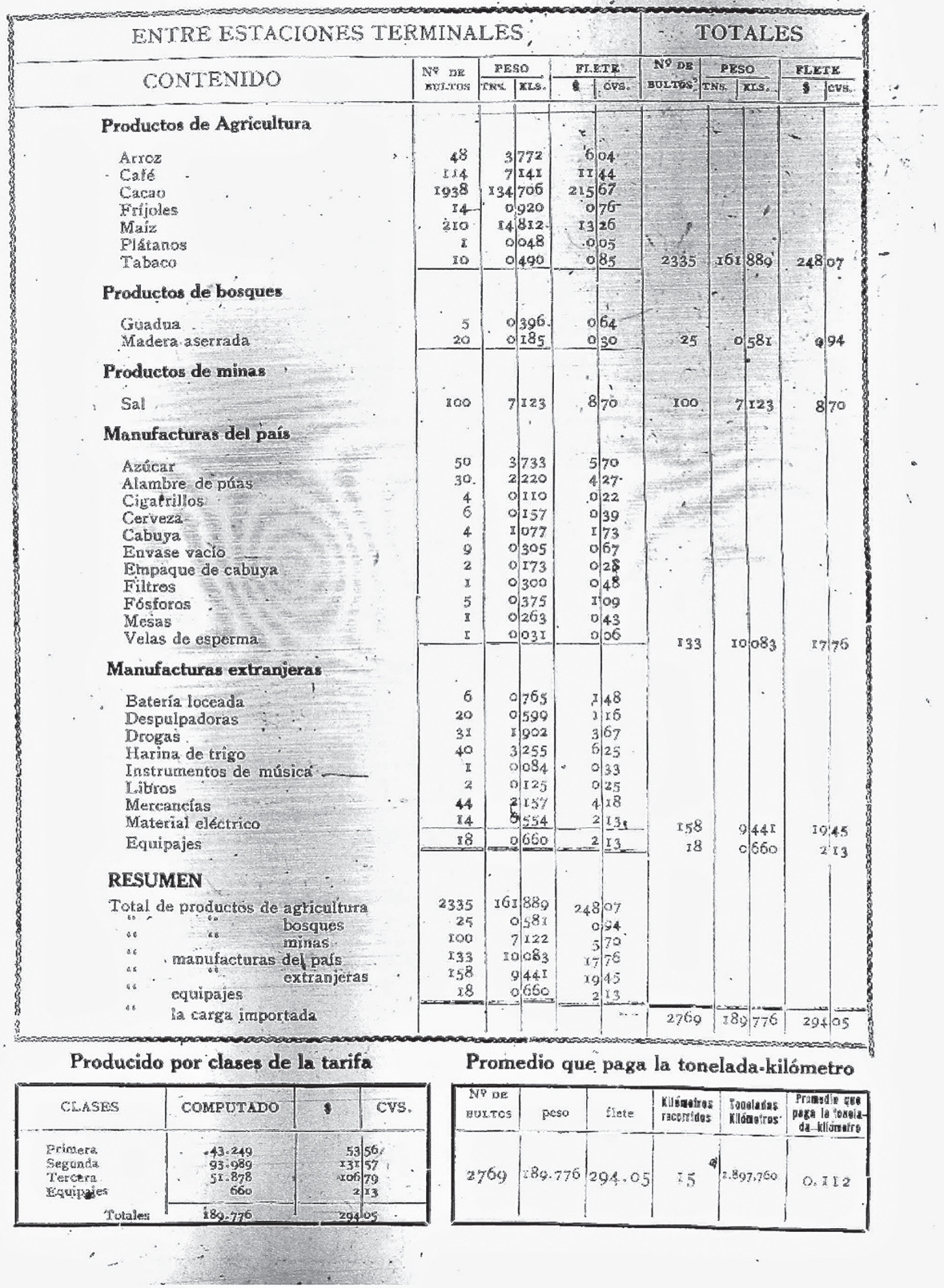




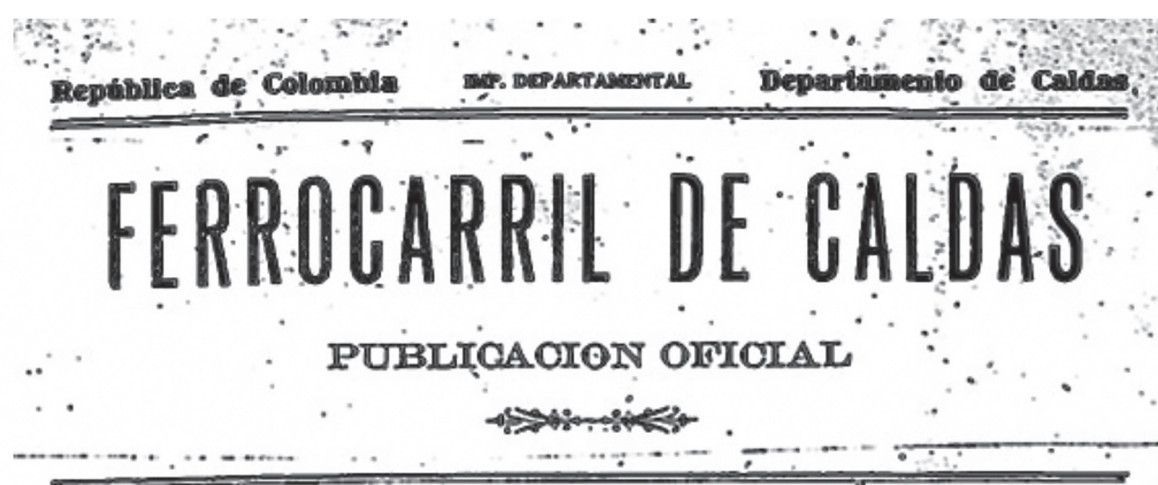

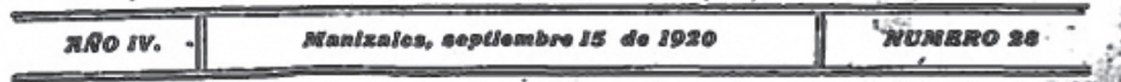

\section{CONTENIDO}

Actas de las sesiones de los dias ab y 23 de marno $y 14.16 \mathrm{y}$ as de abril de igig.....

Balances del Libro Mayor de in Superinten. dencia del Perrocartil do Caldan,correspon. dientes a los meses de enero, lebreco, mag.

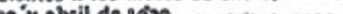

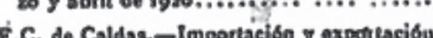
en el mes de enero de $1920 . .$. ...........

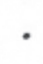

200

aม3

215

ACTA

DE LA SEstox ORL DLA af DE MARzo dE 8919

En la ciudad de Manizales, a las tres p. m., del dia veintiscis do marzo de mil nove. cientos diez y nueve, en el local de coștambre y bajo la presidencia del selor Gobernador del Departamento, se reunio la Junta Directiva del Ferrocarril de Caldas.Concurricron: sofor Secretarió de Hacieinda, don Miguel Sala zar, don Manucl F. Calle, don Leonidas Villegas y el suscrito Secretario.

Se trató de lo siguiente:

t. ACTA ANTERIOk,-Abierta la sesión so dio lectura al acta anterior de al de los corrien. res $y$ se aprobo sin observación alguna,

if. RMPRxstro DEL baxce DE CALDAs, - EI señot Secretario de Ilacienda informó a Lu Junta sobre las gestiones que ha estado ha. ciendo con el señor Gerente del Banco de. Cal. das parn la consccución de un̉ ompréśtito para el I'errocarril por la cantidad de $\$>300.000$. Después de discutir muy-detenidamente las

F condiciones de la negociacisín projectada. lós vocales Salazar y Calle sentaron la siguiente proposicibhoque lue áprobada: "Autoriznse: al señor Secretario da Hacienda parn celebras con el Banco de Caldas unia negociación soble estas bases:-1 Capital - 300.000 que sc. destina para prgar al mismo Banco la cántidad

de $\$ 60.000$ que se le adeudin. comprome.

tiéndóse el Banco a r recibirla renunciando el

- plazoj; 50.000 para pagar en él grúximo mes de octubre al Bancn Alemán. Antiogueño; los . go. 000 restantes se dejarán en deposito dis. ponible en ef Banco prestamista para que: el Ferrocarril los gire en cantidades imensuales. de $\$ 15.000$, poco más o menós, para atender a los trabajos de su construccion. - ap Plazo para la amortizacion diez afos, pudiendo renunciarlo el Departámento en cualquief momento, pagnando el capital y. lós intereses ven. cidos más una cuota de intereses correspion. diente 2 un semestre. $-3^{*}$ Intereses atdiez por ciento anval. $-4^{3}$ Pago de intereses $y$ capital por cuotas semestrales vencidas, $-5^{*}$ EI Departamento queda obligado a depositar en el Banco rodos sus fondos, en depósito disponi-. -ble, sin interés y a recibir a laopar en el pago de todas sus rentas y contribuciones las cédu. las hipotecarias del Banco,-6 Fste contrafo se celebra por la Gobernacion y únicamente requiere para su valides la aprobación de la . Junta Directiva del I. de Caldas en 'cuanto se refiere al Ferrucarril. - $\$$ Garantia engeci. fica que so dara al Banco, el trayecto de $\mathrm{Pe}$. srocarril ya construido".

IIt. manectsiento de cuenras.-Se leyeron los informes do las comisiones que estodiaton las crentas de la Superintendencia . co'. rrespondientes a enero y febrero ulltimos y se aprobaron las proposiciones con que terminan y que dicen: "Fenécense.en primera instancia. las cuentas de la Superintendencia del Ferro. earril de Caldas, correspondientes al mes de enero de 1919. sin aleance de hinguna clase contra el responsable sefior don Ricardo Aran. go. Quecla una existencia en caja de 6,59 para el mes siguiente" "Eenócense.en pritne. ratinstancia, sin alcance ni multa a earró del respousable sefior Ricardo Arango D. - Jas cuentas de la Superintendencia del Ferrocarril de Cildas, correspondientes al mes de febtero de 1919. Queda para la cuenta de marzo un saldo cn cija de $122.630^{\circ}$

Tiv pronosicion de tion Jioure saiazak. - El vocal Salazar sento la siguienté proposición gue fue aprobadar "Irascribase al 'sefior 
"Al convenir la Junta unánimementéen remover de sus puestos a los señores Restrepo y Alzate, tuvo en cuenta más que todo el afirmar la autoridad del señor Superintendente, castigando a dos individuos que según informes se manifestarch en abierta desobediencia a las órdenes del señor Superintendente el día de la última inauguración, manteniendo así la disciplina y obediencia que debe existir en una Empresa como la del Ferrocarril.

Además se deja constancia de la deferencia y confianza con que la Junta ha querido tratar siempre al señor Superintendente, en quien reconoce con gusto competencia y honorabilidad, por lo cual la Junta vería con complacencia que la renuncia que está sobre la mesa fuera retirada por su autor". Se comisionó a los vocales Salazar y Calle para entenderse sobre esto con el doctor Jorge Escobar E., Superintendente e Ingeniero Jefe del Ferrocarril.

No habiendo más de que tratar, se levantó la sesión a las cinco de la tarde.

El Presidente, Pompilio Gutierrez

El Secretario, Ricardo Arango.

\section{ACTA}

DE LA SESION DEL DIA IO DE TEBRERO DE I9I9

En la ciudad de Manizales, a las tres de la tarde del día diez de febrero de mil novecientos diez y nueve, en el local de costumbre y bajo la presidencia del señor Gobernador del Departamento, se reunió la Junta Directiva del Ferrocarril de Caldas. Concurrieron: señor Secretario de Hacienda, don $\mathrm{Mi}$ guel Salazar, don Manuel Felipe Calle, don Leonidas Villegas y el suscrito Secretario.

Se trató de lo siguiente:

I. ACTA ANTERIOR.-Abierta la sesión se dió lectura al acta anterior de seis de los corrientes y se apróbó sin observación alguna.

II. PETICION POR ACCIDENTE DE TRABAJO.-Se dio lectura al memorial que con fecha de hoy dirigió Dolores Giraldo a la Junta Directiva pidiendo se le pague el jornal de su hijo Alejandro Patiño correspondiente a un año de trabajo, por haber muerto a concecuencia de una caida que se dió al ejecutar un trabajo en la línea del Ferrocarril. llegas.

Pasó en comisón al vocal Leonidas Vi-

I I. CARTAS DEL JEFE DE TALLER Y ADMINISTRADOR UEL FERROCAKRIL. - Se dió lectura alas que estos empleados dirigen a la Junta. con fecha 8 del mes en curso pidiendo explicaclón de los motives que tuvo la Junta para declarar insubsistentes esos nombramientos. En comisión al señor Secretaria de Hacienda. $\because$ Iv. cotrzaciones. Se leyeron dos cables de Antioquia C. C. y de Mecke \&. C en que cotizan nuevamente rieles y accesorios y se dispuso esperar un poco para hacer el pedido. v. FENECIMIENTO DE LAS CUENTAS DE NOVIEMBRE Y DICIEMBRE. - Se dí lectura a los intormęs de las comisiones que estudiaron las cuentas de la Superintendencia, correspondientes a los meses de noviembre y diciembre de 1918 , y se aprobaron las proposiciones con que terminan y que dicen: Fenécense en primera instancia, sin alcance ni multa, lás cuentas de la Superintendencia del . Ferrocarril de Caldas, correspondientes al mes de noviembre de 1918 . Queda en caja un saldo para nueva cuenta de siete pesos con treinta y tres centavos oro $(7,33)$. Fenécense en primera instancia las cuentas de la Superintendencia del Ferrocarril de Caldas correspondientes al mes de diciembre de 1918 , sin cargo de ninguna clase contra el responsable de ellas señor don Ricardo Arango. Queda en caja para el mes siguiente, una existencia de trece pesos con veinticuatro centavos oro $(13,24)$.

VI: PROPOSICION SOBRE REVOCATORIA DE UNA RESOLUcion.-El vocal Calle sentó la siguien. te proposición: Revócase la resolución tomada for la Junta en sesión del día cuatro de los corrientes sobre insubsistencia de los nombramientos del Jefe del Taller y Administrador Inspector del Ferrocarril en los señores, Carlos Martín Restrepo y Polidoro Alzate V. El proponente la sustituyó y el señor Secretario de Hacienda en uso de la palabra la combatió haciendo ver los inconvenientes de aprobarla mientras estuviera pendiente la renuncia del señor Superintendente, indicando a la vez como forma transaccional y para salvar el decoro de la Junta, el que el señor Superintendente retirara previamente, su renuncia. En seguida el autor de la proposición sentó otra que fue aprobada por todos los miembros de la Junta y que dice: Suspéndase lo que se discute hasta la próxima sesión.

No habiendo más de que tratar se levantó la sesión a las $4 \frac{1}{2}$ de la tarde.

El Presidente, Pompilio Gutierrez

El Secretario, Ricardo Arango.

\section{ACTA}

DE LA SESION DEL DIA II DE FEBRERO I 9 I 9 .

En la ciudad de Manizales, a las dos y media de la tarde del día once de febrero de mil novecientos diez y nueve, en el local de costumbre y bajo la presidencia del señor Gobernador del Departamento, se reunió la Junta Directiva del Ferrocarril de Caldas. Concurrieron: señor Secretario de Hacienda, don 
Ferrocarril. Concurrieron: don Miguel Salazar, don I eonidas Villegas, don Manuel F. Calle G., y el señor Superintendente. Por enfermedad del señor Secretario-Contador actuó como Secretario "ad-hoc" el vocal señor Calle. I. ACTA ANTERIOR. - Abierta la sesión fúe leida y aprobada el acta de la sesión del 28 de marzo, advirtiendo que el asunto cercos en la via pasó en comisión al señor Secretario de Hacienda y a don Miguel Salazar.

it. CUENTA DEL DR. ALFonso BERNal. - Se puso en conocimiento de la Junta la cuenta que, por cien pesos oro, ha pasado el doctor Alfonso Bernal por sus hororarios como comisionado del Gobierno Nacional para recibir los kilómetros del i i al i 5 últimainente inaugurados. Se dispuso contestar al doctor Bernal que, en concepto de la Junta, estos honorarios son de cargo de la Nación.

III. INFORME DEL DR. BERNAL. - Dispuso el señor Presidente que se extendiera un acta de - entrega de los cinco kilómetros inaugurados últimamente, en la cual consten todos los detalles técnicos contenidos en el informe del doctor Alfonso Bernal, como comisionado del Gobierno Nacional y que dicha acta, firmada por el doctor Bernal y el señor Superintendente, se remita al Ministerio de Obras Públicas.

Iv. SUPLENTE DEL SECRETARIO CONTADOR.Sabiendo la Junta que el señor don Ricardo Arango, Secretario Contador de la Superinten. dencia, está gravemente enfermo, el vocal $\mathrm{Ca}$ lle propuso y se aprobó unánimemente:" Mientras dura la enfermedad del Secretario Contador, señor don Ricardo Arango, nómbrase en interinidad al señor don Francisco Botero A., para desempeñar este empleo. Comuniquese".

v. AUTORIZACION AL SENOR SUPERINTTENDEN-

TE. - Los vocales Calle y Villegas propusieron:

"Autorizase al señor Ingeniero Jefe para que organice el cuerpo de Ingenieros, así:

Un Ingeniero Divisionario, con sueldo mensual de........ s

Tres Ingenieros de Sección, con sueldo mensual cada uno de.

Tres. Ingenieros Ayudantes, con sueldo mensual cada uno de.

Tres Ingenieros segundos ayudantes, con sueldo mensual cada uno de...............

Un Ingeniero de Sostenimiento, con sueldo mensual de......

Un Ingeniero Dibujante, con - sueldo mensual de.........

Un Escribiente, con sueldo mensual de..............

Digase al señor.............. 40, oo estos puestos". Puesto en discusión fue aprobada.

vi. Nombramientos. - A continuación el señor Ingeniero-Jefe hi:o las siguientes proposiciones que después de discutidas, una a una, fueron aprobadas:

$1^{\text {a }}$ Nómbrase Ingeniero-Divisionario al doctor Eleuterio Serna; este señor tendrá a su cargo la $1^{a}$ y la $2^{a}$ División uel F.C. y las de más funciones que le señale el Ingeniero-Jefe. $2^{a}$ Nómbrase Ingeniero de Sostenimiento al doctor Carlos de la Cuesta.

$3^{\text {a }}$ Nómbrase Ingeniero de la $1^{\text {a }}$ Sección de la $2^{\text {a }}$ División al señor Julián Arango.

$4^{\text {a }}$ Nómbrase primer Ayudante de la $1^{\text {a }}$ Sección de la $2^{\text {a }}$ División al señor Francisco Luis Arango.

$5^{\mathrm{a}}$ Nómbrase segundo Ayudante de la $1^{\text {a }}$ Sección de lá $\mathbf{2}^{\mathbf{a}}$ División al señor Benjamín Suárez.

$6^{\text {a }}$ Nómbrase Ingeniero Dibujante al sêñor Rafael Botero S.

$7^{\mathrm{a}}$ Nómbrase al señor Martín Llano, Ingeniero de la $2^{\text {a }}$ Sección de la. $1^{\text {a }}$ División.

$8^{\text {a }}$ Nómbrase al señor Jorge Rodas, primer Ayudante de la $2^{\mathbf{a}}$ Sección de la ${ }^{\text {a }}{ }^{\text {Divi- }}$ sión.

Estos empleados empezarán a ejercer sus funciones el $I^{\circ}$ de mayo próximo.

vit. PEDIDo.-Presentó el señor Superintendente una lista de materiales para Ingenieros, herramientas, cemento, explosivos, etc., solicitando autorización para hacer un pedido por estos materiales. Puesta en discusión se convino en aplazar el pedido hasta la próxima semana y llamar al Jefe-Mecánico para que indique las máquinas y herramientas que deben pedirse para el taller, con el objeto de a. gregarlas a esta nota.

VIII. CERCOS EN LA VIA.-En su propio nombre $y$ en el del señor Secretario de Hacicnda, presentó e! vocal Salazar la siguiente proposición que fue aprobada: "Aplácese la 200, oo consideración del arreglo de las cercas de las fajas compradas a los señores Jaranillo, VéI 70,00 lez, Cadavid y Echeverri U., hasta que se hava construído la banca en dichas fajas y $\mathrm{co}$ I 20, 00 muniquese así a los interesados. Manifiésteseles, además, que el Ferrocarril no cuenta todavía con los fondos necesarios para pagar su va100,00 lor, y que ellos, por otra parte, no tendrán necesidad de hacer dichas cercas, ni podrán I 20,00 hacerlas, hasta que esté terminada la expresada banca".

Siendo las cuatro y treinta p.m. se levantó la sesion.

El Presidente, Pompilio Gutifrrez

El Secretario ad-hoc, Iconidas l illegas. 


\section{$\therefore$ ACTA}

DE LA SESION DEL DIA I6 DE ABRIL DE 1919.

En la ciudad de Manizales, a las dos p, m.,del día diez y seis de abril de mil novecientos diez y nueve, en el local de costumbre $y$ bajo la presidencia del señor Gobernador del Departamento, se reunió la Junta Directiva del Ferrocarril de Caldas con asistencia del señor Superintendente y de lós vocales doctor Daniel Gutiérrez y Arango, don Miguel Salazar J., don Leonidas Villegas, don Samuel Angel y el suscrito Secretario interino.

Se trató de to siguiente:

I. ACTA ANTERIOR - Se leyó y aprobó el acta anterior con las siguientes modificaciones: "Que conste que en dicha sesión paso el señon Presidente en comision, para estudio y reforma los estatutos o reglamentos del Ferrocarril de Caldas, a los vocales Salazar y Villegas y que donde dice Ingeniero Jefe se lea Superintendente".

II. PEDIDO. - El vócal señor Villegas presentó la siguiente proposición que fue aprobada: "No siendo posible la venida a esta ciudad del Mecánico de la Empresa, hágase el pedido presentado por el señor Superintendente por materiales para Ingenicros, herramientas, cemento, explosivos, etc. Hágase este pedido por vía de ensayo; a la casa de Alejandro Angel \&: C?".

II. FAJAS.-El yocal señor Villegas propuso y fue aprobado por la Junta: "Acéptase el contrato celebrado por el señor Superintendente con el señor Carlos Echeverri, sobre faja y cercos y autorizase a girar por el valor íntegro una vez otorgada la escritura correspondiente".

IV. FAJAS, -El doctor Guitiérrez propuso y fue aprobado por la Junta: "En los contratos que se hagan con los dueños de fajas sobre cercos, éstos quedan obligádos a construírlos y sostenerlos, no quedando el Ferrucarril obligado a pagar perjuicios de ninguna clase".

v. NOMBRAMIENTO. - El señor Superintendente propuso y fué aprobado 'por la Junta: "Nómbrase al señor Gabriel Mejía Villa, Ayudanté de la $2^{\mathrm{a}}$ Sección de la $\mathrm{I}^{\mathrm{a}}$ División del Ferrocatril de Caldas".

vI.-Se dio lectura a una nota de la $\mathrm{H}$. Asamblea sobre paso del río Cauca en Puerto Caldas y otra nota de la misma corperación sobre estudio de electrificación del Ferrocarril. Ambas notas fueron pasadas en comisión por el señor Presidente, la primera al vocal Salazar y al señor Superintendente, y la segunda al vocal Gutiérrez y al señor Superintendente.

Siendo las cuatro $p$. m., se levantó la se sión por no haber otro asunto de qué tratar.

El Presidente, Pompilio Gurierrez

El Secretario, Leonidas Villegas.

\section{ACTA}

DE LA SESION DEL DIA 2 I DE ABRIL DE I9I9.

En la ciudad de Manizales, a la una p.m. del día veintiuno de abril de mil novecientos diez y nueve, en el local acostumbrado, se reunió la Junta Directiva del Ferrocarril de Caldas, bajo la presidencia del señor Gobernador del Departamento. Concurrieron el señor Superintendente, el señpr Secretario de Hacienda y los vocales señores doctor Daniel Gutiérrez y Arango, don Roberto Vélez, don Leonidas Villegas J., y el doctor Alejandro Restrepo I. Actuó como Secretario el vocal yillegas.

Se trato:

I. INFORME DE UNA COMISION. - -LOS vOcales señor Secretario de Hacienda y don Miguel Salazar presentaron un informe relativo a cercas en las fajas del Ferrocarril. Se dispuso pasar dicho informe a un nuevo estudio y se comisionó a los vocales doctor Gutiérrez y Arango, y don, Roberto Vélez.

II. NOMBRAmiento. -En reemplazo del señor don Ricardo Arango, muerto en esta ciudad el día I 7 del presente mes, propuso el señor Superintendente al señor Tulio Arango A. La Junta lo áceptó y dispuso que se le comunicara el nombramiento al señor Contador-Cajero de la Empresa.

III. NOMBRAMIENTO DE SUPERINTENDENTE.Manifestó el señor Secretario de Hacienda que en atención al desarrollo que se va a dar a los trabajos del Ferrocarril del próximo mes de mayo en adelante, se hace necesario el nombramiento de Superintendente, puesto que ha venido desempeñando el sènor Ingeniero-Jefe. El mismo señor Secretario de Hacienda opina que este puesto lo puede desempeñar, hoy por hoy, uno de los miembros de la Junta, sin remuneración, agregando que él no tendría in convenienteien aceptarlo. En tal virtud el doctor Gutiérrez propuso, y la Junta aprobrí "Teniendo en cuenta el ofrecimiento que hace el señor Secretario de Hacienda de desempeñar la Superintencia del Ferrocarril, gratuitamente, y en vista de su competencia, la Juntaresuelve nombrarlo".

IV. PENIOO DE COTIZACion.-El señor Presidente prupuso y la Junta aprobó: "Pídase al Exterior una cotización de puentes, para estudiar la que convenga para el ramal a Cartago".

v. PROPOSICION. - Lil señor Superintendente y el vocal Villegas sentaron la siguiente proposición que fue aprubada por unanimidad: "Los gastos de médicos, medicamentos y funerales del señor don Ricardo Araingo D., serán por cuenta de la Eimpresa del Ferrocarril de Caldas".

$A$ las 3 p. m. se levantó la sesión.

El Presidente, Pompilio Gutierrez

El Secretario, Leonidas Villegas. 
BALANCE del Libro Mayor de la Superintendencia del Ferrocarril de Caldas, correspondiente al mes de eviero de 1920.

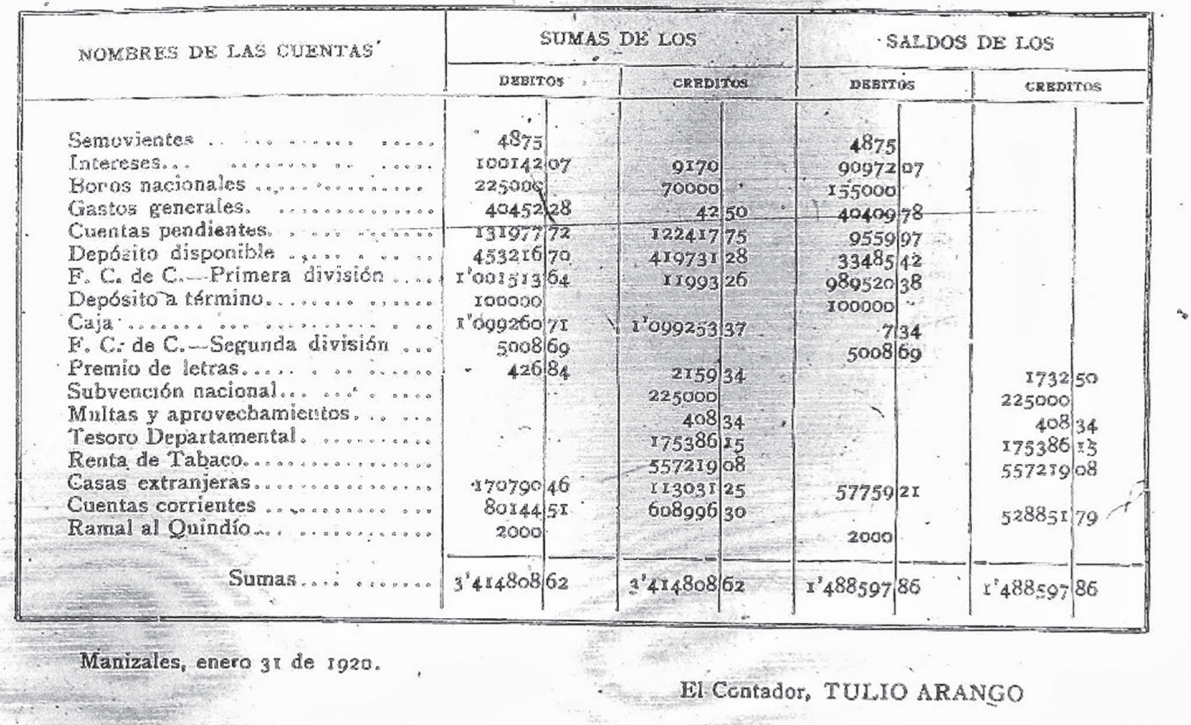

BALANCE del Libro Mayor de la Superintendencia del Ferrocarril de Caldas, correspondiente al mes die febrero de 1920.

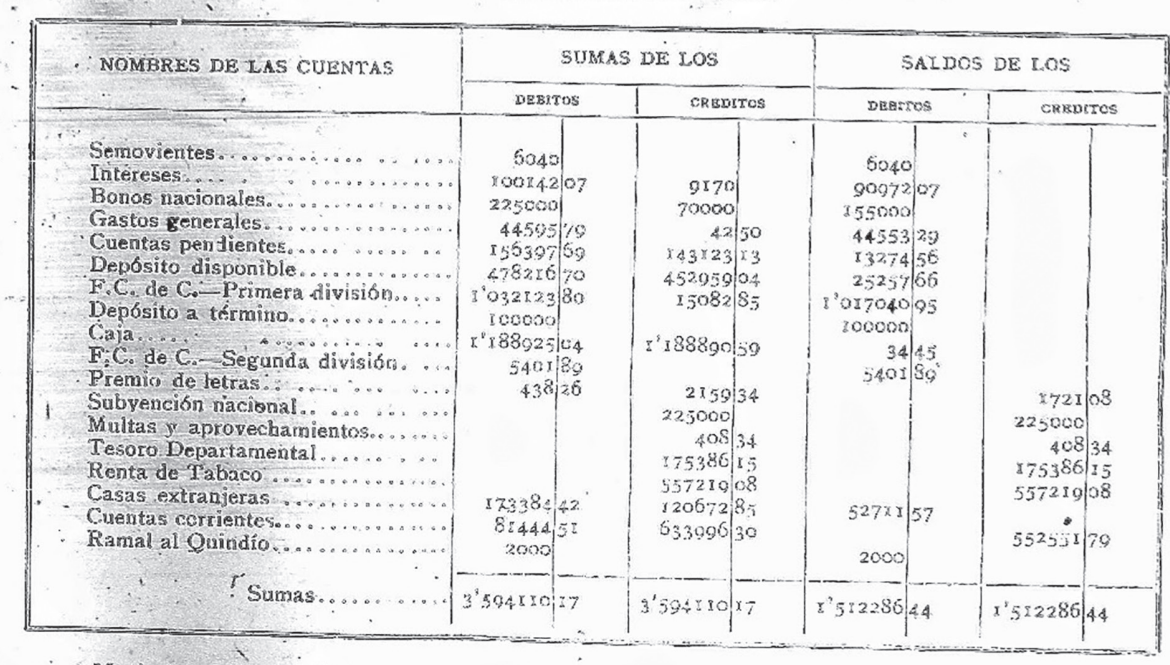

Manizales, febrero 29 'de rgzo. 
BALANCE del Libro Mayor de la Superintendencia del Ferrocinril de Caldas, correapondiente al mes de mario de 1920.

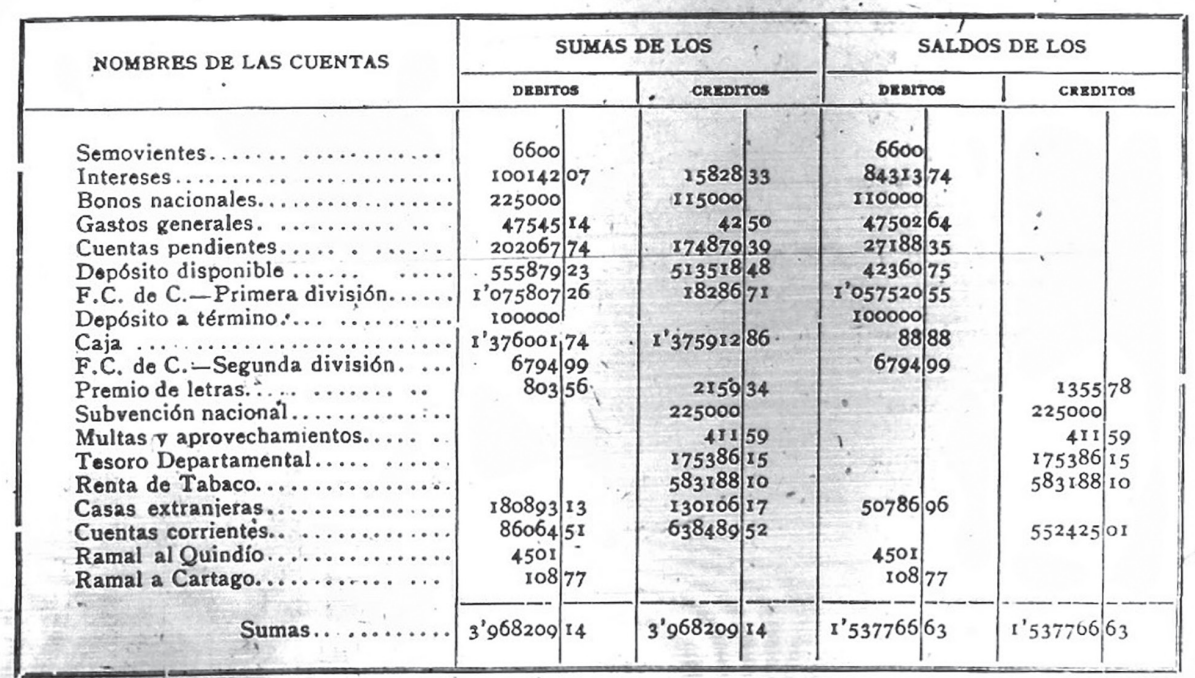

Manizales, marzo 31 de 1920.

El Contador, TULIO ARANGU

BALANCE del Libro Mayor de la Superintendencia del Ferrocarril de Caldas, correspondiente al mes do abril do 1920.

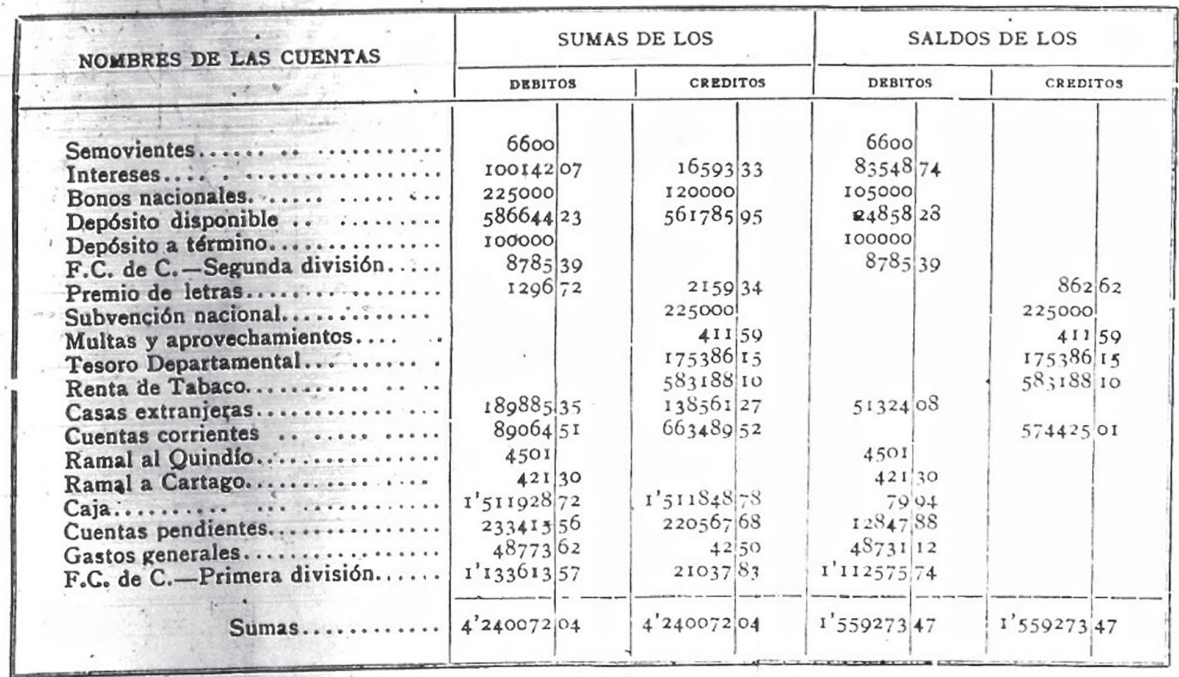

Manizales, abril 30 de 8920. 


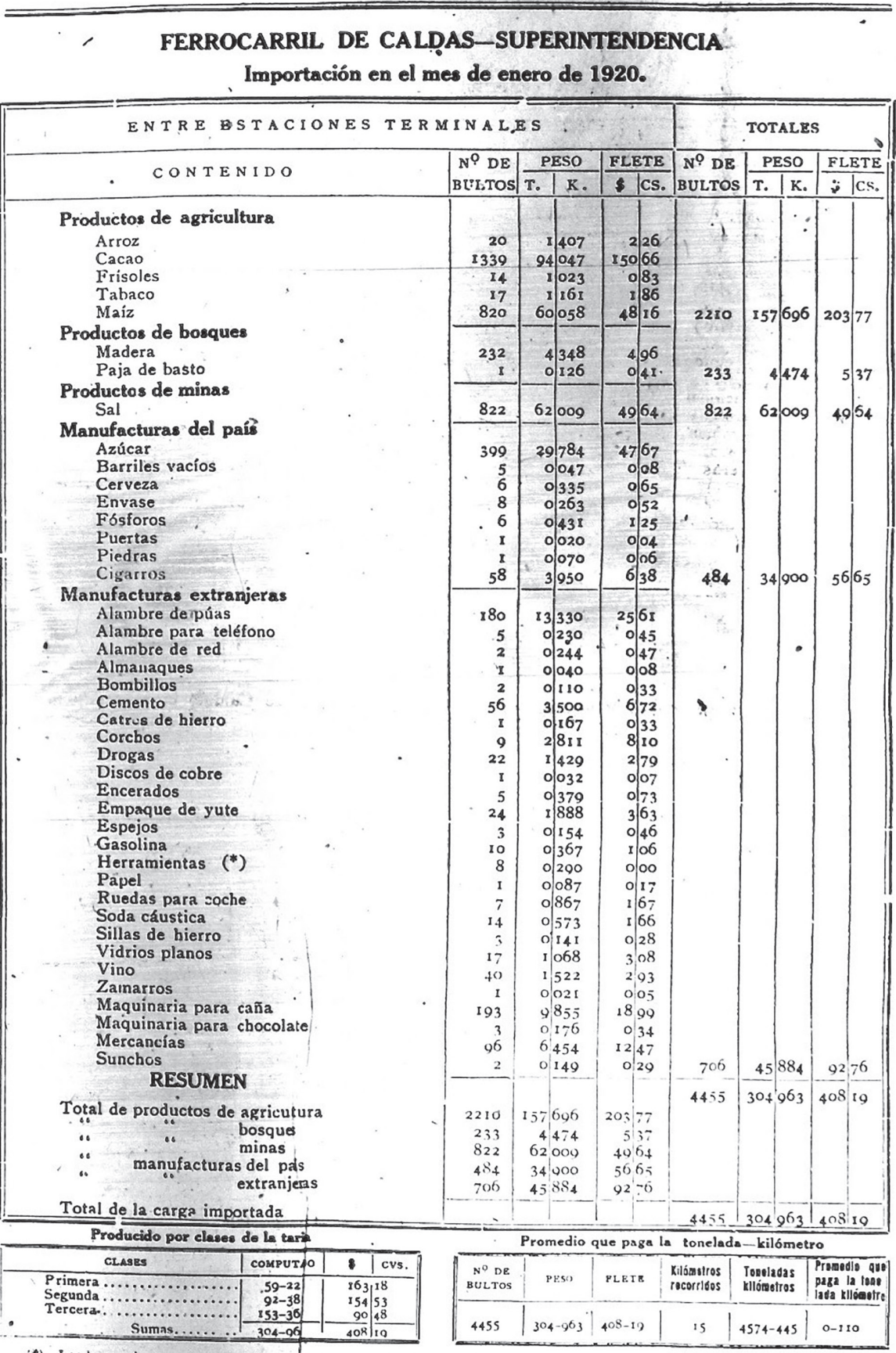

(“)-Las herramieutas no pagaron fete poser para el Municipio de Pereira. 


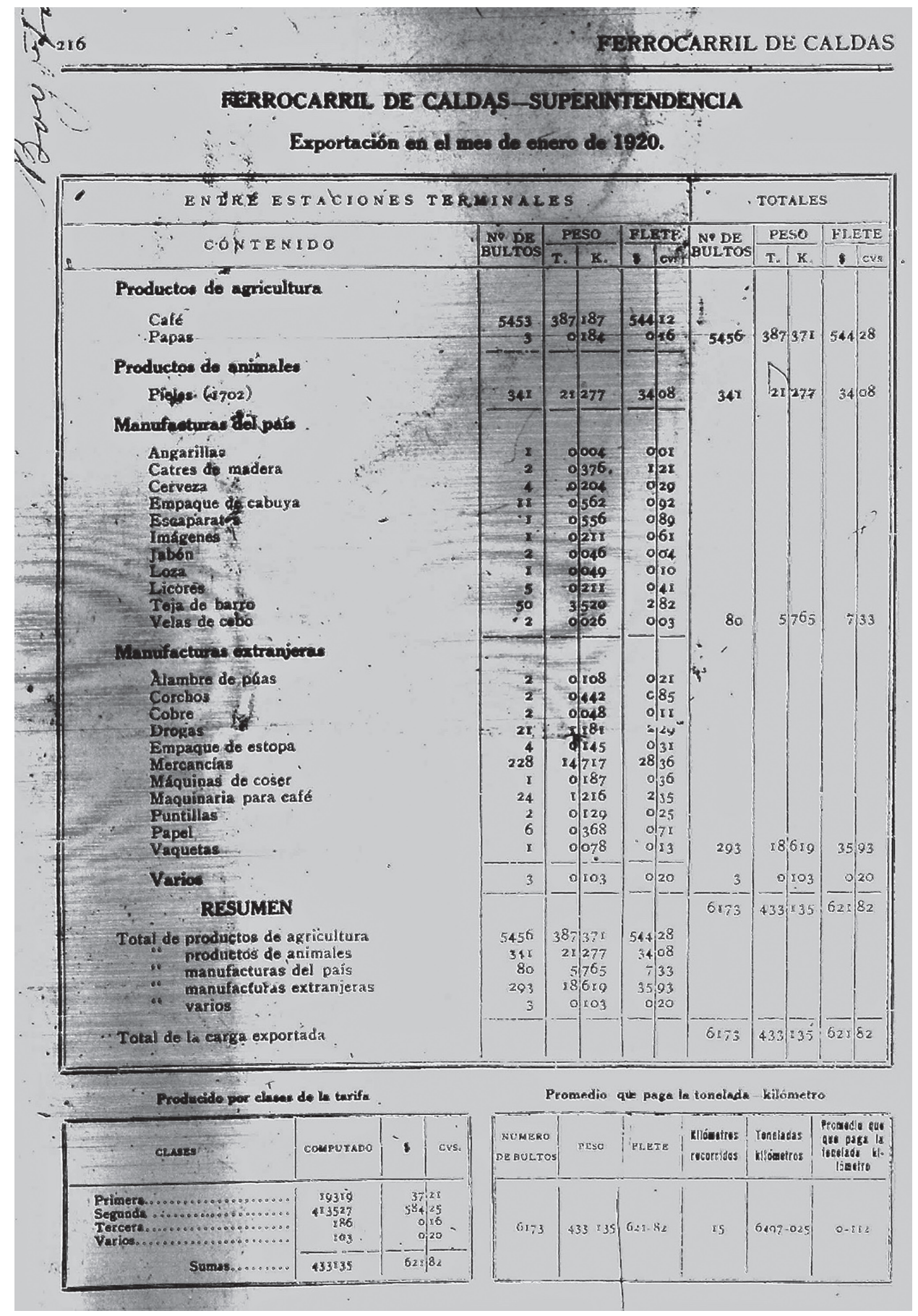




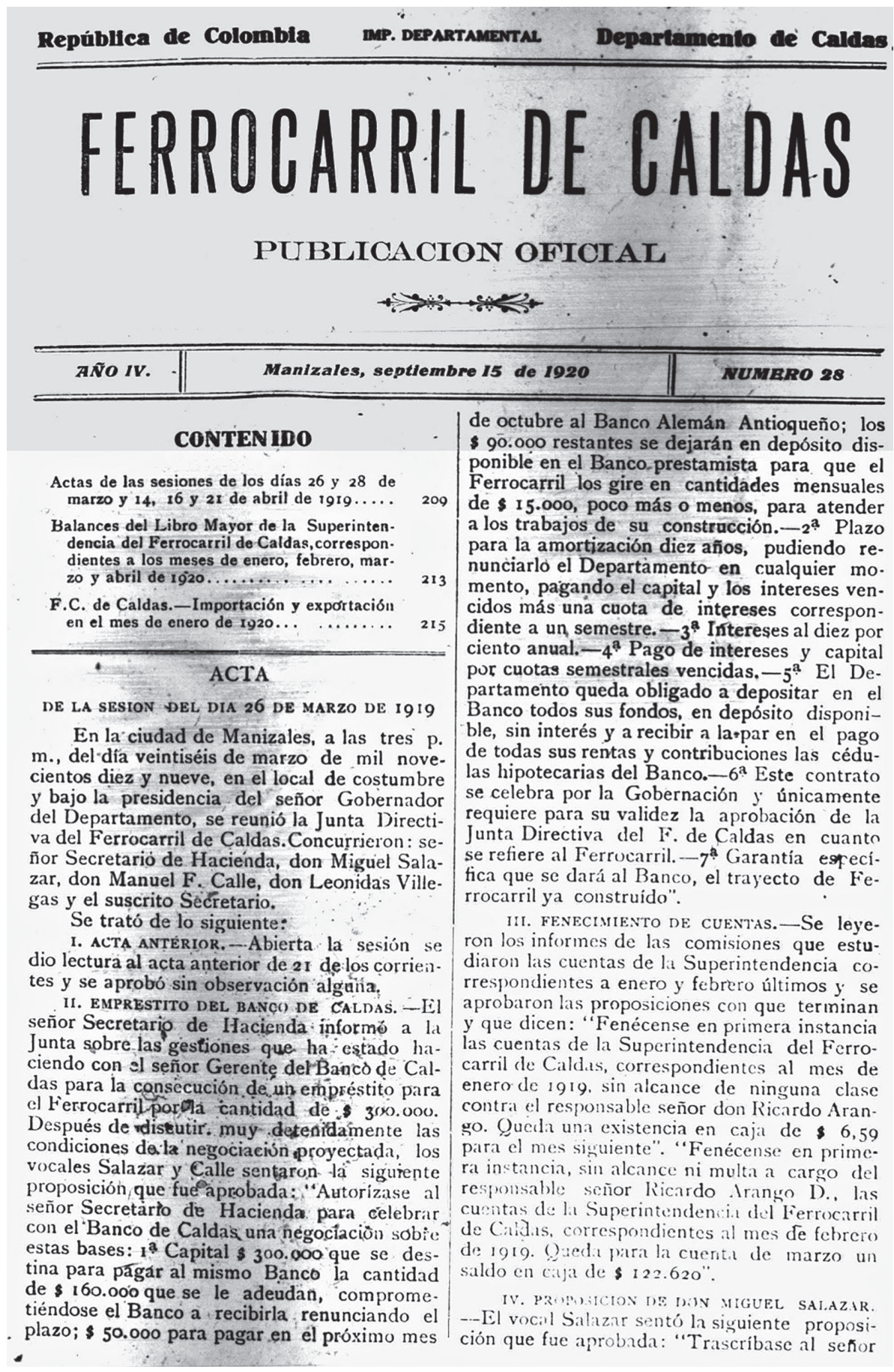


Superintendente la parte del informe del señor Manuel F. Calle en que hábla de los enfermos del Ferrocarril y llámesele la atención al artículo publicado sobre el mismo asunto en el "Bien Social" de Pereira, correspondiente al veintidós de los corrientes".

No habiendo otro asunto de qué tratar se levantó la sesión a las cuatro de la tarde.

El Presidente, Pompilio Gutierrez El Secretario, Rucardo Arango $D$.

\section{ACTA}

DE LA SESION DEL DiA 28 DE MARZo DE 1919.

En la ciudad de Manizales, a las tres p. m., del día veintiocho de marzo de mil nove: cientos diez y nueve, en el local de costumbre y bajo la presidencia del señor Gobernador del Departamento, se reunió la Junta Directiva del Ferrocarril de Caldas. Concurrieron: el señor Secretario de Hacienda; señor Superintendente, don Miguel ' Salazar, don Manuel F. Calle, don Leonidas Villegas y el suscrito Secretario.

Se trató de lo siguiente:

I. ACTA ANTERT(O) - Abierta la sesión se dio lectura al acta anterior de $26 \mathrm{de}$. los corrientes y se aprobó sin observación.

II. ADICION Y REFORMAS A LOS REGLAMENTOS SOBRE SERVICIO-DE BODEGAS.--Se dio lectura al informe de la comisión a cuyo estudio pasó este asunto y puesto en discusión el proyecto de resolución con que termina y que dice: "Considérense las adiciones y reformas a los reglamentos sobre servicio de bodegas del Ferrocarril de Caldas que en pliego aparte os presentamos". La Junta aprobó este proyecto. .En seguida se pusieron en discusión los artículos en que constan tales adiciones y reformas y la Junta les dio su aprobación, artículo por àrtículo, en el orden siguiente:

-4. "Artículo I - En la estación terminal de Puérto-Caldas no se cobrará bodegaje a aquellos comisionistas que teniendo completamente-llenas sus bodegas necesiten ocupar las del Ferrocarril para el exceso de su carga, pero quedan en la obligación de sacarla en el primer embarque que hagan.

Artículo $2^{\circ}$ Los comisionistas $\odot$ particulares que depositen carga en la bodega del $\mathrm{Fe}$ rrocarril, que no haya sido ni sea trasportada por él, pagarán un bodegaje de o, ro por cada bulto y por cada día en los primeros diez días y de $\$ 0,02$ en los. siguientes.

Artículo $3^{\circ}$ La Empresa desembarcará la carga que sea trasportada por el Ferrocarril y la colocará en las bodegas respectivas a la altura del hombro de un hombre; la remontada será por cuenta de los dueños de aquélla.
Cuando los interesados no estuviesen presentes para recibir la carga, el bodeguero la hará desembarcar en tierra de acuerdo con la condición del conocimiento de embarque.

Artículo $4^{\circ} \mathrm{El}$ que aforare carga deberá presenciar el peso, estado de los bultos $y$ calidad del empaque.

Artículo $5^{\circ}$ La caja o saco que con el movimiento regular de bodega se rompa, dejando escapar el contenido o parte de él, no será embarcado si el interesado no hace la reparación oportunamente. La Empresa no reempaca ni responde por la pérdida de efectos que por la mala calidad del empaque se derramaren.

Artículo $6^{\circ}$ Los bultos que sean presentados para aforarlos tendrán una marca clara con el fin de evitar cambios de los de un mismo artículo y de distinto dueño. Cuando por causa de no estar convenientemente marcados ocurrieren aquellos, la Émpresa no responde por los perjuicios que sufran los interesados.

Artículo $7^{\circ}$ Para el efecto de considerar la clase del artículo que se va a aforar el dueño de él está en la obligación de declarar el contenido, y caso de no quererlo hacer, el bodeguero podrá negarse a embarcarlo.

Artículo $8^{\circ} \mathrm{El}$ bódeguero de Puerto-Caldas queda en la obligación de recibir y despachar la carga de los buques y la de cualquiera otra persona, después de las seis de la tarde y antes de las seis de la mañana, siempre que el Capitán del buque, el comisionista o el dueño de ella pague al bodeguero una remuneración de $\$ 0,60$ por cada hora.

Artículo $9^{\wedge} \mathrm{La}$ presente adición y reforma empezará a regir desde el día primero de abril próximo venidero".

III. CERCOS EN LA VIA. - je dio lectura al informe del señor Superintendente en que comunica a la Junta algunos arreglos que hizo "ad-referendum" con varios de los dueños de terrenos adyacentes a la vía del F.C. sobre conservación de cercos. Pasó en comisión al señor Secretario de Hacienda y al vocal Salazar.

No habiendo otro asunto de qué tratar se levantó la sesión a las 4 p. m.

El Presidente. Pompilio Gutierrez

El Secretario "ad-hoc", Lconidas Villegas.

$$
\overline{\mathrm{C}} \overline{\mathrm{T} A}
$$

IE LA SESION I)EL DIA I 4 DE ABRIL DE I9I9.

En la ciudad de Manizales, a las tres p. m., del día catorce de abril de mil novecientos diez y nueve, en el local de costumbre y bajo la presidẹncia del señor Gobernador del Departamento, se ręunió la Junta Directiva del 
Ferrocarril. Concurrieron: don Miguel Salazar, fon I eonidas Villegas, don Manuel F. Calle G., y el señor Superintendente. Por enfermedad del señor Secretario-Contador actuó codad del senor "ad-hoc" el vocal señor Calle. I. ACTA ANTERIOR. - Abierta la sesión fúe leída y aprobada el acta de la sesión del 28 de matzo, advirtiendo que el asunto cercos en la vía pasó en comisión al señor Secretario de Hacienda y a don Miguel Salazar.

iI. CUENTA DEL DR. AlFonso Bernal. - Se puso en conocimiento de la Junta la cuenta que, por cien pesos oro, ha pasado el doctor Alfonso Bernal por sus hororarios como comisionado del Gobierno Nacional para recibir los kilómetros del i i al 15 últimainente inaugurados. Se dispuso contestar al doctor Bernal que, en concepto de la Junta, estos honorarios son de cargo de la Nación.

III. INFORME DEL DR. BERNAL. - Dispuso el señor Presidente que se extendiera un acta de entrega de los cinco kilómetros inaugurados últimamente, en la cual consten todos los detalles técnicos contenidos en el informe del doctor Alfonso Bernal, como comisionado del Gobierno Nacional y que dicha acta, firmada por el doctor Bernal y el señor Superintendente, se remita al Ministerio de Obras Públicas.

Iv. SUPLENTE DEL SECRETARIO CONTADOR.Sabiendo la Junta que el señor don Ricardo Arango, Secretario Contador de la Superintendencia, está gravemente enfermo, el vocal $\mathrm{Ca}$ lle propuso y se aprobó unánimemente:" Mientras dura la enfermedad del Secretario Contador, señor don Ricardo Arango, nóınbrase err interinidad al señor don Francisco Botero A., para desempeñar este empleo. Comuniquese".

v. AUTORIZACION AL SENOR SUPERINTTENDENTE. - Los vocales Calle y Villegas propusieron: "Autorízase al señor Ingeniero Jefe para que organice el cuerpo de Ingenieros, así:

Un Ingeniero Divisionario, con sueldo mensual de......... s

Tres Ingenieros de Sección, con sueldo mensual cada uno de.

Tres. Ingenieros Ayudantes, con sueldo mensual cada uno de.

Tres Ingenieros segundos ayudantes, con sueldo mensual cada uno de...............

Un Ingeniero de Sostenimiento, con sueldo mensual de......

Un Ingeniero Dibujante, con

- sueldo mensual de........

Un Escribiente, con sueldo mensual de

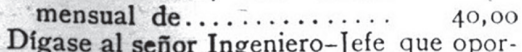
tunamente al señor Ingeniero-jefe que opor estos puestos". Puesto en discusión fue aprobada.

vi. Nombramientos. - A continuación el señor Ingeniero-Jefe hi:o las siguientes proposiciones que después de discutidas, una a una, fueron aprobadas:

$1^{\text {a Nómbrase Ingeniero-Divisionario al }}$ doctor Eleuterio Serna; este señor tendrá a su cargo la $1^{\mathrm{a}}$ y la $2^{\mathrm{a}}$ División uel F.C. y las de más funciones que le señale el Ingeniero-Jefe. $2^{\mathrm{a}}$ Nómbrase Ingeniero de Sostenimiento al doctor Carlos de la Cuesta.

$3^{a}$ Nómbrase Ingeniero de la $1^{a}$ Sección de la $2^{\text {a }}$ División al señor Julián Arango.

$4^{\text {a }}$ Nómbrase primer Ayudante de la $1^{\text {a }}$ Sección de la $2^{\text {a }}$ División al señor Francisco Luis Arango.

$5^{\mathrm{a}}$. Nómbrase segundo Ayudante de la $1^{\mathbf{a}}$ Sección de lá $2^{\mathbf{a}}$ División al señor Benjamín Suárez.

$6^{\text {a }}$ Nómbrase Ingeniero Dibujante al señor Rafael Botero S.

$7^{a}$ Nómbrase al señor Martín Llano, Ingeniero de la $\mathbf{2}^{\mathbf{a}}$ Sección de la. $1^{\mathbf{a}}$ División.

$8^{a}$. Nómbrase al señor Jorge Rodas, primer Ayudante de la $2^{\text {a }}$ Sección de la $1^{\text {a }}$ Division.

Estos empleados empezarán a ejercer sus funciones el $1^{\circ}$ de mayo próximo.

vit. PEDIDo.-Presentó el señor Superintendente una lista de materiales para Ingenieros, herramientas, cemento, explosivos, etc., solicitando autorización para hacer un pedido por estos materiales. Puesta en discusión se convino en aplazar el pedido hasta la próxima semana y llamar al Jefe-Mecánico para que indique las máquinas y herramientas que deben pedirse para el taller, con el objeto de a. gregarlas a esta nota.

VIII. CERCOS EN LA VIA.-En su propio nombre $y$ en el del señor Secretario de Hacienda, presentó e! vocal Salazar la siguiente proposición que fue aprobida: "Aplácese la consideración del arreglo de las cercas de las fajas compradas a los señores Jaramillo, Vé-
170,00 I $20, \infty$

100,00 I 20,00

100, 00

para Cadavid y Echeverri hasta que se haya construido la banca en dichas fajas y comuníquese así a los interesados. Manifiésteseles, además, que el Ferrocarril no cuenta todavia con los fondos necesarios para pagar su valor, y que ellos, por otra parte, no tendrán necesidad de hacer dichas cercas, ni podrán hacerlas, hasta que esté terminada la expresada banca".

Siendo las cuatro y treinta p.m. se levantó la sesion.

$$
\text { El Presidente, Pompilio Gutifrrez }
$$

El Secretario ad-hoc, Lconidas lillegas. 


\section{ACTA} m.,del día diez tos diez y nueve, en el local de costumbre $y$ bajo la presidencia del señor Gobernador del Departamento, se reunió la Junta Directiva del Ferrocarril de Caldas con asistencia del señor Superintendente y de lós vocales doctor Daniel Gutiérrez y Arango, don Miguel Salazar J., don Leonidas Villegas, don Samuel Angel y. el suscrito Secretario interino.

Se trató de to siguiente:

I. ACTA ANTERIOR - Sé lejó y aprobó el acta anterior con las siguientes modificaciones: "Que conste que en dicha sesión pasó el señor Presidente en comision, para estudio y reforma los estatutos o reglamentos del Ferrocarril de Caldas, a los vocales Salazar y Villegas y que donde dice Ingeniero Jefe se lea Superintendente".

II. PEDIDO. - El vócal señor Villegas presentó la siguiente proposición que fue aprobada: "No siendo posible la venida a esta ciudad del Mecánico de la Empresa, hágase el pedido presentado por el señor Superintendente por materiales para Ingenicros, herramientas, cemento, explosivos, etc. Hágase este pedido por vía de ensayo; a la casa de Alejandro - Angel \&. Ca".

IIx. FAJAS. - El yocal señor Villegas propuso y fue aprobado por la Junta: "Acéptase el contrato celebrado por el señor Superintendente con el señor Carlos Echeverri, sobre faja y cercos y autorizase a girar por el valor íntegro una vez otorgada la escritura correspondiente".

IV. FAjas. - El doctor Gutiérrez propuso y fue aprobado por la Junta: "En los contratos que se hagan con los dueños de fajas sobre cercos, éstos quedan obligádos a construírlos y sostenerlos, no quedando el Ferrucarril obligado a pagar perjuicios de ninguna clase".

v. NOMBRAMIEnTo.-El señor Superintendente propuso y fue aprobado 'por la Junta: "Nómbrase al señor Gabriel Mejía Villa, Ayu-

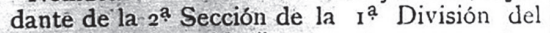
Ferrocarril de Caldas".

vi. - Se dio lectura a una nota de la $\mathrm{H}$. Asamblea sobre paso del río Cauca en Puerto Caldas y otra nota de la misma corperación sobre estudio de electrificación del Ferrocarril. Ambas notas fueron pasadas en comisión por el señor. Presidente, la primera al vocal Salazar y al señor Superintendente, y la segunda al vocal Gutiérrez y al señor Superintendente.

Siendo las cuatro p. m., se levantó la se sión por no haber otro asunto de qué tratar.

E] Presidente, Pompilio Gurierrez

El Secretaiio, Leonidas Villegas.

\section{ACTA}

DE LA SESION DEL DIA 2 I DE ABRIL DE I9I9.

En la ciudad de Manizales, a la una p.m. del día veintiuno de abril de mil novecientos diez y nueve, en el local acostumbrado, se reunió la Junta Directiva del Ferrocarril de Caldas, bajo la presidencia del señor Gobernador del Departamento. Concurrieron el señor Superintendente, el señpr Secretario de Hacienda y los vocales señores doctor Daniel Gutiérrez y Arango, don Roberto Vélez, don Leonidas Villegas J., y el doctor Alejandro Restrepo I. Actuó como Secretario el vocal Yillegas.

Se trató: $\sim$

I. INFORME DE UNA COMISION. - -LOS vOcales señor Secretario de Hacienda y don Miguel Salazar presentaron un informe relativo a cercas en las fajas del Ferrocarril. Se dispuso pasar dicho informe a un nuevo estudio y se comisionó a los vocales doctor Gutiérrez y Arango, y don, Roberto Vélez.

II. NOMBRAmiento. -En reemplazo del señor don Ricardo Arango, muerto en esta ciudad el dia 17 del presente mes, propuso el señor Superintendente al señor Tulio Arango A. La Junta lo aceptó y dispuso que se le comunicara el nombramiento al señor Contador-Cajero de la Empresa.

III. NOMBRAMIENTO DE SUPERINTENDENTE. Manifestó el señor Secretario de Hacienda que en atención al desarrollo que se va a dar a los trabajos del Ferrocarril del próximo mes de mayo en adelante, se hace necesario el nombramiento de Superintendente, puesto que ha venido desempeñando el sènor Ingeniero-Jefe. El mismo señor Secretario de Hacienda opina que este puesto lo puede desempeñar, hoy por hoy, uno de los miembros de la Junta, sin remuneración, agregando que él no tendría in convenientesen aceptarlo. En tal virtud el ductor Gutiérrez propuso, y la Junta aprobí: "Teniendo en cuenta el ofrecimiento que hace el señor Secretario de Hacienda de desempeñar la Superintencia del Ferrocarril, gratuitamente, y en vista de su competencia, la Junta resuelve nombrarlo".

IV. PEDiOO DE COTIZACion. - El señor Presidente prupuso y la Junta aprobó: "Pídase al Exterior una cotización de puentes, para estudiar la que convenga para el ramal a Cartago".

v. Proposicicin. - lil señor Superintendente y el vocal Villegas sentaron la siguiente proposición que fue aprubada por unanimidad: "Los gastos de médicos, medicamentos y funerales del señor don Ricardo Arango D., se- rán por cuenta de la Eimpresa del Ferrocarril de Caldas".

A las 3 p. m., se levanto la sesión. El Presidente, Pompilio Gutierrez El Secretario, Leonidas Villegas. 
BALANCE del Libro Mayor de la Superintendencia del Ferrocarril de Caldas, correspondiente al mes de enero de 1920.

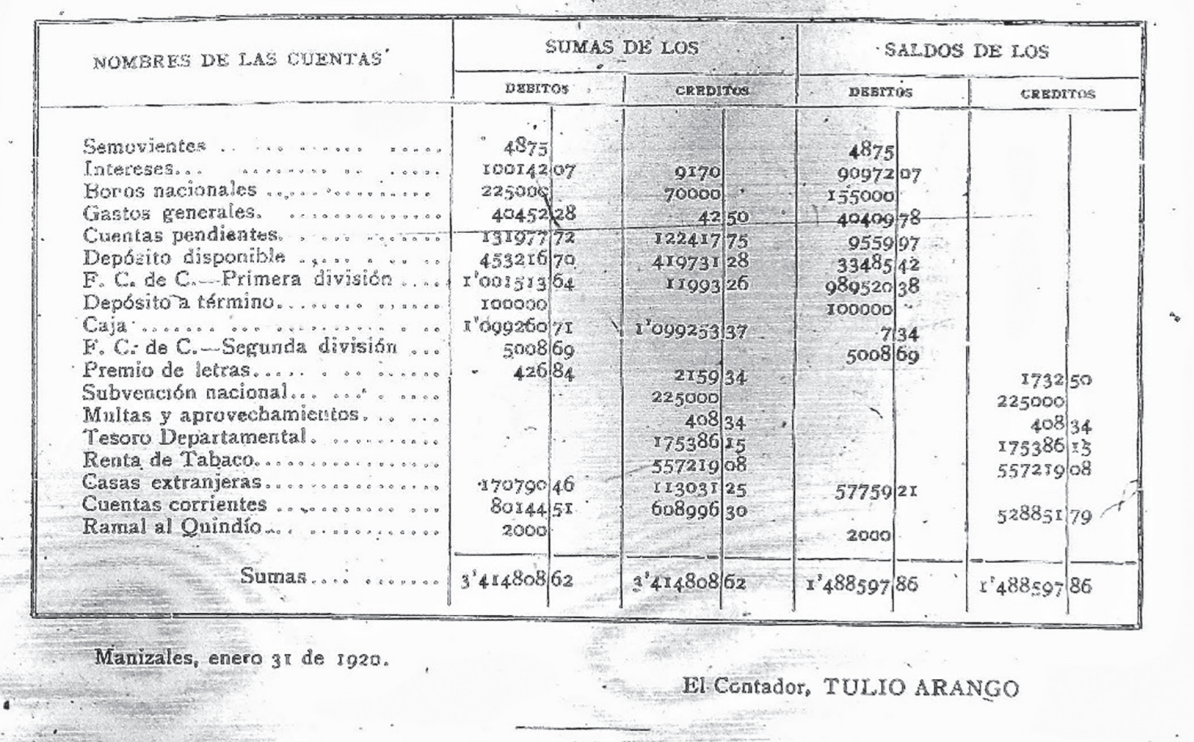

BALANCE del Libro Mayor de la Superintendencia del Ferrocarril de Caldas, correspondiente al mes de febrero de 1920.

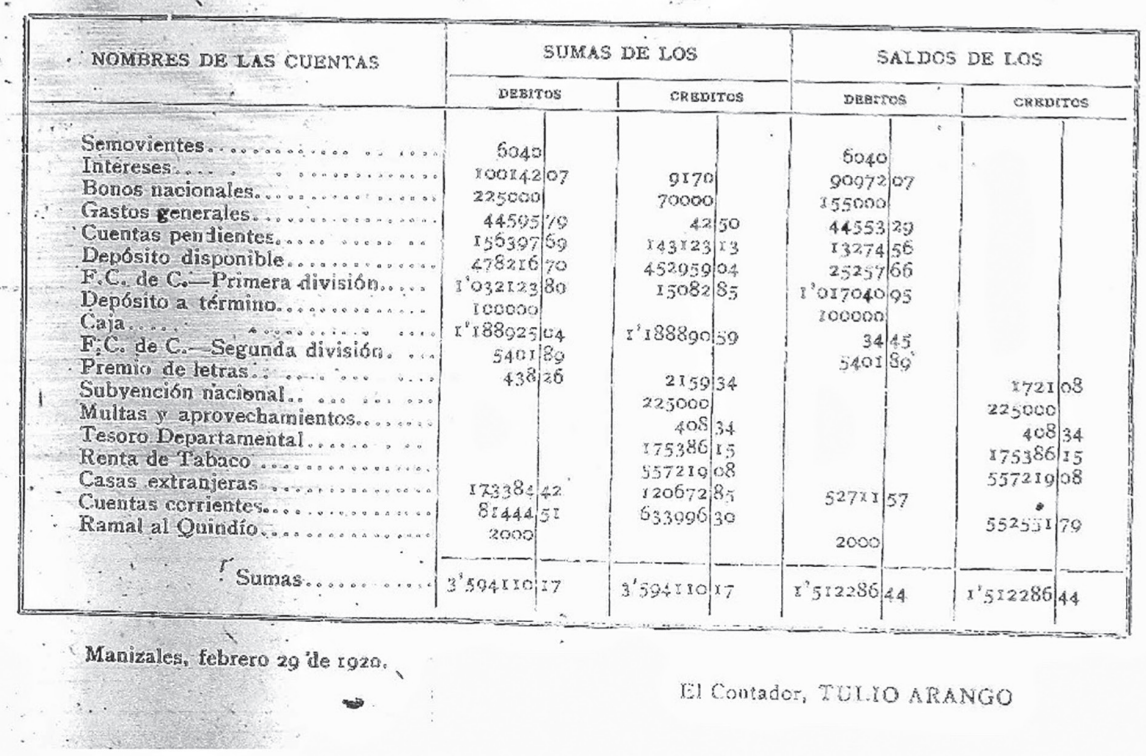


BALANCE del Libro Mayor de la Superintendencia del Ferroearril de Caldas, correapondiente al mes de marzo de 1920.

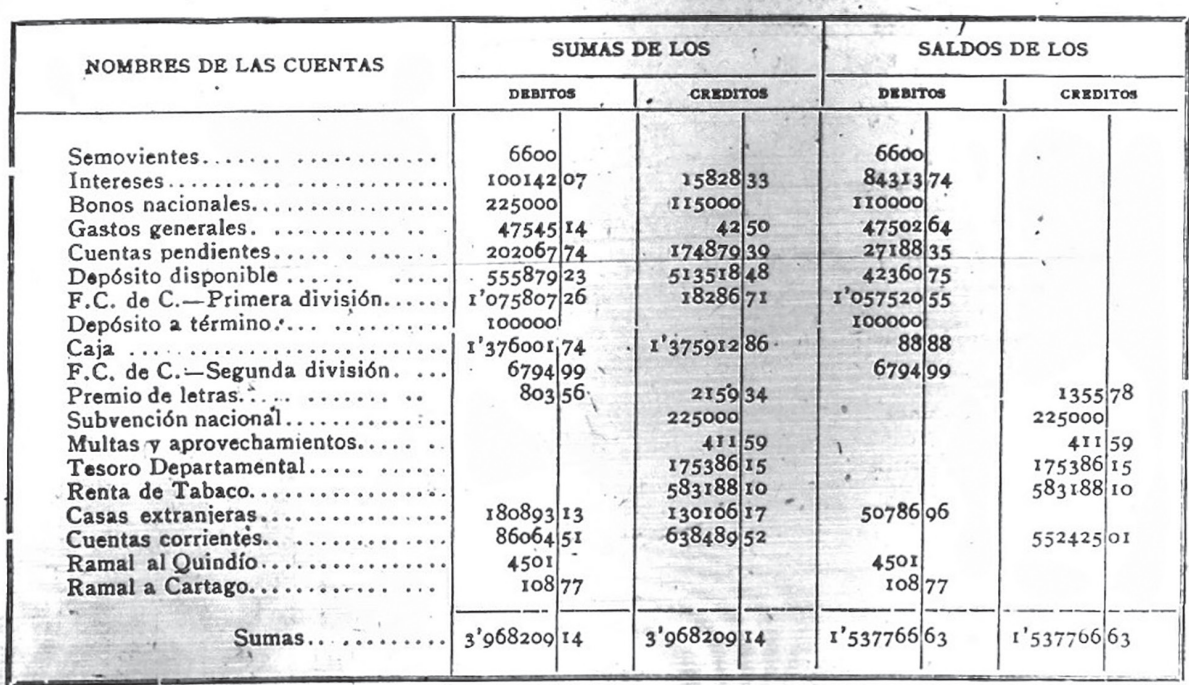

Manizales, marzo 31 de 1920.

El Contador, TULIO ARANGU

BALANCE del Libro Mayor de la Superintendencia del Ferrocarril de Caldas, correspondiente al mes do abril do 1920.

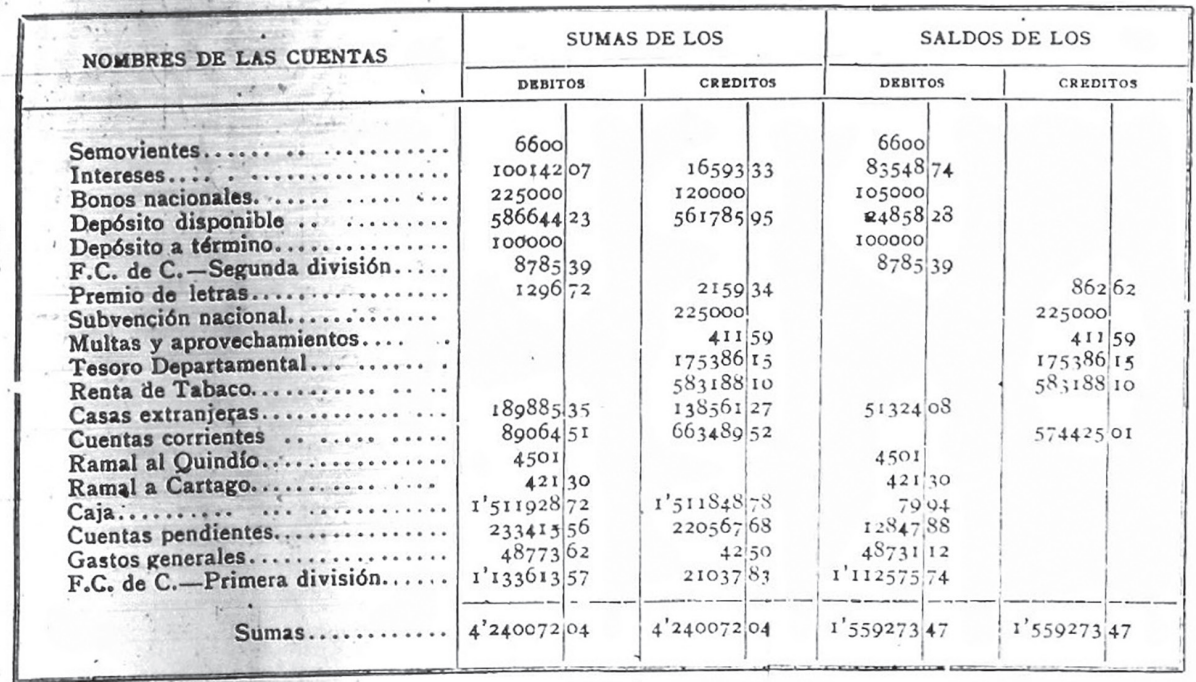

Manizales, abril 30 de 8920. 
FERROCARRIL DE CALḌAS-SUPERINTENDENCIÁ

Importación en el mes de enero de 1920.

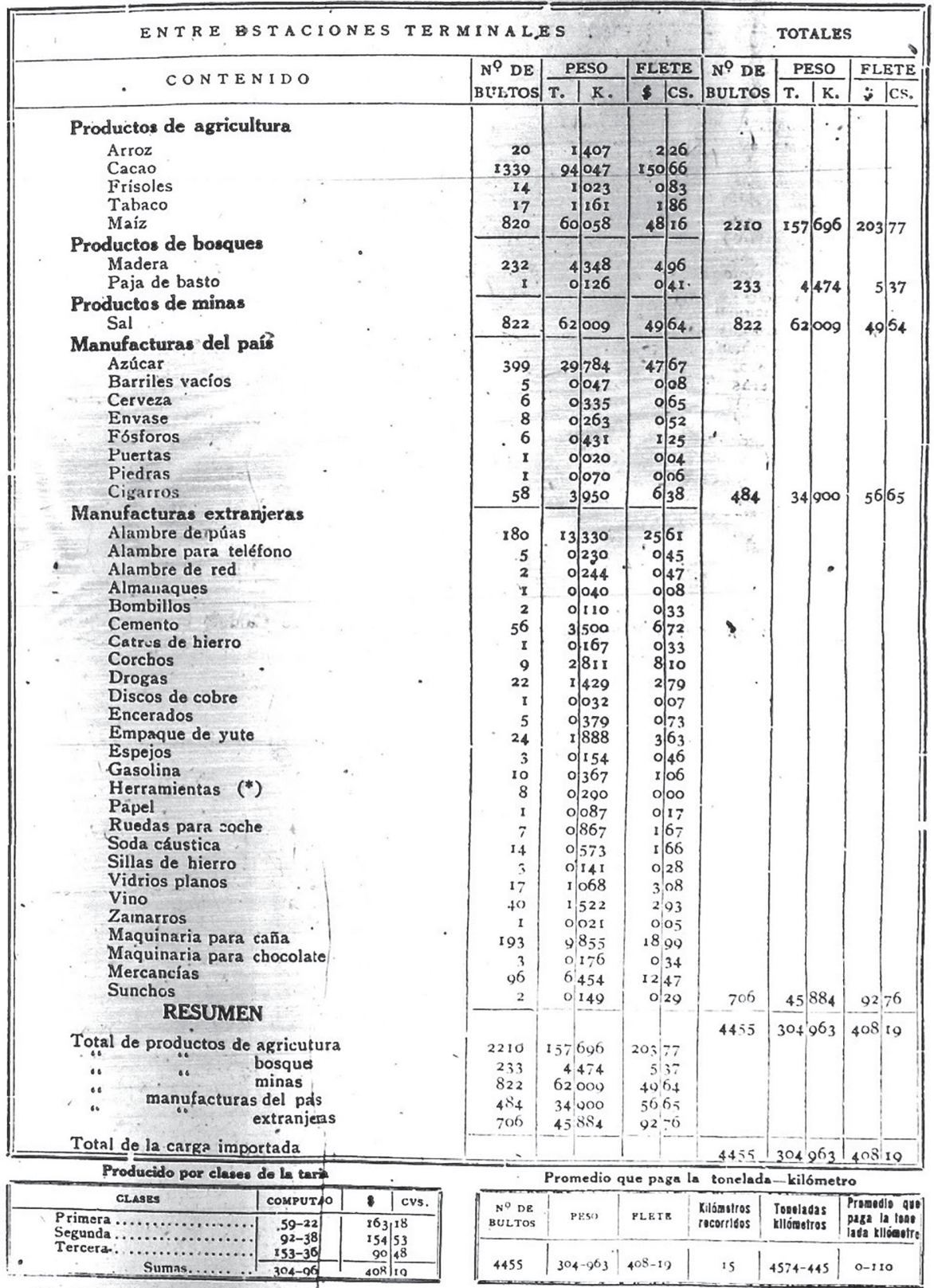

( 4 - Las berramieutas no pagaron fete poser para el Municipio de Pereira. 


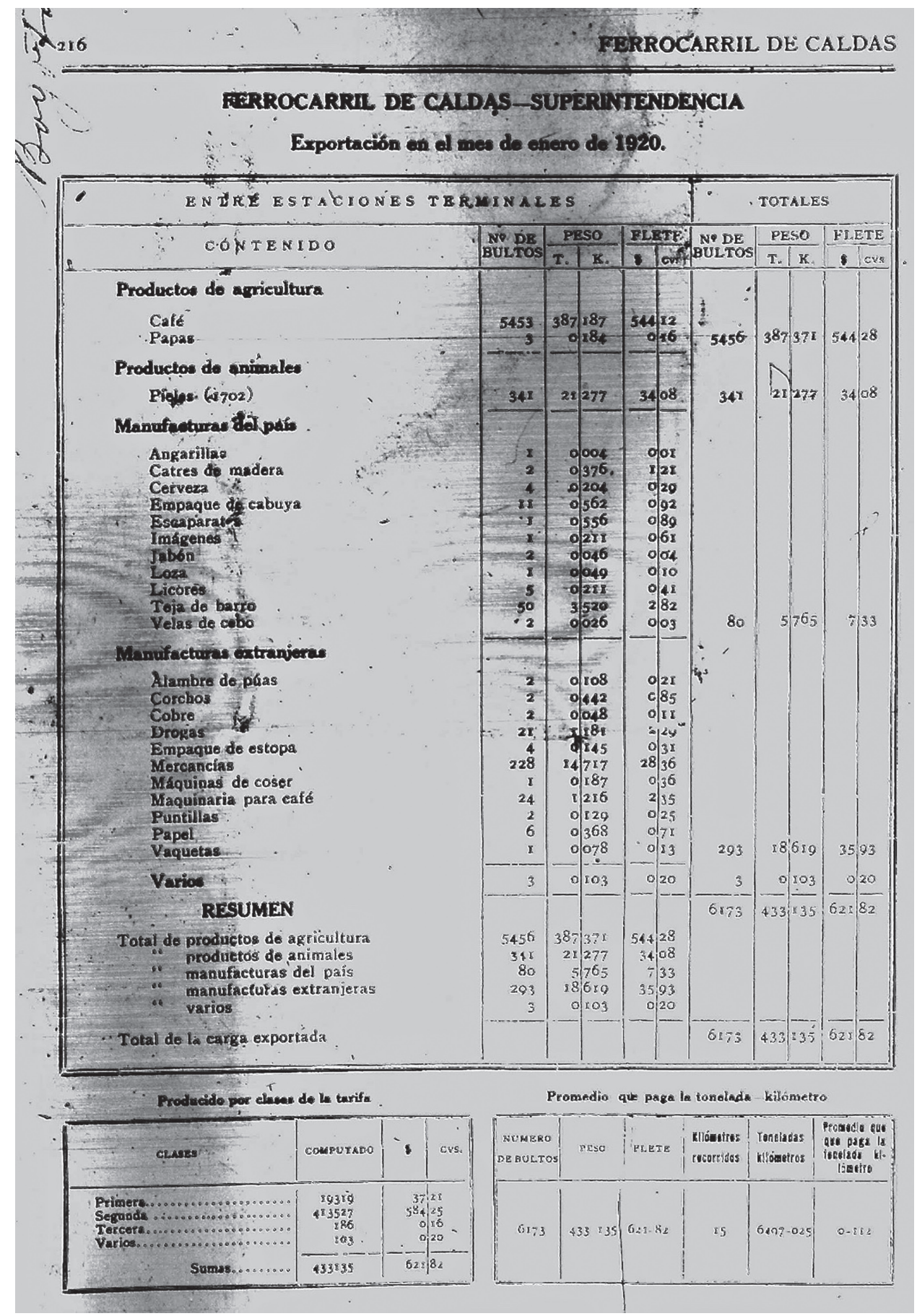




\section{República de Colombla mp. departamental Departamento de Caldas FERROCARRIL DE CALDAS}

\section{PUBLICACION ONITCIAL}

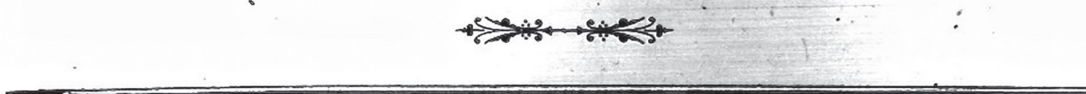

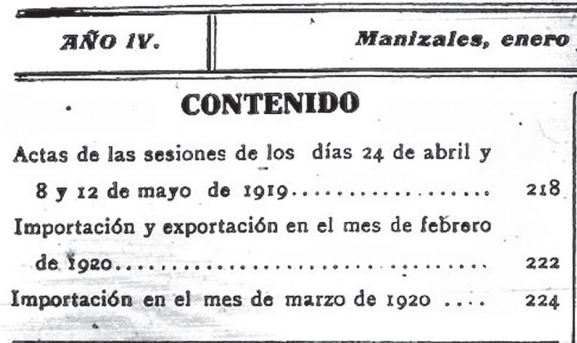

\section{ACTA}

(DE LA SESION DEL DIA 24 DE ABRIL DE I9I9)

En la cuidad de Manizales, a las tres y media $\mathrm{p} . \mathrm{m}$, del día veinticuatro de abril de mil novecientos diez y nueve, se reunib la Junta Directiva del Ferrocarril de Caldas en el local acostumbrado y bajo la presidencia del señor Gobernador. Concurrieron: el señor Superintendente, el señor Secretario de Hacienda, y los vocales señores doctor Daniel Gutiérrez y Arango, don Roberto Vélez, doctor Alejandro Restrepo I. y don Leonidas Villegas. Actuó como Secretario el último.

ACTÁ ANTERIOR. - Se leyó y firmó el acta anterior modificada así: "para la próxima la resolución aprobada sobre honores a la memoria de don Ricardo Arango D., que dice: "La Junta Directiva del Ferrocarril de Caldas, considerando: "Que el 18 del presente dejó de existir en la ciudad el señor don Ricardo Arango Duque, Secretario Tesorero de esta Junta; Que el señor Arango presto importantes servicios a la Empresa del Ferrocarril; Que fue un empleado ejemplar por su consagración y competencia, Resuelve: Lamentar, como lamenta, de la manera más sincera la muerte del señor Arango, y recomendar a todos los empleados del $\mathrm{Fe}$ rrocarril las virtudes de țan cumplidó ciudadano. Copia de esta Resolución será enviada a la señora viuda del extinto, como manifestación de condolencia de esta Junta.

Dada en Manizales, a veintiuno de abril de mil novecientos diez y nueve". Esta resolución fue presentada por el señor Gobernador y se aprobó por unanimidad.

El doctor Daniel Gutiérrez propuso: "Reconsidérese la aprobación dada a la proposición sobre separación de las funciones de $\mathrm{Su}$ perintendente e Ingeniero Jefe. Acto continuo el doctor. José M. Villegas propuso y se aprobó: "Suspéndase esta proposición y considérese la renuncia que con carácter de irrevoca. ble present 6 del puesto de Superintendente del Ferrocarril". Después de discutida la proposición del doctor Gutiérrez fue aprobada por unanimidad.

El señor Gobernador propuso y fue aprobado: "Facúltase al señor Superintendente para anticipar a los Ingenieros, a cuenta de sus sueldos, los fondos necesarios para trasladarse a esta ciudad".

El mismo señor Gobernador sentó la siguiente proposición que fue aprobada:

"Comisiónase al señor Jaime Gutiérrez para gestionar en New York la reclamación que se tiene pendiente a la casa Antioquia Comercial Corporatión, por el mal despacho de una locomotoria".

En seguida el señor Secretario de $\mathrm{Ha}$. cienda presentó a la Junta las bases de la negociación del empréstito que hace el Banco de Caldas por la suma de cuatrocientos mil pesos ( $\$$ 400.000) y discutidas una a una fueron aprobadas $\sin$ modificación. Dichas bases dicen así:

"Nosotros, José M. Villegas, obrando en su calidad de Secretario de Hacienda del Departamento de Caldas y a nombre de éste, que en el curso de este contrato se denominará el Departamento, por una parte, y Nepomuceno Mejfa M., en su carácter de Gerente 
del Banco de Caldas, Sociedad Anónima con domicilio en esta plaza, que en el presente se conocerá con el nombre del Banco, por la otra, ambos mayores de edad y vecinos de esta ciudad, declaramos que en nuestras calidades dichas hemos celebrado el contrato contenido en las cláusulas siguientes:

Primera. - El Banco, por conducto de su Sección Hipotecaria, da er préstamo al Departamento la suma de cuatrocientos mil pe. sos $(400000)$ en oro inglés acuñado; por su parte el Departamento declara tener recibida la expresada cantidad en la moneda dicha.

Segunda.-La indicada cantidad devenga intereses a razón del diez por ciento anual, que se pagarán, así como las cuotas del capital, en la forma que se enuncia en la cláusula siguiente.

Tercera. - El Departamento amortizará el capital y pagará los intereses en cuotas semestrales de............. oro inglés acu. ñádo, cada una, de tal manera que tanto los intereses como el capital se cubrirán totalmente en el curso de diez años. La primera cuota la pagará el Departamento el día........ y la subsiguiente a medida que se venzan, 0 sea cada seis meses una por cantidad igual a la ya expresada.

Cuarta.-Declara el Departamento y el Bañco acepta como es lo cierto, que en esta misma fecha ha pagado a éste la suma de.............. que en el día le adeudaba. y que dàn por terminado el contrato que anteriormente habian celebrado y que consta é la escritura pública número......... otorgada en esta ciudad ante el Notario.......de este Circuito, el día..................

Quinta.-El Departamento se obliga a consignar y mantener en el Banco en cuenta de Depósito Disponible todos los fondos departamentales tanto comunes como especiales, sin obligación para el Banco de pagar interés por tal depósito.

Sexta.-Igualmente se compromete el Departamento a recibir en el pago de sus rentas y contribuciones las cédulas hipoteca. rias que emita el Banco de Caldas obligación que dura necesariamente por el término de diez años a partir del día de hoy; por su lado el Banco se obliga para con el Departamento a abonarle las cédulas que le consigne por su valor nominal, como si se tratara de moneda corriente.

Bien entendido que las cédulas que queda obligado a recibir el Banco son las mismas que él emita.

Séptima:-Eil Departamento puede en cualquier tiempo dar por vencido el plazo que se ha pactado para la amortización del capi- tal, pagándole al Banco lo que le adeude por capital $e$ intereses, más un semestre de intereses a la rata estipulada, liquidado sobre el saldo del capital que adeude el Departamento en la fecha en que quiera saldar definitivamente la obligación. En caso de que el Departamento renunciare el plazo en virtud de esta cláusula, deberá avisarlo al Banco con noventa días de anticipación.

Octava.-Declara el Departamento que aún en el evento de pagar lo que por el presente debe, renunciando el plazo de acuerdo con la cláusula anterior, queda con la obligacion de continuar recibiendo en el pago de sus rentas y contribuciones las cédulas hipoteca. rias que emita el Bancc de Caldas hasta que se completen los diez años estipulados para la licencia de este contrato o sea hasta el día...

A su turno el Banco adquiere el compro. miso de cambiarle tales cédulas en el caso contemplado por esta cláusula por moneda legal y a su presentación.

Novena. - -Las letras de cambio que el Ferrocarril de Caldas tenga que enviar al Ex terior, las romará el Departamento al Banco en caso de que ofrezca condiciones iguales a las de otro Banco o entidad comercial. Por otra parte, las letras que expidan en el Exterior a cargo del Ferrocarril se harán en letras cruzadas o sea en giros que solamente sean pagaderos mediante cobro por el Banco de Caldas. Para dar cumplido efecto a esta cláusula la Junta del Ferrocarril avisará a su clientela en qué forma debe hacer la expedición de las letras o giros.

Décima. - Los cheques que el Administrador General del Tesoro o el Tesorero Especial de la Junta de Caminos, de la del Ferrocarril, o de cualquiera otra que maneje fondos departamentales gire a cargo del Banco, serán cubiertos por éste en moneda legal o en cédulas de las que emita este último, a eleccion del portador.

Undécima. Si el Departamento retardare el pago de las cuotas semestrales de que habla la cláusula tercera, más allá de la fecha en que deba hacerlo, patyará durante la mora y por los saldos vencidos el interés del quince por ciento anual; pero si la demora cubriere por lo menos tres cuotas semestrales, el Banco podrá, ifso jure, dar por vencido el plazo para el pago del capital y en tal evento será exigible la obligación inmediatamente y desde la fecha en que el Banco declare vencido e! plazo, empezará la suma total que deba el Departamento a devengar los intereses de! quince por ciento anual hasta la solución completa de la obligación. 
Cuando caduque el contrato por motivo de mcras en los pagos que contempla la presente cláusula, el Departamento deberá pagar el semestre de intereses de que habla la cláusula séptima del presente contrato.

Duodécima.- El Departamento queda con la obligación de asegurar contra incendio inmediatamente, y a mantener asegurados todos aquellos edificios $y$ dependencias del Ferrocarril que puedan ser destruibles por el fuego, tales como bodegas, estaciones; carros, etc.; el aseguro se hará en una Compañ́a respetable y por la suma que valgan esas dependencias a juicio de expertos designados, uno por el Banco, otro por el Departamento y el tercero, en caso de discordia de los dos primeros, nombrado por estos mismos.

Decimatercia. - Fuera de la causál enunciada conforme a la cual puede el Banco, por derecho propio, dar por terminado el plazo pactado, según las cláusulas anteriores, se consigna cono motivo que trae consigo ipso jure el vencimiento de la obligación, cualquiera de los siguientes hechos:

a) No manteter en la entidad prestamista los fondos departamentales de que habla la cláusula quinta;

b), No recibir en el pago de las rentas y contribuciones departamentales las cédulas que emita el Banco de Caldas;

c) No conservar aseguradas contra incendio las dependencias del Ferrocarril de que trata la cláusula doce;

d) No comprar al Banco, en igualdad de condiciones con otro establecimiento similar, las letras de cambio que necesite la Empresa del Ferrocarril;

e) Aceptar y pagar letras a cargo de la Empresa del Ferrocarril que no vengan giradas por conducto del Banco de Caldas de conformidad, con lo estipulado en la cláusula novena.

Antes de declarar el Banco la caducidad del contrato por cualquiera de los motivos a que le dé derecho el mismo, todos los cuales se refieren a falta de cumplimiento por parte del.Departamento de alguna de sus obligaciones, el Banco deberá exigir previamente tal cumplimiento y solamente en el caso de que el Departamento se niegue a satisfacer la obligación que ha dejado de cumplir, podrá hacerse la declaratoria de caducidad dicha.

Decimacuarta. - El Departamento se obli. ga a ceder y endosar en favor del Banco las Pólizas de Seguro que expidan en favor del Departamento por razón de las dependencias del Ferrocarril, así como también sus renova: ciones. Caso de que alguno de los bienes asegurados fuese destruído por el fuego, el
Banco hará efectiva la indemnización proveniente del seguro y mantendra êl valor que obtenga en depósito a favor del Ferrocarril con la obligación por parte de éste, de invertir el importe del seguro en la 'reconstrucción de lo destruido por siniestro, con el finde que la seguridad nodesmerezca.

Decimaquinta.-Paragàrantizar el cumplimiento de todas y cada una de las obliga. ciones aqui consignadas en favor del Banco,el Departamento hipoteca especial y expresamente a aquel, losisiguientes bienes de su pertenencia exclusiva, o sea tódos los que componen el Ferrocarril de Caldas, hasta la concurrencia de setecientos mil pesos ( 700.000$)$.

PROPIEDADES RAICES. - Un lote de terreno situado entre las confluencias de los ríos Cauca " "La Vieja", denominado hoy \&Puerto Caldas y anteriormente <La Isla», que fue comprado a los señores Miguel y David Mata $y$ otros, y que linda: $<$ Por el oriente y norte con terrenos de <La Triguera), de los herederos de Evangelista Sanz; por el occidente el río Cauća y por el sur el río <La Vieja». Una faja de treinta metros de ancho y una longitud hasta ahora de quince (15) kilometros, donde está construfdo el Ferrocarril y adquirida por compras hechas a los señores Luis Botero, Dolores Potes de Concha, Federico Campo, Alejandro Concha, Enrique Fernández y esposa, y Pedro J. Soto E. Se advierte que en el kilometró $4^{\circ}$ la faja no se ha pagado en una extensión de un kilómetro próximamente, por ser propiedad de un ausente cuyo paradero se ignora; que del kilómetro once (I I ) al diez y seis (16), la Empresa tiene acciones y derechos proindivisos en las fincas denominadas «La Isla» y «La Hoya»; que del kilómetro diez y seis (16) al veinte (20) la faja pertenece a la instrucción pública de Cartago, en forma litigiosa con varios individuos; del kilómetro veinte $(20)$ al veintitrés $(23)$ vuelve a ser la faja de propiedad del Ferrocarril por compras hechas a los señores Emiliano:González, Félix Cadavid, Carlos Echeverri y otros. En el paraje de \&La Marina posee la Empresa además de la faja, un lote de dos hectáreas de terreno, cedido por el señor don Alejandro Concha. En esta ciudad pusee la Empresa un lote de terreno situado al oriente, que mide cuarenta $y$ ocho $(4 \delta)$ varas al frente de la calle primera y que linda: «Por el norte $y$ sur con propiedad del señor Rutino E. Murillo; y por el oriente con propiedad del Departamentos.

entficios. - ctin Puerto Caldas: Un edificin para taller; una casa para habitación de empleados; una bodega para carga: un cobertizo en constuccion; otro pequeño construido; otro para fragua; otro para hospital; una casa 
pequeña; un campamento para trabajadores; un edificio para almacén.

En La Marina. - Un edificio de tapias y tejas para estación».

Fn La Hoya. - Un edificio para bodega: uno para oficinas; otro para hotel.

Matertal Rodante, - C Tres (3) locomotoras, diez y ocho (18) carros para trasporte de animales, un ( $I$ ) carro gara pasajeros de segunda clase, cuatro (4) carros de empujes.

El terreno de Puerto Caldas fue adquirido por la"escritura número: 3 I 2 otorgada en la Notaría de Percira el $I \bar{I}$ de mayo de 1915. Ia faja de 30 metros de ancho la hubo la Empresa del Ferrocarril por lás siguientes escrituras: Número I 8 de la Notaría de Cartago, de ro de abril de 1916 ; número 238 de la misma Notaría de Cartago, de i' de julio de 1916. El terreno situado en esta ciudad, al oriente, se adquirió por la escritura número 788 de la Notarfa $2^{\text {a }}$ de este Circuito, de 18 de noviembre de 1918. Existen además otros títulos de estas propiedades los cuales no se citan por encontrarse en la Notaría de Pereira. Las propiedades del. Ferrocarril están libres de gravamen, censo e hipoteca. Se entiende que en la presente hipoteca quedan comprendidos, todos aquellos accesorios del Ferrocarril que aunque en sí mismos son muebles, por su déstinación'se reputan inmuebles, tales como carros, locomotoras, herramientas, etc. Esta seguridad especifica no viene en modo alguno a. exicluir la general de los bienes y rentas departamentales, los cuales quedan también a. fectos al cumplimiento de esta obligación.

Decimasexta.-Declara el Demartamento que los bienes que hipoteca son de su plena y absoluta propiedad y que los títulos están debidamente saneados.

Decimaséptima. -- Igualmente se obliga el Departamento a invertir $\sqrt{\text { a suma }}$ que recibc por causa de este empréstito en la construc. ción y dotación del Ferrocarril de Caldas, una vez deducido el valor de los créditos a cargo del Ferrocarril, que se expresan; lo que ha pagado al Banco de Caldas según la cláasula cuarta; y cíncuenta mil pesos $(\$ 50 .-0)$ que adeuda al Banco Alemán Antioqueño de Medellin.

A las 5 p. m., se levantó la sesión.

El Presidente, Pompilio Gujhikez

El Secretario ad-hoc, Livin. '? illegas. |
AC'TA

DE LA SESION DEL DIA 8 DE MAYO DE IgIG.

- En la ciudad de Manizales, siendo las 3 p. "m., del día 8 de mayo de r9ig, y bajo la Presidencia del señor Gobernador del Departamento, se reunió la Junta Directiva del Ferrocarril de Caldas, cor asistencia de sus miembros principales señores Miguel Salazar, Leonidas Villegas, Roberto Vélez y del suscrito-Secretario.

Abierta la sesión, se leyó y aprobó el acta de la sesión anterior sin observación alguna.

Se dio lectura a un oficio en que el Secretario Contador interino de la Superintendencia remite a la Junta para su estudio y fenecimiento en primera instancia las cuentas de su cargo correspondientés a los meses de rrarzo y abril últimos. Sé dispuso por la Presidencia fueran pasadas en comisión, respectivamente. a los vocales señores Salazar y Villegas. Acto seguido el señor Gobernador sentó la siguiente proposición que fue aprobada: <Dígase al señor Superintendente, por telégrafo, aplace el viaje a Cali a asunto carboneras, hasta nueva orden; y por correo, suspenda, también hasta nueva orden, todà negociación sobre fajas, cercos y estación de Pereira hasta que la comisión a quien se habla encomerdado este asunto rinda el informe del caso y la Junta resuelva lo que estime convenientes.

Habiéndose dado cuenta de que en el pedido hecho a la casa de Alejandro Angel etc. $C^{a}$, se había extralimitado el señor Superintendente haciéndolo por mayor suma de la que se le habia autorizado por la Junta, el señor Gobernador sentó la siguiente proposición: «Comisiónase a los vocales señores Salazar y Villerras para que se entiendan con el Agente. he Aleindro Angel etc. C a fin de reformar for c ble el pedido hecho por el señor Superintendentes. Puesta en consideración de la. funta, fue aprobada.

El Vocal señor Salazar rindió verbalmen te un informe sobre las gestiones hechas en su último viaje a Cali y relacionadas con la Empresa del Ferrocarril.

No habiendo utro asunto de yue tratar se levantó la sesión a las $5 \mathrm{l}$. m.

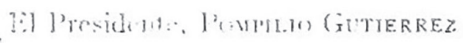

El Secretario, Tulio Alrongo. 


ACTA
DE LA SESION DEL DIA I 2 dE MAYO DE IgI9.

En la ciudad de Manizales, siendo las dos y treinta minutos del día doce de mayo de mil novecientó diez y nueve, se reunió la Junta Directiva del Ferrocarril de Caldas, presidida por el señor Gobernador del Departamento y con la asistencia de todos sus miembros, señores doctor Daniel Gutiérrez y Arango, don Miguel Salazar, don Leonidas Villegas, don Roberto Vélez y el suscrito Secretario.

Abierta la sesión se dio lectura al acta de la sesión anterior la cual fue aprobada con la observación del vocal señor Villegas de que las cuentas del.Contador de la Superintendencía correspondientes a los meses de marzo y abril, se había pasado en comisión, respjectivamente, a los vocales Villegas y Salazar, y no como se dejó constancia en ella.

Se dio lectura al informe de la comisión que estudió las cuentas de la Superintendencia correspondientes al mes de marzo último, y la Junta aprobó por unanimidad la proposicion con que termina dicho informe y que dice: <Fenécense en primera instancia las cuentas de la Superintendencia del Ferrocarril de Caldas, correspondientes al mes de marzo de I919, sin cargo contra el responsable de ellas señor Franciscc Botero $A$, quedando en caja una existencia para el mes de abril de \$167,94. Del mes de mayo en adelante se agregará a los balancés del libro mayor la descomposición de las cuentas de casas extranjeras, cuentas corrientes y cuentas pendientes».

El vocal señor Villegas quień fue el autor del informe anterior, presentó también las siguientes proposiciones que fueron aprobadas: «Digase nuevamente al señor Superintendente que comola Junta tiene conocimiento de que algunos de los Ingenieros se están excediendo en el uso de bebidas embriagantes, con grave perjuicio para los trabajos, se espera que él hará aplicar de acuerdo con los Règlamentos, la correspondiente sanción a los que tal hacien. De la determinación que tome o haya tomado debe dar aviso. oportuno a la Junta>.
«Comisiónase al señor Contador Cajero de la Superintendencia para que personalmente se èncargue de conseguir en la ciudad y a los mejores precios posibles, haciendo averiguaciones en varios almacenes, los útiles y herramientas que se pidan del Ferrocarril y que haya que comprar en la ciudad».

Acto continuo el vocal doctor Gutiérrez y A. sentó la siguiente proposición que fue aprobada: «Todo pedido y todo giro que venga de la Empresa debe llevar el visto bueno del Superintendente o de la persona que legalmente lo represente. Dése cuenta a quien corresponda》.

En seguida el vocal Vélez propuso lo siguiente que fue aprobado: $<$ Nombrase una comisión para que se traslade a la Empresa de Ferrocarril a organizar debidamente el servi. cio de hospital, haga un estudio de los demás servicios que hacen parte de ella y rinda un informe concreto sobre cada uno de ellos para que la Junta disponga lo que estime conveniente». Fue designado por la Presidencia para desempeñar esta comisión, el vocal señor Leonidas Villegas.

Informó la comisión a quien se encargó de estudiar el pedido hecho al Agente de la casa de Alejandro Angel etc. Ca. que no había habido extralimitación por parte del señor Superintendente, sino que se había incurrido en un error numérico al confeccionarlo $y$ que todavía se ocupaba en el estudio de él para ver si había necesidad de modificarlo en algún sentido.

Se pasó en comisión a los vocales Saldzar y Vélez una carta dirigida por el señor Carlos Hollman al señor Gobernador, mara que informen acerca de lo que en ellis se trata.

No habiendo otro asunto $d \cdot 1: t_{1}:$ se levantó la sesión a las 4 y $3^{0}$ miliutu.

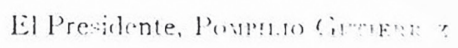

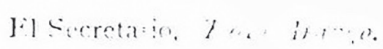


F. C. DE CALDAS. - MMPORTACION EN El MIS DE FEBRrRo DE 1920

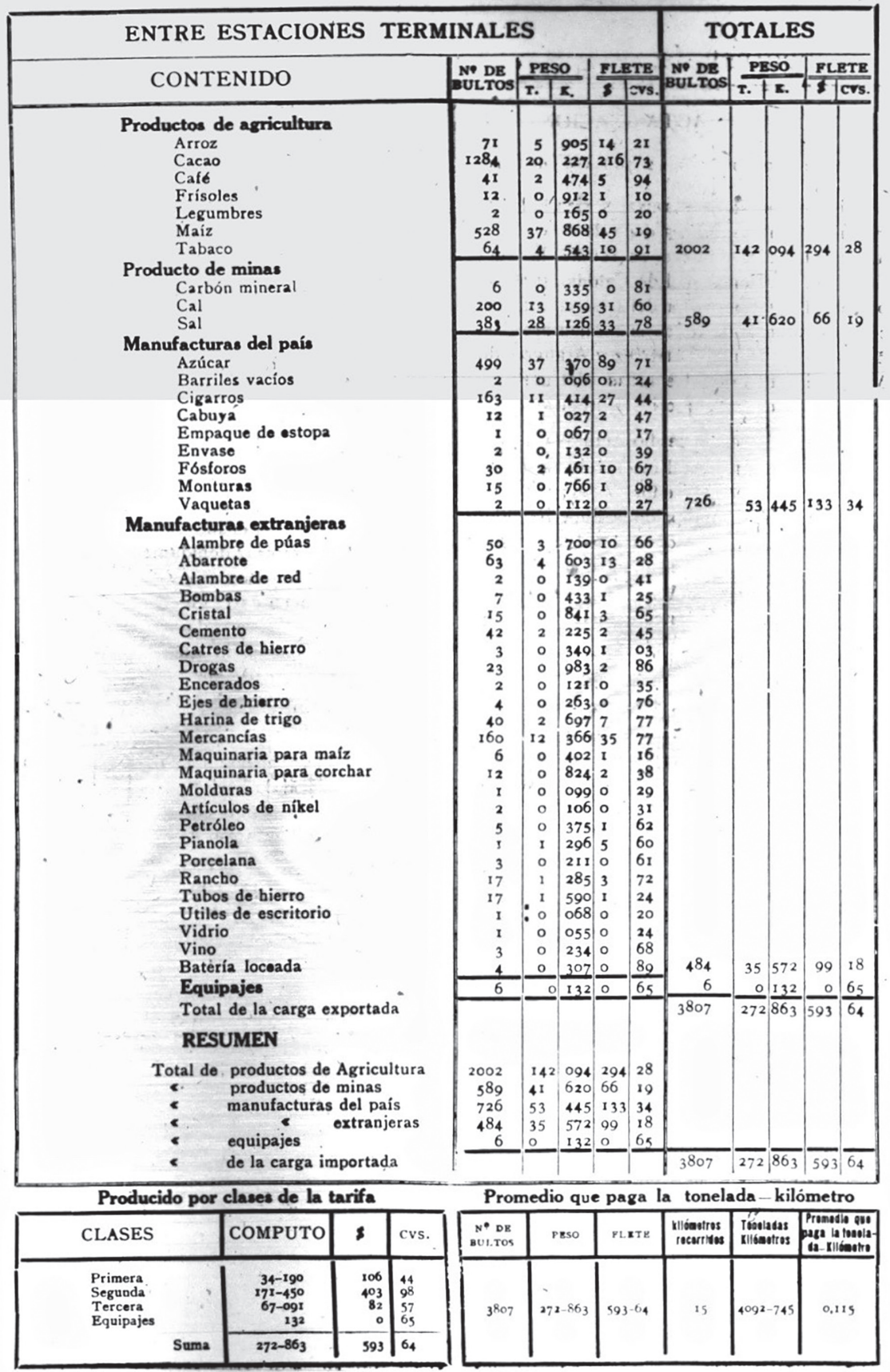


EXPORTACIUN EN EL MES DE FEBRERO DE 1920

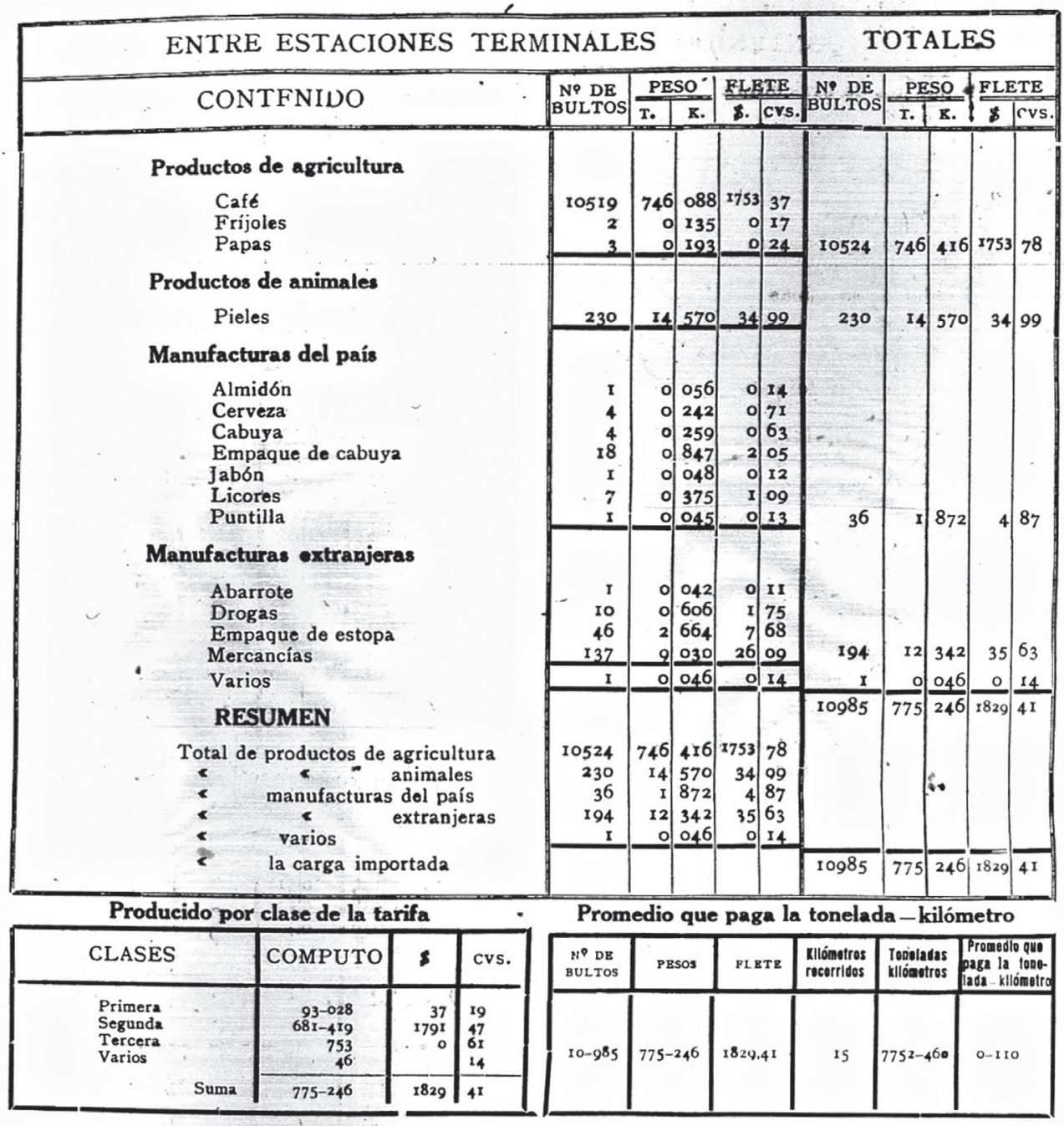




\section{Anexo $\mathbf{N}^{0} 6$}

Semanario Publicado en Pereira en 1912

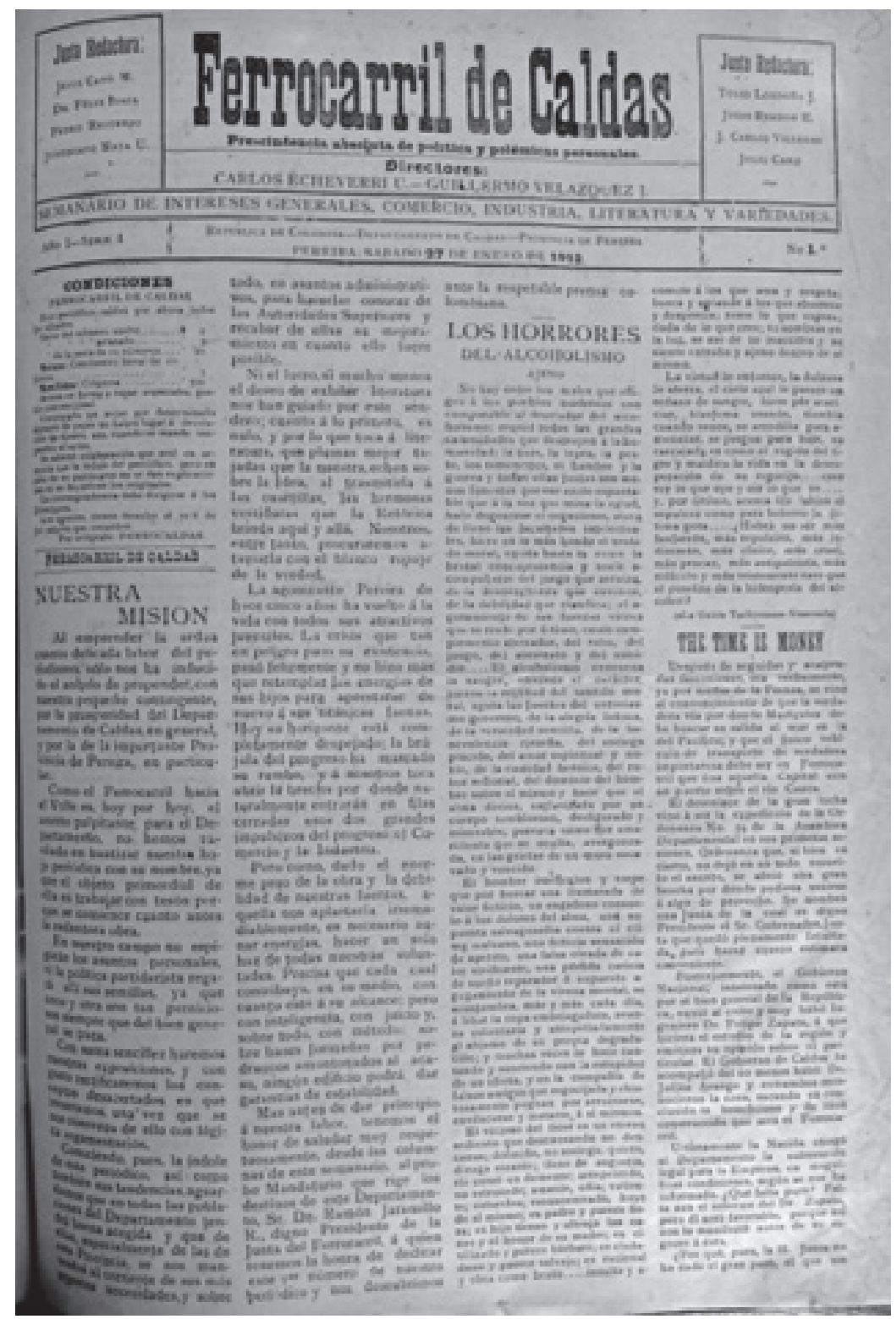




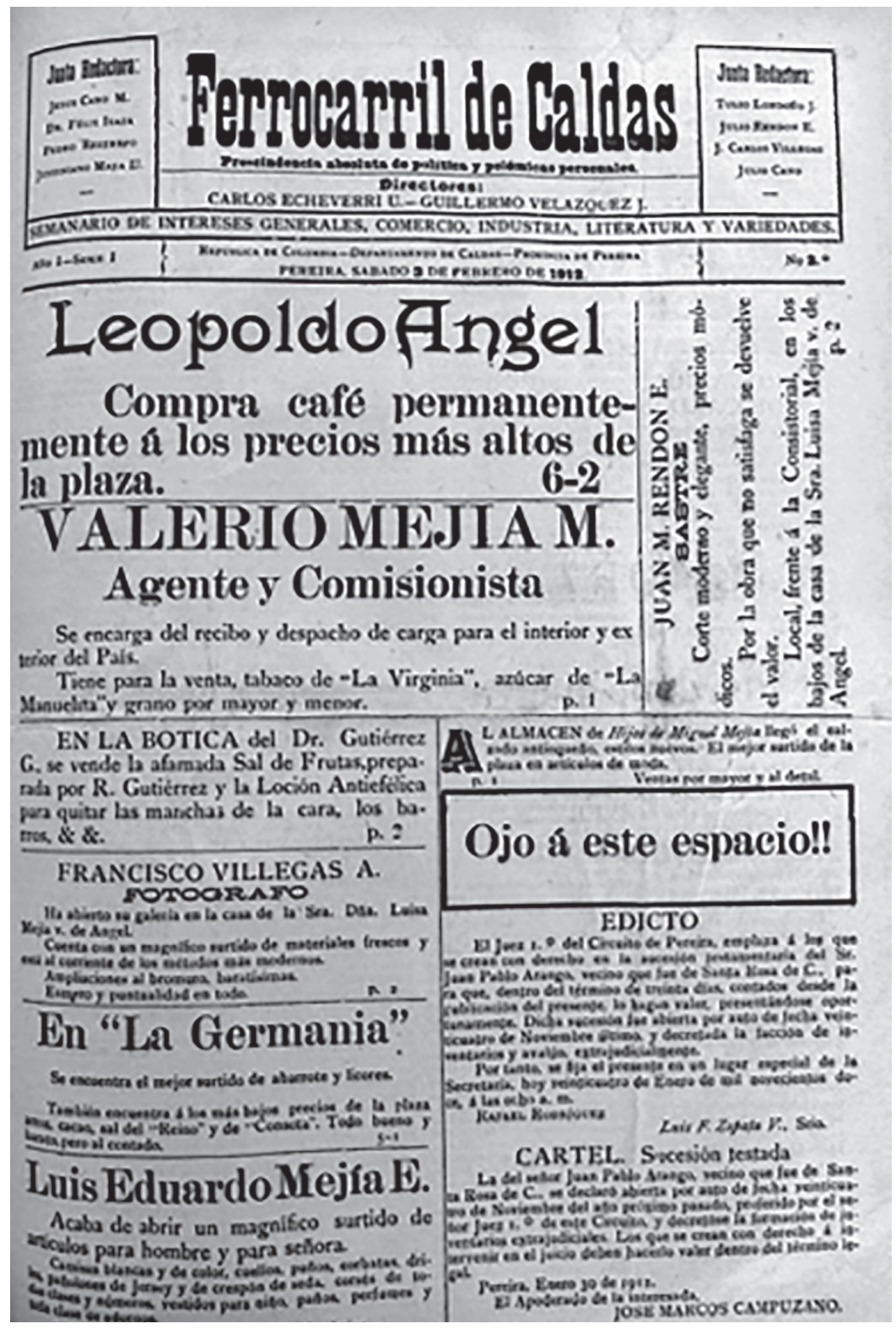




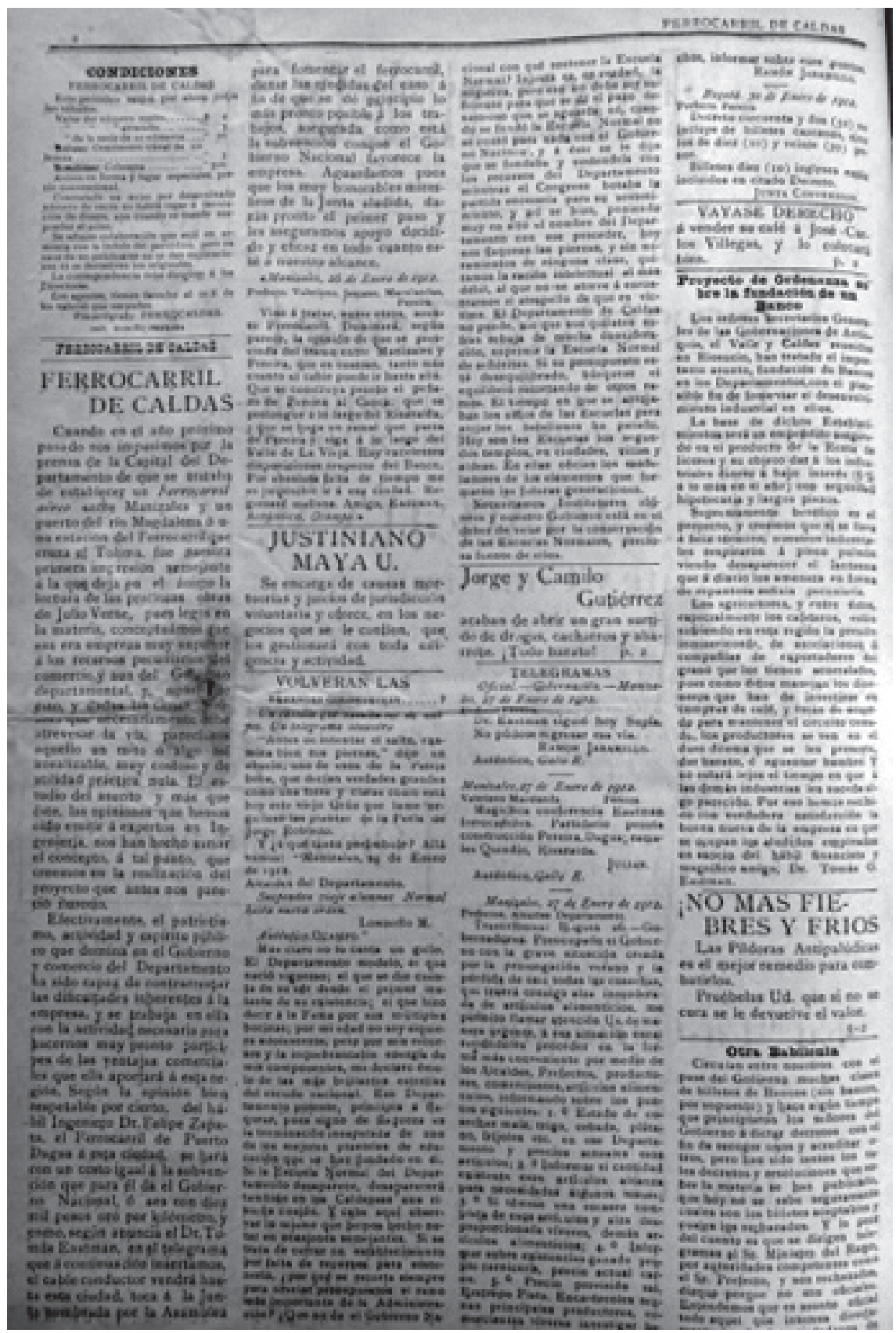




\title{
Anexo $\mathbf{N}^{0} 7$ \\ Informe del Gobernador del Departamento, Dr. Francisco José Ocampo, correspondiente al año de 1926
}

\author{
OBRAS PÚBLICAS
}

\section{Oficina de ferrocarriles y cables}

\begin{abstract}
Aunque esta oficina depende hoy de la Secretaria de Hacienda, he creído de conveniencia tratar de ella en el capítulo de Obras Públicas, para indicar con ello la necesidad de crear la Secretaria de Obras Públicas, como tuve el honor de proponerlo ante la Honorable Asamblea en sus sesiones pasadas. Son tantos, tan delicados y complejos los problemas de obras públicas en Caldas que alrededor de ellos giran toda la vida y el progreso del Departamento, que parece absurdo exigir al Secretario de Hacienda, que ya tiene a su cargo una buena tarea con las rentas y administración del Tesoro, crédito público, minas y baldíos, se entienda con aquella ponderosa labor. Desde el $1^{\circ}$ de marzo se encargó de esta oficina el doctor Sebastián Ospina, ingeniero de vasta ilustración y de reconocida competencia dentro y fuera del país. Grande ha sido su labor de organización en una oficina de reciente creación que ha tenido a su cargo el manejo de las grandes empresas de Caldas y el empleo de los dineros del empréstito extranjero. De ella dependen la Gerencia de los Ferrocarriles, la Gerencia de Cables, la Agencia de Materiales, la Oficina de Contabilidad y la Oficina de Estadística, estas tres últimas de reciente creación en Caldas, y que han tenido que hacerlo todo sacándolo de la nada. Muchas de las obras realizadas en cada una de las obras a su cuidado, dependen de la eficacia del encargado de la oficina y de ella se hablará al tratar de cada empresa en particular.
\end{abstract}

Ferrocarril de Caldas. Del informe del señor Gerente copio lo que sigue:

"Construcción. Al empezarse el presente año, los rieles estaban en La Capilla, (k, 71). Hoy la punta de los rieles está en el k 88, o sea, en la estación de Montevideo. Se han enrielado, pues 17 kilómetros; se han dado al servicio las estaciones de Campoalegre y San Francisco y está para darse la de Montevideo.

La explanación hasta Rioclaro, k, 93, está terminada y lista para recibir los rieles. La mampostería para el puente de dicho rio, esta lista también para recibir la estructura. De Rioclaro a Chinchiná, $(\mathrm{k}, 11)$, la explanación está hecha en un $92 \%$, según puede verse por los datos sobre movimientos de tierra que escribo adelante. En esta sección el avance de los rieles no tendrá ningún obstáculo, cualquiera que sea la rapidez con que avancen, pues la 
obra de los túneles se adelanta escalonada en forma que cada uno de ellos estará listo para la llegada de los rieles. En la preparación de los cimientos para la erección del puente sobre el rio Chinchiná se trabaja con intensidad necesaria, de manera qué, al llegar los rieles a ese punto, estarán los estribos listos para montar la armadura. De Chinchiná a Manizales (k.117), la explanación está hecha en un 70\% y los rieles, para llegar a esta ciudad, no hallarían ninguno obstáculo por parte del movimiento de tierras. Con la intensidad actual de los trabajos en esta sección, pueden seguirse moviendo 16.000 metros cúbicos mensuales, de modo que los 107.000 metros que faltan por mover, demoraran nada más que cinco meses.

Los datos sobre movimientos de tierra en las secciones de construcción entre San Francisco y Manizales en el presente año, han sido los siguientes hasta el 31 de octubre:

-Sección de San Francisco-Rioclaro: movido 266.249 metros cúbicos. Por mover, 0000.

-Sección Rioclaro- Chinchiná: movidos, 437.394 metros cúbicos. Por mover, 74.915

-Sección Chinchiná- Manizales: movidos, 245.813. Por mover, 107.529

Durante el año presente, incluyendo el costo comercial rodante cuya lista se dará más adelante, se ha invertido la suma de \$2’107.752 hasta el 31 de octubre pasado.

Sostenimiento. Durante el presente año se ha atendido al sostenimiento de la vía en forma que deja bastante que desear, debido a absolutas imposibilidades conocidas de todos, entre las cuales esta como principal la falta de material rodante. Fuera de esto el sostenimiento de la ferrovía se ha recargado enormemente por causa de los grandes derrumbamientos entre Guayabito y San Francisco, trayecto este que ha absorbido todas las actividades y todas las energías con que cuenta para esta sección del Ferrocarril. Sin embargo, el sostenimiento ha podido emprender un buen número de obras importantes de adiciones y mejoras en la ferrovía, entre las cuales pueden contarse las siguientes: refuerzo del puente de Chapas, construcción de la cómoda estación de Cartago, buenos embarcaderos en puerto Caldas, Villegas, Belmonte, Pereira y otras estaciones, principio de la magnífica bodega metálica para Pereira cuyo edificio está llegando a la cuidad, apartaderos y cambios en Puerto Caldas, Belmonte y Pereira -

Explotación -El producto del tráfico en los meses conocidos del presente año, ha sido el siguiente: 


$\begin{array}{ll}\text { El Ferrocarril de Caldas: una obra de tita } \\ \text { Enero } & \$ 47.615,86 \\ \text { Junio } & \$ 48.333,14 \\ \text { Febrero } & \$ 45.879,59 \\ \text { Julio } & \$ 51.976,46 \\ \text { Marzo } & \$ 50.563,71 \\ \text { Agosto } & \$ 61.243,50 \\ \text { Abril } & \$ 45.871,47 \\ \text { Septiembre } & \$ 36.280,75 \\ \text { Mayo } & \$ 50.339,88\end{array}$

En el mes de septiembre bajó mucho el producido, por causa de las largas interrupciones sufridas por el trafico debido a los derrumbes. Puedo decir a usted que en materia de regularizaciones del tráfico se ha llevado a e efecto una verdadera transformación. Ud. ya conoce los informes de este despacho sobre las medidas que se han tomado para reorganizar las oficinas de explotación de la empresa y los pasos efectivos que se han dado para dotarlas a todas de un personal tan apto como es posible conseguirlo entre nosotros, disciplinado en cuanto lo permiten las circunstancias y honorable. En los últimos tiempos han desaparecido los casos de corrupción y de alzamiento de los fondos de la empresa, y esto se debe sin duda al empeño que se ha puesto por moralizar el personal, seleccionándolo, y por mantener una fiscalización lo más constante que ha sido posible. Sin embargo, la obra completa de selección y disciplina del personal implica una labor muy ardua, de largos días. En el tráfico de pasajeros no han faltado descontentos y reclamo de una parte de las gentes, quienes a simple vista han tenido razón. Un tráfico deficiente impacienta demasiado al pasajero aunque sepa la imposibilidad en que está la empresa de dar lo mejor por causa de la falta de material rodante, como es el caso ocurrido en el Ferrocarril de Caldas.

Material rodante. - La grave escasez de material rodante que ha sido una de las principales razones de los muchos trastornos y dificultades que se han encontrado, tanto en la construcción como en el sostenimiento y explotación del Ferrocarril, va quedando solucionada con bastante amplitud con el recibo de suficientes unidades de material rodante compradas en su mayor parte en el año presente. Hasta la fecha han llegado las siguientes:

4 Locomotoras alemanas de 56 ton cada una.

9 Coches de primera de 40 pasajeros cada uno.

3 Coches de segunda de 50 pasajeros cada uno.

24 Vagones para carga de 20 y 25 ton cada una.

11 Jaulas para ganado de 20 y 25 ton cada una.

15 Góndolas de 20 y 25 ton cada una.

23 Plataformas de 20 y 25 ton cada una.

1 Autoferro para 25 pasajeros. 
Fuera de este material están pedidos 12 coches de segunda para pasajeros, que están en New York listos para su embarque.

Del material llegado, esta armada y dadas ya al servicio dos locomotoras, todas las plataformas, varias góndolas, varias jaulas, y el autoferro. En el resto del material se trabaja con toda la actividad que es posible y parece que para mediados del mes entrante este armado y en servicio. Esta holgura, permitirá a los talleres dedicarse mejor a la reparación del material existente, el cual, por la imposibilidad que había de retiro del tráfico en donde era imprescindible, apenas podía recibir reparaciones rápidas.

Materiales. - Al empezarse este año, los materiales escaseaban mucho en el Ferrocarril, se carecían de las existencias necesarias no solamente para satisfacer las previsiones del porvenir de la construcción, sino también para las necesidades del momento presente.

Al tiempo de esto, la contabilidad de los materiales estaba en el mayor del caos. Fue una obra muy dura la de restablecer esa contabilidad para darse cuenta de los materiales que faltaban. Hecho esto, se procedió a hacer todos los pedidos que fueron necesarios. Hoy los almacenes de la empresa están provistos suficientemente para una previsión relativamente larga que nos pone al abrigo de las contingencias que están sufriendo los pedidos al extranjero, por causa de la irregularidad en los transportes. Entre los materiales que posee ya la empresa están los rieles, traviesas y demás accesorios necesarios para enrielar hasta esta ciudad de Manizales. El problema grande de los materiales ha estado en la movilización de estos últimos de Buenaventura. Sin embargo, con el incremento del material rodante tanto en el ferrocarril de Caldas, como en el del Pacifico, ese transporte será en adelante más activo. También ha sido sumamente dificultoso el problema del combustible. Después de muchas dificultades se ha logrado hacer algunas reservas de leñas que nos han puesto en condiciones menos aleatorias y graves que al principio. Pero este es un combustible muy caro y malo que es preciso cambiar cuanto antes.

Bastante adelantadas están ya las gestiones que usted conoce de las instalaciones de tanques para petróleo crudo para las locomotoras de los ferrocarriles de Caldas y el Pacifico. Si no ocurre algún trastorno, antes de un año estará definido ese problema en la forma mejor que pueda idearse por hoy, con la adopción de ese combustible.

Talleres. - Ya hablé de las labores de estos al tratar del material rodante. Durante el año que corre, se ha planeado un proyecto de talleres suficiente y capaz para el ferrocarril de Caldas y sus adiciones y prolongaciones. Se obtuvo un excelente predio cerca a Villa María, se ha levantado el plano y se están estudiando las cotizaciones de maquinarias que se piensan pedir. 
Organización general de la Empresa.-Para la administración de esta empresa se ha buscado la forma de poner al frente de cada departamento un hombre capaz, a quien pueda dársele las facultades y la autonomía necesarias para administrarlo. Cada jefe de departamento, depende directamente de esta Gerencia.

Los departamentos en que se ha dividido la empresa para su administración, son los siguientes:

\section{TRAFICO}

AGENCIA DE MATERIALES

INGENIERO JEFE

JEFE DE CONTABILIDAD

JEFE DE ESTADISTICA

SANIDAD

En cada uno de estos departamentos trabajaba con éxito cada uno de sus jefes, a pesar de las grandes dificultades que ofrece nuestro ambiente y la falta de personal preparado para cualquier obra de reorganización, aunque ella sea muy simple. En la agencia de materiales existe hoy la vacante, debido a la renuncia presentada por el empleado titular. Es un puesto difícil que no se ha podido proveer a pesar de que se ha buscado mucho una persona que pueda desempeñarlo. Para encargarse del ramo de sanidad tampoco se ha podido hallar un médico, pues las condiciones que presentan los muchos que se han solicitado son prohibitivas.

Situación financiera. - En la actualidad, el ferrocarril cuenta con los siguientes recursos de saldos a su favor en el Tesoro del Departamento:

Subvención nacional al Ferrocarril \$ $120.000,00$

Para gastos de explotación al F.C \$ $280.000,00$

Para el sostenimiento del F.C $\$ 180.000,00$

Reintegros de la Nación y mayor producido del F.C. y de la Renta de Tabaco, después de asegurada la cuota del empréstito, y los cuales se aplicarán en primer término al Ferrocarril. ........................................................................\$ $450.000,00$

Dinero en caja................................................................\$ $\quad 64.750,85$

Suma ..... $\$ 1.094 .750,85$

En esta fecha, el Ferrocarril debe las siguientes sumas:

Prestado por los cables aéreos $\$ 524.657,67$

Cuentas por pagar de materiales, etc. 
Es justo consignar aquí un aplauso a la labor altamente benéfica para los intereses del Ferrocarril desarrollada por el doctor Néstor Echeverri durante el corto tiempo de sus gestiones. El acometió con toda entereza una saludable campaña moralizadora, sin temor a la persuasión de los usufructuarios del desgreño; reorganizo todas las dependencias, de acuerdo con el doctor Giraldo; regularizó el tráfico; organizó las finanzas de la empresa, todo con una consagración, honorabilidad, inteligencia y desinterés raros en la cuestión de negocios ajenos.

Ferrocarril del Quindío. - Puede decirse que lo que hay hecho en esta empresa se ha realizado en el curso del año presente. Debido a innumerables obstáculos e inconvenientes emanados principalmente de la manera como el Gobierno Nacional ha ejecutado el contrato para la construcción de esta ferrovía, en el año pasado casi nada pudo hacerse en ella.

Los 10 primeros kilómetros a partir de Nacederos están explanados, no faltando en ellos sino la terminación de cinco cortes y un estribo del puente de El Oso, obras estas que quedaran concluidas en pocos días.

Ese trayecto se empezó ya a enrielar aunque muy lentamente debido, entre otras causas semejantes, a la falta de rieles y traviesas cuyo transporte no ha podido efectuar el Ferrocarril del Pacifico. Hoy está en vigor un contrato con el Ferrocarril Santander-Timba para el transporte de materiales, recurso este que permitirá avanzar un poco más en la enrielada.

Entre el k 10 y el 19 hay trabajos intensos en los que se ocupa un personal de algo más de mil trabajadores. Allí se ha tropezado con el inconveniente de la falta de cemento que ha retardado las obras de arte, y por tanto, trastornado con bastante gravedad el movimiento de tierra. Oportunamente ha enviado el Gobierno de Caldas al Ministerio de Obras Publicas las relaciones, conforme al contrato, para que se hagan los pedidos de este como de los demás materiales que la empresa ha necesitado, y ha apremiado para que esos pedidos se hagan en la forma más rápida. Contando con esos pedidos, se establecieron trabajos, intensos en cierto modo, y a la postre ha venido a resultar que el Gobierno de la Nación, o no ha hecho esos pedidos o los ha hecho mal, o los ha hecho en forma que ha resultado más tardía.

Como consecuencia de todo esto, ha resultado que el trabajo se ha trastornado gravemente y ha llegado a ser en su costo mucho más que lo que hubiera sido, si al Departamento se le hubiese dejado una autonomía racional para ejecutar el contrato de construcción de aquel Ferrocarril. Conviene anotar esto, y que quedo de ello constancia, porque no tardara el día en que a Caldas o sus hombres se les formulen cargos injustos alrededor de este asunto.

Hasta el k 27 la línea está localizada definitivamente. De allí en adelante, hacia Armenia, una comisión muy experta trabaja en el preliminar de la línea con muy buenos rendimientos, según los informes que han llegado a este despacho.

Actualmente trabajan en el ferrocarril del Quindío las siguientes comisiones: 
Sección primera de construcción.

Sección segunda de construcción.

Comisión de localización.

Comisión de trazado hasta Armenia.

Por los pocos pedidos que se han hecho por el Ministerio de Obras Públicas, según las copias de las notas que han sido enviadas a este despacho, puede verse que están llegando los siguientes elementos que serán aplicados a la vía y equipo, sin contar otros para la construcción de la explanación, tales como hierro, puentes, etc.

Aquellos elementos son:

-3.000 metros de carrilera decauville con su equipo;

-1.000 toneladas de rieles con sus accesorios, bastantes para enrielar 18k;

-10 carros plataforma que se arman actualmente en los talleres del Pacifico en Dagua;

-1 pala de vapor "Bucyrus", montada sobre catterpillar, con aparato para montarla sobre rieles y de una capacidad de $3 / 4$ de yarda cubica:

-1 locomotora tipo 2-4-2.

Fuera de lo dicho se tienen compradas hasta hoy unas 22.000 traviesas en Buenaventura y Puerto Caldas.

Hasta el último día de septiembre pasado, los gastos en el Ferrocarril del Quindío habían sido los siguientes:

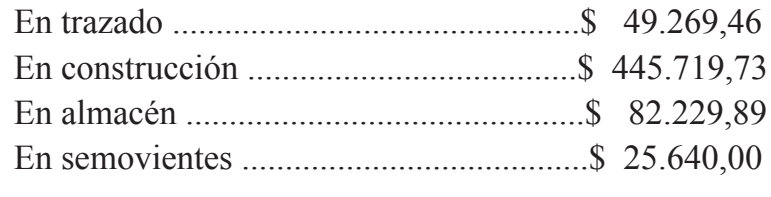

Suma $\$ 602.859,08$

Ferrocarril Manizales-Cauca.-El Gobierno contrato con el doctor Luis A. Isaza el estudio y trazado de esta línea, destinada a unir el ferrocarril de Caldas con la red de los ferrocarriles Antioqueños en el rio de Arma, límite de los dos Departamentos. El doctor Isaza cumplió su cometido, entregando a satisfacción de la oficina de ferrocarriles y cables los estudios, planos del trazado, carteras de tránsito, nivel, topografía, localización, movimiento 
de tierra y coordenada, planos de la región, relación de los propietarios y presupuesto de la obra.

Las características principales de la línea son:

Longitud entre la ciudad de Manizales y el rio Cauca, un poco abajo de la confluencia del rio Tapias, $68 \mathrm{kms}$.

Radio mínimo de curvas 71,85m (16). Tangente mínima entre curvas en sentido contrario $41 \mathrm{~m}$; solo se usó en ese caso, para poder localizar una curva suave (de $6^{\circ}$ ), tangente de 40m. Tangente mínima entre dos curvas en el mismo sentido.

El alineamiento se divide así: alineamiento recto $34.061,39 \mathrm{~m}$, curvo hacia la izquierda 17.133,38; curva derecha $15.805,51 \mathrm{~m}$, o sea prácticamente el $50 \%$ de la longitud.

Grados de curvatura izquierda. $10.207,55$

Grados de curvatura derecha $10.149,60$

Suma $20.357,15$

Dirección general de la ruta $\mathrm{N} 45^{\circ} \mathrm{W}$.

De Manizales, arrancó la línea con el 3\% compensado, se usó 0-5 por grado métrico para la compensación en las curvas hasta caer a la margen izquierda del rio Guacaica a la abscisa 16.100. De este punto hasta la estación 26.460 sigue la línea a nivel, donde principia a bajar con el 2,6\% compensado, hasta la abscisa 34.200 en la quiebra. "La Gregorita". De este lugar continúa bajando con el 3\% compensado hasta la abscisa 59.400 donde cambia la pendiente por el $2 \%$, hasta $800 \mathrm{~m}$, antes de caer a la orilla del Cauca, trayecto este último que se proyectó a nivel.

Cada 5 o 6 kilómetros en las pendientes se dejó un nivel de 200 a 250 metros.

No se usó en ninguna parte pendiente positiva, es decir, no se emplearon contrapendientes, debido a que recurriendo a ellas no se obtenía acortamiento sensible en la longitud de la línea.

El presupuesto de esta obra, muy al alcance de los recursos del Departamento, si se aprovecha la organización del ferrocarril de Caldas, su equipo y herramienta, una vez una vez que llegue a la ciudad de Manizales, es el siguiente:

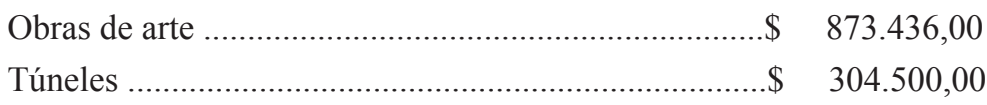


Movimiento de tierra \$ $2.667 .945,53$

Superestructura \$ $680.000,00$

Damon. Ing. e improvistos $\$ \quad 905.176,31$

Fajas de terreno $\$ 136.000,00$

Estaciones y tomas de agua .\$ $100.000,00$

Suma $\$ 5.667 .057,84$

Estoy satisfecho en haber colaborado en el estudio de este grave problema Departamental, dejando los planos de la obra, y opino que el nuevo Gobierno debe solicitar de La Honorable Asamblea autorizaciones para emprenderla, con los recursos asignados al Ferrocarril de Caldas, una vez que llegue a Manizales, y aprovechando los elementos de que dispone esta empresa. Por fortuna el nuevo Gobernante es un amigo entusiasta de la obra.

FRANCISCO JOSÉ OCAMPO

Gobernador del Departamento 
Armando Ramírez Villegas

\title{
Anexo $N^{0} 8$
}

\section{Informe del Señor Emilio Latorre, Administrador del Ferrocarril Nacederos-Armenia}

\author{
Pereira, mayo 24 de 1928
}

Señor

Director General de los Ferrocarriles

Bogotá

Correspondiendo a los deseos manifestados por usted en su atento oficio número 415 de fecha 9 de abril último tengo el gusto de dar a ese despacho el informe relativo al ferrocarril nacederos Armenia en la forma siguiente de acuerdo con lo dispuesto en el artículo primero de la ley 67 de 1923 octubre 23 y después de haber verificado el estudio de una vía férrea entre el municipio de Armenia y un punto del ferrocarril de Caldas entre Cartago y Pereira, cuyos planos fueron aprobados por el Ministerio de Obras Públicas el gobierno nacional procedió a celebrar con el departamento de Caldas el respectivo contrato de construcción con fecha 4 de julio de 1925 el cual suscribieron los señores doctor Laureano Gómez en su calidad de ministro de obras públicas y el señor Roberto Marulanda como representante del departamento y cuyo texto corre publicado en el diario oficial número 19956 de 24 del citado mes de julio. Los trabajos de construcción se iniciaron en los primeros días del mes de agosto del año 25 partiendo del punto denominado Nacederos, corregimiento de Pereira, distante 4 kilómetros de esta ciudad y situado en la línea del ferrocarril de Caldas entre la mencionada población y la de Cartago, bajo la dirección técnica del doctor Manuel M. Mosquera, ingeniero jefe del ferrocarril de Caldas, tuvo como ingeniero ayudante al doctor Hernando Piedrahita hasta el 19 de enero de 1926, en cuyo periodo herencia la empresa el Señor Francisco Jaramillo Ochoa como gerente de Ferrocarril de caldas después y en virtud de nombramiento de hecho por el gobernador del departamento de Caldas doctor Gerardo Arias Mejía, se hizo cargo de la Administración Federal de esta ferrovía el doctor Eduardo Serna y continuando la dirección técnica de la obra el mismo doctor Mosquera ayudado en sus labores por el doctor Francisco Londoño ingeniero de construcción y mediante contrato celebrado entre aquel Mosqueda y el doctor Sebastián Ospina y el desempeño por algún tiempo las funciones de director general de ferrocarriles y cables en el departamento de caldas durante el tiempo del contrato de construcción hecho con el citado otro Mosquera estuvo súper vigilada la obra por el doctor Eleuterio serna $\mathrm{G}$ ingeniero jefe del ferrocarril de caldas y administrada por el señor Justiniano Londoño quién reemplazó al doctor Eduardo Serna en los primeros días de octubre de 1926.

Terminado el contrato con el doctor Mosquera, a mediados del mes de diciembre de 1927, los trabajos de construcción han seguido adelantándose en forma de administración hasta el momento actual bajo la dirección inmediata del mismo doctor Eleuterio Serna G. como ingeniero jefe acompañado a los doctores Ernesto Ramírez y Rafael Botero estos 
últimos como ingeniero de construcción el primero y de sostenimiento el segundo de la parte construida y en explotación la cual se está haciendo informalmente de acuerdo con disposiciones del Ministerio de obras públicas y a exigencias de los habitantes de la región que atraviesa la línea ya que esta no ha sido entregada definitivamente al Gobierno Nacional, pues no ha sido posible balastarla convenientemente por escasez de tal material en el trayecto construido y además por carecer de los recursos pecuniarios indispensables para atender a que el gasto. No estará por demás hacer constar aquí la conveniencia que resultaría para la estabilidad y la seguridad de los 32 kilómetros construidos el gobierno nacional procediera a la mayor brevedad posible a contratar suba la estaba con el Ferrocarril de caldas empresa está que posee actualmente en los puntos denominados Las Peñas y mira lindo situados aquel entre estaciones de la capilla de guayabito y este entre las estaciones de Villegas y la Marina, apreciables balaceras de las cuales podría tomarse la cantidad que se requiere para el efecto indicado.

Es verdad que del río llamado "Barbas" en el ferrocarril Nacederos-Armenia, se ha venido extrayendo balasto para atender a las necesidades más apremiantes de la línea, pero el que allí resulta, no es de una calidad satisfactoria, porque contiene un elevado porcentaje de arena y piedra gruesa y defectuosa, que no presta el servicio que fuera de desearse, pero que tenemos que utilizar, en fuerza de las circunstancias, por carecer de un material de mejor calidad.

Fuera de esto y para facilitar la extracción del balasto, la administración anterior tuvo necesidad de construir una carrilera falsa de unos 500 metros de extensión, la cual demanda algunos gastos para su sostenimiento, pues hay que defenderla de las continuas avenidas o crecientes del río, porque en esa región llueve la mayor parte del año, y bien comprende el señor Director que para atender oportunamente al arreglo de los puntos débiles de la carrilera, sobre todo en los rellenos y en los lugares húmedos se requiere el balasto y por lo tanto es absolutamente indispensable conservar aquella instalación falsa, no obstante los desembolsos que ella ocasiona.

El suscrito Administrador, seriamente preocupado por la definitiva terminación de los kilómetros construidos, encarece a UD., de la manera más atenta, se sirva interponer sus buenos oficios ante el Ministerio de Obras Públicas, con el fin de que a la balastada de la línea se le preste la atención del caso para evitar, hasta donde sea posible, que la demora en satisfacer esta necesidad pueda traer daños de importancia, cuya reparación sería demasiado costosa y traería complicaciones no previstas que dilatarían demasiado la terminación de una obra cuya importancia para la Nación y el Departamento de Caldas es obvia y no requiere, por lo tanto, de que alrededor de ella de hagan demasiados comentarios.

De los kilómetros construidos, se ha logrado balastar, próximamente un cuarenta por ciento de ellos de la mejor manera posible, pero para afirmarlos convenientemente será necesario emplear alguna cantidad mayor y eso podría obtenerse rápida y eficientemente, si se lograra que el Gobierno Nacional adoptara la fórmula que me he permitido sugerir atrás o sea la celebración del contrato respectivo, con el Ferrocarril de Caldas. 
El material rodante que posee esta Empresa es el siguiente:

Tres locomotoras, de las cuales la \#1 está prestando servicios en la balastada de la línea desde meses atrás; la \#2, de construcción belga, que por razón de su excesivo peso no ha sido posible utilizar y ha sido prestada al ferrocarril de Caldas, en cambio de las número 1 y 2 de aquella Empresa. La primera de estas máquinas apenas si sirve para los trabajos de limpia de la línea y enrielada de la misma y la segunda que está destinada a hacer los servicios de pasajeros y carga entre las estaciones de Pereira y Quimbaya, en cuya población se inauguraron los rieles el día 16 del pasado abril. La locomotora \#3, también de construcción belga, y en un todo igual a la \#2, esta prestada al ferrocarril del Pacífico, en cambio de la \#15, que está dedicada al transporte de materiales y combustible desde el Departamento del Valle hasta la línea, pues solo de aquel lugar podemos proveernos de carbón y leña.

Coches para pasajeros, de procedencia belga, llegaron a esta Empresa en el transcurso de los meses de marzo y abril, seis, de los cuales tenemos armados y en servicio uno de primera clase y dos de segunda y se trabaja activamente por la armada de los otros tres, operación esta que esperamos terminar al finalizar el mes de junio próximo, por ser imposible antes, debido a la falta de los elementos apropiados para el efecto, pues la mayor parte de los trabajos que se ocurren relacionados con armada de vehículos, reparación de los mismos y de herramientas, se llevan a cabo en los talleres del Ferrocarril de Caldas, cuya empresa ha prestado y presta muy eficaces y oportunos servicios al Ferrocarril Nacederos-Armenia. Además tiene esta ferrovía diez plataformas, cuatro góndolas, dos gamarras, una pala de vapor y diez vagones de carga, de los cuales únicamente hay dos debidamente acondicionados; el resto está en plataformas, pero, se trabaja en el montaje de sus complementos aunque con una lentitud desesperante, porque entre otras muchas cosas se carece de martillos compresores de aire para verificar correctamente el remache de todas los tornillos que llevan aquellos vehículos.

En el trayecto de los 32 kilómetros construidos existen las siguientes Estaciones: "Nacederos" en el kilómetro 0, "San Joaquín" en el kilómetro 6, "La Selva", en el kilómetro 14, "Sucre" en el kilómetro 20, "Alcalá" en el kilómetro 26 y "Quimbaya" en el kilómetro 32 y los paraderos denominados "Morelia", "Betulia" y "Venecia" en los kilómetros 11, 18 y 23 , respectivamente.

Las Estaciones de "Nacederos" y "San Joaquín” están situadas en territorio del Departamento de Caldas, lo mismo que la de "Quimbaya" y los paraderos de "Morelia" y "Betulia". Las Estaciones de "Sucre" y "Alcalá" y el paradero de Venecia, en jurisdicción del Departamento del Valle del Cauca.

Las perspectivas para el futuro son demasiado halagadoras, pues la región que atraviesa la línea férrea en toda su extensión, que es de 54 kilómetros, hasta la ciudad de Armenia, es de una feracidad y riqueza extraordinarias y está dedicada a la agricultura y la ganadería, con especialidad al cultivo de la caña de azúcar y el café, productos estos que son de excelente calidad, sobre todo el último en cuyo beneficio ponen un esmerado cuidado los interesados. La región tiene además un número de habitantes demasiado crecido, de sanas costumbres, 
vida sobria y totalmente entregados a sus labores de campo, sin otra preocupación que mejorar en todo sentido sus labranzas y dehesas, de tal manera que en la actualidad, no solo producen lo suficiente para atender a sus diarias necesidades, sino que abastecen también una parte considerable de los Departamentos de Caldas y el Valle del Cauca, con artículos de primera necesidad. En cuanto al cultivo del café, esta industria está tomando un enorme incremento y no es aventurado conceptuar que en el curso de pocos años, este grano será uno de los elementos primordiales que habrán de alimentar al ferrocarril del Quindío, con efectivo provecho para el fisco nacional.

Como se dijo atrás, después de terminado el contrato de construcción celebrado con el Dr. Manuel M. Mosquera, los trabajos de la Empresa han seguido llevándose por administración en todas las dependencias de ella, adoptándose en el movimiento de tierras el sistema de tareas dadas a los Capitanes de las cuadrillas y directamente a los peones, con lo cual se han obtenido los mejores resultados, pues se hace lo más, gastando lo menos.

El promedio total de los trabajadores ha sido en los últimos meses de unos 700 hombres, de los cuales se han venido empleando en el sostenimiento y mejora del trayecto construido unos 300 obreros y el resto en movimiento de tierras y construcción de mampostería de Quimbaya hacia adelante.

El personal directivo del ferrocarril es actualmente el siguiente:

Un administrador general

Un Secretario (Jefe de Estadística)

Un Contador General

Un Cajero

Un Pagador

Un Proveedor de materiales

Un Almacenista General

Un Ingeniero Jefe

Un Ingeniero de Construcción

Un Ingeniero de Sostenimiento

Un Ingeniero Interventor

Dos Inspectores

UnMédico

Un Practicante.

Todos estos empleados son de libre nombramiento y remoción del Gobernador del Departamento de Caldas, de acuerdo con la cláusula $6^{\text {a }}$ del contrato de construcción celebrado el 4 de julio de 1925, con excepción del Ingeniero Interventor que depende directamente del Ministerio de Obras Públicas. ${ }^{8}$

8. Informe Latorre, Ferrocarril Nacederos-Armenia, AGN,1928 


\section{Anexo $\mathbf{N}^{\circ} 9$}

\section{1) INGENIEROS JEFES DEL FERROCARRIL}

1) Julián Arango Arango 1911 a 1915

2) Luis A. Isaza 1915 a 1917

3) Jorge Escobar 1917 a 1918

4) Eleuterio Serna Gómez 1918 a 1919

5) Mayor Morris 1919 a 1920

6) Eleuterio Serna Gómez 1921 a 1922

7) Gabriel Mejía Villa 1923 a 1923

8) Luis A. Isaza 1923 a 1925

9) Manuel M. Mosquera 1925 a 1929

\section{2) SUPERINTENDENTES}

1918 Leonidas Villegas

1918 Manuel Felipe Calle hasta diciembre de 1924

1919 Francisco Jaramillo O.

\section{Anexo $\mathbf{N}^{0} 10$}

\section{Perfiles Biográficos de Algunos de los Ingenieros del Ferrocarril}

\section{FELIPE ZAPATA CUENCA}

Nació en Bogotá el 9 de septiembre de 1885 y muere en Bogotá en 1917, a los 31 años de edad (Según Poveda Ramos, muere en la población de Ubaté en 1915). Hijo de José Felipe Zapata Vargas (Periodista del liberalismo radical del siglo XIX, Ministro del Interior, Ministro de Relaciones Exteriores y Embajador Plenipontenciario ante el Gobierno Inglés) y Soledad Cuenca y Flórez. Estudió en Bruselas y Londres. Se graduó en la University College en 1906 y regresó al país en 1915 (Según Poveda Ramos, a mediados de 1910). Participó en el trazado de los ferrocarriles de Girardot y de Caldas, y propuso la comunicación férrea entre Pereira y Armenia.

"Fue uno de los pioneros de la Ingeniería de los Ferrocarriles en Colombia. Luego de estudiar esta carrera en el University College de Londres, viajo contratado por la compañía constructora de ferrocarril Central del Uruguay en donde construyó gran parte de los ferrocarriles de ese país. A mediados de 1910 se trasladó a Bogotá a trabajar como gerente del ferrocarril de la Sabana donde desempeño una magnífica labor de la cual resultó el edificio, aún en pie, de la Estación de la Sabana.’(Revista del Rosario)

Como un reconocimiento a su labor en pro del Ferrocarril de Caldas, se bautizó a la primera locomotora con el nombre de "La Zapata", conocida después como "La Pichinga", que hoy en día luce como monumento en la entrada a la Estación de Manizales. 


\section{JULIÁN ARANGO ARANGO}

Hijo de Federico Arango Palacio y María del Rosario Arango Uribe, nace en Manizales el 20 de junio de 1874. Hace sus estudios de secundaria en el colegio del educador Restrepo Maya en donde fue compañero de José Ignacio Villegas, Pompilio Gutiérrez, Valerio Hoyos y muchos más de la pléyade de eminentes personajes de Manizales. Formó parte de una Sociedad Literaria, que fundaran algunos jóvenes y que fuera apreciada por el Padre Fabo, como "los colonizadores del pensamiento literario". Se traslada luego a Bogotá para estudiar ingeniería en la Escuela Nacional de Ingeniería. En el año 1915 actúa como el primer Ingeniero Jefe del Ferrocarril de Caldas. Organiza y ejecuta los primeros trazados del ferrocarril. Invita al ingeniero Felipe Zapata Cuenca, en nombre del Ferrocarril de Caldas, para que expida un concepto sobre la viabilidad técnica y económica de la obra propuesta. Con los ingenieros Jorge Páez González, Héctor Acevedo y Alonso Restrepo, elaboran el primer trazado que partiendo de un punto a orillas del río Cauca, ascendía por la finca Alsacia y continuaba hasta la Quiebra de Vásquez. El 16 de julio de 1915 estuvo presente en la inauguración oficial del Ferrocarril de Caldas en Puerto Caldas. En octubre de 1919 traza una preliminar entre Galicia y la ciudad de Armenia. Poco después de entregar este estudio, el 18 de agosto de 1920, y a la edad de 47 años, fallece repentinamente, llenando de tristeza y pesar a sus compañeros y a la sociedad entera, que siempre lo apreciaron por su calidad humana, sus conocimientos y su entrega total a la obra del ferrocarril.

Obituario en el periódico "El Heraldo Liberal" de Manizales, del jueves 19 de agosto de 1920:

"Dr. Julián Arango.

En la mañana de ayer, y en la plena madurez de la vida rindió su tributo a la tierra este noble amigo y eminente ciudadano.

Con la desaparición de Julián ha perdido Manizales uno de sus primeros elementos de progreso, y la sociedad uno de sus más íntegros varones.

Descendiente digno de aquella extirpe de viejos patriarcales que nunca supieron de dobleces ni de hipocresías, su vida tuvo siempre la noble valentía de la línea recta sin curvas ni claudicaciones.

Amoldado a las severas disciplinas matemáticas, fue siempre incapaz de eufemismos literarios, y por eso sus conceptos aparecían siempre rudos pero exactos como los términos de una ecuación algebraica.

El principal punto de mira de aquel noble ingeniero era la honradez, y a través de sus obras - como entre una roca viva- se veía brillar, como oro nativo, la pureza de sus intenciones. 
Que la tierra sea blanda a las cenizas de este muerto querido, y que el dulce espíritu de la resignación descienda sobre los seres que le fueron caros en la vida."

\section{LUIS A. ISAZA}

Ingeniero Jefe entre los años 1915 y 1917. Reasumió la Jefatura en 1923 hasta 1925, año en que presentó la renuncia a su cargo para atender la Gerencia de las Empresas Públicas de Medellín.El 16 de julio de 1915, en su calidad de Ingeniero Jefe, estuvo presente en la ceremonia de iniciación de los trabajos del ferrocarril. En repetidas ocasiones y en distintas fechas, aparece elnombre de esteingeniero comogenerador deideas, reparadorde dificultadesolíderentusiasta. En 1914 propone el cambio del trazado inicial, elaborado por los ingenieros Páez, Arango, Acevedo y Restrepo, para acercar el ferrocarril de Caldas al del Pacífico, con el propósito de lograr una comunicación inmediata con el puerto de Buenaventura, idea que fue aceptada, dándosele el nombre de Variante Consota, y cuyos beneficios no tardaron en manifestarse con el aumento de las mercancías de exportación entre las cuales estaba en primer lugar el café de exportación y la importación de materiales y elementos para la reconstrucción de la ciudad de Manizales en el año 1922. Le correspondió la dirección de la construcción de la línea férrea entre Puerto Caldas y la estación La Marina, afrontando todas las dificultades generadas por un intenso invierno como no se presentaba hacía mucho tiempo. Fue convocado en 1923 por el Gobernador para ponerse al frente de la jefatura de los ingenieros, en un momento crítico de la construcción, cuando se enfrentaban las dificultades del ascenso a Boquerón originadas por la inestabilidad del terreno, las pendientes del mismo y la tenacidad del invierno, logrando controlar las adversidades y dando tranquilidad a los directivos y a la ciudadanía. En 1924, la Junta, por recomendación del ing. Isaza, encargó al ing. Serna para que en asocio con los ingenieros Ramírez, Arango Tavera, Escobar, Pardo, Suarez, Juan de D. Villegas, Alfredo Castillo y Emilio Domínguez, realizara el trazado desde San Francisco hasta Manizales. En febrero de 1926 hace un estudio para comunicar a Manizales con el río Cauca, que entrega el 6 de noviembre del mismo año.

\section{JORGE PÁEZ GONZÁLEZ}

Nació en Bogotá el 28 de abril de 1872. Recién graduado de Ingeniero Civil en la Facultad de Ingeniería Civil y Matemáticas de la Universidad Nacional en 1896, trabajó en el Ferrocarril de Antioquia ocupando todos los cargos desde el trazado y la construcción hasta llegar a la Gerencia del mismo. Fue enviado por la Empresa a Europa y Estados Unidos para estudiar diversos aspectos relacionados con ella, entre otros el paso de La Quiebra. En 1911 se vincula con el Ferrocarril de Caldas para efectuar sus primeros trazados. En 1913 se hizo cargo del trazado del Ferrocarril del Norte que se planteaba entre Bogotá y Bahía Honda en el Departamento del Magdalena. En 1921 fue Presidente de la Sociedad Colombiana de Ingenieros. En los años 30 fue el primer Administrador General de los Ferrocarriles Nacionales. Casado con la pianista Carmen Martín, fue un hombre sensible y apreciador del arte y la música. Era una persona alegre, tocaba el piano y disfrutaba de la fiesta sin dejar de ser serio y correcto en todo sentido.

Murió en Bogotá el 5 de enero de 1943. 


\section{ELEUTERIO SERNA GÓMEZ}

Nació en Támesis Antioquia el 14 de mayo de 1887, graduado en la Escuela de Minas en Medellín, en 1905. Se casó, en Pereira, con doña Elvira Gutiérrez Hincapié, de Marsella, el 2 de octubre de 1920 y tuvieron los siguientes hijos: Ligia, Stella, Alberto, Libia y Jaime, algunos de ellos residenciados en Pereira. Sus padres fueron don Silvestre Serna y doña Mercedes Gómez.

Asumió la Jefatura de los Ingenieros del Ferrocarril de Caldas en 1918, cuando la Junta del Ferrocarril había decidido dividir el trabajo de Superintendente e ingeniero Jefe; en 1920 entregó temporalmente la dirección al ingeniero W. Morris, quien había sido contratado por la Junta como asesor temporal, para retomarla en 1921. En diciembre de 1922 se retira del cargo de ingeniero jefe.

\section{RAFAEL ÁLVAREZ SALAS}

Nació en Purificación el 7 de noviembre de 1859, cursó los estudios de secundaria en Vélez, fue alumno de literatura en la Universidad Nacional en 1874 y se graduó de ingeniero civil en la misma Universidad en 1879. Trabajó en el Ferrocarril de Caldas y entre sus labores le correspondió el trazado de la variante Consota en los años 1916 a 1917. Fue ingeniero jefe del ferrocarril del Pacífico y posteriormente, ingeniero subjefe en la Comisión de Límites con Venezuela, bajo la dirección de Ruperto Ferreira.

La Sociedad Colombiana de Ingenieros instituyó el Premio Rafael Álvarez Salas en el año 2011, que se otorgará al ingeniero nacional que haya concluido o liderado en el país en los últimos tres años, la obra o el proyecto (diseño) o haya publicado el mejor libro sobre asuntos técnicos, económicos o histórico sobre ferrocarriles. Este premio será conferido anualmente y entregado en Sesión Solemne, que la Sociedad Colombiana de Ingenieros celebra el 29 de mayo de cada año en el aniversario de su fundación.

Falleció en Nueva York el 30 de julio de 1920 y, posteriormente, se promulgó la Ley 28 de 1920, por medio de la cual se honraba su memoria.

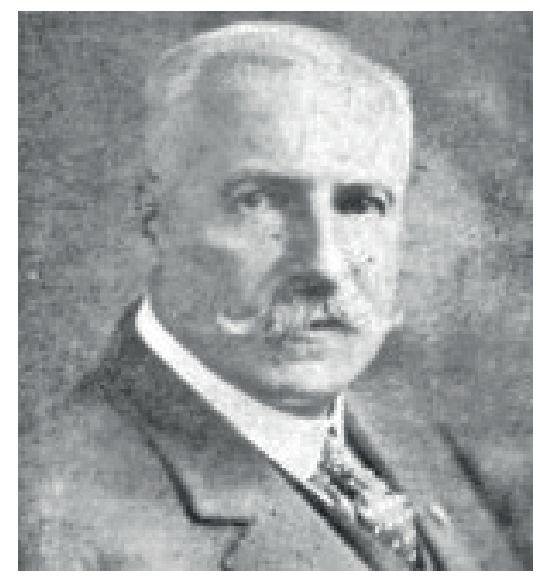


Armando Ramírez Villegas

\section{Anexo No 11}

Aprobación de planos para la conexión La Marina-Cartago

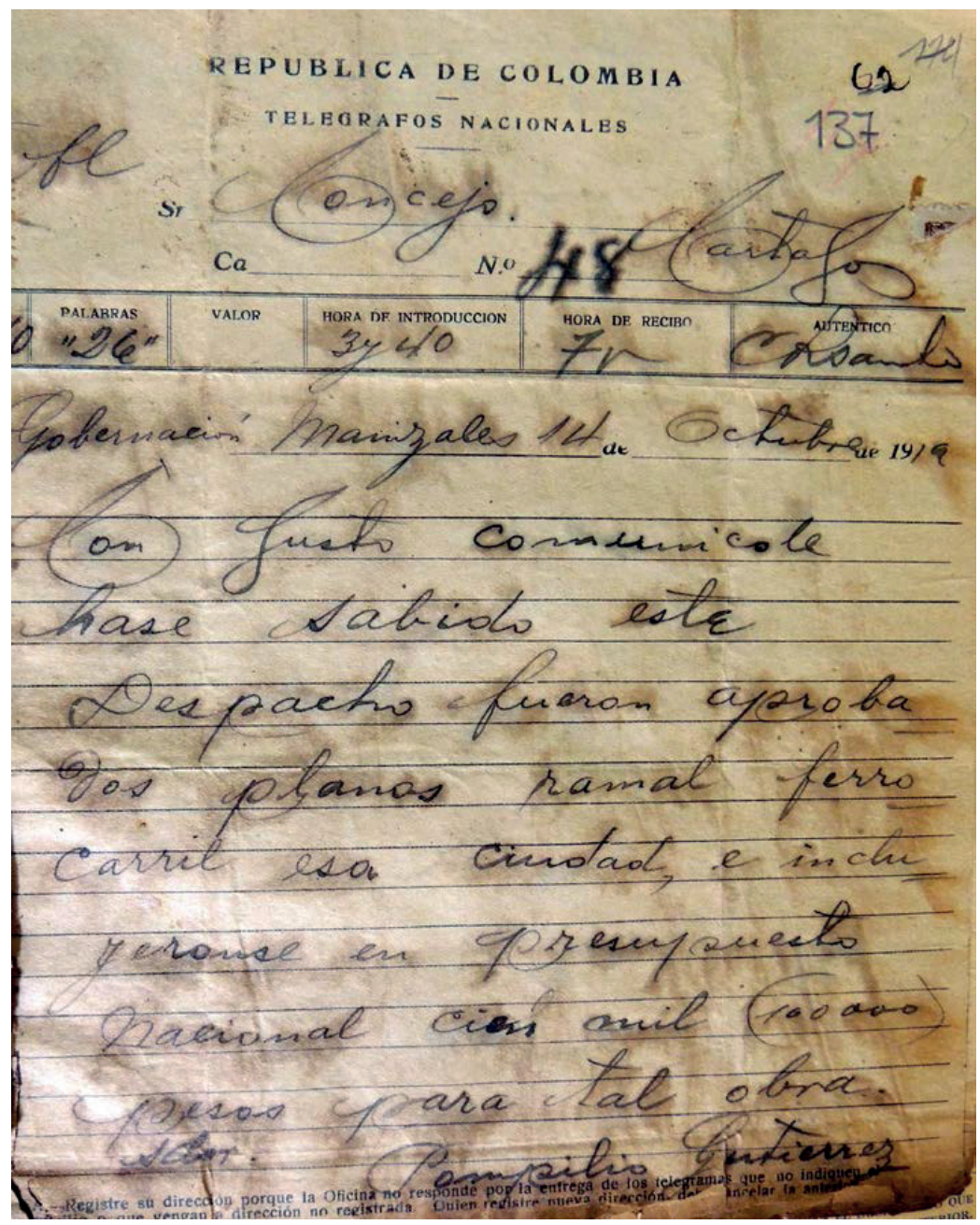




\section{ANEXO No 12}

\section{Escritura de compra de terrenos}

Archivo Histórico de Cartago, Fondo: Notaria Primera, Leg: 263, Folios: 80v-85v, Fechas: 1921, Escritura No 46 de 25 de enero 1921

[...] "Compareció el Señor ALEJANDRO CONCHA, Varón, mayor de edad, vecino de este municipio [...] que a título de venta real y enajenación perpetua transfiere a la Nación el derecho de dominio en una zona de terreno tomada de la Hacienda denominada "La Marina", situada en el paraje del mismo nombre, jurisdicción del municipio de Pereira, zona destinada para el ramal del Ferrocarril de Caldas a Cartago que partiendo de la línea principal (frente al kilómetro 8 abscisa 186, sigue por la hacienda "La Marina" hacia el rio "La Vieja" hasta encontrar sus aguas en una extensión de novecientos veintidós metros de longitud por 10 de latitud, mas 140 metros $^{2}$ en el lugar límite con la zona propiedad hoy del Ferrocarril, parte de la extensión que ocupara la Y de inversión. Segundo. Que los terrenos de los cuales se segrega la zona o faja vendida” [...] 


\section{ANEXO No 13}

Invitación de la Junta del Ferrocarril al Concejo de Cartago - Enero de 1919

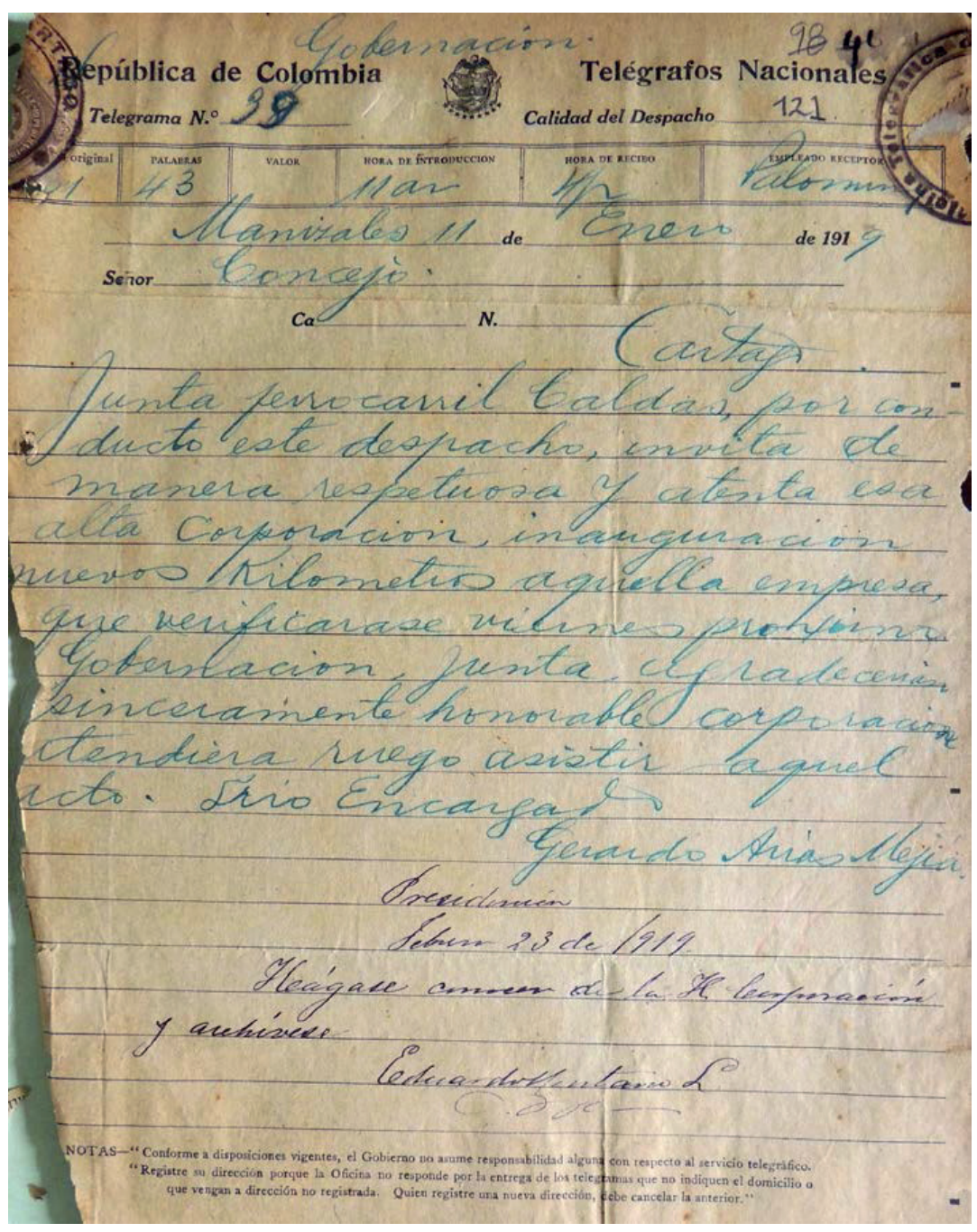




\section{Lista de figuras}

Figura 1. Premio Rafael Álvarez Salas ........................................................................ 10

Figura 2. Ingeniero Ernesto Ramírez Jaramillo ............................................................ 11

Figura 3. Talleres del Ferrocarril en Pereira ......................................................................... 12

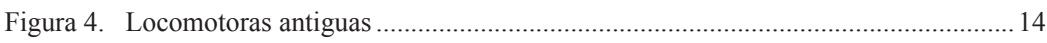

Figura 5. Transporte a las estaciones férreas ............................................................... 15

Figura 6. Bueyes arrastrando carga a las estaciones férreas................................................. 15

Figura 7. Construcción de un Ferrocarril. ............................................................................ 19

Figura 8. Desarrollo Ferroviario de Colombia ....................................................................... 19

Figura 9. Alegoría al Departamento de Caldas. .................................................................... 20

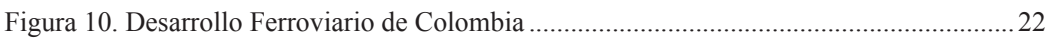

Figura 11. El recorrido del Ferrocarril de Caldas ............................................................... 23

Figura 12. Vagones impulsados por vapor ........................................................................ 23

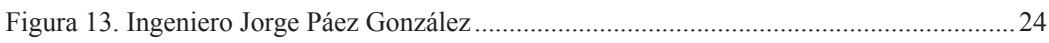

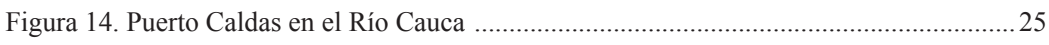

Figura 15. Excursionistas en Puerto Caldas ........................................................................... 27

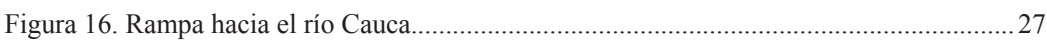

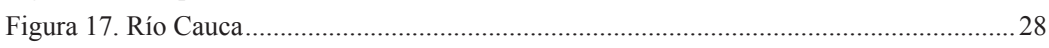

Figura 18. Vestigios de la Estación del Ferrocarril en Puerto Caldas ..................................... 28

Figura 19. La Vieja en su desembocadura al río Cauca en Puerto Caldas ..............................2 29

Figura 20. Puente sobre la quebrada Chapas........................................................................... 30

Figura 21. Antigua banca del Ferrocarril en la entrada a la estación ........................................31

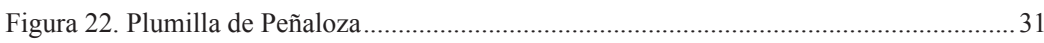

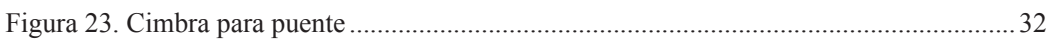

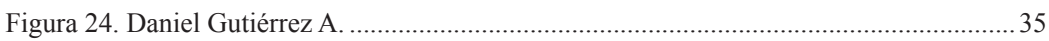

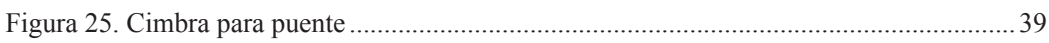

Figura 26. Banca del Ferrocarril entre Estación La Marina y La Hoya ................................... 39

Figura 27. Paradero La Hoya............................................................................................... 40

Figura 28. Aspecto de la Banca en Cercanías del Túnel de Consota. $\mathrm{N}^{\circ} 1$. ............................ 40

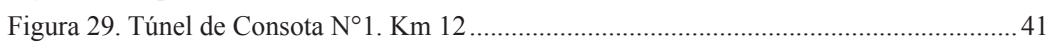

Figura 30. Túnel del Consota. Portal Oriental. .................................................................... 41

Figura 31. Túnel de Consota. Portal Occidental........................................................................ 41

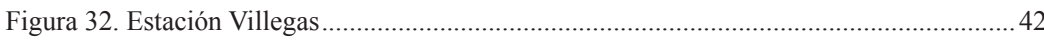

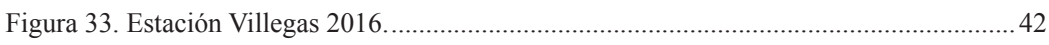

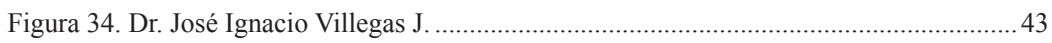

Figura 35. General Pompilio Gutiérrez ................................................................................... 43

Figura 36. Primera locomotora en Pereira ................................................................................. 44

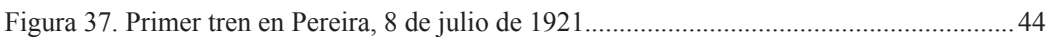

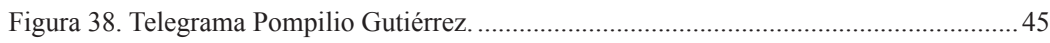

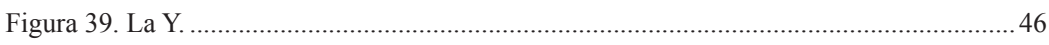

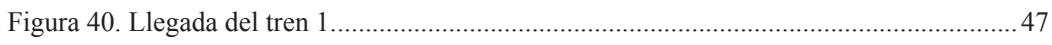

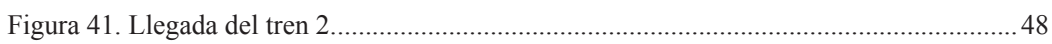


Figura 42. Locomotoras en Pereira. ................................................................................. 48

Figura 43. Primera Locomotora en Pereira............................................................................ 51

Figura 44. Inauguración del Ferrocarril en Pereira ....................................................................51

Figura 45. La estación de Pereira a través de los años 1922-1960. ........................................52

Figura 46. Derrumbe de la banca del ferrocarril en la subida a La Popa, 1926. .....................54

Figura 47. Tragedia en Pereira como consecuencia de un derrumbe

en la banca del ferrocarril, 2 de noviembre de 1926 . ................................................................ 54

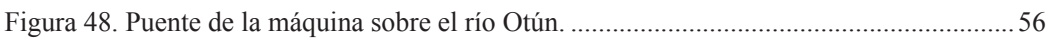

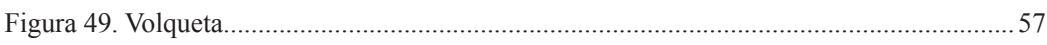

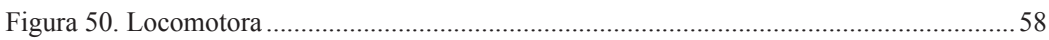

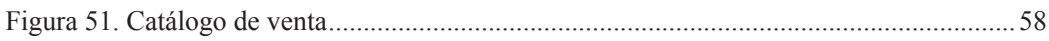

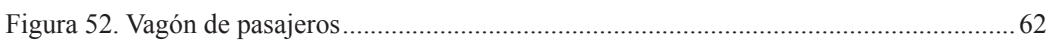

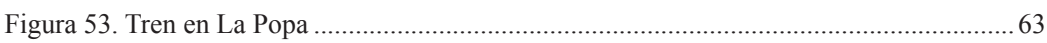

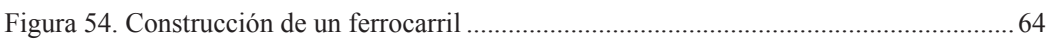

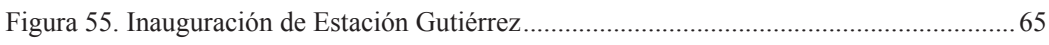

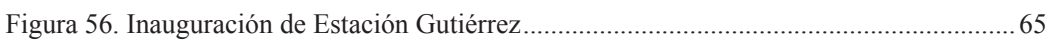

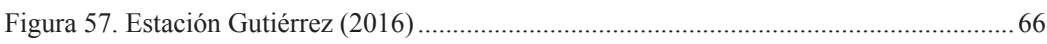

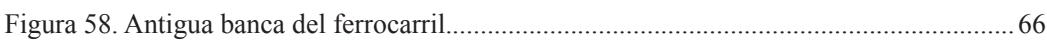

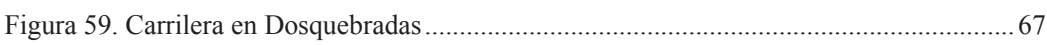

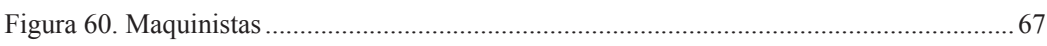

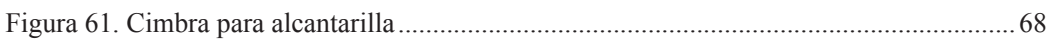

Figura 62. Trazado del ferrocarril. De la estación Gutiérrez a Santa Rosa de Cabal ..............69

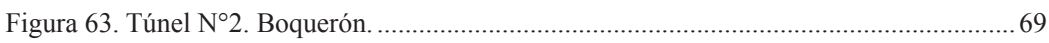

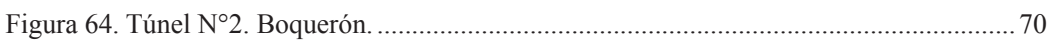

Figura 65. Puente sobre el río San Eugenio. 1923-2016 .......................................................... 70

Figura 66. Puente sobre el río San Eugenio. ............................................................................ 71

Figura 67. Comparación estación Santa Rosa de Cabal. 1906-2016. ..................................... 71

Figura 68. Tren saliendo del puente sobre el río San Eugenio hacia Pereira. ......................... 72

Figura 69. Ascenso hacia la estación La Capilla ................................................................... 72

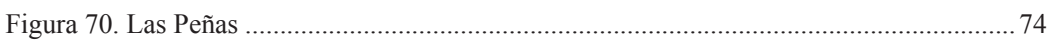

Figura 71. Puente sobre el río Campoalegre ……..................................................................... 75

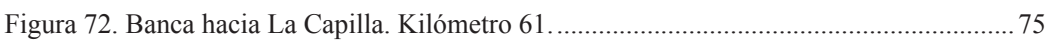

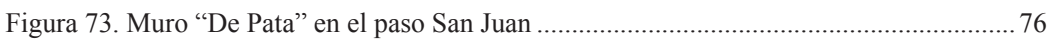

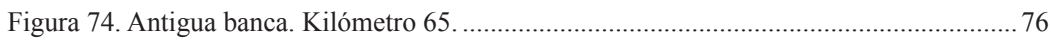

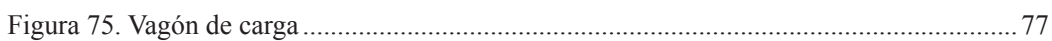

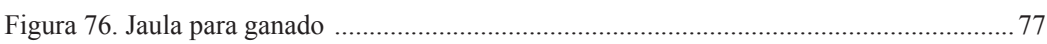

Figura 77. Parque y antigua banca del ferrocarril en La Capilla. Kilómetro 71 ..................... 78

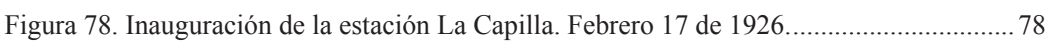

Figura 79. Nota de prensa sobre la inauguración de La Capilla ............................................ 79

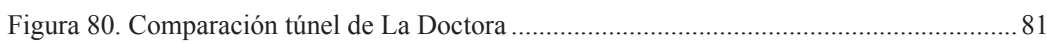

Figura 81. Antiguo puente sobre la vía a San Francisco. ........................................................ 81

Figura 82. Banca del ferrocarril cerca a San Francisco ............................................................. 82

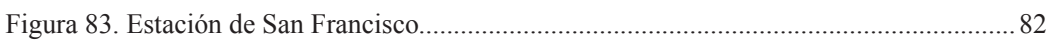




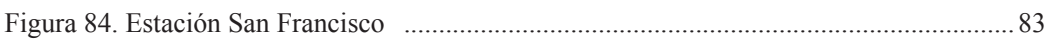

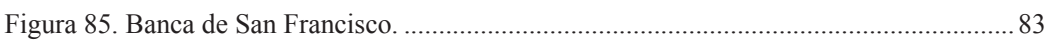

Figura 86. Túnel La Doctora. Kilómetro 81. Longitud 40 metros. ........................................... 84

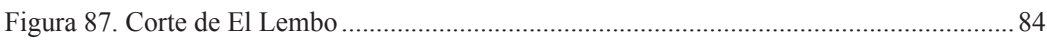

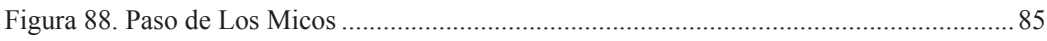

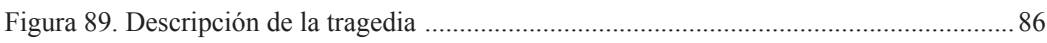

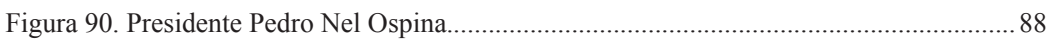

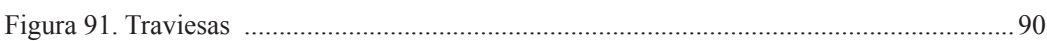

Figura 92. Antigua capilla de Rio Claro ............................................................................... 90

Figura 93. Tienda con placa conmemorativa. ........................................................................ 91

Figura 94. Tabla del ingeniero Jorge E. Ardila Rueda........................................................ 92

Figura 95. Construcción sobre el puente de Río Claro 1 ........................................................93

Figura 96. Construcción del puente sobre el Río Claro ....................................................... 93

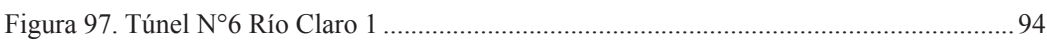

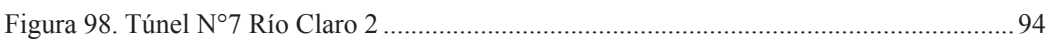

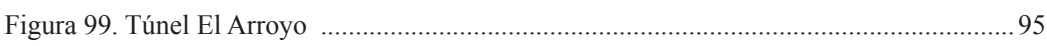

Figura 100. El Arroyo. Kilómetro 101. Longitud 58 metros ............................................... 96

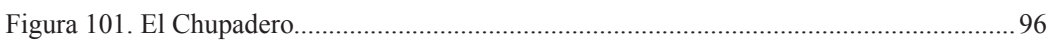

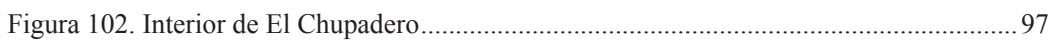

Figura 103. Caballo en El Chupadero ................................................................................. 97

Figura 104. Túnel El Chupadero. Kilómetro 101. Longitud 64 metros ................................... 98

Figura 105. Antigua banca del ferrocarril próxima a Villamaría........................................... 98

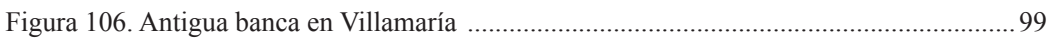

Figura 107. Tren en Villamaría .............................................................................................. 100

Figura 108. Línea del ferrocarril de Villamaría a Manizales sobre foto de Google ................ 100

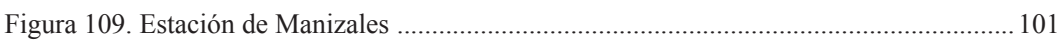

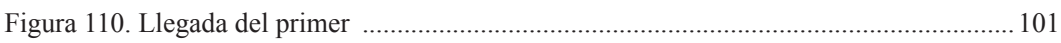

Figura 111. Túnel $\mathrm{N}^{\circ} 10$ Avenida Cervantes tren a Manizales............................................... 102

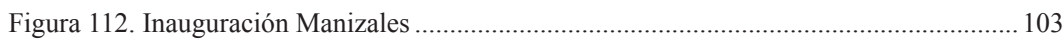

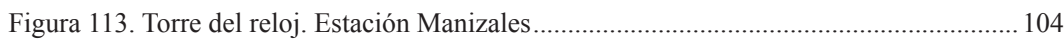

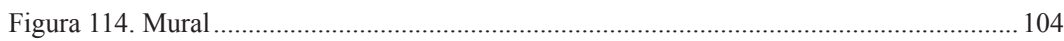

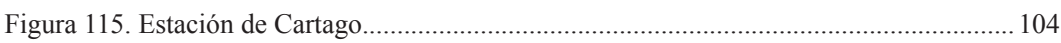

Figura 116. Itinerario de los trenes de pasajeros ................................................................ 107

Figura 117. Llegada del primer tren de Caldas a Cartago ..................................................... 108

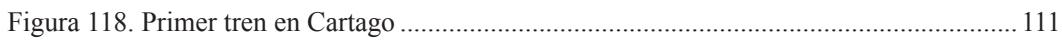

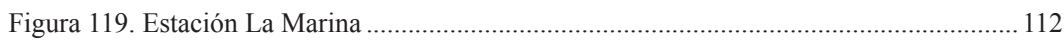

Figura 120. Primer vagón de pasajeros a Cartago .................................................................... 112

Figura 121. Construcción del puente sobre el río La Vieja .................................................... 113

Figura 122. Puente actual sobre el río La Vieja......................................................................... 113

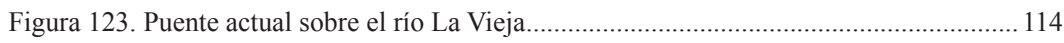

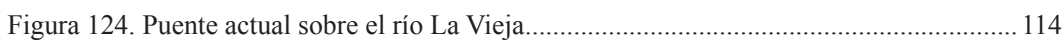

Figura 125. Inauguración del ferrocarril del Pacífico en Cartago. ........................................ 115

Figura 126. Ingeniero Eleuterio Serna G.......................................................................... 115 
Figura 127. Medalla del municipio de Cartago por la llegada del tren, 1922 ........................ 116

Figura 128. Medalla del municipio de Alcalá por la llegada del tren, 1927...........................116

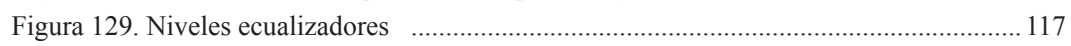

Figura 130. Locomotora doce ruedas. Locomotora diseñada para Colombia

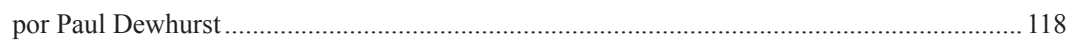

Figura 131. Ingeniero Paul C. Dewhurst ................................................................................. 118

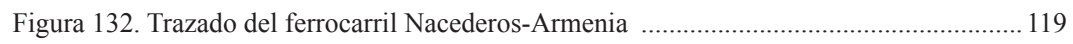

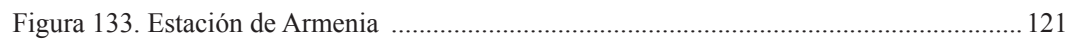

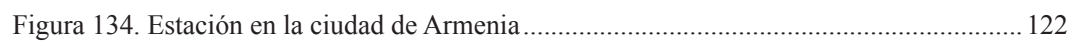

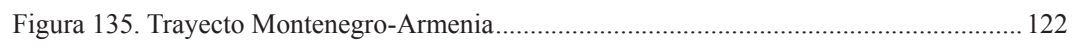

Figura 136. Puente sobre el río Buena Vista. Kilómetro 34 .................................................. 124

Figura 137. Puente sobre el río Espejo.................................................................................... 125

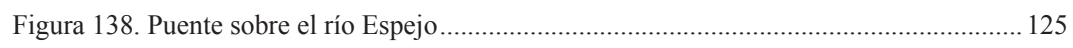

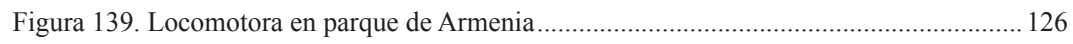

Figura 140. Locomotora Baldwuin N² en Universidad Autónoma de Manizales ................. 126

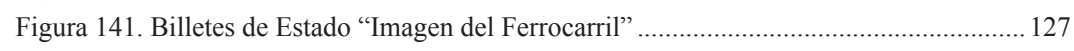

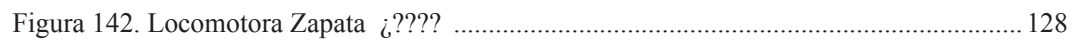

Figura 143. Vagones basculantes “Oshner”, de Godarville, Bélgica. ...................................... 138

Figura 144. Vagones basculantes "Oshner”, de Godarville, Bélgica. ...................................... 138

Figura 145. Vagones basculantes “Oshner”, de Godarville, Bélgica. ...................................... 138

Figura 146. Retrato Manuel Felipe Calle ......................................................................... 139

Figura 147. Manuel Felipe Calle G. Comandante de la Policía de Antioquia.......................... 141

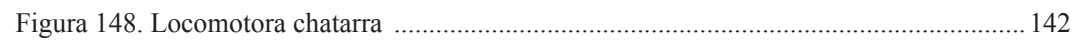

Figura 149. Descarrilamiento del tren en el puente sobre el río Otún ...................................... 148

Figura 150. Choque del tranvía con el tren en las calles de Pereira.......................................... 148

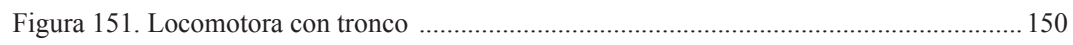

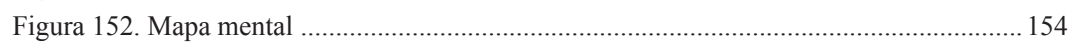

Figura 153. Posibles rutas del tren rápido trazadas sobre mapa del IGAC .............................. 155

Figura 154. Tren rápido de Líneas Españolas, AVE. ................................................................ 156

Figura 155. Archivo personal de Ernesto Ramírez Jaramillo ................................................ 159

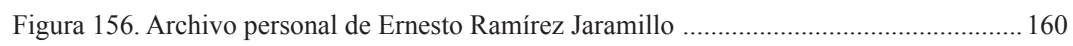

Figura 157. Archivo personal de Ernesto Ramírez Jaramillo ................................................. 161

Figura 158. Archivo personal de Ernesto Ramírez Jaramillo ................................................ 162

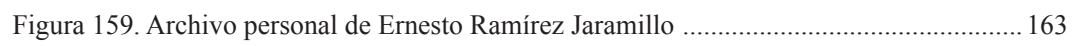

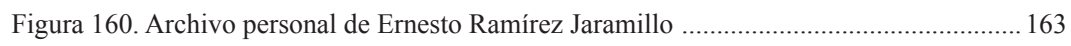

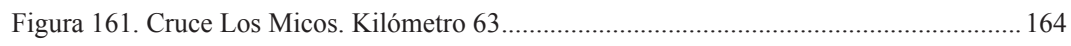

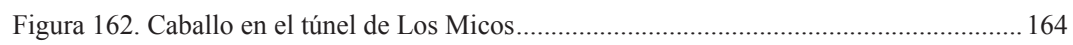




\section{BIBLIOGRAFÍA}

Ardila Rueda, Jorge E. (2012). Los Túneles en el antiguo Ferrocarril de Caldas. Bogotá: Trabajo de Grado, Pontificia Universidad Javeriana.

Arias A. Pablo y García, Pablo. (2005). La línea férrea del Atlántico y su programa de rehabilitación. Manizales: Universidad Nacional de Colombia.

Arias de Greiff, J. (1989). Ferrocarriles en Colombia 1836-1930. Bogotá: Credencial Historia.

Arreola, Juan José. (1952). El Guardagujas, Confabulario. México: Fondo de Cultura Económica.

Bateman Q. Alfredo. (2005). Historia de los ferrocarriles de Colombia. Bogotá: Página Maestra Editores.

Betancur, Belisario y Zuluaga, Conrado (1995). El tren y sus gentes. Bogotá: El Navegante Editores.

Correa R., Juan. Santiago. (2012). De Buenaventura al Caribe. Cali: Colegio de Estudios Superiores de Administración CESA.

De Greiff, León. (2018). Il Intermezzo-Scherzo Assai Vivace. Obra completa, poesía Vol. I, Bogotá: Universidad Nacional de Colombia.

Echeverri Mejía, Néstor. (1927). El Ferrocarril de Caldas. Bogotá: Imprenta Nacional.

Fabo FR. P. (1926). Historia de la ciudad de Manizales. Manizales: Editores Limitada.

Henao Correa, H. (1999). Villa María y su historia. Villa María: Editorial Alcaldía de Villa María.

Gutiérrez Arango, E. (1994). Breve Historia del Ferrocarril de Caldas. Manizales:

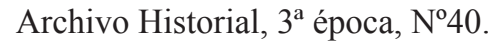

Gutiérrez, Rufino. (1921). Monografías. Bogotá: Tomo II, Biblioteca de Historia Nacional, Imprenta Nacional.

Lopera Gutiérrez, Jaime. (2012). Historia del Túnel de La Línea. Armenia: Academia de Historia del Quindío. 
Meisel R. Adolfo, Ramírez M.T. y Jaramillo, J. (2014). Los ferrocarriles en Colombia durante el periodo 1920-1950. Bogotá: Cuadernos de Historia, Económica y Empresarial- Banco de la República.

Mejía V., Florencio. (1939). Trazado de ferrocarriles y carreteras. Medellín: Imprenta Oficial.

Monsalve, Diego. (1927). Colombia Cafetera-1927. Barcelona, Artes Gráficas.

Ocampo, Francisco J. (1926). Informe del Gobernador del Departamento. Manizales.

Ortega, Alfredo. (1932). Ferrocarriles Colombianos: última experiencia ferroviaria del país (1920-1930). Bogotá: Imprenta Nacional.

Pachón, Álvaro y Ramírez, María Teresa. (2006). La infraestructura de transporte en Colombia durante el siglo XX. Bogotá: Banco de la República y Fondo de Cultura Económica.

Poveda Ramos, Gabriel. (2003). Antiguo Ferrocarril de Caldas, Medellín: DYNA, Revista de la Facultad de Minas de la Universidad Nacional de Colombia.

Pereira Antigua. (2017). Archivo Fotográfico, Grupo de Facebook.

Pérez, Jesús Elías. (1996). Historia de Chinchiná. Chinchiná: Biblioteca Pública Municipal.

Periódico La Patria. Ediciones 1926-1927

Periódico La Voz de Caldas. Ediciones 1926

Periódico Ferrocarril de Caldas, Publicación Oficial, 1919

Revista Cromos. Ediciones 1919-1924

Sánchez, Gonzalo. Breve reseña histórica de la estación del Ferrocarril, Manizales: Centro de Historia

Valencia Barrera, Gonzalo, Rojas, Miguel y Beltrán M. E. (2016). Armenia enclave exportador de café 1927-1959. Bogotá: Ministerio de Cultura de Colombia. 
El Ferrocarril de Caldas: una obra de titanes 

Este libro se terminó de imprimir en los talleres gráficos de Gráficas Olimpica bajo el cuidado de su autor en el mes de enero de 2020.

Pereira, Colombia 
Es sin duda, la obra de ingeniería de mayor envergadura que se haya construido en la región del antiguo Caldas, no solo por su costo y duración de su construcción, sino, por lo que representó en su momento para el desarrollo del Departamento y específicamente, para la transformación de la ciudad de Pereira.

La llegada del tren a Pereira, en 1921, constituye el inicio de la que se conoce históricamente, como la década de oro en el desarrollo de la ciudad.

Ninguna otra obra: ni el Viaducto, ni la Autopista del Café, ni el puente helicoidal, para mencionar las más sobresalientes, ha tenido tanta repercusión en el desenvolvimiento económico de Pereira y en general para las tres principales ciudades del antiguo Caldas.

Nacida la idea en 1912, en cabeza del gobernador Ramón Jaramillo, fue propuesta en la primera Asamblea del Departamento de Caldas y materializada a través de la ordenanza No 24 de 1915, que declara de utilidad pública los terrenos para la construcción del ferrocarril. Se da inicio a la obra el 16 de julio de 1915, en el sitio bautizado como Puerto Caldas, en la desembocadura del rio La Vieja al río Cauca.

Se extiende su construcción a través de las estaciones: La Marina, Villegas, Belmonte, Nacederos, Pereira, Gutiérrez, Santa Rosa, Guayabito, La Capilla, Campoalegre, San Francisco, Río Claro, Villamaria y Manizales, para completar una longitud de 117 kilómetros en su línea principal. A lo largo de su trayecto se construyen 9 túneles, con longitudes entre 40 y 130 metros y 5 puentes, con luces superiores a 20 metros.

En 1922 se terminó el ramal que comunica la estación La Marina con Cartago, para lo cual fue necesario construir el puente sobre el río La Vieja que tiene una luz de 70 metros. El ferrocarril llegó a Manizales en septiembre de 1927, es decir, doce años después de su iniciación en Puerto Caldas. En 1926 se había iniciado la línea Nacederos-Armenia, de 54 kilómetros, que se termina en octubre de 1929.

La investigación compilada en el libro que hoy presento, pretende recoger la información dispersa que existe sobre el tema, verificar - o corregir en algunos casos- los hechos narrados en esos documentos y complementar, con nuevos aportes, una historia muy importante para el desarrollo de nuestro territorio, y a la vez, muy desconocido entre nosotros.

Quisiera solicitarle a mis amables lectores que acompañen esta lectura con su propia imaginación: que se sitúen a principios del siglo veinte y mediten en las condiciones del modus vivendi de ingenieros, cadeneros, enrieladores y demás trabajadores. Sin luz eléctrica, sin teléfonos, sin carreteras ni vehículos motorizados, internados en inmensos bosques y guaduales; afrontando los permanentes acechos de pumas, tigrillos, culebras, abejas, zancudos y cuanto animal salvaje hubiere.

¿Y de la maquinaria? Ni hablar; simples valerosos peones con picas, palas y carretas de mano, ayudados por caballos, mulas y bueyes, como elementos de transporte.

¿Y la logística para organizar y atender las necesidades de mil trabajadores? Su alojamiento, alimentación y transporte; la consecución de provisiones, las instalaciones sanitarias, etc. etc.

Por estas razones y por mucho más, he denominado el libro como "UNA OBRA DE TITANES".

ARMANDO RAMÍREZ VILLEGAS

elSBN: 978-958-722-528-0

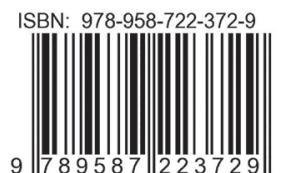

